\title{
OCEAN AND TERRESTRIAL RESPONSE TO A PLEISTOCENE WARM INTERGLACIAL (MIS11) AS REVEALED BY POLLEN AND DINOFLAGELLATES FROM MARINE SEDIMENT CORES, SOUTH ISLAND, NEW ZEALAND
}

BY

JOSEPH GRAHAM PREBBLE

\author{
A thesis \\ submitted to the Victoria University of Wellington \\ in fulfilment of the requirements for the degree of \\ Doctor of Philosophy
}

Victoria University of Wellington 



\begin{abstract}
The response of the surface ocean and terrestrial climate in the New Zealand region to interglacial Marine Isotope Stage (MIS) 11 (423-380ka) is documented, using assemblages of fossilised marine algae (dinoflagellate cysts, or dinocysts) and spores/pollen from terrestrial plants, analysed from marine sediment cores. This work is underpinned by studies on the modern distribution of dinocysts, factors that influence their accumulation in marine sediment, and the use of dinocyst assemblages to quantify past sea surface temperature (SST).

In the first of the modern-process studies, a dataset of modern sea-floor dinocyst assemblages from the Southern Hemisphere is collated, including new observations from the SW Pacific. Variations in the assemblages are related to environmental gradients. Cluster analysis reveals distinct biogeographic assemblage zones, individual taxa indicative of specific water masses are identified, while ordination of the databases indicates that the assemblages vary most with changes in SST.
\end{abstract}

A second modern process study reports on the dinocyst assemblages from two timeincremental sediment traps (3 years of data) moored north and south of the Subtropical Front in the ocean east of New Zealand. This study provides observations of seasonal and inter-annual variability of dinocyst flux to the deep sea, which are used to identify possible biases in the sea-floor dinocyst assemblages.

Observations from these first two studies are used in a systematic analysis of the strengths and weakness of using dinocyst assemblages to quantify SST in the SW Pacific. The best transfer function performance achieved was a root mean squared error of $1.47^{\circ} \mathrm{C}$, for an artificial neural network model, and the benefits in considering a range of model results are also established.

Fossil records that document the oceanographic and terrestrial response to MIS11 are developed from two areas around New Zealand; (i) dinocysts assemblages are collected from the east Tasman Sea, from giant piston cores MD06-2987, -2988, and 
2989, and (ii) dinocysts and pollen assemblages are analysed from Deep Sea Drilling Project (DSDP) Site 594, from the east of New Zealand.

Dinocyst assemblages confirm that SST in the east Tasman Sea was $\sim 2-3^{\circ} \mathrm{C}$ warmer than the present during late MIS11 (415-400ka), while SSTs were slightly below modern levels during an early phase (428-415ka). Two assemblage - based productivity indices suggest that the elevated SSTs during MIS11 were accompanied by lower rates of primary productivity in the east Tasman Sea study area than the present.

As in the east Tasman Sea, two distinct phases of MIS11 are recognised in both the dinocyst and pollen assemblages at DSDP 594. The dinocyst assemblages of late MIS11 are similar to, but qualitatively represent warmer waters than the Holocene. The succession of pollen assemblages during MIS12-11 is very similar to that observed during the previous two interglacials at this site (MIS1 and MIS5), with two notable variations: (i) the deglacial vegetation succession during MIS11 was prolonged, and (ii) the pollen assemblage representing the warmest forest type was also present for longer (ca. 15ky) than later interglacials.

Changes in the pollen record during MIS11 at DSDP 594 correlate more closely to SST variations in the east Tasman Sea than to ocean variations at DSDP 594, suggesting that the eastern ocean had only limited influence on conditions on the adjacent landmass during MIS11. 


\section{Acknowledgements}

I have benefited enormously from help and guidance from many people over the past three years.

I have been supervised by Lionel Carter, Erica Crouch and Giuseppe Cortese. I have really enjoyed working with you all; your time, guidance, and wisdom is very much appreciated.

I have been assisted by a number of friendly and helpful people from around the world. You have generously shared all of the things required to keep the wheels of the palaeoclimate research machine spinning: time, humour, information, advice, ideas, software, honest opinions and small bags of sediment:

Scott Nodder, Helen Neil, Helen Bostock, Lisa Northcote, Hoe Chang, Alan Orpin, George Scott, Marcus Vandergoes, Martin Crundwell, Greg Brown, Dallas Mildenhall, Lucia Roncaglia, Sonja Fry, Roger Tremain, Bob Carter, Gavin Dunbar, Peter Barrett, Michelle Dow, Mike Hannah, Matt Ryan, Dan Bassett, Kylie Christiansen, Bella Duncan, Bruce Hayward, Taoufik Radi, Anne de Vernal, Fabienne Marret, Karin Zonneveld, Barrie Dale, and Thomas Verleye.

I have been hosted by GNS Science in Lower Hutt and the Antarctic Research Centre at Victoria University. I am very grateful to both institutions.

Thank you to my parents Lesley and Mark and parents-in-law Kevin and Lata for your love and support.

Thank you to my wonderful family for putting up with a distracted fossil hunter for so long - Priya and our lovely children Amelia, Charlotte and Tim. You give so much colour to my world.
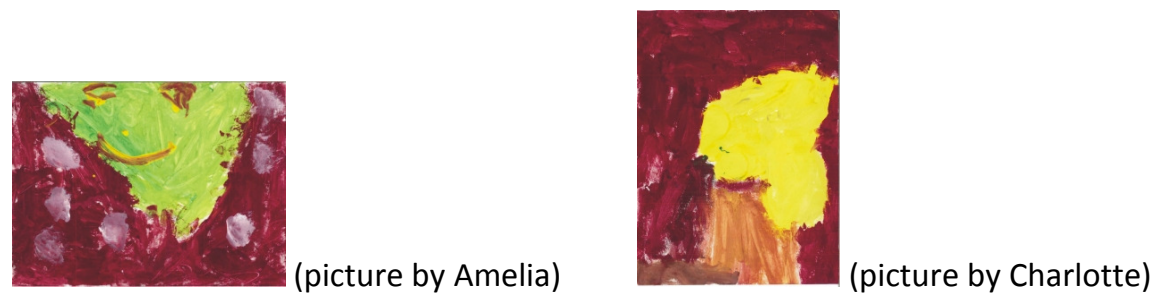


\section{Contents}

ABSTRACT

ACKNOWLEDGEMENTS

CONTENTS

v

LIST OF FIGURES Xii

LIST OF TABLES Xiv

$\begin{array}{ll}\text { 1. INTRODUCTION } & 1\end{array}$

1.1. MIS11 and the southwest Pacific 3

1.2 Chapter summary 4

1.3 Papers from this thesis for submission to peer-reviewed journals: $\quad 8$

1.4. Conference presentations from this thesis 8

2. SEA FLOOR DINOFLAGELLATE CYSTS FROM THE SOUTHWEST PACIFIC AND SOUTHERN HEMISPHERE

$\begin{array}{ll}\text { Abstract } & 11\end{array}$

2.1. Introduction 12

2.2. Modern Oceanography, SW Pacific 15

2.3. Data collection and compilation of dataset 16

$\begin{array}{ll}\text { 2.3.1. Modern samples } & 16\end{array}$

2.3.2. Compilation of dinocyst dataset 20

2.3.3. Modern environmental data 23

2.3.4. Classification 24

2.3.5. Ordination 25

2.4. Results and Discussion 26

2.4.1 Spatial distribution of dinocyst assemblages 26 
2.6. Acknowledgements 58

$\begin{array}{ll}\text { Appendix 2.1. Ordination methodology } & 61\end{array}$

Appendix 2.2. Weighted correlation tables 62

$\begin{array}{ll}\text { Supplementary Material } & 63\end{array}$

\section{HOLOCENE AND MODERN DINOFLAGELLATE CYST FLUX IN SUBTROPICAL AND} SUBANTARCTIC WATERS, SOUTHWEST PACIFIC OCEAN. 65

$\begin{array}{ll}\text { Abstract } & 65\end{array}$

3.1. Introduction $\quad 66$

3.2. Oceanographic Setting and trap locations 69

$\begin{array}{ll}\text { 3.3. Methods } & 70\end{array}$

3.3.1. Mooring deployment and sample processing 70

$\begin{array}{ll}\text { 3.3.2. Data collection } & 72\end{array}$

3.3.3 Comparison with sediment assemblages 73

3.4. Results $\quad 74$

3.4.1. Dinocyst composition and abundance patterns 74

3.4.2. Cyst flux: seasonality 77

3.4.3. Cyst flux: inter-annual variability 80

3.4.4. Cyst flux: comparison with Holocene sediment assemblages 83

3.5. Discussion $\quad 85$

3.5.1. Seasonal variation between water masses 85

$\begin{array}{ll}3.5 .2 \text { Inter-annual variability } & 87\end{array}$

3.5.2. Trap flux compared to sediments 91 
$\begin{array}{ll}\text { 3.6. Conclusions } & 95\end{array}$

3.7. Acknowledgements 96

$\begin{array}{ll}\text { Appendix 3.1. Flux calculations } & 97\end{array}$

$\begin{array}{ll}\text { Supplementary Material } & 99\end{array}$

4. A DINOFLAGELLATE CYST-BASED SEA SURFACE TEMPERATURE TRANSFER FUNCTION FOR THE SOUTHWEST PACIFIC 101

$\begin{array}{ll}\text { Abstract } & 101\end{array}$

$\begin{array}{ll}\text { 4.1. Introduction } & 102\end{array}$

4.1.1. Requirements of a transfer function 103

4.1.2. Assumptions of a transfer function: 104

$\begin{array}{ll}\text { 4.2. Dinoflagellate ecology } & 104\end{array}$

$\begin{array}{ll}\text { 4.2.1. Dinoflagellate nutrition } & 105\end{array}$

$\begin{array}{ll}\text { 4.2.2. Habitat and cyst formation } & 105\end{array}$

4.2.3. Growth rate and encystment studies 107

4.3. Dinocysts on the sea-floor 108

$\begin{array}{ll}\text { 4.3.1. Transport and deposition } & 108\end{array}$

$\begin{array}{ll}\text { 4.3.2. Preservation } & 110\end{array}$

4.4. Training set compilation 111

4.4.1. Quality of dinocyst count data 112

4.4.2. Transformation of count data 113

4.4.3. Quality of environmental data 114

4.4.4. Age control 115

$\begin{array}{ll}\text { 4.5. Selection of environmental gradients } & 116\end{array}$

4.5.1. Relationship of assemblages to environmental gradients 116

4.5.2. Selection of transfer function targets 117

4.5.3. Influence of minor environmental gradients 117 
4.7.4. Weighted Averaging and WA with Partial Least Squares

4.7.5. Modern Analogue Technique

4.7.6. Artificial Neural Networks

4.8. Performance measurement

4.8.1. Introduction

4.8.2. Measurement statistics

4.8.3. Assessing prediction error

4.9.2. Leave-one-out prediction error 
4.12.2. Errors of best models.

4.12.3. Improvements to dinocyst-based environmental estimates 157

4.13. Acknowledgements

A 4.1.1. - Introduction

A 4.1.2. Spatial autocorrelation in the $\mathrm{SH}-311$ training set

A 4.1.3. A comment on the approach

Appendix 4.2. - Foraminifera training set

\section{SEA SURFACE CONDITIONS DURING WARM MARINE ISOTOPE STAGE 11, EAST}

5.1. Introduction

5.2. Background

5.2.1 East Tasman Sea: setting and oceanography

5.2.2 Dinoflagellate cysts

5.3.3 SST estimates from dinocyst assemblages

5.3.4 SST estimates using foraminifera assemblages

5.3.5 Productivity using dinocysts 
5.4.1 Dinocyst abundance

5.4.2 Dinocyst assemblages

5.4.3 SST models

5.4.4 Productivity indices

5.4.5 Water mass affinities

5.5.1 Duration and relative warmth of MIS11: comparison with other records

5.5.2 Water mass estimates 198

5.5.3 Productivity in the east Tasman Sea MIS12-10 199

5.5.4 A different productivity regime during MIS11? 201

5.6. Conclusions 205

5.7. Acknowledgements 206

Supplementary Material 206

\section{MARINE-TERRESTRIAL CLIMATE DURING MARINE ISOTOPE STAGE 11 , SOUTH} ISLAND, NEW ZEALAND.

Abstract

6.1. Introduction 208

6.2. Oceanographic setting 209

6.3. Warm interglacials in the SW Pacific

6.4.2. Sample processing and counting 
6.4.5. Interpreting the pollen record 218

6.5. Results

6.5.1. Dinocyst assemblages

6.5.2. Water mass indicators

6.5.3. SST models

6.5.4. Pollen assemblages

6.6. Discussion

6.6.1 Comparison of dinocyst records from MIS11, MIS5 and MIS1 east of New Zealand

6.6.2 Pollen record of MIS11

6.6.3 The MIS12-11 deglacial pollen succession

6.6.4 Duration of peak warmth during MIS11 from pollen 


\section{List of Figures}

1.1. Summary Quaternary climate records 2

1.2. Location map 4

2.1 Map of surface currents, samples processed and environmental gradients 14

2.2 Map of NZ-98 compilation 21

$\begin{array}{lll}2.3 & \text { Map of SH-311 compilation } & 21\end{array}$

$\begin{array}{lll}2.4 & \text { Dinocyst diversity against SST } & 23\end{array}$

2.5 Dinocysts per gram, sea floor sediments New Zealand region 28

$\begin{array}{lll}2.6 & \text { Photographs of dinocysts } & 30\end{array}$

$\begin{array}{lll}2.7 & \text { Photographs of dinocysts } & 31\end{array}$

$\begin{array}{lll}2.8 & \text { Photographs of dinocysts } & 32\end{array}$

2.9 Distribution maps of S. antarctica, I. pallidum, N. labyrinthus 33

2.10 Distribution of D. chathamensis, P. reticulata, Brigantedinium, S. quanta 34

2.11 Distribution of S. nephroides, Echnidinium, S.ramosus, S. mirabilis 36

2.12 Distribution of O. centrocarpum LP and SP, O. jandaucheri, I. strialatum 37

2.13 Distribution of I. variaseptum, I. paradoxum, I. aculeatum, I. plicatum 39

2.14 Stability histogram of k-means clusters 40

2.15 Distribution map of k-means clusters for NZ-98 42

2.16 Taxonomy of NZ-98 k-means clusters 43

2.17 SST and productivity distribution of NZ-98 k-means clusters 45

$\begin{array}{lll}2.18 & \text { Distribution map of k-means clusters for } \mathrm{SH}-311 & 47\end{array}$

2.19 Taxonomy of SH-311 k-means clusters 48

2.20 SST and productivity distribution of SH-311 k-means clusters 49

2.21 Distribution of SH-311 k-means clusters against chlorophyll- $a$ biomes $\quad 50$

2.22 Map of eigenvalues for RDA axes 1 and 2, NZ-98 54 
2.23 RDA biplot for NZ-98 55

3.1 Location map of sediment traps 68

3.2 Sediment trap dinocyst flux - time series 76

3.3 Photo plate of dinocysts from sediment trap 81

3.4 Sediment trap dinocyst flux - annual average 82

3.5 Comparison of trap assemblages with sea floor assemblages 84

3.6 Sediment trap dinocyst flux compared to upwelling and chlorophyll- $a \quad 88$

4.1 Dinocyst:Pollen ratio from sea floor sediments around New Zealand 110

4.2 Distribution of samples over clusters divided by publication 111

$\begin{array}{lll}\text { 4.3 Sampling density for SST in World Ocean Atlas } & 115\end{array}$

$\begin{array}{lll}\text { 4.4 MAT cross validation residuals against dissimilarity score } & 128\end{array}$

$\begin{array}{lll}\text { 4.5 Map of test sets for SH-311 } & 136\end{array}$

$\begin{array}{lll}\text { 4.6 } & \text { RMSE charts for SH-311 and NZ98 } & 138\end{array}$

$\begin{array}{lll}4.7 & \text { Correlation plots for NZ-98 } & 140\end{array}$

$\begin{array}{lll}4.8 & \text { Correlation plots for SH-311 } & 142\end{array}$

4.9 RMSEP charts and correlation plots for NZ-98 and SH-311 144

$\begin{array}{lll}\text { 4.10 Spatial distribution of residuals, SW Pacific } & 148\end{array}$

4.11 Taxonomic distribution of residuals, SH-311 150

4.12 DCA of SH-311 and DSDP594 dinocyst counts 151

$\begin{array}{lll}4.13 & \text { Climate records from DSDP594 } & 152\end{array}$

$\begin{array}{lll}5.1 & \text { East Tasman Sea location map } & 175\end{array}$

$\begin{array}{lll}\text { 5.2 Dinocyst Productivity Index } & 185\end{array}$

$\begin{array}{lll}5.3 & \text { G. bulloides against chlorophyll-a biome } & 185\end{array}$

$\begin{array}{lll}\text { 5.4 Dinocyst absolute abundance in east Tasman Sea cores } & 187\end{array}$

5.5 Dinocyst relative abundance in east Tasman Sea cores 188 
5.6 SST models east Tasman Sea

$\begin{array}{lll}\text { 5.7 Water mass estimates east Tasman Sea } & 195\end{array}$

$\begin{array}{lll}\text { 5.8 Stacked SST and productivity indices, east Tasman Sea } & 197\end{array}$

5.9 Correlation between SST and G. bulloides since 450ka 202

$\begin{array}{lll}6.1 & \text { Location map } & 210\end{array}$

6.2 Dinocyst counts, DSDP594, MIS12-MIS10 222

6.3 Dinocyst counts, DSDP594, MIS6-Present 223

$\begin{array}{lll}\text { 6.4 DSDP594, SST estimates } & 226\end{array}$

6.5 DCA of SH-311 and DSDP594 dincoyst counts 227

6.6 Pollen counts, DSDP594, MIS12-10 230

6.7 Pollen counts, DSDP594, MIS12-Present 231

$\begin{array}{lll}6.8 & \text { Pollen absolute abundance, MIS11 } 238\end{array}$

6.9 West-East comparison of climate, MIS11 242

\section{List of Tables}

$\begin{array}{lll}2.1 & \text { Modern sea floor samples examined } & 17\end{array}$

2.2 Summary statistics of sea floor dinocyst datasets 22

2.3 Summary of dinocyst distribution within water masses 29

$\begin{array}{lll}2.4 & \text { Ordination results } & 52\end{array}$

$\begin{array}{lll}3.1 & \text { Sediment trap summary statistics } & 74\end{array}$

$\begin{array}{lll}3.2 & \text { Sediment trap dinocyst flux data } & 78\end{array}$

3.3 Comparison of trap flux with sea floor flux, STM 86

4.1 Performance statistics of transfer functions of NZ-98 and SH-311 137

$\begin{array}{lll}\text { 6.1 Pollen interpretation chart } & 221\end{array}$ 


\section{Introduction}

The study of past climates improves our understanding of the range of possible environmental responses to current anthropogenic warming. There are several interglacial periods during the Late Quaternary that had optima warmer than the Holocene. One such interglacial, Marine Isotope Stage 11 (MIS11, 423ka - 380ka) is of special interest in light of its orbital configuration, which is similar to the Holocene or MIS 1 ( 13ka - present). Thus MIS 11 can help evaluate (i) the future natural behaviour of MIS 1 and (ii) the response of the surface ocean and terrestrial climate to warmer temperatures during MIS 1.

In this thesis, assemblages of fossilised marine algae (dinoflagellate cysts, or dinocysts) and spores and pollen from terrestrial plants, collected from marine cores, have been used to document the response of the surface ocean and terrestrial climate in the New Zealand region to MIS11. This work is underpinned by studies on the modern distribution of dinocysts which enhance their use as a palaeoenvironmental proxy in the southwest Pacific, in particular the development of quantitative models for sea surface temperature using dinocyst assemblages.

There are three aims of this thesis:

- To better understand the distribution of modern dinocysts in the SW Pacific and the environmental factors that control their distribution.

- Develop models from the modern dinocyst data to quantify past climatic conditions with the focus on MIS 11.

- Use these models in conjunction with pollen records both during MIS11 and other late Quaternary interglacials in order to compare sea surface and terrestrial signal, thus illustrating a range of past responses to warm environments in the New Zealand region

Chapter 1 contains a brief outline of the setting, including a regional map and reference diagram of key global and regional Quaternary environmental records, along with an overview of each chapter and acknowledgement of unpublished data provided by collaborators. 
A.

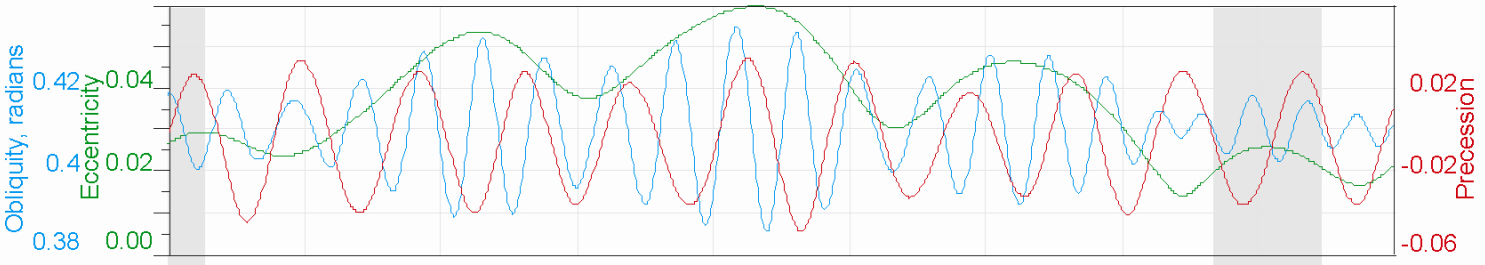

B.

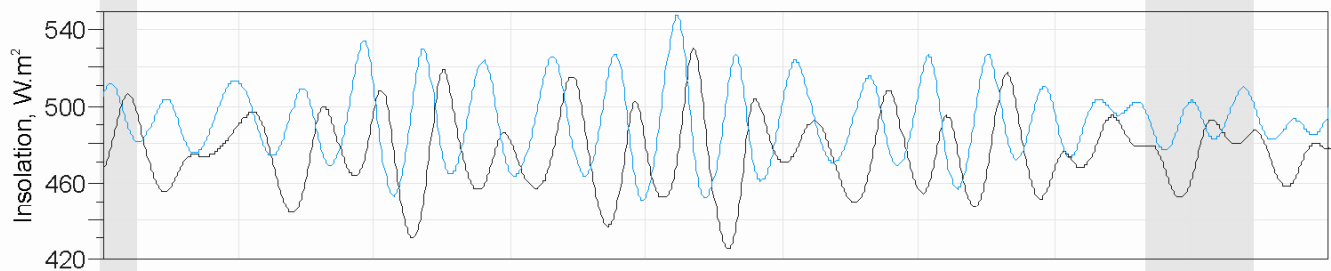

C.

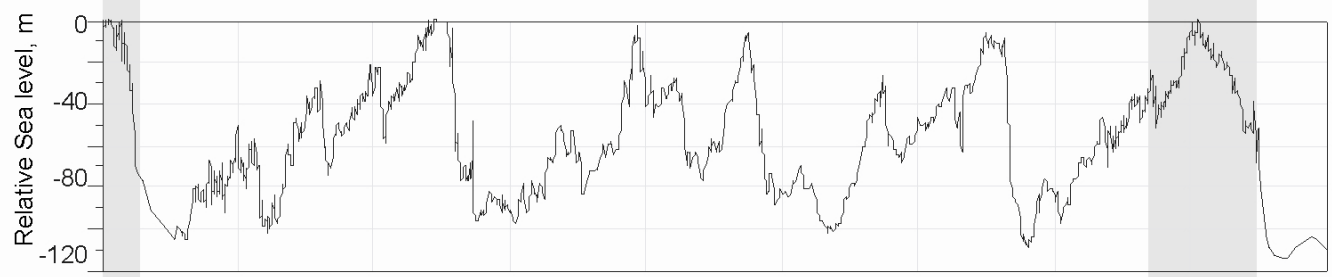

D.

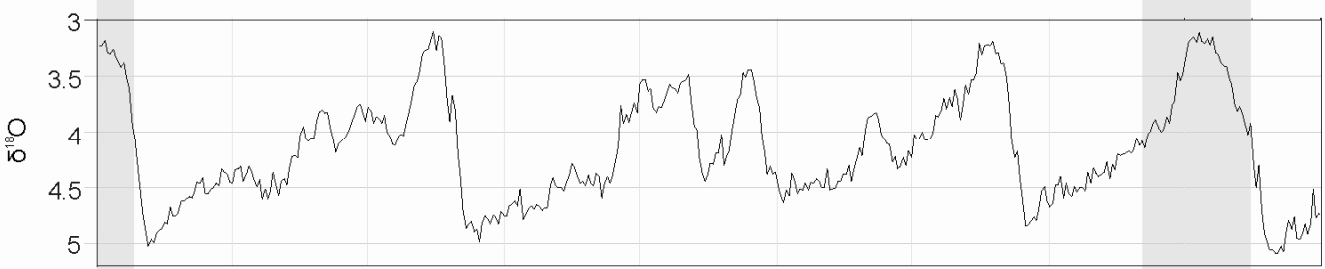

E.

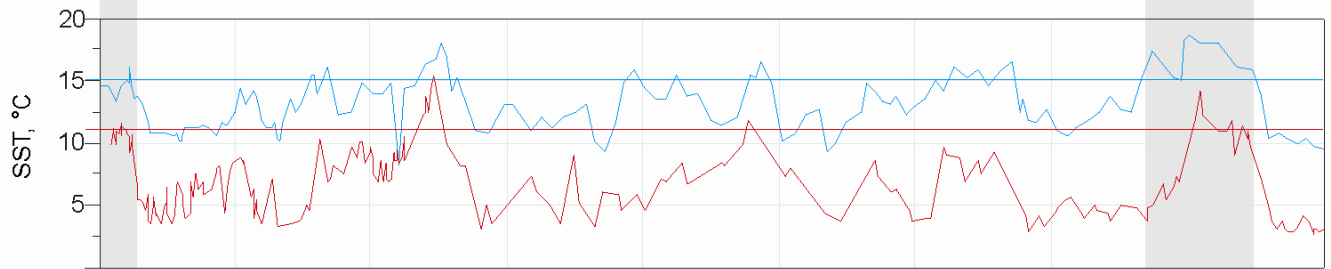

F.

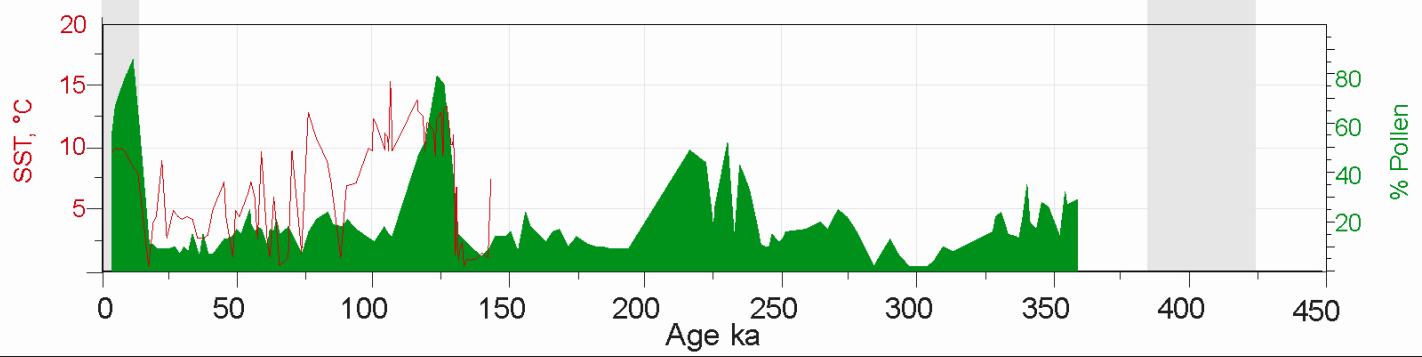

Figure 1.1. Global environmental parameters and regional environmental proxies from the NZ sector of the SW Pacific for the past 450ka, MIS11 and MIS1 shaded. A. Orbital parameters eccentricity (green), precession (red) and obliquity (blue) (Laskar et al., 2004), showing both MIS11 and the Holocene share a similar orbital configuration, characterised by low eccentricity. B. Maximum monthly insolation at $60^{\circ} \mathrm{N}$ (black, June) and $42^{\circ} \mathrm{S}$ (blue, December) (Laskar et al 2004), showing the relativity muted variation in insolation associated with the eccentricity minima of MIS11 and the Holocene, and the distinctive "double peak" in the $60^{\circ} \mathrm{N}$ solution during MIS11. C. Relative sea level, using the "Red Sea Method" (Rohling et al., 2010), showing (i) sea level within the Holocene range during MIS11, and (ii) the largest sea level rise of the last 450ka at the MIS12-11 transition. D. Global stack of benthic oxygen isotopes, LRO4 (Lisiecki and Raymo, 2005), E. Two long records of SST from the New Zealand region, using faunal transfer functions from foraminifera assemblages. Blue = Site MD06-2986 (Hayward et al., 2012), east Tasman Sea in Subtropical Water, Red = DSDP Site 594 (Schafer et al., 2005; Hayward et al., 2008), east of New Zealand in Subantarctic Water, horizontal lines = modern SST. F. Two additional long environmental proxy records from DSDP 594 relevant to this study, Red = SST estimates from the longest dinocyst record in the New Zealand region, MAT method (Marret et al., 2001), and Green = \% Podocarpus/Prumnopitys (conifer hardwood) pollen (Heusser and van der Geer, 1994) 


\subsection{MIS11 and the southwest Pacific}

MIS11 (423ka - 380ka) is the first interglacial for the fully developed quasi-100ky cycle following the climate reorganisation of the Mid-Pleistocene transition, prior to which a 40ky cycle dominated (Clark et al., 2006; Holden et al., 2011). Unlike the shorter-duration MIS5e, MIS7 and MIS9 interglacials, ice core records covering MIS11 show a sustained ( $\sim 30 \mathrm{ka}$ ) period of Holocene-like climatic stability, with mean atmospheric $\mathrm{CO}_{2}$ being close to pre-industrial levels (Siegenthaler et al., 2005). The orbital configuration during MIS11 is similar to the Holocene (Loutre and Berger, 2003), although the Holocene contains one insolation peak so far, while the MIS 11 interglacial extends over two insolation peaks (Tzedakis, 2010; Rohling et al., 2010) (Figure 1.1).

In addition to the prolonged duration of stable climate, and similarities to the Holocene orbital configuration, the sea level during MIS11 has attracted considerable attention in recent decades, with tropical marine terrace records suggesting sea level was up to $20 \mathrm{~m}$ above present day levels (e.g. Siddall et al., 2007, Olson \& Hearty, 2009). This amount of sea level rise would require melting of the West Antarctic and Greenland Ice Sheets (Scherer, 2003). This is not supported, however, by oxygen isotope studies (e.g. Rohling et al., 2010), or by ice-proximal Antarctic records (Naish et al., 2009), although a pollen record from the Labrador Sea contains high abundances of spruce pollen during MIS11 that is inferred to originate from an ice-free Greenland (de Vernal and Hillaire-Marcel, 2008). Interestingly, MIS11 appears to not have been exceptionally warm at high southern latitudes (Hodell et al., 2000; Droxler et al., 2003), although the Dome C ice core record from Antarctica shows drill site air temperature was slightly higher than late Holocene levels (Masson-Delmotte et al., 2010).

Published records of MIS11 in the New Zealand region of the SW Pacific are considered in more detail in later chapters, but mainly consist of SST estimates from foraminiferal assemblages (Wells and Okada, 1997; Weaver et al., 1998; Schaefer et al., 2005; Wilson et al., 2005; Crundwell et al., 2008; Hayward et al., 2008, 2012), estimates of dust flux into the Tasman Sea (Hesse, 1994) and a low resolution pollen record from distal marine core Ocean Drilling Project (ODP) Site 1123 (Mildenhall, 2003; Mildenhall et al., 2004). The location of key paleoenvironmental records in the New Zealand region for MIS11, and other locations mentioned in this thesis, are shown in Figure 1.2. 


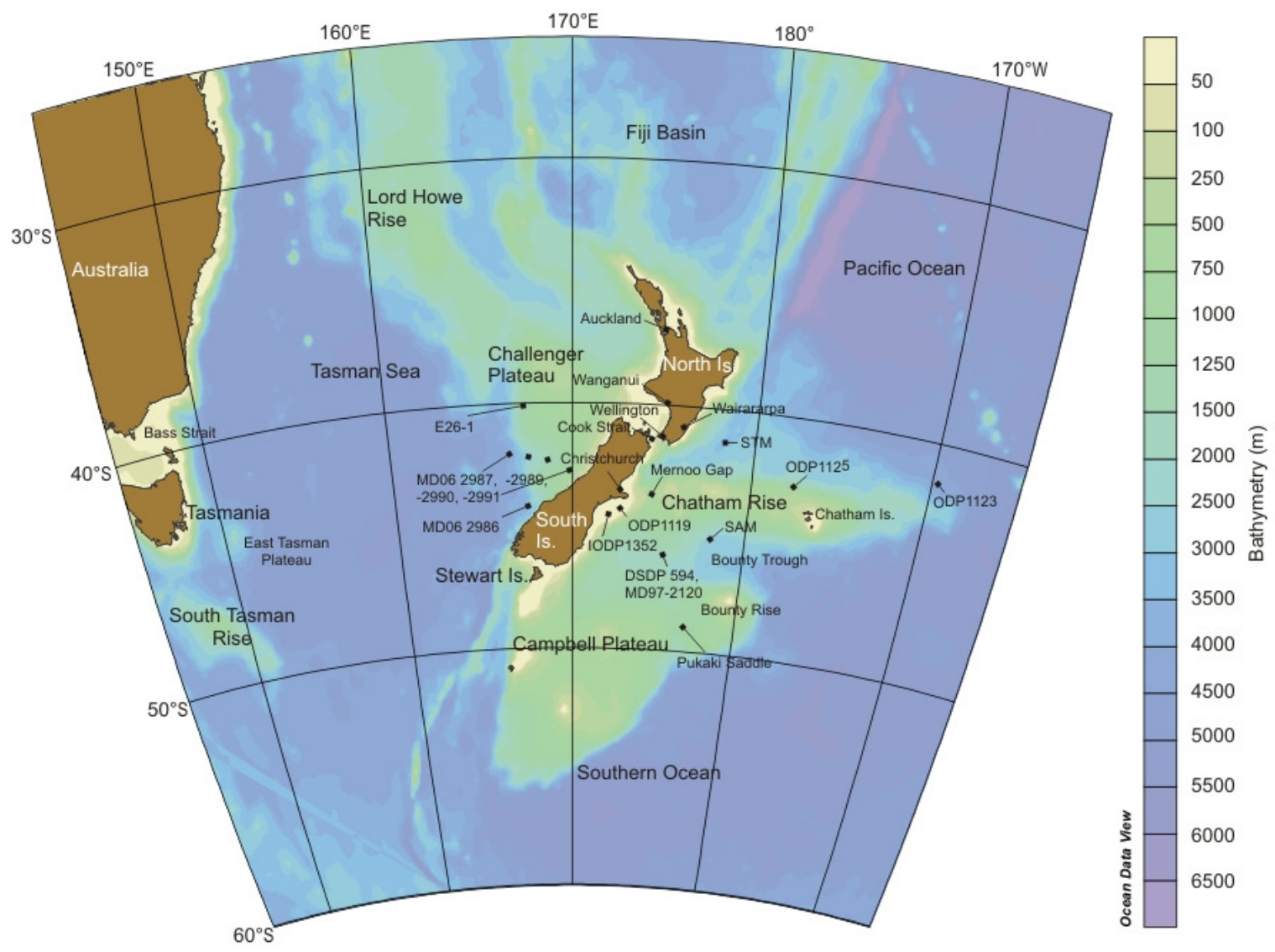

Figure 1.2. New Zealand regional bathymetric map, showing locations mentioned in this thesis. Circulation of the modern surface ocean is shown in Chapter 2, Figure 2.1.

\subsection{Chapter summary}

There are seven chapters in this thesis. Chapters 2 to 6 are designed to be distinct pieces of research, the results of which contribute to the aims of the thesis. Most chapters are intended for publication, and the format reflects this. As a consequence, the reader may encounter a degree of repetition, particularly in descriptions of methodology and regional setting.

Chapters 2-4 develop a proxy for sea surface temperature (SST) and water masses in the SW Pacific using assemblages of dinoflagellate cysts from sea floor sediments, supported by observations from sediment traps.

In Chapter 2, a dataset of modern sea floor dinocyst assemblages is collated, and variations in the assemblages are related to environmental gradients. Modern sea floor assemblages from 120 sites in the SW Pacific are examined for dinocysts, and census counts from 40 of 
these samples are combined with previously published counts to form a 311-sample Southern Hemisphere dataset (SH-311). Cluster analysis of SH-311 and a 98-sample subset from the SW Pacific region (NZ-98), reveals distinct biogeographic assemblage zones, and taxa indicative of specific water masses are identified. Ordination of the datasets indicates that assemblages vary most with changes in SST, with a lesser association with productivity.

Contributed unpublished data include ${ }^{14} \mathrm{C}$ ages of 48 samples from planktic foraminifera populations, which were picked by Helen Bostock at NIWA, Wellington, and analysed at the Rafter Laboratory, GNS Science, Lower Hutt, New Zealand. The sea floor samples were collated by Giuseppe Cortese, GNS Science, with many coming from NIWA archives. Details about which were provided by Helen Neil at NIWA. This chapter is to be submitted to Marine Micropaleontology (title and authorship below).

Chapter 3 reports the results of a study of dinocyst assemblages from two time-incremental sediment traps ( 3 years of data) moored north and south of the Subtropical Front, east of New Zealand (Locations "STM" and "SAM" shown in Figure 1.2). This study provides observations of seasonal and inter-annual variability of dinocyst flux to the sea floor, which are used to identify possible biases in the sea floor assemblages and the possible processes causing the biases. A large discrepancy between dinocyst flux and assemblages of nearby sea-floor sediments is observed. Dinocysts known to be susceptible to degradation in oxygenated sediments are highly under-represented in the sea-floor assemblages. More surprisingly, the flux of several cyst types that are relatively resistant to oxidation is over 30 times more abundant in sea-floor sediments than would be expected from the three years of flux into the traps. Various causes and implications of this discrepancy are explored. The differences between the seasonality of dinocyst flux between the Subtropical and Subantarctic water masses, and the large interannual variability in the flux composition, suggest mean annual rather than seasonal climatologies are more appropriate for dinocystbased quantitative palaeoenvironmental reconstructions in the region.

Samples used in this study were from a decade-long sediment trap experiment run by Scott Nodder at NIWA. In addition to sample material, Scott provided unpublished data on mass flux, elemental analyses, and unprocessed data on sediment trap 'tip' and ocean current intensity. This chapter is to be submitted to Marine Geology. 
Chapter 4 contains a systematic analysis of the strengths and weakness of using dinocyst assemblages as a proxy for SST in the SW Pacific. The chapter includes consideration of the effects of dinoflagellate ecology, lifecycle, transport, and preservation on the dinocyst sedimentary record. Biasing effects in data collection and spatial correlation in the training set, and the implication of conflicting environmental gradients on the performance of dinocyst-based transfer functions are also considered. The performance of four transfer function models is explored: weighted averaging, weighted averaging with the addition of partial least squares, the modern analogue technique, and an artificial neural network (ANN) model. Under a "leave-one-out" cross validation routine, the ANN model performed best for the SW Pacific dataset, with a root mean square error (RMSE) of $1.14^{\circ} \mathrm{C}$. The best performance achieved for the Southern Hemisphere dataset was a RMSE of $1.47^{\circ} \mathrm{C}$, also for the ANN model. These errors are similar to those achieved using foraminifera-based training sets in the SW Pacific, which is the other microfossil group commonly used for quantitative faunal SST estimates in the region. The key advantage of this detailed analysis of errors is a robust identification of situations where accuracy of estimates are likely to vary from the range observed in modern validation routines.

Chapters 5 and 6 explore the oceanographic and terrestrial response to interglacial MIS11 in the New Zealand region.

In Chapter 5, the development of MIS11 in the east Tasman Sea is documented (Figure 1.2). Dinocyst assemblages from three giant piston cores, confirm that SST in the east Tasman Sea was $\sim 2-3^{\circ} \mathrm{C}$ warmer than present during late MIS11 (415-400ka), while SSTs fluctuated slightly below modern levels during the earlier part of MIS11 (428-415ka). Although dinocysts vary most with SST at a hemispheric scale, aspects of the assemblage are particularly sensitive to productivity. A semi quantitative dinocyst-based productivity index, along with productivity indicators from published foraminiferal records, suggest that the elevated SSTs during MIS11 were accompanied by lower rates of primary productivity than present. Both proxies suggest productivity was highest during glacial periods, while the productivity during the peak of MIS11 was likely lower than the present. These glacialinterglacial variations in productivity are inferred to arise from migrations of the STF, overprinted by the influence of terrestrially derived nutrients from the adjacent New Zealand landmass. Furthermore, during the time period covered by this study, a strong 
correlation is documented between a long (1Mya) published SST record from the study area and the foraminifera-based proxy for productivity. This correlation is strongest during the MIS12-11 deglacial transition, and remains strong until the MIS9-8 transition, 300ka. Between $\sim 300 \mathrm{ka}$ and the present, the correlation between the two records is weak. This step-change in correlation between SST and productivity may be due to one or more of the following: (i) an artefact of the prolonged MIS12-11 deglaciation, (ii) increased variability in the input of locally terrestrially- derived nutrients into the study area after $\sim 300 k a$, or (iii) the onset of iron fertilisation by Australian-derived dust after MIS9. Notwithstanding the cause of the shift in strength of correlation, the observation has implications for interpretation of faunal proxies used to infer MIS11 environments in the east Tasman Sea.

The unpublished isotopic analyses in this study for both the age models and the mixing indices, and the age models themselves, were provided by Helen Bostock and Helen Neil at NIWA, Wellington.

Chapter 6 introduces a second MIS11 dinocyst record from the New Zealand region, from Deep Sea Drilling Project (DSDP) Site 594, off the eastern South Island (Figure 1.2). In addition to dinocysts, spores and pollen were counted at this site, which record changes in eastern South Island vegetation during MIS11. These new data allow comparison of dinocyst records either side of the South Island of New Zealand, and also allow comparison with published dinocyst and pollen records from younger sediments at DSDP594. As in the east Tasman Sea, two distinct phases of MIS11 are recognised at DSDP 594 in the dinocyst and pollen assemblages. The dinocyst assemblages at DSDP594 of the early phase of MIS11 are most similar to those observed at the site during MIS5e, while the assemblages of late MIS11 are similar to, but qualitatively represent warmer waters than, MIS1. Estimates from the dinocyst-based transfer functions indicate SSTs during late MIS11 were likely warmer than the present at DSDP 594, but they do not appear to have been as warm as during MIS5e. The succession of pollen assemblages during MIS12-11 is very similar to that observed in MIS2-1 and MIS6-5, but differs in two critical respects: (i) the deglacial succession was much slower than younger transitions, with a two-step expansion of Podocarpus/Prumnopitys conifer hardwood forest, and (ii) the maximum abundance of Podocarpus/Prumnopitys pollen, from $\sim 420 \mathrm{ka}$, was of a similar relative abundance to that observed at the site during the early Holocene climatic optimum. These high abundances of 
Podocarpus/Prumnopitys pollen persisted for $\sim 15 \mathrm{ky}$, more than twice as long as during MIS5e and MIS1. Changes in the pollen record at DSDP 594 correlate more closely to SST variation in the east Tasman Sea during MIS11, than to variations in marine conditions at DSDP 594, both in terms of timing, and reflection of the magnitude of warmth, as the latter was stronger to the west than east of the South Island during MIS11. This suggests that marine conditions from the east coast had only limited influence on conditions on the adjacent landmass during MIS11.

The concluding Chapter 7 reviews and discusses the achievements and conclusions of this thesis, and identifies areas that would benefit from further research.

\subsection{Papers from this thesis for submission to peer-reviewed journals:}

Prebble, J.G., Crouch, E.C, Carter, L., Cortese, G., Neil, H., submit July 2012. Environmental implications of dinoflagellate cysts in modern sea floor sediments from the SW Pacific and Southern Hemisphere. From Chapter 2, for submission to Marine Micropalentology

Prebble, J.G., Crouch, E.C, Nodder, S., Carter, L., Cortese, G., submit July 2012. Holocene and modern dinoflagellate cyst flux in subtropical and subantarctic waters, SW Pacific Ocean. From Chapter 3, for submission to Marine Geology

Prebble, J.G., Crouch, E.C, Carter, L., Cortese, G., Neil, H. In preparation. Marine productivity during warm MIS11, east Tasman Sea, SW Pacific. From Chapter 5.

Prebble, J.G., Crouch, E.C, Carter, L., Cortese, G. In preparation Marine-terrestrial climate during MIS11, South Island, New Zealand. From Chapter 6.

\subsection{Conference presentations from this thesis:}

Prebble, J.G., Crouch, E.C, Carter, L., Cortese, G., Neil, H. Marine response to warm MIS11, east Tasman Sea, New Zealand. To be presented at IPC, Tokyo, August 2012

Prebble, J.G., Crouch, E.C, Carter, L., Cortese, G., Neil, H. Reduction in coastal marine productivity during warm MIS11, offshore West Coast, New Zealand. To be presented at IGC, Brisbane, August 2012 
Prebble, J.G., Crouch, E.C, Carter, L., Cortese, G., Neil, H. A Marine Isotope Stage 11 environments using dinoflagellate cysts. GSNZ annual conference, November 2011, Nelson Prebble, J.G., Crouch, E.C, Carter, L., Cortese, G., Warm Quaternary interglacials: dinocysts and pollen from Site U1352, IODP Exp 317 Post Cruise Meeting, November 2012, Oamaru Prebble, J.G., Crouch, E.C, Carter, L., Cortese, G. A Dinoflagellate cyst temperature transfer function for the Southwest Pacific Ocean and Southern Hemisphere, Dino9 Conference, August 2011, Liverpool.

Prebble, J.G., Crouch, E.C, Carter, L., Cortese, G. Extending the Late Holocene dinoflagellate Cyst reference dataset for the New Zealand region. GSNZ annual conference, November 2010, Auckland. 


\section{Chapter 1}


Chapter 2

\title{
2. Sea floor dinoflagellate cysts from the Southwest Pacific and Southern Hemisphere
}

\begin{abstract}
Dinoflagellate cyst (dinocyst) assemblages are examined in 120 sea floor sediment samples from the SW Pacific and Tasman Sea to build up a picture of dinocyst distribution in the region. From these, census counts of 40 samples are added to previously published census data from the Southern Hemisphere to form a modern dataset of 311 samples.

Cluster analysis ( $k$-means clustering) of a 98 SW Pacific subset reveals four distinct assemblages, whose distribution coincides with known oceanographic boundaries and water masses with distinct assemblages identified within: Subantarctic surface water, the Subtropical Front and Subtropical surface water. A similar clustering exercise of the 311 sample Southern Hemisphere dataset reveals an additional three assemblages, two associated with Polar waters colder than those sampled in the SW Pacific, and one that may be endemic in the Southern Hemisphere to the South Atlantic.

Multivariate ordination (canonical correspondence analysis and redundancy analysis) indicates that the dinocyst assemblages change most along a sea surface temperature (SST) gradient, in both the Southern Hemisphere and regional SW Pacific datasets. SST accounts for $38 \%$ to $56 \%$ of the species-environmental relationship after removal of covarying variables, and contributes 2-3 times the explainable inertia than any of the secondary environmental variables tested.
\end{abstract}

The modern dataset is suitable for use as a training set for quantitative paleotemperature transfer functions applied to the Late Quaternary records in the New Zealand region, with the caveat that the modern assemblage also displays considerable 
Chapter 2

sensitivity to productivity, shoreline proximity, and water mass; sensitivity that may be exploited in certain situations.

\subsection{Introduction}

Dinoflagellates are unicellular planktonic protists (Fensome et al., 1996). A small proportion of dinoflagellate species (about 10-20\%) produce an organic-walled cyst that may be preserved in the fossil record (Dale, 1996). More detail on dinoflagellate ecology is presented in Chapters $\mathbf{3}$ and $\mathbf{4}$.

The composition of dinoflagellate cyst (dinocyst) assemblages in modern sediments has been shown to vary along various environmental gradients. Statistical ordination techniques applied to a global dataset of modern sea floor samples indicate that changes in relative composition of cyst assemblages are most pronounced along gradients of SST, phosphate, and nitrate concentrations (Marret and Zonneveld, 2003). The empirical relationships observed in modern sediments have been used to interpret Quaternary paleoenviromental conditions using fossil assemblages. These include semiquantitative approaches (e.g., Esper at al., 2004; Verleye and Louwye, 2010a) or mathematical transfer functions that quantify environmental parameters such as SST, salinity, sea ice cover or productivity (e.g., Peyron and de Vernal, 2001; Marret et al., 2008; Bonnet et al., 2010).

Exploration of regional datasets reveals significant local exceptions to these global, latitudinal trends. The most common exception is faunal change in response to changes in primary productivity (Radi and de Vernal, 2004, 2008; Marret et al., 2008; Pospelova et al., 2008; Verleye and Louwye, 2010), and significant variability in dinocyst assemblages has also been identified along gradients of sea-ice cover and salinity (Rochon et al., 1999; de Vernal et al., 2001; Radi et al., 2001; Bonnet et al., 2012). The reports of regional variations at odds with global trends, combined with a degree of endemism in modern distributions apparently uncorrelated to major environmental 
gradients (Marret and Zonneveld, 2003; Verleye et al., 2011), strongly suggest that regional studies of modern dinocyst distributions are necessary prior to attempting paleo-reconstructions from that region.

In the SW Pacific, the basis for a regional modern dinocyst dataset suitable for faunal transfer functions already exists (Marret and de Vernal, 1997; Marret et al., 2001; Crouch et al., 2010), building on earlier work documenting the diversity of assemblages in this region (McMinn, 1990, 1992; Sun and McMinn, 1994). Further, the utility of fossil dinocysts for quantitative reconstruction of Late Quaternary sea surface conditions has been demonstrated in the region, where dinocyst assemblages from sediment core samples from 125 ka to present at Deep Sea Drilling Project (DSDP) Site 594 were used to infer SST and salinity (Marret et al., 2001). That reconstruction of SST (and salinity, which largely covaries with SST in the waters around DSDP 594) is largely supported by the results of an ordination of 38 sea floor samples from the east of New Zealand (Crouch et al., 2010), which found SST correlated strongly to assemblage changes. However, assemblage variation was also correlated with autumn chlorophyll- $a$ concentrations, particularly in the vicinity of the Subtropical Front, a zone of regionally elevated primary productivity.

In this chapter, we present new dinocyst census counts of 40 sea floor sediment samples from the SW Pacific $\left(15^{\circ} \mathrm{S}-68^{\circ} \mathrm{S}, 145^{\circ} \mathrm{E}-170^{\circ} \mathrm{W}\right)$, along with additional counts from 80 samples of lower dinocyst density. Areas previously unsampled for dinocyst assemblages are examined, including the east and central Tasman Sea and the New Zealand sector of the Southern Ocean, and the sampling density in waters to the east of New Zealand is also increased. These data are combined with published dinocyst census data from the SW Pacific region to form a regional data base of 98 samples (NZ-98), and a Southern Hemisphere dataset of 311 samples (SH-311). We document the extent to which cyst assemblages in the regional and hemispheric datasets respond to known environmental variables, including SST and productivity. The reason for exploring a regional subset of the Hemispheric dataset are to confirm that the broader trends 


\section{Chapter 2}

A
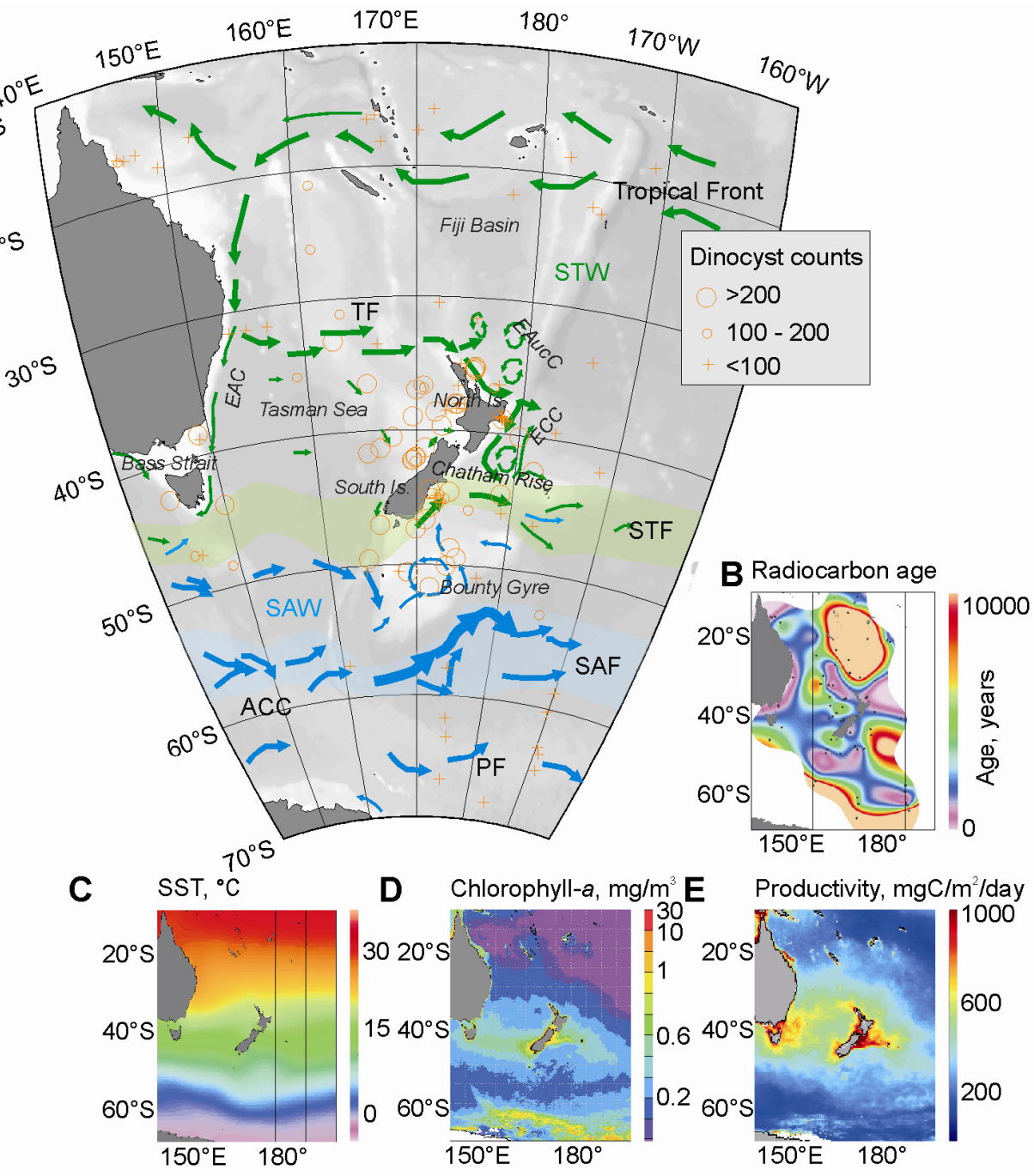

D Chlorophyll-a, $\mathrm{mg} / \mathrm{m}^{3} \mathbf{E}$
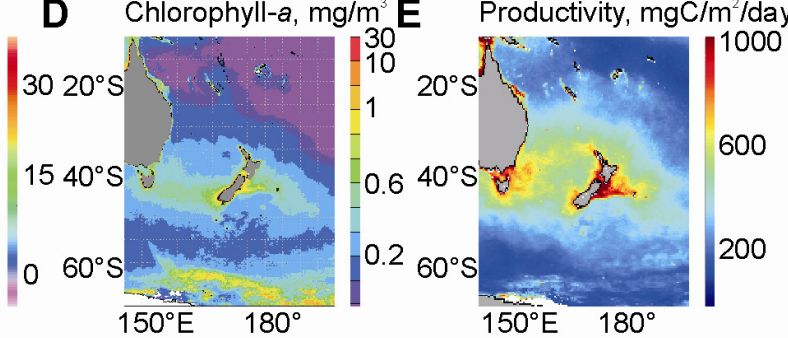

$\mathbf{F}$

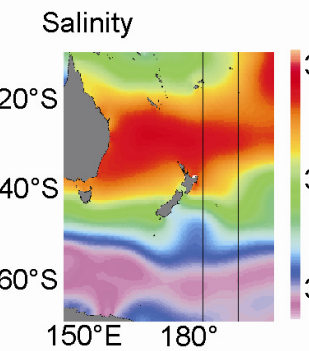

G Nitrate, $\mu \mathrm{mol} / /$

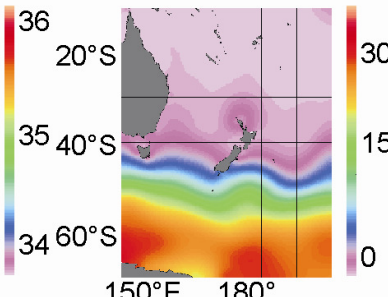

H Phosphate, $\mu \mathrm{mol} / \mathrm{I}$

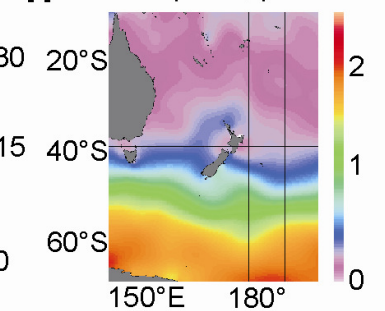

Figure 2.1. A. Sea floor samples examined for dinocysts in this study (orange circles), along with significant surface oceanographic features mentioned in the text. Front locations from Orsi et al., (1995), Carter et al., (1998), Orsi and Harris (2001). EAC = East Australian Current, ECC = East Cape Current, EAucC = East Auckland current, STW = Subtropical water, TF = Tasman Front, STF = Subtropical Front, SAW = Subantartic water, $\mathrm{SAF}=$ Subantarctic Front, $\mathrm{ACC}=$ Antarctic Circumpolar Current, $\mathrm{PF}=$ Polar Front. B. Uncorrected ${ }^{14} \mathrm{C}$ ages of 48 of the 120 sea floor samples examined in this study, contoured with DIVA-gridding from Ocean Data View (Schlitzer, 2011), sample locations black dots. C. Mean annual sea surface temperature (World Ocean Atlas $20091^{\circ}$ climatology, Locarnini et al., 2010). D. Average satellite derived chlorophyll-a, Jul 2002Dec 2010, (MODIS-Aqua data, http://disc.sci.gsfc.nasa.gov/giovanni/, Acker and Leptoukh, 1997). E. Average satellite-derived productivity, Jan 2003 to Dec 2009, (MODIS and SeaWIFSs data, Behrenfeld and Falkowski, 1997). F. Mean annual sea surface salinity (World Ocean Atlas $20091^{\circ}$ climatology, Antonov et al., 2010). G., H. Mean annual nitrate, phosphate (World Ocean Atlas $20091^{\circ}$ climatology, Garcia et al., 2010). 
observed in the Southern Hemisphere apply to the SW Pacific, and to determine the relative merits of regional versus larger training sets for palaeo-environmental reconstructions.

\subsection{Modern Oceanography, SW Pacific}

The study area covers almost $60^{\circ}$ of latitude, from the tropics to Southern Ocean waters surrounding Antarctica, and extends from the east Australian margin to the eastern edge of the submerged continental platform of New Zealand (Figure 2.1).

A major oceanographic feature of the region is the Subtropical Front (STF). Not only does this feature separate Subtropical from Subantarctic surface water masses, but it also forms the boundary between two contrasting circulation systems.

North of the STF is the counter-clockwise South Pacific Gyre, whose path is controlled by the Australian and New Zealand continents as well as regional winds (Heath, 1985; Roemmich, 2007; Roemmich et al., 2007). The northernmost part of this gyral flow is a wide band of the westward flowing waters between the equator and about $30^{\circ} \mathrm{S}$, with flows concentrated into several jets (Kessler and Gourdeau, 2007), some of which feeds the southward-flowing East Australian Current (EAC) (Ridgway and Dunn, 2003). Part of the EAC is deflected east across the Tasman Sea, where it forms the diffuse Tasman Front zone around $30^{\circ} \mathrm{S}$ (Chiswell et al., 1997; Ridgway and Dunn, 2003), while the remainder of the EAC continues south as far as Tasmania (Ridgway, 2007). After crossing the northern Tasman Sea, this western limb of the gyral circulation continues down the eastern continental margin of the North Island, New Zealand, as the East Auckland and East Cape currents (Stanton et al., 1997; Tilburg et al., 2001). At $\sim 44^{\circ} \mathrm{S}$, it is deflected eastwards along the northern flank of Chatham Rise, which forms a local bathymetric guide for the STF situated along the east-west rise crest (Chiswell, 1994; Uddstrom and Oien, 1999).

South of the STF, the circulation is dominated by the eastward flowing Antarctic Circumpolar Current (ACC) (Carter et al., 1998; Morris et al., 2001; Sokolov and Rintoul, 
2009). As the flow approaches New Zealand, the dominant frontal systems that form the northern part of the ACC, namely the Subantarctic (SAF) and Polar (PF) fronts are forced to return north by the western boundary of the Campbell Plateau to around $50^{\circ} \mathrm{S}$ before returning eastward. Part of the SAF flow passes northwestward though a gap in the plateau to contribute to the clockwise Bounty Gyre, part of which flows along the southern flank of the Chatham Rise.

\subsection{Data collection and compilation of dataset}

\subsubsection{Modern samples}

One hundred-twenty sea floor sediment samples from the SW Pacific $\left(15^{\circ} \mathrm{S}-68^{\circ} \mathrm{S}, 145^{\circ} \mathrm{E}\right.$ - $170^{\circ} \mathrm{W}$ ) have been analysed for dinocysts (Figure 2.1; Table 2.1). Sample collection devices include piston corers (topmost sample), multicorers (top 20mm), box corers, and grabs.

Radiocarbon ages were obtained for 48 of the samples examined. Between 100-200 individual mixed planktic foraminifera (Globigerina bulloides and Globigerina inflata) were picked for each sample, equivalent to 5-10 mg of $\mathrm{CaCO}$. Of these, nine samples had a ${ }^{14} \mathrm{C}$ age greater than $7 \mathrm{ky}$ and were not included in the dinocyst dataset (although all samples with pre-Holocene ${ }^{14} \mathrm{C}$ ages also had very low concentrations of dinocysts). This cutoff age was selected as local SST records varied less than $2^{\circ} \mathrm{C}$ during the last $7 \mathrm{ka}$ (Pahnke et al., 2003; Pahnke and Sachs, 2006;

Barrows et al., 2007; Sikes et al., 2009; Haywood et al., 2008; 2012). The distribution of ages (Figure 2.1B) shows that samples from the New Zealand continental shelf, and most from the Tasman Sea, had radiocarbon ages younger than 4000 years. PreHolocene $14 \mathrm{C}$ ages were most common in polar and tropical waters, in water depths $>2500 \mathrm{~m}$. There is a particularly strong gradient of increasing sea floor age across the Subantarctic Front. Although the $\sim 1200$-year ${ }^{14} \mathrm{C}$ age of surface waters in high latitudes of the Southern Ocean contributes to this gradient (Sikes et al., 2000; Hall et al., 2010), the assemblages from these high latitude sea floor samples may represent an 


\section{Chapter 2}

Table 2.1. Sea floor samples examined in this study. Institutions supplying samples: $K=$ Kochi University; $\mathrm{O}=$ Oregon State University; $\mathrm{G}=$ Texas $\mathrm{A} \& \mathrm{M}$ University; $\mathrm{N}=\mathrm{NIWA}$; $\mathrm{S}=$ Canterbury University; $W=$ Woods Hole Oceanographic Institute; $V=$ Victoria University of Wellington. Ages for samples 110-120 are not based on direct C-14 determinations, but on accumulation rate studies of the Poverty Bay margin (Miller and Kuehl, 2010)

\begin{tabular}{|c|c|c|c|c|c|c|c|c|c|}
\hline & Station & $\begin{array}{c}\text { GNS } \\
\text { Science } \\
\text { laboratory } \\
\text { number }\end{array}$ & Longitude & Latitude & $\begin{array}{l}\text { Depth } \\
(\mathrm{m})\end{array}$ & $\begin{array}{c}\text { Distance } \\
\text { from shore } \\
(\mathrm{km})\end{array}$ & $\mid \begin{array}{c}\text { Source and } \\
\text { device }\end{array}$ & $\begin{array}{c}\text { Age } \\
\text { (radiocarbon } \\
\text { years } \mathrm{C}_{14} \text { ) }\end{array}$ & $\begin{array}{l}\text { Dinocyst } \\
\text { Sum }\end{array}$ \\
\hline 1 & $1172 \mathrm{C}$ & L24193 & 149.93 & -43.96 & 2622 & 185 & K HPC & $4242 \pm 25$ & 295 \\
\hline 2 & $593 \mathrm{~A}$ & L24194 & 167.68 & -40.51 & 1068 & 356 & $\mathrm{KHPC}$ & $5443 \pm 30$ & 303 \\
\hline 3 & $588 \mathrm{~B}$ & L24195 & 161.23 & -26.11 & 1533 & 656 & K HPC & $5716 \pm 25$ & 165 \\
\hline 4 & 592 & L24196 & 165.44 & -36.47 & 1088 & 830 & K HPC & $6439 \pm 30$ & 343 \\
\hline 5 & $1170 \mathrm{C}$ & L24197 & 146.05 & -47.15 & 2703 & 389 & K HPC & $6899 \pm 30$ & 59 \\
\hline 6 & $1169 \mathrm{~A}$ & L24198 & 145.24 & -47.07 & 3568 & 380 & K HPC & & 184 \\
\hline 7 & $1171 \mathrm{C}$ & L24199 & 149.11 & -48.50 & 2148 & 558 & K HPC & & 171 \\
\hline 8 & $590-B$ & L24200 & 163.36 & -31.17 & 1299 & 971 & $\mathrm{KHPC}$ & $5069 \pm 25$ & 120 \\
\hline 9 & $1168 \mathrm{C}$ & L24201 & 144.41 & -42.61 & 2464 & 66 & K HPC & & 334 \\
\hline 10 & 587 & L24202 & 161.33 & -21.19 & 1101 & 292 & K HPC & $2598 \pm 25$ & 145 \\
\hline 11 & $01 \mathrm{BC}$ & L24203 & 173.73 & -48.73 & 638 & 392 & O Box & $4566 \pm 40$ & 224 \\
\hline 12 & $11 \mathrm{BC}$ & L24204 & -169.32 & -63.63 & 2783 & 2347 & $\mathrm{OBox}$ & $1045 \pm 50$ & 22 \\
\hline 13 & $10 \mathrm{MC} 1$ & L24205 & -174.69 & -53.04 & 5470 & 1307 & O Multi & & 183 \\
\hline 14 & $7 \mathrm{BC}$ & L24206 & 174.24 & -66.83 & 3260 & 481 & $\mathrm{OBox}$ & $15417 \pm 80$ & 0 \\
\hline 15 & $9 B C$ & L24207 & -176.37 & -68.41 & 3730 & 571 & O Box & & 0 \\
\hline 16 & 02BC & L24208 & 174.23 & -57.81 & 5344 & 1250 & O Box & & 2 \\
\hline 17 & $820 \mathrm{~B}$ & L24209 & 146.30 & -16.64 & 279 & 20 & G HPC & & 96 \\
\hline 18 & $830 \mathrm{~A}$ & L24210 & 166.78 & -15.95 & 1018 & 35 & G HPC & & 18 \\
\hline 19 & $1119 \mathrm{C}$ & L24211 & 172.39 & -44.76 & 396 & 90 & G HPC & & 102 \\
\hline 20 & $1121 \mathrm{~A}$ & L24212 & 177.00 & -50.90 & 4492 & 720 & G HPC & & 0 \\
\hline 21 & TAN0803-27 & L24213 & 164.61 & -49.52 & 3250 & 361 & N Piston & & 203 \\
\hline 22 & TAN0803-9 & L24214 & 166.06 & -47.00 & 1648 & 102 & N Piston & & 305 \\
\hline 23 & Q633 & L24215 & 148.89 & -38.46 & 2350 & 66 & N Grab & $764 \pm 30$ & 326 \\
\hline 24 & H555 & L24216 & 178.98 & -45.92 & 2738 & 530 & N Grab & $8044 \pm 35$ & 332 \\
\hline 25 & J39 & L24217 & 170.00 & -37.00 & 2096 & 382 & N Grab & $2030 \pm 35$ & 326 \\
\hline 26 & J1037 & L24218 & 172.97 & -45.08 & 1349 & 150 & N Grab & & 119 \\
\hline 27 & F150 & L24219 & 174.47 & -49.47 & 501 & 487 & N Grab & $609 \pm 50$ & 368 \\
\hline 28 & $\mathrm{~J} 668$ & L24220 & 177.65 & -36.39 & 2571 & 132 & N Grab & $478 \pm 20$ & 202 \\
\hline 29 & G944 & L24221 & 179.99 & -40.12 & 2890 & 200 & N Grab & $2718 \pm 40$ & 227 \\
\hline 30 & $\mathrm{~J} 484$ & L24222 & 168.99 & -50.58 & 575 & 380 & N Grab & $4120 \pm 25$ & 313 \\
\hline 31 & J1049 & L24223 & 178.73 & -44.50 & 1339 & 458 & N Grab & $6760 \pm 35$ & 306 \\
\hline 32 & S569 & L24224 & 171.99 & -30.47 & 2550 & 430 & N Grab & $10972 \pm 40$ & 2 \\
\hline 33 & S0136-11 & L24225 & 170.00 & -42.00 & 1000 & 113 & S Gravity & $1456 \pm 50$ & 313 \\
\hline 34 & Q703 & L24226 & 170.92 & -41.40 & 202 & 121 & N Grab & & 302 \\
\hline 35 & Q722 & L24227 & 169.60 & -42.20 & 167 & 139 & N Grab & & 325 \\
\hline 36 & SR223 & L24286 & 166.53 & -33.53 & 2860 & 587 & O Piston & $674 \pm 20$ & 6 \\
\hline 37 & SR177 & L24287 & 156.91 & -31.51 & 4280 & 395 & O Piston & & 5 \\
\hline 38 & SR167 & L24288 & 155.02 & -31.51 & 4650 & 200 & O Piston & & 6 \\
\hline 39 & SR156 & L24289 & 153.56 & -31.57 & 3770 & 56 & O Piston & $-1537 \pm 50$ & 51 \\
\hline 40 & $06 \mathrm{BC}$ & L24290 & 174.78 & -63.29 & 2429 & 1826 & O Box & $4753 \pm 55$ & 3 \\
\hline 41 & $08 \mathrm{MC1}$ & L24291 & -169.98 & -58.69 & 4324 & 1916 & O Multi & $4893 \pm 55$ & 9 \\
\hline 42 & $05 \mathrm{MC1}$ & L24292 & -169.74 & -63.11 & 2927 & 2266 & O Multi & $1429 \pm 50$ & 2 \\
\hline 43 & $07 \mathrm{MC1}$ & L24293 & -170.19 & -60.24 & 3860 & 1978 & O Multi & $3418 \pm 50$ & 54 \\
\hline 44 & $4 \mathrm{BC}$ & L24294 & 174.42 & -61.77 & 4240 & 1672 & O Box & $6827 \pm 40$ & 1 \\
\hline 45 & $10 \mathrm{BC}$ & L24295 & -168.78 & -65.03 & 2930 & 2435 & O Box & $13837 \pm 70$ & 2 \\
\hline 46 & $1120 \mathrm{C}$ & L24296 & 173.37 & -50.06 & 546 & 477 & G HPC & & 208 \\
\hline 47 & $834 \mathrm{~B}$ & L24297 & -177.86 & -18.57 & 2688 & 62 & G Rotary & & 15 \\
\hline 48 & $813 \mathrm{~A}$ & L24298 & 149.49 & -17.83 & 539 & 268 & G HPC & $5269 \pm 30$ & 0 \\
\hline 49 & $824 \mathrm{~B}$ & L24299 & 147.76 & -16.45 & 1002 & 201 & G HPC & $1279 \pm 20$ & 7 \\
\hline 50 & $1124 \mathrm{~A}$ & L24300 & -176.53 & -39.50 & 3968 & 473 & G HPC & & 9 \\
\hline 51 & $1122 \mathrm{C}$ & L24301 & -177.39 & -46.58 & 4432 & 804 & G HPC & & 14 \\
\hline 52 & $823 \mathrm{~B}$ & L24302 & 146.78 & -16.62 & 1638 & 80 & G HPC & $2150 \pm 20$ & 6 \\
\hline
\end{tabular}




\section{Chapter 2}

Table 2.1. Continued

\begin{tabular}{|c|c|c|c|c|c|c|c|c|c|}
\hline & Station & $\begin{array}{c}\text { GNS } \\
\text { Science } \\
\text { laboratory } \\
\text { number }\end{array}$ & Longitude & Latitude & $\begin{array}{c}\text { Depth } \\
(\mathrm{m})\end{array}$ & $\begin{array}{c}\text { Distance } \\
\text { from shore } \\
(\mathrm{km})\end{array}$ & $\begin{array}{c}\text { Source and } \\
\text { device }\end{array}$ & $\begin{array}{c}\text { Age } \\
\text { (radiocarbon } \\
\text { years } \mathrm{C}_{14} \text { ) }\end{array}$ & $\begin{array}{c}\text { Dinocyst } \\
\text { Sum }\end{array}$ \\
\hline 53 & $840 B$ & L24303 & -175.75 & -22.22 & 743 & 728 & $\mathrm{G} \times \mathrm{CB}$ & $2398 \pm 25$ & 31 \\
\hline 54 & $822 \mathrm{~A}$ & L24304 & 146.22 & -16.42 & 955 & 68 & G HPC & $324 \pm 20$ & 17 \\
\hline 55 & 1123B & L24305 & -171.50 & -41.79 & 3290 & 989 & G HPC & $2927 \pm 50$ & 11 \\
\hline 56 & TAN803-127 & L24307 & 160.87 & -57.56 & 3830 & 1230 & N Gravity & & 6 \\
\hline 57 & TAN803-40 & L24308 & 164.29 & -50.43 & 3524 & 416 & N Piston & & 92 \\
\hline 58 & S0136-003 & L24309 & 169.88 & -42.30 & 958 & 94 & S Gravity & $4205 \pm 50$ & 195 \\
\hline 59 & Q723 & L24310 & 169.56 & -42.22 & 507 & 115 & S Grab & & 236 \\
\hline 60 & Q699 & L24311 & 169.30 & -42.42 & 698 & 110 & S Grab & & 249 \\
\hline 61 & $\mathrm{~J} 50$ & L24312 & 170.65 & -36.67 & 2112 & 292 & N Grab & $1564 \pm 35$ & 204 \\
\hline 62 & J51 & L24313 & 170.70 & -36.87 & 2000 & 306 & N Grab & $2770 \pm 35$ & 177 \\
\hline 63 & $\times 250$ & L24314 & 177.19 & -36.67 & 2835 & 135 & N Grab & $2290 \pm 35$ & 118 \\
\hline 64 & Q636 & L24315 & 149.01 & -38.82 & 2450 & 109 & N Grab & $2356 \pm 30$ & 95 \\
\hline 65 & S631 & L24316 & 172.11 & -45.33 & 1329 & 86 & N Grab & $1502 \pm 35$ & 32 \\
\hline 66 & U203 & L24317 & 159.10 & -35.55 & 4744 & 740 & N Grab & & 140 \\
\hline 67 & P933 & L24318 & 165.22 & -41.66 & 4421 & 350 & N Grab & $2260 \pm 30$ & 321 \\
\hline 68 & G820 & L24319 & 162.60 & -33.15 & 793 & 931 & N Grab & $8710 \pm 35$ & 211 \\
\hline 69 & F88 & L24320 & 168.00 & -50.53 & 444 & 364 & N Grab & & 25 \\
\hline 70 & $\mathrm{~J} 21$ & L24321 & 169.65 & -39.00 & 560 & 302 & N Grab & $7765 \pm 35$ & 250 \\
\hline 71 & I168 & L24322 & 188.98 & -18.26 & 4833 & 28 & N Grab & & 88 \\
\hline 72 & U614 & L24323 & 175.29 & -31.58 & 3700 & 370 & N Grab & $11537 \pm 50$ & 16 \\
\hline 73 & G977 & L24324 & 185.93 & -33.86 & 5883 & 431 & N Grab & & 11 \\
\hline 74 & 1171 & L24325 & 185.01 & -22.66 & 3496 & 498 & N Grab & $5899 \pm 35$ & 2 \\
\hline 75 & Z3230 & L24326 & 177.73 & -21.99 & 4115 & 374 & N Grab & $29670 \pm 200$ & 0 \\
\hline 76 & P937 & L24327 & 166.46 & -41.32 & 3253 & 331 & N Grab & $4263 \pm 30$ & 209 \\
\hline 77 & $21-209 A$ & L24328 & 152.19 & -15.94 & 1428 & 203 & K Rotary & & 0 \\
\hline 78 & 70PC & L24329 & 171.38 & -15.48 & 3312 & 327 & W Piston & $14631 \pm 50$ & 0 \\
\hline 79 & $59 \mathrm{PC}$ & $\mathrm{L} 24330$ & 166.20 & -16.27 & 4490 & 96 & W Piston & & 11 \\
\hline 80 & 57PC & L24331 & 167.19 & -18.06 & 4215 & 97 & W Piston & & 18 \\
\hline 81 & $54 \mathrm{PC}$ & L24332 & 170.15 & -17.18 & 3069 & 164 & W Piston & & 0 \\
\hline 82 & 1125B & L24506 & -178.17 & -42.55 & 1366 & 493 & G HPC & & 211 \\
\hline 83 & $\mathrm{H} 347$ & L24575 & 173.42 & -44.54 & 543 & 80 & N Grab & & 280 \\
\hline 84 & $\mathrm{H} 534$ & L24576 & 172.70 & -45.35 & 1462 & 128 & N Grab & & 38 \\
\hline 85 & $\mathrm{H} 562$ & $\mathrm{~L} 24577$ & 175.49 & -45.87 & 1777 & 351 & N Grab & & 111 \\
\hline 86 & A811 & L24578 & 171.36 & -44.40 & 22 & 6 & N Grab & & 223 \\
\hline 87 & A812 & L24579 & 171.65 & -44.68 & 79 & 36 & N Grab & & 112 \\
\hline 88 & H531 & L24580 & 172.14 & -44.86 & 209 & 76 & N Grab & & 18 \\
\hline 89 & $\mathrm{H} 533$ & L24581 & 172.37 & -45.05 & 1302 & 94 & N Grab & & 119 \\
\hline 90 & S632 & L24582 & 172.48 & -45.31 & 1428 & 111 & N Grab & & 145 \\
\hline 91 & G678 & L24583 & 171.42 & -45.72 & 1400 & 49 & N Grab & & 204 \\
\hline 92 & C169 & L24584 & 172.42 & -39.67 & 234 & 92 & N Grab & & 362 \\
\hline 93 & C266 & L24585 & 174.50 & -38.33 & 49 & 12 & N Grab & & 8 \\
\hline 94 & $\mathrm{C} 275$ & L24586 & 173.73 & -38.33 & 137 & 77 & N Grab & & 0 \\
\hline 95 & C293 & L24587 & 173.96 & -38.02 & 238 & 64 & N Grab & & 65 \\
\hline 96 & E405 & L24588 & 169.92 & -47.33 & 1004 & 87 & N Grab & & 425 \\
\hline 97 & E411 & L24589 & 170.98 & -46.64 & 1244 & 80 & N Grab & & 215 \\
\hline 98 & E441 & L24590 & 172.83 & -38.50 & 498 & 111 & N Grab & & 29 \\
\hline 99 & E453 & L24591 & 173.83 & -38.00 & 794 & 75 & N Grab & & 334 \\
\hline 100 & E544 & L24592 & 175.39 & -35.33 & 797 & 81 & N Grab & & 379 \\
\hline 101 & E577 & L24593 & 174.04 & -34.99 & 108 & 4 & N Grab & & 19 \\
\hline 102 & E898 & L24594 & 173.88 & -38.00 & 506 & 69 & N Grab & & 26 \\
\hline 103 & E900 & L24595 & 173.63 & -38.02 & 974 & 91 & N Grab & & 325 \\
\hline 104 & F58 & L24596 & 175.32 & -35.23 & 922 & 79 & N Grab & & 310 \\
\hline
\end{tabular}


Table 2.1. Continued

\begin{tabular}{|c|c|c|c|c|c|c|c|c|c|}
\hline & Station & $\begin{array}{c}\text { GNS } \\
\text { Science } \\
\text { laboratory } \\
\text { number }\end{array}$ & Longitude & Latitude & $\begin{array}{c}\text { Depth } \\
\text { (m) }\end{array}$ & $\begin{array}{c}\text { Distance } \\
\text { from shore } \\
(\mathrm{km})\end{array}$ & $\begin{array}{c}\text { Source and } \\
\text { device }\end{array}$ & $\begin{array}{c}\text { Age } \\
\text { (radiocarbon } \\
\text { years } \mathrm{C}_{14} \text { ) }\end{array}$ & $\begin{array}{c}\text { Dinocyst } \\
\text { Sum }\end{array}$ \\
\hline 105 & $\mathrm{~F} 59$ & L24597 & 175.39 & -35.13 & 1176 & 90 & N Grab & & 341 \\
\hline 106 & F137 & L24598 & 171.52 & -51.70 & 519 & 576 & N Grab & & 224 \\
\hline 107 & F728 & L24599 & 171.80 & -38.63 & 1233 & 181 & N Grab & & 214 \\
\hline 108 & 120 & L24600 & 175.21 & -35.42 & 514 & 61 & N Grab & & 231 \\
\hline 109 & E887 & L24601 & 173.88 & -36.67 & 379 & 29 & N Grab & & 23 \\
\hline 110 & RR1001-S102 & L24663 & 178.08 & -38.79 & 34 & 14 & V Grab & $<500$ & 4 \\
\hline 111 & RR1001-S103b & L24664 & 178.04 & -38.74 & 24 & 9 & V Grab & $<500$ & 14 \\
\hline 112 & RR1001-S105 & L24665 & 178.23 & -38.88 & 110 & 31 & V Grab & $<500$ & 32 \\
\hline 113 & RR1001-S119b & L24666 & 178.06 & -38.77 & 29 & 12 & V Grab & $<500$ & 9 \\
\hline 114 & RR1001-S130 & L24667 & 178.20 & -38.94 & 128 & 34 & V Grab & $<500$ & 237 \\
\hline 115 & RR1001-S131 & L24668 & 178.23 & -38.99 & 882 & 39 & V Grab & $<500$ & 2 \\
\hline 116 & RR1001-S146 & L24669 & 178.16 & -38.83 & 52 & 23 & V Grab & $<500$ & 19 \\
\hline 117 & RR1001-S147 & L24670 & 178.22 & -38.85 & 77 & 28 & V Grab & $<500$ & 38 \\
\hline 118 & U1747 4-6cm & L24703 & 178.53 & -39.03 & 1468 & 62 & N Multi & $<500$ & 42 \\
\hline 119 & W696 & L24704 & 178.41 & -38.97 & 1303 & 50 & N Multi & $<500$ & 45 \\
\hline 120 & W695 4-6cm & L24705 & 178.70 & -39.10 & 2384 & 78 & N Multi & $<500$ & 38 \\
\hline
\end{tabular}

accumulation period covering deglacial to modern times. There are consistently old (>10,000 year) ${ }^{14} \mathrm{C}$ ages from samples in the Fiji Basin, between Norfolk Island, New Caledonia and Tonga.

Samples were processed for dinocyst examination as described in Crouch et al. (2010). Cold $10 \% \mathrm{HCl}$ was added to the dried sample to remove carbonates, followed by 24 hours in cold $52 \% \mathrm{HF}$ and a second $10 \% \mathrm{HCl}$ wash. A Lycopodium tablet was added to obtain absolute abundance counts (batch number 938934) (Mertens et al., 2009, 2012). Samples were placed in an ultrasonic bath for up to a minute, sieved through a $6 \mu \mathrm{m}$ mesh to remove small particulate material, then mounted on glass slides in glycerine jelly. All slides and residues are held at GNS Science.

All counts were completed on a Leica binocular light microscope at 500x magnification. For each sample, at least one entire slide was examined, and subsequent slides were examined where fewer than 200 specimens had been identified and reasonable additional effort would surpass this target. Taxonomy followed Rochon et al. (1999), Marret and Zonneveld (2003), and Zonneveld (1997), and references therein, with identification to species level where possible. Broken cysts were counted per 0.25 of a specimen. Count data are in Supplementary Material S2.1. 


\subsubsection{Compilation of dinocyst dataset}

Dinocyst quantitative data from other sources have been combined with the census counts completed here, to collate a Southern Hemisphere dataset (SH-311) and a SW Pacific/ New Zealand region subset (NZ-98). Census data from 311 published samples have been collated. Location maps of each dataset are shown in Figures 2.2 and 2.3. Summary details of each dataset are shown in Table 2.2, while sample details, including environmental variables assigned to each sample, are provided in Supplementary Material S2.2 and S2.3.

Compiled samples are mainly from the Atlantic and SW Pacific, and are from the following sources:

(i) Atlantic sector: 153 samples (Marret and de Vernal, 1997; Harland et al., 1998; Vink et al., 2000, Zonneveld et al., 2001; Holzwarth et al., 2007; Esper and Zonneveld, 2002; 2007; Laurijssen and Zonneveld, unpublished),

(ii) Southern Indian Ocean: 6 samples (Marret and de Vernal, 1997),

(iii) New Zealand/ south of Australia: 98 samples (Marret and deVernal, 1997, Esper and Zonneveld, 2007; Marret et al., 2001; Crouch et al., 2010, this study),

(iv) Central Pacific: 7 samples (Esper and Zonneveld, 2007), and

(v) Eastern Pacific: 48 samples (Verleye and Louwye, 2010b).

Taxonomic groupings followed Marret and Zonneveld (2003), to allow easy integration of these data. Brigantedinium cariacoense, B. simplex, and Dubrudium capitatum were grouped into Brigantedinium spp.; Lejeunecysta spp., cysts of Protoperidinium stellatum, Quinquecuspis concreta, and Votadinium calvum were assigned to Protoperidiniacean cysts; all Nematosphaeropsis were assigned to N. labyrinthus; Spiniferites hyperacanthus was combined with S. mirabilis; S. bulloideus was combined with S. ramosus; S. belerius was combined with S. membranaceus, and cysts of Protoperidinium nudum were assigned to Selenopemphix quanta. 


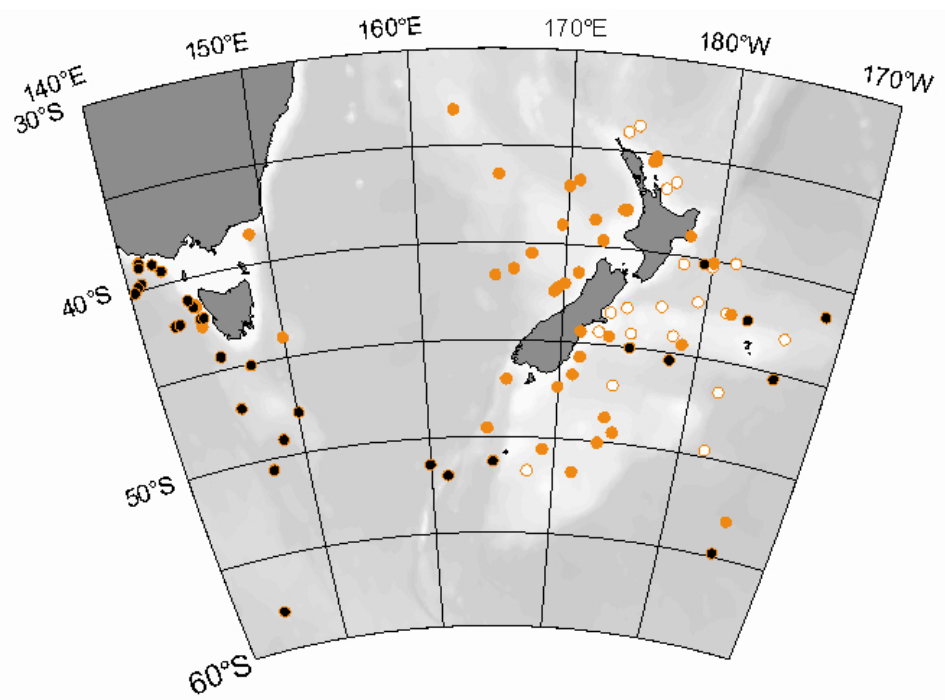

Figure 2.2. Samples included in the NZ-98 compilation. Full circles: this study; white centers: Crouch et al. (2010); black centers: Marret and de Vernal, (1997) and Marret et al., (2001), compiled by Marret (2007) in Esper and Zonneveld (2007).

Figure 2.3. Samples included in the Southern Hemisphere sea floor dinocyst compilation (SH-311). For references see text and supplementary data.

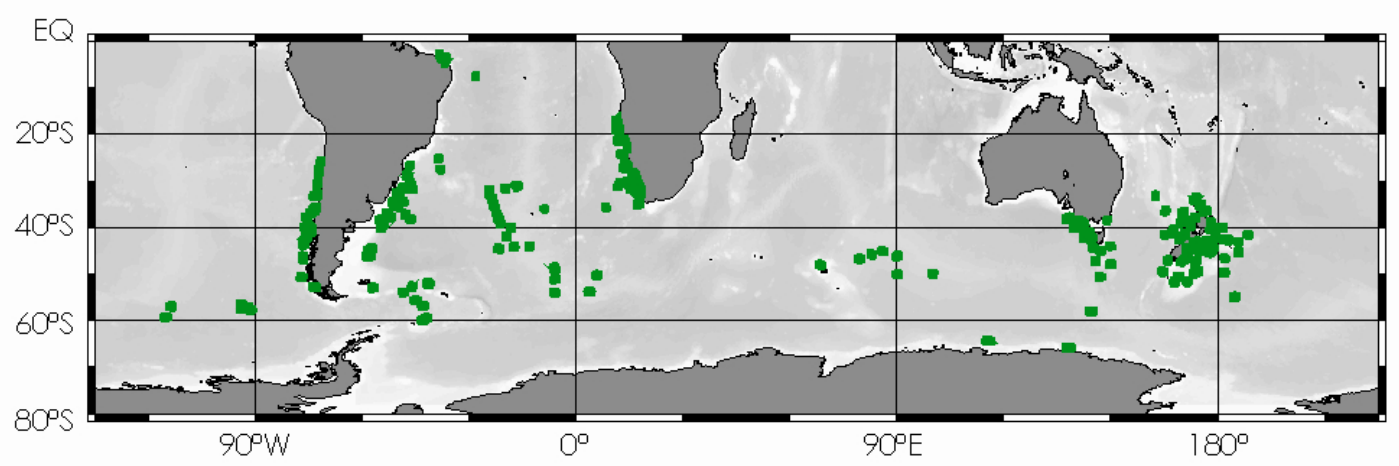

Rare specimens of Selenopemphix sp. 1 (Esper and Zonneveld, 2007) were combined with Selenopemphix antarctica. All Echnidinium were grouped.

Undifferentiated Impagidinium and Spiniferites specimens were removed from the initial counts and the relative abundance of the remainder recalculated. Very rare species (less than two specimens in less than two samples) were removed. Only samples with $>200$ specimens were included in the dataset, except for high latitude sites with a mean annual SST of $<8^{\circ} \mathrm{C}$, where this limitation was relaxed and a minimum 
count size of 100 specimens was allowed. In a global compilation of 460 sea floor dinocyst census counts (with count sum >300) mean diversity for samples with a SST of $<10^{\circ} \mathrm{C}$ is almost half the mean diversity of samples from warmer waters (Figure 2.4). In addition to Southern Hemisphere references mentioned above, data from Rochon et al. (1999), de Vernal et al. (2001), Pospelova et al. (2008), Limoges et al. (2010), and Holzwarth et al. (2010) are included in this compilation for a global comparison. The reduced count size for southern high-latitude samples allows incorporation of cold samples into the dataset with a minimal reduction in predictive power (Traverse, 2007).

Table 2.2. Summary statistics of dinocyst sea floor sample compilations.

\begin{tabular}{|l|c|}
\hline \multicolumn{2}{|c|}{ NZ-98 } \\
\hline Number of stations & 98 \\
\hline Number of taxa & 34 \\
\hline Exclusions & Taxa with proportion $<0.5 \%$ \\
\hline $\begin{array}{l}\text { Mean annual temperature, }{ }^{\circ} \mathrm{C} \\
\text { (minimum, mean, maximum) }\end{array}$ & $2.1,13.4,20.1$ \\
\hline Mean annual salinity & $33.88,34.93,35.59$ \\
\hline $\begin{array}{l}\text { Mean annual productivity, } \\
\text { mgC/m }{ }^{2} / \text { day }\end{array}$ & $163,570,1252$ \\
\hline Mean annual nitrate, $\mu m o l / l$ & $0.63,4.97,20.05$ \\
\hline Mean annual phosphate $\mu$ mol// & $0.20,0.51,1.73$ \\
\hline Mean cyst count & 294 \\
\hline Minimum cyst count for inclusion & 200 where MAT $>8^{\circ} \mathrm{C}$ \\
\hline
\end{tabular}

\begin{tabular}{|c|c|}
\hline \multicolumn{2}{|c|}{ SH-311 } \\
\hline Number of stations & 311 \\
\hline Number of taxa & 37 \\
\hline Exclusions & Taxa with proportion $<0.5 \%$ \\
\hline $\begin{array}{l}\text { Mean annual temperature, }{ }^{\circ} \mathrm{C} \\
\text { (minimum, mean, maximum) }\end{array}$ & $-1.3,14.5,27.2$ \\
\hline Mean annual salinity & $33.31,34.79,36.62$ \\
\hline $\begin{array}{l}\text { Mean annual productivity, } \\
\mathrm{mgC} / \mathrm{m}^{2} / \mathrm{day}^{1}\end{array}$ & $60,664,3816$ \\
\hline Mean annual nitrate, $\mu \mathrm{mol} / \mathrm{l}$ & $0.04,5.73,30.67$ \\
\hline Mean annual phosphate $\mu \mathrm{mol} / \mathrm{l}$ & $0.07,0.63,2.09$ \\
\hline Mean cyst count & 318 \\
\hline Minimum cyst count for inclusion & $\begin{array}{l}200 \text { where MAT }>8^{\circ} \mathrm{C} \\
100 \text { where MAT }<8^{\circ} \mathrm{C}\end{array}$ \\
\hline
\end{tabular}




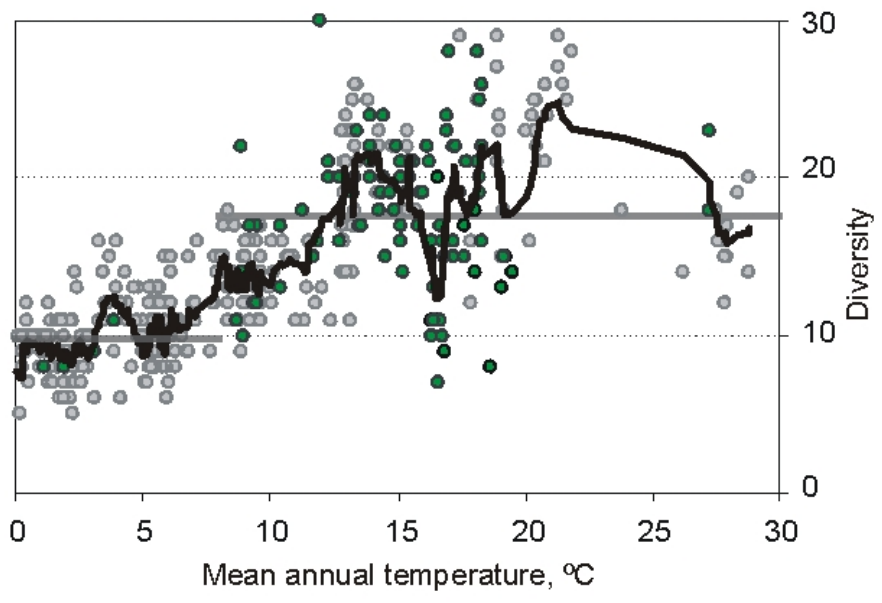

Figure 2.4. Compilation of dinocysts census counts from 451 sea floor samples from around the globe, mean annual temperature plotted against diversity. Minimum count size is 300 specimens. Green points are samples from the Southern Hemisphere, grey points Northern Hemisphere. Black line is a 10 point running mean through all 451 samples, while thick horizontal lines show mean diversity of all samples with mean annual temperature of $<8^{\circ} \mathrm{C}(\mathrm{n}=206$ samples $)$ and $>8^{\circ} \mathrm{C}(\mathrm{n}=245$ samples $)$. See text for data sources.

\subsubsection{Modern environmental data}

SST, salinity, nitrate, phosphate and silica were obtained from the $1^{\circ}$ resolution World Ocean Atlas 2009 (Locarnini et al., 2010; Garcia et al., 2010a; Antonov et al., 2010), and extracted using the interpolation algorithm available in Ocean Data View (Schlitzer, 2011). Phytoplankton tows in the New Zealand region have shown dinoflagellates to be present throughout the euphotic zone, the base of which varies spatially and seasonally between $15 \mathrm{~m}$ and $75 \mathrm{~m}$ (Chang and Gall, 1998). At each sample location, the following variables were extracted for $0 \mathrm{~m}$ and $50 \mathrm{~m}$ water depths: mean annual SST, mean austral seasonal SST, seasonal range (mean SST during the warmest season minus mean temperature during the coldest season), and mean annual nitrate and phosphate. In addition, the average depth for the base of the mixed layer, and oxygen concentration at the sea floor were extracted (Monterey and Levitus, 1997; Garcia et al., 2010b).

Satellite-derived monthly productivity data at $1 / 6^{\circ}$ resolution were also extracted for each sample (Behrenfeld and Falkowski, 1997). The productivity algorithm uses ocean colour and temperature observations from MODIS satellite to calculate average monthly productivity in $\mathrm{mgC} \cdot \mathrm{m}^{2} \cdot \mathrm{d}^{-1}$. For each sample location, the mean annual, mean seasonal, 
and maximum monthly productivity were calculated using January 2006 - December 2009 data, during which time the average monthly ENSO index was close to $0(-0.077)$ (NOAA, 2011). While the reliability of satellite-derived ocean colour and productivity estimates is constantly improving, caution is required with such products. For example, to the south of the SH-311 dataset region, in the Ross Sea, observation of high ocean colour-derived chlorophyll result in muted estimates of productivity (Figure 2.1D, E), while studies of that region have identified the need for productivity algorithms specific to the Ross Sea (e.g., Barbini et al., 2005; Fiorani et al., 2007). Around New Zealand waters, there is generally a better agreement between the ocean colour and productivity estimates, where the SEAWIFS ocean colour algorithm performed well in New Zealand waters for chlorophyll-a concentrations $<0.6 \mathrm{mgm}^{-3}$, but overestimated productivity by a factor of two or more at higher concentrations (Murphy et al., 2001). A recent review of the skill of 21 productivity algorithms found that of Behrenfeld and Falkowski, (1997) had the lowest error rate, but cautioned against over-reliance of ocean colour measurements in coastal waters (Saba et al., 2011).

The environmental variables were subjected to various transformations (square root, cube root, fourth root, squaring, cubing, and $\left.\log _{10}\right)$, with the transformation result closest to a normal distribution retained for gradient analysis (Brooks et al., 2001; Dieffenbacher-Krall et al., 2007). No transformation was required for SST, but the marked negative skew in the nitrate and phosphate distribution curve were brought significantly closer to normal using a $\log _{10}$ transformation, while a similar distribution of productivity data was most improved by using a cubed root. A marked bimodality observed in the SH-311 salinity data was reduced, but not completely removed, with a $\log _{10}$ transformation. The transformations explored did not reduce skew in the distribution for the variables distance from shore, water depth, and temperature range.

\subsubsection{Classification}

Classification allows spatial relationships of the entire dinocyst assemblage to be visualized more easily than inspection of the distribution of individual taxa. It also allows 
examination of relationships independent of environmental gradients, which are explored later by ordination.

Two classification approaches are available: (i) hierarchical classification, which produces a dendrogram output with decreasing similarity as one moves up the tree; and (ii) flat (non-hierarchical) clustering, where the assemblages are assigned to a predefined number of groups. We applied a $k$-Means (non-hierarchical) clustering algorithm to the NZ-98 and SH-311 datasets, using the PAST software (Hammer et al., 2001; Bow, 1984). Hierarchical methods were also explored for the NZ-98 dataset, and resulted in similar groups (Ward's method and UPGMA, Unweighted Pair Group Method with Arithmetic Mean, with Euclidean and Bray-Curtis distance measures), but we found the more primitive non-hierarchical method, with the addition of multiple runs to explore sample instability, more informative and easier to manipulate than hierarchical methods as the datasets became large (Shaw, 2003). In k-Means clustering, the initial cluster assignments are random, and samples are moved iteratively to the cluster, which has the closest cluster mean until the solution stabilizes. The solution varies due to the initial random order, so the stability of samples within clusters was investigated by fifty clustering run replications. Where a sample was assigned to the same cluster for $80 \%$ of the 50 clustering model runs, the allocation of that sample to a given cluster was judged to be 'stable'.

\subsubsection{Ordination}

Environmental gradients that correlate strongly with faunal distribution may be appropriate targets for reconstruction using transfer function inference models. We used ordination methods on both the SH-311 and NZ-98 datasets to determine which of the available environmental variables correlated most strongly to dinocyst distribution. The analysis was completed using CANOCO version 4.53 (ter Braak and Smilauer, 2002).

Two complementary treatments were explored to identify the environmental variables that correlated to change in faunal assemblage: Canonical Correspondence Analysis (CCA)/ Redundancy Analysis (RDA) with automatic forward selection (Marret and 
Zonneveld, 2003; Pospelova et al., 2008; Verleye and Louwye, 2010b) and CCA/RDA with manual identification and removal of covarying environmental variables prior to forward selection (Brooks et al., 2001; Dieffenbacher-Krall et al., 2007). Details of the steps for each approach are contained in Appendix 2.1, and results of the manual forward selection process are described here. We concluded that both treatments produced essentially the same result when considering the contribution of individual environmental variables to total inertia, because the removal of variables following manual forward selection has the effect of reducing the total explainable inertia without altering the contribution of the variables that remain. However, the two treatments produced a different result in the balance of eigenvalues between the ordination axes. Manual removal of covarying environmental variables had the effect of assigning a greater proportion of the total explainable inertia to the first axis, apparently because many of the covarying variables were aligned more closely to subsequent axes. This effect was most pronounced in the NZ-98 dataset, where $43 \%$ of the speciesenvironmental variance was explained by the first axis when all environmental variables were included, but $59 \%$ was explained by the first axis when covarying variables were excluded. In contrast, this effect was subdued in the SH-311 dataset, where the proportion of the species - environmental relationship explained by the first axis rose from $27 \%$ to $38 \%$ with the removal of covarying variables.

\subsection{Results and Discussion}

\subsubsection{Spatial distribution of dinocyst assemblages}

The abundance of dinocyst assemblages varied markedly with latitude and proximity to land (Figure 2.5). High (south of $55^{\circ} \mathrm{S}$ ) and low (north of $35^{\circ} \mathrm{S}$ ) latitudes, and the central Tasman Sea, had particularly low abundances. Illustrations of common taxa are included in Figures 2.6-2.8.

Of the 120 samples examined, $>200$ specimens were counted in 40 samples, with a latitudinal range of $30^{\circ} \mathrm{S}-55^{\circ} \mathrm{S}$ (Figures 2.1-2.2). Their average cyst concentration was 
1640 cysts $\mathrm{g}^{-1}$ dry weight, with a maximum concentration of 6200 cysts $\mathrm{g}^{-1}$ from a sample north of Tasmania in Bass Strait. This range of abundance is similar to previous dinocyst studies in the region (Crouch et al., 2010). The high proportion of nearly barren samples in this study reflects the large number of samples speculatively processed from polar, equatorial, and deep oceanic settings far from land, both to examine regions not previously studied, and to extend the environmental range for the dataset compiled here. The decrease in abundance in oceanic settings is particularly noticeable around New Zealand, where adequate census counts were recorded across the large areas of the submarine plateau and rises but many samples from the abyssal zone were virtually barren. Higher abundances were generally observed in waters off the west coast of New Zealand than those from the east coast of South Island, New Zealand, possibly reflecting higher current action on the east coast shelf compared to the relatively quiescent east Tasman Sea. Such a difference may also reflect higher production of dinoflagellates at localised upwelling hotspots such as submarine canyon heads and Kahurangi Shoals (Chang and Bradford, 1985; Heath and Gilmour, 1987; Chang et al., 1995; Bradford-Grieve et al., 1996) and their subsequent settling in relatively quiet water settings beyond the continental shelf, in contrast to the eastern South Island where productivity in the largely Subantarctic waters is less (e.g. Murphy et al., 2001) and deposition on the continental slope is likely impeded by the rapid flow associated with the local STF (Chiswell, 1996; Sutton, 2003). 
Figure 2.5. Dinocysts per gram dry weight for the 120 samples examined in this study. Samples north of $20^{\circ} \mathrm{S}$ and south of $60^{\circ} \mathrm{S}$ are not shown, as fewer than 100 specimens per sample were observed.

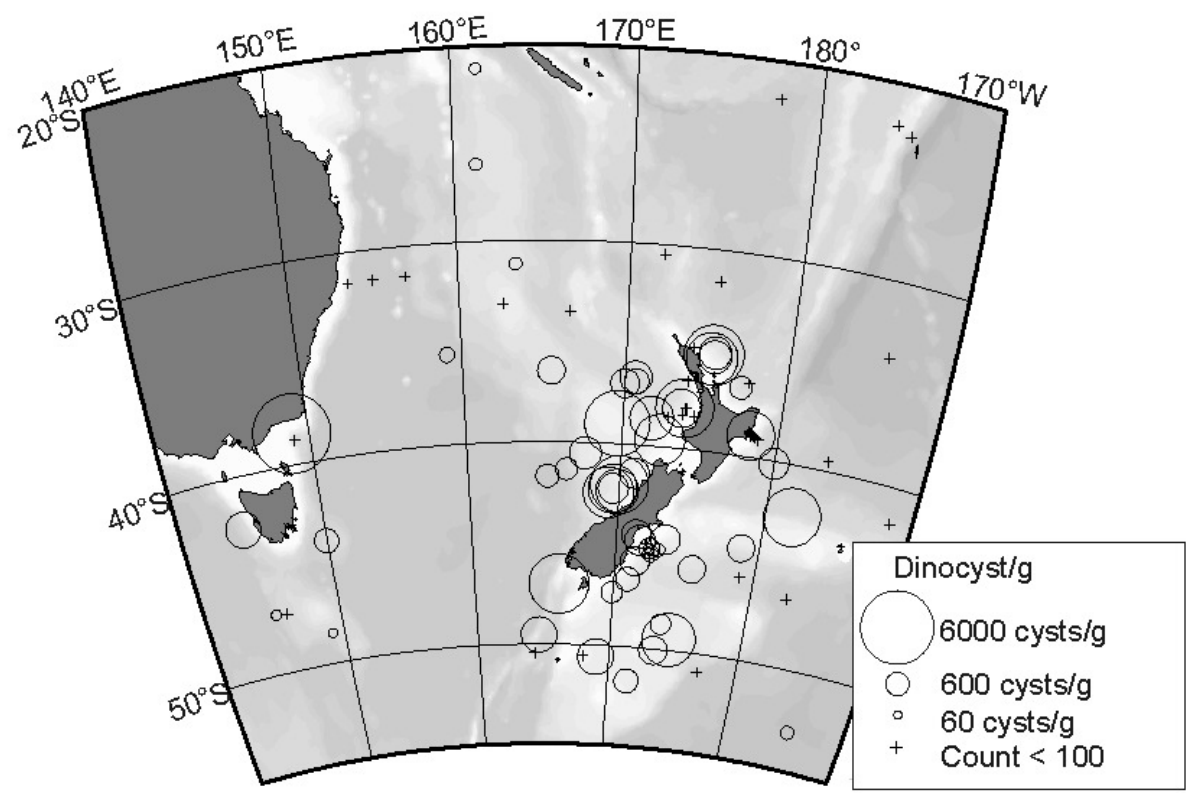

Thirty-four dinocyst taxa were identified in the samples, with the maximum diversity in a single sample being 18 taxa, from a sample within STF waters west of Stewart Island, New Zealand.

While few dinocysts were observed in the tropical samples, those assemblages were characterized by Impagidinium aculeatum, Impagidinium variaseptum, Impagidinium paradoxum, and Impagidinium strilatum in proportions that suggested assemblages different from those of the Tasman Sea. Likewise, dinocysts were too sparse in the high latitude samples for census counts, but Impagidinium pallidum, Selenopemphix antarctica, Brigantedinium spp. and Nematosphaeropsis labyrinthus were the main components of these sparse assemblages.

Within the New Zealand regional (NZ-98) dataset, many taxa show clear trends related to the significant features of the surface ocean. The quantative trends are described below, and their relationship to the position of the STF are summarised in Table 2.3. For this table, and Figures 2.9-2.13, the position of the STF and SAF is described by a single 
Table 2.3. Abundance observations of modern SW Pacific assemblages in relation to the position of the STF, from maps and charts in Figures 2.9 - 2.13. i.e. samples containing $>2 \%$ I. pallidum are only observed south of the STF position defined by Orsi et al., (1995) and Orsi and Harris (2001).

\begin{tabular}{|c|c|c|c|}
\hline & $\begin{array}{l}\text { South of } \\
\text { STF }\end{array}$ & $\begin{array}{c}\text { In STF } \\
\text { and north }\end{array}$ & $\begin{array}{l}\text { North of } \\
\text { STF }\end{array}$ \\
\hline Impagidinium pallidum & $>2 \%$ & & \\
\hline Nematosphaeropsis labyrinthus & $>50 \%$ & & \\
\hline Selenopemphix antarctica & $>1 \%$ & & \\
\hline $\begin{array}{l}\text { Operculodinium centrocarpum LP } \\
\text { sensu Wall and Dale (1966) }\end{array}$ & & $>20 \%$ & \\
\hline $\begin{array}{l}\text { Operculodinium centrocarpum SP } \\
\text { sensu Wall and Dale (1966) }\end{array}$ & & $>1.5 \%$ & \\
\hline Operculodinium janduchenei & & $>1 \%$ & \\
\hline Spinifeities mirabilis group & & $>7 \%$ & \\
\hline Selenopemphix nephroides & & $>2 \%$ & \\
\hline Spiniferities ramosus & & $>15 \%$ & \\
\hline Trinovantedinium applanatum & & $>2 \%$ & \\
\hline Selenopemphix quanta & & $>10 \%$ & \\
\hline Spiniferities membranaceous & & $>2 \%$ & \\
\hline Impagidinium paradoxum & & $>3 \%$ & \\
\hline Impagidinium aculeatum & & & $>30 \%$ \\
\hline Impagidinium plicatum & & & $>1 \%$ \\
\hline Impagidinium strialatum & & & $>2 \%$ \\
\hline Impagidinium variaseptum & & & $>2 \%$ \\
\hline Operculodinium israelianum & & & $>2 \%$ \\
\hline Spiniferities delicatus & & & present \\
\hline
\end{tabular}

line, as estimated by Orsi and Harris $(2001 ; 2008)$. Such an estimate is more appropriate in places where the SST gradient across the front is relatively steep and thus the position of the front is well defined (such as over the Chatham Rise, Chiswell, 1994; 2001), rather than other sectors where the front is more diffuse and variable, such as in the south Tasman Sea (e.g. Hamilton, 2006). However, even in places where the STF is well defined, such a line fails to adequately describe the broader area of the ocean influenced by mixing across the front (e.g. Figure 2.1D-E). It is essentially this broader zone of frontal influence that is captured by the middle column ("In STF and north") of Table 2.3. 


\section{Chapter 2}
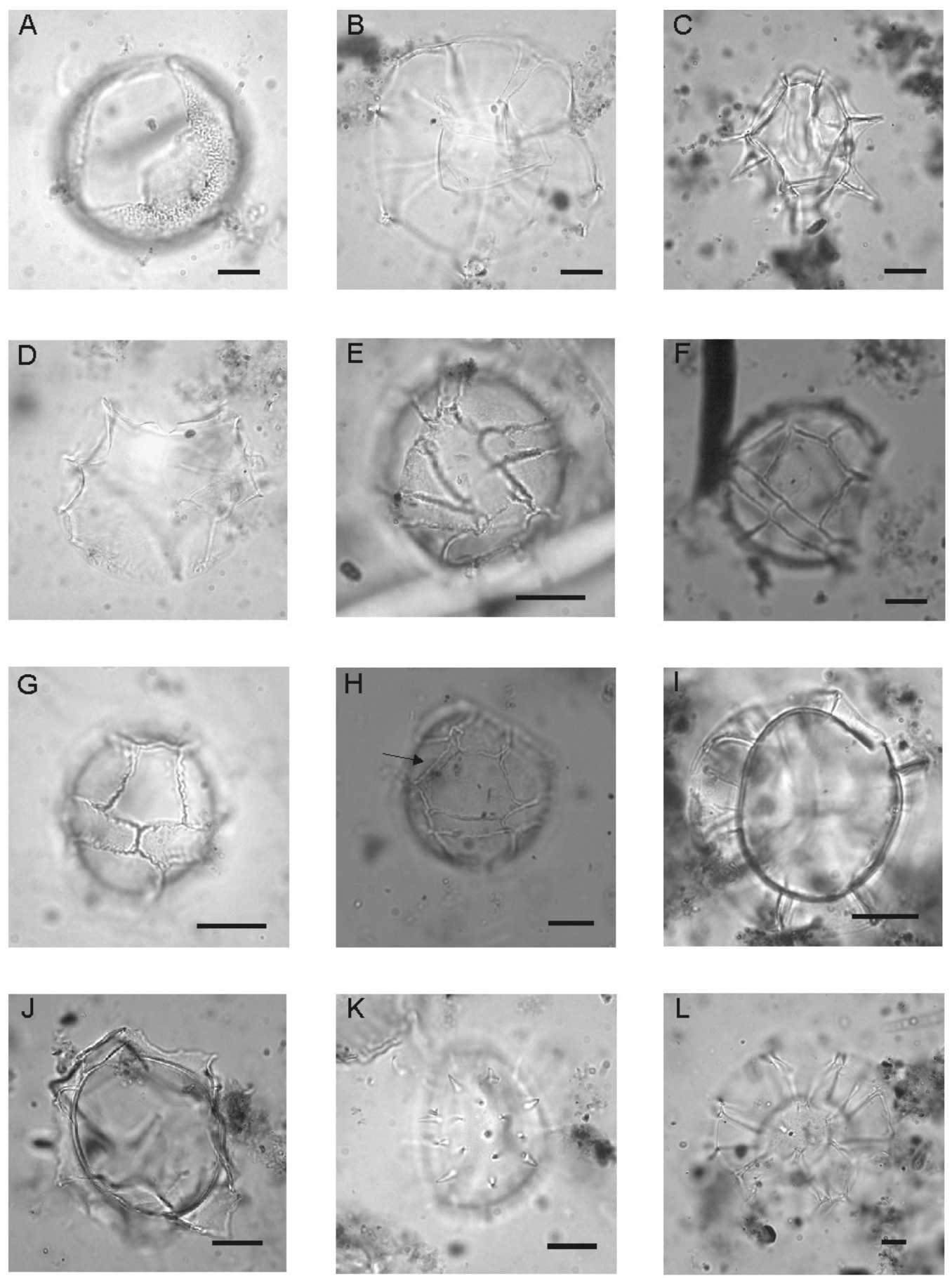

Figure 2.6. A. Bitectatodinium tepikiense, (Sample number: TAN0803-S1), B. Dalella chathamensis, (01BC), C. Impagidinium aculeatum, (J39), D. Impagidinium pallidum,(01BC), E. Impagidinium paradoxum, (590B), F. Impagidinium patulum, (1168C), G. Impagidinium plicatum, (569-B), H. Impagidinium sphaericum, sulcal tabulation arrowed (1168C), I. Impagidinium strialatum, (1169A), J. Impagidinium variaseptum, (Q633), K. Lingulodinium machaerophorum, (587), L. Nematosphaeropsis labyrinthus, (1169A). All scale bars $\sim 10 \mu \mathrm{m}$.. 


\section{Chapter 2}
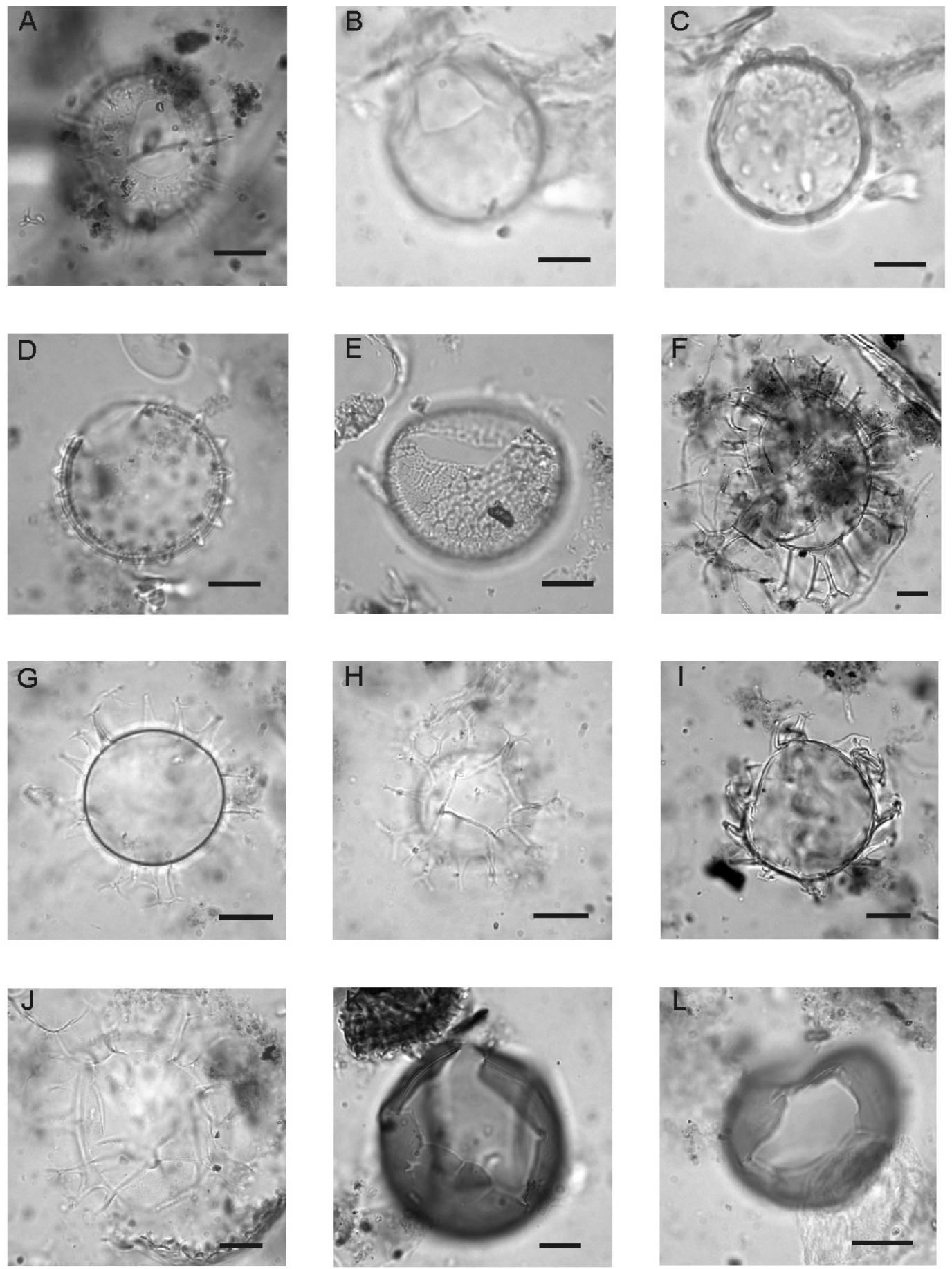

Figure 2.7. A. Operculodinium centrocarpum sensu Wall and Dale (1966), long processes, (10MC1), B, C. Operculodinium centrocarpum sensu Wall and Dale (1966), short processes, (587), D. Operculodinium cf. $O$. janduchenei, (587), E. Pyxidinopsis reticulata , (1119C), F. Spiniferities hypercanthus, (582), G. Spinifeities mirabilis, (587), H. Spiniferities ramosus, (587). I. Spiniferities bentorii, (592), J. Spiniferities pachydermus, (587), K., L. Brigantedinium cariacoense, $(590 \mathrm{~B}, 01 \mathrm{BC})$. All scale bars $\sim 10 \mu \mathrm{m}$.. 


\section{Chapter 2}
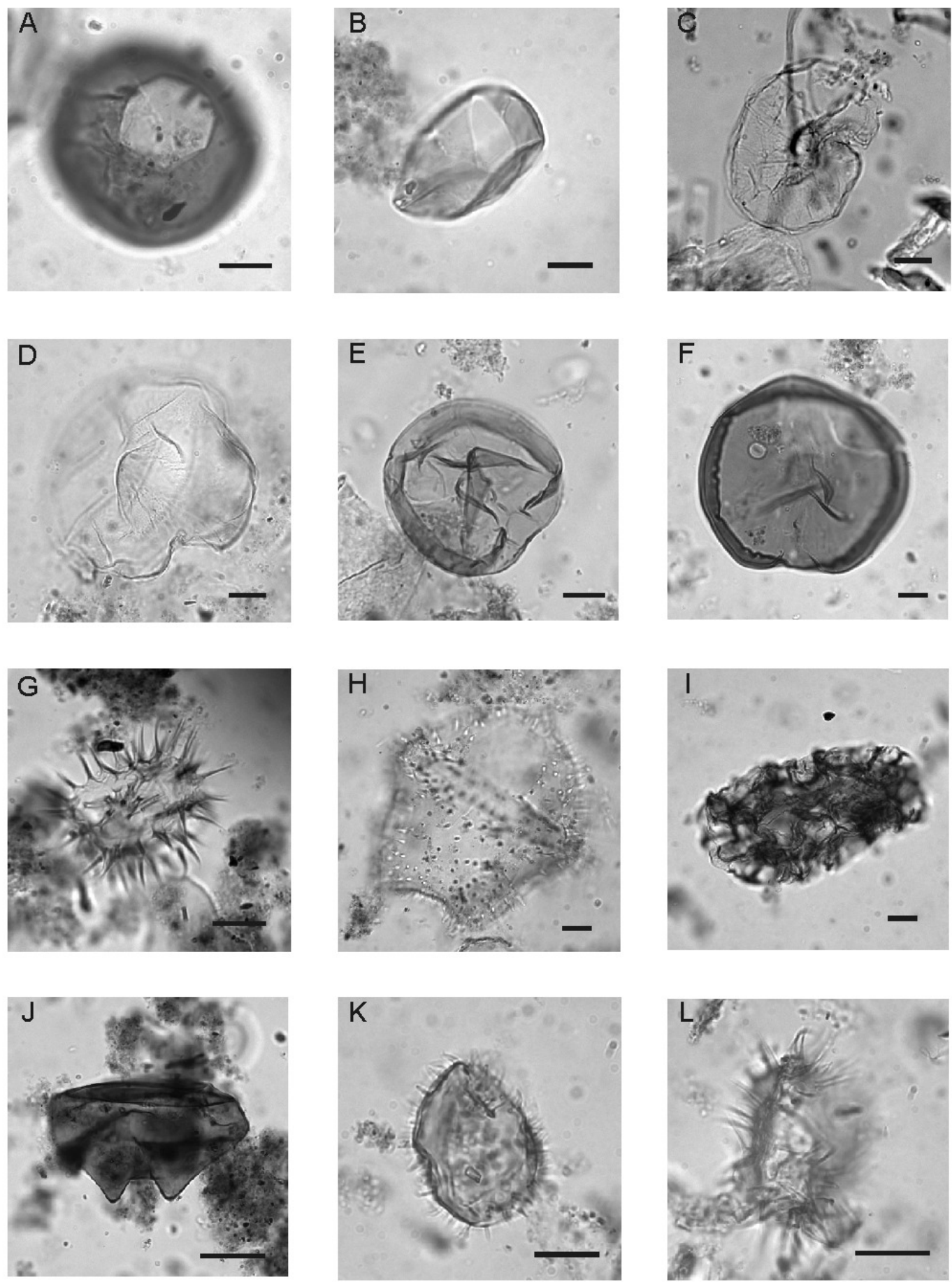

Figure 2.8. A., B., Brigantedinium simplex, (TAN0803-9, 01BC), C., D. Selenopemphix antarctica, (1171C, 01BC), E. Selenopemphix nephroides , (1119C), F. Selenopemphix undulata , (Q633), G. Selenopemphix quanta, (1172C), H. Trinovantedinium applanatum (TAN0803-9), I. Polykrikos sp. (1172C), J. Quinquecuspis concreta, (1172C, TAN08039) ,K., L., Echinidinium sp. (TAN0803-9, 1119C). Allscale bars $\sim 10 \mu \mathrm{m}$. 

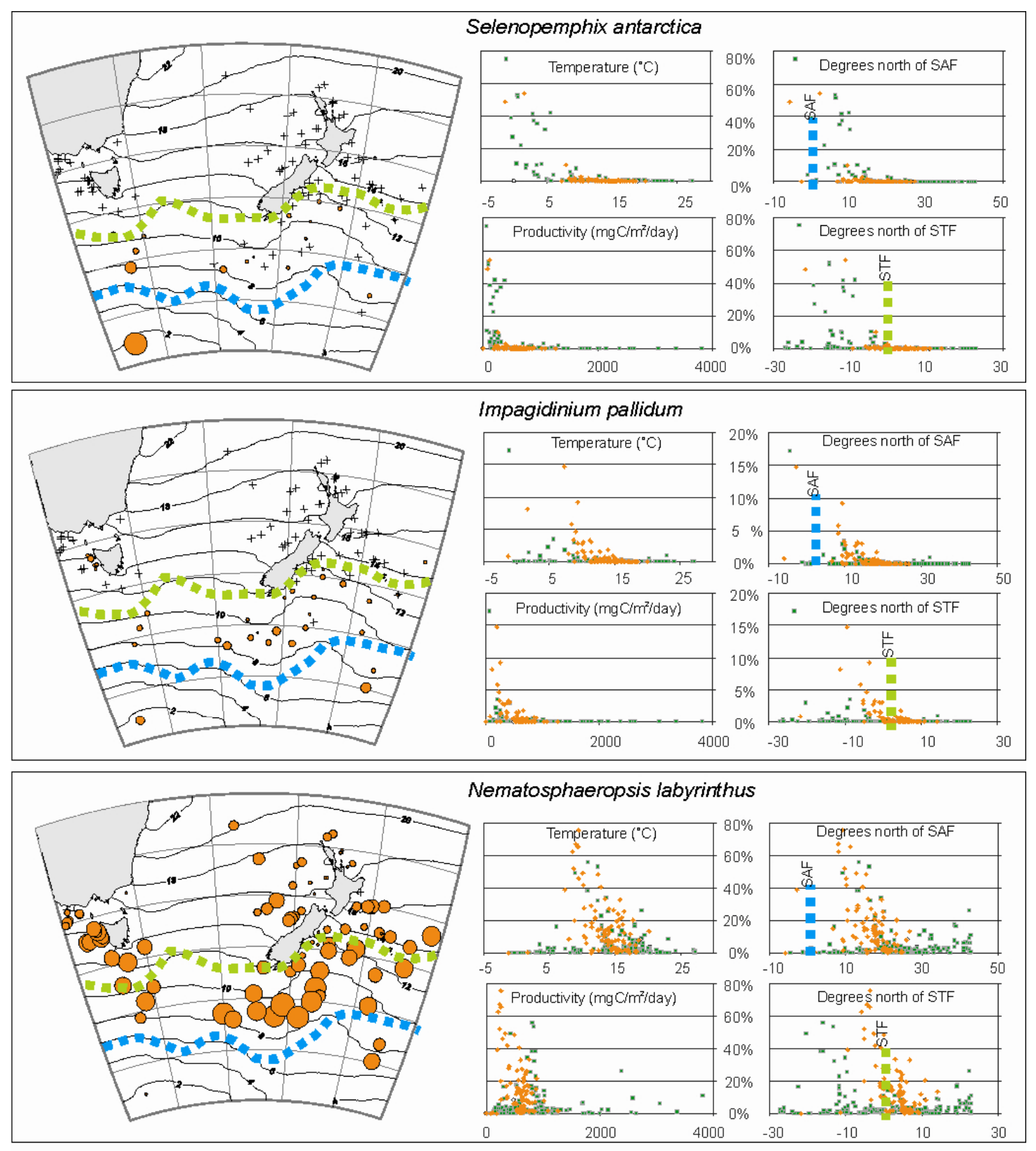

Figure 2.9-2.13. Distribution maps of key dinocyst taxa on the sea floor of the New Zealand region, and scatter plots against mean annual sea surface temperature, mean annual productivity, distance north of the STF and distance north of the SAF (while these two fronts are roughly parallel in the SW Pacific, they diverge in other parts of the Southern Hemisphere). Contours on maps = mean annual SST. NZ-98 samples are plotted orange, samples from the rest of the Southern Hemisphere are green. In the abundance maps, size of the orange circles shows relative abundance (all maps are to the same scale, with maximum relative abundance in Selenopemphix antarctica map is $50 \%$ ), black crosses show absence. Blue line $=\mathrm{SAF}$, green line $=\mathrm{STF}$, front locations after Orsi et al., (1995); Orsi and Harris, (2001). 
Figure 2.10. For caption see Figure 2.9.
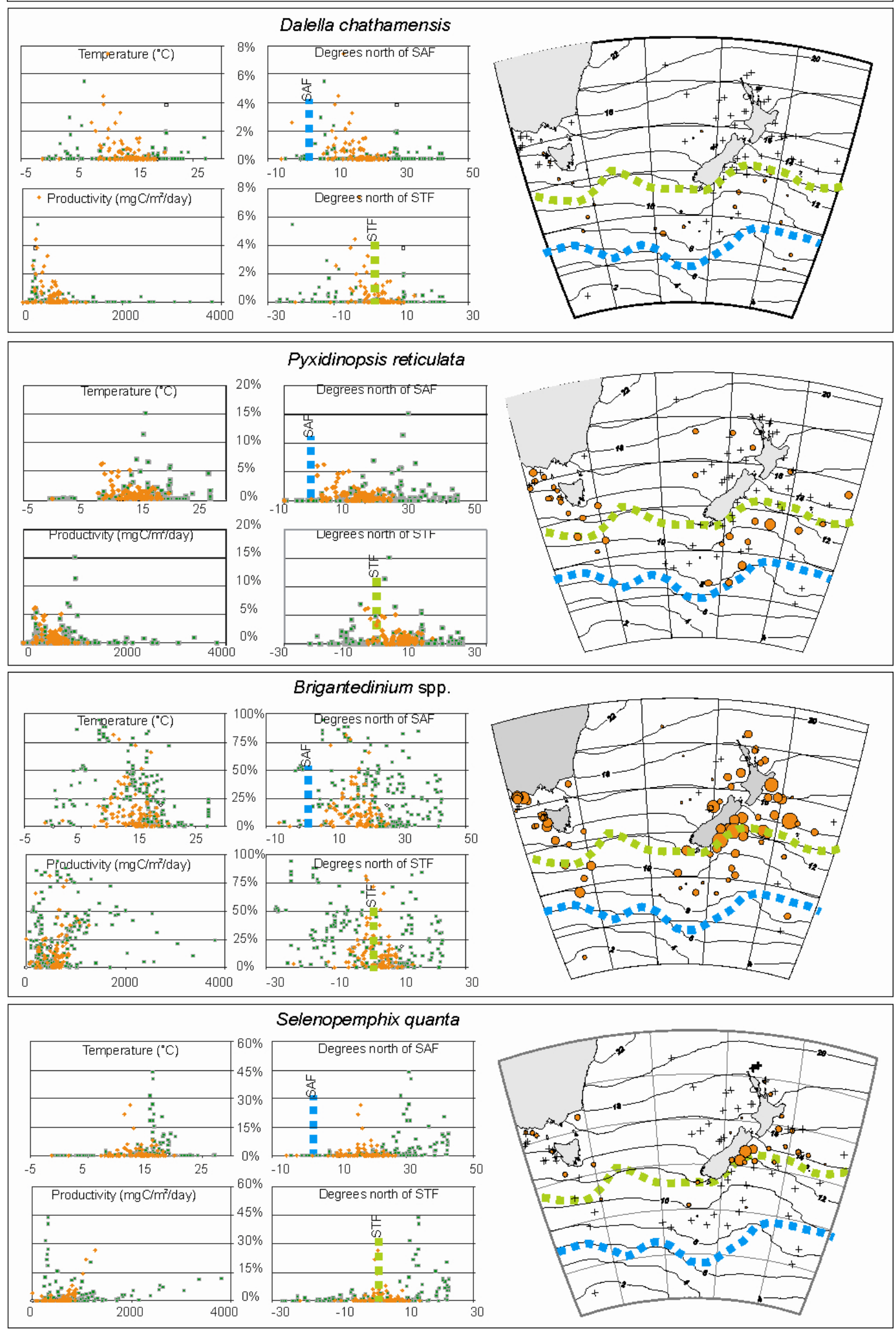
Three taxa, Selenopemphix antarctica, Dalella chathamensis, and Impagidinium pallidum are largely restricted to SAW south of the STF (Figure 2.9-2.10). I. pallidum is present in all but one of the SAW samples, but distribution of S. antarctica and D. chathamensis is more sporadic: each of these latter species are present in about half of the samples beneath SAW. Nematosphaeropsis labyrinthus is recorded north and south of the STF and is present in almost all samples, but is most abundant in samples south of the STF ( $>40 \%$ relative abundance).

The peridinoid cyst Brigantedinium spp. is also found in most samples in the region, although it was absent from some samples in the east Tasman Sea, and deep ocean samples east of New Zealand (Figure 2.10$)^{1}$. The highest relative abundances $(>50 \%)$ were observed in samples to the east of New Zealand, from the eastern South Island shelf samples and from the Chatham Rise (Figure 2.1), both of which are beneath the STF. In comparison, the peridinoid taxa Selenopemphix quanta is found in relatively few samples, although the highest abundances were observed in the same settings as for Brigantedinium spp. S. quanta is virtually absent from the east Tasman Sea, and low concentrations were observed in only three samples south of the STF. Two other frequently occurring peridinoid cysts, $S$. nephroides and Echnidinium spp., have very similar distributions to Brigantedinium spp. (Figures 2.10-2.11) and are present in approximately half of the samples processed east of New Zealand in STW and the STF, although rarely in concentrations $>5 \%$. They are very rare in SAW and beyond the western New Zealand shelf in the east Tasman Sea. Although a few specimens of $S$. nephroides have been recorded in Bass Strait, they are also generally absent from the sea floor sediments around Tasmania.

\footnotetext{
${ }^{1}$ peridinoid describes a form of cyst tabulation frequently produced by heterotrophic dinoflagellates, formed by dinoflagellates assigned to Protoperidiniaceae. The remaining cysts described here have a gonyaulacoid tabulation, and are produced by chloroplast-bearing dinoflagellates assigned to Gonyaulaceae. More information on dinoflagellate nutrition is introduced in Section 4.2.1
} 


\section{Chapter 2}

Figure 2.11. For caption see Figure 2.9.
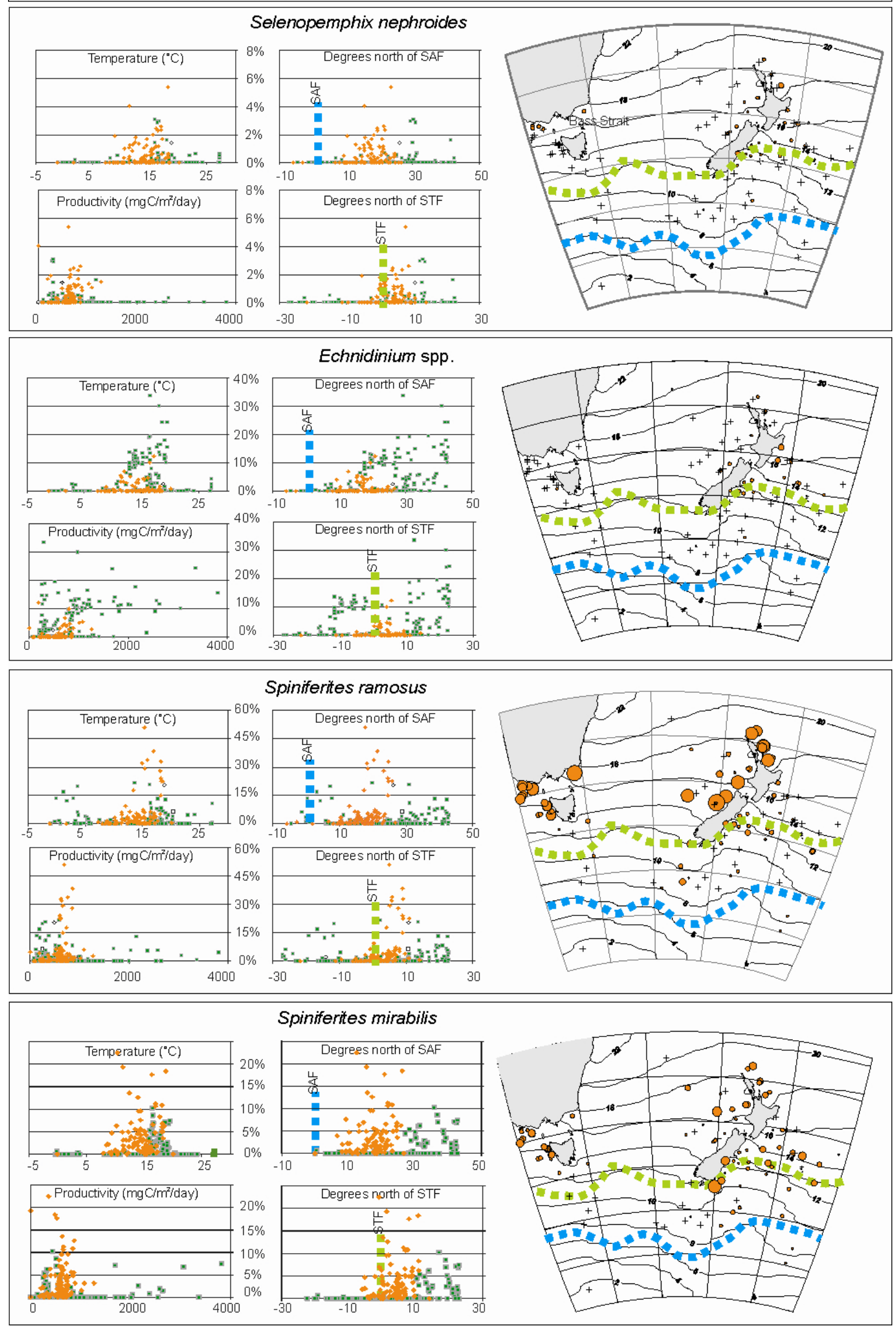


\section{Chapter 2}

Figure 2.12. For caption see Figure 2.9.
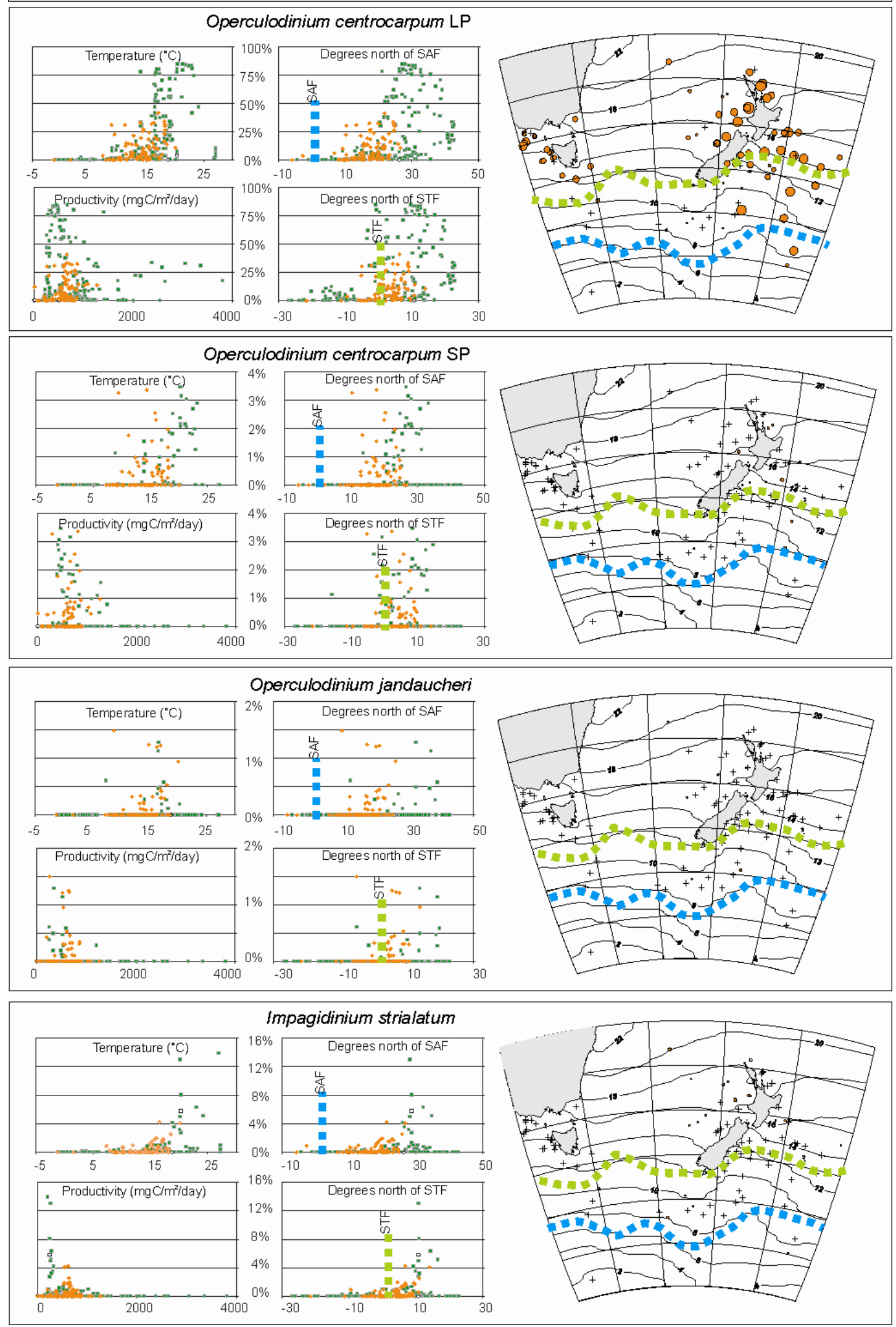
A number of gonyaulacoid taxa are only found in samples within or north of the STF, or are found in greatest abundance in that setting. Impagidinium aculeatum, Spiniferities ramosus and S. mirabilis are present in samples either side of the STF (Figures 2.11 and 2.13), and $I$. aculeatum is even observed south of the SAF. However, the highest concentrations of all three taxa are observed in samples beneath the STF or STW, particularly (i) in the east Tasman Sea where I. aculeatum is common in off-shore samples and S. ramosus is common in more shore-proximal settings, and (ii) from the continental shelf east of the North Island of New Zealand. I. paradoxum (Figure 2.13) has a similar distribution to I. aculeatum, but while it is slightly more common north of the STF, it infrequently forms $>3 \%$ of the assemblage. Impagidinium plicatum, Impagidinium strialatum, Operculodinium centrocarpum with short processes (SP), and O. jandaucheri are rare, but appear (with a few exceptions) to be restricted to STW. Impagidinium variaseptum is common in STW samples of the East Tasman Sea and around Tasmania (Figures 2.12-2.13).

Variation in the relative abundance and distribution of two remaining common taxa, Operculodinium centrocarpum with long processes (LP) (Figure 2.11) and Pyxidinopsis reticulata (Figure 2.10) does not appear to correlate in an obvious way to water mass in the SW Pacific. However, there is some tendency for higher abundances of the cosmopolitan O. centrocarpum LP in samples north of the STF (Figure 2.12, Table 2.3), while $P$. reticulata is more common in offshore/deeper sites around New Zealand, but is also present near to shore off the Australian Coast.

The relative abundance of most of the common dinocyst taxa from the SW Pacific vary within the SST and productivity range observed for the rest of the Southern Hemisphere. The main exception is Spiniferities mirabilis: across the rest of the Southern Hemisphere, this taxa has only been observed north of $30^{\circ} \mathrm{S}$, in SST $>15^{\circ} \mathrm{C}$ (Figure 2.11), but in the SW Pacific, it is found beneath surface water of a mean annual SST of $8^{\circ} \mathrm{C}$. Other minor outliers in the SW Pacific region compared to the rest of the Southern Hemisphere are high concentrations of $O$. centrocarpum LP in SST $<15^{\circ} \mathrm{C}$, while I. pallidum is observed in 


\section{Chapter 2}

Figure 2.13. For caption see Figure 2.9.
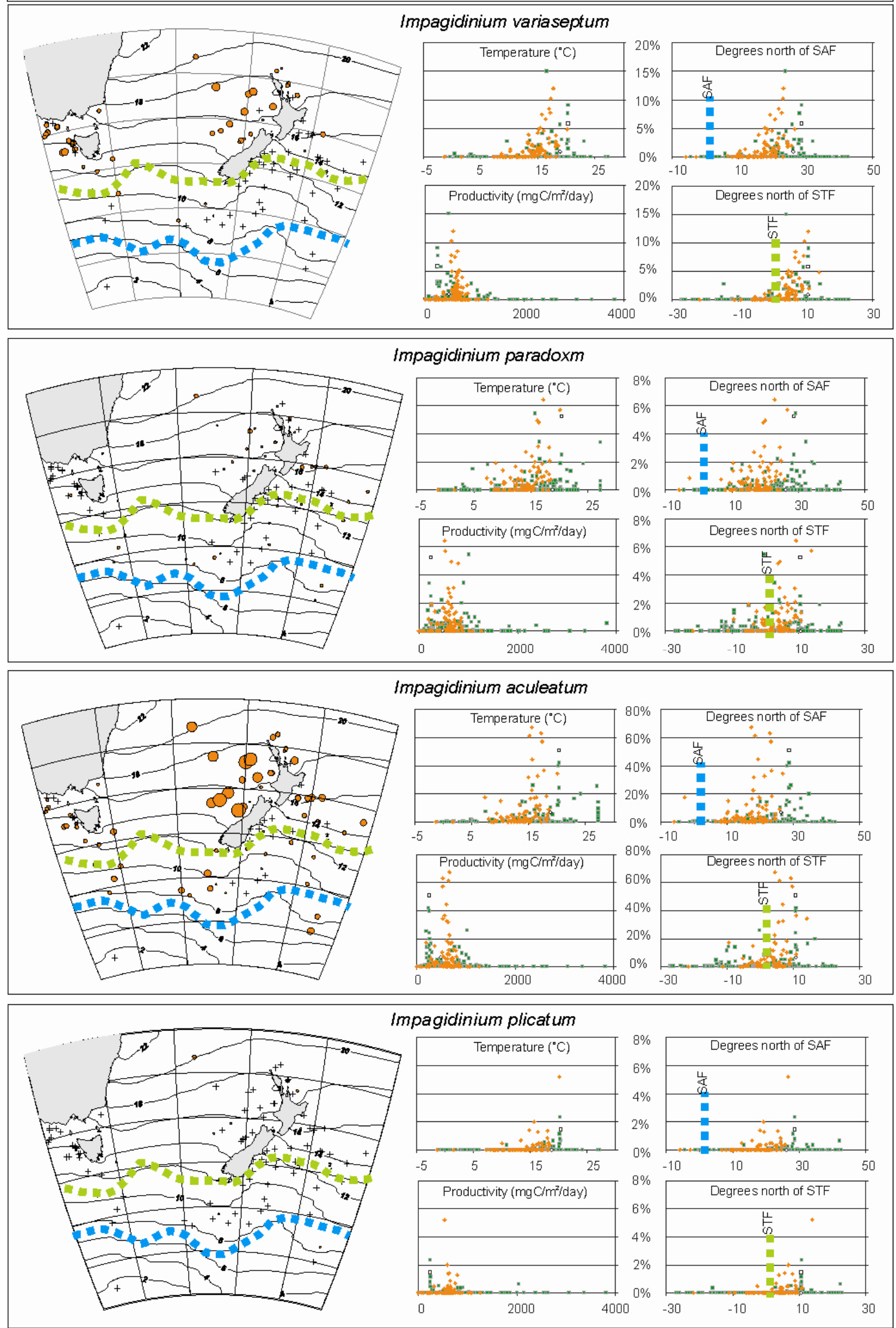
greater concentrations north of the STF in the SW Pacific than other parts of the Southern Hemisphere.

\subsubsection{Classification of dinocyst assemblages: SW Pacific}

Using k-means clustering, the NZ-98 dataset was explored for two, three, four, five and six cluster solutions. Sample '1955Mar', from SAW south of Tasmania, was removed as it had a destabilizing effect on the clustering and on the following ordination, probably due to its position as an environmental outlier (in water $\sim 5^{\circ} \mathrm{C}$ colder than the next warmest sample, and south of the SAF). The two, four, and five cluster solutions contained the highest proportion of stable samples, with 92\%, 74\% (Figure 2.14) and $64 \%$, respectively, of samples consistently assigned to specific clusters.

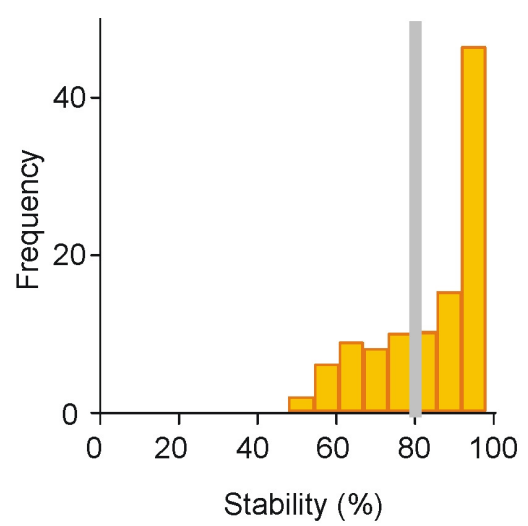

Figure 2.14. Frequency histogram of sample stability of the NZ-98 samples during k-means clustering of the four cluster solution. Grey line shows $80 \%$ threshold used to define "stable samples" during exploratory clustering.

The two-cluster solution displays a latitudinal division centered on the STF (Figure 2.15C). Although a large cluster in Subantarctic waters was a feature in the threecluster solution, relatively few of the samples north of the STF were consistently assigned to any cluster. The four-cluster model contained clearly resolved biogeographic zones, the best correlation to surface ocean conditions, and is described in more detail below (Figure 2.15A). The five-cluster model had similar division to the four cluster, but a lower proportion of stable samples, while the six-cluster model was not able to divide the assemblage in a decisive manner, with a number of unstable samples (Figure 2.15C). 
The four clusters are numbered 3 to 6 , ordered by increasing median SST (colder Clusters 1 and 2, and a warmer Cluster 7 are identified during later clustering of the entire SH311 dataset, thus the confusing numbering system retains consistency throughout this chapter).

Cluster 3 occurs primarily south of the STF, but extends slightly north of the STF in the region west of Tasmania. Samples of Cluster 4 are generally within the STF or near to shore, and includes samples east of the South Island, along the Chatham Rise, as far north as $38^{\circ} \mathrm{S}$, and near-shore sites on the west coast of the South Island and in Bass Strait north of Tasmania. The remaining two clusters (5 and 6 ) are restricted to Subtropical waters. Cluster 5 has samples that are generally near to shore, from the northeast of the North Island, the West Coast of the South Island, and Bass Strait, while Cluster 6 has samples in the eastern Tasman Sea.

There are distinctive features of the average assemblage within each cluster of the fourcluster solution (Figure 2.16).

Cluster 3 consists of 34 samples, 29 of which are stable in the four cluster model. The key feature of these samples is the high abundance of Nematosphaeropsis labyrinthus, and also the highest average abundances of Impagidinium pallidum and Pyxidinopsis reticulata (Figure 2.16). Other noticeable, but non-unique, components are $I$. aculeatum, Operculodinium centrocarpum LP, and Brigantedinium spp.

Cluster 4 consists of 22 samples, of which 19 were stable, and is dominated by Peridinioid taxa. The key taxon is Brigantedinium spp., which is $>30 \%$ in every sample, with an average abundance of $41 \%$ (Figure 2.16). Other characteristic taxa, are Selenopemphix quanta, S. nephroides, and Echnidinium spp., while I. aculeatum, $O$. centrocarpum LP, Spiniferites ramosus and N. labyrinthus are important components.

Cluster 5 has 32 samples, with 18 stable. This cluster has the highest average abundances of $O$. centrocarpum LP, Spiniferites miribilis, and S. ramosus. Approximately 
Figure 2.15. Results of k-means clustering of the NZ-98 dataset. A. Four cluster solution. Blue = Cluster 3 , green $=$ Cluster 4 , yellow $=$ Cluster 5 , orange $=$ Cluster 6 . Samples shown with a ' + ' were not assigned consistently to any one cluster, B. Four cluster solution, with all samples included left map shows all samples. C. Two, three, five and six cluster solutions..

A.

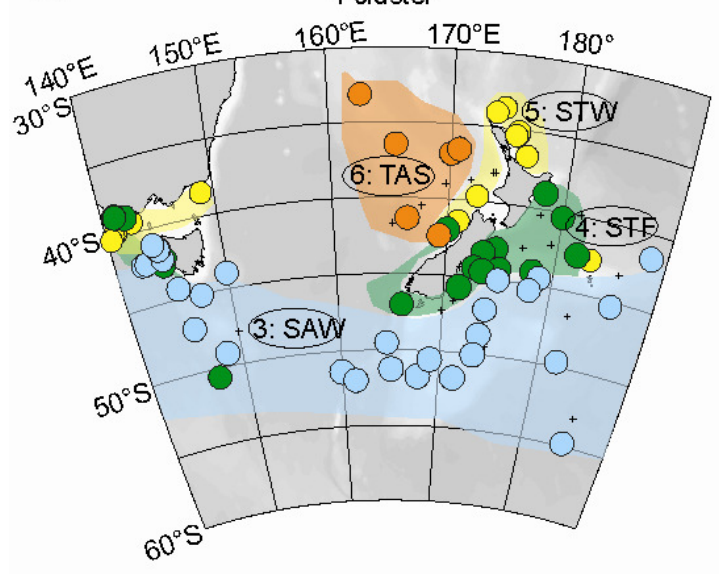

C.

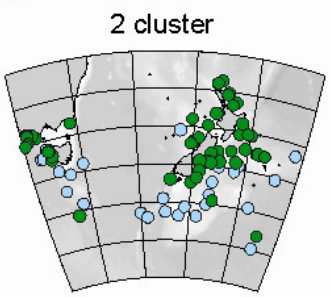

3 cluster

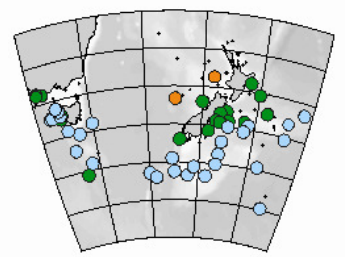

4 cluster

B. $\quad 4$ cluster, all samples included

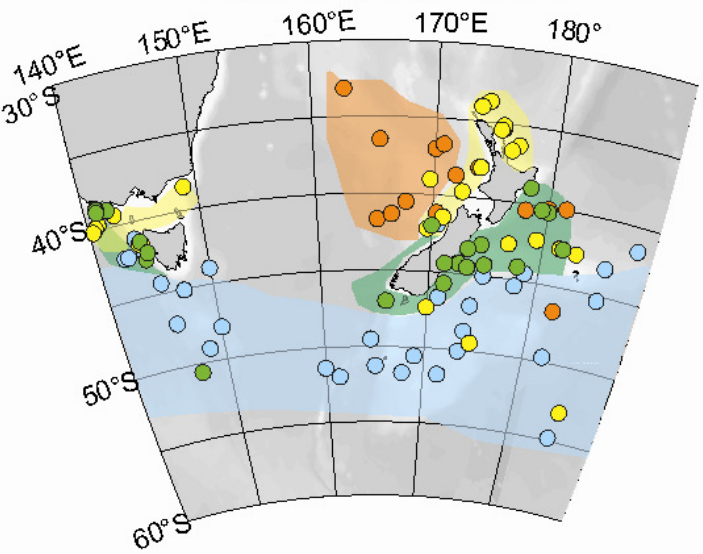

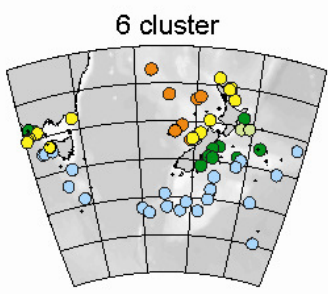

$40 \%$ of the samples contained $O$. centrocarpum SP. The taxa Dalella chathamensis, I. strialatum and S. antarctica are near to absent from this cluster.

Cluster 6 contains only 9 samples, of which 6 are stable, and is dominated by Impagidinium of all types, particularly $I$. aculeatum. The virtual absence of representatives of the genera Brigantedinium and Selenopemphix are a feature of this cluster and, despite the abundance of other members of the genus, Impagidinium pallidum is absent. N. labyrinthus is also common in these samples.

The classification described here reflects previous observations of dinocyst distribution to the east of New Zealand. As in the present classification, both Sun and McMinn (1994) and Crouch et al. (2010) identified the STF as a significant biogeographic boundary in the region. Indeed, along the western Chatham Rise, the boundary of 


\section{Chapter 2}

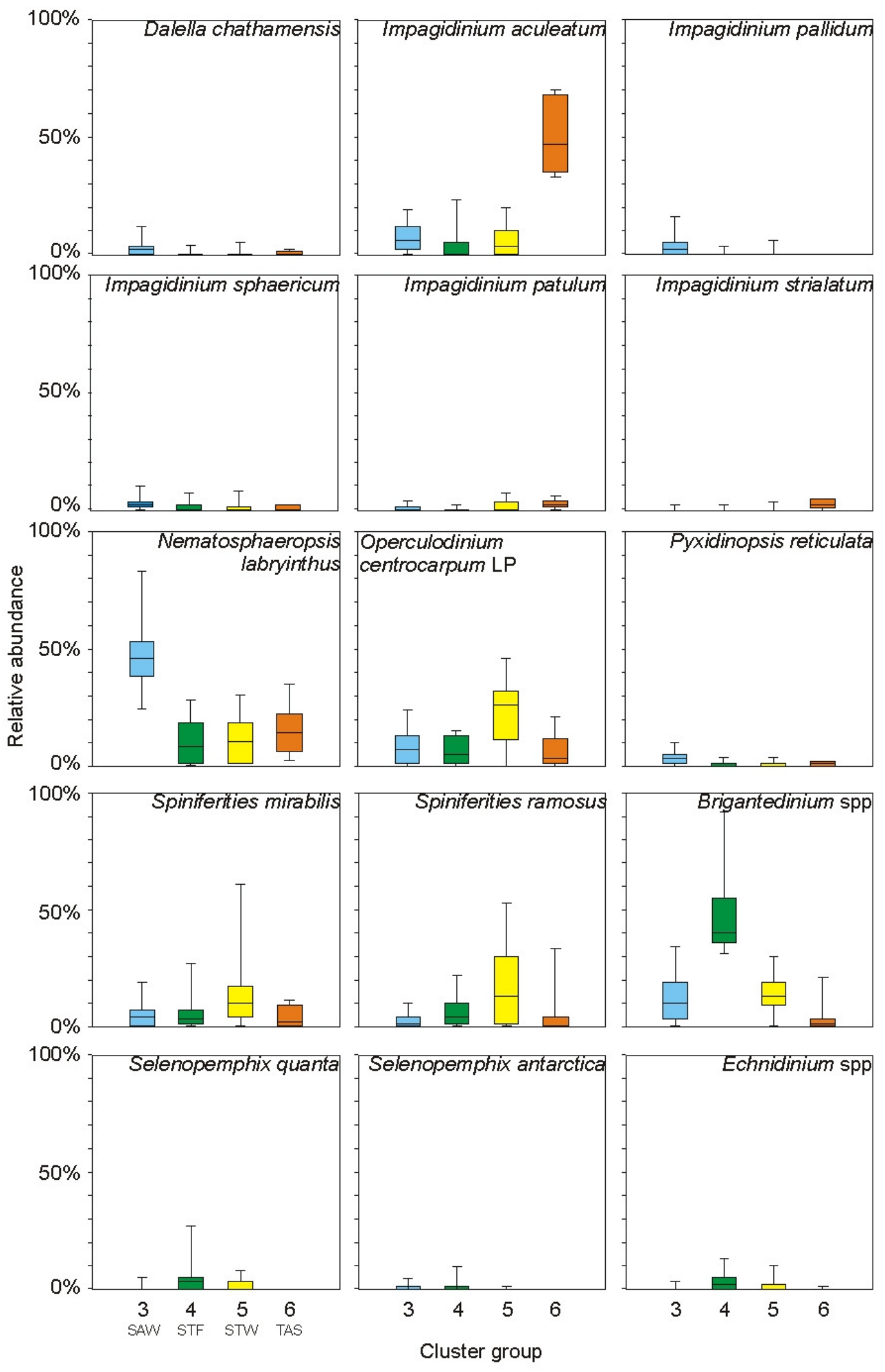

Figure 2.16. Relative abundance of selected taxa in NZ-98 samples of the four-cluster solution. Range of bars $=$ maximum, minimum, range of boxes $=25$ th and 75 th percentiles, center line $=$ median 
cluster analysis-derived assemblages identified by Sun and McMinn (1994) mirrors the boundary between the Clusters 3 and 4 (Figure 2.15). In the present study, we are able to extend the biogeographic boundaries beyond those identified by Sun and McMinn (1994).

A number of geographic outliers are present when all samples, including the "unstable" samples (see Section 1.3.4 for explanation of this terminology) are considered in the four-cluster solution (Figure 2.15B). Most of the outlying samples are south of the geographic area of their stable counterparts, a feature particularly apparent in the cluster associated with Subtropical coastal waters, Cluster 5 . The overlapping range of all the clusters are consistent with known mixing across ocean boundaries, particularly over the STF, which in the SW Pacific is frequently crossed by eddy migration north and south (Grieg and Gilmour, 1988; Shaw and Vennell, 2000; Chiswell, 2001; Sikes et al., 2009). The southward extent of samples with weak affinity to the Cluster 5 , particularly along the Chatham Rise, but also south of the STF, may reflect southward transport of components of the assemblage by the East Cape Currents (Figure 2.1). The presence of assemblages characteristic of the east Tasman Sea in samples from the east of the North Island may also be due to transport on ocean currents, as there is a mean eastwards flow from the Tasman Sea through Cook Strait (Carter et al., 1998), or may be a reflection of warm offshore sites to the east of New Zealand.

The mean SST of samples from the four cluster groups are distinct, although the ranges overlap (Figure 2.17). The cold tail in Cluster 5 may be due to the southerly transport of cysts in ocean currents discussed above. There is considerable overlap of mean annual productivity between all four cluster groups, although the mean productivity of the more coastal Clusters 4 and 5 are higher than the two oceanic clusters. The Impagidinium-dominated Cluster 6 from the east Tasman Sea is restricted to a narrow range of productivity, possibly a feature of the intolerance of Impagidinium to excessive nutrient levels (Dale, 1996). 
A.

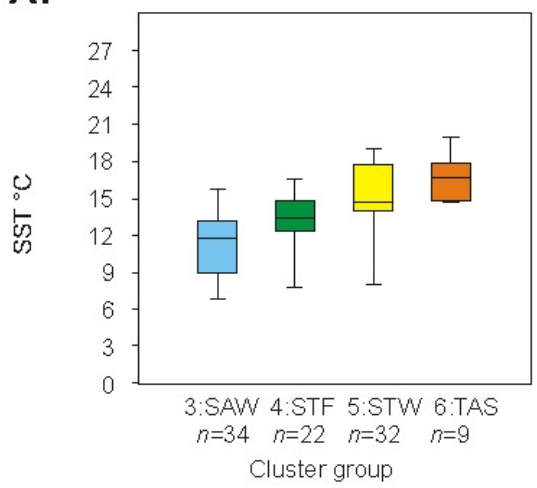

B.

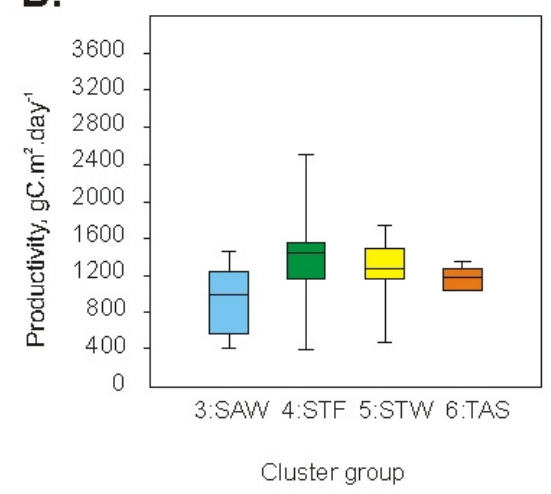

Figure 2.17. A. Mean annual SST ranges of the four k-means clusters of the NZ-98 dataset. Range of bars = maximum, minimum, range of boxes $=25$ th and 75 th percentiles, center line $=$ median. B. Mean annual productivity ranges of the four clusters

The dinocyst clusters have similarities to the regional biogeographic distribution identified in other surface sediment microfaunal records, including radiolaria (Hollis and Neil, 2005), diatoms (Cochran and Neil, 2010), and foraminifera (Weaver et al., 1997, Crundwell et al., 2008; Hayward et al., 2008, 2012). The largest assemblage changes in all three groups also occurred across the STF. Both radiolaria and diatom studies recognise distinct assemblages broadly coinciding with dinocyst Cluster 4. Furthermore, the radiolaria study of Hollis and Neil (2005) recognised a biogeographic boundary coinciding with the boundry between dinocyst Clusters 4 and 5 on the east coast of New Zealand. Biogeographic variation within SAW was observed in both radiolaria (Hollis and Neil, 2005) and diatom (Cochran and Neil, 2010) assemblages, where no systematic change is observed in dinocyst assemblages. The lower biogeographic variation of dinocyst assemblages in SAW compared to diatoms and radiolaria may be due to the reduced diversity of dinocyst assemblages with temperature observed in Figure 2.4, a characteristic shared by foraminifera, a group in which biogeographic variation in SAW is also relatively low (e.g. Crundwell et al., 2008).

This study is the first to examine dinocyst assemblages from sea floor sediments in the eastern Tasman Sea. Interestingly, a dinocyst assemblage distinct from others in the region was identified, dominated by Impagidinium aculeatum. It is unlikely, however, that this assemblage is unique to the Tasman Sea in the SW Pacific, as oceanic 
environments with similar temperature and nutrient conditions, for example to the east of the North Island that have not yet been sampled, and may contain similar assemblages (Figure 2.1).

\subsubsection{Classification of dinocyst assemblages: Southern Hemisphere}

The classification approach applied to the SW Pacific samples (NZ-98 dataset) was extended to the entire SH-311 dataset. As in the SW Pacific dataset, a number of cluster solutions were trialled. In this instance, the number of clusters were selected that best replicated the geographic divisions observed in the SW Pacific dataset. Five-cluster and six-cluster solutions in the $\mathrm{SH}-311$ dataset resulted in similar geographic divisions in the SW Pacific region as observed in the two-cluster and three-cluster solutions of the NZ-98 dataset. A seven-cluster solution of the $\mathrm{SH}-311$ dataset reproduced the geographical divisions observed in the New Zealand region most coherently (Figures 2.18-2.19), although not exactly (compare Figure 2.15 to Figure 2.18). Cluster solutions with higher numbers of divisions ( $>7$ ) divided the existing four SW Pacific clusters, beginning with the splitting of Cluster 4 in the eight-cluster solution.

All four of the cluster assemblages observed from the NZ-98 dataset are also represented in the east Pacific and Atlantic Oceans, which illustrates the cosmopolitan nature of sea floor dinocysts assemblages. The three "new" clusters identified within the SH311 dataset are:

Cluster 1: A high latitude cluster of samples exclusively south of the SAF, dominated by S. antarctica (navy-blue samples in Figure 2.18 - 2.19). Sample 1955_Mar, excluded from the previous SW Pacific clustering, is included in this group.

Cluster 2: A cluster of samples generally south of the STF, characterized by high relative abundances (>60\%) of Brigantedinium spp. in all samples (dark blue samples in Figure 2. 18 - 2.19). Samples of this cluster are generally in the open ocean of the South Atlantic and East Pacific around the STF and SAF, also within and slightly south of, the regional 
Figure 2.18. Results of k-means clustering of the SH-311 dataset, seven cluster solution, which most closely matches the distribution of clusters in the NZ-98 dataset. All samples are included in the plot, which is degrees longitude against mean annual SST. The position of significant land masses are approximate. STF= Subtropical Front, SAF = Subantartic Front, PF = Polar Front. SST of fronts are from the World Ocean Atlas 2009 using locations of Orsi et al., (1995) and Orsiand Harris (2001).

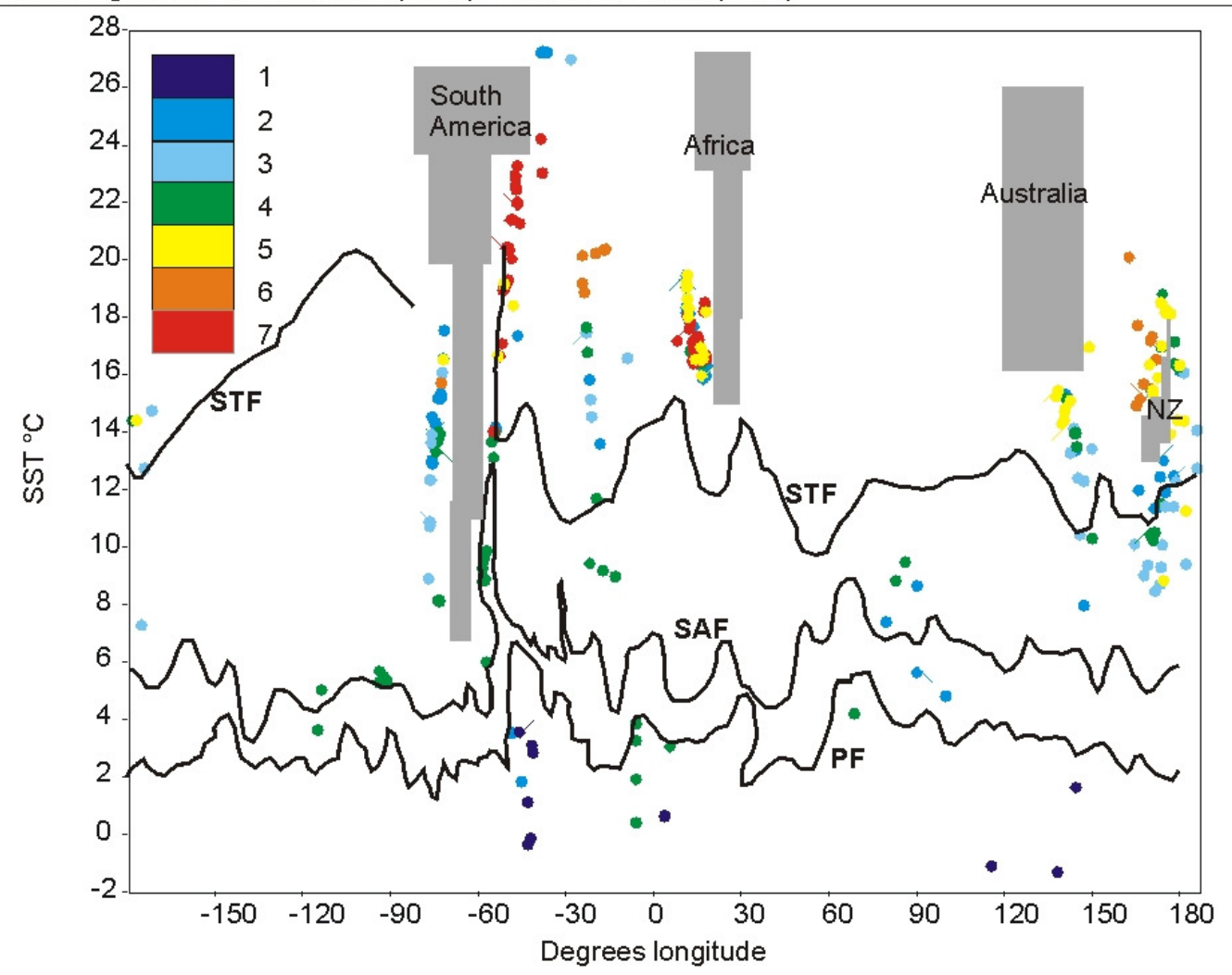

upwelling in the Chilean coast (Verleye and Louwye, 2010). Three samples of this cluster are within the STF region to the east of New Zealand.

Cluster 7: A cluster of continental shelf samples from mid-latitudes of the South Atlantic, characterized by high abundances of $O$. centrocarpum LP ( $>55 \%)$ (red samples in Figure 2. 18 - 2.19).

The SSTs of the three new clusters $(1,2$, and 7$)$ extend the range of the average SSTs of the four SW Pacific clusters (Figure 2.20). Although Cluster 7 (red dots) is only represented by samples from the South Atlantic, the present sample coverage is insufficient to determine whether this is an assemblage type endemic to the South Atlantic. However, this is a distinct possibility, as the coolest SST attributed to Cluster 7 sample in the South Atlantic is $14^{\circ} \mathrm{C}$, which is cooler than the maximum SSTs $\left(18-20^{\circ} \mathrm{C}\right)$ 


\section{Chapter 2}

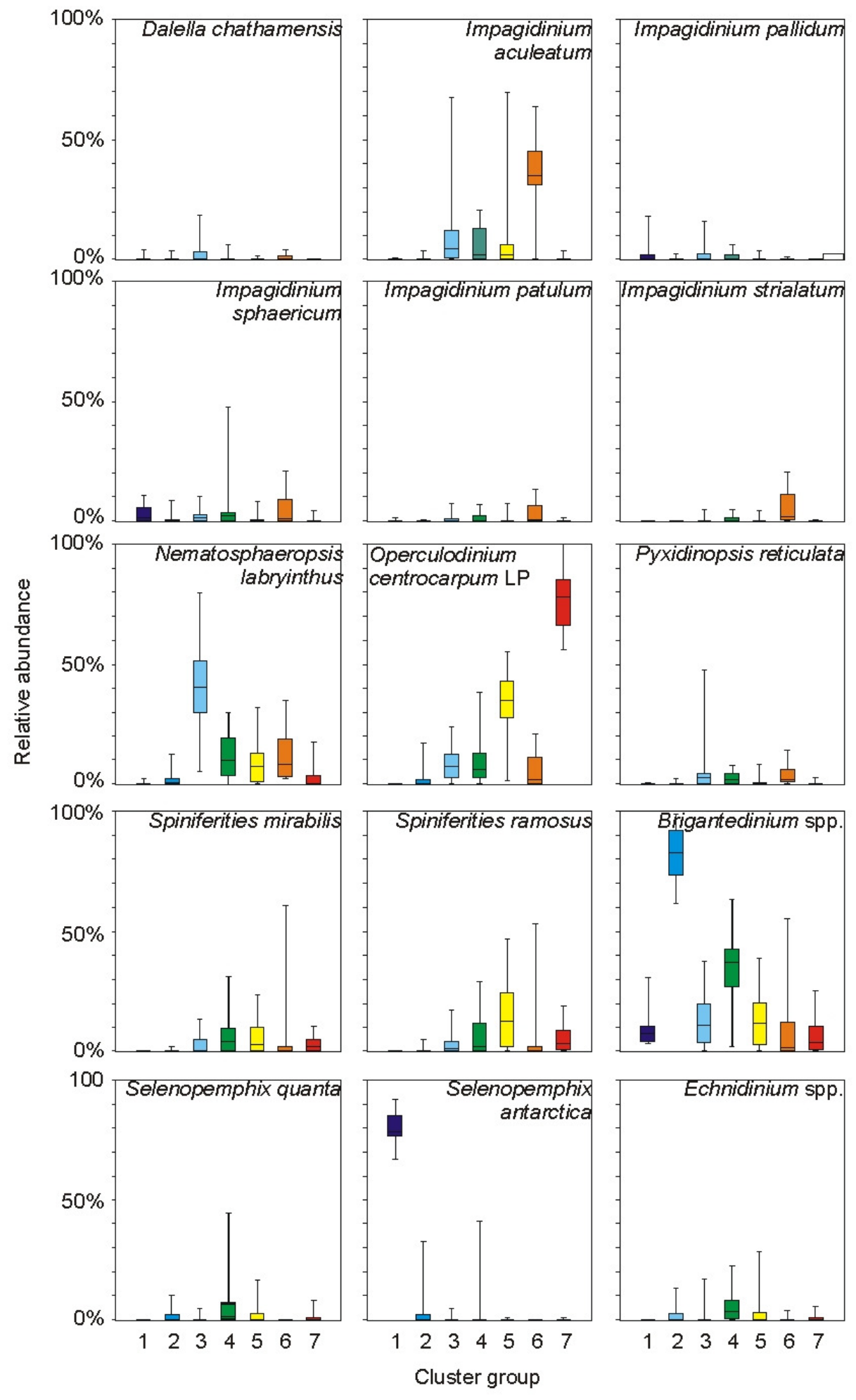

Figure 2.19. Relative abundance of selected taxa in SH-311 samples of the seven-cluster solution. Range of bars $=$ maximum, minimum, range of boxes $=25$ th and 75 th percentiles, center line $=$ median. 
A.

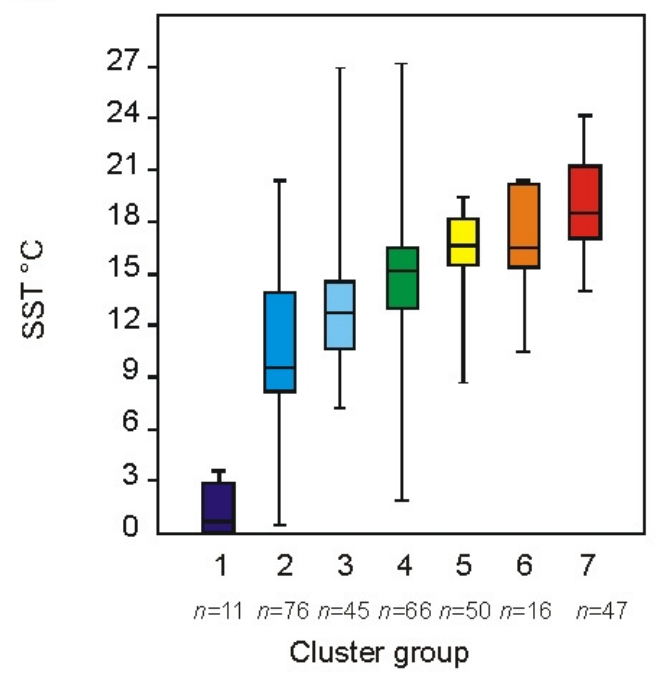

B.

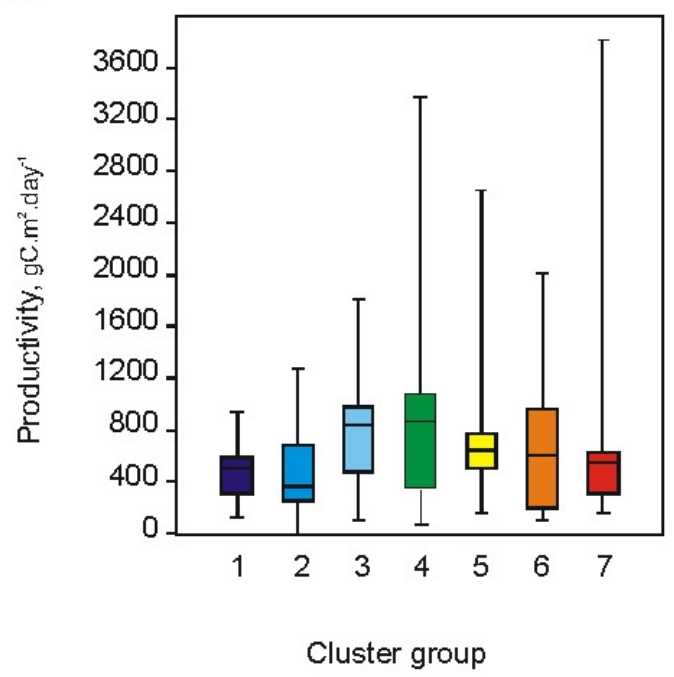

Figure 2.20. A. Mean annual SST and productivity ranges of the seven k-means clusters of the SH-311 dataset. Range of bars $=$ maximum, minimum, range of boxes $=25$ th and 75 th percentiles, center line $=$ median

sampled in the western and eastern margins of the Pacific basin (Figure 2.18). If "assemblage endemism" is indeed a feature of these South Atlantic assemblages, it may reduce the value of assembling a Southern Hemisphere dataset for quantitative reconstruction of SW Pacific paleo records. The additional samples are retained pending further exploration of modern samples from low latitudes of the Indian and Pacific Oceans, although such endemism may result in biases when cross-validating quantitative models due to spatial autocorrelation (Telford and Birks, 2005; 2009), considered in Chapter 4.

As in the four-cluster solution for the NZ-98 dataset, the seven SH-311 dinocyst cluster groups cannot be separated on the basis of mean annual productivity (Figure 2.20), despite the larger mean annual productivity range within the SH-311 dataset. Another way to explore the relationship of the dinocyst clusters and productivity is to compare them with objectively analysed chlorophyll-a based biomes (Hardman-Mountford et al., 2008), where the global ocean is divided into seven biomes of increasing mean chlorophyll-a concentration. One advantage of comparing the clusters to the chlorophyll-a biomes rather than mean annual productivity is the rigorous consideration 
Figure 2.21. Distribution of SH-311 clusters between chlorophyll- $a$ biomes of the global oceans (HardmanMountford et al., 2008). Circle size denotes proportion of each cluster within each biome, i.e. no samples are within the "very low" chlorophyll- $a$ biome (1), while only samples from clusters 3 and 6 are found in biome (2), and approximately $50 \%$ of the samples in Cluster 5 are within biome (6).

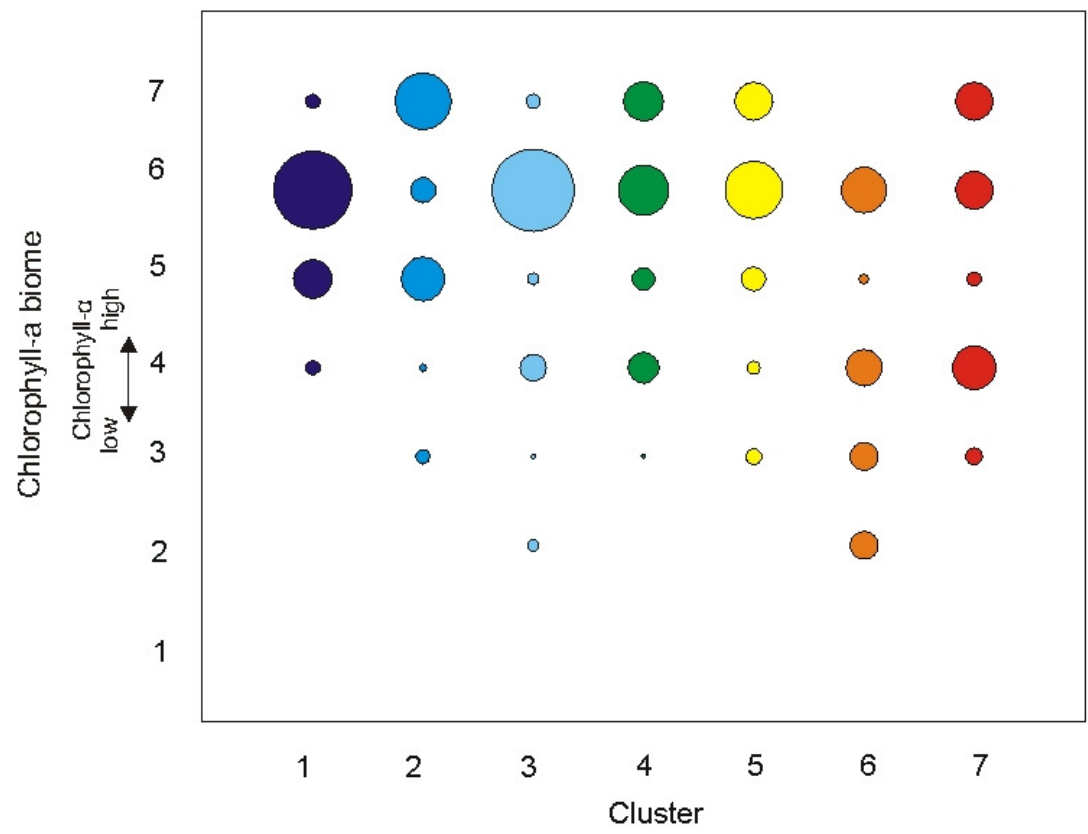

of temporal and spatial scale in the selection of the Hardman-Mountford et al., (2008) boundaries. In contrast, the interpolation process of attributing "mean annual productivity" values to the samples of the SH-311 dataset from a relatively short time series may result in erroneous values (e.g. Winder and Cloern, 2010), particularly for areas with significant terrestrial influence (Cloern and Jassby, 2010). Comparing the seven clusters with chlorophyll-a concentration reveals several interesting observations (Figure 2.21). In the Impagidinium-dominated Cluster 6, no samples are present within the highest chlorophyll-a "Biome 7", while in the low chlorophyll-a "Biome 2" only two clusters, those dominated by Impagidinium and N. labyrinthus, are represented (Clusters 3 and 6). The cold S. antarctica-dominated Cluster 1 is the only cluster apparently restricted to higher chlorophyll-a settings, although the relatively low sample size (11 samples) may not fully represent the range of this group.

Inspection of the SH-311 cluster and SST distributions (Figures 2.19-2.20) reveals one interval that may be under-sampled. While the SST range of Cluster groups 2-7 overlap, 
there is a $\sim 5^{\circ} \mathrm{C}$ gap between the $75^{\text {th }}$ percentile limits of Clusters 1 and 2 . This SST gap is highlighted by the discrete high concentrations of $S$. antarctica in Cluster 1 compared to the other clusters, and the highly skewed apparent distribution of S. antarctica along the SST gradient. While this distribution may be "real", additional samples in the $3-8^{\circ} \mathrm{C} \mathrm{SST}$ range may reveal an additional assemblage cluster that contains intermediate concentrations of $S$. antarctica, possibly accompanied by $N$. labyrinthus and Brigantedinium spp.

The observations above are largely consistent with the biogeographic distributions recorded in the global compilation of Marret and Zonneveld (2003) (as the current study includes many of the same samples). The main addition our study makes to their observations is the possibility that some dinocyst associations, specifically very high abundances of $O$. centrocarpum LP, may be unique in the Southern Hemisphere to the South Atlantic.

\subsubsection{Gradient analysis}

Gradient analysis found variance along the first ordination axis accounted for $38 \%$ of the species-environmental relationship after removal of covarying explanatory variables in the SH-311 dataset, and 56\% in the NZ-98 dataset (Table 2.4, Figures 2.22-2.23, Appendix 2.2), and SST was the environmental variable that correlated most strongly to variation along the first axis. The variation in dinocyst distribution that correlated to SST was 2-3 times greater than the variation along any of the secondary environmental variables.

The eigenvalue length of the first axis of a correspondence analysis was 4.1 standard deviations (SD) for SH-311 and 2.3 SD for NZ-98, so subsequent ordination assuming a unimodal taxa distribution appeared appropriate for both datasets (ter Braak, 1994; Birks, 1995). However, removal of environmental outlier '1955Mar' (discussed in Section 2.4.2) shortened the environmental gradients and the total inertia of the first axis to only $1.94 \mathrm{SD}$, so a linear ordination method, redundancy analysis (RDA) was applied to the NZ-98 dataset (ter Braak, 1994). CCA was also trialled on the reduced 


\section{Chapter 2}

Table 2.4.CCA and RDA results for SH-311 and NZ-98 after covarying environmental variables are excluded. The significance of environmental variables is determined by Monte Carlo forward selection. Environmental variables with $<5 \%$ contribution to canonical eigenvalues, and $\mathrm{p}$-value $>0.05$ excluded.

SH-311 - Canonical Correspondence Analysis

\begin{tabular}{|c|c|c|c|c|c|}
\hline Axes & 1 & 2 & 3 & 4 & Total inertia: \\
\hline & & & & & 1.181 \\
\hline Eigenvalues: & 0.44 & 0.27 & 0.19 & 0.10 & \\
\hline Species-environment correlations: & 0.85 & 0.75 & 0.70 & 0.65 & \\
\hline \multicolumn{6}{|l|}{ Cumulative percentage variance: } \\
\hline of species data: & 10.4 & 16.7 & 21.2 & 23.4 & \\
\hline \multirow[t]{3}{*}{ of species-environment relationship: } & 37.6 & 60.5 & 76.8 & 84.9 & \\
\hline & & \multicolumn{3}{|c|}{ Sum of all eigenvalues: } & 4.276 \\
\hline & \multicolumn{4}{|c|}{ Sum of all canonical eigenvalues: } & 1.181 \\
\hline
\end{tabular}

\begin{tabular}{|l|c|c|}
\hline Conditional effects: & lambda-A & $\begin{array}{c}\text { \% contribution to } \\
\text { canonical } \\
\text { eigenvalues }\end{array}$ \\
\hline Summer temperature & 0.43 & $36 \%$ \\
\hline Nitrate & 0.26 & $22 \%$ \\
\hline Salinity & 0.19 & $16 \%$ \\
\hline Spring Mixed Layer Depth & 0.12 & $10 \%$ \\
\hline Temperature range & 0.11 & $9 \%$ \\
\hline Sea floor $O_{2}$ & 0.1 & $8 \%$ \\
\hline Phosphate & 0.09 & $8 \%$ \\
\hline
\end{tabular}

NZ-98 - Redundancy Analysis

\begin{tabular}{|c|c|c|c|c|c|}
\hline Axes & 1 & 2 & 3 & 4 & Total inertia: \\
\hline & & & & & 0.338 \\
\hline Eigenvalues: & 0.189 & 0.103 & 0.024 & 0.014 & \\
\hline Species-environment correlations: & 0.774 & 0.593 & 0.388 & 0.379 & \\
\hline \multicolumn{6}{|l|}{ Cumulative percentage variance: } \\
\hline of species data: & 18.9 & 29.2 & 31.6 & 33 & \\
\hline \multirow[t]{3}{*}{ of species-environment relationship: } & 55.9 & 86.3 & 93.4 & 97.6 & \\
\hline & & \multicolumn{3}{|c|}{ Sum of all eigenvalues: } & 1 \\
\hline & \multicolumn{4}{|c|}{ Sum of all canonical eigenvalues: } & 0.338 \\
\hline
\end{tabular}

\begin{tabular}{|l|c|c|}
\hline Conditional effects: & lambda-A & $\begin{array}{c}\% \text { contribution to } \\
\text { canonical } \\
\text { eigenvalues }\end{array}$ \\
\hline Summer temperature & 0.18 & $53 \%$ \\
\hline Distance from shore & 0.06 & $18 \%$ \\
\hline Water depth & 0.02 & $6 \%$ \\
\hline Sea floor $0_{2}$ & 0.02 & $6 \%$ \\
\hline Spring Mixed Layer Depth & 0.02 & $6 \%$ \\
\hline
\end{tabular}


NZ-98 dataset, and similar results to RDA were obtained, demonstrating a degree of resilience in the CCA to such reduced gradients.

For the NZ-98 dataset, $56 \%$ of the species - environmental relationship was explained by the first axis (Table 2.4). The samples of the first axis were distributed along a latitudinal gradient while the second axis was related to shoreline proximity and productivity (Figure 2.22). Eighteen environmental variables were included in the initial RDA in addition to the seventeen available for the SH-311 (information on distance from shore was only available for NZ-98 dataset; all environmental values variables are in Supplementary data S2.2-S2.3). Of these, eleven covariance relationships were identified (Appendix 2.2). All of the SST measurements covaried, and SST also covaried with sea surface salinity, and had a negative correlation with sea surface phosphate and nitrate (Figure 2.23). Mean annual productivity covaried with maximum monthly productivity (Figure 2.23). The remaining ten environmental variables (with a correlation of $<0.9$ ) were summer SST, distance from shore, SST range, water depth, mean annual productivity and salinity, dissolved phosphate and nitrate at $50 \mathrm{~m}$ water depth, depth to the mixed layer, and oxygen concentration at the sea floor. A second RDA, constrained only by these ten variables, found that the five most significant variables contributed $89 \%$ of the explained variance (Table 2.4). Summer SST contributed $53 \%$ to the explained variance, almost three times that of the next most significant variable, distance from shore.

The distribution of dinocyst taxa along the first RDA axis confirms the earlier observations of 'warm' and 'cool' species in this chapter, and in previous compilations (e.g. Marret and Zonneveld, 2003). The coldest three taxa, in the upper right quadrant of the biplot (Figure 2.23), are Selenopemphix antartica, Impagidinium pallidum and Dallela chathamensis, which in the SW Pacific dataset are also present furthest from land. Temperate taxa in the region include Nematosphaeropsis labyrinthus, Pyxidinopsis reticulata and Impagidinium sphaericum, while the warmest samples in the 
A.

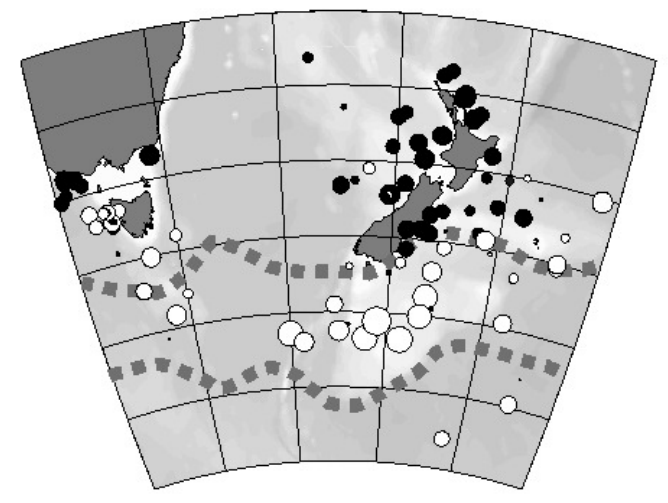

B.

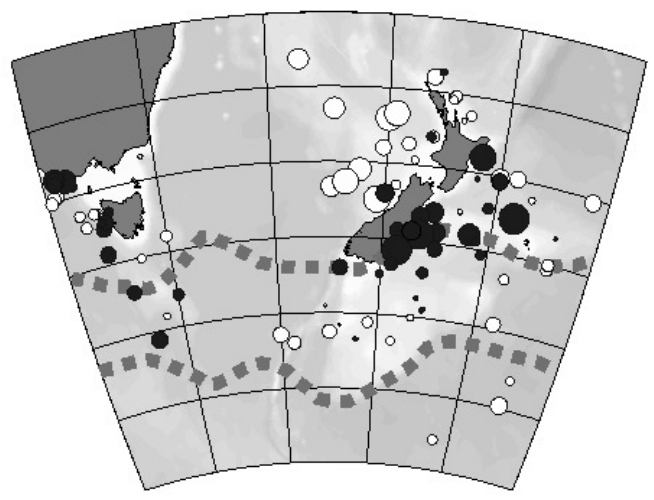

Figure 2.22. Sample locations of the NZ-98 data set with size of circles showing eigenvalues for A: the first ordination axis and $\mathbf{B}$ : the second ordination axis. Black circles $=$ negative eigenvalues, white $=$ positive values, largest circles $=1$, smallest circles approach 0 .

SW Pacific compilation include Spiniferities ramosus, Impagidinium variasepum and Impagidinium aculeatum.

For SH-311, the explained variance in the species - environmental relationship described by the first axis represents less than half $(44 \%)$ of the total variance within the first four axes, less than the NZ-98 data set (Table 2.4). Of the initial 18 environmental variables included in the first CCA, 10 covariance relationships were identified by inspection of a weighted correlation matrix (Appendix 2.2). A second CCA with automatic forward selection, constrained by the eight remaining variables, revealed that seven of them contributed more than $5 \%$ of the total explainable variance (Table 2.4). SST explained the greatest proportion of the variance (36\%), while the next two longest gradients (phosphate and salinity) cumulatively contributed another $38 \%$.

Gradient analysis indicates that both the assemblages of the SH-311 and NZ-98 datasets vary most along a SST gradient. SST is therefore the most reasonable target should these datasets be used for quantitative environmental interpretation of the Late Quaternary fossil record. In the New Zealand region, dinocyst assemblages are more closely correlated to SST than across the entire Southern Hemisphere. This may be due to the absence of large scale high-productivity upwelling systems in the SW Pacific, which have distinctive dinocyst assemblages in other parts of the Southern Hemisphere (Holzwarth 
Figure 2.23. RDA biplot of Axes 1 and 2 of NZ-98 dataset, showing A. Species locations and B. sample locations

A.

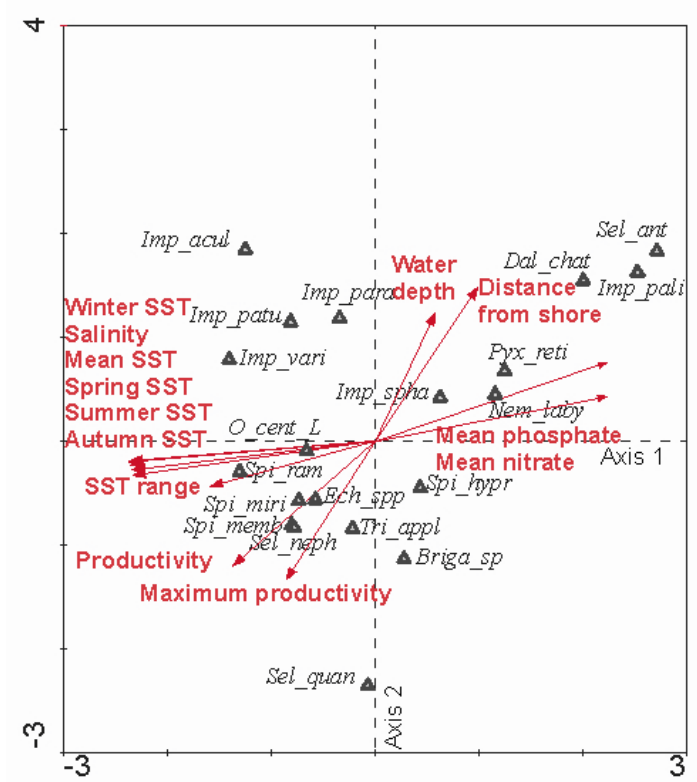

B.

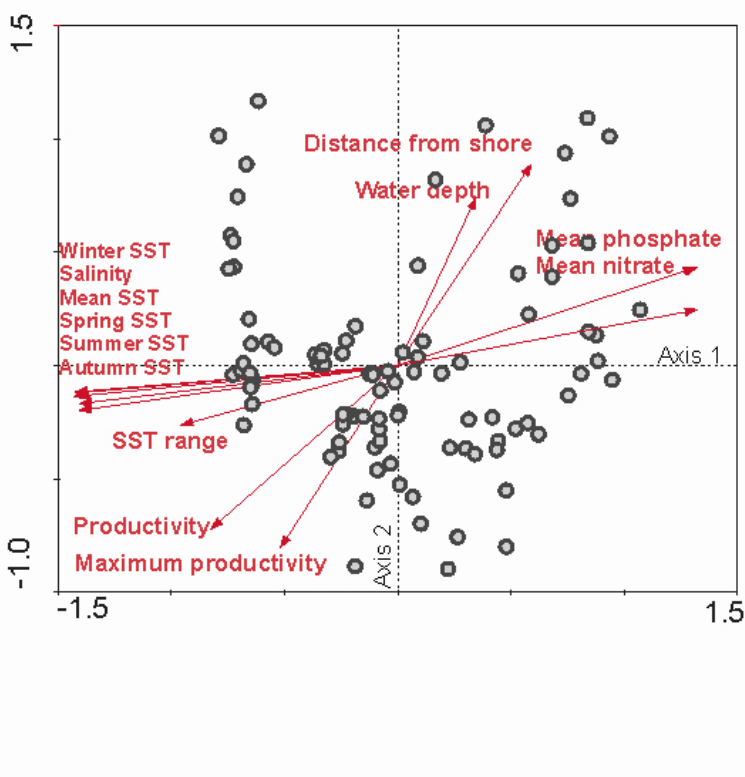

et al., 2007; Verleye and Loweye, 2010a), although the cluster analysis and ordination of the NZ-98 dataset also reflects the importance of both latitudinal and secondary shoreline and productivity gradients in the region. The most pervasive split in assemblages in the SW Pacific dataset is across the STF, but some of the finer divisions are along productivity-related boundaries. These results suggest that these dinocyst datasets are not suitable for use as training datasets for SST inference models in all cases, and care must be taken when analysing the suitability of completing SST reconstructions. Across the Southern Hemisphere, the gradient analysis also revealed significant assemblage changes along gradients not correlated to SST, particularly relating to proximity to land and productivity (e.g. Holzwarth et al., 2007; Pospelova et al., 2008; Verleye and Loweye, 2010a), while dinocyst assemblages associated with high productivity zones are also present in the SW Pacific. Further consideration on assessing the suitability of dinocyst datasets for SST reconstruction in the context of competing environmental gradients is in Chapter 4. 
Two numeric approaches are used here to consider the variation of dinocyst assemblages in the ocean, one that groups similar assemblages and another that places them along continuous gradients. The similar, but subtly contrasting, results highlight the tensions implicit in isolating a single environmental parameter from observation of a biological system. Although the ordination results provide the (relatively) simple answer that assemblages vary most along the SST gradient, the classification exercises show that geographic location and water masses also have important influences on assemblage composition. Thus, the 'unimodal' or 'linear' variation assumed for the ordination (e.g. ter Braak, 1994; Birks, 1995; Birks et al., 2010), and for some transfer function models considered in Chapter 4, is at best step-wise along this gradient. Although boundaries between water masses are frequently defined by gradients in SST, there is also significant biogeochemical variation within these water masses, such as fundamentally different regimes of productivity, nutrient limitation, seasonality, and export production (e.g. Sathyendranath et al., 1995; Longhurst, 1995; Behrenfeld et al., 2006), which cannot be described by the few variables included in an ordination. Thus, SST, or any single environmental gradient, as a target for quantitative environmental reconstruction using biological proxies must be treated with caution, not only for the mathematical reasons explored in Chapter 4.

\subsection{Conclusions}

This study expands on the modern dinocyst assemblage dataset in the SW Pacific region. It is the first report of sea floor dinocyst assemblages from the Tasman Sea and provides information about southern and northern regions of the SW Pacific, including the difficulty in obtaining well preserved and abundant dinocyst assemblages from these regions. This study shows the following:

1. A distinctive assemblage dominated by Impagidinium aculeatum was found in the Tasman Sea. Tropical samples were sparse, and characterized by $I$. aculeatum, I. variaseptum, I. paradoxum, and I. strialatum in proportions that suggested assemblages different from those of the Tasman Sea. Likewise, 
dinocysts in the high latitude samples were too sparse to achieve census observed, but Impagidinium pallidum, Selenopemphix antarctica, Brigantedinium, and Nematosphaeropsis labyrinthus were the main components of these sparse assemblages.

2. Cluster analysis of $98 \mathrm{SW}$ Pacific samples revealed four distinct biogeographic provinces: a) SAW south of the STF, dominated by N. labyrinthus b) STF and near shore sites, dominated by Brigantedinium spp, Selenopemphix quanta and Echnidinium spp., c) STW near shore sites, dominated by Operculodinium centrocarpum, Spiniferities ramosus and S. mirabilis, and d) STW oceanic sites from the Tasman Sea, dominated by Impagidinium aculeatum.

3. When cluster analysis was extended to a compilation of 311 samples across the Southern Hemisphere, three additional distinct assemblages were recognized. Two of the clusters appear to occupy ecological niches not present in the $98 \mathrm{SW}$ Pacific samples, of a) Polar waters dominated by Selenopemphix antarctica and b) cool temperate and high productivity waters, containing relatively lowdiversity assemblages dominated by Brigantedinium and other peridinoid genera. A final cluster, of assemblages characterized by high relative abundances of Operculodinium centrocarpum, was only observed in the South Atlantic samples.

4. RDA and CCA ordination found variance along the first ordination axes accounted for $38 \%(\mathrm{SH}-311)$ and $56 \%$ (NZ-98) of the species-environmental relationship after removal of covarying explanatory variables, and SST was the environmental variable that correlated most strongly to variation along the first axis.

5. Modern dinocyst assemblages are yet to be examined from many parts of the Southern Hemisphere. Further studies, particularly from the Indian and Pacific Oceans at all latitudes, will significantly enhance our understanding of Southern Hemisphere dinocyst biogeography. In the SW Pacific, additional samples would 
be useful from the Tasman Sea portion of the STF, the West Coast of the South Island, and from waters of the North and West Tasman Sea.

6. The two dinocyst datasets compiled here are suitable as training sets for quantitative SST reconstruction. The oceans of the SW Pacific, where most variation in dinocyst assemblages occurs along the meridonal gradient that is best characterised by variation in SST, is a suitable region in which to apply such approaches.

\subsection{Acknowledgements}

Samples were processed by Sonja Fry and Roger Tremain at the GNS Science Palynology Laboratory. Samples were collated from numerous sources by Giuseppe Cortese. George Scott and Marcus Vandergoes, GNS Science, are thanked for discussion on

ordination and variation in natural environments. ${ }^{14} \mathrm{C}$ dates were processed at GNS Science, from material picked by Helen Bostock.

\section{Appendix 2.1. Ordination methodology}

Automatic forward selection runs as many ordinations as there are environmental variables, and in every ordination step the environmental variable that explained the greatest proportion of total inertia in the previous run is removed (e.g., Verleye and Louwye, 2010; Pospelova et al., 2008; Marret and Zonneveld, 2003). We used Monte Carlo Forward Selection with 499 unrestricted permutations. Table A5a shows that automatic forward selection found sea surface temperature contributed the largest proportion to the total inertia in both datasets. Mean summer SST explained $27 \%$ of the total inertia in SH-311, and 35\% in the RDA ordination of NZ-98. The secondary environmental variables in all three ordinations (the next most significant 'marginal effects') contributed about half to one third of the variance of the primary environmental effects. For SH-311, mean annual nitrate and salinity at 50m water depth 
contributed $16 \%$ and $9 \%$ respectively, while distance from land (12\%) was the second largest contributor to explainable inertia for both NZ-98 ordinations.

An alternative approach that achieves a similar result is to manually identify and remove environmental variables that covary, then perform a final ordination constrained by the remaining environmental variables (Dieffenbacher-Krall et al., 2007; Brooks et al., 2001). This is completed in three steps: CCA runs were completed with each environmental variable as the sole constraining variable, with a Monte Carlo simulation to assess the significance of the contribution of the environmental variable to variation along the first axis (Table A2.1.1). Environmental variables that covaried (with a correlation of $>0.95$ ) were identified from a weighted correlation matrix. Although Dieffenbacher-Krall et al. (2007) applied Detrended CCA at this step, we observed detrending made no difference to the result, as the effect of detrending is only to remove artifacts from the second axis and has no bearing on first axis variation.

The environmental variable within each group of co-varying variables with the greatest contribution to the first axis variation was selected. Finally, a CCA with Monte Carlo forward selection was run with only the remaining variables constraining the ordination. What is implicit in this manual removal of co-varying variables is that each of the discarded variables is interchangeable with those finally selected. The results of the first two steps (the individual CCA analyses and the weighted correlation matrices) are included in supplementary material. The final CCA and RDA ordinations (Table A2.1.2) show sea surface temperature contributed $36 \%$ to the total explainable inertia in the SH-311 dataset. In the NZ-98 dataset, sea surface temperature contributed $53 \%$ to the RDA ordination. 


\section{Chapter 2}

Table A2.1.1. Canonical correspondence analysis and Redundancy analysis results for $\mathrm{SH}-311$ and NZ-98, and significance of selected environmental variables determined by Monte Carlo forward selection. Only environmental variables that contribute more than $5 \%$ to canonical eigen values, and have a $p$-value of $<.05$ are shown.

\begin{tabular}{|c|c|c|c|c|c|}
\hline \multicolumn{6}{|l|}{ CCA - SH-311 } \\
\hline Axes & 1 & 2 & 3 & 4 & Total inertia: \\
\hline Eigenvalues: & 0.483 & 0.327 & 0.289 & 0.148 & \\
\hline Species-environment correlations: & 0.868 & 0.829 & 0.79 & 0.767 & \\
\hline $\begin{array}{l}\text { Cumulative percentage variance: } \\
\text { of species data: }\end{array}$ & 11.3 & 19.0 & 25.7 & 29.2 & \\
\hline of species-environment relationship: & 30.1 & $\begin{array}{c}50.5 \\
\text { Sum }\end{array}$ & 68.5 & & \\
\hline & \multicolumn{4}{|c|}{ Sum of all canonical eigenvalues: } & $\begin{array}{l}4.276 \\
1.604\end{array}$ \\
\hline Conditional effects: & \multicolumn{2}{|c|}{ lambda-A } & \multicolumn{2}{|c|}{$\%$ contribution to } & \\
\hline Summer temperature $0 \mathrm{~m}$ & \multicolumn{2}{|c|}{0.43} & \multicolumn{2}{|c|}{27} & \\
\hline Nitrate $50 \mathrm{~m}$ & \multicolumn{2}{|c|}{0.26} & \multicolumn{2}{|c|}{16} & \\
\hline Salinity - 50m depth & \multicolumn{2}{|c|}{0.19} & \multicolumn{2}{|c|}{12} & \\
\hline Winter temperature $0 \mathrm{~m}$ & \multicolumn{2}{|c|}{0.11} & \multicolumn{2}{|c|}{7} & \\
\hline Phosphate $0 \mathrm{~m}$ & \multicolumn{2}{|c|}{0.11} & \multicolumn{2}{|c|}{7} & \\
\hline Salinity $0 \mathrm{~m}$ & \multicolumn{2}{|c|}{0.10} & \multicolumn{2}{|c|}{6} & \\
\hline \multicolumn{6}{|l|}{ RDA - NZ-98 } \\
\hline Axes & 1 & 2 & 3 & 4 & Total inertia: \\
\hline Eigenvalues: & 0.224 & 0.172 & 0.072 & 0.027 & \\
\hline Species-environment correlations: & 0.81 & 0.756 & 0.648 & 0.663 & \\
\hline $\begin{array}{l}\text { Cumulative percentage variance: } \\
\text { of species data: }\end{array}$ & $\begin{array}{r}22.4 \\
43.3\end{array}$ & $\begin{array}{l}39.6 \\
76.4\end{array}$ & $\begin{array}{l}46.8 \\
90.3\end{array}$ & $\begin{array}{l}49.5 \\
95.5\end{array}$ & \\
\hline & \multicolumn{4}{|c|}{ Sum of all eigenvalues: } & : \\
\hline & \multicolumn{4}{|c|}{ Sum of all canonical eigenvalues: } & 0.518 \\
\hline Conditional effects: & \multicolumn{2}{|c|}{ lambda-A } & \multicolumn{2}{|c|}{$\%$ contribution to } & \\
\hline Summer temperature $0 \mathrm{~m}$ & \multicolumn{2}{|c|}{0.18} & \multicolumn{2}{|c|}{35} & \\
\hline Distance from shore & \multicolumn{2}{|c|}{0.06} & \multicolumn{2}{|c|}{12} & \\
\hline Winter temperature $0 \mathrm{~m}$ & \multicolumn{2}{|c|}{0.04} & \multicolumn{2}{|c|}{8} & \\
\hline Annual temperature $10 \mathrm{~m}$ & \multicolumn{2}{|c|}{0.03} & \multicolumn{2}{|c|}{6} & \\
\hline Productivity & 0.0 & & 6 & & \\
\hline
\end{tabular}




\section{Chapter 2}

Table A2.1.2. Canonical correspondence analysis and Redundancy Analysis with individual environmental gradients as the sole constraining variable to determine the contribution of variance to the first axis.

\begin{tabular}{|c|c|c|c|}
\hline \multicolumn{4}{|l|}{ SH-311 } \\
\hline & $p$-value & $\begin{array}{l}\text { CCA Axis } 1 \\
\text { eigenvalue }\end{array}$ & $\begin{array}{l}\% \text { species } \\
\text { variation } \\
\text { explained }\end{array}$ \\
\hline Annual temperature $0 \mathrm{~m}$ & 0.002 & 0.422 & 9.9 \\
\hline Summer temperature $0 \mathrm{~m}$ & 0.002 & 0.425 & 9.9 \\
\hline Winter temperature $0 \mathrm{~m}$ & 0.002 & 0.407 & 9.5 \\
\hline Autumn temperature $0 \mathrm{~m}$ & 0.002 & 0.414 & 9.7 \\
\hline Spring temperature $0 \mathrm{~m}$ & 0.002 & 0.424 & 9.9 \\
\hline Temperature range $0 \mathrm{~m}$ & 0.002 & 0.135 & 3.2 \\
\hline Annual temperature $50 \mathrm{~m}$ & 0.002 & 0.412 & 9.6 \\
\hline Annual temperature $10 \mathrm{~m}$ & 0.002 & 0.421 & 9.8 \\
\hline Depth & 0.002 & 0.16 & 3.7 \\
\hline Annual phosphate $0 \mathrm{~m}$ & 0.002 & 0.328 & 7.7 \\
\hline Annual nitrate $0 \mathrm{~m}$ & 0.002 & 0.332 & 7.8 \\
\hline Annual salinity $0 \mathrm{~m}$ & 0.002 & 0.273 & 6.4 \\
\hline Annual productivity & 0.002 & 0.148 & 3.5 \\
\hline Maximum monthly productivity & 0.002 & 0.1 & 2.3 \\
\hline Annual salinity $50 \mathrm{~m}$ & 0.002 & 0.33 & 7.7 \\
\hline Annual nitrate $50 \mathrm{~m}$ & 0.002 & 0.32 & 7.5 \\
\hline Annual phosphate $50 \mathrm{~m}$ & 0.002 & 0.305 & 7.1 \\
\hline \multicolumn{4}{|l|}{ NZ-98 } \\
\hline & $p$-value & $\begin{array}{l}\text { CCA Axis } 1 \\
\text { eigenvalue }\end{array}$ & $\begin{array}{c}\% \text { species } \\
\text { variation } \\
\text { explained }\end{array}$ \\
\hline Annual temperature $0 \mathrm{~m}$ & 0.002 & 0.178 & 17.8 \\
\hline Summer temperature $0 \mathrm{~m}$ & 0.002 & 0.179 & 17.9 \\
\hline Winter temperature $0 \mathrm{~m}$ & 0.002 & 0.177 & 17.7 \\
\hline Autumn temperature $0 \mathrm{~m}$ & 0.002 & 0.178 & 17.8 \\
\hline Spring temperature $0 \mathrm{~m}$ & 0.002 & 0.175 & 17.5 \\
\hline Temperature range $0 \mathrm{~m}$ & 0.002 & 0.103 & 10.3 \\
\hline Annual temperature $50 \mathrm{~m}$ & 0.002 & 0.115 & 11.5 \\
\hline Annual temperature $10 \mathrm{~m}$ & 0.002 & 0.121 & 12.1 \\
\hline Depth & 0.002 & 0.063 & 6.3 \\
\hline Annual phosphate $0 \mathrm{~m}$ & 0.002 & 0.161 & 16.1 \\
\hline Annual nitrate $0 \mathrm{~m}$ & 0.002 & 0.169 & 16.9 \\
\hline Annual salinity $0 \mathrm{~m}$ & 0.002 & 0.172 & 17.2 \\
\hline Annual productivity & 0.002 & 0.054 & 5.4 \\
\hline Maximum monthly productivity & 0.008 & 0.041 & 4.1 \\
\hline Annual salinity $50 \mathrm{~m}$ & 0.3104 & 0.013 & 1.3 \\
\hline Annual nitrate $50 \mathrm{~m}$ & 0.002 & 0.078 & 7.8 \\
\hline Annual phosphate $50 \mathrm{~m}$ & 0.002 & 0.085 & 8.5 \\
\hline Distance from shore & 0.002 & 0.088 & 8.8 \\
\hline
\end{tabular}




\section{Appendix 2.2. Weighted correlation tables}

Appendix 2.2. Weighted correlation tables used to identify environmental gradients that co-varied. Correlations greater than 0.95 highlighted bold, environmental gradients retained for final CCA and RDA analysis in Table 2.4 highlighted bold.

\begin{tabular}{|c|c|c|c|c|c|c|c|c|c|c|c|c|c|c|c|c|c|}
\hline \multicolumn{18}{|l|}{ SH-311 } \\
\hline Annual temperature $\mathrm{Om}$ & 1.00 & & & & & & & & & & & & & & & & \\
\hline Summer temperature $0 \mathrm{~m}$ & 0.99 & 1.00 & & & & & & & & & & & & & & & \\
\hline Winter temperature $\mathrm{Om}$ & 0.99 & 0.97 & 1.00 & & & & & & & & & & & & & & \\
\hline Autumn temperature $\mathrm{Om}$ & 1.00 & 0.99 & 0.99 & 1.00 & & & & & & & & & & & & & \\
\hline Spring temperature $0 \mathrm{~m}$ & 1.00 & 0.99 & 0.99 & 0.99 & 1.00 & & & & & & & & & & & & \\
\hline Temperature range $0 \mathrm{~m}$ & 0.34 & 0.46 & 0.22 & 0.32 & 0.34 & 1.00 & & & & & & & & & & & \\
\hline Depth & -0.18 & -0.22 & -0.12 & -0.15 & -0.21 & -0.41 & 1.00 & & & & & & & & & & \\
\hline Annual temperature $50 \mathrm{~m}$ & 0.99 & 0.97 & 0.99 & 0.99 & 0.98 & 0.29 & -0.11 & 1.00 & & & & & & & & & \\
\hline Annual temperature $10 \mathrm{~m}$ & 1.00 & 0.99 & 0.99 & 1.00 & 1.00 & 0.34 & -0.17 & 0.99 & 1.00 & & & & & & & & \\
\hline Annual phosphate $50 \mathrm{~m}$ & -0.68 & -0.68 & -0.68 & -0.69 & -0.65 & -0.21 & -0.20 & -0.75 & -0.69 & 1.00 & & & & & & & \\
\hline Annual phosphate Om & $\begin{array}{l}-0.78 \\
-0.78\end{array}$ & $\begin{array}{l}-0.00 \\
-0.78\end{array}$ & $\begin{array}{l}-0.00 \\
-0.78\end{array}$ & $\begin{array}{l}-0.05 \\
-0.79\end{array}$ & $\begin{array}{l}-0.03 \\
-0.76\end{array}$ & $\begin{array}{l}-0.21 \\
-0.27\end{array}$ & -0.07 & -0.83 & $\begin{array}{l}-0.09 \\
-0.79\end{array}$ & 0.96 & 1.00 & & & & & & \\
\hline Annual nitrate $50 \mathrm{~m}$ & -0.68 & -0.68 & -0.69 & -0.70 & -0.66 & -0.21 & -0.25 & -0.75 & -0.69 & 0.94 & 0.90 & 1.00 & & & & & \\
\hline Annual nitrate $0 \mathrm{~m}$ & -0.74 & -0.74 & -0.74 & -0.75 & -0.72 & -0.25 & -0.13 & -0.78 & -0.74 & 0.88 & 0.88 & 0.95 & 1.00 & & & & \\
\hline Annual salinity Om & 0.72 & 0.68 & 0.75 & 0.74 & 0.69 & -0.01 & 0.20 & 0.74 & 0.72 & -0.64 & -0.69 & -0.62 & -0.61 & 1.00 & & & \\
\hline Annual salinity $50 \mathrm{~m}$ & 0.81 & 0.79 & 0.83 & 0.82 & 0.79 & 0.15 & 0.11 & 0.84 & 0.81 & -0.73 & -0.77 & -0.71 & -0.68 & $\begin{array}{l}3 \\
0.94\end{array}$ & 1.00 & & \\
\hline \multirow{3}{*}{$\begin{array}{l}\text { Annual productivity } \\
\text { Maximum monthly productivity }\end{array}$} & 0.28 & 0.34 & 0.22 & 0.28 & 0.29 & 0.51 & -0.39 & 0.21 & 0.28 & 0.05 & -0.08 & 0.09 & -0.04 & $4-0.09$ & -0.06 & 1.00 & \\
\hline & 0.11 & 0.17 & 0.05 & 0.11 & 0.11 & 0.49 & -0.37 & 0.04 & 0.11 & 0.20 & 0.08 & 0.24 & 0.14 & -0.17 & -0.15 & 0.95 & 1.00 \\
\hline & 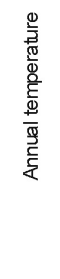 & 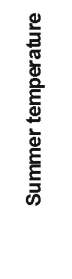 & 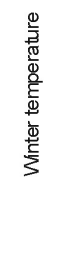 & 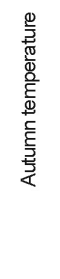 & 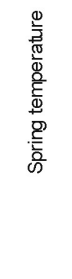 & 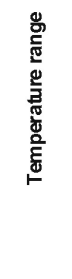 & $\begin{array}{l}\text { 言 } \\
\text { 产 }\end{array}$ & 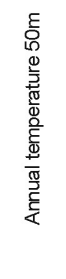 & 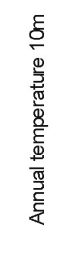 & 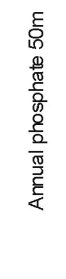 & 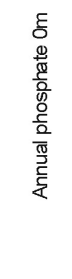 & 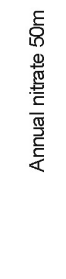 & 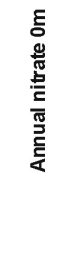 & 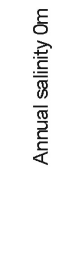 & 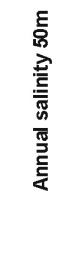 & 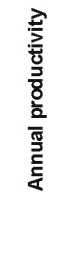 & 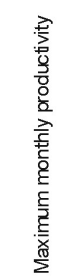 \\
\hline
\end{tabular}

\section{NZ-98}

Annual temperature $0 \mathrm{~m}$ Annual temperature $50 \mathrm{~m}$ Annual temperature $10 \mathrm{~m}$ Summer temperature $0 \mathrm{~m}$ Distance from shore Winter temperature $0 \mathrm{~m}$ Temperature range $0 \mathrm{~m}$ Depth

Autumn temperature $0 \mathrm{~m}$ Spring temperature $\mathrm{Om}$ Annual productivity Maximum monthly productivity Annual salinity $0 \mathrm{~m}$ Annual salinity $50 \mathrm{~m}$ Annual phosphate $0 \mathrm{~m}$ Annual phosphate $50 \mathrm{~m}$ Annual nitrate $0 \mathrm{~m}$ Annual nitrate $50 \mathrm{~m}$
1.00

$0.88 \quad 1.00$

$\begin{array}{lll}0.88 & 1.00 & 1.00\end{array}$

$\begin{array}{llll}0.98 & 0.86 & 0.87 & 1.00\end{array}$

$\begin{array}{lllll}-0.40 & -0.47 & -0.48 & -0.47 & 1.00\end{array}$

$\begin{array}{llllll}1.00 & 0.88 & 0.88 & 0.98 & -0.42 & 1.00\end{array}$

$\begin{array}{lllllll}0.65 & 0.56 & 0.59 & 0.79 & -0.48 & 0.64 & 1.00\end{array}$

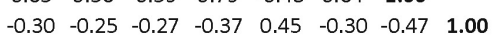

$\begin{array}{lllllllll}1.00 & 0.86 & 0.87 & 0.98 & -0.42 & 0.99 & 0.68 & -0.33 & 1.00\end{array}$

$\begin{array}{llllllllll}1.00 & 0.88 & 0.88 & 0.98 & -0.40 & 1.00 & 0.64 & -0.29 & 0.99 & 1.00\end{array}$

$\begin{array}{llllllllllll}0.49 & 0.46 & 0.47 & 0.48 & -0.37 & 0.48 & 0.37 & -0.16 & 0.49 & 0.49 & 1.00\end{array}$

$\begin{array}{llllllllllll}0.36 & 0.34 & 0.35 & 0.37 & -0.34 & 0.34 & 0.34 & -0.14 & 0.36 & 0.36 & 0.97 & 1.00\end{array}$

$\begin{array}{lllllllllllll}0.98 & 0.88 & 0.87 & 0.94 & -0.44 & 0.98 & 0.57 & -0.24 & 0.97 & 0.98 & 0.50 & 0.35 & 1.00\end{array}$

$\begin{array}{llllllllllllll}0.28 & 0.56 & 0.56 & 0.32 & -0.40 & 0.29 & 0.32 & -0.27 & 0.30 & 0.28 & 0.21 & 0.17 & 0.27 & 1.00\end{array}$

$\begin{array}{llllllllllllllll}-0.95 & -0.85 & -0.86 & -0.93 & 0.43 & -0.94 & -0.64 & 0.30 & -0.95 & -0.96 & -0.54 & -0.42 & -0.94 & -0.31 & 1.00\end{array}$

$\begin{array}{llllllllllllllll}-0.75 & -0.85 & -0.85 & -0.72 & 0.41 & -0.74 & -0.45 & 0.13 & -0.73 & -0.76 & -0.49 & -0.39 & -0.79 & -0.27 & 0.84 & 1.00\end{array}$

$\begin{array}{lllllllllllllllll}-0.97 & -0.85 & -0.86 & -0.95 & 0.34 & -0.95 & -0.67 & 0.29 & -0.96 & -0.97 & -0.49 & -0.38 & -0.93 & -0.27 & 0.98 & 0.81 & 1.00\end{array}$

$\begin{array}{lllllllllllllllllll}-0.64 & -0.60 & -0.59 & -0.58 & 0.11 & -0.63 & -0.25 & -0.05 & -0.60 & -0.64 & -0.32 & -0.22 & -0.68 & 0.22 & 0.66 & 0.84 & 0.69 & 1.00\end{array}$

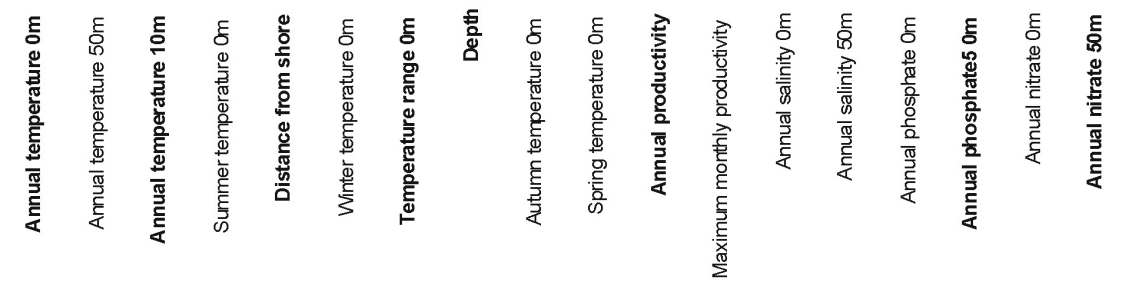


Chapter 2

\section{Supplementary Material}

The following data tables are included at the end of this thesis

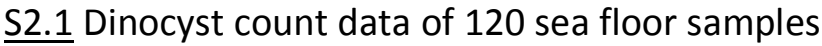

S2.2 NZ-98 count and environmental data

$\underline{\mathrm{S} 2.3} \mathrm{SH}-311$ count and environmental data 
Chapter 2 


\title{
3. Holocene and modern dinoflagellate cyst flux in subtropical and subantarctic waters, Southwest Pacific Ocean.
}

\begin{abstract}
A three year (2005-2008) record of dinoflagellate cyst (dinocyst) flux is derived from two time-incremental sediment traps deployed at $1500 \mathrm{~m}$ water depth in two biogeochemically distinct water masses to the east of New Zealand: (i) warm, seasonally macronutrient-depleted Subtropical waters and (ii) cold, micronutrient-limited Subantarctic waters. Dinocyst compositions in core-top sediments from within the vicinity of the trap moorings are compared with these modern fluxes to evaluate the biases inherent in using dinocysts as palaeoceanographic environmental proxies.
\end{abstract}

Trap assemblages are dominated by peridinoid cysts, notably Brigantedinium spp, which comprise almost $\sim 98 \%$ of the cyst flux. Nineteen dinocyst taxa or taxonomic groups were identified from the trap samples. The seasonality of dinocyst flux differs between the traps, with a pronounced spring flux coincident with peak productivity in the northern Subtropical trap, while annual variation in the southern Subantarctic trap is relatively muted.

There is a large discrepancy between dinocyst flux and cyst assemblages of nearby seafloor sediments. Dinocysts known to be susceptible to degradation in oxygenated sediments (particularly representatives of the genera Echinidinium and Brigantedinium) are highly under-represented in the sea-floor assemblages. In contrast, cysts that are relatively resistant to oxidation, including species belonging to the genera Spiniferites, Nematosphaeropsis and Operculodinium, are over 30 times more abundant in sea-floor sediments than would be expected from the three years of flux measurements. The most likely explanation for the under-representation of the less resistant cyst types in sea-floor sediments is degradation by oxidation in the water column and sedimentwater interface. The reason for over-representation of resistant cysts in the sediment is 
less clear. Two likely possibilities are considered, transport in bottom currents from near-shore waters, or the restriction of cyst formation to optimal years not sampled by our trap record. Available data support the latter hypothesis, although lateral transport and production during sampling gaps within the time series cannot be conclusively discounted.

The major differences between the two water masses examined, being the seasonality of dinocyst flux, and the large inter-annual variability in the flux composition, suggest mean-annual rather than seasonal climatologies are more appropriate for dinocystbased quantitative palaeoenvironmental reconstructions in the New Zealand region.

\subsection{Introduction}

Dinoflagellates make a significant contribution to primary productivity and grazing in modern oceans, at times forming blooms that dominate carbon fixation and primary carbon cycling in surface waters (Chang, 1988; Verity et al., 1993; Sherr and Sherr, 2007; Wasmund et al., 2011). About $10-20 \%$ of modern dinoflagellates form fossilisable organic-walled cysts (Dale, 1996; de Vernal and Marret, 2007), resulting in approximately 80 identifiable sub-fossil taxa in modern sea-floor samples (Marret and Zonneveld, 2003). The organic-walled dinoflagellate cyst (dinocyst) represents a resting stage in the dinoflagellate life cycle, and is generally formed after sexual reproduction (Pfiester and Anderson, 1987; Figueroa et al., 2007; Kremp et al., 2009).

Late Quaternary fossil dinocyst assemblages are frequently interpreted in terms of varying environmental conditions, based on observations of cyst assemblages in modern sediments (e.g., Marret and Zonneveld, 2003; Radi et al, 2007; Pospelova et al., 2008; Crouch et al., 2010; Limoges et al., 2010), either by semi-quantitative interpretation of trends (e.g., Esper at al., 2004; Verleye and Louwye, 2010) or by mathematical transfer functions that quantify environmental gradients, such as sea surface temperature, salinity, sea ice cover or marine productivity (e.g., Peyron and deVernal, 2001; Marret et al., 2008; Bonnet et al., 2010). Although the distribution of dinocysts in modern 
sediments is the primary archive used to interpret palaeo-assemblages, additional information on dinoflagellate ecology allows exploration of the implicit assumptions required to attempt reconstructions based on correlations to selected abiotic gradients, specifically the ecological relevance of the target environmental variable to the dinoflagellate (e.g. Birks et al., 2010). Observations of modern dinocyst flux from timeseries sediment trap samples are one tool with which one can gain insight into such aspects of dinoflagellate ecology.

Previous multi-year observations of seasonal scale variation in dinocyst flux have been mainly from near-shore and continental margin environments (e.g., Fuji and Matsuoka, 2006; Ribeiro and Amorim, 2008; Pitcher and Joyce, 2009; Pospelova et al., 2010; Price and Pospelova, 2011), although there are a few records from open oceanic settings (e.g., Zonneveld and Brummer, 2000; Harland and Pudsey, 1999; Zonneveld et al., 2010). A common theme of these studies is the observation of marked seasonal and interannual variability of cyst fluxes, occasionally accompanied by large differences between the observed trap assemblages and nearby sea-floor samples, with the latter observation particularly a feature of deep-water oceanic settings. In addition to improving understanding of the near-surface marine conditions that correspond to cyst formation, trap experiments have provided information on a range of factors relevant to regional palaeoenvironmental interpretations using dinoflagellate cysts; for example nutritional modes (Fuji and Matsuoka, 2006; Pospelova et al. 2010; Zonneveld et al. 2010) and the effects of degradation on dinocyst assemblages (e.g., Zonneveld and Brummer, 2000, Zonneveld et al., 2008).

Here, we present multi-annual dinocyst flux measurements at monthly resolution from two time-incremental sediment traps to the east of New Zealand. The traps were moored at $1500 \mathrm{~m}$ water depth beneath subtropical and subantarctic surface water masses (STW and SAW, respectively) (Figure 3.1). The three years of dinocyst flux (May 2005 to May 2009, with some time gaps due to mooring and sample losses) provide an initial investigation into seasonal and inter-annual variability of cyst fluxes in this region 
Chapter 3

and their relationship to nearby sea-floor samples. As such, these are the first observations from oceanic waters in the mid-latitudes of the Southern Hemisphere. The main emphasis of this study is on application of these observations to palaeoenvironmental interpretation, as deep water sediment trap studies provide an opportunity to link the observations of surface water productivity with observations from the fossil record on the sea-floor. The objectives of this study are to:

1. investigate the dinocyst flux for seasonal and/or inter-annual variability in STW and SAW, which may assist in interpretation of dinocyst assemblages in the sediment record, and,

2. investigate the degree of similarity between dinocyst flux and assemblages from nearby sea-floor sediments.

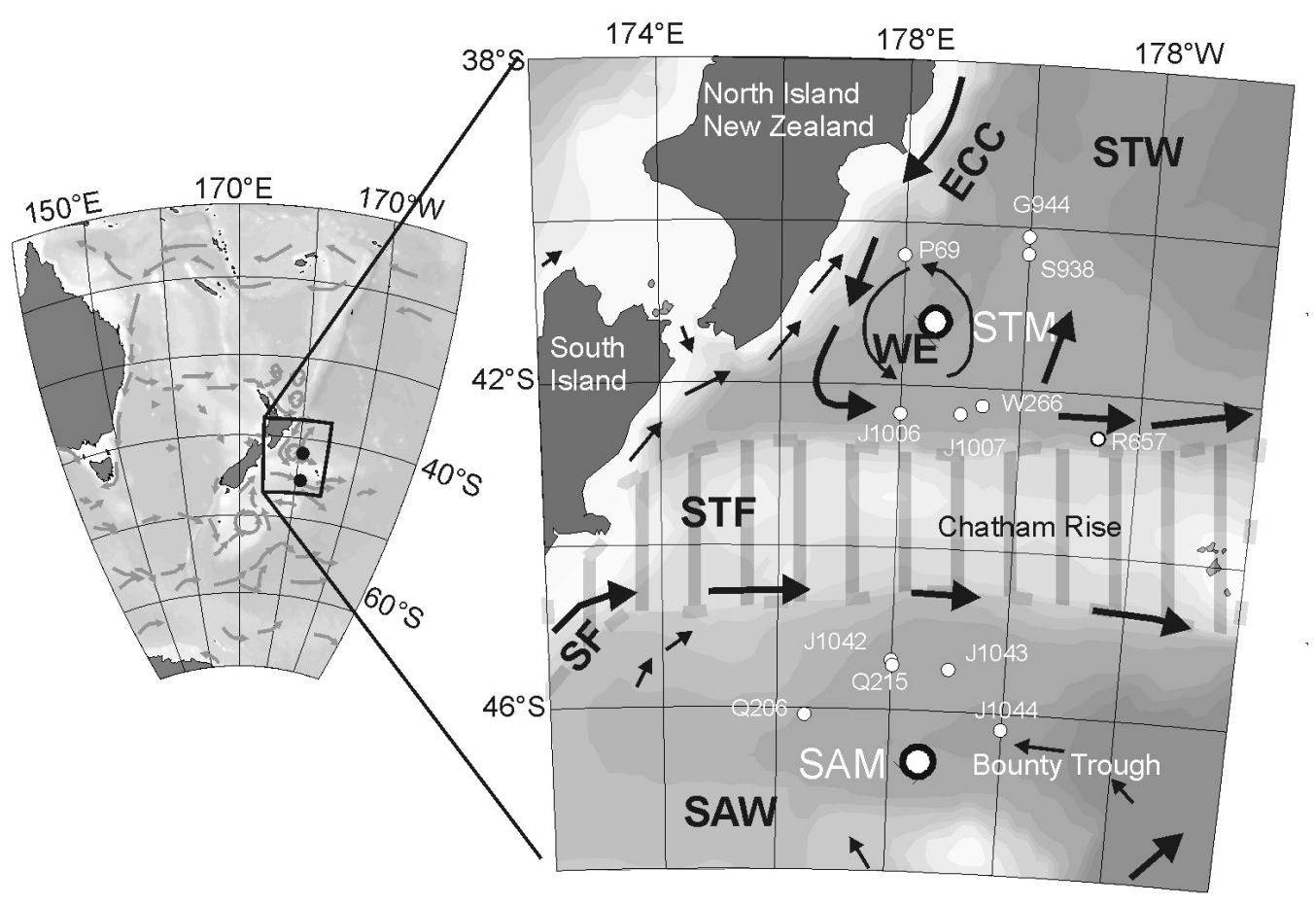

Figure 3.1. Location map, showing the position of the Subtropical (STM) and Subantarctic (SAM) sediment trap moorings, and sea floor sediment samples discussed in the text. ECC = East Coast Current, WE = Wairarapa Eddy, SF, Southland Front, STW = Subtropical Water, SAW = Subantarctic Water, STF = Subtropical Front. 


\subsection{Oceanographic Setting and trap locations}

A significant oceanographic feature to the east of New Zealand is the Subtropical Front (STF), formed by the convergence of STW transported by the South Pacific Gyre and SAW carried by local flows some of which are linked to the Antarctic Circumpolar Current (ACC) (e.g. Morris et al., 2001).

Around New Zealand, the STF follows the outer edge of the continental shelf up the east coast of the South Island (where it is called the Southland Front), then strikes eastwards along the crest of the Chatham Rise, at $43-44^{\circ}$ S (Heath, 1985; Carter et al., 1998; Uddstrom and Oien, 1999; Sutton, 2001) (Figure 3.1). Maximum productivity is typically observed in the frontal zone, where STW and SAW converge and mix (e.g., BradfordGrieve et al., 1997).

Compared to SAW, STW is warmer, saltier, relatively poorer in macronutrients, such as nitrate and phosphate, but is relatively enriched in micronutrients, such as iron (Boyd et al., 1999, 2004). This results in higher primary productivity in the STW to the east of New Zealand, particularly during spring months, compared to the lower production and muted seasonal variation observed in SAW (Murphy et al., 2001). Annual productivity in STW east of New Zealand appears to follow a classic spring bloom cycle, with the introduction of nutrients to surface waters by mixing during winter storms, followed by a spring bloom, dominated by diatoms initiated in thermally-stratified near-surface waters, with surface productivity reduced by early summer due to the depletion of macronutrients (Chang and Gall, 1998; James and Hall, 1998; Boyd et al., 1999; Bradford-Grieve et al., 1997, 1999; Murphy et al., 2001; Hall et al., 2004; Chiswell, 2011). A close coupling between the spring bloom and export of biogenic material to the deep ocean has been observed in STW eddies east of New Zealand, with rapidly-sinking aggregations of diatoms observed in deep-ocean traps during spring (Nodder and Northcote, 2001; Nodder et al., 2005). However, this coupling of productivity and export appears transient, with flux at $1500 \mathrm{~m}$ ceasing prior to the end of the spring bloom. In contrast, primary productivity in SAW is limited by iron and silicia, and is 


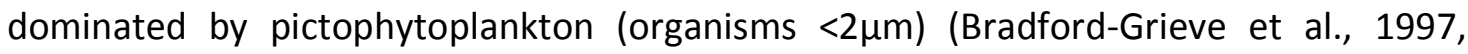
1999; Chang and Gall, 1998; Boyd et al., 1999, 2004). A consequence of the small size of the dominant phytoplankton is generally a reduced export flux from surface waters due to low settling rates, although they too may aggregate into more rapidly sinking particles (Waite et al., 2000). Thus, although the peak mass flux (dominated by biogenic silica) to the deep ocean in New Zealand SAW also occurs in spring, it precedes the peak productivity in surface waters, which is observed during summer (Nodder and Northcote, 2001; Nodder et al., 2005).

The northern sediment trap mooring (Subtropical Mooring, STM) is located $200 \mathrm{~km}$ east of the North Island, New Zealand, in $3100 \mathrm{~m}$ of water $\left(41^{\circ} 15^{\prime} \mathrm{S}, 178^{\circ} 33^{\prime} \mathrm{E}\right)$, with the sediment trap moored at a depth of $1500 \mathrm{~m}$ (Figure 3.1). The surface waters above the trap are STW associated with the East Cape Current (ECC) (Roemmich and Sutton, 1998), which is part of the western boundary flow of the South Pacific Gyre. The ECC turns east along the northern flank of the Chatham Rise, approximately $150 \mathrm{~km}$ to the south of site STM (Heath, 1985). A feature of the ECC is the formation of the transient, cyclonic Wairarapa Eddy (Chiswell and Roemmich, 1998; Chiswell, 2003, 2005). The STM is located near the eddy centre (Nodder et al., 2005).

The southern sediment trap mooring (Subantarctic Mooring, SAM) is below SAW, $600 \mathrm{~km}$ east of the South Island, New Zealand, in a water depth of $2700 \mathrm{~m}\left(46^{\circ} 33^{\prime} \mathrm{S}\right.$, $\left.178^{\circ} 33^{\prime} \mathrm{E}\right)$. The trap is also moored at $1500 \mathrm{~m}$ below the sea surface. The SAM is on the southern flanks of the Bounty Trough, and is located in a region of relatively slow surface currents (Heath, 1985; Morris et al., 2001; Nodder et al., 2005).

\subsection{Methods}

\subsubsection{Mooring deployment and sample processing}

Both STM and SAM traps have been deployed almost continuously since October 2000, with three- to six-monthly collection and maintenance voyages from the RV Tangaroa over this time (Nodder et al., 2005). Both moorings are of a similar design, comprising 
current meters with pressure and temperature sensors at nominal depths of $60 \mathrm{~m}$ and $1500 \mathrm{~m}$, and a time-incremental, conical sediment trap with $0.5 \mathrm{~m}^{2}$ trap area moored at 1500 m depth (McLane PARFLUX 7G-21). In addition, thermistors were placed every 20 $\mathrm{m}$ above $120 \mathrm{~m}$ depth (Brancker XL105). Each trap has 21 collection bottles programmed to rotate to a new bottle, which for the present study was on average every 9 days, with saturated $7 \% \mathrm{HgCl}_{2}$ used as a preservative (0.3\% by volume). Additional information on the mooring deployments is available in Nodder et al. (2005).

Trap samples were refrigerated at sea within two hours of collection. Onshore, zooplankton "swimmers" (large mobile organisms) were removed by sieving at $200 \mu \mathrm{m}$ and using a light microscope (magnification 60-200x) to remove individuals using tweezers. The entire sample was then wet-split using a five-way rotary splitter (McLane WSD10). Four of the five $1 / 5$ splits were utilised for total mass and other chemical measurements (Nodder et al., 2005). The remaining 1/5 subsample was wet-split again: 4/25 was examined for foraminifera and coccolithophores (not discussed further here), and the final $1 / 25$ examined for organic and silicic micro-flora and fauna.

For the micro-flora and fauna analyses, trap subsamples were washed three times with distilled water to remove residual $\mathrm{HgCl}_{2}$, followed by treatment to remove the carbonate component using cold $10 \% \mathrm{HCl}$. The material was sieved through a $45 \mu \mathrm{m}$ mesh for radiolarian studies (not discussed here). The fine fraction was sieved through a $6 \mu \mathrm{m}$ mesh. Depending on the volume of the residue, either a known proportion was mounted on glass slides in glycerine jelly using a micro-pipette from a standard volume, or the entire residue was mounted onto one or more slides.

Approximately every third sample of the available trap material between May 2005 and May 2009 was examined for palynomorphs, with 35 samples examined from SAM and 38 from STM, although sampling was denser (every second sample or every sample) during selected early and late spring bloom periods (Figure 3.2, Supplementary Material S3.1). Although we focused our study on a time period with a relatively continuous time-series, some sample gaps exist. No samples were recovered from the 
STM during May - June 2005 (due to a delay in mooring recovery), July 2007 - April 2008 (when a small fish got stuck in the rotating mechanism), nor after February 2009 (when the trap motor flooded), while the SAM could not be deployed between October 2005 - April 2006 due to adverse sea conditions during the 2005 spring voyage. Although five samples were identified as being collected over an interval when the average daily tilt was greater than $10^{\circ}$ (Supplementary Material S3.1), assessment of current velocity data reveals little correlation between tilt and currents. Given this lack of relationship, we conclude that the collected material provides a reasonable indication of the actual flux (Gardner, 1985; Boyd and Trull, 2006). Therefore, we examined samples representing over 30\% of the time between May 2005 and May 2009. This sampling captured most of the large seasonal variations in mass flux in both water masses (Figure 3.2), and covers both moderately strong positive and negative phases of the Southern Oscillation Index, although no strong El Niño or La Nĩna phases were sampled Climate Prediction Centre, http://www.cpc.ncep.noaa.gov/data/indices/, accessed November 2011).

\subsubsection{Data collection}

Dinocysts and spores/pollen were counted using a light microscope. Dinocysts were identified to species level where possible, and the presence of cell contents noted. The dinocyst - motile theca nomenclature used are those given in Head (1996), and cyst taxonomy follows Rochon et al. (1999), Fensome and Williams (2004), and Marret and Zonneveld (2003). Brigantedinium cariacoense and B. simplex were grouped into Brigantedinium spp. Selenopemphix undulata was combined with Selenopemphix nephroides. All Echnidinium were grouped. Pollen identification was mostly to a generic level, and followed Pocknall (1981a, b, c), Large and Braggins (1991), and Moar (1993). All counts were converted to flux (specimens $\mathrm{m}^{2} /$ day) (Example calculation in Appendix 3.1).

In addition to examining individual samples across the time-series, samples were aggregated into mean monthly statistics for each site. Mean daily flux for each month 
was estimated by taking the average of daily flux calculations from each bottle that had an opening date that fell within the month. Mean monthly flux is the mean daily flux of every sample with a bottle opening date in a given month, multiplied by days in that month. Average annual and average seasonal dinocyst flux was estimated by taking the sum of the monthly cyst flux, with October-December denoted as spring.

In addition to the moored instrumental and bulk flux data provided from the mooring deployments, four satellite-derived parameters were compared to the flux data. They were: monthly primary productivity data (Behrenfeld and Falkowski, 1997), eight-day composite sea surface temperature and surface chlorophyll-a estimates (NASA MODIS data, extracted using the Giovanni web-interface, Acker and Leptoukh, 2007), and an estimate of the Ekman upwelling driven by the wind-stress curl derived from daily NOAA QuikSCAT wind data ( P. Calil, NIWA, pers. comm.). In the Ekman upwelling estimate ( $\mathrm{m}$ $\left.{ }^{1} s^{-1}\right)$, positive values correlate to upwards motion, negative values to downwards motion.

\subsubsection{Comparison with sediment assemblages}

Trap data were compared with sea-floor sediment samples collected using a variety of methods (corers, grabs) from within $175 \mathrm{~km}$ of the STM and SAM sites. These areas of seabed are similar to the modelled particle source areas for each trap, which are 180 $\mathrm{km}$ and $\sim 150 \mathrm{~km}$ diameter cones for STM and SAM, respectively, for a sinking speed of $100 \mathrm{~m} /$ day (Nodder et al., 2005). Also, the seafloor samples within each zone are in areas of similar sea-floor assemblages determined by previous cluster analyses (Chapter

\section{2 , this study).}

First, average relative abundance of the dinocyst flux from the traps was compared to relative abundance census counts from the sea-floor samples in the area. Seven sediment samples from STW and six from SAW were examined. ${ }^{14} \mathrm{C}$ dates are available for three of the sea-floor samples, all of which were of Holocene age, with radiocarbon ages of 2700, 6700 and 8000 years. Dinocyst relative abundance data were 
Table 3.1. Summary statistics of sediment trap observations.

\begin{tabular}{|r|c|c|c|c|}
\hline & $\begin{array}{c}\text { Number of sample } \\
\text { bottles examined }\end{array}$ & $\begin{array}{l}\text { Number of } \\
\text { dinocysts } \\
\text { identified }\end{array}$ & $\begin{array}{c}\text { Number of } \\
\text { peridinoid } \\
\text { dinocysts } \\
\text { identified }\end{array}$ & $\begin{array}{c}\text { Average } \\
\text { dinocyst flux, } \\
\text { cysts/m² }\end{array}$ \\
\hline Northern Biophysical Mooring: & 38 & 2042 & 1973 & \\
\hline Bottle opening date: & & & & \\
\hline January - March & 6 & 120 & 115 & 313 \\
\hline April - June & 7 & 20 & 12 & 35 \\
\hline July - September & 12 & 200 & 176 & 371 \\
\hline October - December & 13 & 1702 & 1670 & 4793 \\
\hline Southern Biophysical Mooring: & 35 & 1878 & 1823 & \\
\hline Bottle opening date: & & & & 272 \\
\hline January - March & 4 & 217 & 214 & 492 \\
\hline April - June & 5 & 395 & 379 & 450 \\
\hline July - September & 11 & 353 & 338 & 640 \\
\hline October - December & 15 & 913 & 892 & \\
\hline
\end{tabular}

taken from Sun and McMinn (1994), Crouch et al. (2010), and Chapter 2 (this study).

Second, the average dinocyst flux into the traps was compared to the average flux of individual taxa to the sea-floor samples. The sediment accumulation rates and sea-floor dinocyst observations required for this comparison were available for four sea-floor samples within $175 \mathrm{~km}$ of the STM (Figure 3.1) (Carter et al., 2000; Crouch et al., 2010). Average daily cyst flux $/ \mathrm{m}^{2}$ was calculated for these four sediment samples, and the flux rate compared to that observed in the traps (calculations for cyst abundance to flux in sediment are included in Appendix 3.1). No samples were available in the vicinity of SAM for a similar comparison.

\subsection{Results}

\subsubsection{Dinocyst composition and abundance patterns}

An average of 53 cysts were identified from each trap sample across the 73 samples examined (Tables 3.1- 3.2). Dinocyst counts were particularly low in autumn and winter (April - September), which were frequently barren of cysts (and any sample material), with an average of just 12 cysts per sample at STM and 42 cysts per sample at SAM at these times. The highest dinocyst count from one 9.4-day bottle sample was 526 cysts, 
during the 2006 spring bloom at STM. While many of the counts in individual samples were low, 2000 cysts have been counted at each mooring across the entire deployment, sufficient to determine the composition of the mean flux, and observe inter-annual and inter-seasonal variations.

Nineteen dinocyst taxa or taxonomic groups were identified from the trap samples (Flux data are reported in Table 3.2 and Figure 3.2, key taxa are illustrated in Figure 3.3, and count data are included in Supplementary Material S3.1). Eighteen taxa were identified at the northern mooring, while diversity was lower at the southern mooring, where nine taxa were identified.

Peridinoid cysts dominated the assemblage at both sites, comprising almost $99 \%$ of the dinocyst flux at STM and over $97 \%$ at SAM. The peridinoid cysts were mainly Brigantedinium spp., which comprised $77 \%$ of the total cyst flux at STM and over $95 \%$ of the total cyst flux at SAM. Other peridinoid cysts that contributed more than $1 \%$ of the total cyst flux at STM were Selenopemphix nephroides, Quinquecuspis concreta and Echinidinium spp. Selenopemphix nephroides is combined with Selenopemphix undulata. Lejeunecysta spp. and Trinovantedinium appalatum were also present. No peridinoids, other than Brigantedinium spp., contributed more than $1 \%$ of the total flux at SAM, although Echinidinium spp. contributed $0.5 \%$.

At both mooring sites the most common gonyaulacoid cysts were species of Impagidinium, which formed approximately $70 \%$ of the gonyaulacoid cyst flux. $I$. pallidum was only observed at SAM, while I. aculeatum and I. patulum were only found at STM. I. sphaericum was the most abundant Impagidinium at SAM, forming $20 \%$ of the gonyaulacoid flux, about twice that observed to the north. Rare specimens of $I$. variaseptum were recorded at both trap sites. Other gonyaulacoid cysts recorded at both sites were Nematosphaeropsis labyrinthus and Lingulodinium machaerophorum. A single specimen of Spiniferites spp., and rare specimens of Operculodinium centrocarpum were identified at STM. 

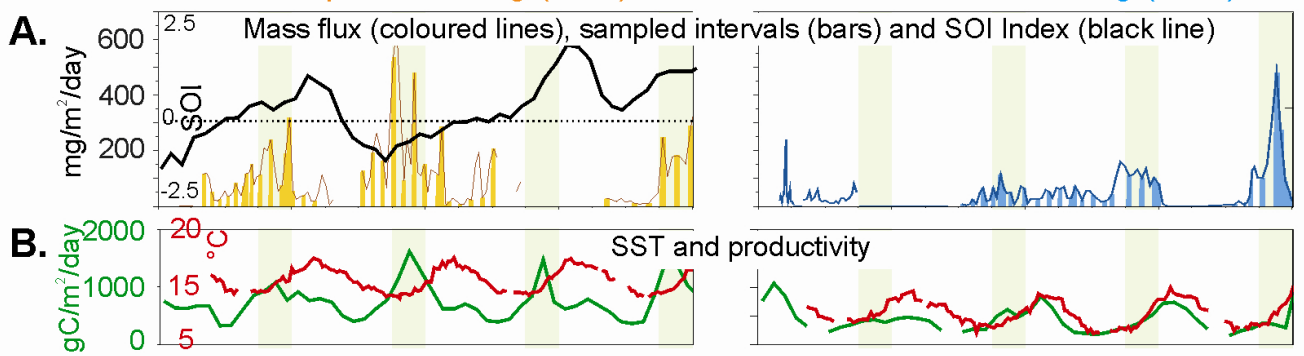

c.

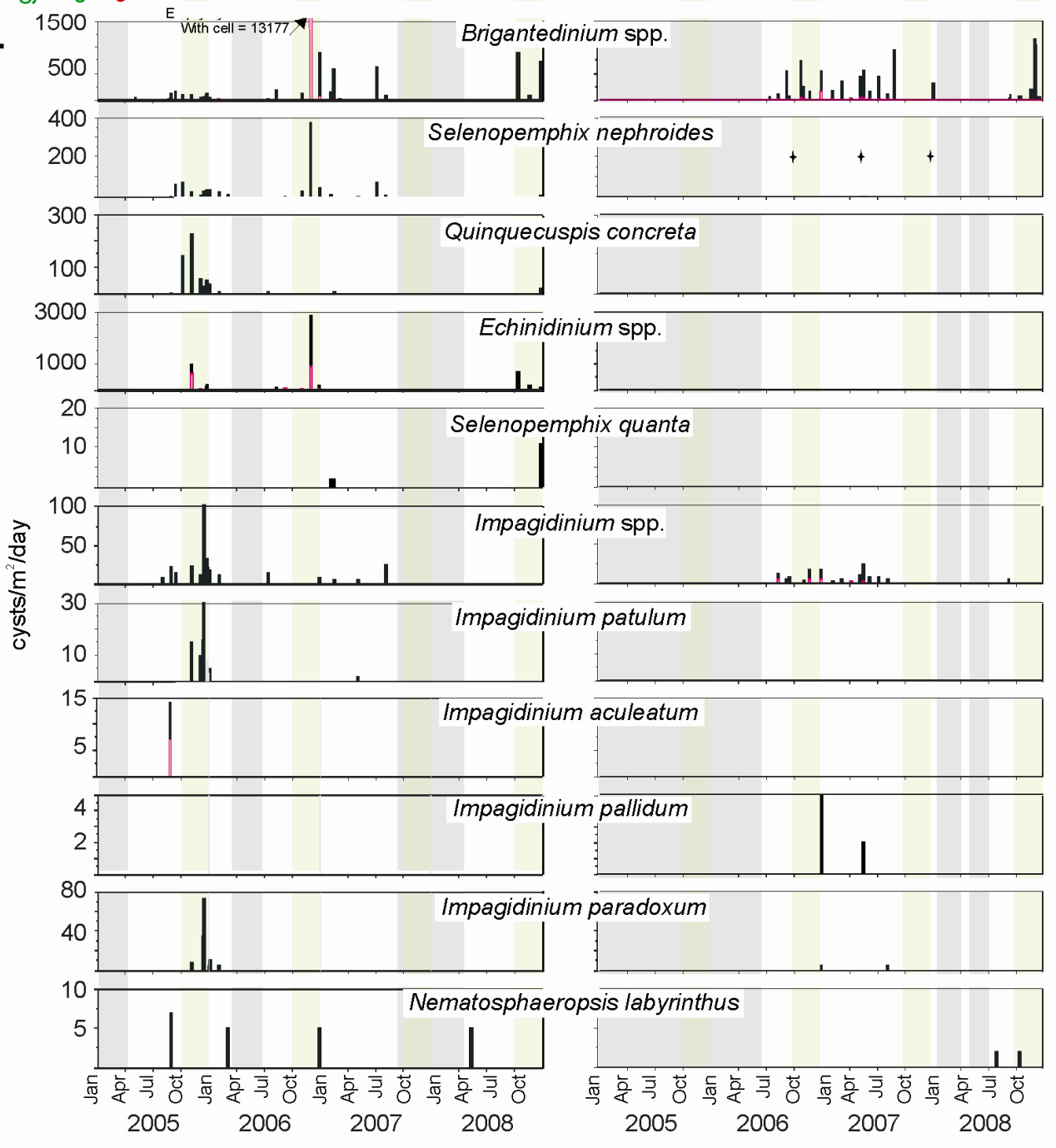

Figure 3.2. Fluxes of selected dinocyst taxa at STM (left, orange) and SAM (right, blue). Vertical green bars denote austral spring (October-December), vertical grey bars show sample gaps $>1$ month. A. Mass flux (line graph), with samples analysed in this study highlighted by coloured bars, black line on left- hand panel = Southern Oscillation Index (SOI). B. Sea Surface Temperature (red, ${ }^{\circ} \mathrm{C}$ ) and productivity (green, $\mathrm{mgC} / \mathrm{m}^{2} /$ day). C. Dinocyst flux, specimens $\mathrm{m}^{2} /$ day, of the 11 most common taxa. Pink bars $=$ cell contents observed in cyst. 
Cell contents were observed in many of the cysts. While approximately $20 \%$ of Impagidinium cysts were unhatched (i.e. cell contents were present), empty cysts were more common in the other groups. Of the 147 Quinquecuspis concreta specimens identified at STM, cell material was observed in only one sample, while no cellular material was observed in any of the 79 Selenopemphix nephroides cysts identified. Cellular material was common in Brigantedinium spp. during the 2006 spring bloom at STM, in which $66 \%$ of the round brown cysts (inferred to be Brigantedinium spp. although no archeopyle could be observed) that arrived at the trap contained cellular material. Cell material was observed in only $2 \%$ of Brigantedinium spp. cysts during the rest of the time-series at STM.

\subsubsection{Cyst flux: seasonality}

Seasonal variation in average cyst flux was observed at both sites. The highest average cyst flux at both sites occurred during the austral spring (October - December). The season of lowest cyst flux differed, being autumn (April - June) at STM and summer (January - March) at SAM. Large seasonal variations of dinocyst flux were observed at STM, while seasonal variations at the SAM were comparatively muted (Table 3.1, 3.2, Figure 3.4).

At STM, the average daily cyst flux during spring was 5-20 times greater than the average seasonal daily flux for the rest of the year. An average daily flux (largely represented by Brigantedinium spp.) of 6400 cysts $/ \mathrm{m}^{2} /$ day was observed over the three spring blooms sampled at STM (note that this reduced to an average of 1360 cysts $/ \mathrm{m}^{2} /$ day when the short-lived Brigantedinium bloom during November 2006 is removed from the seasonal average). In contrast to the average daily flux, during late summer to autumn the flux was 29 cysts $/ \mathrm{m}^{2} /$ day, with 0 cysts $/ \mathrm{m}^{2} /$ day during April. Average flux during 'shoulder' times, January - February, and July - September, was $\sim 345$ cysts $/ \mathrm{m}^{2} /$ day. Variation occurred within these average seasonal trends, including a brief peak in cyst flux during winter 2007 (July), of almost 1500 cysts $/ \mathrm{m}^{2} /$ day, again composed mostly of Brigantedinium spp. 


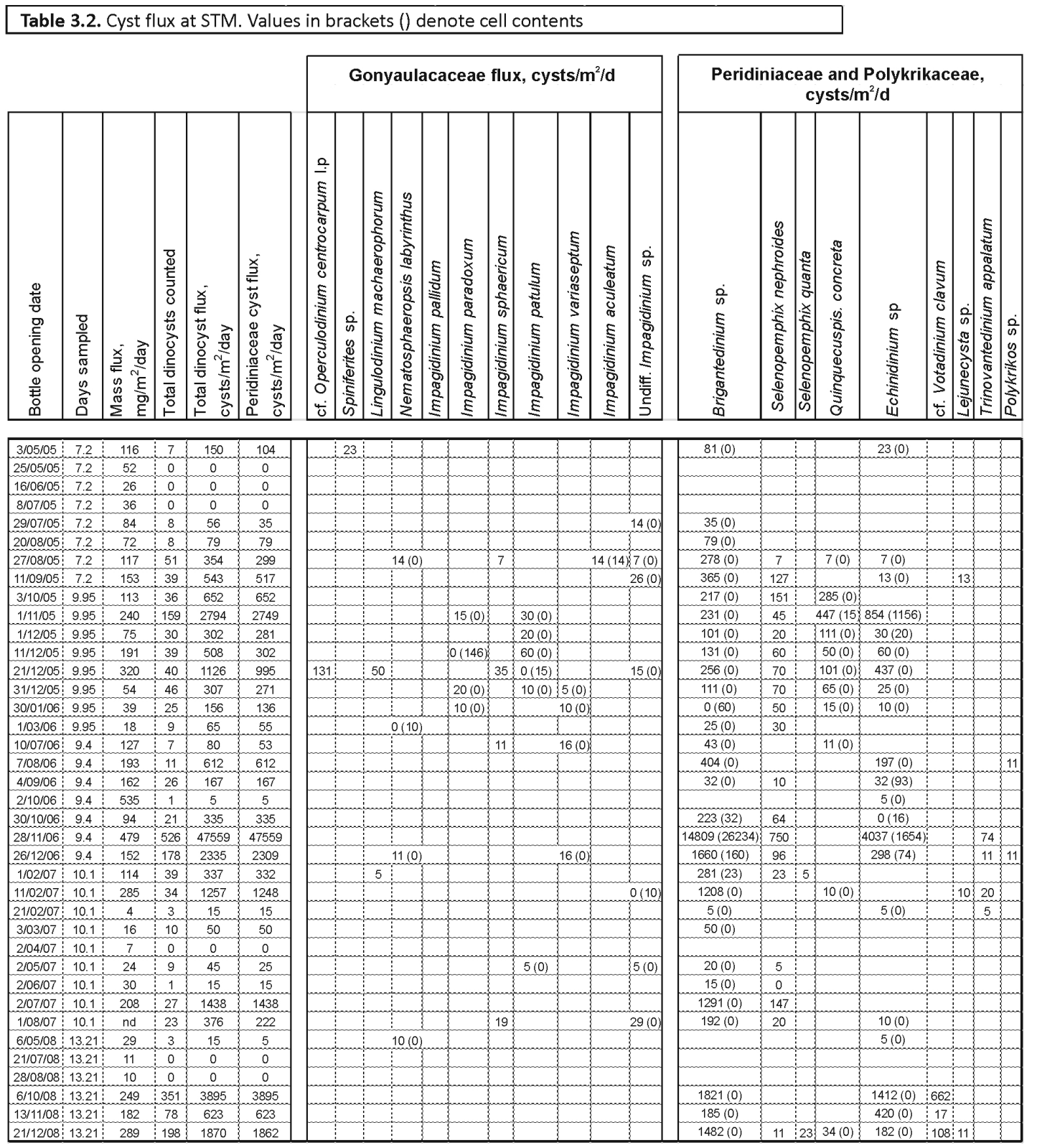

A similar seasonal pattern of enhanced spring flux is observed in most of the other dinocyst groups at STM. Subtle variations in timing are apparent, however. For example, the average Echinidinium spp. spring flux returned to low (winter) levels by January, while cysts of Selenopemphix nephroides were observed for a relatively greater proportion of the year, between July and February (Figure 3.4). Although few specimens of Impagidinium were identified, the flux of this taxa appears to have a less pronounced seasonality than other cysts at STM, with only $60 \%$ of the mean annual 
Table 3.2 continued. Cyst flux at SAM.

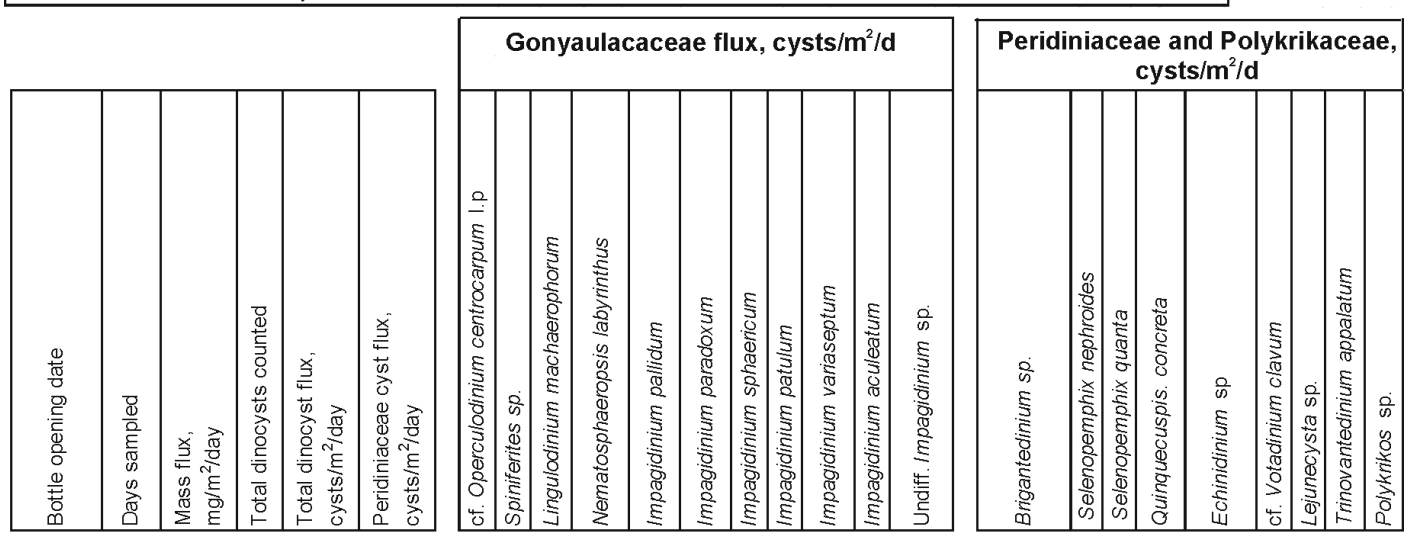

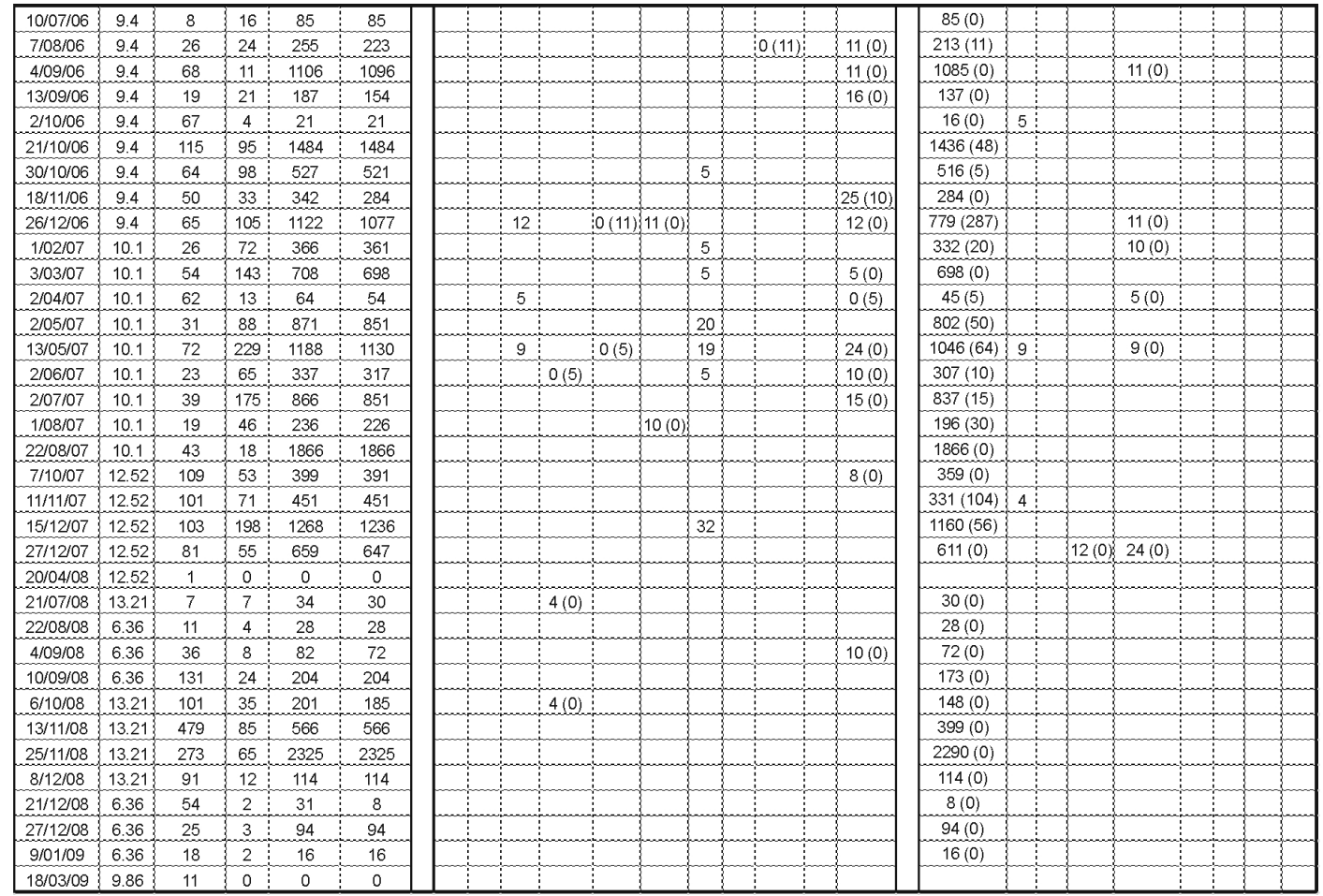

flux collected during spring. In contrast to STM, seasonal variation of dinocyst flux at SAM was relatively muted for much of the time-series. Only $34 \%$ of the average annual Brigantedinium cyst flux was collected during spring, and $25 \%$ of both Echinidinium and Impagidinium cyst flux occurred during the spring quarter. Brigantedinium cysts that contained cellular material were also distributed evenly throughout the year; half were collected during spring-summer, and half during autumn-winter. 
From July 2006 until October 2007, the SAM cyst flux was characterized by short-term (monthly) episodic variability, which obscures the average seasonal variation (Figure 3.2). Flux peaks (of $1100-1800$ cysts $/ \mathrm{m}^{2} /$ day) were recorded during September, October, December, May and August, punctuated by flux minima of 20-350 cysts $/ \mathrm{m}^{2} /$ day. In contrast, between April 2008 and April 2009 at SAM, a seasonal cycle of dinocyst flux reminiscent of that observed at STM occurred. Most dinocysts entered the trap during November, and a very low flux was observed during autumn and winter. Across the whole SAM record, the lowest average monthly cyst fluxes occurred during January and April (16 and $32 \mathrm{cysts} / \mathrm{m}^{2} /$ day in summer-autumn), with the average monthly fluxes for the remaining months ranging from 300 to $1000 \mathrm{cysts} / \mathrm{m}^{2} /$ day, with an average of 509 cysts $/ \mathrm{m}^{2} /$ day.

\subsubsection{Cyst flux: inter-annual variability}

In the samples examined, average daily cyst flux at STM was 1770 cysts $/ \mathrm{m}^{2} /$ day while the average daily flux at SAM was markedly less at $430 \mathrm{cysts} / \mathrm{m}^{2} /$ day. Large inter-annual variations in annual dinocyst flux were observed, particularly at STM, while cyst assemblages varied between years at both sites.

At STM, the average daily dinocyst flux during spring over the three years sampled (2005, 2006 and 2008) varied from 900 cysts $/ \mathrm{m}^{2} /$ day during spring 2005, to 12500 cysts $/ \mathrm{m}^{2} /$ day during 2006 and 2100 cysts $/ \mathrm{m}^{2} /$ day during 2008. Most of the spring 2006 dinocyst flux was recorded in one 9.4 day sample, for which a daily cyst flux of $>40000$ cysts $/ \mathrm{m}^{2} /$ day is calculated. Many of the samples collected during 2005 at STM contained Brigantedinium spp. (but in lower flux rates than later years), S. nephroides, Q. concreta, and Impagidinium spp. A large Brigantedinium spp. bloom occurred during 2006 , with relatively high fluxes also recorded in 2008. In contrast, very few specimens of $Q$. concreta or Impagidinium spp. were observed in 2006 or 2008 samples, while $S$. nephroides was observed in 2006 but not in 2008 . 

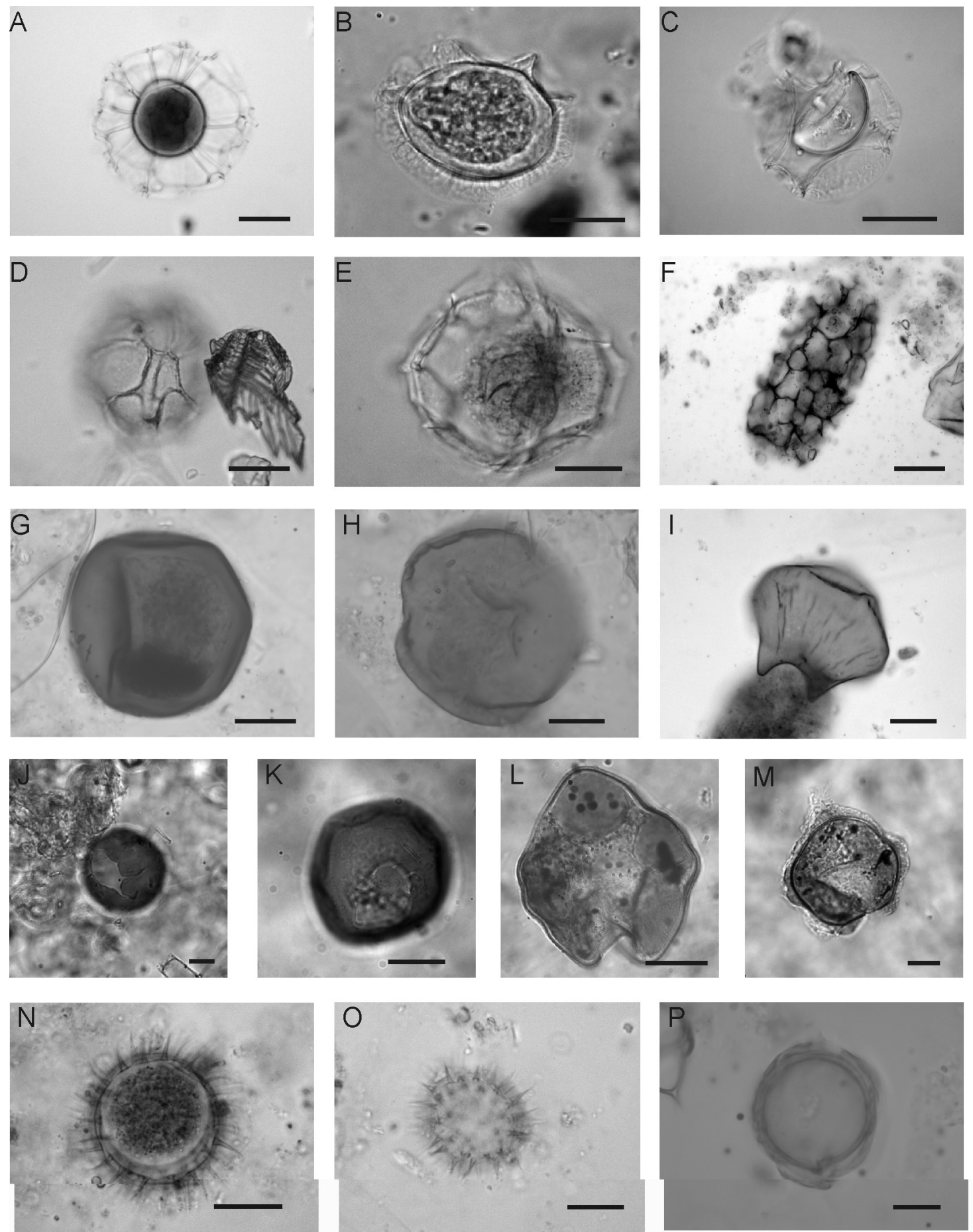

Figure 3.3. A. Nematosphaeropsis labyrinthus with cell material, (GNS Science sample number: L26002), B. Impagidinium cf aculeatum, with cell material, L25557, C. Impagidinium pallidum, L25969, D. Impagidinium sphaericum, L25975, E. Undiff. Impagidinium spp. with cell material, L26004, F. Polykrikos spp., L25992, G. Brigantedinium spp. with cell material, L25988, H. Selenopemphix undulata, L25988, I. Quinquecuspis concreta, L25977, J., K. Brigantedinium spp. RD3361, L., M. cf. Votadinium clavum, RD3362, N., 0. Echinidinium spp., L25997, L25988, P. Unidentified cyst, L25422. All scale bars $10 \mu \mathrm{m}$. 
A.

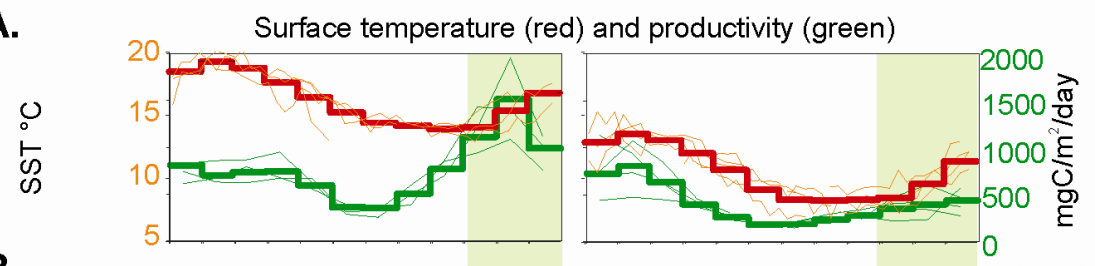

B.

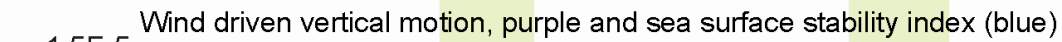

$$
\frac{\frac{0}{8}}{\frac{\pi}{0}}
$$

c.
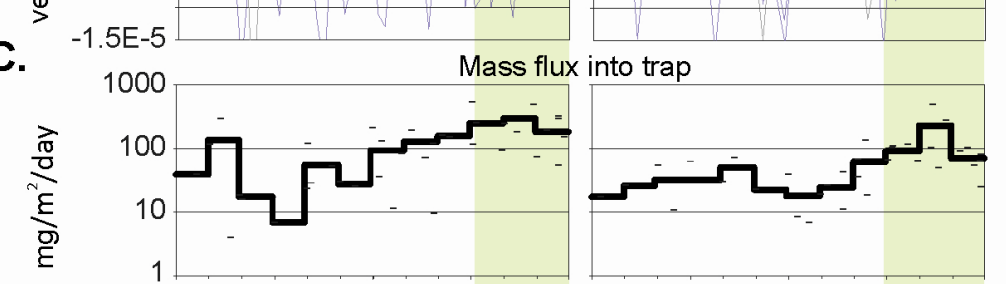

D.

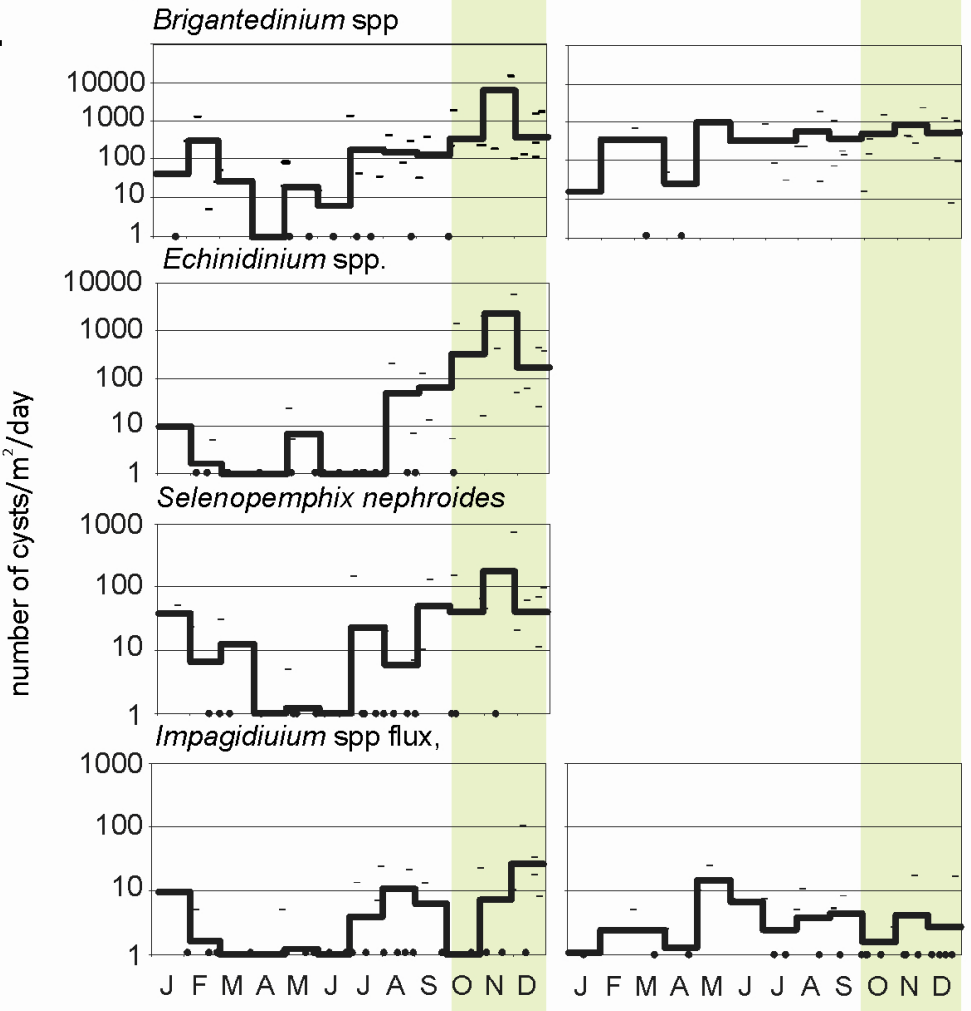

Figure 3.4. Average monthly cyst flux of the four most common taxa at STM and SAM for the years 20052008. Raw values that form all monthly averages are shown as thin lines or dashes, and are the data from Figure 2. Vertical green bars denote spring months. A. Average monthly sea surface temperature $\left({ }^{\circ} \mathrm{C}\right.$, orange) and productivity $\left(\mathrm{mgC} / \mathrm{m}^{2} /\right.$ day, green); B. Purple = average monthly wind-driven vertical motion at the sea surface $(\mathrm{m} / \mathrm{s}$, positive values $=$ upwards motion), blue = sea surface stability index (dimensionless, monthly average of absolute wind-driven vertical motion value); $\mathbf{C}$. Average monthly mass flux into sediment traps, only including samples examined for dinocysts $\left(\mathrm{mg} / \mathrm{m}^{2} /\right.$ day); D. Average monthly flux (cysts $/ \mathrm{m}^{2} /$ day) into sediment traps of Brigantedinium spp., Echinidinium spp., Selenopemphix nephroides, and total Impagidinium spp. No Echinidinium spp. or S. nephroides were identified at SAM. 
The average daily flux during spring at SAM ranged between 700 and $1500 \mathrm{cysts} / \mathrm{m}^{2} /$ day during the three years sampled, which is a similar range to that observed at STM if a brief 2006 Brigantedinium spp. bloom is excluded. Two key differences in the 2006 to winter 2007 assemblages from flux in the later years was the frequent presence of Impagidinium in samples prior to spring 2007, but it was only observed in one of the 13 samples collected after that date. In contrast, Brigantedinium spp. was present in most samples, but was absent from the spring of 2007.

\subsubsection{Cyst flux: comparison with Holocene sediment assemblages}

Dinocyst assemblages from sea-floor samples near the moorings differed from the average flux assemblages in the traps. Peridinoid cysts, particularly Brigantedinium spp., were over-represented in sea-floor samples, while several cyst taxa present in seafloor dinocyst assemblages were not observed in the trap samples (Figure 3.5).

At STM, 77\% of the average flux was Brigantedinium spp., while this genus does not exceed $40 \%$ in the six sediment samples examined. In contrast, Nematosphaeropsis. labyrinthus and Operculodinium centrocarpum each contributed $<0.1 \%$ to the average sediment trap flux, but each form on average $~ 20 \%$ of the sea-floor assemblages. Of the six dinocyst taxa that contribute $>5 \%$ to the nearby sea-floor assemblages (Figure 3.5), only Spiniferities mirabilis was completely absent from the trap samples.

At SAM, many of the significant components of the sea-floor dinocyst assemblages were observed in the trap samples, except for Dalella chathamensis, Impagidinium aculeatum, and Spiniferities mirabilis. Combined, these three taxa form $17 \%$ of the average sea-floor assemblage in the vicinity of the southern mooring, but no specimens were observed in the trap samples.

The comparison between sediment trap flux at STM and that estimated for four proximal sea-floor samples reveals a similar picture to the comparison of percentage composition, and allows taxa to be placed on a gradient of 'relative representation' (Table 3.3). In the middle of this gradient, the observed concentrations in sea floor 
samples of total Impagidinium and selected peridinoid cysts, including $Q$. concreta, $S$. quanta, S. nephroides and T. appalatum, were similar to that expected from the fluxes observed in the traps. About four times as many specimens of Impagidinium were recorded in the sea-floor samples as would be expected from the traps, while concentrations of the four peridinoid taxa were about a third of that expected from the observed trap flux (Table 3.3). At the extreme ends of this gradient, only about $6 \%$ of the trap Brigantedinium spp. cyst flux was observed in sea-floor sediments, while $O$. centrocarpum and $N$. labyrinthus concentrations in sea-floor sediments were between 33 and 36 times greater than would be expected from the observed trap flux. The main taxon missing from this gradient was Spiniferites: only one specimen was identified in the trap samples, although average sediment concentrations were similar to $N$. labyrinthus (range 2-18\%).
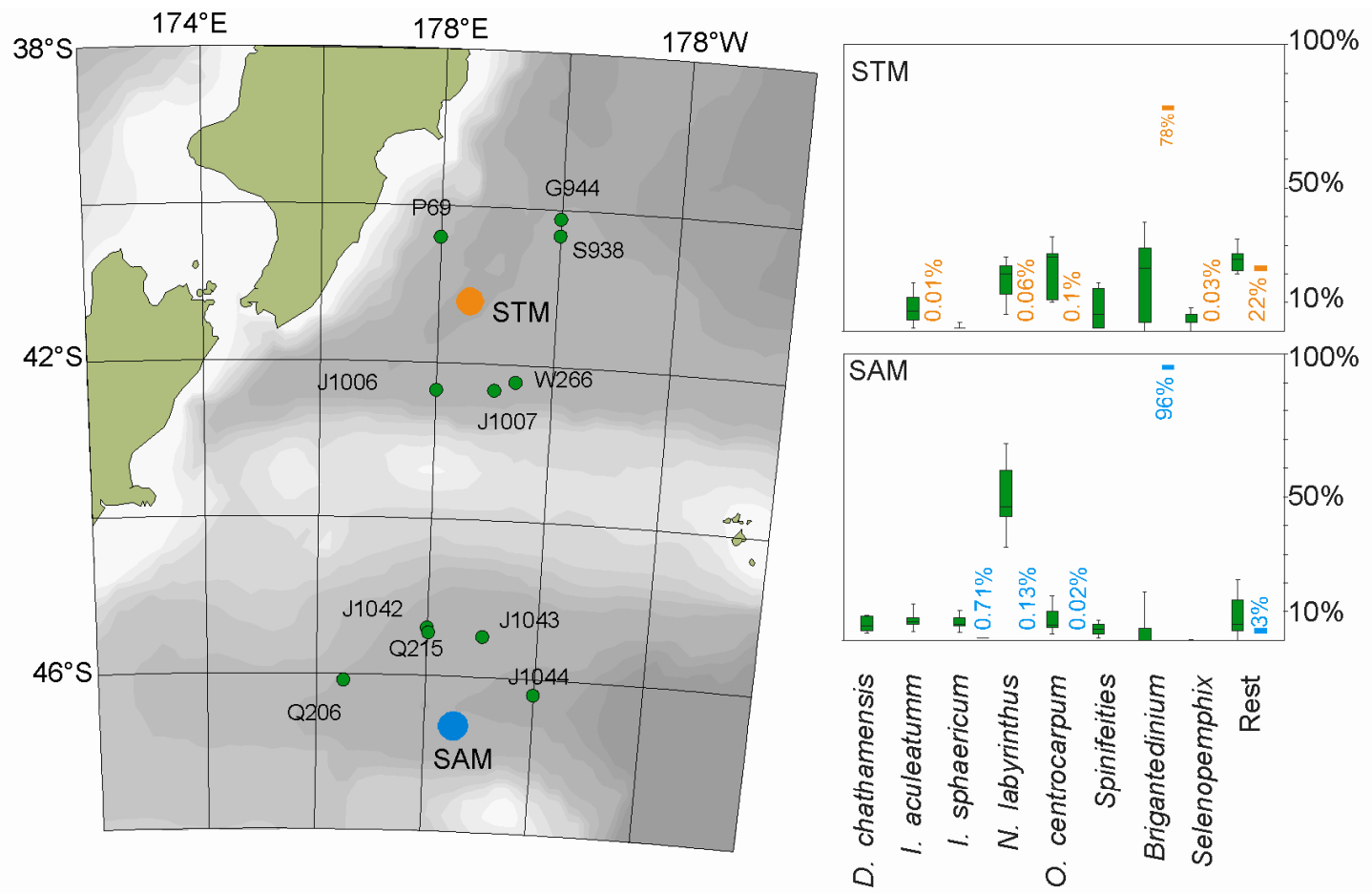

Figure 3.5. Comparison of relative abundance (\%) of dinocyst assemblage at the northern and southern moorings (orange $=\mathrm{STM}$, blue $=\mathrm{SAM}$ ), calculated from the average flux data in Table 2.2 compared to relative abundance of nearby sediments (green). Box plots show maximum, 75th percentile, medium, 25th percentile, minimum. 


\subsection{Discussion}

\subsubsection{Seasonal variation between water masses}

One of the most pronounced differences between the two mooring sites is the degree of seasonality in dinocyst flux. At STM, a significant proportion of the dinocyst flux occurred during spring, while seasonal variation was more muted for most of the SAM record, although a flux pattern reminiscent of the STW spring bloom was observed at the end of the SAM record in spring 2008 (Figure 3.2).

Over the three years studied at STM, the average seasonal progression appears consistent with the conceptual model of Chiswell (2011), of wind-driven mixing during winter coincident with the annual minima in productivity, followed by increasing productivity during the relatively calm months of August and September, which is accompanied by ocean warming and increased irradiance. (Figures 3.2 and 3.4) (see also Longhurst, 1995; Nodder et al., 2005). Further late spring mixing precedes the annual productivity maxima in November, with the annual maximum temperature occurring three months later, in February. Timing of total mass (and dinocyst) flux to the STM trap largely reflected trends in surface productivity. For example, 2005 was a year of relatively low productivity and coincided with relatively low mass and dinocyst flux, while above-average productivity during 2006 coincided with higher total mass and dinocyst fluxes (Figure 3.2). These observations are supported by the moderate linear correlation between mean monthly productivity, mass flux, and dinocyst flux (mean monthly productivity:dinocyst flux $r^{2}=0.58$, mean monthly mass flux:dinocyst flux $r^{2}=$ 0.47). Although other factors have varying influence on primary productivity, such as stratification, nutrient availability, grazing and mortality (e.g. Longhurst, 1995), primary productivity has been shown to be controlled principally by deep mixing along the east coast of the North Island, particularly within the eddy systems within one of which (the Wairarapa Eddy) STM is located, with local upwelling also important north of the study area (Bradford et al., 1982; Chiswell and Roemmich, 1998). 
Table 3.3. Observed flux in sea floor samples surrounding the northern mooring, compared to expected flux from sediment trap observations. The ratio on the last column is the ratio of the average concentration across the four samples: a high number indicates that the taxa is under-represented in sediment, while a value of 1 indicates the observed flux in the sediment trap equals that in the sediment.

\begin{tabular}{|c|c|c|c|c|c|c|c|}
\hline Station & S938 & R657 & P69 & W266 & \multirow{8}{*}{ 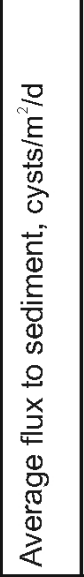 } & \multirow{8}{*}{ 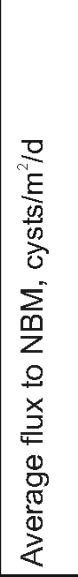 } & \multirow{8}{*}{ 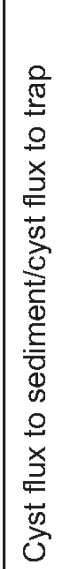 } \\
\hline Latitude & -40.4 & -42.22 & -40.33 & -42.72 & & & \\
\hline Longitude & 177.99 & 179.36 & 179.99 & 176.91 & & & \\
\hline Water depth $(\mathrm{m})$ & 3003 & 1408 & 2195 & 2347 & & & \\
\hline Distance to NBM (km) & 112 & 122 & 168 & 203 & & & \\
\hline Sea floor $\mathrm{O}_{2}{ }^{1}(\%)$ & 4.2 & 4.0 & 4.2 & 4.7 & & & \\
\hline Depth to MIS $1-2$ boundary $^{2}(\mathrm{~cm})$ & 100 & 30 & 164 & 47 & & & \\
\hline MIS $1 \mathrm{flux} x^{2}, \mathrm{~g} / \mathrm{m}^{2} / \mathrm{d}$ & 0.22 & 0.06 & 0.28 & 0.07 & & & \\
\hline \multicolumn{8}{|c|}{ Flux to sediment ${ }^{3}$, cysts $/ \mathrm{m}^{2} / \mathrm{d}$} \\
\hline Spiniferities spp. & 22 & 24 & 23 & 41 & 27 & 1 & 55 \\
\hline Nematosphaeropsis labyrinthus & 74 & 26 & 49 & 25 & 43 & 1 & 43 \\
\hline Operculodinium centrocarpum & 49 & 40 & 40 & 104 & 58 & 2 & 32 \\
\hline Impagidinium spp. & 58 & 10 & 95 & 39 & 50 & 12 & 4.3 \\
\hline $\begin{array}{l}\text { Other peridinoids (Q. concreta, } \\
\text { T. appalatum, S. quanta) }\end{array}$ & 30 & 18 & 38 & 31 & 29 & 55 & 0.54 \\
\hline Selenopemphix nephroides & 22 & 9 & 30 & 12 & 18 & 46 & 0.40 \\
\hline Brigantedinium spp. & 160 & 30 & 83 & 109 & 96 & 1376 & 0.07 \\
\hline Echinidinium spp. & 20 & 6 & 38 & 11 & 19 & 292 & 0.06 \\
\hline $\begin{array}{l}\text { Indigenous pollen flux (exotic } \\
\text { Pinus grains removed) }\end{array}$ & 1617 & 229 & 2961 & 1847 & 1664 & 863 & 1.9 \\
\hline
\end{tabular}

Over represented in sea-floor sediment

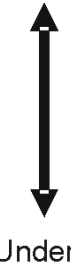

Under represented in sea-floor sediment

1. Gouretski and Koltermann (2004), $\mathrm{ml/l}$

2. Carter at al. (2000), converted from $\mathrm{g} / \mathrm{cm}^{2} / \mathrm{ka}$

3. Crouch et al. (2010), converted from cysts/g

At SAM, seasonal patterns differed from the north in many respects. As in the north, winter mixing coincided with minimum productivity, but wind-driven mixing was a more significant feature of average spring conditions (Figure 3.4). This ongoing mixing may have contributed to the delayed development of maximum productivity in surface 
waters until February (also the warmest month), which followed the two calmest average months: December and January (Figure 3.6), although the availability of micronutrient iron has been shown to influence primary productivity in SAW (e.g. Boyd et al., 1999). Fine Fe-rich particulates from terrestrial run-off and submarine erosion and transport could have substantial residence times in SAW (Nodder et al., 2005) and could be readily converted into biological Fe (e.g. Frew at al., 2006), although a 5-year time-series in the vicinity of SAM found poor correlation between episodic productivity and iron supply (Boyd et al., 2004). Although peak productivity occurred in February, the peak mass flux into the southern trap occurred months earlier, during spring, a decoupling also observed during the previous season (Nodder et al., 2005). This was inferred to be due to rapid export of silica-rich early spring blooms of diatoms, silicoflagellates or radiolaria. This disconnect between the peak productivity and peak flux at the southern trap is reflected in much lower correlation coefficient values between average monthly productivity, mass flux, and dinocyst flux than observed in the north (mean monthly productivity:dinocyst flux $r^{2}=0.12$, mean monthly mass flux:dinocyst flux $\left.r^{2}=0.37\right)$.

The correlation of organic carbon export to the deep sea with the type and nature of ballast material has been recognised as an important control on organic carbon export (Armstrong et al., 2001; Passow and De La Rocha, 2006), and the export of dinocyst organic carbon in this study appears no different. The dinocyst flux does not form a dominant part of the export production at either study area, and their export to the deep sea is likely reliant on the form and timing of accessory ballast. Thus, the performance and variations of other, ballast forming, organisms is likely to have a significant influence on how dinoflagellate communities in surface waters are preserved in sea-floor dinocyst assemblages.

\subsubsection{Inter-annual variability}

The composition of the dinocyst flux varied between years. As with the observed seasonal variability, this longer term variation correlated with productivity, particularly 


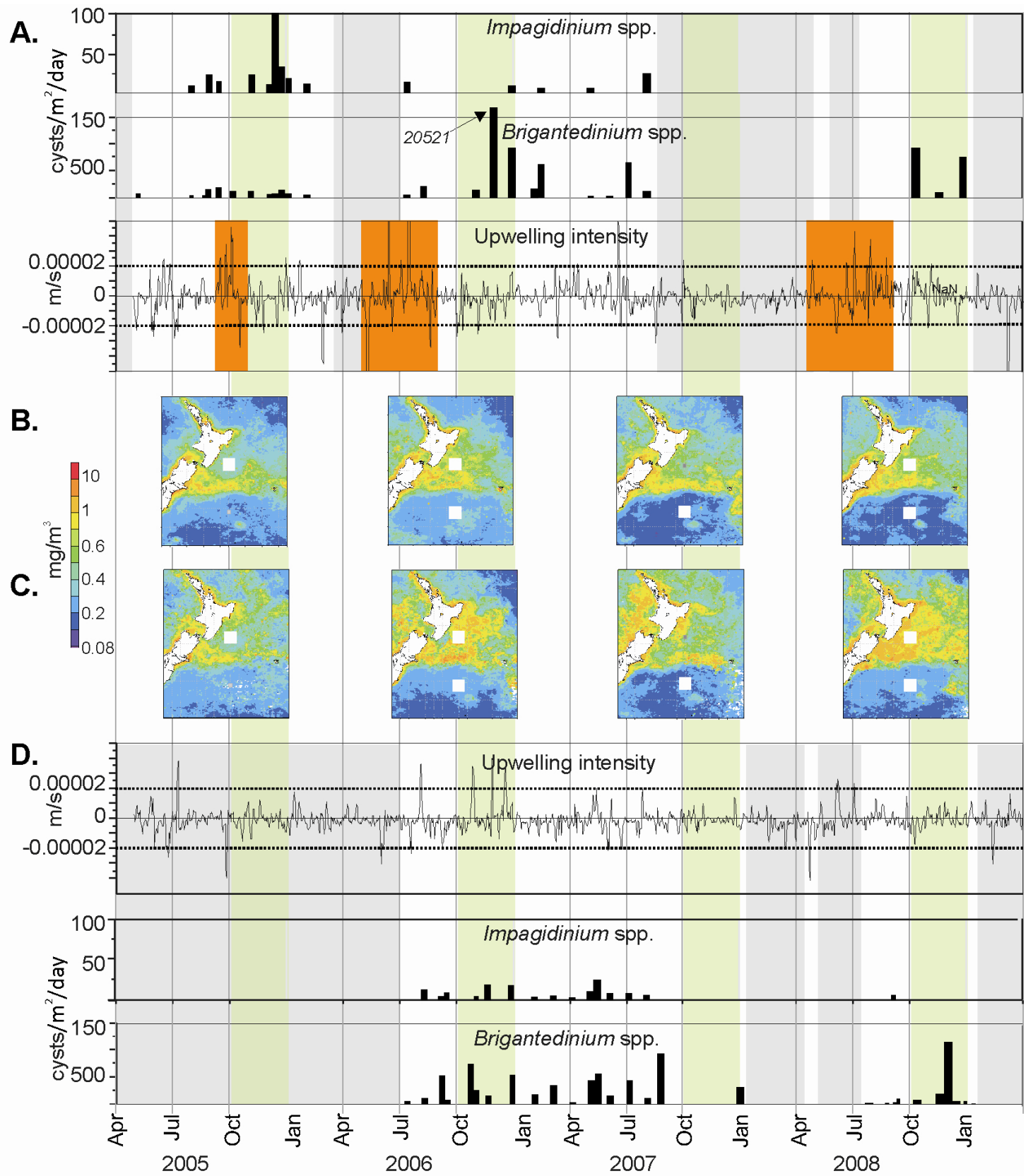

Figure 3.6. Flux of Brigantedinium spp. and Impagidinium spp. (cysts $/ \mathrm{m}^{2} / \mathrm{day}$ ) compared to upwelling intensity ( $\mathrm{m} / \mathrm{s}$, positive values = upwards motion) and remotely sensed surface chlorophyll- $a$ concentration $\left(\mathrm{mg} / \mathrm{m}^{3}\right)$. Green vertical bands show austral spring, grey bars show sample gaps $>1$ month. A. STM flux and upwelling intensity, orange bars show intervals of maximum mixing prior to spring, B. mean chlorophyll-a concentration, August- January, C. mean chlorophyll-a concentration 14 September - 16 October for each year 2005-2008, showing approximate extent of maximum bloom conditions, D. SAM flux and upwelling intensity. 
at STM. Over the three years that were sampled at STM, productivity (Figure 3.2), and surface chlorophyll- $a$ were high during spring-summer 2006 and 2008, while average surface chlorophyll-a was lower during 2005, and did not reach the intensity of other years (Figure 3.6). The Impagidinium flux during the low-productivity year in 2005 was higher than the latter two years, which were characterized by well-developed spring blooms. Meanwhile, the highest Brigantedinium spp. fluxes occurred during the high productivity years (2006 and 2008). One possible reason for this inter-annual variation in productivity is the timing of winter and spring mixing events (e.g. Chiswell, 2011). The winter of 2005 was generally characterized by limited mixing of surface water, while three deep mixing events occurred during the spring, as measured by the intensity of wind stress curl (Figure 3.6). In contrast, four prominent mixing events occurred during winter 2006 (May - August), which was followed by a relatively stable spring. The 2006 pattern was repeated in 2008, although spring appeared less settled. The impact of these mixing events on seasonal productivity can be considered within the conceptual model of Chiswell (2011): the relatively calm winter of 2005 would have limited opportunity for deep mixing to bring nutrients into the surface waters, while fortnightlymixing events during mid-spring may have slowed algae growth by reducing the opportunity for stratification to become established. The flux of Impagidinium cysts, which derive from a genus generally intolerant of high-nutrient conditions (Dale, 1996), may be highest during the low productivity year in this setting not due to the low productivity per se, but due to the relatively extensive oligotrophic, nutrient-depleted waters following a calm winter (Figure 3.6). In contrast, the correlation of higher Brigantedinium cyst flux with years of higher productivity is more likely to reflect greater food availability of these heterotrophic dinoflagellates, which have been observed to prefer diatoms and flagellates over other food sources (Jacobson and Anderson 1986; Kjaeret et al., 2000; Zonneveld et al. 2010).

In contrast to STM, correlation of inter-annual variability in dinocyst flux at SAM with surface productivity, chlorophyll- $a$, and mixing events is limited. Impagidinium was observed during 2006 and the winter of 2007, and was absent after spring 2007. The 
pattern of Brigantedinium spp. flux was the same as for Impagidinium, except for the reappearance of Brigantedinium spp. in the late spring of 2008 (Figure 3.6). Primary productivity in SAW is different to that in STW, being dominated by pico-phytoplankton and limited by the availability of micronutrients (Boyd et al., 1999; 2004; Bowie et al., 2009; Mongin et al., 2011). Average chlorophyll- $a$ concentrations were much lower, and the seasonal variation in chlorophyll- $a$ was much more muted. Although the 2005 year that Brigantedinium spp. is absent from the SAM flux is also that of lowest average chlorophyll-a concentrations, the scale of variation between years is small (Figure 3.6). While the accompaniment of Impagidinium with Brigantedinium spp. seems incongruous in the context of the observations in STW, the chlorophyll-a concentrations during the entire SAM time-series are less than the low-chlorophyll-a 2005 year at STM. However, the absence of Impagidinium in the later part of the SAM record is more unexpected.

The causes of inter-annual variability of cyst flux at SAM remain enigmatic. It is possible that the two modes of cyst flux observed at SAM (July 2006- October 2007 compared to after October 2007) may reflect differences in wider functioning of food webs between years, but food web studies in the region are generally limited to single seasons (e.g. Nodder and Gall, 1998; Hall et al., 1999; Bradford- Grieve et al., 1999). Alternatively, the variability may relate to transient influx of limiting nutrients, but the mechanisms by which this occurs (e.g. aeolian deposition, mixing of waters across the STF, periodic upwelling) remain unresolved (Boyd et al., 2004). Longer time-series, and observations of many biophysical parameters at sufficient spatial and temporal resolution, along with variation in the species composition of other plankton groups may be required to understand the causes of dinocyst flux in this water mass.

The difference in seasonal development on either side of the STF, and the differences in how this variation is preserved in deep-sea sediments, have implications for interpreting the fossil record. Although summer SST correlates most closely to variations in dinocyst assemblages on a hemispheric scale (e.g. Marret and Zonneveld, 2003; Chapter 2, this 
study), the interpretation of the two short time-series presented here implies that cyst flux is controlled by a much more complex combination of physico-chemical factors rather than merely temperature of any one season. Rather, if temperature is to be used as a target for quantitative palaeo-reconstructions, these observations of different modes of seasonal variation suggest that the mean annual temperature is the best target, but with the caveat that other environmental factors, only broadly related to mean annual temperature, such as wind-driven mixing, upper ocean stratification, and the growth-rate of other ballast-producing organisms may also have significant impacts on cyst flux.

\subsubsection{Trap flux compared to sediments}

Under-representation of peridinoid cysts in sea-floor sediments, compared to concentrations predicted from ocean particle fluxes, has been noted in other sediment trap experiments (e.g., Harland and Pudsey, 1999; Zonneveld and Brummer, 2000). One explanation for this discrepancy is preferential post-depositional oxidation of peridinoid cysts (e.g., Zonneveld et al., 2008). Bottom water oxygen concentrations in the vicinity of the sediments used for comparison (Table 3.3) are well within the range that Zonneveld et al. (1997) predict to cause extensive alteration of the dinocyst assemblage by oxidation of sensitive cysts, and represent a plausible process to explain apparent under-representation of peridinoid cysts in surface sediments to the east of New Zealand. However, it is worth noting that despite the large numbers of peridinoid cysts that fail to appear in the record, a considerable number remain, and form an important component of differentiation between biogeographic zones (Chapter 2, this study). In addition, bottom water oxygen concentrations explain little (6-8\%) of the variance in hemispheric and regional sea floor dinocyst compilations compared to other available environmental gradients (Chapter 2, this study). In contrast, traps studies in coastal and estuarine settings (e.g. Pospelova et al., 2010; Price and Pospelova, 2011) show much stronger correlation between trap and sea floor assemblages, likely due to reduced transport times, better constrained source areas, and in some instances, more rapid sedimentation. 
A more unusual observation in this study is the over-representation of oxidationresistant gonyaulacoid cysts in sea-floor sediments, compared to that predicted from the observed flux, such as $N$. labyrinthus, Spiniferities, and O. centrocarpum. Two possible scenarios for this discrepancy are: (i) lateral transport of gonyaulaucoid cysts to the sea-floor sampling sites by deep currents, such that they are not collected by the sediment traps, or (ii) episodic cyst formation that has been missed by the trap sampling programme undertaken here. Both would have implications for the use of sea-floor samples as modern analogues, as either a significant proportion of the assemblage did not live in the overlying water mass (scenario i), or the formation of their fossilisable remains in the overlying water is a relatively "unusual" event, that may be best correlated to environmental parameters of those exceptional years instead of a mean annual climatologies (scenario ii).

Two lines of evidence support episodic cyst formation during optimal years, as opposed to extensive lateral transport as a most likely explanation. This evidence is based on the characteristics of pollen flux in the traps, and on the episodic nature of the dinocyst flux that has already been observed.

Firstly, terrestrially-derived organic material, including pollen, is abundant in both the sea-floor and trap samples (Crouch et al., 2010; Chapter 2, other incidental observation during this study). Nodder et al. (2005) also noted lithogenic material in both STM and SAM traps was up to $10-15 \%$ of the total annual mass flux, and inferred this to be terrigenously sourced, although the pathway of this terrigenously-sourced sediment to the samples has not been determined (i.e. directly by surface currents or aeolian transport, with possibly extended and variable residence times in terrestrial and marine sinks). Most of the pollen found in the traps and sea-floor sediments are of anemophilous plants (e.g. Pinus [Pine], Nothofagus [Southern Beech]), and eastwards aeolian dispersal of such pollen from the New Zealand landmass over great distances $(<750 \mathrm{~km})$ has been established (Mildenhall, 1976; Holt et al., 2010). However, there is an order-of-magnitude decrease in the average pollen concentration in sea-floor 
sediments within $100 \mathrm{~km}$ of the New Zealand landmass (Crouch et al., 2010, incidental observations during this study, Figure 4.1), suggesting that the majority of pollen to enter the ocean east of New Zealand is either via rivers, or by a near-shore pollen rain, an observation consistent with other ocean margin settings (Traverse, 2007). Assuming the pollen and dinocysts originating from coastal waters are approximately hydrodynamically equivalent (both have a similar size range), both would be expected in the trap and sea-floor sediment assemblages in similar diluted/enriched proportions. Direct comparison of terrestrial organic flux in the traps and recent marine sedimentation is hindered by ca. 700 years of anthropogenic deforestation and ca. 70 years of extensive plantation forestry of Pinus spp. in New Zealand (McGlone and Wilmshurst, 1999), and pollen is over-represented by a factor of $\sim 1.9$ in the sea-floor sediments. However, in the context of the over- and under-representation of dinocysts by factors of $>30$ (e.g. for Nematosphaeropsis, Operculodinium, and Spiniferites genera), the pollen flux is relatively 'balanced' (Table 3.3). There is additional circumstantial evidence of the tight coupling of pollen flux into the traps and events on land. Incidental observations made during this study are that the order of peak pollen flux in the traps corresponds with the progression of flowering on land (i.e. Pinus spp. followed by Nothofagus fusca, followed by Poaceae), and there are some signs of higher Nothofagus fusca fluxes in the 3-15 months following masting (high flowering) years. These data require additional counting prior to more detailed presentation. Thus, it appears the transport pathway of dinocyst-sized palynomorphs via waters of continental shelves to the STM is active (i.e. much of the pollen is accounted for between source-trap-deep-sea sediment), and transport of such particles to the trap sites may be relatively rapid (months). However, dinocysts do not appear to have been transported in large abundances from coastal waters of continental shelves to the STM during the trap deployment.

Secondly, high inter-annual, and between-sample, variability of cyst fluxes and assemblages supports the alternative hypothesis. For example, one 9.4 day sample during November 2006 at the northern site collected 60\% of the total Brigantedinium spp. flux observed at STM, and over $98 \%$ of the cysts contained cell material. Given this 
highly episodic event, it is most likely that some of the "missing" cysts were deposited into the trap during the unsampled intervals, or during a season not yet sampled. Interannual variability is a common feature of multi-annual marine time-series, investigating other components of the marine food web (e.g., Cloen and Jassby, 2008; Mackas and Beaugrand, 2010), while significant decadal-scale variability is also becoming apparent in results from more recent time-series (e.g. Ayon et al., 2004; Alheit and Bakun, 2010; Wasmund et al., 2011). One example from Baltic Sea records show strong spring blooms of dinoflagellates during the 1990s, but blooms dominated by diatoms at the same sites during the 1980s and 2000s (Wasmund et al., 2011). These results contrast with a similar comparison of foraminiferal flux from the waters east of New Zealand (King and Howard, 2001), who found a strong similarity between the sediment trap assemblages and those of near-by sea-floor samples from a 12-month deployment during the 1990s, although more variability has been observed in subsequent years (Northcote pers comm., 2010).

The scenario of episodic cyst formation, suggested here, does not require the cysts to be formed in the water mass immediately overlying the traps. As we observe there is likely an active transport pathway from coastal waters, it is possible that the episodic cyst formation during optimal years proposed above partly takes place in coastal waters. Thus, although we cannot exclude the possibility that some cysts in the traps and surrounding deep sea sediments are transported from shallower waters of the shelf, there is also evidence that cyst-forming dinoflagellates occupy the more proximal surface waters. The thecate (swimming) stage of dinoflagellates that form the cysts observed in the seafloor and sediment traps have been observed in the surface waters near the mooring (Chang and Gall, 1998; F.H. Chang, pers. comm., 2011).

Variations in the Southern Oscillation Index (SOI) to the east of New Zealand have been observed to coincide with SST anomalies and variations in the intensity of gradients across the STF (e.g., Goring and Bell, 1999; Sutton and Roemmich, 2001; Hopkins et al., 2010), with a local response lagging the SOI by some months. Correlation of 
productivity in New Zealand waters to SOI variation is, however, enigmatic (Murphy et al., 2001; Hopkins et al., 2010). The sampling conducted here covers two negative and one positive (but poorly developed) phases of the SOI, and does not sample the local response to a well-developed El Niño event (Figure 3.4). It is tempting to infer that the differences between the observed flux and sediment assemblages may become reconciled during a well-developed El Niño event or other longer term climate modes affecting ENSO, such as the Interdecadal Pacific Oscillation (Power et al., 1999; Mantuna and Hare, 2002), and the Southern Annular Mode (Ummenhofer and England, 2007; Ummenhofer et al., 2009) A final possibility is that the discrepancy may be due to a permanent regime shift in SW Pacific waters, but identification of such a shift from natural variability would require significantly longer and more complete time-series, both of traps and sediments, than are available here (Wasmund et al., 2011; Hensen et al., 2010).

\subsection{Conclusions}

A three year record (2005-2008) of dinocyst flux into time-incremental sediment traps moored north and south of the STF in two different surface water masses, to the east of New Zealand, reveals the following:

1. In the trap in STW, dinocyst flux peaks during the spring bloom. The composition of this flux varied annually. The flux of the peridinoid genera Brigantedinium was higher in years of high spring productivity, while flux of the oceanic genera Impagidinium was higher in a year when the spring bloom failed to peak (2005), possibly due to insufficient winter mixing, or unstable surface waters during spring.

2. The seasonal cycle of dinocyst flux of the trap in SAW is relatively muted. Although the composition of cyst flux also varied between years, the relationship between environment and flux is less well resolved than STW. 
3. The average dinocyst flux differs from that observed in nearby sea-floor samples. Peridinoid cysts, notably Brigantedinium spp., are under-represented in sea-floor sediments, with about $6 \%$ of the Brigantedinium spp. cyst flux preserved. In contrast, Nematosphaeropsis, Operculodinium, and Spiniferites are overrepresented; concentrations in sea-floor sediments are $\sim 30-40$ times greater than predicted from the trap flux.

4. The under-representation of peridinoid dinocysts may reflect oxidation of these cysts on the sea-floor, while the most likely explanation for under-representation of gonyalaucoid cysts is the restriction of cyst production to years outside the range of our sampling, although lateral transport and production during sampling gaps within the time series cannot be conclusively discounted.

5. The variability of seasonality of cyst flux in each water mass has implications for palaeoclimate studies. Quantitative models should use mean annual, as opposed to seasonal, resolution as targets. Although sea-floor dinocyst assemblages vary with SST on regional and hemispheric scales, the processes revealed here highlight great complexity in the larger-scale correlations.

\subsection{Acknowledgements}

We thank the officers and crew of the RV Tangaroa for over twenty 3- to 6-monthly deployment voyages over the last decade of this trap experiment, including the current mooring team (Craig Stewart, Brett Grant, Fiona Elliot). Lisa Northcote at NIWA and Sonja Fry at GNS Science split and processed the trap and sediment samples, respectively. Paulo Calil, NIWA, provided modelled wind data. We also acknowledge the MODIS mission scientists and associated NASA and NOAA personnel for production of the satellite environmental data used in this study. Scott Nodder provided samples, advice, access to unpublished geochemical and trap monitoring data, and allowed JP to attend a very enjoyable 10-day deployment voyage on the RV Tangaroa in winter, 2011. 


\section{Chapter 3}

\section{Appendix 3.1. Flux calculations}

Calculations of flux into sediment and traps - worked examples

\begin{tabular}{|c|c|c|c|c|}
\hline Calculation 1 & $\begin{array}{l}\text { Determine accumulation rate of dinocysts } \\
\text { in sediment }\end{array}$ & $\begin{array}{l}\text { Worked example for total } \\
\text { Impagidinium in sample } \\
\text { S938 }\end{array}$ & & \\
\hline Input 1 & $\begin{array}{l}\text { dinocyst concentration from Crouch et al. } \\
2010 \\
\text { mass accumulation rate MIS1-2 from } \\
\text { Carter et al. } 2001\end{array}$ & $\begin{array}{l}\text { sum of carbonate and non- } \\
\text { carbonate accumulation } \\
\text { rates }\end{array}$ & 262 & $\begin{array}{l}\text { cysts } / \mathrm{g} \\
\mathrm{g} / \mathrm{cm} 2 / \mathrm{ka}\end{array}$ \\
\hline Step 1 & convert mass accumulation to $\mathrm{g} / \mathrm{m} 2 /$ day & $\begin{array}{c}8^{*} 10000 \\
80000 / 1000 \\
80 / 365\end{array}$ & $\begin{array}{l}80000 \\
80 \\
0.22\end{array}$ & $\begin{array}{l}\mathrm{g} / \mathrm{m} 2 / \mathrm{ka} \\
\mathrm{g} / \mathrm{m} 2 / \mathrm{a} \\
\mathrm{g} / \mathrm{m} 2 / \text { day }\end{array}$ \\
\hline $\begin{array}{l}\text { Step } 2 \\
\text { Step } 3\end{array}$ & $\begin{array}{l}\text { calculate number of days to accumulate } 1 \\
\mathrm{~g} \text { over } 1 \mathrm{~m} 2 \\
\text { calculate cyst flux (number of cysts per } \mathrm{m} 2 \\
\text { per day) }\end{array}$ & $\begin{array}{l}1 / 0.22 \\
262 / 4.56\end{array}$ & $\begin{array}{l}4.56 \\
57.43\end{array}$ & $\begin{array}{l}\text { days } \\
\text { cysts/m2/day }\end{array}$ \\
\hline Calculation 2 & $\begin{array}{l}\text { Determine average cyst flux from sediment } \\
\text { trap samples, cysts } / \mathrm{m} 2 / \text { day }\end{array}$ & $\begin{array}{l}\text { Worked example for total } \\
\text { Impagidinium into >40um } \\
\text { fraction of a single sample } \\
\text { bottle at the NBM mooring, } \\
\text { sample } L 26004 \text {, bottle } \\
\text { opening date } 11 \text { Dec } 2005\end{array}$ & & \\
\hline Input 1 & counts from > 40um fraction of L26004 & & 13 & cysts counted \\
\hline Step 1 & $\begin{array}{l}\text { convert }>40 \text { um counts into cysts } / \text { day } / \mathrm{m} 2 \\
\text { proportion of sample examined }=0.33 \\
\text { proportion of trap bottle processed }=0.04 \\
\text { days trap bottle open }=9.5 \\
\text { area sampled by trap }=0.5 \mathrm{~m} 2\end{array}$ & $\begin{array}{l}13 * 3 \\
13 / 0.04 \\
325 / 9.95 \\
34.57 * 2\end{array}$ & $\begin{array}{l}39 \\
975.10 \\
98 \\
196\end{array}$ & $\begin{array}{l}\text { cysts per } 1 / 25 \text { th trap } \\
\text { bottle, }>40 \text { um fraction } \\
\text { cysts per trap bottle, } \\
>40 \text { um fraction } \\
\text { cysts per day in trap } \\
\text { bottle, }>40 \text { um fraction } \\
\text { cysts } / m 2 / \text { day, }>40 \text { um } \\
\text { fraction }\end{array}$ \\
\hline Step 2 & $\begin{array}{l}\text { Determine flux for each sample bottle, sum } \\
\text { of flux from }>40 \text { and }<40 \text { size fraction }\end{array}$ & $196+10$ & 206 & $\begin{array}{l}\text { cysts/m2/day, sample } \\
\text { bottle } 11 \text { Dec } 05\end{array}$ \\
\hline Step 3 & $\begin{array}{l}\text { Determine average daily flux for each } \\
\text { month }\end{array}$ & & & \\
\hline Step 4 & $\begin{array}{l}\text { Determine average flux into trap, by taking } \\
\text { average of monthly fluxes }\end{array}$ & $\begin{array}{c}\text { Numbers from file } \\
\text { Sed_trap_counts_organic_ } \\
\text { Dec11 }\end{array}$ & 11.6 & $\begin{array}{l}\text { Impagidinium } \\
\text { cysts } / \text { m } 2 / \text { day into mooring }\end{array}$ \\
\hline
\end{tabular}


Flux calculations into sediment for Table $\mathbf{3 . 3}$

\begin{tabular}{|c|c|c|c|c|c|c|c|c|}
\hline Taxon & \multicolumn{4}{|c|}{ Nematosphaeropsis labyrinthus } & \multicolumn{4}{|c|}{ Spiniferities } \\
\hline Sample & S938 & P69 & R657 & W266 & S938 & P69 & $\mathrm{R} 657$ & W266 \\
\hline $\begin{array}{r}\text { cysts/g } \\
\mathrm{g} / \mathrm{cm} 2 / \mathrm{ka}\end{array}$ & $\begin{array}{l}337 \\
8.00\end{array}$ & $\begin{array}{c}172 \\
10.36\end{array}$ & $\begin{array}{l}436 \\
2.17\end{array}$ & $\begin{array}{l}355 \\
2.54\end{array}$ & $8.00^{98}$ & $10.36^{83}$ & $\begin{array}{c}386 \\
2.17\end{array}$ & $\begin{array}{l}595 \\
2.54\end{array}$ \\
\hline $\mathrm{g} / \mathrm{m} 2 / \mathrm{ka}$ & 80000.00 & 103600.00 & 21700.00 & 25400.00 & 80000.00 & 103600.00 & 21700.00 & 25400.00 \\
\hline $\begin{array}{r}\mathrm{g} / \mathrm{m} 2 / \mathrm{a} \\
\mathrm{g} / \mathrm{m} 2 / \mathrm{day}\end{array}$ & $\begin{array}{c}80.00 \\
0.22\end{array}$ & $\begin{array}{c}103.60 \\
0.28\end{array}$ & $\begin{array}{c}21.70 \\
0.06\end{array}$ & $\begin{array}{c}25.40 \\
0.07\end{array}$ & $\begin{array}{c}80.00 \\
0.22\end{array}$ & $\begin{array}{c}103.60 \\
0.28\end{array}$ & $\begin{array}{c}21.70 \\
0.06\end{array}$ & $\begin{array}{c}25.40 \\
0.07\end{array}$ \\
\hline days & 4.56 & 3.52 & 16.82 & 14.37 & 4.56 & 3.52 & 16.82 & 14.37 \\
\hline cysts/m2/day & 73.86 & 48.71 & 25.93 & 24.71 & 21.57 & 23.56 & 22.97 & 41.37 \\
\hline Taxon & \multicolumn{4}{|c|}{ Operculodinium centrocarpum } & \multicolumn{4}{|c|}{ Impagidiniumsp. } \\
\hline Sample & S938 & P69 & R657 & W266 & S938 & P69 & R657 & W266 \\
\hline $\begin{array}{r}\text { cysts/g } \\
\mathrm{g} / \mathrm{cm} 2 / \mathrm{ka}\end{array}$ & $\begin{array}{l}222 \\
8.00\end{array}$ & $\begin{array}{c}141 \\
10.36\end{array}$ & $\begin{array}{l}677 \\
2.17\end{array}$ & $\begin{array}{l}1489 \\
2.54\end{array}$ & $\begin{array}{l}262 \\
8.00\end{array}$ & $\begin{array}{c}333 \\
10.36\end{array}$ & $\begin{array}{l}164 \\
2.17\end{array}$ & $\begin{array}{l}564 \\
2.54\end{array}$ \\
\hline $\mathrm{g} / \mathrm{m} 2 / \mathrm{ka}$ & 80000.00 & 103600.00 & 21700.00 & 25400.00 & 80000.00 & 103600.00 & 21700.00 & 25400.00 \\
\hline $\mathrm{g} / \mathrm{m} 2 / \mathrm{a}$ & 80.00 & 103.60 & 21.70 & 25.40 & 80.00 & 103.60 & 21.70 & 25.40 \\
\hline $\mathrm{g} / \mathrm{m} 2 /$ day & 0.22 & 0.28 & 0.06 & 0.07 & 0.22 & 0.28 & 0.06 & 0.07 \\
\hline days & 4.56 & 3.52 & 16.82 & 14.37 & 4.56 & 3.52 & 16.82 & 14.37 \\
\hline cysts/m2/day & 48.69 & 39.93 & 40.23 & 103.60 & 57.52 & 94.62 & 9.72 & 39.28 \\
\hline Taxon & \multicolumn{4}{|c|}{ Selenopemphix nephroides } & \multicolumn{3}{|c|}{ Other peridinoids } & \\
\hline Sample & $\$ 938$ & P69 & R657 & W266 & $\$ 938$ & P69 & $\mathrm{R} 657$ & W266 \\
\hline $\begin{array}{r}\text { cysts/g } \\
\mathrm{g} / \mathrm{cm} 2 / \mathrm{ka}\end{array}$ & $\begin{array}{c}98 \\
8.00\end{array}$ & $\begin{array}{c}107 \\
10.36\end{array}$ & $\begin{array}{l}154 \\
2.17\end{array}$ & $\begin{array}{l}178 \\
2.54\end{array}$ & $\begin{array}{l}137 \\
8.00\end{array}$ & $\begin{array}{c}135 \\
10.36\end{array}$ & $\begin{array}{l}305 \\
2.17\end{array}$ & $\begin{array}{l}444 \\
2.54\end{array}$ \\
\hline $\mathrm{g} / \mathrm{m} 2 / \mathrm{ka}$ & 80000.00 & 103600.00 & 21700.00 & 25400.00 & 80000.00 & 103600.00 & 21700.00 & 25400.00 \\
\hline $\mathrm{g} / \mathrm{m} 2 / \mathrm{a}$ & 80.00 & 103.60 & 21.70 & 25.40 & 80.00 & 103.60 & 21.70 & 25.40 \\
\hline $\mathrm{g} / \mathrm{m} 2 /$ day & 0.22 & 0.28 & 0.06 & 0.07 & 0.22 & 0.28 & 0.06 & 0.07 \\
\hline days & 4.56 & 3.52 & 16.82 & 14.37 & 4.56 & 3.52 & 16.82 & 14.37 \\
\hline cysts/m2/day & 21.57 & 30.34 & 9.15 & 12.36 & 30.07 & 38.33 & 18.11 & 30.89 \\
\hline Taxon & \multicolumn{4}{|c|}{ Echinidinium sp } & \multicolumn{4}{|c|}{ Brigantedinium spp. } \\
\hline Sample & S938 & P69 & R657 & W266 & S938 & P69 & R657 & W266 \\
\hline $\begin{array}{r}\text { cysts/g } \\
\mathrm{g} / \mathrm{cm} 2 / \mathrm{ka}\end{array}$ & $\begin{array}{c}89 \\
8.00\end{array}$ & $\begin{array}{c}135 \\
10.36\end{array}$ & $\begin{array}{l}103 \\
2.17\end{array}$ & $\begin{array}{l}159 \\
2.54\end{array}$ & $\begin{array}{l}731 \\
8.00\end{array}$ & $\begin{array}{c}293 \\
10.36\end{array}$ & $\begin{array}{l}507 \\
2.17\end{array}$ & $\begin{array}{l}1573 \\
2.54\end{array}$ \\
\hline $\mathrm{g} / \mathrm{m} 2 / \mathrm{ka}$ & 80000.00 & 103600.00 & 21700.00 & 25400.00 & 80000.00 & 103600.00 & 21700.00 & 25400.00 \\
\hline $\mathrm{g} / \mathrm{m} 2 / \mathrm{a}$ & 80.00 & 103.60 & 21.70 & 25.40 & 80.00 & 103.60 & 21.70 & 25.40 \\
\hline $\mathrm{g} / \mathrm{m} 2 /$ day & 0.22 & 0.28 & 0.06 & 0.07 & 0.22 & 0.28 & 0.06 & 0.07 \\
\hline days & 4.56 & 3.52 & 16.82 & 14.37 & 4.56 & 3.52 & 16.82 & 14.37 \\
\hline cysts/m2/day & 19.61 & 38.33 & 6.10 & 11.03 & 160.13 & 83.05 & 30.12 & 109.44 \\
\hline Taxon & \multicolumn{4}{|c|}{ Indigenous pollen flux (exotic Pinus grains } & & & & \\
\hline Sample & S938 & P69 & $\mathrm{R} 657$ & W266 & & & & \\
\hline $\begin{array}{r}\text { cysts/g } \\
\mathrm{g} / \mathrm{cm} 2 / \mathrm{ka}\end{array}$ & $\begin{array}{l}7377 \\
8.00\end{array}$ & $\begin{array}{l}10432 \\
10.36\end{array}$ & $\begin{array}{l}3850 \\
2.17\end{array}$ & $\begin{array}{c}26546 \\
2.54\end{array}$ & & & & \\
\hline $\begin{array}{c}\mathrm{g} / \mathrm{m} 2 / \mathrm{ka} \\
\mathrm{g} / \mathrm{m} 2 / \mathrm{a}\end{array}$ & $\begin{array}{c}80000.00 \\
80.00\end{array}$ & $\begin{array}{c}103600.00 \\
103.60\end{array}$ & $\begin{array}{c}21700.00 \\
21.70\end{array}$ & $\begin{array}{c}25400.00 \\
25.40\end{array}$ & & & & \\
\hline $\mathrm{g} / \mathrm{m} 2 /$ day & 0.22 & 0.28 & 0.06 & 0.07 & & & & \\
\hline days & 4.56 & 3.52 & 16.82 & 14.37 & & & & \\
\hline cysts/m2/day & 1616.81 & 2961.05 & 228.91 & 1847.30 & & & & \\
\hline
\end{tabular}


Chapter 3

\section{Supplementary Material}

The following data table is included at the end of this thesis:

S3.1. Raw dinocyst counts from sediment trap samples 
Chapter 3 


\title{
4. A dinoflagellate cyst-based sea surface temperature transfer function for the Southwest Pacific
}

\begin{abstract}
A dinoflagellate cyst (dinocyst) dataset of 311 Southern Hemisphere sea-floor samples is examined for its suitability as a training set to quantitatively reconstruct sea surface paleotemperatures from the New Zealand region in the Late Quaternary.

Four sea surface temperature (SST) transfer functions are tested: the modern analogue technique (MAT), an artificial neural network (ANN), weighted averaging (WA), and weighted averaging with the addition of partial least squares (WA-PLS).

Under a leave-one-out cross validation routine, the ANN model performed best for the Southwest (SW) Pacific dataset, with a root mean square error (RMSE) of $1.14^{\circ} \mathrm{C}$. The best performance achieved for the Southern Hemisphere dataset was a RMSE of $1.47^{\circ} \mathrm{C}$, also for the ANN model. The WA model had little predictive power due to a pervasive bias in the residuals, while the WA-PLS and MAT models had RMSE $\mathrm{j}_{\text {jack }}$ errors of $2.29^{\circ} \mathrm{C}$ and $1.88^{\circ} \mathrm{C}$, respectively.
\end{abstract}

The performance of the models decline when assessed using spatially independent test sets. The exact decline in performance of the models depends on the test set selected, but on average there is little to differentiate the performance of MAT and ANN models when assessed in this way, while prediction error of the WA-PLS model is slightly superior to the others. This is likely due to the tendency of MAT and ANN models to exploit spatial autocorrelation characteristics of the training dataset.

When applying these models to fossil assemblages, MAT and ANN models are likely to be superior to WA-PLS when operating within familiar assemblages, but as fossil assemblages become more dissimilar to the modern training set, WA-PLS has a slight edge over MAT and ANN models. This study confirms that it is important to assess both 
model and fossil datasets when using transfer function models and to critically examine the proxy results that are produced. Various sources of bias (regional vs. global and hemispheric datasets, spatial distribution of the training set, including spatial autocorrelation, dissimilarity between fossil and recent samples) strongly affect model performance.

\subsection{Introduction}

Since the development of multivariate transfer functions in the 1970s (Imbrie and Kipp 1971), the use of faunally-derived quantitative environmental proxies has become well established in paleoecology (e.g. Kucera et al., 2005; Guiot and de Vernal 2007; HillaireMarcel and de Vernal, 2007). Early progress, along with many recent advances, in the application of transfer functions to paleoceanographic problems have used assemblages of fossil foraminifera (e.g. Imbrie and Kipp, 1971; Hutson, 1980; Malmgren and Nordlund, 1997; Kucera et al., 2005), but the same mathematical approaches have been applied to other groups of marine microfossils, including diatoms (e.g. Koc et al., 1993), radiolaria (e.g. Abelmann et al., 1999, Cortese et al., 2005), ostracods (e.g. Cronin, 1991) and dinoflagellate cysts (e.g. de Vernal et al., 2001; 2005).

Numerous mathematical approaches have been developed that quantitatively reconstruct past environments based on faunal assemblages (Birks, 1995; Guiot and de Vernal, 2007). While there is a great diversity in methods, they are similar in that all may be relied upon to produce a result. The quality of the result, however, depends on a number of important factors, such as the quality of the underlying datasets, the temporal control, and the numerical approaches used (Birks et al., 2010).

An extensive dataset of Northern Hemisphere dinoflagellate cyst (dinocyst) assemblages has been created over a number of years (e.g. Rochon and de Vernal, 1994; Rochon et al., 1999; de Vernal et al., 2001; Radi et al., 2007; Pospelova et al., 2008), and has been used to reconstruct sea surface temperature (SST), productivity, salinity, and ice cover (de Vernal et al., 2005; Bonnett et al., 2011) using MAT and ANN models. In the SW 
Pacific, the general utility of dinocysts in faunal transfer functions has been demonstrated. Late Quaternary SST and salinity was reconstructed from Deep Sea Drilling Project (DSDP) Site 594, off the East Coast of the South Island, using a MAT model and a Southern Ocean dataset of 118 Southern Hemisphere surface sediment samples (Marret et al., 2001).

In this chapter, we further develop dinocysts as a tool for quantitative paleo reconstruction in the SW Pacific, by exploring the performance of four different dinocyst-based transfer function models, using a newly compiled 311-sample Southern Hemisphere and 98-sample SW Pacific dataset (Chapter 2, this study). The relative performance of the best analogue method (Modern Analogue Technique; MAT) artificial neural network (ANN), weighted averaging (WA), and weighted averaging with the addition of partial least squares (WA-PLS) are compared. Furthermore, their performance is explored by revisiting the existing Late Quaternary dinocyst record from DSDP Site 594 (Marret et al. 2001), for which other environmental proxy records are available for comparison.

In a recent review, Birks et al., (2010) compiled lists of seven basic requirements and six assumptions of quantitative climate reconstructions using biological assemblages. These assumptions and requirements are important: they are the difference between reasonable and unreliable reconstructions. The degree to which each of these 13 requirements and assumptions are met for dinocysts in the Southern Hemisphere is documented in this chapter, with a particular emphasis on application of the quantitative models to the New Zealand region. The assumptions and requirements overlap to some extent (Birks et al., 2010) and are summarized below:

\subsubsection{Requirements of a transfer function}

1. A biological system that produces abundant identifiable fossils, that is responsive and sensitive at the required spatial and temporal scales to the climatic variables of interest 
Chapter 4

2. A large, high quality data-set of modern biological and associated climatic data are available

3. Fossil datasets used for reconstruction are comparable in quality and sedimentary environment to the modern datasets

4. Independent chronological control for both modern and fossil data

5. Robust numerical methods for regression and calibration

6. Reliable and realistic numerical estimation of errors of prediction

7. Critical ecological, numerical, and paleoclimatic evaluations of reconstructions

\subsubsection{Assumptions of a transfer function:}

a. The taxa are systematically related to the climate in which they live

b. The climatic variable to be reconstructed is related to an ecologically important determinant in the system

c. The modern taxa are the same biological entities as the fossil taxa

d. Other environmental variables have negligible influence on the assemblage

e. The mathematical models adequately model species responses and produce sufficient predictive power

f. Prediction errors are estimated on statistically independent test sets

\subsection{Dinoflagellate ecology}

Requirement 1 A biological system that produces abundant identifiable fossils, that is responsive and sensitive at the required spatial and temporal scales to the climatic variables of interest. 
Assumption $b$ The climatic variable to be reconstructed is related to an ecologically important determinant in the system

\subsubsection{Dinoflagellate nutrition}

Dinoflagellates are unicellular organisms that employ both heterotrophic and autotrophic feeding strategies (Jacobson, 1999), while examples of mixotrophy (photosynthetic dinoflagellates opportunistically consuming other cells) have been observed in all dinoflagellate orders (Stoecker, 1999; Hansen, 2011). Most of the dinocysts recognised in Southern Hemisphere sea-floor samples are gonyalaucoid, which are cysts of chloroplast-bearing dinoflagellates, and about a quarter of the assemblage are formed by dinoflagellates assigned to peridinioid genera, many of which have hetrotrophic feeding strategies (e.g. Zonneveld and Brunner, 2000; Zonneveld et al., 2010 and references therein). Samples may consist almost exclusively of peridinoid or gonyalaucoid cysts (Smayda and Reynolds, 2003; de Vernal and Marret, 2007; Chapter 2). Dinoflagellates are mobile and can regulate their depth to maximize light or nutrients (Dale, 1996), which is a characteristic that leaves them better suited to stratified water masses than other micro plankton (e.g., diatoms) that require more vigorous physical mixing for nutrient supply.

This diversity of nutritional strategies is relatively unusual among biological training sets used for quantitative reconstructions. Most are restricted to one trophic level, being either primary producers (e.g., diatoms or plant pollen) or primary consumers (e.g. radiolaria or chironomids), although obligate symbiotic relationships between some planktonic foraminifera and photosynthetic dinoflagellates effectively result in a similar trophic division in foraminiferal training sets (Zaric et al., 2005; Kucera, 2007) to that observed in dinoflagellates.

\subsubsection{Habitat and cyst formation}

Dinoflagellates make a significant contribution to productivity and primary grazing in modern oceans, at times forming blooms that dominate carbon fixation and primary carbon cycling in surface waters (Chang, 1988; Verity et al., 1993; Sherr and Sherr, 2007; 
Wasmund et al., 2011). About $10-20 \%$ of modern dinoflagellates form fossilisable organic-walled cysts (Dale, 1996; de Vernal and Marret, 2007), resulting in approximately 80 identifiable sub-fossil taxa in modern sea-floor samples (Marret and Zonneveld, 2003). Moreover, new sub-fossil taxa continue to be documented from lightly explored regions (e.g., the south Pacific, Verleye et al., 2011).

The organic-walled dinoflagellate cyst (dinocyst) represents a resting stage in the dinoflagellate life cycle, and is generally formed after sexual reproduction (Pfiester and Anderson, 1987; Figueroa et al., 2007; Kremp et al., 2009). Maximum rates of cyst formation have been observed following blooms of dinoflagellates (Heiskanen, 1993), along with diatoms that are frequently the prey of heterotrophic dinoflagellates (Jacobson and Anderson, 1986; Zonneveld et al., 2010).

Dinocysts are preserved in depositional environments from estuaries to the deep ocean (e.g. Marret and Zonneveld, 2003; Riberio and Amorin, 2008), with the assemblage diversity being greatest in mid latitudes (Chapter 2, Figure 2.4). While diversity decreases at higher latitudes, particularly in the Southern Hemisphere, monospecific polar assemblages that are common in other groups such as foraminifera are rare (Kurcea et al., 2005; Esper and Zonneveld, 2007). Global and regional compilations show unimodal distributions of dinocyst relative abundance along various surface water environmental gradients, principally gradients related to latitude, proximity to land, bathymetry, and upwelling (Marret and Zoneveld, 2003; Esper and Zonneveld, 2007; Pospelova et al., 2010). This distribution has important implications for later transfer function model selection, as some approaches, such as factor analysis (Imbrie and Kipp, 1977), assume a linear distribution along the principal environmental gradient.

Environmental factors that influence growth, reproduction and bloom formation are likely to also have a significant influence over dinocyst flux, so will be the most ecologically reasonable environmental gradients for quantitative reconstruction. 


\subsubsection{Growth rate and encystment studies}

While the general relationship between living dinoflagellates and many of the dinocysts found in sea-floor sediments has been established, there is considerable uncertainty below generic level. Single dinoflagellate species, or complexes of dinoflagellate species, can give rise to a large diversity of dinocyst forms. For example, Impagidinium cysts are formed by an unknown species of Gonyaulax (Head, 1996), while the Gonyaulax spinifera complex produces cysts attributable to Spiniferites, Nematosphaeropsis, Bitectatodinium, and Ataxiodinium (Head, 1996; Rochon et al., 1999), with phenotypic expression influenced by environment variations (Ellegaard et al., 2002, 2003; Rochon et al., 2009; Merthens et al., 2011; Verleye et al., 2012).

Many of the dinoflagellate species that form fossilisable cysts have not been subjected to detailed study in laboratories, although Gonyaulax/ Lingulodinium polyedra (cyst Lingulodinium machaerophorum) and Gonyaulax tamarensis (cyst Alexandrium tamarense) are exceptions (Watras et al., 1982; Andersen et al., 1983, 1987; Gibson and Thomas, 1995; Lewis and Hallett, 1997; Hae et al., 2005). These dinoflagellates, and other example from dinoflagellates that either do not form cysts, or form cysts generally too delicate for prolonged preservation in oceanic sediment, are used here to infer possible ecological controls of the wider group (e.g. Grzebyk and Berland, 1997; Navarro et al, 2006; Guerrini et al., 2007).

Numerous environmental triggers for cyst formation by these dinoflagellates have been identified. Temperature has frequently been found to influence growth rate and cyst formation, while salinity, $\mathrm{pH}$ and nutrient limitation are also frequently recognised as important factors (e.g. Jensen and Moestrup, 1997; Grzebyk and Berland, 1997; Hwang and Lu, 2000; Juhl, 2005; Navarro et al, 2006; Guerrini et al., 2007; Laabir et al., 2011). Other environmental factors are those associated with the peak and termination of bloom conditions, such as limitation of various nutrients, threshold concentrations of inhibition chemicals released by the dinoflagellates themselves, or light limitation (Suikkaen, 2011; Figueroa, 2011), while turbulence (in a laboratory setting) has been 
shown to slow growth and bloom formation of Gonyaulax polyedra (Gibson and Thomas, 1995). Although the apparent dominance of temperature as a control of cyst formation may be in part due to the number of experiments that have explored variation along this gradient, temperature does appear to be an ecologically relevant factor in the growth and reproduction of dinoflagellates.

\subsection{Dinocysts on the sea-floor}

Requirement 3. Fossil datasets used for reconstruction are comparable in quality and sedimentary environment to the modern datasets

\subsubsection{Transport and deposition}

Dinoflagellate cysts, with a size range of $\sim 20-100 \mu \mathrm{m}$, are transported in the silt fraction (Dale, 1996), although some studies of dinocyst settling rates in the ocean suggest that they are considerably faster than would be expected of silt-sized particles, possibly due to flocculation into faster-falling aggregates (Zonneveld et al., 2010), ballasted particles such as fecal pellets, and transport during diel (diurnal) migration of zooplankton (Honjo et al., 2008). While the resting dinocyst may remain viable on the sea-floor for months to years, only those that are deposited in coastal zones and the continental shelf have any significant chance of continuing their lifecycle after sexual reproduction. However, an obligatory resting phase is unlikely to be a feature of the truly oceanic genus Impagidinium (Dale, 1996). This obligate association with shallow water for successful sexual reproduction has led some workers to suggest a significant proportion of seafloor assemblages in oceanic settings are transported from the shelf and with ocean currents, and so have little contribution from the overlying water mass (e.g. Dale, 1996). Our observations of the New Zealand region, however, suggest that oceanic sea-floor assemblages should not be dismissed out of hand, particularly those within $1000 \mathrm{~km}$ of land (Chapters $2-3$ ). While cysts formed by dinoflagellates may sink to the deep ocean before they hatch, and oceanic populations of many taxa would require periodic seeding 
from coastal waters, it is a reasonable assumption that growth and cyst formation would be triggered by the same environmental thresholds as those in coastal waters.

The thecate (swimming) stage of cyst-forming dinoflagellates has been observed off eastern New Zealand in surface waters of $>2500$ m deep water column (Chang and Gall, 1998; F.H. Chang, pers. comm., 2011), including Protoceratium reticulatum (cyst Operculodinium centrocarpum), Protoperidinium conicum (cyst Selenopemphix quanta), and other indeterminate Protoperidinium species. Thecae of cyst-forming dinoflagellates have been recovered by surface water plankton tows across the northeast Atlantic in oceanic waters, although not in the central Atlantic, including Gonyaulax digitalis (cyst Spiniferites bentorii), $G$. scrippsae (cyst $S$. ramosus), $G$. spinifera (cysts Nematosphaeropsis labyrinthus, Spiniferites spp.), P. reticulatum (cyst O. centrocarpum), and Protoperidinium conicoides (cyst Brigantedinium simplex) (Dodge and Harland, 1992). Other dinflagellates appear to be restricted to more coastal waters $(<500 \mathrm{~km}$ from shore) in the North Atlantic, such as P. conicum (cyst Selenopemphix quanta) and Lingulodinium polyhedrum (cyst Lingulodinium machaerophorum) and Polykrikos schwarzii. Thecae of Gonyaulax digitale (cyst Bitectatodinium tepikiense) (Lewis et al., 2001) were recorded in oceanic waters of the SW Atlantic, and north of the South Georgia Islands (McKenzie and Cox, 1991).

One way to infer the relative volume of coastally-derived dinocysts, compared to those that are locally produced, is by examining the proportion of pollen/spores and dinocysts in sea-floor sediments around New Zealand (Figure 4.1). Within $100 \mathrm{~km}$ of shore, significantly more pollen than dinocysts are observed in sea-floor sediments. Although pollen is transported to the deep ocean, dinoflagellates are more abundant in $95 \%$ of the samples $>250 \mathrm{~km}$ from shore, and are on average 12 times more abundant (reduced to 9 times more abundant when four out-lying samples are excluded). Although a considerable proportion of the pollen observed in sea-floor samples around New Zealand are from plants with wind-dispersal mechanisms (e.g., Pinus Pine] and Nothofagus [Southern Beech]) (Crouch et al., 2010; incidental observations during this 


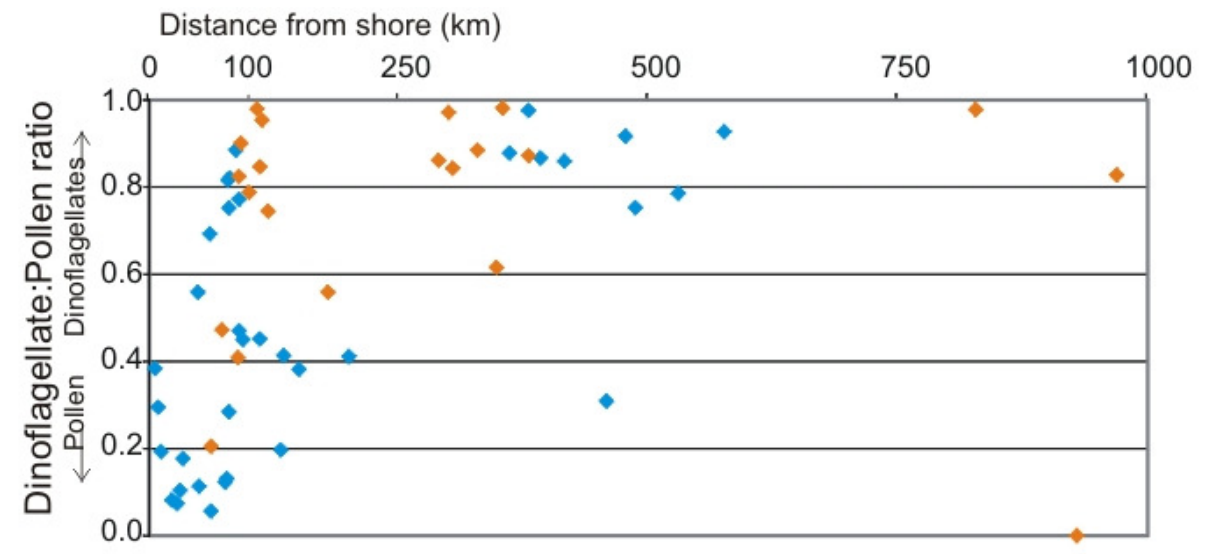

Figure 4.1. Dinoflagellate cyst: pollen ratio of 81 sea-floor samples from around New Zealand. Blue diamonds are samples east of New Zealand, orange are samples to the west. Minimum count size for inclusion into figure is 100 pollen +100 dinocysts.

research), a significant proportion of the pollen appears to enter the deep sea via water rather than aeolian transport, as similar trends are observed in samples upwind (west of New Zealand) and downwind (east of New Zealand) of the prevailing westerly airflow (incidental observations during this research).

A proportion of each sea-floor dinocyst assemblage may have been transported from coastal waters. In rare cases, assuming that pollen is transported in a similar way to dinocysts, this coastal water contribution may represent a large proportion of the total assemblages, but in most samples the near-shore contribution appears to be diluted by local cyst production.

In other parts of the world this transport modality is probably not relevant: as an example, zonal assemblages with increasing distance from the South American and West African coasts suggest limited off-shore transport at those sites (Holzwarth et al., 2007; Verleye and Loweye, 2010).

\subsubsection{Preservation}

Dinocysts are often preserved in areas where calcareous and siliceous microfossils have suffered dissolution or form a less significant part of the plankton (e.g., coastal settings), but are themselves susceptible to degradation by oxidation (Zonneveld et al., 2001). 
This oxidation is a potentially significant taphonomic overprint that may strongly affect quantitative reconstructions, as the assemblage may be degraded unevenly, with peridinoid cysts generally degrading more easily than gonyaulaucoid cysts (Zonneveld et al., 1997; Zonneveld et al., 2008). While an empirical correction, the $k t$ index, has been derived with the aim of identifying fossil assemblages affected by selective degradation (Zonneveld et al., 1997), it is not clear that the correction factor included in the index works beyond the training set, as it assumes a constant ratio of sensitive to resistant cysts in the modern (and fossil) flux. The effects of preferential dissolution are 'built in' to the modern sea-floor dataset, but ordination, discussed in Chapter 2, reveals that bottom water oxygen concentration is not strongly correlated to changes in the assemblage. However, modern dinocyst assemblages from sea-floor samples may prove to be poor analogues to environments with very different sea-floor oxygen regimes compared to the present, such as highly stratified closed basins.

\subsection{Training set compilation}

Requirement 2 A large, high quality data-set of modern biological and associated climatic data are available.

A Southern Hemisphere dinocyst sea-floor dataset (SH-311) and a subset of this training set from the SW Pacific/ New Zealand region (NZ-98) have been compiled (Chapter 2, Figures 2.2 and 2.3). Summary details of each dataset, including environmental parameters assigned to each sample, and taxonomic consolidations, are provided in Chapter 2.

The purpose of compiling the NZ-98 subset is to explore whether there appears to be benefit from a regional, rather than hemispheric, training set. The performance of a global training set has not been explored here. Although a global training set of $>830$ published samples has been compiled for this thesis, many of the Northern Hemisphere samples are from the Arctic and tropical waters, where assemblages are influenced by additional abiotic factors such as nutrient, salinity and productivity perturbations 
Figure 4.2. Distribution of samples across k-means clusters in the SH-311 database (Chapter 2) arranged by publication. The size of each circle is proportional to the number of samples contributed from the entire 311 sample database (i.e., the entire plot $=100 \%$ ), circle colours represent Clusters 1-7.

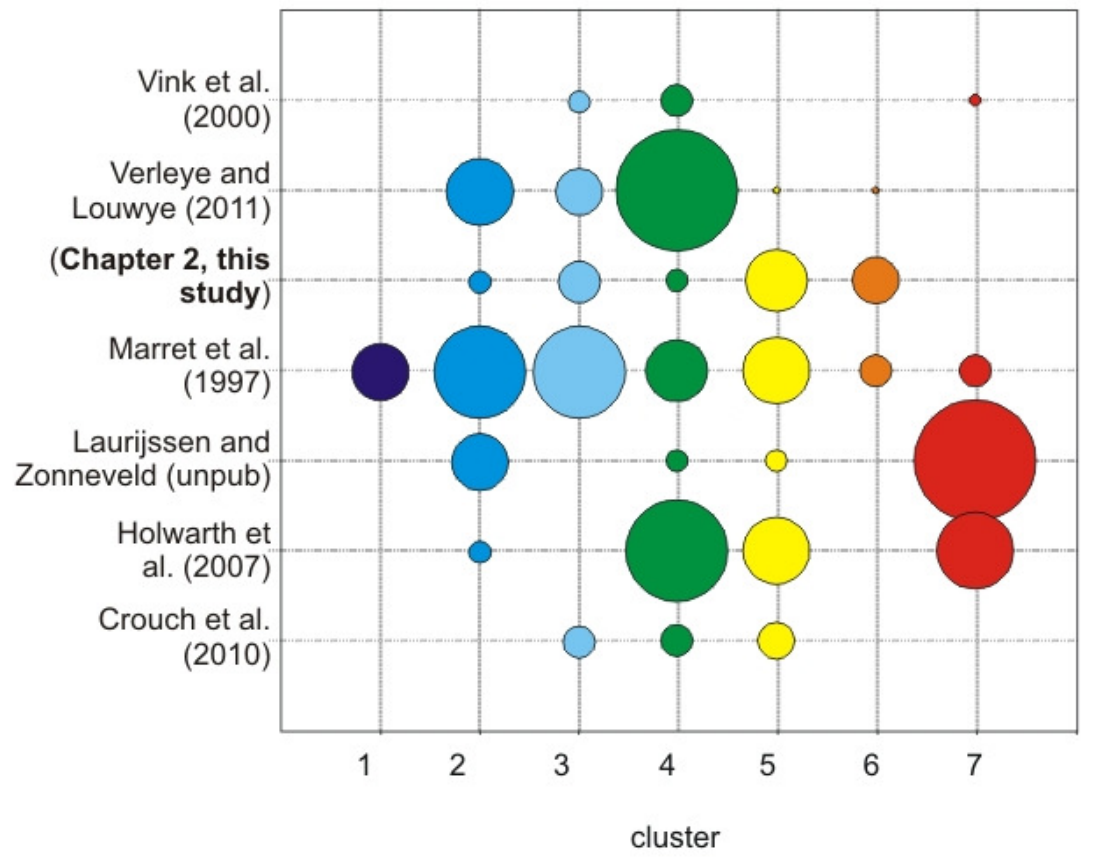

associated with sea ice, and oceanographic effects unique to inland seas that are not envisaged in the Late Quaternary investigations of the SW Pacific planned for this project.

\subsubsection{Quality of dinocyst count data}

The samples included in the SH-311 dataset have been processed by numerous different laboratories, and quantitatively examined by at least 10 different palynologists.

Samples were processed in a consistent way in all studies, with minor differences in sieving size fractions not expected to result in significant differences (Mertens et al., 2009; Verleye and Loweye, 2010). 62 of the samples from the New Zealand region were processed with a wash of warm $30 \% \mathrm{HCl}$ following the $\mathrm{HF}$ step that removes fluorosilicates. While damage to modern peridinoid cysts has been noted following this processing step (Dale, 1976), Merterns et al. (2009) noted traces of deterioration to peridinoid cysts treated with hot $\mathrm{HCl}$ but did not report quantitative assemblage changes despite having designed experiments to test for this. Duplicate dinocyst counts 
of two sea-floor samples from north of the Chatham Rise, east of New Zealand, subjected to both cold (Marret et al., 2001) and warm (Crouch et al., 2010) $\mathrm{HCl}$ processing are available. The assemblages reported in sample S924 are similar, with a maximum difference in an individual taxa count of $6 \%$, and only $1 \%$ difference in total peridinoid cysts. While the diversity in each of the sample R657 duplicates is similar, the proportions differ: 15\% more Nematosphaeropsis labyrinthus was reported by Marret et al., (2001) at the expense of peridinoid cysts, which were $15 \%$ more abundant in the Crouch et al., (2010) data. These two duplicates suggest the warm $\mathrm{HCl}$ treatment does not have a reductive effect on peridinoid cysts, but does raise an interesting issue of variation between palynologists. No significant differences in the relative abundance of dinocyst assemblages were observed in samples that were processed differently from a Late Quaternary record at DSDP 594, offshore Canterbury (Marret et al., 2001), where some samples were prepared using hot acid, a $\mathrm{KOH}$ wash, and acetolysis, while for other samples only cold acids and sieving were used.

Most of the SH-311 dataset is a collection of spatially discrete sample sets collected by different operators (Chapter 2), so there is little opportunity to compare results obtained by different palynologists. The main exception is in waters around New Zealand, where three palynologists have contributed to the dataset. Cluster analysis (Chapter 2) produces four clear biogeographic provinces, and samples of all three palynologists are spread evenly between the biozones. Across the rest of the SH-311 dataset, samples from different palynologists are well distributed across each of the 7 clusters identified (Figure 4.2). Although variation in a duplicate sample has been noted, it appears that inter-operator variation is insufficient to obscure the biogeographical variation.

\subsubsection{Transformation of count data}

In paleoecologial studies, training sets are frequently log-transformed prior to ordination and application of transfer functions (Mix et al., 1999; Marret et al., 2001; Niebler et al., 2003; de Vernal et al., 2001, 2005; Guiot and de Vernal, 2007). This 
practice is based on the observation that much of the variation in assemblages occurs in rare taxa, so a transformation that increases the importance of rare taxa should increase the sensitivity of the dataset to environmental changes. We have not transformed data, as the count sizes in the $\mathrm{SH}-311$ training set (mean count size 310 specimens per sample) do not support increased weighting of infrequently occurring taxa. In fact, it introduces an additional source of error as it ignores the uncertainty associated with the chance of detection of small proportions in a census count (Traverse, 2007; Helsop et al., 2011). Also, a recent dinocyst Southern Hemisphere compilation containing many of the same samples as the $\mathrm{SH}-311$ dataset found no performance improvement using logtransformed data (Verleye and Louwye, 2010).

\subsubsection{Quality of environmental data}

Environmental data attributed to each seafloor sample included seasonal and mean annual water temperature, salinity, dissolved nitrate, phosphate and silica content for Om and $50 \mathrm{~m}$ water depths, average depth to the base of the mixed layer during spring, and bottom water oxygen concentration (discussed in Chapter 2). All the data were obtained from the $1^{\circ}$ climatologies in the World Ocean Atlas (Antonov et al., 2009; Garcia et al., 2009; Locarnini et al., 2010) using the 2D-estimation routine in Ocean Data View (Schlitzer, 2002) and monthly satellite-derived primary productivity data for the period January 2006 - December 2009 (Behrenfeld and Falkowski, 1997).

There are many advantages in using data from the WOA. The input data are restricted to on-site measurements and satellite data are excluded. These data are extrapolated, both temporally and spatially, in a consistent way for the global ocean, and so provide a uniform climatology for comparison between studies. However, the WOA climatology for the New Zealand region, and much of the Southern Hemisphere, is extrapolated from fewer measurements than for the Northern Hemisphere: in the SH-311 dataset, a third of the mean annual SST data are based on fewer than 50 observations (Figure 4.3), while half of the mean annual phosphate data for the NZ-98 dataset are based on fewer than 2 observations. Sampling resolution for seasonal climatologies, particularly colder 


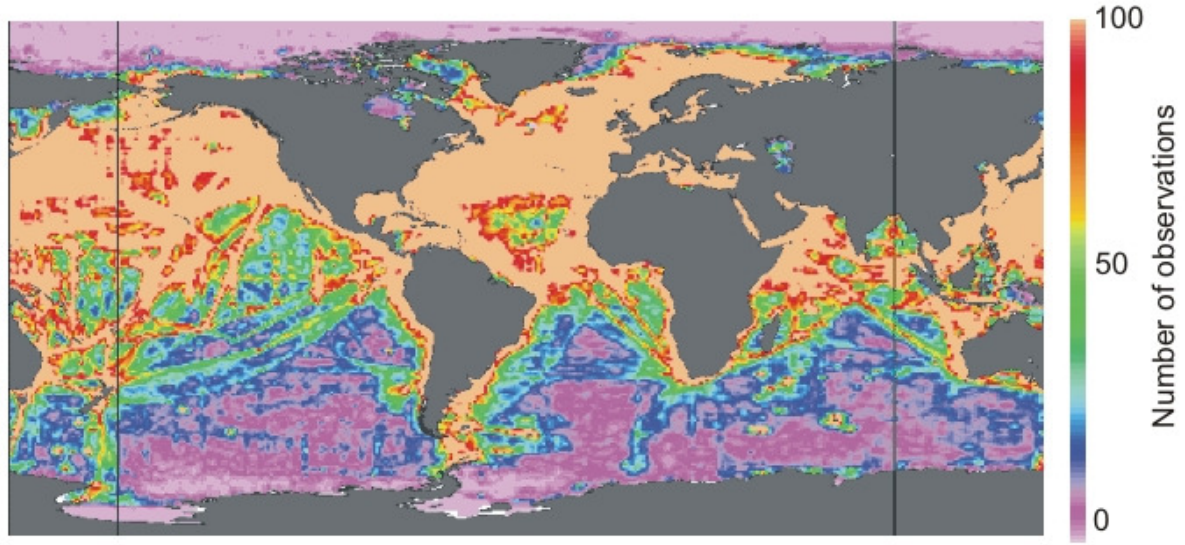

Figure 4.3. Number of SST observations per $1^{\circ}$ grid point in the World Ocean Data (WOD) 2011 database, the database used to create the climatologies of the World Ocean Atlas (WOA), illustrating relatively poor coverage in the Southern Hemisphere.

months, is correspondingly poorer. To overcome imbalances of intra-decadal variability, the mean annual SST is an average of five decadal climatologies since 1955. This climatology is almost certainly more suitable than the higher resolution satellite data that is available, as the sea-floor dinocyst assemblages are an average of hundreds to thousands of years of flux. Comparison of satellite-derived SST data with WOA climatology for the 98 samples from the New Zealand region reveals systematic differences. Satellite SSTs south of the STF are on average $0.5^{\circ} \mathrm{C}$ warmer than the WOA climatology, and $0.5^{\circ} \mathrm{C}$ cooler in the waters of the Subtropical Front (STF), with similar WOA and satellite SSTs to the north of the STF.

The productivity data are satellite derived, so are at a different temporal resolution to the other abiotic variables. Since the productivity algorithm has both ocean colour and SST as inputs, it is worth remembering that the productivity data available may differ from a WOA-style climatology if it was available.

\subsubsection{Age control}

Requirement 4 Independent chronological control for both modern and fossil data

The comparison of sea-floor assemblages with modern (or at best last 100 years) climatologies contains the implicit assumption that the climate of the last century is a 
fair representation of at least the preceding 50 , which is the average radiocarbon age of 48 sea-floor samples analysed from around New Zealand waters (details of 48 sea-floor

${ }^{14} \mathrm{C}$ ages from the SW Pacific are included in Chapter 2). Marine records from the SW Pacific indicate that SST varied less than $2^{\circ} \mathrm{C}$ since $7 \mathrm{ka}$ (Pahnke and Sachs, 2006; Barrows et al., 2007). Although both these SST records also rely on sea-floor based calibrations, albeit using sea-floor sediments from other parts of the world, this range of surface temperature is close to the standard deviation of mean annual temperature climatology of the World Ocean Atlas used here (de Vernal et al., 2005; Giout and de Vernal, 2007; Locarnini et al., 2010; Guiot, 2011). Age control of the remaining samples across the Southern Hemisphere has not been explored, although the pattern observed of old sea floor south of the SAF (Figure 2.1B), is of concern if this is a more uniform feature of southern high-latitudes.

\subsection{Selection of environmental gradients}

Assumption a. The taxa are systematically related to the climate in which they live
Assumption d. $\quad \begin{aligned} & \text { Other environmental variables have negligible influence on the } \\ & \text { assemblage }\end{aligned}$

\subsubsection{Relationship of assemblages to environmental gradients}

Ordination of the SH-311 and NZ-98 data sets indicate that summer SST correlated most strongly to the dinocyst distribution in both datasets, and accounted for between $37 \%$ and $56 \%$ of the species-environmental relationship, respectively, after removal of covarying gradients. SST was 2-3 times more strongly correlated with the dinocyst distribution than the secondary environmental gradients (Chapter 2). The four seasonal SST gradients and mean annual SST co-varied in the ordination, but when considered separately, summer SST explained slightly more of the faunal variation than the other temperature gradients. Ordination of the modern sea-floor flora indicates that summer SST is the most suitable target to reconstruct by transfer function (Chapter 2 ). The 
gradients that covary with temperature on the scale of the modern dataset are salinity, phosphate, and nitrate.

\subsubsection{Selection of transfer function targets}

Although ordination results indicate summer SST correlated most closely to assemblage variation along the first ordination axis, variation in monthly observations of dinocyst flux from two time incremental biophysical moorings east of New Zealand (Chapter 3, this study) suggest that mean annual SST is likely to be a more appropriate target than specific seasonal temperatures. While samples from the mooring to the north of the STF showed very strong seasonal variation in the flux, with most cysts arriving in the trap during spring, cyst flux at the mooring site to the south of the STF is evenly distributed throughout the year, with significant spring blooms occurring in only some years. The effect of spatial variation in the strength of seasonality and productivity has been recognized across the Southern Hemisphere (Hiscock et al., 2003; Vantrepotte and Melin, 2011). As well as being a more appropriate target for the dinocyst dataset in the Southern Hemisphere reconstruction, mean annual SST allows easy comparison with other sea surface proxies in the region, that also frequently select the same transfer function target (e.g., Barrows et al., 2007; Crundwell et al., 2008; Hayward et al., 2012).

\subsubsection{Influence of minor environmental gradients}

The second ordination axis is most closely related to productivity and distance from shore (Chapter 2, this study). This means that Assumption $d$ will hold sometimes, but not all the time. The ecological relationship of these secondary gradients to the dinocyst assemblage is the combination of numerous environmental parameters. Oceanic productivity is driven by a complex interaction of irradiance, nutrient availability and water mass stability (e.g., Longhurst, 1995; Falkowski et al., 1998), while the environmental changes along a land - ocean gradient include nutrient availability, salinity, water stability and clarity (Smayda and Reynolds, 2003). However, while productivity may not be directly related to SST, the location of oceanic productivity belts is a function of global circulation, which in turn is controlled by marine and atmospheric 
temperature gradients, bathymetry, Coriolis forcing and ocean density. Thus, in the open ocean, productivity turns out to have strong meridional variation (e.g. HardmanMountford et al., 2008).

\subsubsection{Reconstruction of multiple gradients}

We choose to quantify only SST, although there are examples of workers extracting multiple environmental proxy records from single biological training sets. This extraction takes two forms.

(i) The first is reconstructing environmental gradients that covary along the first ordination axis, which is effectively a rescaling and change of units between model outputs (Telford and Birks, 2011). An example is the training set used by Marret et al. (2001) to reconstruct SST and salinity for the last 125ka at DSDP Site 594, where the Southern Ocean training set contained samples in which SST and salinity were strongly negatively correlated. However, even this supposed environmental relationship observed by Marret et al. (2001) is not universal: salinity of the tropical north Tasman Sea, with a SST of $\sim 28^{\circ} \mathrm{C}$, is similar to that of the modern day DSDP 594 drill site, with a SST of $\sim 12^{\circ} \mathrm{C}$. In other words, the 'rescaling' is only appropriate within a narrow range of SST.

An equivalent comparison in the $\mathrm{SH}-311$ dataset would be simultaneous reconstruction of SST, salinity, nitrate, and phosphate, which all co-vary along the first axis. However, the limited information available on dinoflagellate ecology suggests that of these variables, SST is the most reasonable target of the four environmental gradients.

(ii) The second form of multiple reconstruction is quantification of environmental gradients that align to subsequent axes of ordination. The implication is that every ordination axis contains unique, and extractable, environmental information. As an example of this approach, SST, sea surface salinity, and sea ice cover were estimated for the high Arctic during the Last Glacial Maximum (LGM) (de Vernal et al., 2005), when ordination showed these three gradients to be approaching orthogonal. This approach 
has been questioned by Telford and Birks (2011a) who propose a statistical test of the validity of reconstructions based on this type of 'lower order' correlations.

A similar reconstruction from the $\mathrm{SH}-311$ dataset would be simultaneous reconstruction of SST and productivity. In general, reconstructions of secondary gradients will have greater error than primary gradients. In the $\mathrm{SH}-311$ dataset, the validation tests of the entire dataset do not support quantitative reconstruction of environmental gradients aligned to the second axis. While we show in Section 4.9 that calibration errors for SST are adequate to resolve orbital scale variation in many depositional settings, calibration errors for productivity are greater than the range of the values in the training set: i.e., predictions are no better resolved than if the mean value of the dataset were used for every reconstruction.

However, the relationship between ecology and environmental gradient is important, and is a question of scale. In some parts covered by the SH-311 dataset, such as the west coast of the South Island, New Zealand, productivity associated with distance from shore and small scale canyon-head upwelling appears to be a strong determinant of dinocyst assemblage change. This balance between SST and productivity, in part possibly due to the two trophic levels occupied by dinoflagellates, highlights the problems of using dinocysts for paleo-temperature reconstructions in high productivity settings, but also represents a considerable opportunity for at least semi-quantitative productivity reconstructions. Generally, if productivity is able to be reconstructed, at least semi-quantitatively and in selected areas, the quality of SST reconstructions in these settings might then require additional consideration.

To explore the interdependence of SST and primary productivity, and the relative contribution of dinocysts with different feeding strategies, transfer model performance of the $\mathrm{SH}-311$ dataset is tested by selective removal of samples and taxa.

When seafloor samples that fall along the second ordination axis (i.e., samples in which primary productivity apparently has a strong correlation to the assemblage) are removed from a cross validation of a transfer function with SST as the target, average 
performance errors increase compared to cross validation of the entire dataset. One interpretation of this result is that a clearly extractable SST signal is included in the second axis, although a more likely cause is sampling irregularities along the SST gradient with respect to primary productivity. Sea-floor samples are included from both major upwelling zones associated with high primary productivity in the Southern Hemisphere (Benguela and Peru). Both have a similar narrow range of SSTs, and the models relate the highly distinctive assemblages associated with these areas to a temperature range narrower than the wider model errors. It is likely exclusion of these unique samples that results in the apparent rise in predictive power.

When autotrophic (gonyaulacoid) taxa are excluded from a similar cross validation exercise, a significant $(\sim 2 \mathrm{x})$ reduction in modern transfer function performance is observed. Hence, assemblages containing only heterotrophic (peridinoid) taxa are poor carriers of a temperature signal. In contrast, cross validation of a dataset that contains cysts from only autotrophic species (although the key heterotrophic cold water species Selenopemphix antartica was included) results in slightly improved $(<5 \%)$ performance compared to a cross validation using the entire dataset. These comparisons are not exact, as variable samples were discarded from each exclusion exercise to ensure that a minimum count size of 100 was retained. However, they do indicate that while peridinoid cysts on their own contribute little to the resolution of a SST signal, their inclusion does not appear to erode it in a significant way. Indeed, there is value in including heterotrophic dinocysts, as consideration of the entire assemblage increases the chance of accurate identification of modern analogues, high productivity zones where the SST signal is obscured, and of non-analogue situations.

The precise identification of samples from high productivity regions, where temperature may be a less important determinant of the assemblage, is difficult to define: if it were easy, a transfer function could be constructed with productivity as its target! Characteristic taxa that are commonly abundant in areas of higher productivity surface waters include Quinquecuspis concreta, Selenopemphix quanta, S. nephroides, 
Chapter 4

Protoperidinium americanum , Echinidinium spp. and Brigantedinium spp. (Radi et al., 2007; Pospelova et al., 2008). Interestingly, among these species, the only one that seems to be a consistent indicator of poor transfer function performance in the SH-311 dataset is a high (>60\%) relative abundance of the Brigantedinium genus.

\subsection{How far back do transfer functions work?}

Assumption C The modern taxa are the same biological entities as the fossil taxa

The stationarity principle states that the properties of fossils and the relationships between them and the environment must remain identical throughout the range of the application of the proxy (Kucera, 2007; Birks et al., 2010). The combination of taxonomic stability of the modern forms back through time, and comparison of fossil assemblages with independent environmental proxies, suggests that dinocyst-based transfer functions will have greatest accuracy in reconstructing SST from Late Pleistocene assemblages. However, Mid Pleistocene assemblages and relationships appear sufficiently similar to those of the present for quantitative reconstruction (Rochon et al., 1999; de Schepper et al., 2011).

Many of the dinocysts observed in modern sea-floor sediments are long lived. Of the 33 taxa recorded in a Northern Hemisphere sea-floor study that are also included in the SH311 dataset, 23 have a first appearance datum (FAD) in the Pliocene or older (Rochon et al., 1999, and references therein). Of these 23 taxa, nine have a FAD during, or prior to, the Oligocene. The remaining 10 taxa mostly have a FAD in the Early or Mid Pleistocene. Thus, with some minor exceptions, modern dinocyst taxa are unchanged since the Mid Pleistocene.

All dinocyst taxa recorded at DSDP Site 594 (Modern - MIS 12) are attributed to extant taxa (Marret et al., 2001; see Chapter 6). Similar stability is observed in a MIS 11 record off the West Coast of New Zealand (see Chapter 5), where all taxa are extant except for an undescribed ?Pyxidinopsis sp., which has a relative abundance of $<2 \%$ in most samples where it is present, and up to $6 \%$ in a single sample. 
In a recent study, de Schepper et al. (2011) demonstrated that the SST range (determined by $\mathrm{Mg} / \mathrm{Ca}$ paleo-thermometry from foraminiferal tests) of most extant dinocyst taxa in Pliocene sediments from North Atlantic Integrated Ocean Drilling Programme (IODP) cores was within the range of modern dinocyst distributions. The most significant variation to modern patterns during the Pliocene was the distribution of Impagidinium pallidum, which was recorded with relative abundances of $>5 \%$ in sediments where $\mathrm{Mg} / \mathrm{Ca}$ SST estimates ranged from $11.6-17.9^{\circ} \mathrm{C}$. In the Modern dinocyst compilation of Marret and Zonneveld (2003), samples with similar concentration of I. pallidum are restricted to waters colder than $7^{\circ} \mathrm{C}$. De Schepper et al. (2011) concluded this represented a significant change in the environmental tolerance of I. pallidum over the last 3Ma. However, in the SH-311 dataset, I. pallidum is present in samples with SST up to $15^{\circ} \mathrm{C}$, with abundances $>3 \%$ in some samples with a SST of $10^{\circ} \mathrm{C}$, and specimens of this species observed in 10 samples beneath waters between 15 $-17^{\circ} \mathrm{C}$ (Chapter 2). While these modern outliers may represent long distance lateral transport or reworking, it is also possible that the tolerance of $I$. pallidum has not changed significantly since the Pliocene. Moreover, the change in relative abundance could also be due to a lower contribution of one of the taxa that commonly coexist with I. pallidum, such as Nematosphaeripsis labrynthis, Brigantedinium spp., or Selenopemphix antarctica, the latter two of which are peridinioid species and susceptible to oxidation. Alternatively, the shift in environmental tolerance in Northern Hemisphere I. pallidum may reflect cryptic speciation of an independent population, with tolerances different to those observed in the Southern Ocean.

\subsection{Transfer function models}

Requirement $5 . \quad$ Robust numerical methods for regression and calibration.

Assumption e. The mathematical models adequately model species responses and produce sufficient predictive power 


\subsubsection{Types of models}

One way to divide the numerous available faunal transfer function methods is differentiating those methods with an underlying assumption of a statistical distribution in the species' environmental response (typically linear or unimodal), from methods that do not consider the underlying faunal distribution.

An (incomplete) list of linear and unimodal methods that seek to exploit an assumed relationship between species abundances and an environmental gradient include factor analysis, weighted averaging (WA), and weighted averaging with the addition of partial least squares, (WAPLS) (ter Braak and van Dam, 1989; ter Braak and Juggins, 1993). Methods not constrained by an assumed distribution either build non-linear models of best fit (artificial neural networks - ANN), or seek to find the most similar assemblages from anywhere within a training set, as done by the modern analogue technique (MAT), and subsequent MAT refinements, such as the artificial training sets of the revised analogue method (RAM) or the preferential selection of proximal analogues in SIMMAX (Hutson, 1980; Malmgren and Nordlund, 1997; Malmgren et al., 2001; Waelbroeck et al., 1998; Pflaumann et al., 1996). Over recent years, many paleoceanographic transfer function studies have focused on the second family of models (e.g., de Vernal et al., 2001; Marret et al., 2001; Kurcea et al., 2005, Hayes et al., 2005, Guiot and de Vernal 2007; Bonnet et al., 2010).

There are a growing number of methodological comparison studies for transfer function models applied to oceanographic settings (Barrows et al., 2000; Malgrem et al., 2001; Kucera et al., 2005; Hayes et al., 2005; Barrows and Juggins 2005; Guiot and de Vernal, 2007). While most conclude that the assumptions of linear distribution in the factor analysis of Imbrie and Kipp (1977) has been superseded by later unimodal and unconstrained approaches, there is less consensus on the relative performance of the other methods.

Kucera et al. (2005) found little to differentiate ANN, RAM, and MAT, and recommended a multi-method approach with a focus on consistent patterns where results diverged. 
Others, however, present the average of multiple techniques (e.g., Racca et al., 2001; Barrows et al., 2007). Guiot and de Vernal (2007) concluded that, of the eight models tested, ANN, RAM, MAT, and WA-PLS performed best, and the results of all models should be considered, regardless whether results were averaged or considered individually.

Following the recent explorations of model performance in the presence of spatial autocorrelation, discussed in Section 4.8 and Appendix 3.1 (Telford, 2006; Telford and Birks, 2009; 2011a), those authors concluded that much of the superior performance in the second family of models is likely to be due to their tendency to exploit characteristics of spatial autocorrelation in training sets. This is based on the observation that when validated using a spatially independent test set, performance of unimodal models is similar to unconstrained models (but see Guiot and de Vernal, 2007; 2011a; 2011b and Bonnett et al., 2010 for alternative interpretations of model performance under conditions of spatial autocorrelation).

\subsubsection{Model selection}

Here, the NZ-98 and SH-311 datasets are used to test four transfer function models: the Modern Analogue Technique (MAT), an Artificial Neural Network (ANN), Weighted Averaging (WA), and Weighted Averaging with Partial Least Squares (WA-PLS). MAT, ANN, and WA-PLS were selected as these models provided reliable performance in a multi-method study of a North Atlantic foraminifera dataset (Guiot and de Vernal, 2007). WA was selected as a unimodal model that is apparently more resilient to the effects of spatial autocorrelation than the other models considered (Telford and Birks, 2009; Birks et al., 2010).

\subsubsection{Weighted Averaging and WA with Partial Least Squares}

WA assumes that a taxon will be most abundant in sites closest to its environmental optimum. The average environmental conditions over those sites where the taxon is present are weighted by the relative abundance of the taxon (ter Braak and Looman, 1986; Birks, 1995). WA requires taxa to be unimodal in distribution, and although the 
NZ-98 gradient is relatively short (1.94 SD units), WA has proved reasonably resistant to linear distributions in other settings (ter Braak and Looman, 1995). As there is an assumed relationship between species abundance and environment, the technique in theory allows extrapolation some distance beyond the range of the calibration set. In practice, this is difficult to reconcile with well documented edge effects of WA, where a negative bias is frequently observed in residuals at the upper end of gradients and the opposite at the lower end (Birks et al., 2010; ter Braak and Juggins, 1993).

WA-PLS adds to the basic WA model by utilizing residual variation: where WA uses only the first axis of variation, WA-PLS explores subsequent axes along which components of the target environmental gradient may lie (ter Braak and Juggins, 1993). Information from the subsequent axes is used to improve the species parameter 'optima' in the final weighting predictors. Thus, a one-parameter WA-PLS produces the same result as a WA model, and subsequent axes are included in the WA-PLS model until there is no increase in predictive power, measured by leave-one-out cross validation. However, the introduction of subsequent 'dimensions' (components) to the WA-PLS model leaves it vulnerable to over fitting. While performance statistics improve with each additional component, after some point this increase is artificial: model error approaches 0 as the number of components approaches the number of samples. Selection of optimum components can be guided either by an independent test set, or a randomized $t$-test of the equality of predictions from each component (van der Voet, 1994). This $t$-test is included in the C2 software, and is used here.

As WA-PLS incorporates variation along subsequent ordination axes into the model, it is important to consider the extent to which variance in assemblages along these axes carry a signal of the target environmental gradient. As explored above, the second axis of the SH-311 dataset is most closely correlated to productivity and proximity to shore, which although passively correlated to SST in the open ocean, is unlikely to be able to contribute additional detail to that extracted from analysis of the first axis only. Thus, in 
some locations, inclusion of additional components is expected to simply increase the noise. WA and WA-PLS analysis was undertaken using C2 software 1.4.2 (Juggins, 2005).

\subsubsection{Modern Analogue Technique}

The key assumption of the MAT is that identical biological assemblages should reflect identical abiotic and biotic conditions (de Vernal and Guiot, 2007). In the MAT, a dissimilarity score is derived between each analogue sample and the fossil assemblage, and the average characteristics of the most similar analogues are used to obtain the reconstructed environmental parameter (Hutson, 1980).

Four dissimilarity coefficients were tested: Chord, Euclidean, Canberra, and Chi-squared. Although performance varied little between them, Chord was retained as it was slightly superior. The Chord distance has also been found most successful by other workers (Hutson, 1980; de Vernal et al., 2005; Guiot and de Vernal, 2007; Crundwell et al., 2008; Hayward et al., 2011; 2012).

A decision is required about the number of analogue samples used. We fixed the number of analogues at five, after trials indicated this produced optimal results in modern calibrations across the entire $\mathrm{SH}-311$ dataset. This approach of setting the number of analogues a priori is often employed, with between 4 and 12 analogues frequently selected, depending on the size of the training set (Barrows and Juggins, 2005; Kucera et al., 2005; Crundwell et al., 2008; Marret et al., 2008; Hayward et al., $2008 ; 2012)$.

However, performance improvement is possible by selecting the optimal number of analogues for each sample, as some samples have fewer good analogues available than others.

Although discarding all samples beyond a set dissimilarity value has intuitive appeal, this has an uneven effect along a SST gradient, because dissimilarity scores are a function of diversity, which varies with SST (Waelbroeck et al., 1998 and Chapter 2, Figure 2.4). One solution is to keep adding analogue samples until a large increase in dissimilarity 
score between samples is observed (Waelbroeck et al., 1998; Barrows et al., 2000; Simpson, 2007). This approach was explored for the SH-311 training set. While there are small improvements in modern cross validation, we concluded the additional complexity does not outweigh the benefits, although careful inspection of all analogues is required when no analogue situations are suspected or reconstructions are near the edges of the training set gradient.

Two key weaknesses of the MAT (and ANN) method are the production of a result even in the case of 1) multi-analogue situations, where similar assemblages are found across a range of environments, and 2) non-analogue situations, where an assemblage and corresponding environment is not included in the training set (Birks et al., 2010). In fossil samples, possible multi-analogue situations are identified where there is a large temperature range across the analogues that have been selected.

Typically, high dissimilarity values are used to identify non analogue situations (e.g., Gersonde et al., 2005; Sikes et al., 2009), although the cut-off value to a 'no analogue' situation remains an arbitrary decision. Recent MAT reconstructions based on dinocysts (de Vernal et al., 2005; Marret et al., 2008) have used a three-point "reliability scale". In the scale, threshold levels were established using various proportions of the mean dissimilarity of the entire training set. There is value in a scale such as this instead of an arbitrary cutoff value. Conceptually, however, there is little justification in using the mean dissimilarity of the entire training set, as this number will be heavily influenced by the frequency distribution of training set samples along the environmental gradient. Instead, we explored the possibility of exploiting the expected relationship between dissimilarity and model performance, where a dissimilarity cut off value could be selected that is equal to some function of the combined dissimilarity values of samples with residuals less than the root mean square error of prediction (RMSEP).

Intriguingly, however, there is no clear relationship in the SH-311 training set between the dissimilarity value of the nearest analogue and residual value $\left(r^{2}=0.03\right)$ (Figure 4.4). Although bigger residuals are (broadly) associated with larger dissimilarity scores at the 
Figure 4.4. Results of a leave-one-out cross validation of the SH-311 database using a MAT model. Sample residuals are plotted against SST (black dots), overlain by the squared chord dissimilarity to the nearest sample (colour scale), which is contoured using an inverse distance weighting algorithm from the Past Software. The figure shows that while there is some trend towards higher dissimilarity scores with poorer model performance (i.e., higher residuals), there is also a trend of higher dissimilarity scores towards the centre of the SST gradient.

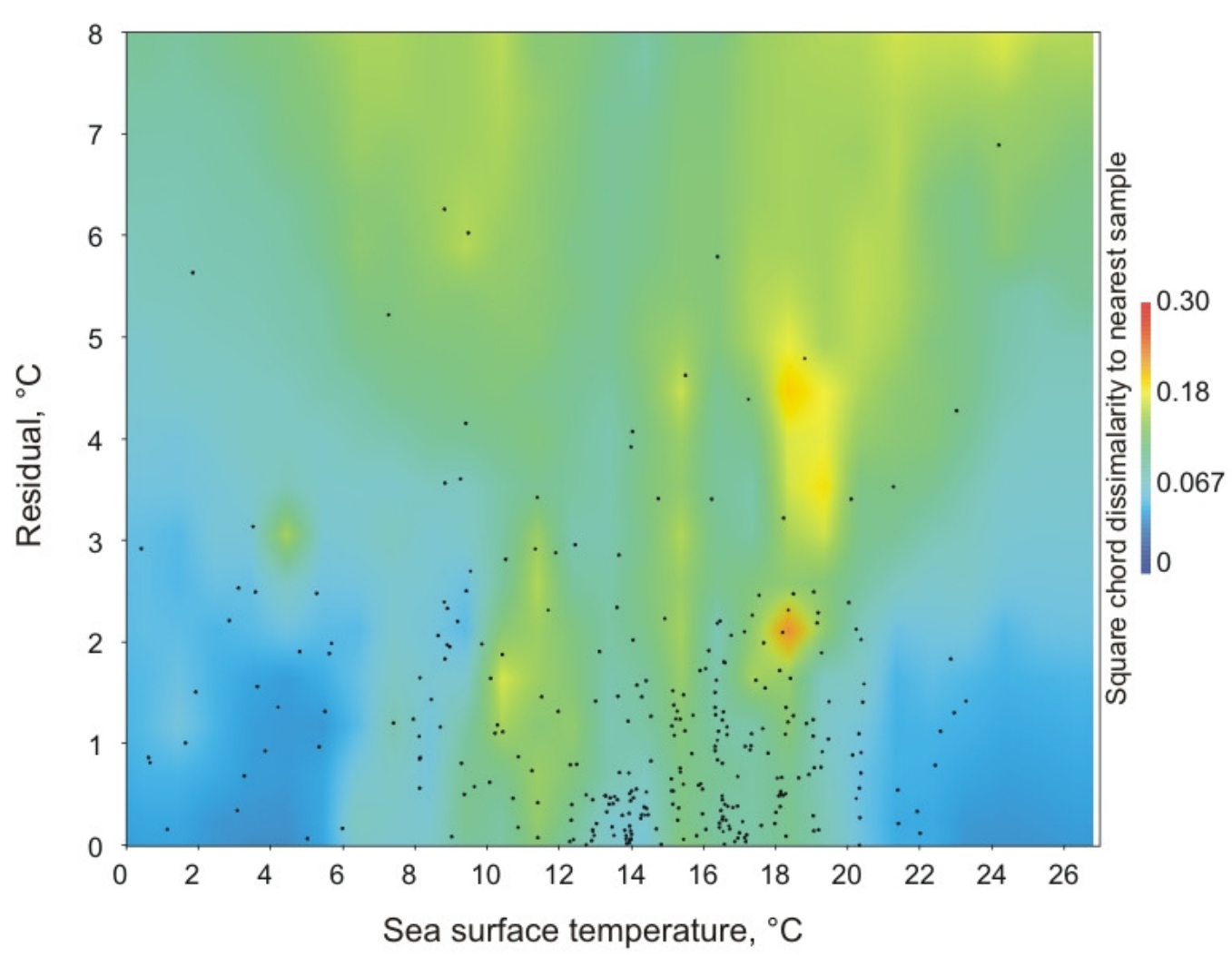

tails of the SST gradient, between $10^{\circ} \mathrm{C}$ and $20^{\circ} \mathrm{C}$ there is no systematic relationship between dissimilarity score and model performance. This observation is apparently not a unique feature of this dinocyst training set, as a similar structure was also observed in the Southern Hemisphere foraminifera training set explored in Appendix 4.2. Other features of residuals have been explored by Kucera et al. (2005). They observed that large standard deviations of the SST of selected analogues generally corresponded to large residuals, but the scatter in this relationship precludes this as a general filter to exclude poor reconstructions.

In the absence of any useful relationship between model performance and dissimilarity score in the modern environment, we can still use dissimilarity scores as a flag for fossil 
samples that have no resemblance to modern assemblages. This is essentially using the same criteria as de Vernal et al. (2005), but without differentiating the quality of reconstruction within the range of dissimilarities encountered in the modern training set. Fossil samples where the dissimilarity score to the nearest sample is greater than that encountered in the modern dataset are flagged as non-analogue samples (Chapters $5-6)$.

As a similar test for poor analogues is not possible using ANN models, this scale is also used to flag possible non-analogue samples in ANN reconstructions.

A second tool explored here to identify fossil samples which may be outside the range of the modern dataset is inspection of a DCA biplot of all samples. This is tested and applied in Section 4.11.2. It is a similar approach to the exploratory tool of plotting variation around single DCA ordination axes through a time series (e.g. Radi and de Vernal, 2008; Bonnet et al., 2010).

MAT calculations were performed both in $r$ using code applied in Guiot and de Vernal (2007), and in C2 (Juggins, 1995).

\subsubsection{Artificial Neural Networks}

An ANN develops algorithms that reproduce a target environmental parameter through iterative review and correction of the function of multiple (typically 2-20) non-linear neurons over multiple repetitions (typically 500-3000 epochs) aimed at minimizing root mean square error (RMSE) (Malmgren and Nordlund, 1997; Malmgren et al., 2001).

ANNs were trained using the program Tiberius (www.tiberius.biz). This software contains a single hidden layer, with one fixed linear neuron, and variable numbers of non-linear neurons containing tan-h functions. Optimal training was achieved using 10 non-linear neurons. The training regime followed Hayes et al. (2005) and Kucera et al (2005): the SH-311 and NZ-98 datasets were randomly split, with $70 \%$ allocated to a training set, and the remaining $30 \%$ used to test the model. The splitting procedure was repeated 10 times to allow for an estimate of the variability in prediction error derived 
from heterogeneity within the dataset. For each split, the software was allowed to train 5 times. Each training was stopped when the root mean squared error (RMSE - defined below) of the test set ceased to improve for 100 epochs (this typically occurred after 12000 epochs, using a software-specific 'training rate' of 0.001). The solution with the lowest RMSE for the test-set of each set of 5 training runs was retained. The best solution for each of the 10 training runs is applied to a fossil assemblage and the average and range of solutions presented.

\subsection{Performance measurement}

\begin{tabular}{|ll|}
\hline Requirement 6 & Reliable and realistic numerical estimation of errors of prediction \\
Assumption $f$ & Prediction errors are estimated on statistically independent test \\
& sets
\end{tabular}

\subsubsection{Introduction}

The development of a transfer function is an optimization of calibration errors and prediction errors. The calibration error describes the reconstructive power of the target environmental parameter within the calibration data set, while the prediction (or validation) error is an estimate of how well the transfer function performs when applied to a dataset different from its calibration dataset (Kucera et al., 2005; Guiot and de Vernal, 2007). Assessment of realistic prediction error is a critical aspect of transfer function design, without which true climatic variation cannot be separated from (frequently noisy) fossil data, and the relative performance of various models and training sets cannot be evaluated.

\subsubsection{Measurement statistics}

Two commonly used measures of calibration error, that are applied during validation of models in this chapter, include 1) the correlation or coefficient of determination between the observed and predicted variable ( $r$, or more commonly $r^{2}$, usually calculated using Pearson's product moment correlation), and 2) the root mean square error (RMSE), which is the square root of the average of the squared residuals (Birks, 
1995). As the distribution of residuals (the actual minus predicted value) is nonparametric, statistics of normal distributions are not appropriate: but in practice, the RMSE statistic describes the equivalent error of about one standard deviation.

A third statistic commonly applied is the mean and maximum bias, which is the mean of the largest residual value of each 10th of the environmental gradient, and the maximum residual value of the entire training set, respectively (ter Braak and Juggins, 1993). Finally, linear regression, or simple visual inspection, of residuals along the environmental gradient is a useful method to check for systematic biases in estimation (Kucera et al., 2005).

\subsubsection{Assessing prediction error}

Following calibration of the transfer function, assessment of its predictive power requires some form of cross validation or split-sampling to test the model, to derive prediction errors, frequently measured by the root mean square error of prediction (RMSEP) (Birks, 1995). As environmental information is required for the samples that are used to test the model, they must be taken from the pool of modern samples, or from a well constrained sediment core deposited during the time covered by instrumental records (Malmgren et al., 2001). Due to the time and expense required to generate modern samples, routines have been developed to conduct cross validations that do not require partition of the calibration set. The simplest of these is a 'leave-oneout' cross validation, where the model is run multiple times with one sample omitted from the calibration set, and solved for, in each model run (ter Braak and Juggins, 1993). This technique is used extensively in paleoclimate research (e.g., Brooks et al., 2001; Kurcea et al., 2005; Hayes et al., 2005), although Telford et al. (2004) demonstrated this approach underestimates model errors when compared to a random split-sampling.

Where a modern calibration set is large enough, the samples should be split into training and test sets, which provides the most robust test of the model's predictive power outside its training set, and is therefore the best measure for inter-model comparison (ter Braak and van Dam, 1989; Birks, 1995; Telford et al., 2004; Guiot and de 
Vernal, 2007). However, even in large training sets ( $n>400$ samples) many workers choose to assess prediction errors using cross validation techniques rather than splitsampling (e.g., Hayes et al., 2005; Kucera et al., 2005; Xu et al., 2010; Lu et al., 2011). One example of a split-sampling technique is $n$-fold cross validation, where the calibration set is randomly divided into training and test sets numerous times (typically 5-10), and the average of the tests used to obtain error estimates (Barrows and Juggins, 2005). While this technique is conceptually a more rigorous test of predictive power due to the greater proportion of excluded samples, in large training sets it tends to produce little change in performance statistics over leave-one-out methods.

Recent attention to the assumptions of cross validation techniques and the methods employed in random split-sampling has identified deficiencies in these methods as they are commonly employed (Telford et al., 2004; Telford, 2006; Telford and Birks, 2009, 2011b). The criticisms are principally based on the observation that the spatial autocorrelation in training sets violates the assumption of statistical independence between the training and test samples (Burrough, 1995). Spatial autocorrelation is the tendency of neighbouring samples to be more similar than randomly selected samples. While this structure of proximal similarity is intuitively desirable for a quantitative paleoreconstruction, it has the effect of under-estimating prediction errors during cross validation compared to prediction errors assessed using spatially-independent test sets. In other words, a split-sampling routine that fails to consider the spatial relationship between the training and test sets does not provide a realistic demonstration of a model's ability to extrapolate beyond its training data.

A 'worst-case' scenario was demonstrated by Telford et al. (2004), where artificial data with no ecological relevance, but with spatially auto-correlated distribution on various scales, produced apparently robust cross validation statistics. The potential effects are non-trivial: trials on five different biological datasets (including foraminifera, dinocysts, lake diatoms, pollen) suggest that model performance may be overestimated by up to a factor of three compared to testing against an artificial, but spatially independent, test 
set (Telford and Birks, 2009). That work found the effects to be particularly pronounced in models with no assumption of underlying structure in the species distribution along the target environmental gradient, such as the modern analogue technique (MAT) and artificial neural networks (ANN). In a similar manner, the effect should become more severe in a weighted averaging with partial least squares (WA-PLS) model as additional components (axes) are incorporated (Telford and Birks, 2005; 2011b).

Some consideration is given here to the presence and effect of spatial autocorrelation in Southern Hemisphere faunal training sets as this topic has received little attention to date. Experiments on the SH-311 and NZ-98 dinocyst datasets, and a 1200 sample Southern Hemisphere foraminifera coretop training set (Crundwell et al., 2008; Hayward et al., 2012), indicates that spatial autocorrelation does improve apparent model performance compared to spatially independent test sets. Although we find the effects are difficult to isolate and quantify using "real" data, we conclude that the effects are likely not as severe as the three-fold reduction in performance cited by Telford and Birks (2009).

A description of the spatial autocorrelation experiments is included in Appendix 4.1, and are summarised below:

1. The presence of spatial autocorrelation in the NZ-98 samples, sufficient to have an impact on transfer function performance, was established by monitoring the performance of a MAT model as analogues were excluded based on increasing geographic distance between the modern samples.

2. The average distance over which samples were spatially autocorrelated was assessed by the range of an empirical semi-variogram (a plot of average variance between samples against distance between the samples). This is approximately $1000-1500 \mathrm{~km}$ for both the SH-311 dinocyst and SH-1200 sample foraminifera training set. 
3. An experiment was designed to document the effects of spatial autocorrelation on different transfer function models. First, the SH-311 training set was systematically pruned to increase the distance between samples, and the performance compared to an equivalent random reduction in the number of samples. Performance of the MAT and ANN models decreased faster than a WAPLS model as training set sample spacing become greater. However, this type of pruning from the 311 sample dinocyst training set was recognised to result in training sets that were too small to make conclusions about the relative performance when reduced to $1000 \mathrm{~km}$ inter-sample distances (average 30 samples).

4. This experiment was duplicated on the 1200-sample Southern Hemisphere foraminifera coretop dataset, again comparing MAT, ANN, and WA-PLS models. Generally, the results from the SH-311 experiment were confirmed when applied to the larger foraminifera-dataset; MAT and ANN model performance decreased more than WA-PLS models when validated on spatially independent test sets.

The key conclusion from these exercises is that the ANN and MAT models do appear to derive a proportion of their performance from their ability to exploit autocorrelative properties of training sets. The particular consequence of this is very poor performance when faced with "unknown" assemblages. In such situations, our trials suggest WA-PLS model estimates are more likely to be reliable.

\subsubsection{Prediction error routines}

Two routines are adopted to test the predictive power for each of the models explored in this chapter: a cross-validation routine and a split-sampling routine using spatially independent test sets.

For the cross-validation routine, WA, WA-PLS and MAT are cross-validated by a jackknifed leave-one out cross validation using the C2 programme (Juggins, 2005). The equivalent cross-validation errors in the ANN model are calculated by the mean of 10 
training runs where the training set is randomly divided 70:30, with the larger split used to train the model until performance (RMSE and $r^{2}$ ) in the smaller test set is optimized. These cross validation routines are reasonably standard so allow comparison of apparent performance against that of other datasets, although with the caveats discussed above (e.g., Malmgren et al., 2001; Hayes et al., 2005; Kucera et al., 2005; Xu et al., 2010; Lu et al., 2011).

The NZ-98 dataset is too small for meaningful split-sampling and sample spacing along the environmental gradient too irregular. Moreover, having completed the exercise described below, we also concluded the SH-311 dataset is too small, and samples inappropriately distributed to employ a splitting routine. However, we explored the split-sampling routine described below. Two splits were explored where a test set is spatially isolated from the training sets by the $c a .1000 \mathrm{~km}$ range determined by semivariograms in Appendix 4.1. As the purpose of the compilation in this thesis is to reconstruct Quaternary environments of the New Zealand region, a 68-sample group was isolated from the SH-311 training set (NZ-68), which are over $1000 \mathrm{~km}$ from the nearest samples on the east coast of Australia (Figure 4.5A). The remaining 243 samples were used for training and cross validation of the models: the repetitions of the $70: 30$ split required to train the ANN used only these 243 samples, while a leave-one-out cross validation was run on the 243 sample training set before testing on the NZ-68 independent test set. Apart from the New Zealand region, the only significant concentration of samples with adequate distribution along a temperature gradient, and for which adequate analogues for the test set appear in the training set is the SW Atlantic. Therefore, a second spatially independent test set of 54 samples was split from the SH-311 training set in this region (WATL-54) to further explore the predictive power of the models beyond the geographies in which they were trained (Figure 4.5B). In this case, 7 samples from the central Atlantic were discarded to preserve the spatial independence of the test set, leaving 250 samples for model training. These two training sets cover an environmental range of $20^{\circ} \mathrm{C}$ and $27^{\circ} \mathrm{C}$ respectively, although samples are distributed unevenly along this gradient. 

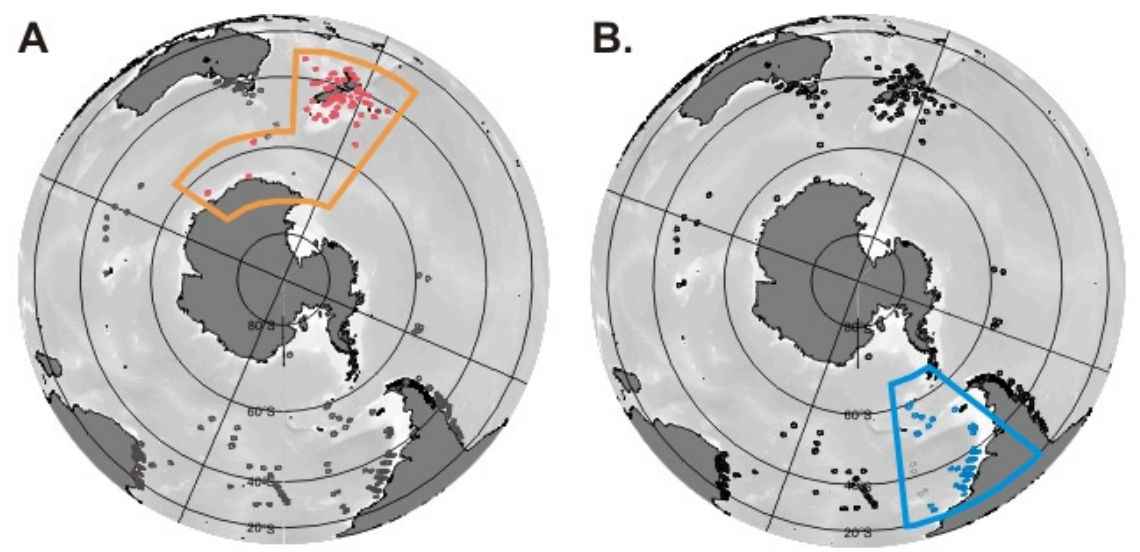

Figure 4.5. Samples used as spatially independent test sets for the SH-311 training set. A: NZ68, B: WATL54

\subsection{Transfer function performance}

\subsubsection{Introduction}

Of the four methods explored, the ANN model had the best performance statistics when assessed using a leave-one-out cross validation routine (Table 4.1, Figures 4.6 - 4.8). The WA model performed the most poorly, while WA-PLS and MAT models were similar. For all models, the NZ-98 part of the SH-311 dataset performed better than the entire SH-311 dataset. The best performance was observed towards the middle section of each environmental gradient, and significant performance reduction was observed at the tails.

All models performed more poorly when assessed using the split-sampling routines (Figure 4.9) compared to the leave-one-out equivalents. In all models, the window of lowest RMSEP remains in the center of the gradient, but all models featured a systematic bias in residuals, resulting in under- and over-estimation of SST at the warmest and coldest parts of the gradient, respectively. As alluded to above, after further consideration of the split-sampling method employed, this systematic bias is considered to be an artifact of a poorly designed test set. The ANN and WA-PLS models are the best of the four tested for SST reconstruction using Southern Hemisphere dinocysts. Although the regional training set performed better than the $\mathrm{SH}-311$ dataset, 
Table 4.1. Performance statistics of the SH-311 and NZ-98 datasets under various split sampling and cross validation routines.

\begin{tabular}{|c|c|c|c|c|c|c|c|}
\hline & \multicolumn{4}{|c|}{ Leave one out cross validation } & & \multicolumn{2}{|c|}{ SH311 split sampling } \\
\hline & NZ-98 & $\mathrm{SH}-311$ & NZ-68 & WATL-54 & & NZ-68 & WATL-54 \\
\hline \multicolumn{8}{|c|}{ Weighted Averaging } \\
\hline RMSE $_{\text {jack }}$ & 1.67 & 2.93 & 2.30 & 3.44 & RMSEP & 2.96 & 4.06 \\
\hline$r_{\text {jack }}^{2}$ & 0.68 & 0.69 & 0.71 & 0.80 & $r^{2}$ & 0.66 & 0.75 \\
\hline Max bias jack & 3.29 & 9.32 & 3.34 & 6.3 & Max bias & 7.30 & 6.10 \\
\hline Average biasjack & 0.01 & 0.02 & 0.07 & 0.03 & Average bias & 1.40 & -1.09 \\
\hline \multicolumn{8}{|c|}{ Weighted Averaging with Partial Least Squares } \\
\hline RMSE $_{\text {jack }}$ & 1.67 & 2.29 & 1.86 & 2.40 & RMSEP & 2.23 & 3.32 \\
\hline$r_{\text {jack }}^{2}$ & 0.68 & 0.81 & 0.81 & 0.90 & $r^{2}$ & 0.74 & 0.84 \\
\hline \# components & 1 & 2 & 2 & 2 & \# components & 3 & 2 \\
\hline Max bias $_{\text {jack }}$ & 3.29 & 2.82 & 1.7 & 3.15 & Max bias & 7.40 & 6.40 \\
\hline Average bias ack & 0.01 & 0.02 & -0.04 & -0.03 & Average bias & 0.45 & -0.64 \\
\hline \multicolumn{8}{|c|}{ Modern Analogue Technique } \\
\hline RMSE, ${ }^{\circ} \mathrm{C}$ & 1.63 & 1.88 & 1.98 & 2.35 & RMSEP & 3.10 & 3.56 \\
\hline$r^{2}$ & 0.70 & 0.86 & 0.80 & 0.91 & $r^{2}$ & 0.53 & 0.84 \\
\hline Max bias & 3.31 & 1.91 & 3.82 & 2.90 & Max bias & 5.70 & 5.80 \\
\hline Average bias & -0.11 & 0.29 & -0.07 & 0.12 & Average bias & 1.10 & -1.40 \\
\hline \multicolumn{8}{|c|}{ Artificial Neural Network } \\
\hline RMSE, ${ }^{\circ} \mathrm{C}$ & 1.14 & 1.47 & 1.69 & 1.57 & RMSEP & 2.65 & 4.19 \\
\hline$r^{2}$ & 0.86 & 0.92 & 0.92 & 0.89 & $r^{2}$ & 0.62 & 0.75 \\
\hline Max bias & 1.69 & 1.91 & - & & Max bias & 4.90 & 8.30 \\
\hline Average bias & 0.06 & 0.15 & - & & Average bias & 1.20 & -0.40 \\
\hline
\end{tabular}

when the performance decline at the tails is considered, the NZ-98 dataset does not cover a sufficiently large SST gradient to be useful for reconstruction on orbital timescales in most settings.

\subsubsection{Leave-one-out prediction error}

Of the four models, the ANN performed best in each of the four high-level statistics examined, with an average RMSE of $1.47^{\circ} \mathrm{C}$ across the entire Southern Hemisphere, reduced to $1.14^{\circ} \mathrm{C}$ when only the NZ-98 training set is considered, and had the lowest maximum and average bias, and highest $r^{2}$ correlation (Table 4.1). The RMSE of the next strongest model, the MAT, was $0.4^{\circ} \mathrm{C}$ higher than the ANN model, while the poorest model, WA, had a RMSE $E_{\text {jack }}$ twice that of the ANN, of $2.93^{\circ} \mathrm{C}$ across the entire $\mathrm{SH}-311$ dataset. For the NZ-98 dataset, the WA-PLS model found no advantage in additional components from further axes, so performs the same as a WA model. For the SH-311 training set, WA-PLS showed significant performance improvement over the WA model by applying two components (Table 4.1). 
Figure 4.6. Leave-one-out cross validation results of the NZ-98 training set (orange) and the SH-311 training set (green). RMSE values are calculated for the entire training set (horizontal lines) and for every 10th of the environmental gradient (line graphs). A: WA model, B: WA-PLS, C: MAT, D: ANN. Histograms in panels B and D show the distribution of samples against SST for the NZ-98 dataset (orange) and SH-311 dataset (green).
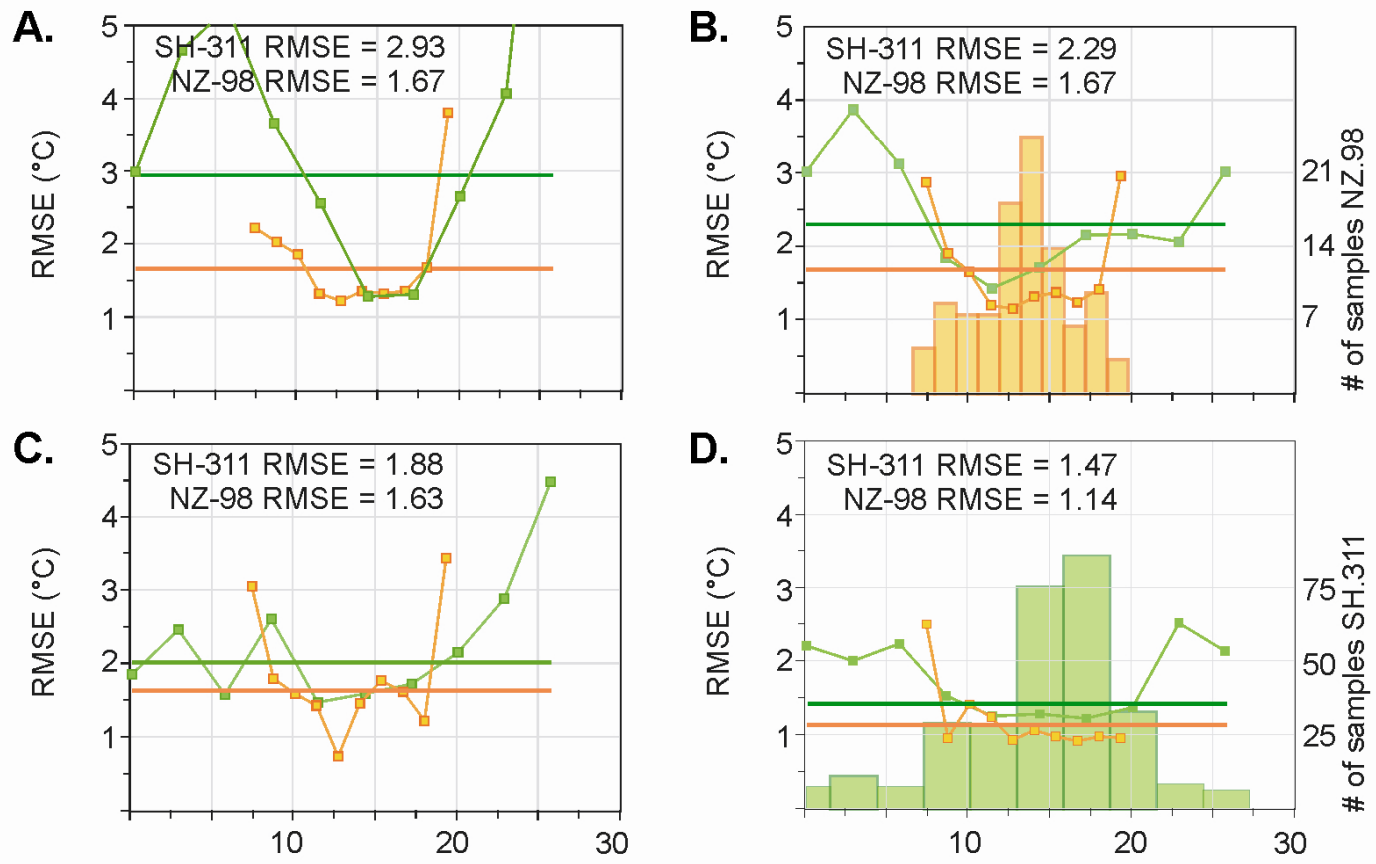

Measured SST $\left({ }^{\circ} \mathrm{C}\right)$

Measured SST $\left({ }^{\circ} \mathrm{C}\right)$

These average RMSE statistics disguise a window of optimum performance in each model at the center of the gradient, where errors are generally well below the average, with the obvious correlative that performance at the tails is poorer than the average (Figure 4.6). This window of optimum performance is longest for the ANN model, where average RMSE for the SH-311 training set between $10^{\circ} \mathrm{C}-20^{\circ} \mathrm{C}$ was $\sim 1.2^{\circ} \mathrm{C}$. Performance reduction at the ends of the gradient is most marked in the WA model, but RMSE is generally above $3^{\circ} \mathrm{C}$ in the WA-PLS and MAT models for SST above $22^{\circ} \mathrm{C}$ and below $8^{\circ} \mathrm{C}$.

Model performance shows a marked correlation to sampling density along the SST gradient, particularly for the WA model. This effect on WA and MAT model performance has been explored using artificial data (Telford and Birks, 2011b), where it was demonstrated that MAT and WA performance is inversely proportional to sample 
density. While Birks et al. (2010) speculate that ANN models should be susceptible in a similar way to low sampling density along the environmental gradient, Figure 4.6 shows that although there is noticeable reduction of performance at the tails in the ANN model, this reduction is not proportional to sampling density to the same degree as in the WA and MAT models. Rather, performance appears to reduce when sample numbers in a given section of the gradient fall below a critical threshold; 10 samples per $10^{\text {th }}$ of the environmental gradient in the case of the SH-311 training set.

Although total bias in the WA models for both the SH-311 and NZ-98 models is very low (Table 4.1), this averaging disguises a pervasive bias in the residuals under leave-oneout cross validation (Figures 4.7 - 4.8): the model always under-estimate SST when measured temperature is warmer than $17^{\circ} \mathrm{C}$, and has a strong tendency to overestimate below $10^{\circ} \mathrm{C}$. This systematic bias is present, although less marked, in the WA-PLS and MAT models using the SH-311 training set, and is virtually absent from the ANN model (Figure 4.8). However, this bias is a more obvious feature of all four models using the NZ-98 training set (Figure 4.7).

The best dinocyst models explored here have RMSE statistics that are within the range of those presented for transfer functions in the SW Pacific using foraminifera, which is the group most commonly applied to paleoenvironmental reconstructions in the region (Barrows et al., 2005; Kucera et al., 2005; Crundwell et al., 2008; Hayward et al., 2008; 2012). Kucera et al. (2005) reported a 1.2 - $1.5^{\circ} \mathrm{C}$ RMSE for SW Pacific core top assemblages at the latitude of New Zealand, while Kolodziej (2010), using the same MAT and ANN models and training sets applied in Crundwell et al., (2008), and Hayward et al. (2009, 2011), reported RMSE errors of $1.21^{\circ} \mathrm{C}$ and $1.01^{\circ} \mathrm{C}$ for MAT and ANN models, respectively. Barrows et al. (2005) reports a five-fold random split-sampling cross validation error of $0.87^{\circ} \mathrm{C}$ for ANN models, and a $0.77^{\circ} \mathrm{C}$ RMSE when the average results of MAT, ANN and Revised Analogue Method models are considered. 

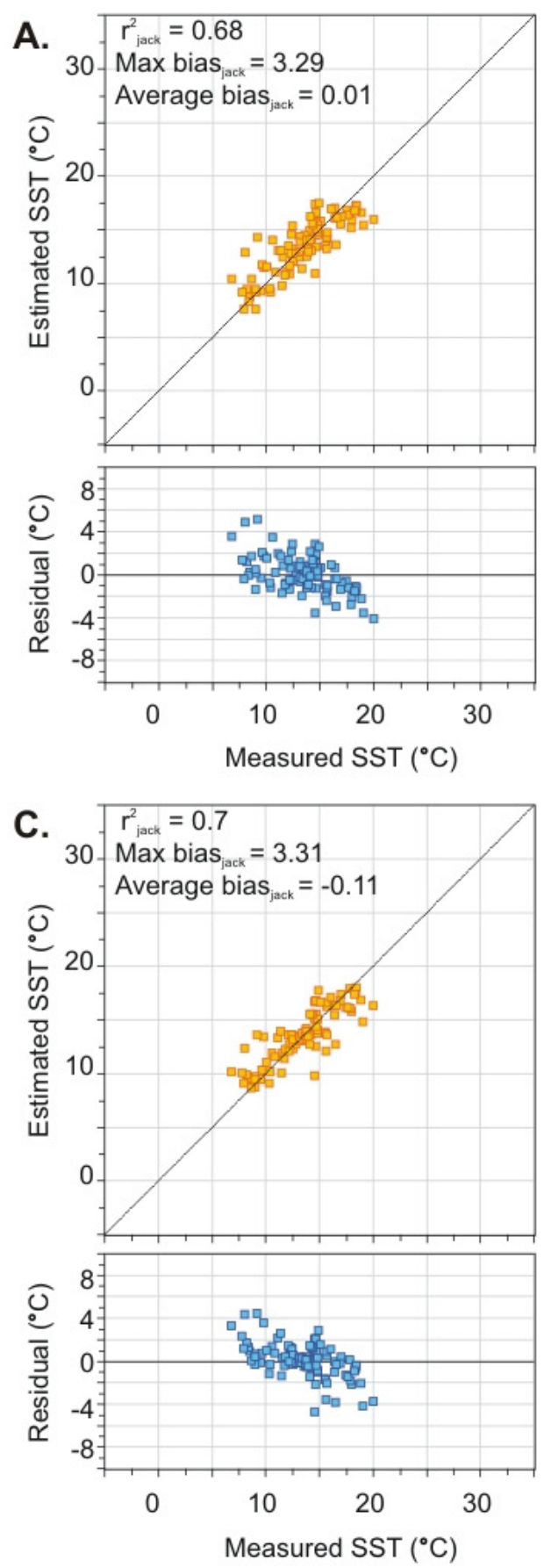
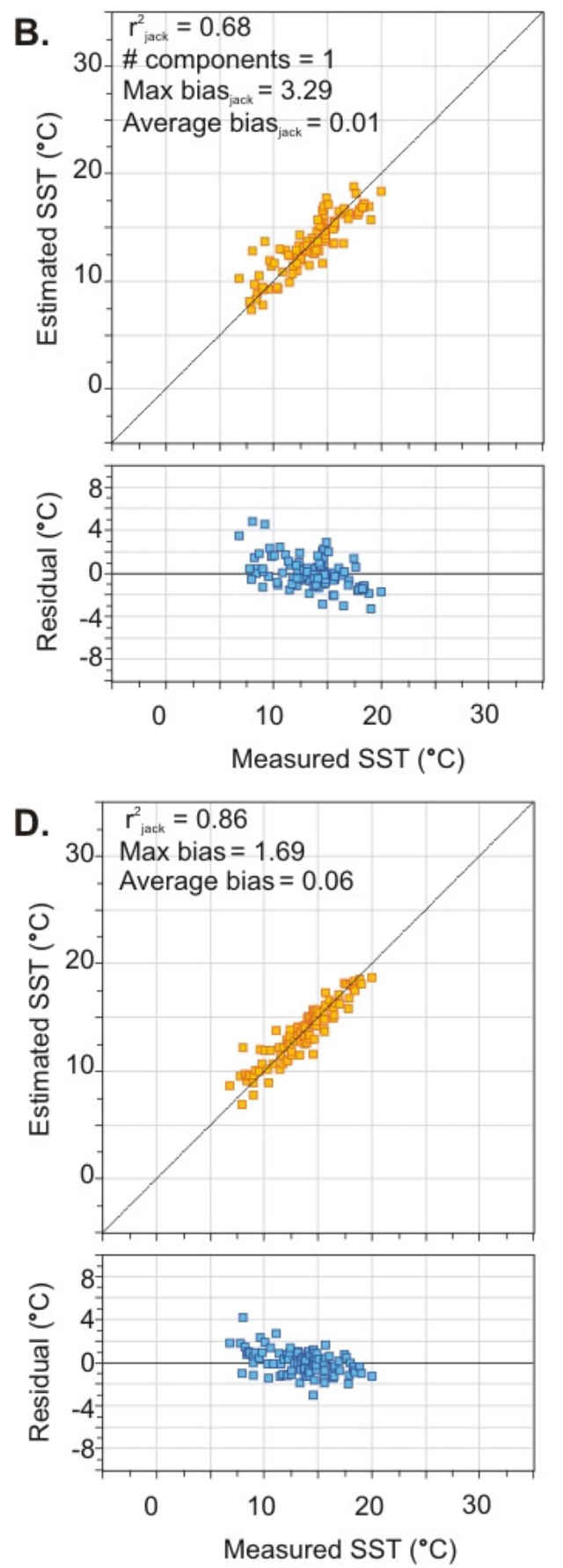

Figure 4.7. Leave-one-out cross validation results of the NZ-98 training set for four models: A: WA model, B: WA-PLS, C: MAT, D: ANN. Upper (orange) scatter chart for each model shows the estimated vs measured SST, lower scatter plot shows the residuals (measured minus estimate SST). 


\subsubsection{Split-sampling prediction error}

The performance errors resulting from the split-sampling routines are larger than leaveone-out cross validation for all four models. The reduction in performance is largest for the ANN models, where the RMSEP is twice that of the comparable leave-one-out errors. RMSEP of the WA and WA-PLS models is $~ 30 \%$ larger in split-sampling cross validation than leave-one-out, while the RMSEP for MAT is 50\% larger (Table 4.1).

As in the leave-one-out cross validation routine, a window of optimum performance is observed towards the center of the gradient (Figure 4.9). Performance is generally strongest between SSTs of $8^{\circ} \mathrm{C}$ and $20^{\circ} \mathrm{C}$, but narrower windows were observed in the WA model for the NZ68 test set, and for the ANN model for the WATL test set.

A significant feature in all four models is the addition of a systematic bias in the test set residuals (Figure 4.9, middle plot). As in the leave-one-out cross validation, this systematic bias is largest in the WA model, which leaves it with almost no predictive power between $8-20^{\circ} \mathrm{C}$. The bias in the other three models is particularly pronounced where SSTs exceed $18^{\circ} \mathrm{C}$, but is a feature of the residuals above $16.5^{\circ} \mathrm{C}$.

This systematic bias illustrates the importance in appropriate selection of test sets, which, if poorly designed, may provide an overly pessimistic view of transfer function performance. Initially, these test sets were selected to ensure there were adequate analogues to the test set in the training set, based on K-means cluster analysis of the training set (Chapter 2). However, a review of these analogues, plotted against SST, suggests that bias is inevitable. Two obvious examples of inappropriate test set selection resulting in systematic bias stand out. A significant feature of the warm end of the WATL-54 test set is assemblages that belong to "Cluster 7" in the k-means cluster analysis in Chapter 1 (Figures 2.15-2.17). Although theses samples have numerous similar samples in the training set that are located at a similar latitude on the other side of the Atlantic (Figure 2.3), the lower SST of these analogues would clearly lead to systematic underestimation of these samples (Figure 2.15). A similar situation exists in the NZ-68 test set. Many of the warmer samples in that test set belong to "Cluster 3" 

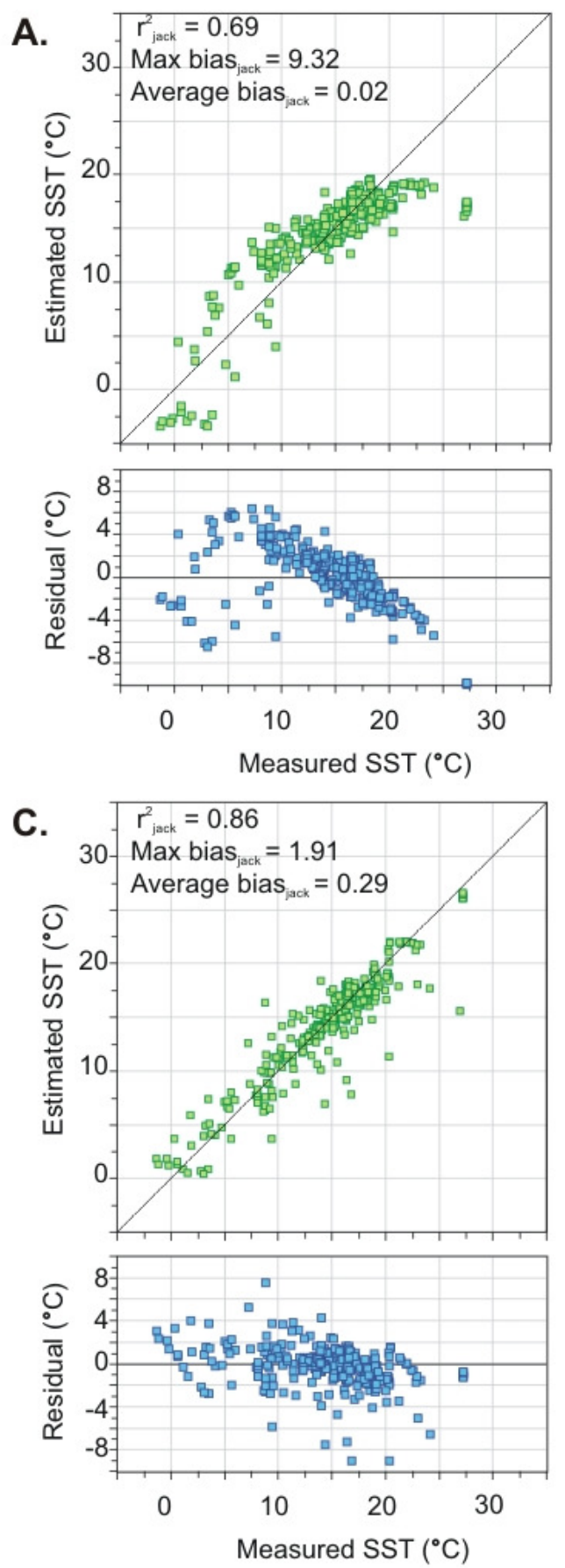
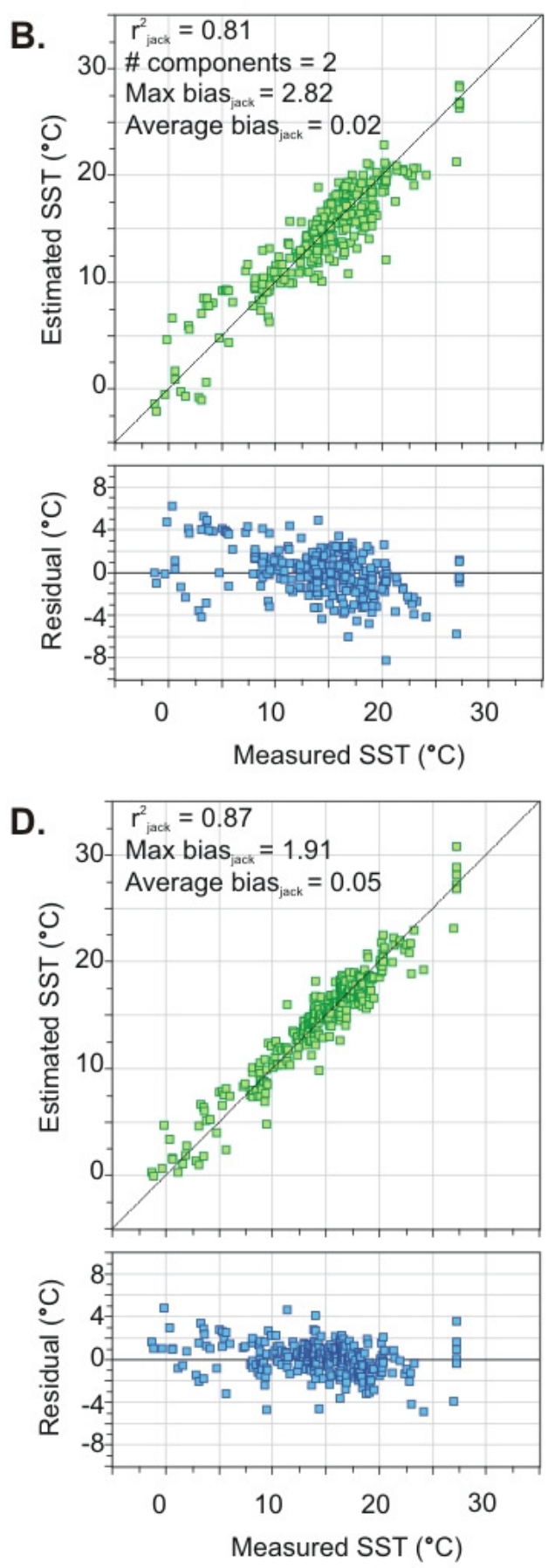

Figure 4.8. Leave-one-out cross validation results of the SH-311 training set for four models: A: WA model, B: WA-PLS, C: MAT, D: ANN. Upper (green) scatter chart for each model shows the estimated vs measured SST, lower scatter plot show the residuals (measured minus estimate SST). 
(Figure 2.13). Although similar assemblages are present, the nearest analogue samples in the training set are around South Australia, in waters over $4^{\circ} \mathrm{C}$ cooler than those of the test set, although in this example there are also a series of similar ("Cluster 3") samples in the South Atlantic (Figure 2.13) within the correct SST range that the transfer function models have clearly not used.

Thus, although there are analogues available for each sample in the test sets, in each case splitting the $\mathrm{SH}-311$ dataset has resulted in significant loss of information on taxonomic ranges along the SST gradient. Although the absolute RMSEP of the splitsampling routine appears to be an inadequate test of true prediction error, the relative performance of the different models remains highly informative. Where fossil assemblages outside the range of the modern training set are encountered, the WA-PLS model has significantly better power than the analogue based MAT or ANN models.

\subsubsection{Prediction error in other training sets}

Having concluded that the predictive errors of the SH-311 dinocyst training cannot be reliably assessed using split-sampling methods, the much larger Southern Hemisphere foraminifera training set was revisited. The purpose of this exercise was two-fold, (i) to further explore the effects of spatial autocorrelation on a training set that is large and (possibly) sufficiently balanced to withstand split-sampling without the same problems encountered in the $\mathrm{SH}-311$ dinocyst training set, and (ii) to better understand the errors associated with the foraminifera faunal SST proxy, as it is a contemporary proxy-record to the dinocyst paleo records generated in the current study.

The methods and results of this exploration are detailed in Appendix 4.2, and are summarised here.

1. Leave one-out cross validation established similar errors to those published using the same training set (Kolodziej, 2010).

2. Spilt-sampling routines, where test sets were spatially independent of the training sets, eroded model performance by a factor of $\sim 2$ for MAT and ANN 
models, $\sim 1.5$ for WA-PLS models, and did not change the performance of WA models.

3. Careful inspection revealed that even with a training set of this size, most of the test and training splits were poorly balanced taxonomically. This resulted in a systematic bias in the residuals that was similar to, but more subtle than, that encountered when split-sampling the SH-311 dinocyst training set. A 'balanced' spatially independent test set and training set was finally selected for the southern part of the SW Pacific. Then, performance reduction of the splitsampling routines compared to the leave-one-out cross validation was between a factor of 1.2 (WA-PLS) and ANN performance reduced by a factor of 1.8.

4. These experiments confirm the general observation (Telford and Birks, 2009, 2010, 2011a, 2011b) that WA and WA-PLS models have generally greater ability to extrapolate beyond their training sets. However, this experiment suggests that for a Southern Hemisphere foraminifera training set, the 'artificial' improvement in model performance due to spatial autocorrelation is at the lower end of the range suggested by Telford and Birks (2009), being about 40\%, or $0.5^{\circ} \mathrm{C}$ RMSEP in an ANN model.

In conclusion, we infer that the effects of spatial autocorrelation on transfer functions using marine micro-faunal or -floral training sets may be similar across all fossil groups that are sourced from the same region, and the assemblage distributions are influenced mostly by the same abiotic gradients. As biogeographic complexity increases, for example with the additional sea ice and salinity gradients seen in the high Arctic, so the effects of spatial autocorrelation in training set performance may become more pronounced, even towards the upper end of that suggested by Telford and Birks (2009). 


\section{Chapter 4}
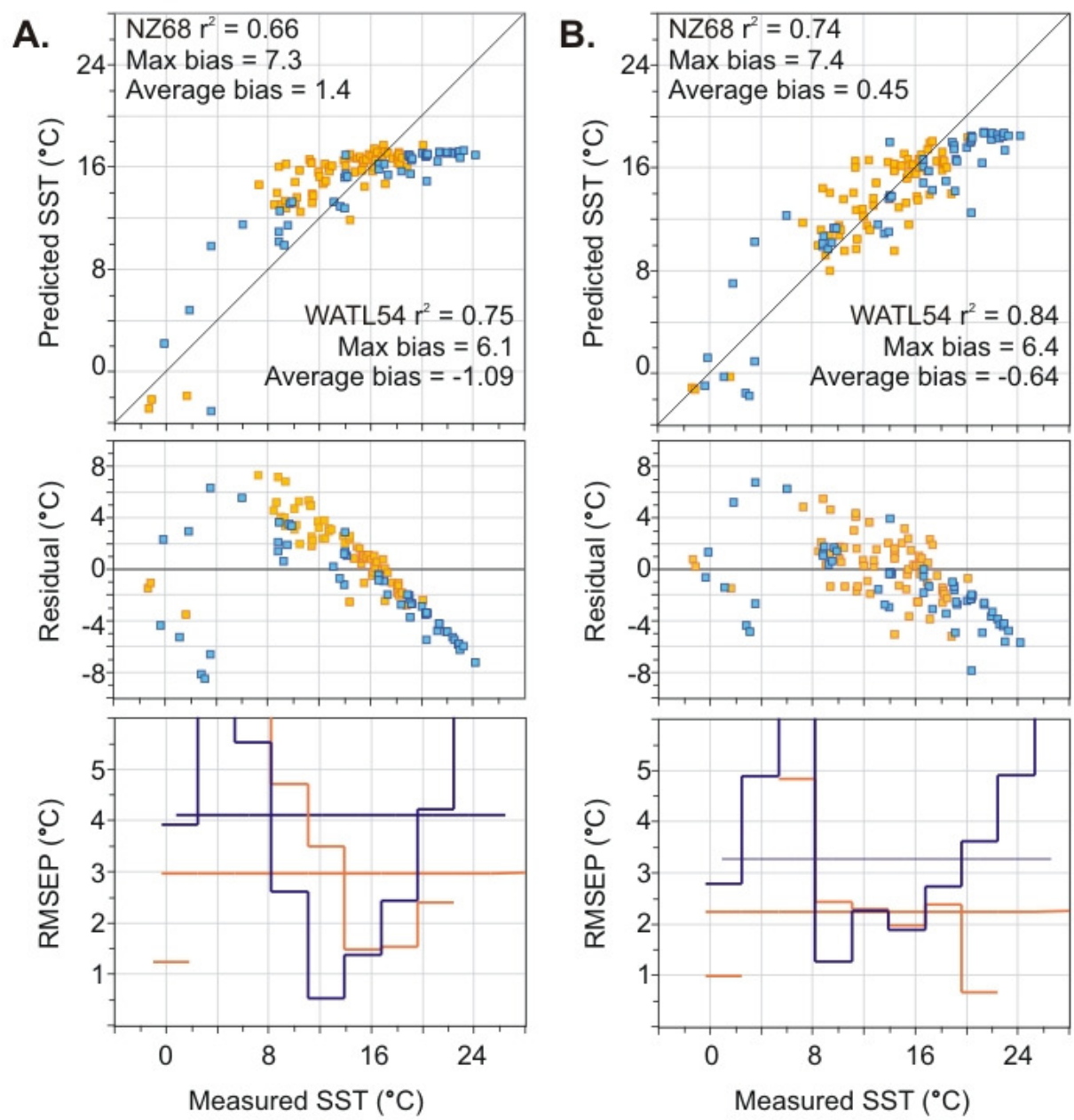

Figure 4.9. (Here and next page). Split-sampling cross validation results of the $\mathrm{SH}-311$ training set for four models: A: WA model, B: WA-PLS, C: MAT, D: ANN. Orange squares show results of NZ68 spatially independent test set, blue squares show results of WATL54 spatially independent test set. Upper scatter chart for each model shows the estimated vs measured SST, middle scatter plot show the residuals (measured minus estimated SST), while the lowest chart shows the average RMSEP (horizontal line) and RMSEP for each 10th of the environmental gradient of the training set. Breaks in that line denote no samples in the test set over that interval 

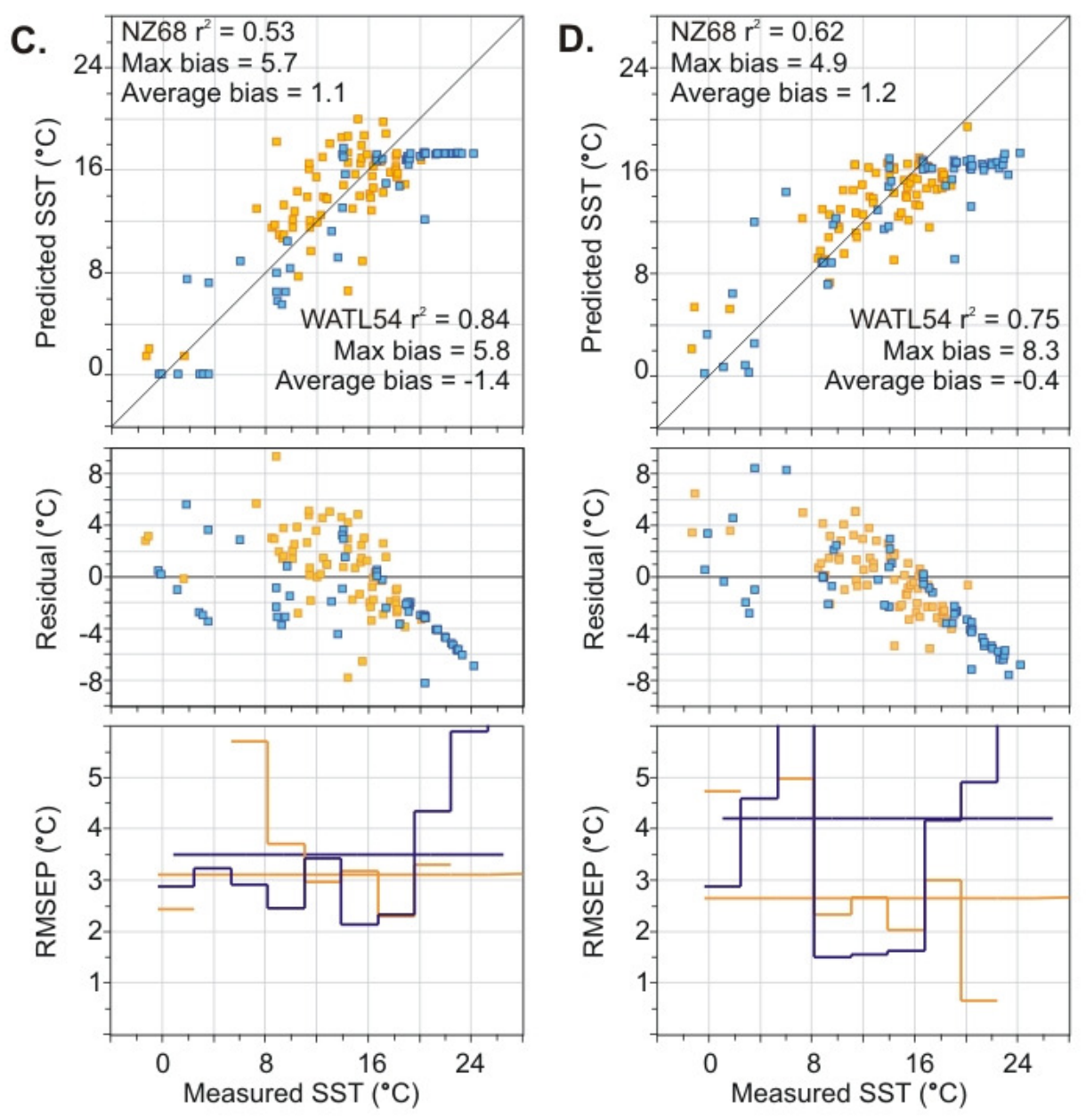

Figure 4.9. Continued

\subsection{Structure of residuals}

\subsubsection{Introduction}

Observation of spatial structure and taxonomic correlation of model residuals provides additional detail of model strengths and weakness than are available by assessing model performance along the SST gradient discussed above. While prediction errors in some regions are relatively uniform and also less than the model average, in other regions, the magnitude and sign of prediction error vary a lot over relatively short distances. Particular care is required when SST reconstructions are made in geographic regions of 
high variability in the residuals, as model skill may be significantly below the average. Model performance also varies across the seven dinocyst clusters identified in Chapter 2. Fossil assemblages that are similar to those of clusters that perform relatively poorly during cross validation may also result in less accurate paleo reconstructions.

\subsubsection{Spatial distribution of error}

The residuals around the New Zealand region are examined from the leave-one-out cross validation procedure of the SH-311 training set, using a gridding algorithm in Ocean Data View (Schlitzer, 2011). All model errors $<2^{\circ} \mathrm{C}$ are recoded to $0^{\circ} \mathrm{C}$ so the areas of most significant error are easily identifiable. Spatial distribution of residuals derived from split-sampling cross validations are not considered due to the systematic bias attributed to the poorly balanced test sets (Section 4.9), so the residuals of the leaveone-out cross validation are plotted (Figure 4.10).

The ANN model (Figure 4.10C) has the fewest samples with large errors.

All three models have patches where SST is underestimated: east of the North Island as far south as the Chatham Rise, and an area of overestimation in the waters off eastern South Island (Figure 4.10). The number of samples and the area affected by these systematic errors are much larger in the WA-PLS and MAT models compared to the ANN model. In the WA-PLS and MAT models, this has the effect of producing a maximum prediction error of $>5^{\circ} \mathrm{C}$ across the STF east of New Zealand. This range of prediction error is at least as large as the SST gradient across the STF (e.g. Chiswell, 2001). Another region to the east of New Zealand where SST is overestimated by the WA-PLS and MAT models is around the Campbell Plateau, south east of the South Island.

Prediction errors in the east Tasman Sea are fairly uniform for all three models, and are lowest in the ANN model. Both the WA-PLS and MAT models have a $>4^{\circ} \mathrm{C}$ total error between some coastal and oceanic samples off the West Coast of the South Island (Figure 4.10A, 4.10B). 
A.

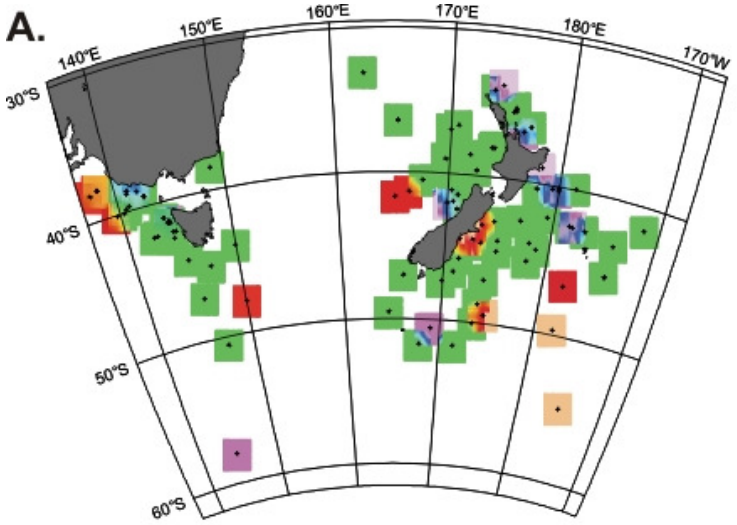

C.

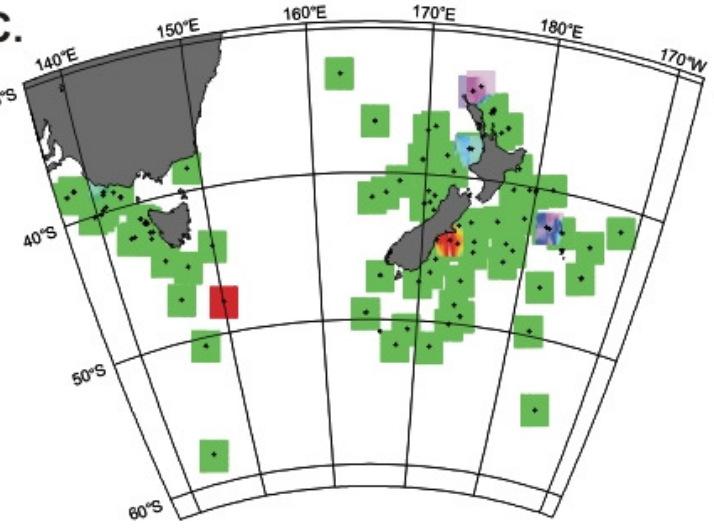

B.

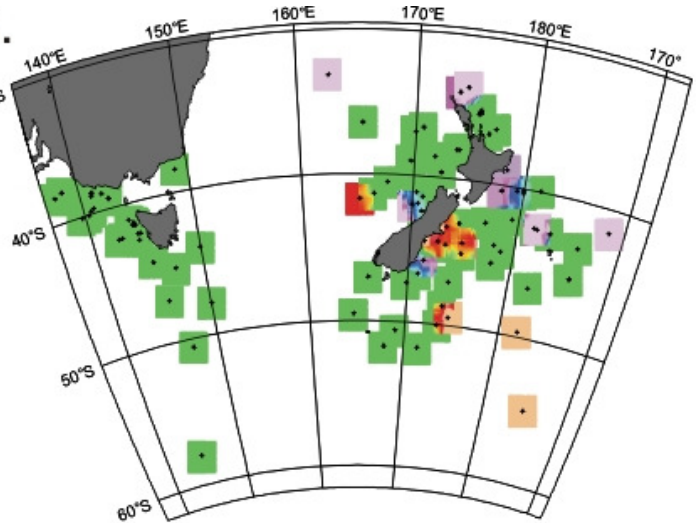

D.

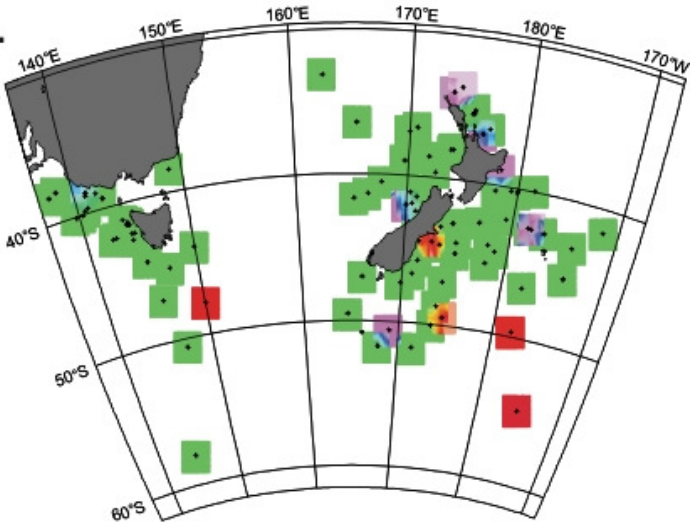

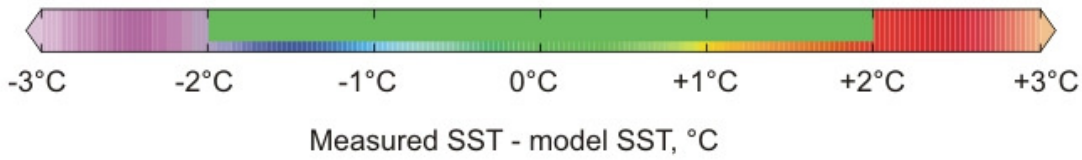

Figure 4.10. Residuals of the leave-one-out cross validation results of the $\mathrm{SH}-311$ training set for samples in the SW Pacific. A: WA-PLS model, B: MAT, C: ANN, D. Average of WA-PLs and ANN models. Residuals $<2^{\circ} \mathrm{C}$ have been re-coded to $0^{\circ} \mathrm{C}$ for ease of interpretation.

The MAT model has the most uniform errors in Bass Strait and south of Australia, while only a single sample in the ANN model has a prediction error of $>2^{\circ} \mathrm{C}$. In contrast, the WA-PLS model has limited success reconstructing the SST in Bass Strait.

Although Barrows and Juggins (2005) reduced RMSE values by $10 \%$ of their planktonic foraminifera training set by using the average of MAT, ANN and Revised Analogue Method models, there appears little performance benefit from merging models in the SH-311 dinocyst dataset (Figure 4.10D). When the two strongest models from each family are tested, and the ANN and WA-PLS are merged, none of the areas of systematic 
bias are improved. Notwithstanding this observation, since the experiments above demonstrate that WA-PLS has superior predictive power over MAT and ANN for "unknown" assemblages, a combination of model results are used to interpret the east Tasman Sea record in Chapter 5.

\subsubsection{Taxonomic distribution of error}

Of the seven clusters based on taxonomic similarity from the SH-311 dataset (Chapter 2), the RMSE of Clusters 1, 2, 3, 4 and 7 all exceed the average RMSE for at least one of the models (Figure 4.11). Of these, Cluster 2 exceeds the average in all three models, and by the greatest amount, Cluster 1 exceeds the average in the WA-PLS and ANN models, and Cluster 7 exceeds that average in the MAT and ANN models. The relatively poor performance of Clusters 1 and 7 is expected, as they sit at each end of the SST gradient, where performance has already observed to be poorest (Figure 4.6). The relatively poor performance of Cluster 2 is of more interest. This cluster has a large SST range, and is most common in the Atlantic, although it is represented in four samples from the New Zealand region (which are the samples with large residuals to the east of the South Island in Figure 4.10). This cluster is characterized by very high relative abundances of Brigantedinium spp., with a minimum relative abundance of $60 \%$, and median of $>80 \%$. Similar concentrations of Brigantedinium spp. in fossil samples may also result in relatively poor SST reconstructions. In contrast, RMSE of samples in Clusters 5 and 6 were consistently lower than the average. Taxa characteristic of (although not restricted to) these clusters are Impagidinium aculeatum, I. strialatum, I. sphaericum, I. patulum, Nematosphaeropsis labyrinthus, Spiniferites mirabilis, S. ramosus, and Operculodinium centrocarpum LP - all taxa shown to be relatively good carriers of a SST signal in Section 4.5.4. 
A.

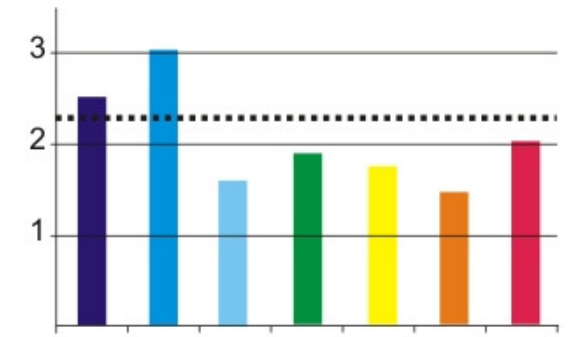

B.

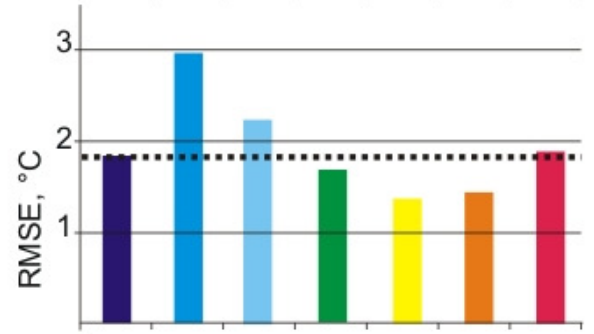

C.

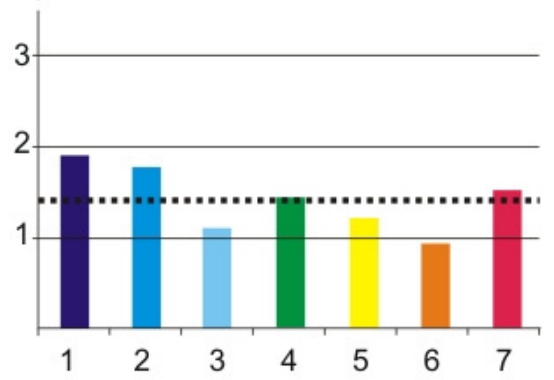

Figure 4.11. Residuals of the leave-one-out cross validation results of the SH-311 training set, divided by the taxonomic clusters established in Chapter 2. A: WA-PLS model, B: MAT, C: ANN. Dotted horizontal line denotes average RMSE for each model.

\subsection{Testing models on Late Quaternary DSDP Site 594}

$\begin{array}{ll}\text { Requirement } 10 & \text { Critical ecological, numerical, and paleoclimatic evaluations of } \\ & \text { reconstructions }\end{array}$

\subsubsection{DSDP Site 594}

The SH-311 training set was tested on a Late Pleistocene dinocyst record from DSDP Site 594 (Marret et al., 2001), using WA-PLS, MAT, and ANN models, and the quality of the reconstruction critically assessed using the tools described in this chapter.

Site 594 was drilled during DSDP Leg 90 in 1983 (Nelson, 1986). The site is located on the southern margin of the Chatham Rise, approximately $300 \mathrm{~km}$ east of Dunedin in 
$1400 \mathrm{~m}$ water depth (Figure 4.1). The dinocyst record used here was generated from the upper $20 \mathrm{~m}$ of core, which consisted of alternating layers of glacial hemipelagic muds dominated by terrigenous silty-clay with subordinate bio-siliceous and nannofossil material, and interglacial foraminifera-bearing nannofossil ooze (Nelson, 1986; Marret et al., 2001). Age control is based on matching $\delta^{18} \mathrm{O}$ of the planktonic foraminifera Globigerinoides bulloides to a globally-tuned benthic $\delta^{18} \mathrm{O}$ stack LR04 (Lisiecki and Raymo, 2005; Ryan, 2010). The upper 20 metres below sea floor (mbsf) covers the last $143 \mathrm{ky}$, and extends back to MIS6. 83 samples were analysed for dinocyst assemblages over this interval (Marret et al, 2001), and one sampling gap occurred at MIS 5d (14.5 $15.5 \mathrm{mbsf}$ ) due to poor core recovery.

Figure 4.12. Detrended Correspondence Analysis (DCA) biplot of the SH-311 training set (grey squares) overlain by the 83 Late Pleistocene samples (red crosses) from DSDP Site 594 . While many of the fossil samples plot in close proximity to modern samples, a proportion (circled) plot out of the modern range of the $\mathrm{SH}-311$ training set.

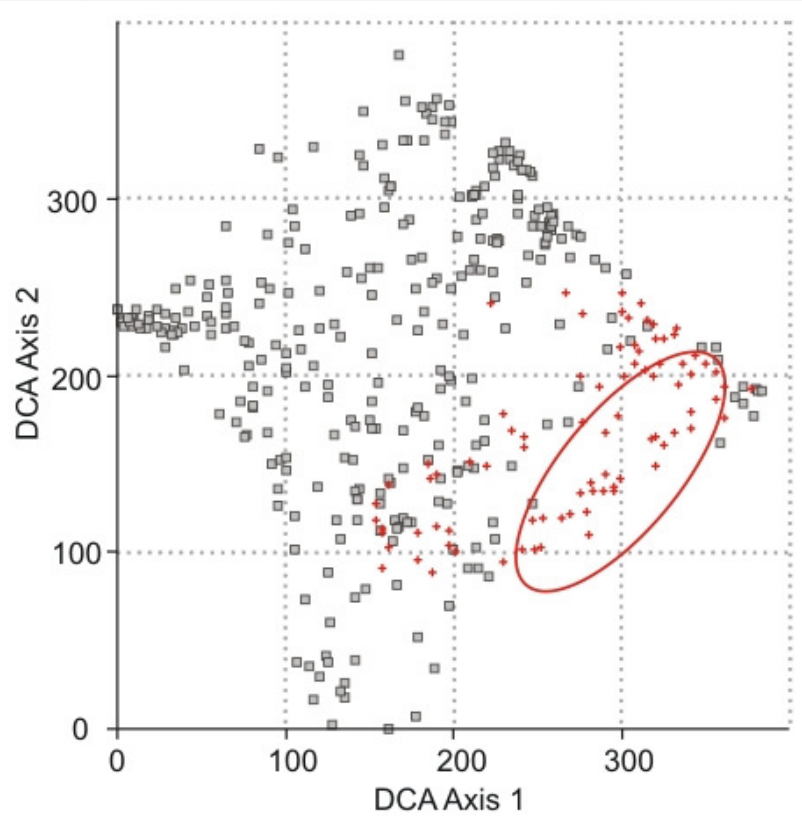

A MAT model using 118 sea-floor analogue samples was previously used to reconstruct winter and summer SST, and sea surface salinity by Marret et al. (2001). Their model recognized periods of relative warmth during MIS $5 e, 5 c, 5 a, 3$ and the Holocene. SST variations were large, up to $10^{\circ} \mathrm{C}$ between the warm/cold stages of MIS 5 . The LGMHolocene transition was modeled as a $6^{\circ} \mathrm{C}$ increase in SST, and modeled Holocene SSTs 


\section{Chapter 4}

A.

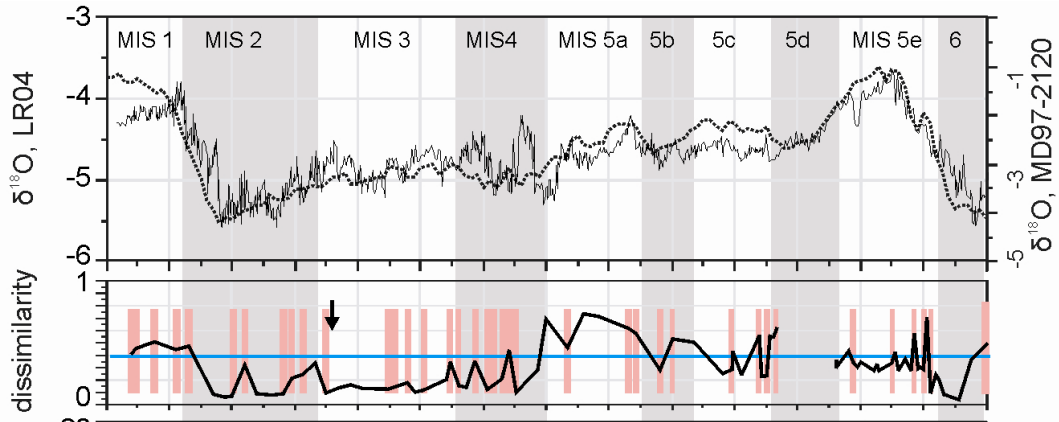

c.

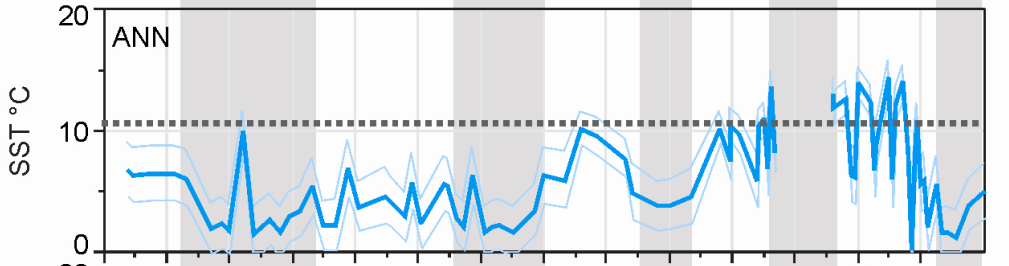

D.

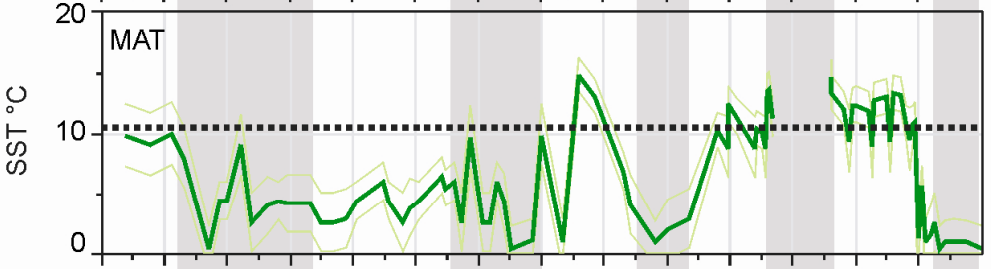

E.

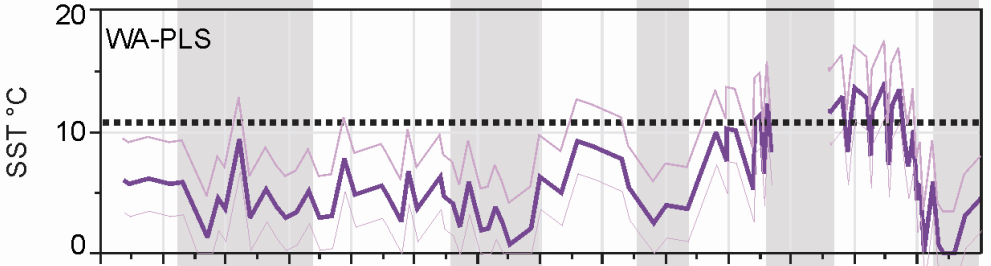

F.

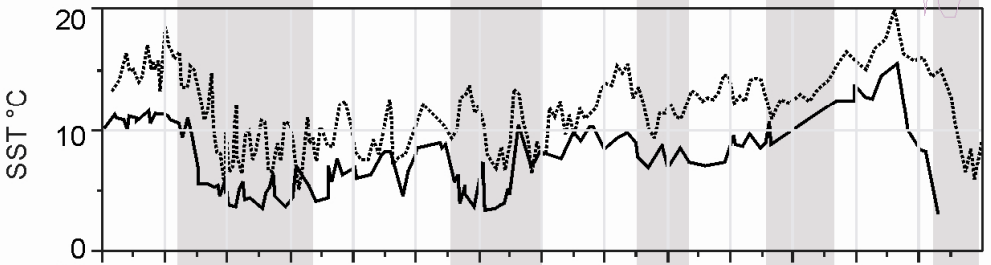

G.

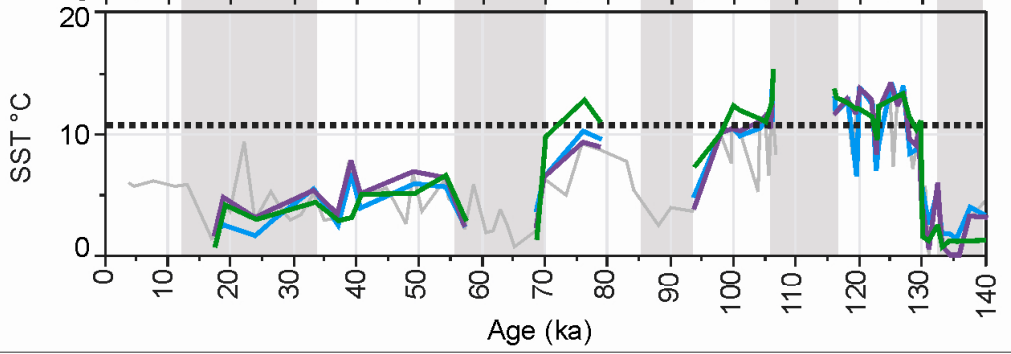

Figure 4.13. Climate records from DSDP Site 594 and nearby core MD97-2120. A. Solid line: $\delta^{18} \mathrm{O}$ of planktic foraminifera, MD97-2120 (Pahnke et al., 2003), dashed line: $\delta^{18} \mathrm{O}$ of global benthic stack LR04 (Lisiecki and Raymo, 2005). B. Black line chord dissimilarity to nearest analogue sample, blue line maximum dissimilarity in modern training set, red rectangles show depth of samples inside circle on Figure 4.12. Black arrow shows sample with $>60 \%$ Brigantedinium spp. C, D, E. ANN (blue), MAT (green), WA-PLS (purple) model results. Error bands are RMSE from leave-one-out cross validation, dotted line shows modern SST at drill site. $\mathbf{F}$. Solid line: foramin ifera-based SST derived using ANN model, DSDP Site 594 (Haywood et al., 2008), dashed line: Mg/Ca SST from MD97-2120 (Pahnke et al., 2003), recalculated using calibration of Marr et al. (2011). G. ANN (blue), MAT (green), WA-PLS (purple) model results, excluding samples within circle in Figure 3.11. 
were $\sim 2-4^{\circ} \mathrm{C}$ cooler than modern measurements.

\subsubsection{Exploration of error indicators}

A Detrended Correspondence Analysis (DCA) is used as an exploratory tool to identify samples in the core that do not have analogues in the modern training set. A biplot of the first two DCA ordination axes of the SH-311 training set, overlain by the 83 DSDP Site 594 samples, shows that about half of the fossil assemblages plot in ordination space not occupied by any of the training set samples (Figure 4.12). The cross validation routines conducted on the modern dataset in Section 4.9 suggest that model errors are likely to be greater for these samples, particularly for MAT and ANN models. These samples are distributed throughout the core, but are a particularly dominant feature of the Holocene (MIS1), MIS4, and MIS5b, but are less common in MIS5e assemblages (Figure 4.13B).

There is some correlation between high MAT dissimilarity scores (scores greater than the maximum $\left[99^{\text {th }}\right.$ percentile] within the training set) and the samples that plot outside of the modern DCA ordination range, particularly in the Holocene, and the early parts of MIS 5a, 5c and 5e (Figure 4.13B). However, there is also a series of samples from MIS3 4 with relatively low dissimilarity scores, but which plot outside the modern range, while some of the assemblages with elevated dissimilarity scores in MIS 5a plotted within the scatter of modern samples. Ideally, all fossil samples would plot within the ordination range of the training set, and all would have dissimilarity scores within the modern range. That a significant number of these samples fail one or both tests suggests that this may be a relatively poor record for quantitative SST reconstruction using dinocyst assemblages. Of the two measures of similarity explored, the ordination approach is used here in preference to the dissimilarity score. A single sample contains $>60 \%$ Brigantedinium spp., at 39ka (arrowed in Figure 4.13B) so has an affinity to the modern cluster of samples that consistently produce poorer than average error rates, and was removed from the final reconstruction in Figure 4.13G. 


\subsubsection{Model reconstructions}

The three transfer function models produce broadly similar reconstructions, but with characteristic differences (Figure 4.13C-E). Each produced a similar magnitude of SSTs variation and maxima, with SST estimates between $-0.2^{\circ} \mathrm{C}$ to $15.3^{\circ} \mathrm{C}$. Neither the WAPLS nor the ANN models reconstructed the MIS2 - Holocene transition, with SSTs remaining within the glacial range, while stable Holocene SSTs similar to modern values were reconstructed by the MAT model. The structure of the MAT estimates obtained here are very similar to those obtained by Marret et al. (2001), possibly reflecting the fact that few new high-latitude analogue samples have become available since their work.

The similarities between the WA-PLS and ANN models are striking, while the MAT reconstruction is generally characterized by much greater SST fluctuations than the other two models. Examples of such behavior in the MAT model are a $14^{\circ} \mathrm{C}$ warming between MIS5b and $5 a$ (the other models reconstruct $<6^{\circ} \mathrm{C}$ change over this interval) and fluctuations of $>10^{\circ} \mathrm{C}$ during MIS4. Fluctuations of this magnitude were also a feature of the MAT results of Marret et al. (2001).

Three other SST proxies are available from the region: a foraminiferal-based faunal transfer function using an ANN model from DSDP Site 594 (Schaefer et al., 2005; Haywood et al., 2008), a Globigerina bulloides Mg/Ca SST record from the nearby giant piston core MD97-2120 (Pahnke et al., 2003), recalculated using a regional $\mathrm{Mg} / \mathrm{Ca}$ calibration for Globigerina bulloides (Marr et al., 2011) (Figure 4.13F) and an alkenone SST record from MD97-2120 (Pahnke and Sachs, 2006). Of the four reconstructions, the dinocyst models generally produce the lowest SSTs (Figure 4.13), with MIS5e being $6^{\circ} \mathrm{C}$ cooler than the $\mathrm{Mg} / \mathrm{Ca}$ record, and $\mathrm{MIS} 2 \sim 2^{\circ} \mathrm{C}$ cooler. All three dinocyst models also exhibit greater variation than the other faunal reconstructions, particularly during MIS5e and $5 c$.

When assemblages that plot outside of the modern ordination space are removed from the reconstruction, the average results of the remaining samples become slightly more 
consistent between the models (from an average range of $2.4^{\circ} \mathrm{C}$ to $2^{\circ} \mathrm{C}$ ), presumably because the remaining samples are more similar to those in the training set (Figure 4.13G). This increased consistency between model results is due only to the removal of the more extreme results from the MAT model. The mean variation between the WAPLS and ANN models remains unchanged at $0.9^{\circ} \mathrm{C}$. This is intriguing, as the modern cross validation exercises here suggest a WA-PLS model should have better success at reconstructing unfamiliar samples than an ANN model, so the mean variation between the model outputs should decrease as unfamiliar samples are removed. The cause of this relative stability of the ANN model in this instance is unknown, but it is a sharp contrast to the great variability observed in the MAT results, and highlights the value in considering the results of multiple transfer models (Guiot and de Vernal, 2007).

\subsection{Conclusions}

In this chapter, assumptions and models to reconstruct SST using the SH-311 Southern Hemisphere dinocyst dataset were explored.

\subsubsection{Selection of best models}

Three models, the WA-PLS, MAT, and ANN models, appear the most suitable for paleo environmental reconstructions, based on their performance under "leave-one-out' cross validation and split-sampling. WA has little value due to the pervasive bias in residuals.

While performance of the WA-PLS model is relatively poor under leave-one-out cross validation, it is retained because of its relative robustness when tested outside of its training set. Although the performance statistics were below the four model average during "leave-one-out" cross validation, they changed relatively little in the splitsampling routine.

The ANN model is preferred over the MAT model. The ANN has better cross validation RMSE and $r^{2}$ statistics. Although the performance of both reduces under split-sampling cross validation, the ANN performance appears slightly more stable. The MAT model may improve as additional training samples become available to the dinocyst dataset. 
Where the ANN model encounters familiar fossil assemblages, it should out-perform WA-PLS. As discussed in Section 4.6, we do not have precise methods to identify nonanalogue situations, but a combination of dissimilarity scores that exceed the range of those encountered in the modern dataset, and the passive inclusion of fossil samples over a principal components analysis of the modern training set both assist. An application of this observation is explored in Chapter 5, where ANN model estimates are discarded in favour or WA-PLS SST estimates where poorer modern analogues are encountered.

\subsubsection{Errors of best models.}

The NZ-98 dataset produced a range of RMSEs from $1.14^{\circ} \mathrm{C}$ (ANN) to $1.67^{\circ} \mathrm{C}$ (WA-PLS). The temperature gradient covered by this dataset was $7^{\circ} \mathrm{C}-20^{\circ} \mathrm{C}$, but the effective range was reduced by edge effects.

RMSEs of the SH-311 dataset were $1.47^{\circ} \mathrm{C}$ (ANN) to $2.29^{\circ} \mathrm{C}$ (WA-PLS), with temperature extremes reconstructed more poorly than mid-latitude temperatures. Mid-latitude RMSE for the ANN model is $<1.2^{\circ} \mathrm{C}$.

For the SH-311 training set, prediction errors obtained using split-sampling of spatially independent test sets were 1.3 times (WA-PLS) and 2.1 times (ANN) poorer than leaveone-out cross validation. Further exploration revealed the test sets to be poorly balanced: so the split-sampling was not an adequate test of transfer function performance. Initial split-sampling cross validation using spatially independent test sets of a larger faunal training set for foraminifera suggests a similar performance reduction compared to leave-one-out cross validation to that observed in the $\mathrm{SH}-311$ dinocyst training set. However, even with the larger training set, a spatially independent test set that is appropriately balanced is difficult to achieve. For the part of the SW Pacific SST gradient where an appropriate spatially independent test set was identified, performance reduction of the ANN model was about 1.8 times, while performance reduction of the WA-PLS model was about 1.2 times. 


\subsubsection{Improvements to dinocyst-based environmental estimates}

The following work would improve the use of dinocyst assemblages as quantitative environmental proxies in the SW Pacific, listed in decreasing order of importance.

- Additional high quality sea-floor samples from key areas. In the SW Pacific, areas that would benefit from additional sampling include the south Tasman Sea and north Tasman Sea, and off-shore east of the North Island of New Zealand (10-20 samples from each area). Although dinocysts are sparse in the area, additional (20-30) samples from the south west Pacific sector of the Southern Ocean would contribute significantly to the predictive power of the models for SSTs $<10^{\circ} \mathrm{C}$. In addition, while new samples from much of the Southern Hemisphere would be useful, the Indian Ocean and margins remain poorly sampled.

- Better-resolved environmental climatologies, particularly across frontal systems. In some places, such as across the STF, dinocyst assemblages appear to change more abruptly than the more gradual change shown by $1^{\circ}$ WOA climatology, for example the $0.5^{\circ}$ resolution CSIRO Atlas of Regional Seas, which is progressively improving resolution and quality control, particularly in data-rich regions.

- Novel modeling approaches. Other machine learning approaches, such as classification-based 'Random Forest' models (Breiman, 2001) do produce better calibration statistics on foraminifera training sets than the models explored here (G. Scott, pers comm, 2012), and may have other advantages in that they appear easier to describe and "see" the decisions paths than, for example, ANN models. However, like ANN models, rigorous assessment of prediction errors would be necessary to guard against spurious over-fitting during training.

\subsection{Acknowledgements}

Thanks to George Scott and Marcus Vandergoes for discussions on performance and assumptions of transfer functions, and to George for sharing his Southern Hemisphere 
foraminifera training set. Thanks also to Thomas Verleye, Fabienne Marret, Anne de Vernal, Taoufik Radi, and Karen Zonneveld for access to data and $r$ code, and to Phil Briely (Tiberius) and Steve Juggins (C2) for providing free access to their software.

\section{Appendix 4.1. Spatial autocorrelation}

\section{Appendix 4.1.1. - Introduction}

Spatial autocorrelation of faunal datasets is the condition of a spatial dataset where analogue samples are located too close to be effectively independent of one another. In such a situation, the assemblage of a sea-floor sample can be (partially) predicted by the composition of its neighbours. In a sea-floor assemblage, three types of increased similarity between neighboring samples occur:

1. Lateral transport before deposition results in a mixing of otherwise distinct assemblages, resulting in a degree of similarity between adjacent sites;

2. Lower spatial variation than sampling density in the primary environmental variable results in similarity between adjacent sites;

3. Lower spatial variation than sampling density in secondary environmental variables also results in similarity between adjacent sites;

The focus of recent papers on spatial autocorrelation has considered the effects of type (3) correlation, i.e. the contribution the secondary "nuisance" environmental gradients have on the performance of transfer functions (Telford et al., 2004; Telford and Birks, 2009, 2011). In other words, they were exploring whether model performance relies only on variation due to the primary environmental variable, or whether the assemblages and models also incorporate variation from other environmental gradients. They therefore start with the following test:

"If performance deteriorates more when geographical neighbors are deleted than when environmental neighbors are deleted, the performance loss relative 
to the random deletion cannot just be because the environmental variable being reconstructed is autocorrelated" (Telford and Birks, 2009).

Having demonstrated this is so for various marine training sets, they conclude that the best way to account for the effects of secondary environmental gradients is to determine the average distance over which secondary gradients have an effect on model performance, then exclude samples nearer than this distance in a subsequent cross validation (the $h$-block cross validation of Telford and Birks, 2009).

They acknowledge that the distance of $h$ is therefore critical: too large a distance will result in overly conservative estimation of performance, as unnecessary samples will be excluded, while if too small, the effects of spatial autocorrelation will remain. Telford and Birks (2009) suggest that the range of an empirical semivariogram is the most suitable way to obtain $h$. An empirical semivariogram is a plot of the difference-squared of the values between each sample point in the training set, averaged into regular bins of separation distance, (typically bins of $\sim 250 \mathrm{~km}$ in a marine dataset) (Burrough, 1995). In a spatially autocorrelated dataset, this graph has a positive slope for small-distance bins, then flattens out. The distance at which the graph flattens is the range beyond which the average difference between samples does not increase. Since Telford and Birks (2009) were seeking to account for variation in secondary gradients, they constructed empirical semivariograms using residuals of transfer function models, because if there was a perfect relationship between the assemblage and the primary environmental gradient, there would be no residuals. On the other hand, if an important autocorrelated predictor is omitted from a regression analysis, the residuals will be autocorrelated (Telford and Birks, 2005).

\section{Appendix 4.1.2. Spatial autocorrelation in the SH-311 training set}

The presence of spatial autocorrelation was established by comparing the reduction of MAT performance during progressive removal of proximal samples (i.e. samples near to 
each target sample during a leave-one-out cross validation) to performance during random removal of the same proportion of samples. Calculations were undertaken in Excel, and distances between samples were calculated as great circle distances and each plotted point is the average of 15 random deletion runs. When applied to the $\mathrm{SH}-311$ training set, the MAT model appears to exhibit a degree of spatial autocorrelation. Performance is (slightly) worse when nearby samples are excluded than when nearby samples in environmental space are excluded, and is much worse than when random samples are removed, to the extent that removal of samples within $200 \mathrm{~km}$ from consideration during cross validation had the same reduction in $r^{2}$ as random removal of $80 \%$ of all available analogue samples (Figure A.4.1.1).

An empirical semivariogram was constructed of model residuals from a WAPLS model with leave-one-out cross validation of the SH-311 training set, following Telford and Birks (2009), and applying $250 \mathrm{~km}$ bins. The result is surprising, with a high nugget, and very little structure (Figure A.4.1.2). While a flat empirical semivariogram is characteristic of a purely random variable with no correlation structure (e.g. Thompson et al., 2007), it is more likely this structure is due to the training set covering a range of variances in the residuals. A similar problem was encountered by Telford and Birks (2009) when constructing semivariograms for a Northern Hemisphere dinocyst training set that included samples from the Pacific and Atlantic oceans. A semivariogram of only the SW Pacific (Figure A.4.1.2) shows slightly clearer structure. Although we have not attempted to formally fit variogram models to the empirical semivariograms, an approximate fit of a spherical or exponential model would result in a range of $~ 1500-$ $1750 \mathrm{kms}$. For the SW Pacific part of the training set, then, one could infer that samples more distant than this are not spatially autocorrelated. However, the nugget variance is a high fraction of the sill variance, which has been used as a diagnostic characteristic of 


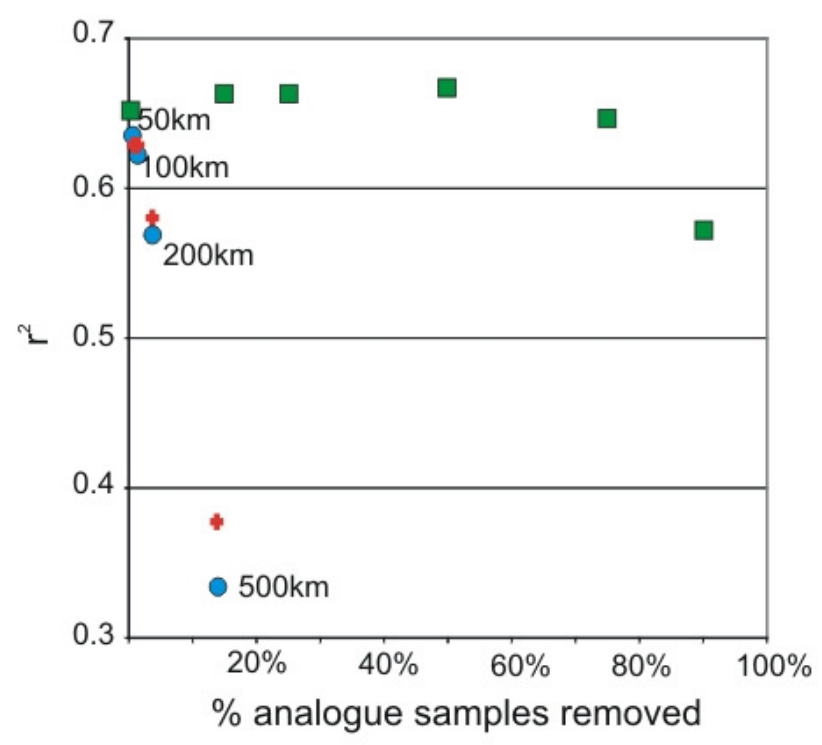

Figure A.4.1.1. MAT model performance measured by leave-one-out cross validation, shown as $r^{2}$ (of predicted vs actual SST), with different criteria used to exclude samples from the training set. The training set is the dinocyst SH-311 set, results are shown for only the NZ-98 part of that training set. Blue circles = analogue samples excluded by distance around test sample $(50,100,200,500 \mathrm{~km}$ results shown), red crosses = analogue samples excluded by environmental proximity. Number of samples removed expressed as a proportion of total training set (x-axis). Green squares = random removal of samples, expressed as a proportion of total training set (x-axis). Exclusion of samples within $200 \mathrm{~km}$ has a roughly equivalent effect to random removal of $80 \%$ of the training set. Beyond $100 \mathrm{~km}$, when the equivalent number of samples are excluded by environmental gradient as by distance, the cross validation with exclusion by environmental gradient performs better. Therefore, model performance is improved when given the opportunity to utilize nearby samples, but this performance is not due to SST influence on the assemblage, but by autocorrelation of secondary environmental variables.

generally low spatial autocorrelation of a lake based diatom training set (Telford and Birks, 2009).To test the performance of WA, WA-PLS, MAT and ANN techniques on spatially independent datasets, we pruned the SH-311 analogue dataset toward one that is approaching "independent" following the criteria established in the empirical semivariogram. These 'spatially independent' datasets were created by progressively pruning the most highly connected samples from a randomly ordered $\mathrm{SH}-311$ sample list until no analogue samples were closer than $1000 \mathrm{kms}$. As multiple solutions are possible in this iterative pruning, we created five random datasets to estimate the range of outcomes from this approach. A second group of five datasets was also created by random deletion of the same proportion of samples required to create the spatially independent datasets above (Figure A.4.1.3A). When sampling the "random" datasets, 
Figure A.4.1.2. Empirical semivariograms of residuals from WA-PLS model. Blue diamonds $=\mathrm{SH}-311$ training set, Red squares $=$ NZ-98 subset. See text for explanation.

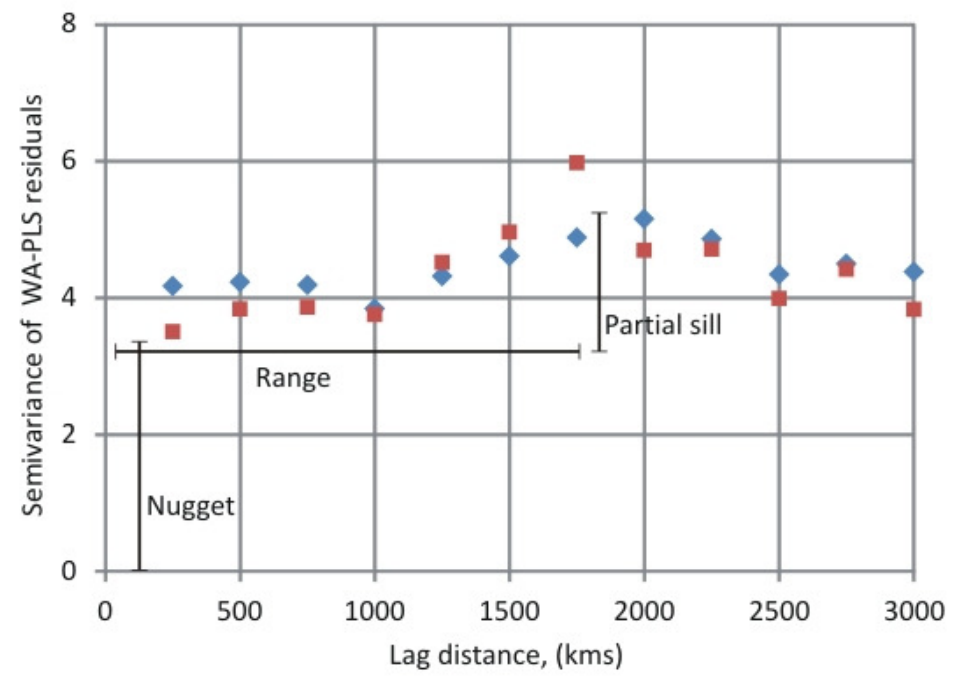

sampling was constrained to ensure that the sampling frequency along the environmental gradient matched that of the spatially sampled training set (Figure A.4.1.4). In order to ensure that the "random" data sets also had significantly lower distance between samples, the source of the samples was restricted to two geographic areas (Figure A.4.1.3B). WA-PLS, MAT and ANN models were created from each of these pruned datasets using the same settings as described in Section 4.8, except that the optimum number of MAT analogue samples was determined for each dataset, as this decreased with training set size (typically 3 analogues were used). Two observations are possible from the results of this exercise (Figure A.4.1.5): 1) there is a slight difference in model performance between WA-PLS, MAT and ANN models for the "spatially independent" test sets, with WA-PLS slightly out-performing ANN and MAT, but 2) there is no significant difference between model performance of the "spatially independent" training sets and the "random" training sets. Either proximity of samples in a training set does not matter, or pruning the 311-samples training set in this way results in training sets that are too small for meaningful comparison.

The same exercise as above was repeated on a much larger Southern Hemisphere foraminifera coretop training set. This training set is the one used in Crundwell et al. 


\section{Chapter 4}
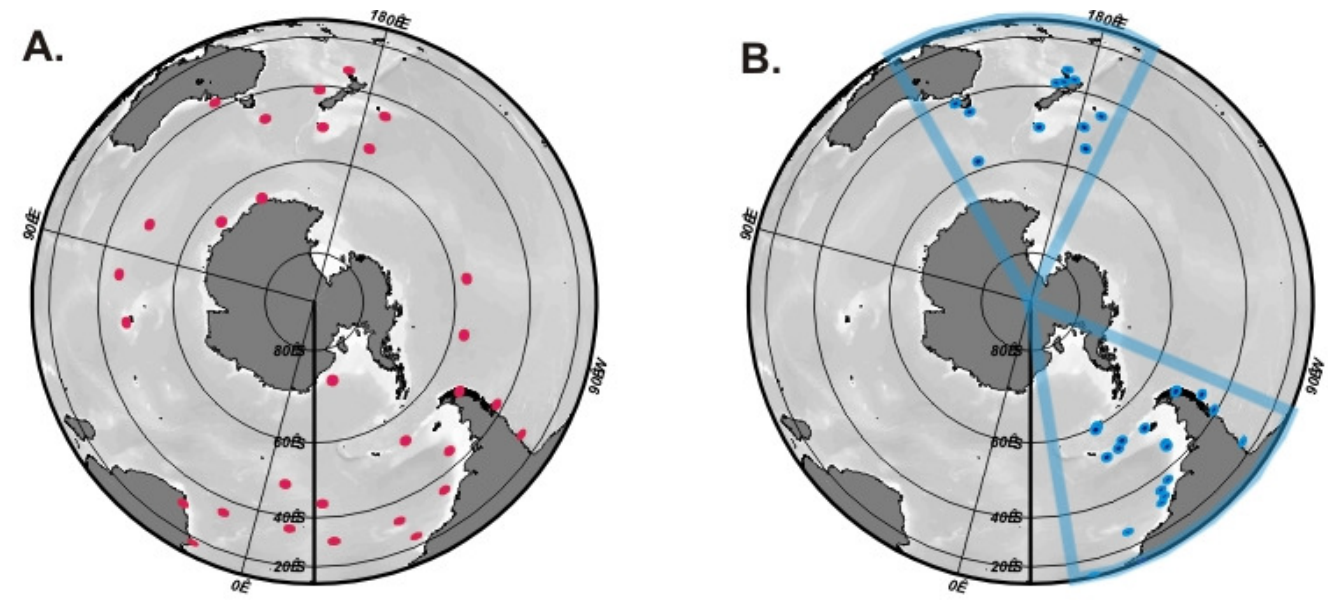

Figure A.4.1.3. Sampling the SH-311 training set to create a "spatially independent" dinocyst training set. A: Samples were removed from the SH-311 training set until samples were no closer than $1000 \mathrm{~km}$ apart. Five training sets were created in this format, one is illustrated. B: As a comparison, a training set of equivalent size was sampled randomly. The random sampling was restricted to samples within the two blue areas shown, to ensure that the remaining samples were closely spaced. Five training sets were also created in this format, one is illustrated

Figure A.4.1.4. Characteristics of representative "spatially independent" (red) and "random" (blue) dinocyst training sets. A: shows that the samples of the randomly selected training set are more densely spaced than the "spatially independent" training set, plotted as a frequency histogram of the distance to the nearest neighboring sample. B: shows that the "randomly selected" training set was confined to have a similar sample frequency distribution along the SST gradient.

A.

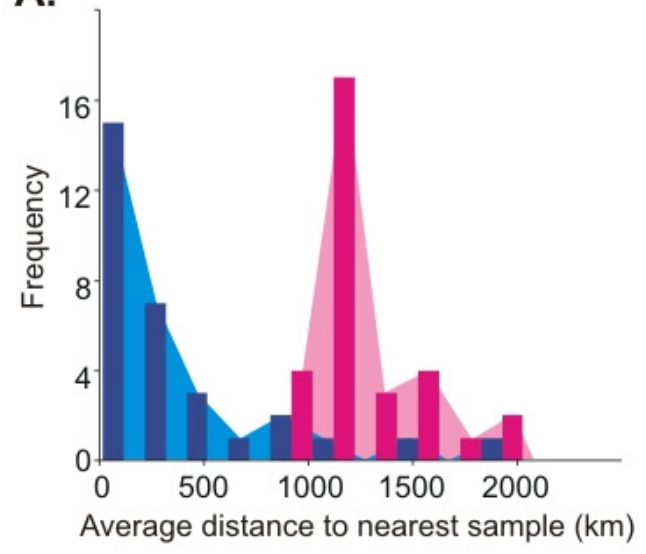

B.

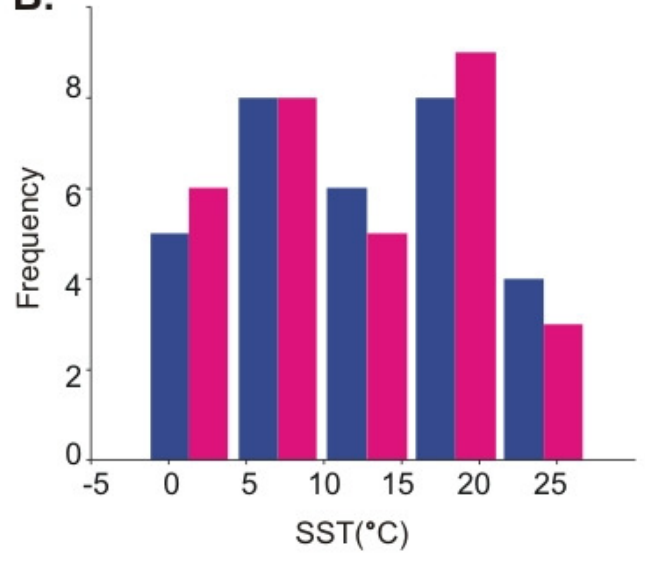


(2008) and Hayward et al. $(2008,2012)$. Version 0611C3 was used, which is the 35-taxa version of the training set compiled by G. Scott in August 2011. Some duplicates were removed from the dataset, leaving 1157 coretop samples from across the Southern Hemisphere (Figure A.4.1.6E). An empirical semivariogram of the entire training set shows clearer results than for the dinocysts, with a range of $\sim 1000 \mathrm{kms}$ (Figure A.4.1.6D). Given the size and distribution of the training set, in addition to the spatially constrained training set with no samples nearer than $1000 \mathrm{kms}$, three separate "random" training sets were created in the Pacific, Indian and Atlantic ocean basins (Figure A.4.1.6B), with the same frequency distribution along the environmental gradient (Figure A.4.1.6C), and five duplicates were created of each of the four training sets. The range of model performance represents the range of the five models (Figure A.4.1.6A). For the MAT models, RMSE from leave-one out cross validation of the randomly sampled training sets (solid bars) was $\sim 1^{\circ} \mathrm{C}$ lower than for the $1000 \mathrm{~km}$ training set. RMSE of the $1000 \mathrm{~km}$ training set was similar to that when each of the randomly sampled training sets were alternately used as test and training sets. In other words, when the MAT model was asked to reconstruct SST of unseen assemblages, the performance was $1^{\circ} \mathrm{C}$, or on average 1.8 times worse, than a leave-one-out cross validation. The WA-PLS model was similar to the MAT, in that the leave-one-out cross validation performance of the $1000 \mathrm{~km}$ training set was poorer than the three randomly selected training sets, although there was less to differentiate them. Although performance declined when the randomly sampled training sets were used as spatially independent test sets, the proportional decline in performance was not as severe as the MAT model, being about $0.4^{\circ} \mathrm{C}$, or 1.2 times. ANN clearly struggles more with small training sets than the other two models, with performance poorer across all permutations in this simulation. Although the magnitude of error is much greater in the ANN models, the structure of those errors is most similar to the MAT models. RMSEs are generally lower for the randomly sampled training sets where the samples are closer together, than for the $1000 \mathrm{~km}$ training sets. Like the MAT, performance is erratic when 


\section{Chapter 4}
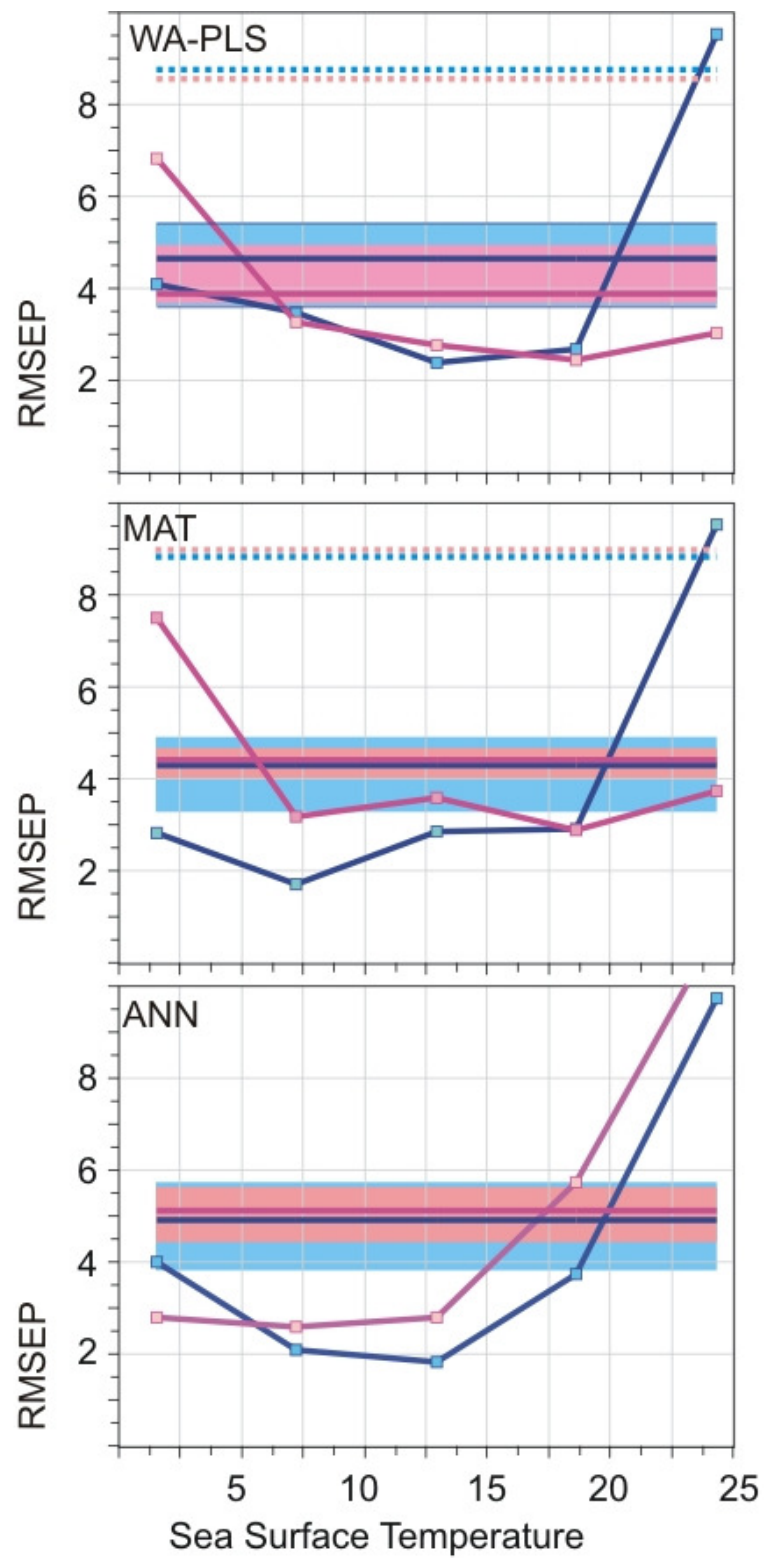

Figure A.4.1.5. Model performance for "spatially independent" (red) and "random" (blue) dinocyst training sets, using WA-PLS, MAT, and ANN models RMSEPs against SST. Average performance is shown by the horizontal lines, with minimum and maximum errors from five models shown by the height of the coloured boxes. Average model performance for every $1 / 5$ of the SST gradient is shown by the line charts (range of error not shown). Dashed lines show model performance when SST were randomly assigned to the training set samples from the pool of available training set SSTs. There is no clear difference between model performance of the "spatially independent" training sets and the "random" training sets: either proximity of samples does not matter, or this pruning exercise has resulted in training sets that are too small to make meaningful comparisons. 
the models built for each region are used to determine SST on another region, with RMSE declining by a similar proportion to the MAT models, about 1.8 times.

\section{Appendix 4.1.3. A comment on the approach}

The small-training set sampling undertaken here fails to get to the heart of the actual effects of spatial autocorrelation on training sets, but it does provide some interesting insights on the relative performance of different models when faced with unknown analogues, which is of utility when weighing up conflicting model results from fossil assemblages.

The method recommended by Telford and Birks (2009) to account for the effects of spatial autocorrelation (of $h$-block cross validation) has not been attempted here. While it appears a conceptually elegant solution, Telford and Birks (2009) themselves acknowledge that the averaging process in selecting a single distance $h$ for the entire training set is not ideal: "One key assumption of geostatistics is that the variable is stationary, i.e. that the difference between observations depends only on their geographical separation. This assumption is not satisfied for ocean data: much of the environmental variability is encapsulated in oceanic fronts, whereas gyres have only small environmental gradients" (Telford and Birks 2009). They justify their treatment of the ocean as a water mass of fixed variability by the need to obtain a value of $h$, but do not explicitly consider the effects of this assumption. This blanket approach probably results in a more conservative $h$ than is necessary. Since much of the environmental, and assemblage, variability is concentrated at ocean fronts, wholesale exclusion of surrounding samples within $h$-distance of the test sample will frequently result in the unnecessary exclusion of independent samples during a cross validation exercise. Likewise, the most important secondary environmental gradients in the $\mathrm{SH}-311$ training set are distance from shore and productivity, variability of which are also not 'stationary'. The spatial effects of these environmental gradients varies over different distances, depending on e.g. coastal effects (riverine input), bathymetry (wide vs narrow shelves), and the source of the productivity (small scale transient upwelling vs oceanic 
scale upwelling). The SH-311 training set covers extremes of all these situations, while simply taking the average of such disparate environments would result in a poor test of model performance.

A better solution, also not attempted here, might be to derive sample-specific values of $h$, thus accommodating the non-stationary nature of the modelled environment. If this were attempted, a useful additional refinement would be to consider directionality in the variance at this scale. Variance of the environmental gradients would frequently be anisotropic: the intense SST variation across fronts in the SW Pacific open ocean is generally north-south, while the amount of variation of the secondary gradients will also have a degree of anisotropy, such as shore line proximity.

More generally, it is worth remembering that the effects of artificially improved model performance due to assistance from secondary environmental variables can be managed in other ways. While Telford and Birks (2009) advocate identifying possible reductions on model performance during cross validation, identification of samples in the fossil record that are likely to be influenced by environmental gradients other than that under reconstruction has essentially the same result, that of providing a more accurate estimate of paleo-SST. For example, in the dinocyst transfer functions, SST reconstructions from assemblages indicative of high productivity (e.g. Cluster 2, Figure 4.11) are treated with more suspicion than those in lower productivity environments.

\section{Appendix 4.2. - Foraminifera training set}

Following the initial exploration in Appendix 4.1, the performance of the 1157 sample foraminifera training set was explored further by splitting it to form spatially independent test sets, with particular emphasis on its ability to perform reconstructions in the New Zealand region.

The purpose of this exercise was two-fold, i) to explore the effects of spatial autocorrelation on a training set that is large and (possibly) balanced enough to better withstand split-sampling without the same problems encountered in the SH-311 

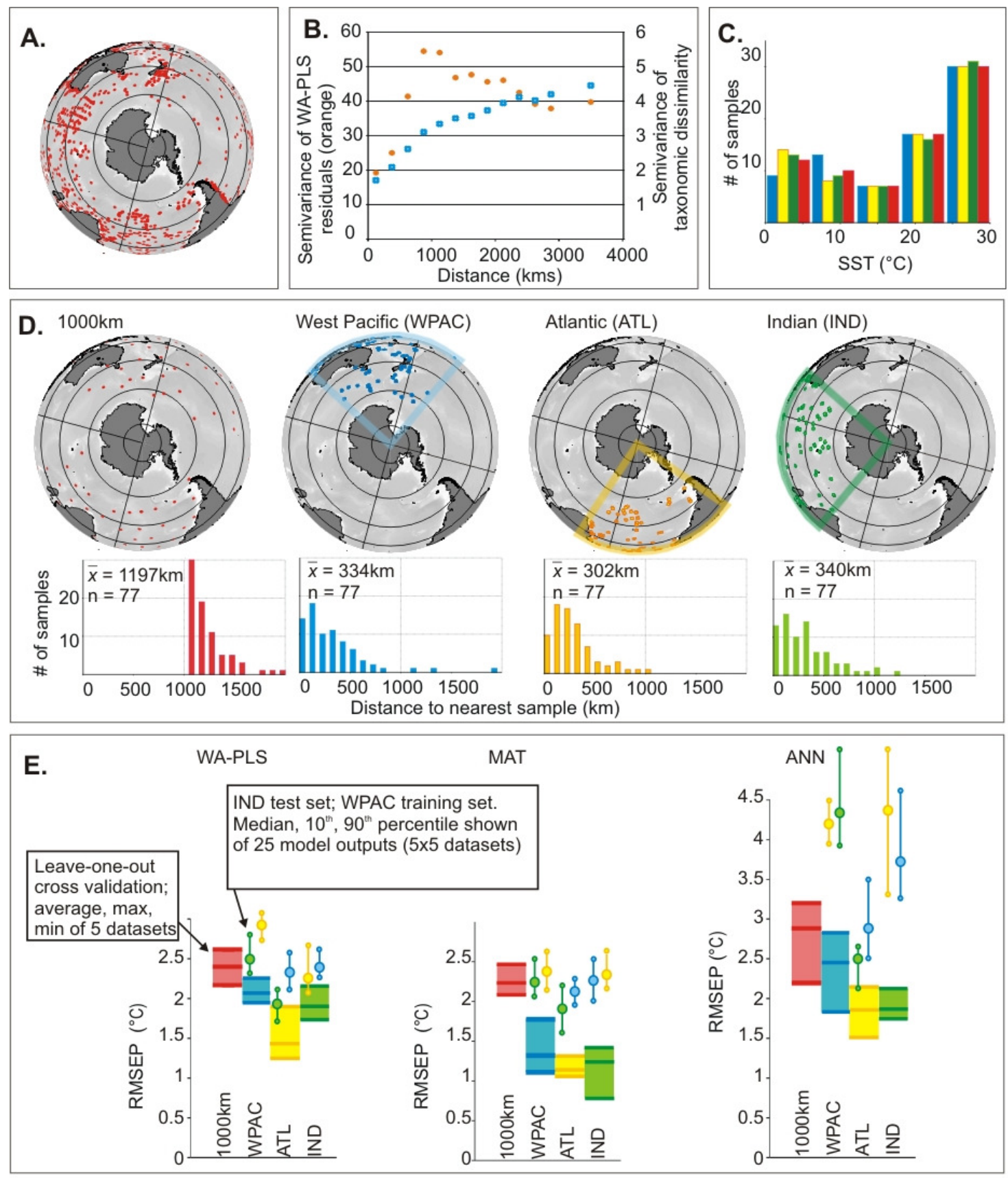

Figure A.4.1.6. Exploration of a 1157-sample foraminifera training set from the Southern Hemisphere. A: Sample locations, B: Empirical semivariogram of WA-PLS model residuals, showing a range of $\sim 1000 \mathrm{~km}$, C: Randomly sampled training sets were constrained to have similar distribution of samples along the SST gradient to the "spatially independent" training set with $1000 \mathrm{~km}$ sample spacing, D: Four types of training sets were created, each with 5 duplicates; a representative of each is shown. The entire 1157 sample training set was progressively pruned until no sample was closer than $1000 \mathrm{~km}$, leaving a training set of 77 samples ( $\min 75$, max 77 samples). Three training sets of the same size as the $1000 \mathrm{~km}$ training sets were created by randomly sampling from three ocean basins: the West Pacific (WPAC), the south Atlantic (ATL) and the Indian Ocean (IND). The average distance to the nearest neighboring sample in each of the three randomly sampled training sets was $\sim 1 / 4$ that of the $1000 \mathrm{~km}$ training sets. E: Results of WA-PLS, MAT, and ANN models. Solid bars show leave-one out cross validation results of each training set (maximum, average and minimum results from the five training sets are shown). Circle 'box and whiskers' plots show the results of each randomly selected training set used as a test set (i.e., 25 combinations per icon median, 10th and 90 th percentile shown). 
dinocyst training set, and ii) to better understand the errors associated with the foraminifera faunal SST proxy, as it is a contemporary proxy-record to the paleo-records generated in the current study.

First, for the entire dataset, performance results assessed using leave-one-out cross validation for MAT and ANN models, and were found to be similar to those reported in Kolodziej (2010) (Table A.4.2.1). Then, a WPAC subsample was taken, to determine the regional performance of the training set. This subsample covers a similar area to the WPAC subsample of Appendix 4.1, (Figure A.4.1.6), but differs in that no samples are removed from the test set (although in this exercise, samples from the 'rest-of the world' training set are excluded in a $1000 \mathrm{~km}$ buffer from the WPAC test set), in an attempt to retain 'spatial independence' (Figure A.4.2.1A).

The model results for WA, WA-PLS, MAT and ANN models under leave-one-out cross validation are similar for the WPAC and the entire 1157 sample training set (Table A.3.2). Consistent with the patterns observed previously, model performance is poorer when the WPAC is used as an independent test set, and the "rest of the world" used as a training set: WA and WA-PLS performance drops the least, while MAT and ANN performance decline by a factor of $\sim 2$. A k-means clustering exercise constrained to 6 clusters shows a strong, coherent latitudinal division across the training set (Figure A.4.2.1B), suggesting that it is unlikely that the poorer performance is due to provincialism.

However, this possibility is explored by further splitting samples from the New Zealand region into two data sets, WPAC_A (208 samples) and WPAC_B (156 samples), separated by a $1000 \mathrm{~km}$ buffer of discarded samples (Figure A.4.2.2A) (the original area of these samples slightly exceeds the WPAC subset, to provide even samples in the test and training sets). The rationale for exploring the performance within this more confined area is that provincialism (not identified by the k-means clustering), either purely represented by presence/absence of taxa, or by changes in their relative abundances, may be the cause of the poorer performance under the spatially 


\section{Chapter 4}

Table A.4.2.1. Performance statistics of the foraminifera SH-1150 dataset under various split sampling and cross validation routines.

\begin{tabular}{|c|c|c|c|c|c|c|c|c|}
\hline & \multicolumn{4}{|c|}{ Leave-one-out cross validation } & & \multicolumn{3}{|c|}{ Split sampling } \\
\hline & SH-1150 & WPAC & WPAC_B & WPAC_B & & WPAC & WPAC_B & WPAC_B \\
\hline & 35 taxa & & & $0-18^{\circ} \mathrm{C}$ only & & $\begin{array}{c}\text { reminder of } \\
\text { SH used for } \\
\text { training }\end{array}$ & $\begin{array}{c}\text { WPAC_A } \\
\text { used for } \\
\text { training }\end{array}$ & $\begin{array}{c}\text { WPAC_A } \\
\text { used for } \\
\text { training } \\
0-18^{\circ} \mathrm{C} \text { only }\end{array}$ \\
\hline \multicolumn{9}{|c|}{ Weighted Averaging } \\
\hline RMSEP $_{\text {jack }}$ & 2.32 & 2.14 & 2.02 & - & RMSEP & 2.52 & 2.13 & - \\
\hline$r^{2}{ }_{\text {jack }}$ & 0.91 & 0.91 & 0.94 & - & $r^{2}$ & 0.93 & 0.94 & - \\
\hline Max bias jack & 2.4 & 2.5 & 2.64 & - & Max bias & 3.04 & 0.02 & - \\
\hline Average biaşack & 0.004 & -0.006 & -0.008 & - & Average bias & -0.46 & 3.10 & - \\
\hline \multicolumn{9}{|c|}{ Weighted Averaging with Partial Least Squares } \\
\hline RMSEP $_{\text {jack }}$ & 2.16 & 2.05 & 1.84 & 1.54 & RMSEP & 2.36 & 3.08 & 1.92 \\
\hline$r_{\text {jack }}^{2}$ & 0.92 & 0.93 & 0.95 & 0.90 & $r^{2}$ & 0.93 & 0.86 & 0.81 \\
\hline \# components & 3 & 4 & 2 & 2 & \# components & 2 & 2 & 2 \\
\hline Max bias $_{\text {jack }}$ & 1.6 & 2.68 & 2.99 & - & Max bias & 2.68 & -4.40 & - \\
\hline Average biaşack & 0.002 & -0.002 & 0.008 & - & Average bias & -0.38 & -0.72 & - \\
\hline \multicolumn{9}{|c|}{ Modern Analogue Technique } \\
\hline RMSE, ${ }^{\circ} \mathrm{C}$ & 1.22 & 1.19 & 1.09 & - & RMSEP & 2.12 & 2.18 & - \\
\hline$r^{2}$ & 0.98 & 0.98 & 0.98 & - & $r^{2}$ & 0.96 & 0.95 & - \\
\hline Max bias & 0.34 & 0.39 & 4.01 & - & Max bias & 2.3 & 0.03 & - \\
\hline Average bias & -0.14 & -0.04 & -0.05 & - & Average bias & -0.47 & -0.01 & - \\
\hline \multicolumn{9}{|c|}{ Artificial Neural Network } \\
\hline RMSE, ${ }^{\circ} \mathrm{C}$ & 0.97 & 1.20 & 1.35 & 1.18 & RMSEP & 2.85 & 2.54 & 2.10 \\
\hline$r^{2}$ & 0.98 & 0.96 & 0.98 & 0.88 & $r^{2}$ & 0.92 & 0.92 & 0.80 \\
\hline Max bias & - & - & - & - & Max bias & 2.69 & 3.26 & - \\
\hline Average bias & - & - & - & - & Average bias & -0.7 & -0.25 & - \\
\hline
\end{tabular}


B.
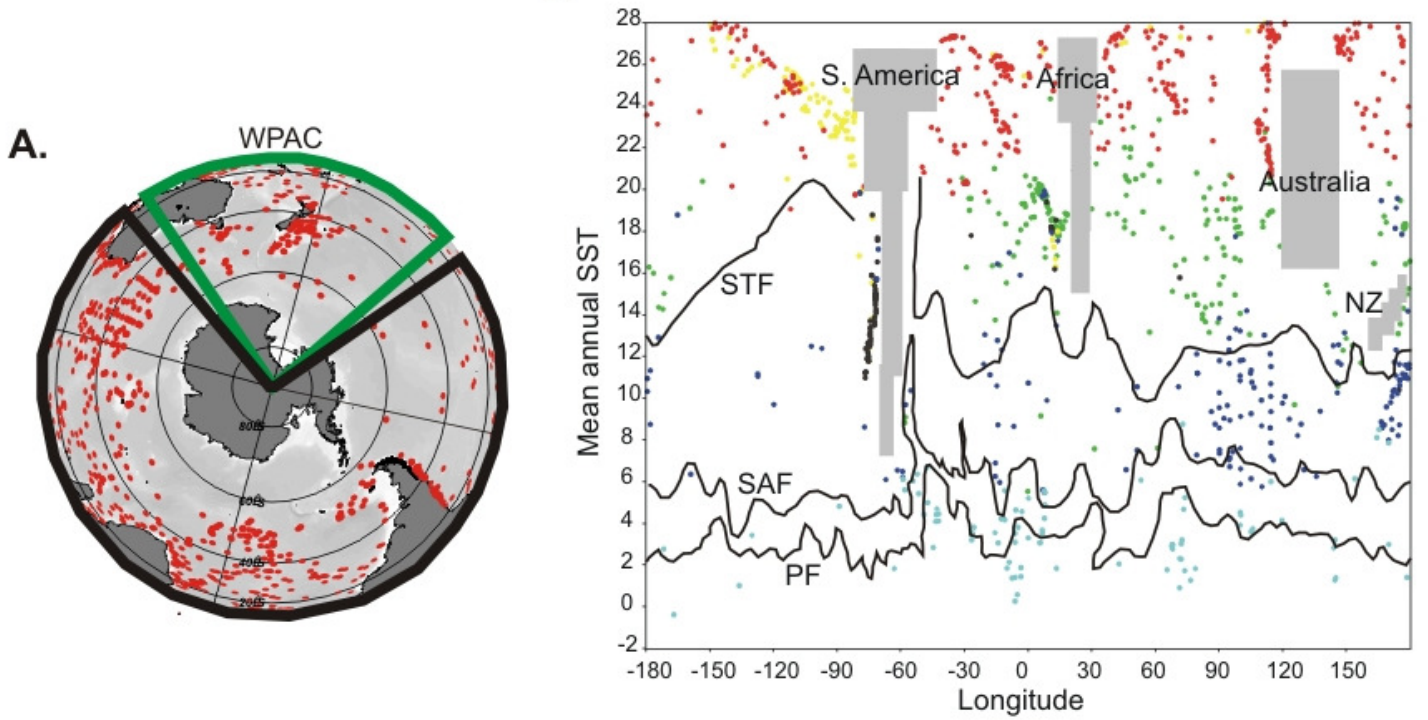

Figure A.4.2.1. A: 1157-sample Southern Hemisphere foraminifera training set. Samples included in WPAC test set within green polygon, samples used to train within black polygon. B: k-means cluster analysis of $1157-$ sample Southern Hemisphere foraminifera training set, confined to 6 clusters, showing generally meridonal distribution of cluster boundaries, but with two clusters (yellow and black) restricted mainly to the east Pacific. Longitude plotted against mean annual SST. Approximate location of major landmasses plotted, along with Polar Front (PF), Subantarctic Front (SAF) and Subtropical Fronts (STF).

Figure A.4.2.2. A: Samples from eastern Indian Ocean and west Pacific divided into two: WPAC_A (red) and WPAC_B (blue), with a $1000 \mathrm{~km}$ buffer of excluded samples (clear). B: $k$-means cluster analysis of WPAC_A and WPAC_B, confined to 6 clusters, showing distinct clusters in tropical waters north of Australia and North of New Zealand. Dashed line at $25^{\circ} \mathrm{S}$ shows northern boundary of samples included in final cross validation

A.
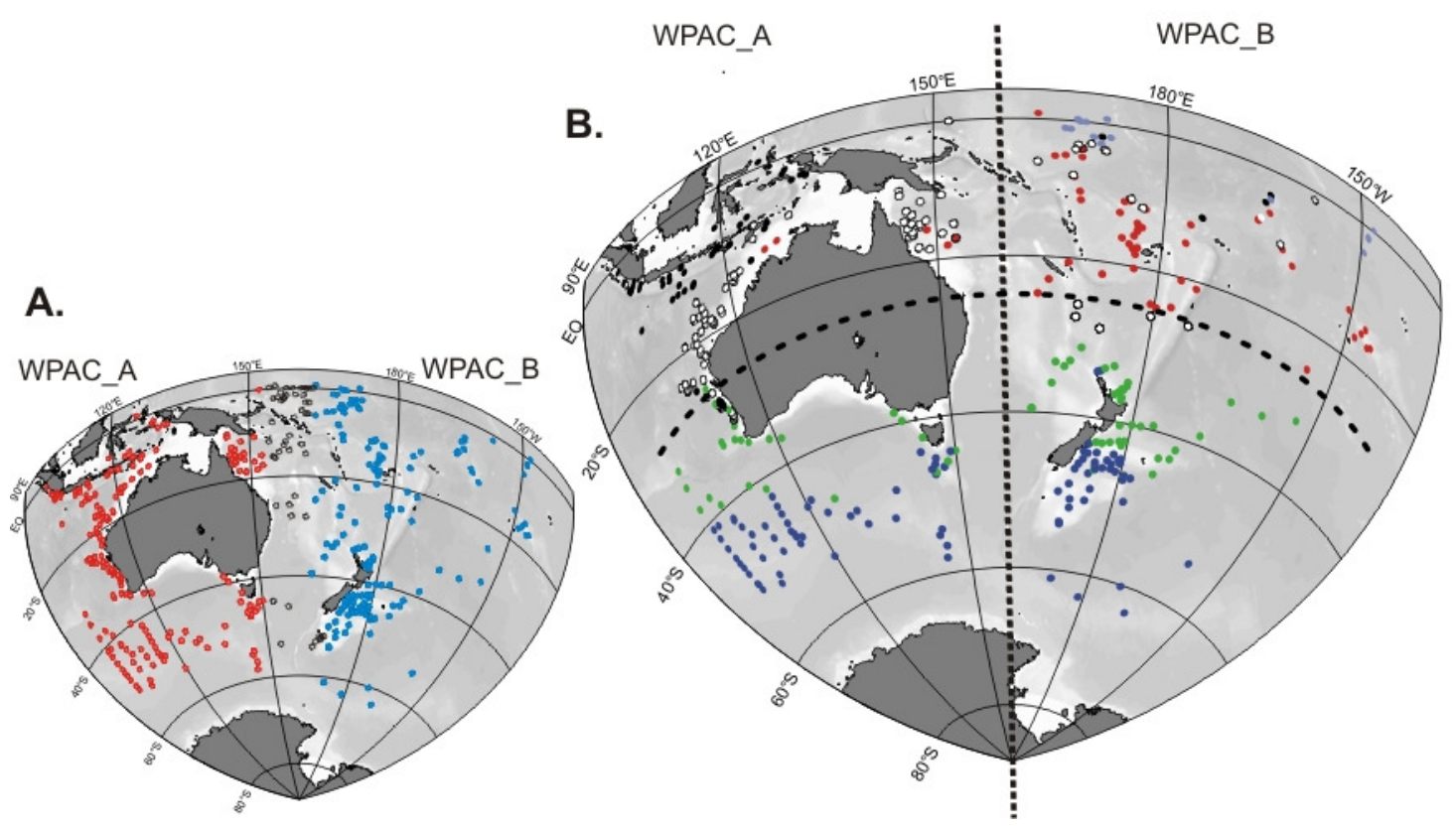
independent cross validation exercises undertaken. In other words, better performance statistics may be achievable for SW Pacific samples by allowing analogue sample from within the region, but in a way that still accounts for spatial autocorrelation. Although spatially independent cross validation again produces poorer results than the leave-oneout cross validation (Table A.4.2), another clustering exercise of the WPAC training set, again constrained to six clusters, clearly shows provincialism at this scale in the warmer part of the training set (Figure A.4.2.2B). The white and black cluster groups, well represented in WPAC_A, occur infrequently in WPAC_B, while the equivalent parts of the SST gradient in the WPAC_B dataset are occupied by orange and light blue cluster groups. However, when the split-sampling exercise is confined to the samples south of $25^{\circ} \mathrm{S}$ (shown by samples south of the dashed line in Figure A.4.2.2B), i.e. within a range where there appear to be similar assemblages in both the test and training sets, the differences in model performance remains (Table A.4.2). The ANN model performance under split-sampling (RMSEP $2.10^{\circ} \mathrm{C}$ ) is $\sim 1.8$ times worse than leave-one-out cross validation (RMSE $1.18^{\circ} \mathrm{C}$ ), and is comparable to (but slightly worse than) the splitsampling performance of the WA-PLS model (RMSEP $\left.1.92^{\circ} \mathrm{C}\right)$.

This exercise suggests that the ANN and MAT models do derive a proportion of their performance from their ability to exploit autocorrelative properties of training sets. The particular consequence of this is poor performance when faced with "unknown" assemblages. In such situations, WA-PLS model estimates are likely to be the more accurate of the three. 


\title{
5. Sea surface conditions during warm Marine Isotope Stage 11, east Tasman Sea, Southwest Pacific
}

\begin{abstract}
Marine sediment cores of Marine Isotope Stage 11 (MIS11, 423ka - 380ka) from the east Tasman Sea, SW Pacific Ocean, are examined for dinoflagellate cyst (dinocyst) assemblages, which are sensitive to changes in sea surface temperature (SST) and marine productivity. SST estimates from dinocyst assemblages confirm previously published SST data from foraminifera assemblages, that the east Tasman Sea was $\sim 2-$ $3^{\circ} \mathrm{C}$ warmer than the present during the peak warmth of MIS11. A two-step warming of MIS11 is observed. Between 428-415ka, SSTs were slightly below modern levels, with a pronounced cooling at $\sim 420 \mathrm{ka}$, and maximum warmth occurred between 415-400ka. These fluctuations were accompanied by assemblage changes indicative of an increased influence of Subantarctic Surface Water during glacial periods, inferred to correspond with a northward migration of the STF of at least 3 degrees of latitude from the present.
\end{abstract}

Two semi-quantitative proxies for primary productivity in surface waters, based on dinocyst and foraminifera assemblages, show a broad correlation between higher SST and decreased productivity on glacial-interglacial timescales. Both proxies suggest productivity during the peak of MIS11 way likely lower than the present. These glacial-interglacial variations in productivity are inferred to arise from migration of the STF, as well as influence of terrestrially derived nutrients from the adjacent New Zealand landmass.

During the time period covered by this study, a strong correlation occurs between a long (1Mya) published SST record from the study area and the foraminifera-based proxy for productivity. This correlation is strongest during the MIS12-11 deglacial transition, and remains strong until the MIS9-8 transition, $300 \mathrm{ka}$. In contrast, between $\sim 300 \mathrm{ka}$ and the present, the correlation between the two records is weak. This step-change in correlation may be due to one or more of the following: (i) an 
artefact of the prolonged MIS12-11 deglaciation, (ii) increased variability in the input of locally terrestrially- derived nutrients into the study area after $\sim 300 \mathrm{ka}$, or (iii) the onset of Fe fertilisation by Australian-derived dust after MIS9.

\subsection{Introduction}

Global marine productivity over the next century is projected to decrease with increasing temperatures, broadly as a result of less energetic circulation leading to enhanced stratification and lower nutrient concentrations in the upper ocean, although regional variation is expected (Bopp et al., 2001; Sarmiento et al., 2004; Beardall et al., 2009; Steinacher et al., 2010; Hoegh-Guldberg and Bruno, 2010). Although observations of a decade long satellite record show a trend of decreasing productivity coinciding with increasing SST, particularly in tropical oceans (Brenfield et al., 2006), enhanced productivity has been observed in some regions of the Southern Ocean accompanied by a strengthened Antarctic Circumpolar Current (Sarmiento et al., 2004; Behrenfeld et al., 2006; Toggweiler and Russel, 2008). Moreover, there are observations of increases in primary productivity in the major eastern-ocean upwelling systems (Demarcq, 2009; Gutiérrez et al., 2011). It is likely to take some decades to unambiguously separate longer-term trends from the natural multi-decadal variability of oceanic systems (Henson et al., 2010).

One way to explore the baseline (pre-industrial) natural variability of marine systems, is to examine long time series of fossil plankton and other environmental proxies from the sedimentary record. The variability over periods longer than are available from the historical record can provide additional information on the range of future projections, illustrate local and regional responses to previous environmental perturbations, and identify the long-term consequences of change.

Here, we describe dinoflagellate cyst (dinocyst) assemblages, which are sensitive to changes in sea surface temperature (SST) and productivity, recovered from three marine sediment cores (MD06-2987, -2988, -2989) in the east Tasman Sea off western South Island, New Zealand (Figure 5.1), to evaluate environmental responses to the prominent interglacial, Marine Isotope Stage (MIS) 11 (423ka - 


\section{Chapter 5}

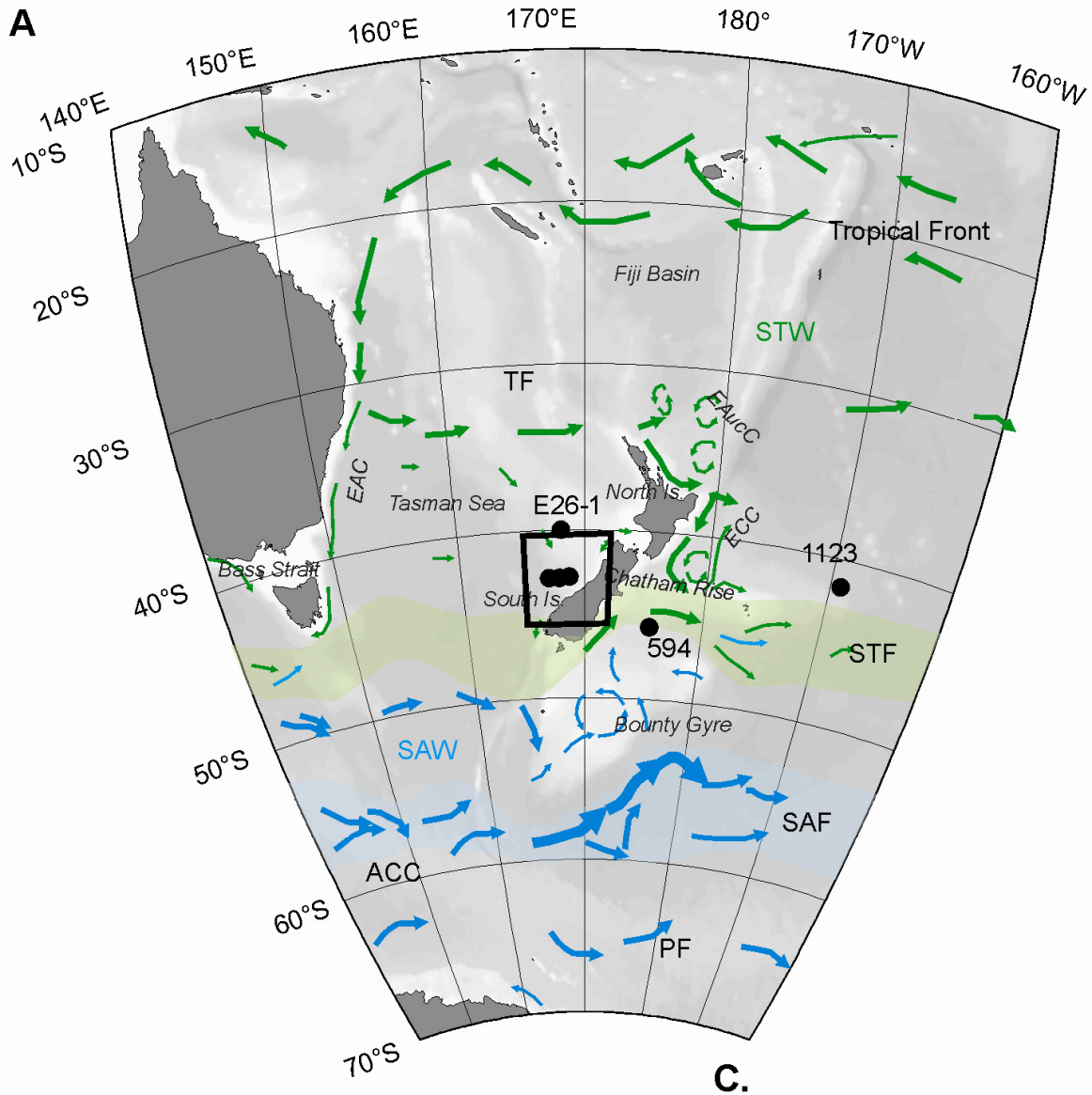

B.

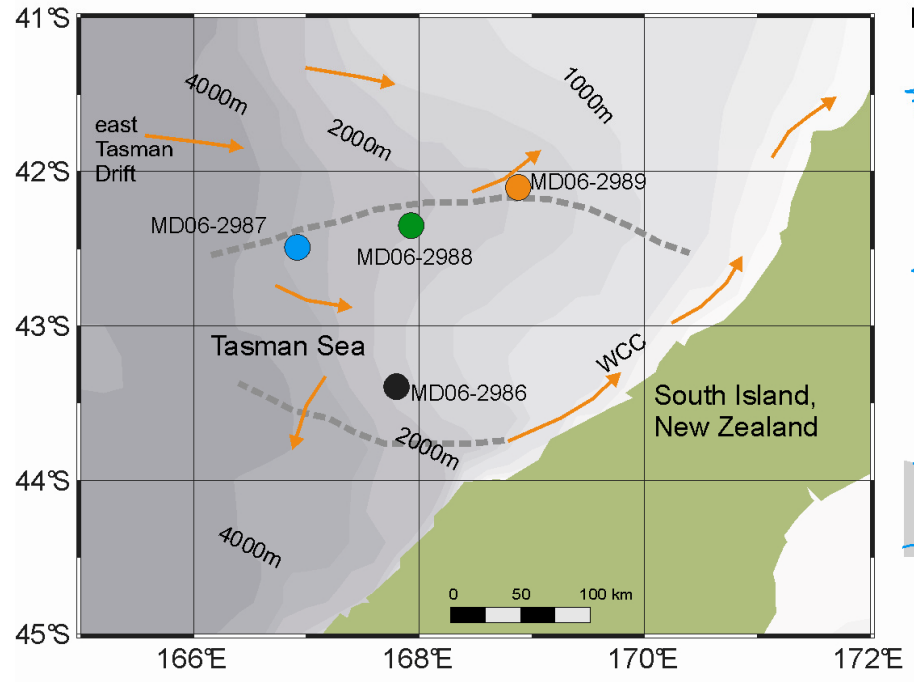

MD06-2987 MD06-2988 MD06-2989

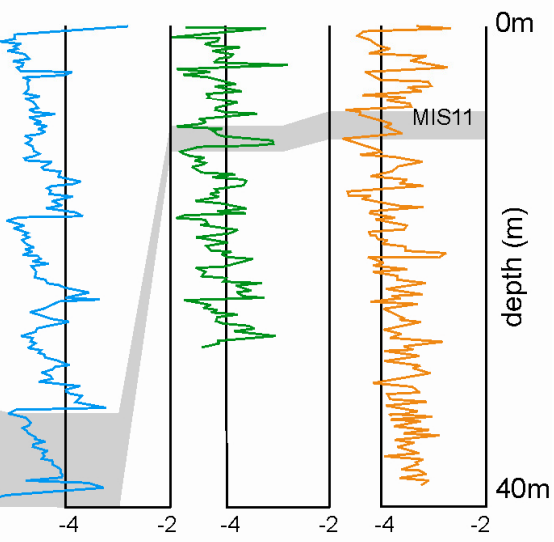

$\delta^{18}$ O Uvigerina sp.

Figure 5.1. Location maps and core summary. A. Regional circulation of southwest Pacific, showing the east Tasman Sea study area (black box), and additional core sites mentioned in the text. Acronyms from north to south: $\mathrm{STW}=$ Subtropical Water, TF = Tasman Front, EAC = East Australian Current, STF = Subtropical Front, SAW = Subantarctic Water, ACC = Antarctic Circumpolar Current. B. Map of east Tasman Sea study area, showing locations of cores discussed in text. $W C C=$ West Coast Current. Approximate location of Hokitika and Cook Canyons are northern and southern dashed line, respectively. C. Benthic isotope record from three piston cores (MD06-2987 - blue, MD06-2988 - green, MD06-2989 - yellow) examined in this study, with MIS10-12 highlighted. 
380ka) (Lisiecki and Raymo, 2005). Although the orbital forcing configuration for MIS11 was similar to the last deglacial and Holocene (Loutre et al., 2004), SSTs off the western South Island appear to have been $\sim 2.5^{\circ} \mathrm{C}$ warmer than the Holocene optimum (ca. 12-6ka), and $\sim 3.5{ }^{\circ} \mathrm{C}$ warmer than the present (Hayward et al., 2012). The aims of this study are to:

1. Create a dinoflagellate-based MIS11 SST record for the east Tasman Sea, to test the existing foraminifera-based estimates and build a local multi-proxy stack of SST.

2. Document the response of proxies for marine productivity to this warm interglacial in the east Tasman Sea.

\subsection{Background}

\subsubsection{East Tasman Sea: setting and oceanography}

The central West Coast of the South Island, New Zealand, is bordered by a continental shelf, 20 - 50km wide, which is incised by the heads of the large Hokitika and Cook submarine canyons, that extend to abyssal depths of the east Tasman Sea (Proust et al., 2006) (Figure 5.1B). On the New Zealand landmass, to the east, uplift rates in the Southern Alps are up to $10 \mathrm{~mm} / \mathrm{yr}$ (Norris and Cooper, 2001; Little et al., 2005 ) and there are numerous peaks $>3000 \mathrm{~m}$. The rapid uplift and high rainfall (c.3 $\mathrm{m}^{-1} \mathrm{yr}^{-1}$ at the coast, up to $10 \mathrm{~m}^{-1} \mathrm{yr}^{-1}$ in the mountains) results in large volumes of river discharge, and high suspended sediment loads transported to coastal waters (Hicks et al., 1996, 2011).

The local ocean circulation is subdued (Tilburg, 2001; Waugh et al., 2006) (Figure 5.1A). The Subtropical Front (STF) is $\sim 500 \mathrm{~km}$ to the south of the study area, where it forms a diffuse zone in the south Tasman Sea (Hamilton, 2006). It crosses the south Tasman Sea (Stanton, 1998) before deflecting around and along the southern and eastern coasts of the South Island (Heath, 1985; Chiswell, 1996; Sutton, 2003). The eastward flowing Tasman Front lies $>1000 \mathrm{~km}$ to the north of the study area, and stems from the southwards flowing tropical waters of the East Australian Current 
(Tilburg et al., 2001; Ridgway and Dunn, 2003), then turns south around the eastern continental margin of the North Island (Figure 5.1A). Between these prominent ocean fronts and associated currents, there is an ill-defined easterly drift across the central Tasman Sea (Stanton, 1976; Heath, 1985; Ridgway and Dunne, 2003). The main body of this drift reaches New Zealand at about the central west coast of the South Island, where it splits into northerly and southerly components. A weak and ephemeral wind-driven current inshore of this easterly drift, called the West Coast Current (WCC), flows northeast along the continental shelf before swinging east into Cook Strait as the D'Urville Current (Stanton, 1976; Heath 1985). The WCC is seasonally perturbed by wind and freshwater inflow from rivers (Heath and Gilmour, 1987; Greig et al., 1988).

The offshore east Tasman Sea is generally an oligotrophic (low nutrient and productivity) setting compared to the nearshore environment, although chlorophylla concentrations are elevated compared to the open Pacific Ocean (Tilburg et al., 2002). Seasonal productivity in the area has been modelled by introducing nutrients to surface waters by mixing from winter storms, with peak productivity occurring during spring following a rapid shoaling of the thermocline (Rahmstorf, 1992; Hadfield and Sharples, 1996; Hadfield, 2000; Tilburg et al., 2002). Nearer to shore, wind-driven upwelling occurs sporadically within $20 \mathrm{~km}$ of the coast (Bradford, 1983; Heath, 1985; Stanton and Moore, 1992), while input from numerous large rivers frequently forms a 30-50 km wide plume of low-salinity sediment-bearing surface water, which occasionally extends further offshore in the form of jets or filaments (Stanton, 1976; Stanton and Moore, 1992; Moore and Murdoch, 1993). This reduces the near-shore mixed layer depth, and, combined with the extra nutrient input, result in higher levels of productivity in inshore relative to offshore waters (Chang and Bradford, 1985; Bradford-Grieve et al., 1996). Despite the relatively high nutrient levels, spring blooms in inshore waters result in seasonal depletion of nitrate (Chang et al., 1995).

\subsubsection{Dinoflagellate cysts}

Dinoflagellates make a significant contribution to productivity and primary grazing in modern oceans, at times forming blooms that dominate carbon fixation 
and primary carbon cycling in surface waters, including in the study area (Chang, 1988; Verity et al., 1993; Sherr and Sherr, 2007; Wasmund et al., 2011). About 20\% of modern dinoflagellates form fossilisable cysts (Dale, 1996; de Vernal and Marret, 2007) resulting in approximately 80 identifiable sub-fossil taxa in modern sea-floor samples (Marret and Zonneveld, 2003). The organic-walled cysts (dinocysts) examined in this study represent a resting stage in the dinoflagellate life cycle, which is generally formed after sexual reproduction or in response to environmental stress (Pfiester and Anderson, 1987; Figueroa et al., 2007; Kremp et al., 2009). Two types of dinocysts are most common in Quaternary sediments: gonyaulacoid, which are generally formed by dinoflagelates containing chloroplasts, and peridinoid, which are generally formed by dinoflagellates with heterotrophic nutritional strategies (Zonneveld and Brunner, 2000; Zonneveld et al., 2010).

\subsubsection{Marine Isotope Stage (MIS) 11}

In the New Zealand region, six marine records document paleoceanographic change during MIS11, with most attention focused on understanding the dynamics of the Subtropical Front (STF) to the east of New Zealand. SST estimates from foraminifera assemblages, both north and south of the STF east of New Zealand, indicate that SSTs during MIS11 were $\sim 2-3.5^{\circ} \mathrm{C}$ above present-day temperatures (Weaver et al., 1998; Schaefer et al., 2005; Wilson et al., 2005; Crundwell et al., 2008; Hayward et al; 2008,2012 ). In a regional-scale qualitative oceanographic reconstruction based on these foraminifera-based SST estimates, Hayward et al $(2008,2012)$ inferred surface water circulation was largely similar to the present. Specifically, they suggest the position of the STF to the east of the New Zealand was unchanged compared to the present, where it is today constrained by the west-east flow of SAW and STW along the southern and northern flanks of the Chatham Rise, respectively (Uddstrom and Oien, 1999). The main variation that Hayward et al. (2008) inferred, compared to present day circulation, was an enhanced southwards flow of STW across the STF into the Bounty Trough area. In the east Tasman Sea, a 1-million year record of SSTs derived from foraminifera assemblages was recently presented from a composite of two cores (MD06-2986 and MD06-2989) that overlap at MIS11 (Figure 5.1B) (Hayward et al., 2012). SST estimates from the ANN25 model for MIS11 from the 
two east Tasman Sea cores indicates a $10 \mathrm{ka}$ period of SSTs $\sim 3.5^{\circ} \mathrm{C}$ above present-day temperatures (Hayward et al., 2012). In contrast, SST estimates using another model (the modern analogue technique) on the same foraminifera assemblages suggest that MIS11 was no warmer than the Holocene (Hayward et al., 2012). In this chapter, all further references to foraminifera SST refer to the ANN25 model, as this model is preferred by Hayward et al. (2012), and its superior performance supported by trials in this study (Chapter 4 , this study).

\subsection{Methods}

\subsubsection{Core locations and chronology}

Samples from three sediment cores are examined, which have been collected in an offshore-onshore transect: MD06-2987, -2988, -2989 (Figure 5.1B). All cores were collected using a Calypso giant piston corer from the RV Marion Dufresne during the 2006 MATACORE Cruise (Proust et al., 2006), from water depths of 3220m (MD062987), 1790m (MD06-2988) and 1250m (MD06-2989). The cores, each 30-40m long, were retrieved from channel-proximal levees of the Hokitika and Cook Canyons, with the aim of recovering a high resolution Quaternary record of mid-latitude environmental change. The core sites are positioned to sample a range of bottom water masses, and allow high resolution linkage with terrestrial proxies. Site surveys, including multibeam seafloor topography and multiple short sediment cores revealed sinuous channels, particularly in the Hokitika Canyon, with significant levee accumulation on the north banks of oxbow bends (Proust et al., 2006). Each target was chosen to lie within 5-10 km of the north canyon wall, in locations unlikely to be subject to downslope movement of sediment and which had a seismic signature indicative of relatively rapidly deposited, flat-lying strata with no signs of sub-seafloor gas accumulation (Proust et al., 2006). Cores are stored refrigerated at the NIWA core store, Wellington.

Sediment recovered at each site was extensively bioturbated greenish to olive grey silty clays, containing abundant foraminifera (Proust et al., 2006), with the percent $\mathrm{CaCO}_{3}$ at MD06-2989 over the interval sampled in the this study $70-80 \%$ (Hayward et 
al., 2012). The age model adopted for the cores is based on matching low resolution benthic foraminiferal oxygen isotopes (Uvigerina spp.) to the global LRO4 benthic stack (Lisiecki and Raymo, 2005) (Figure 5.1C), supported by the occurrence of three rhyolitic tephras from New Zealand's Taupo Volcanic Zone in MD06-2989, that are well-dated off eastern New Zealand (11.18 $\mathrm{m}=$ matched with tephra in Site ODP 1125, 550 ka; 20 m = Kaukatea Tephra, 880 ka; 24.01 m = Potaka Tephra, 1000 ka; Carter et al., 2004; Hayward et al., 2012). The highest average accumulation rates were observed in the deepest core, MD06-2987 $(39 \mathrm{~m}=435 \mathrm{ka}, 9 \mathrm{~cm} / \mathrm{kyr})$, while accumulation rates were lower in the mid-slope levee cores MD06-2988 $(27 \mathrm{~m}=$ $980 \mathrm{ka}, 2.7 \mathrm{~cm} / \mathrm{kyr})$ and MD06-2989 (39m = 1766ka, 0.46 cm/kyr).

\subsubsection{Dinocyst census counts}

Ninety samples spanning MIS12-10 were collected from the three cores. From MD06-2988, 44 samples were sub-sampled (average 1 sample/1.8kyr), and 33 samples were collected from MD06-2989 (average 1 sample/3kyr). At site MD062987, 13 samples were collected from the early part of MIS11 (423ka - 390ka, average 1 sample/2.5kyr), as that was the base of the core.

All samples were processed using standard dinocyst techniques for Quaternary marine sediments. Cold $33 \% \mathrm{HCl}$ was introduced into $c a .5 \mathrm{~g}$ of dried sample to remove carbonate, silicate was removed by 24 hours in cold $40 \% \mathrm{HF}$, followed by a second cold $33 \% \mathrm{HCl}$ wash, brief ultrasonic treatment, removal of fines with $6 \mu \mathrm{m}$ filter and mounting on glass coverslips in glycerine jelly (Merthens et al., 2009; Crouch et al., 2010). A single Lycopodium tablet (batch number 938934) was added to each sample for determination of absolute abundances. A minimum of 300 dinocysts were counted for each sample. Dinocyst count data are included in

\section{Supplementary Material S5.1.}

\subsubsection{SST estimates from dinocyst assemblages}

In the SW Pacific, the general utility of dinocysts in faunal transfer functions has been demonstrated in the late Quaternary from Deep Sea Drilling Project (DSDP) Site 594 off the east coast of New Zealand (Figure 5.1A), where Late Quaternary SST and salinity were reconstructed using a training dataset of 118 surface sediment samples 
(Marret et al., 2001). There is also extensive Northern Hemisphere experience, where a large (>1000 sites) dinocyst training set (Rochon and deVernal, 1994; Rochon et al., 1999; de Vernal et al., 2001; Radi et al., 2007; Pospelova et al., 2008) has been used to reconstruct productivity, salinity, SST, and ice cover (e.g., de Vernal et al., 2005; Bonnett et al., 2010) using modern analogue technique (MAT) and artificial neural network (ANN) models in numerous North Atlantic sites.

For this study, a 311-sample training set (SH-311) of dinocyst census counts from seafloor samples from the Southern Hemisphere is compiled (Marret et al., 1997; Harland et al., 1998; Vink et al., 2000; Zonneveld et al., 2001; Holwarth et al., 2007; Esper and Zonneveld, 2002, 2007; Crouch et al., 2010; Verleye and Louwye, 2010; Laurijssen and Zonneveld, in press; Chapter 2). Ordination techniques indicated that SST correlated most strongly to the dinocyst distribution, and accounted for $37 \%$ of the species-environmental relationship after removal of covarying gradients. SST was twice as strongly correlated with the dinocyst distribution than apparent secondary environmental gradients (Chapter 2). This ordination, along with observations of the importance of water temperature as a control of dinoflagellate growth and cyst formation (e.g., Jensen and Moestrup, 1997; Grzebyk and Berland, 1997; Hwang and Lu, 2000; Juhl, 2005; Navarro et al, 2006; Guerrini et al., 2007; Laabir et al., 2011), make SST the most suitable target for quantitative reconstruction.

SSTs were estimated from dinocyst assemblages for each sample using three methods: weighted averaging with partial least squares (WA-PLS), the modern analogue technique (MAT) and an artificial neural network (ANN). For most samples, the average of the three models is presented, with exceptions discussed below.

In weighted averaging, the average environmental conditions over those sites where the taxon is present are weighted by the relative abundance of the taxon (ter Braak and Looman, 1986; Birks, 1995). WA-PLS explores subsequent axes along which components of the target environmental gradient may lie (ter Braak and Juggins, 1993). In contrast, a MAT model does not seek to define a relationship between assemblage composition and environment, but instead selects similar biological 
assemblages to the fossil assemblages from the modern training set as environmental analogues, using a dissimilarity measure (Hutson, 1980; Guiot and de Vernal, 2007). Here, a chord dissimilarity measure was used to select the five nearest analogues. An ANN develops algorithms that reproduce a target environmental parameter through iterative review and correction of multiple (typically 2-20) nonlinear neurons (typically for 500-3000 training epochs) (Malmgren and Nordlund, 1997; Malmgren et al., 2001). ANNs were trained using the program Tiberius (www.tiberius.biz). This software contains a single hidden layer, with one fixed linear neuron, and variable numbers of non-linear neurons containing tan- $h$ functions. Optimal training was achieved using 10 non-linear neurons. The training regime followed Hayes et al. (2005) and Kucera et al. (2005):

In a "leave-one-out" cross validation, root mean square errors (RMSE) of the SH-311 database were $\pm 1.2^{\circ} \mathrm{C}(\mathrm{ANN}), \pm 1.5^{\circ} \mathrm{C}$ (MAT), and $\pm 1.8^{\circ} \mathrm{C}$ (WA-PLS), over the SST range in this study. The SH-311 training set is found to be spatially autocorrelated using the tests of Telford and Birks (2009). One way to assess the effects of spatial autocorrelation on apparent model performance is to assess prediction errors using spatially independent test sets (Birks at al., 2010). Although difficult to obtain appropriate balance in the relatively small training set assembled here, a 68-sample test set of samples around the New Zealand region was split from the training set and each sample separated by $>1000 \mathrm{~km}$ from the nearest training set sample. Model performance of this spatially independent test set was 1.3 times (WA-PLS) and $\sim 2$ times (ANN and MAT) poorer than leave-one-out cross validation (Chapter 4).

High dissimilarity values in MAT are often used to identify non-analogue situations (e.g., Gersonde et al., 2005; Sikes et al., 2009). Recent MAT reconstructions based on dinocysts (deVernal et al., 2005; Marret et al., 2008) have used a three point "reliability scale". We do not observe a strong relationship between model performance and the dissimilarity score in our training set (Chapter 4), and so only use a dissimilarity score higher than the $99^{\text {th }}$ percentile of those observed within the modern training set to identify fossil samples with poor similarity to modern assemblages (a chord distance of 0.41 ). 
Where the ANN and MAT models encounter familiar fossil assemblages, they are likely to predict with greater accuracy than WA-PLS, but WA-PLS performance should be superior as assemblages become less similar. For most fossil assemblages, we present the average of MAT, ANN and WA-PLS results. Where fossil dissimilarity scores exceed 0.41, MAT and ANN results are discarded, and only the WA-PLS model retained. This approach results in a RMSEP (RMSE of prediction) of $\sim \pm 1.5-1.8^{\circ} \mathrm{C}$.

\subsubsection{SST estimates using foraminifera assemblages}

We compare our record to published SST records for MD06-2986 and MD06-2989, where SST was estimated using an ANN model based on a Southern Hemisphere training set of $\sim 1200$ assemblages of planktonic foraminifera (Hayward et al., 2012). That record applied the ANN-25 SST model of Crundwell et al. (2008), which excludes many deeper-dwelling globorotalid taxa. We have added SST estimates from five new foraminifera census counts from MD06-2989 to create a SST record of 15 samples between $\sim 370-430 \mathrm{ka}$ (average sample resolution of 5kyr) (B. Hayward, pers. comm.). "Leave-one-out" cross validation errors are $\sim \pm 1.1^{\circ} \mathrm{C}$ for this method and training set (Kolodziej, 2010, Chapter 4).

\subsubsection{Productivity using dinocysts}

Although variation in SST is the strongest factor influencing dinocyst assemblages across the Southern Hemisphere, the diversity of dinoflagellate nutritional strategies (Jacobson, 1999; Stoecker, 1999) and an obligate association of many cyst-forming dinoflagellates with shallow shelf sediments for successful reproduction (Dale, 1992; Dale and Dale, 1992), lead to strong associations of dinocyst assemblages with both proximity to land and marine productivity (Marret and Zonneveld, 2003; Esper and Zonneveld, 2007; Pospelova et al., 2010).

Productivity in the modern east Tasman Sea is highest along the West Coast of the South Island. Further from shore, elevated chlorophyll-a concentrations extend westward into the Tasman Sea between $\sim 43-47^{\circ} \mathrm{S}$ (Figure 5.2), a broad zone coinciding with mixed surface waters of the diffuse STF in the south Tasman Sea (Figure 5.1A). Although the cores in the study area sample a transect of increasing water depth, they are located along the northern boundary of elevated chlorophyll-a 
associated with the modern STF. Hence, the cores are well positioned to record variation in chlorophyll- $a$ associated with changes in the position of the STF, although also under the influence of terrestrially-derived nutrient input. Dinocyst assemblages from sea-floor samples from east Tasman Sea change with distance from shore and productivity (details Chapter $\mathbf{1}$ ). This is clearly illustrated using a "dinocyst productivity index" established here based on observations from the east Tasman Sea. The "dinocyst productivity index" is the ratio of peridinoid taxa Selenopemphix nephroides, S. quanta, Echnidinium spp. and Brigantedinium spp. to all Impagidinium taxa, which are gonyaulacoid (Figure 5.2).

In the east Tasman Sea, there is a strong relationship $\left(r^{2}=0.72\right)$ between this index and the satellite - derived chlorophyll-a concentration (Figure 5.2). (NASA MODIS data, extracted using the Giovanni web-interface; Acker and Leptoukh, 2007). Seafloor samples from modern shelf and slope settings, the surface waters of which are associated with upwelling and freshwater input-driven productivity described in Section 5.2, are characterised by high values of this index, due mainly to high abundances of Brigantedinium spp. and Selenopemphix nephroides. Although the full SH-311 training set does not support quantitative reconstruction of productivity (Chapters 2 and 4), due to the strength of the gradient observed in the east Tasman Sea, we interpret high values of this "dinocyst productivity index" in the fossil record to infer the presence of a similar productivity regime to that of present-day nearshore waters.

\subsubsection{Productivity using foraminifera}

Across the Southern Hemisphere, foraminifera assemblages vary most with SST (Morely et al., 2005), but in the SW Pacific, a higher frequency of three planktic foraminiferal species, Globigerina bulloides, Turborotalita quinqueloba, Globigerinita glutinata have been observed in productive settings of well-mixed surface waters (e.g. Schiebel et al., 2001; Crundwell et al., 2008). We explored this relationship for modern SW Pacific samples, by comparing the relative abundance of these taxa in 262 sea-floor samples (Crundwell et al., 2008; Hayward et al., 2012) against six chlorophyll-a based biomes for the SW Pacific (Hardman-Mountford et al., 2008). Of the three taxa, only the proportion of $G$. bulloides varies in consistent way with 
A.

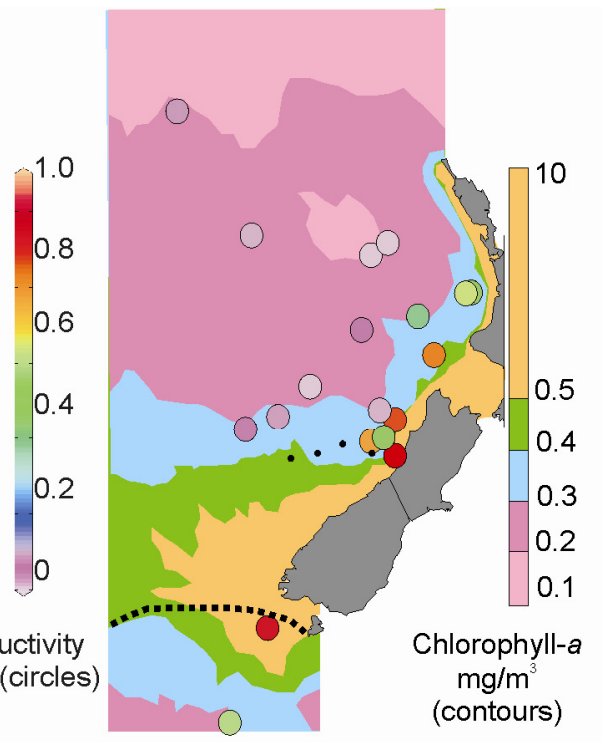

B.

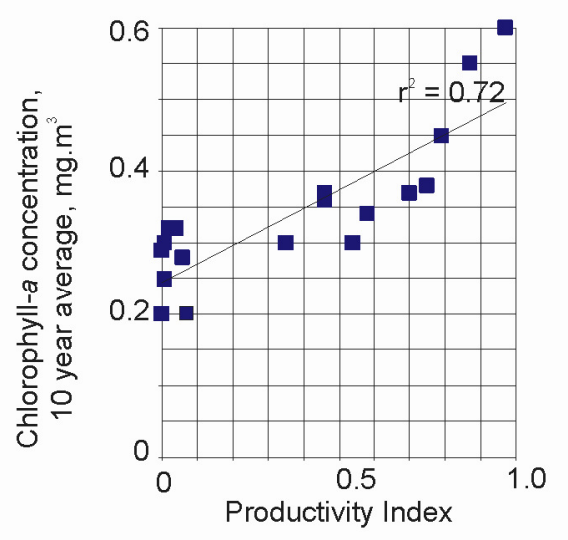

Figure 5.2. A. Distribution of a dinocyst-based eutrophic index in sea floor samples in the east Tasman Sea (circles), underlain by satellite-derived chlorophyll-a concentrations, 10-year average. Approximate position of STF shown by dashed line. B. Same data plotted showing an approximately linear relationship between the two variables, with a coefficient of determination $r^{2}=0.72$.

Figure 5.3. A. Distribution of chlorophyll-a based biomes in the SW Pacific (Hardman-Mountford et al., 2008), and the location of sea floor foraminifera samples, (additional samples north, west and east of this map are included in the graphs) (Hayward et al., 2012), B. Box plot of G. bulloides against chlorophyll-a biome, showing maximum, 75th percentile, medium, 25th percentile, minimum. C. Box plots of G. glutinata and T. quinqueloba against chlorophyll-a biome.

A.

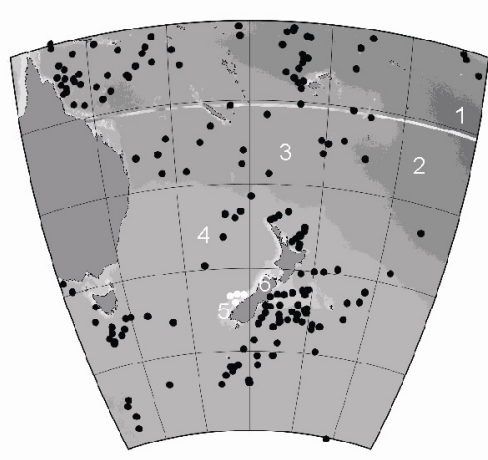

B.

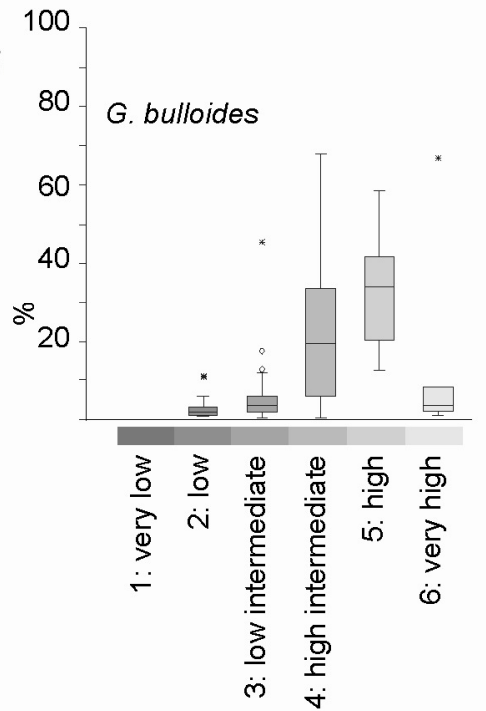

C.

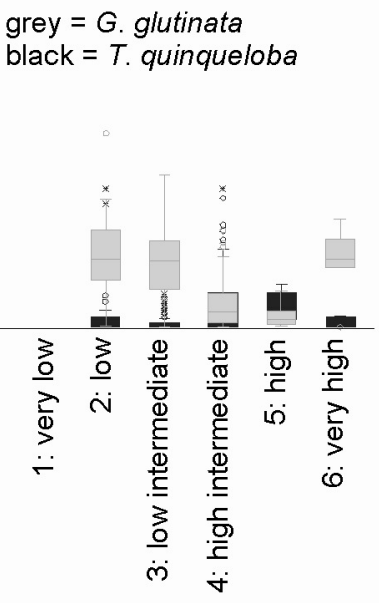

the chlorophyll-a biomes (Figure 5.3). Although a there is a degree of overlap between each biome, the relative abundance of $G$. bulloides increases with increasing chlorophyll- $a$, from the "low" through to the "high" chlorophyll- $a$ biomes, 
although this relationship does not hold for the highest chlorophyll-a biome, which in the SW Pacific is generally a feature of near-shore shelf settings. We use the percentage of $G$. bulloides as a proxy for relative chlorophyll-a concentration. Low abundances (< 15\%) indicate chlorophyll-a biomes 1-4, while higher abundances (> 40\%) are likely indicative of chlorophyll-a biomes 4-5. Notwithstanding the correlation observed here, we acknowledge that in ordination of a hemispheric-wide modern training set (Morely et al., 2005), G. bulloides also exhibits a close relationship with SST.

A poor correlation has been noted between the \% G. bulloides and another productivity proxy, using benthic foraminifera, (the Bulimina Index), in the cores examined in this study (Hayward et al., 2012). However, the Bulimina Index in these cores is based on incidental observations made during census counts of planktonic foraminifera. Due to the resulting low count sum in most samples, we prefer to use the percentage of $G$. bulloides.

\subsubsection{Water mass indicators from dinocysts}

In the New Zealand region, the most significant change in sea-floor dinocyst assemblages is observed across the STF (Sun and McMinn, 1994; Crouch et al., 2010; Chapter 2), reflecting the strongly contrasting properties (e.g., temperature, seasonality, kinetic energy, and nutrients; Bradford-Grieve et al., 1997; Boyd et al., 1999; Murphy et al., 2001) of water masses either side of the front. In modern sediments, the relative abundances of 19 dinocyst taxa were observed to change across the STF (Table 2.3). The presence of these taxa is used here as a semiquantitative indicator of water mass overlying the study area between MIS12-10, by charting the proportion of taxa in each sample that fulfil the criteria in Table 2.3. No attempt was made to weight the relative importance or abundance of these occurrences. For example, the sample at $1041 \mathrm{~cm}$ (432.9ka) in MD06-2988 had the following taxa that fulfilled the criteria in Table 2.3: I. pallidum (2.5\%), S. antarctica (2\%), and Impagidinium paradoxum (3.4\%), thus was plotted 2/3 'SAW indicators' and $1 / 3$ 'STW indicators'. 


\subsection{Results}

\subsubsection{Dinocyst abundance}

Dinocysts were abundant and well-preserved in all samples. The average dinocyst concentration across all samples was 1800 specimens per gram sediment (dry weight) (Figure 5.4). All three cores had an abundance minimum of ca.12ka duration

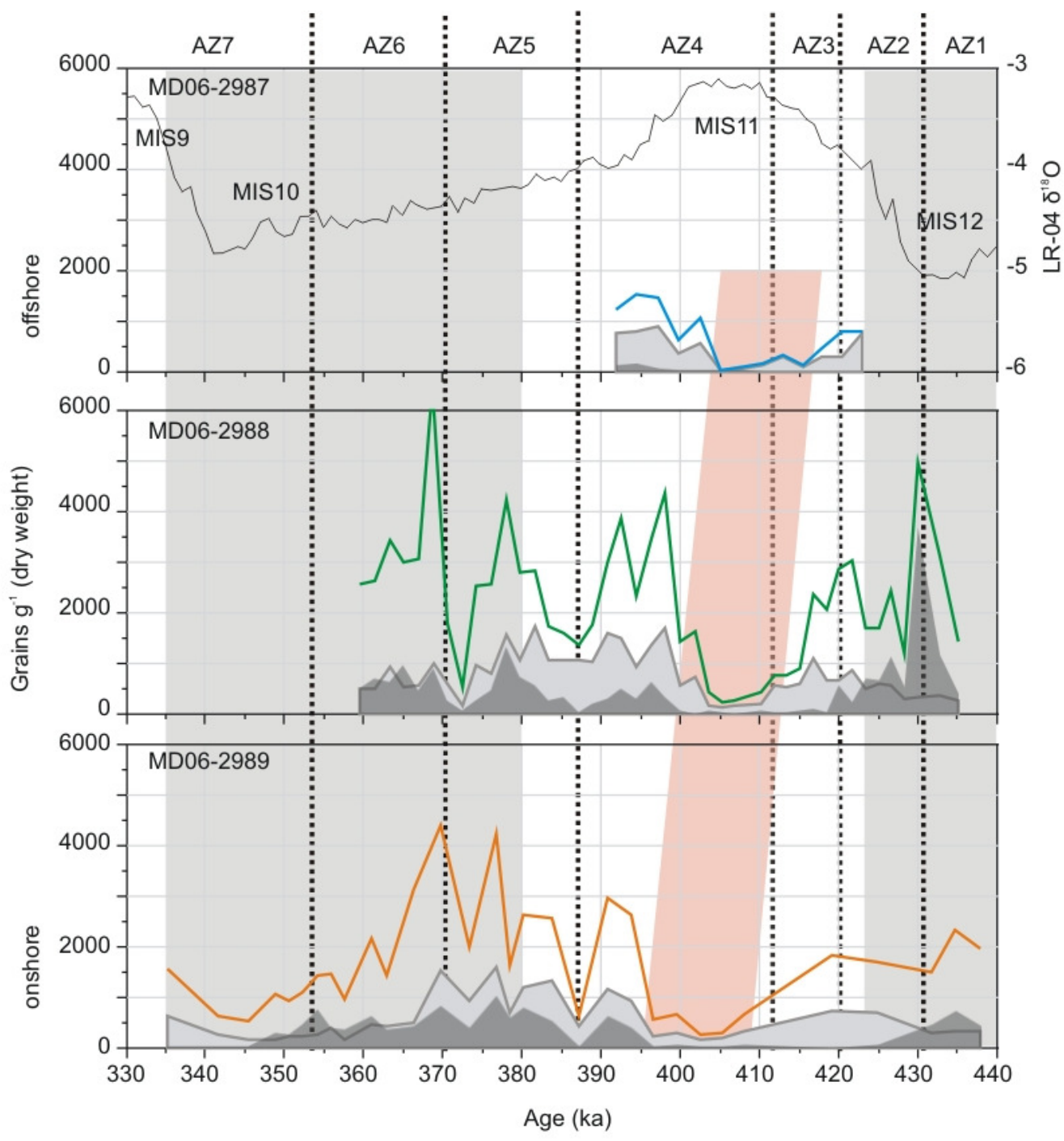

Figure 5.4. Palynomorph abundance over MIS11 in east Tasman Sea cores. Coloured (blue, green and orange) lines = total dinocyst abundance (cysts. $\mathrm{g}^{-1}$ dry weight), light grey = total Impagidinium spp., dark grey = total peridinioid. Peachcoloured bar shows ca. $5 \mathrm{ka}$ offset in flux minima during the peak of MIS11 between the south-western, offshore core MD06-2987 and the north-eastern, most inshore core MD06-2989. Global stack of benthic isotopes (LR04) shown for temporal scale (Lisiecki and Raymo, 2005).

during the early part of MIS11, when average abundance reduced to ca. 400 specimens per gram. The timing of these minima overlap, but are staggered over $c a$. 20ka, starting at distal site MD06-2987 at ca. 418ka, and terminating at the shallower MD06-2989 ca. 395ka (Figure 5.4). These intervals of minimal abundance 


\section{Chapter 5}

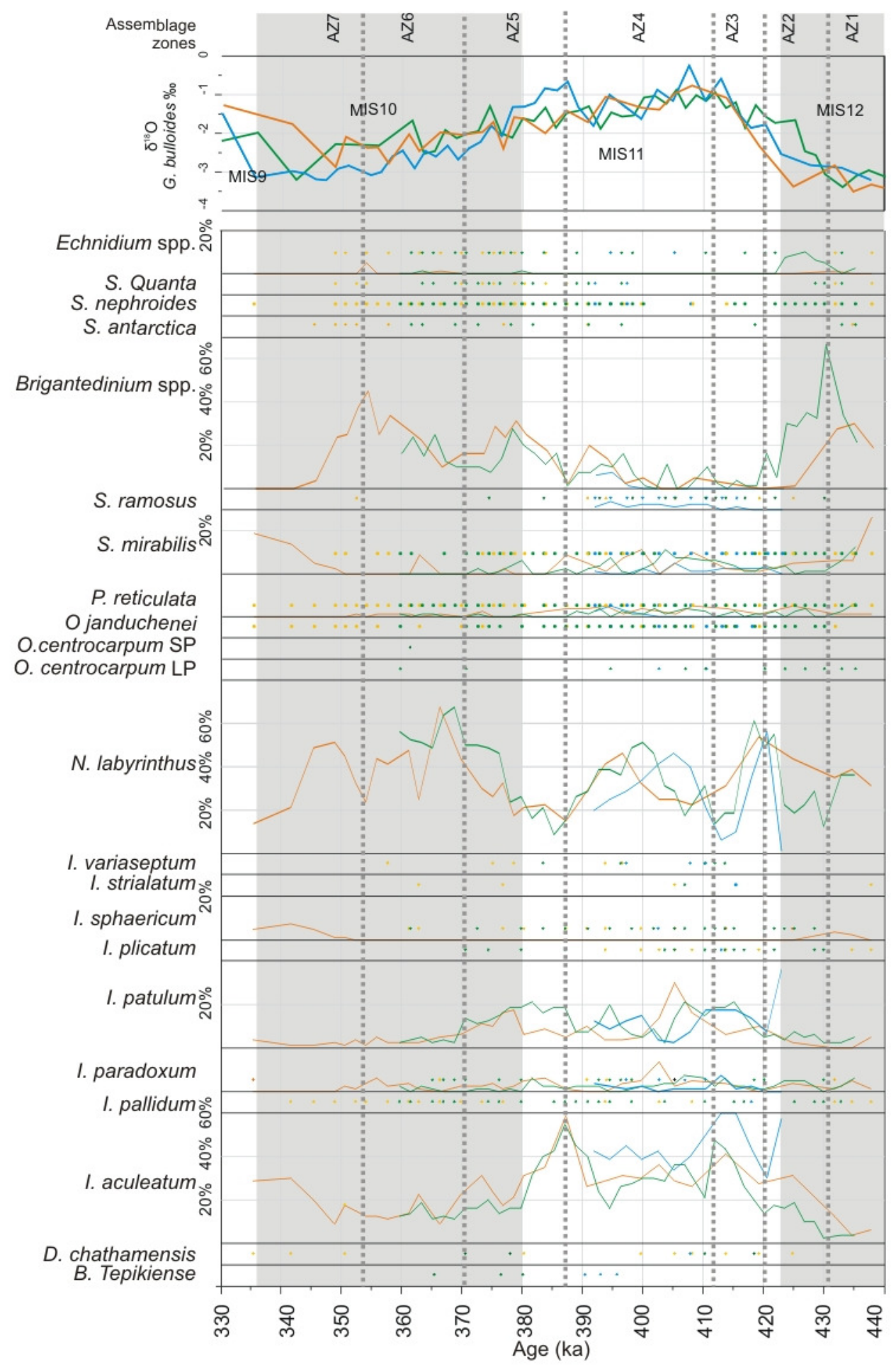

Figure 5.5. Dinocyst relative abundance for 90 samples for the MIS12-MIS10 interval. Cores are coded as follows: MD06-2987 = blue, MD06-2988 = green, MD06-2989 = yellow. Dot indicates presence $<5 \%$. Composition of assemblage zones AZ1 AZ7 discussed in text. 
Chapter 5

coincide with very low concentrations of peridinioid cysts, particularly Brigantedinium spp. Low concentrations of peridinioid cysts are not only restricted to these intervals, but are sparse for the preceding 5-10ka when total abundances were closer to average concentrations (Figures 5.4 and 5.5).

\subsubsection{Dinocyst assemblages}

Dinocyst assemblages of all the three cores were dominated by the peridinoid genus Brigantedinium spp, and gonyaulacoid species Impagidinium aculeatum and Nematosphaeropsis labyrinthus (Figure 5.5). A mean diversity of 15 taxa per sample was recorded, and a maximum diversity in a single sample of 20 taxa. Variation in the relative abundances of these three genera characterised much of the glacial/interglacial variation between MIS12-MIS10. A similar succession is observed in the three cores, with some local exceptions (Figure 5.5). Some of the variations associated with shoreline proximity observed in modern sea-floor sediments are observed between the cores; for example samples from the most distal core, MD062987 , contain the highest relative abundance of $I$. aculetaum, and generally lowest relative abundance of Brigantedinium spp.. Interestingly, Operculodinium centrocarpum, a dinocyst common in modern sea-floor samples from the SW Pacific and to the east Tasman Sea, particularly from shelf and slope settings, is rare in the core samples. To describe the succession from MIS12-MIS10, the section was qualitatively divided into 7 "assemblage zones" (AZ1-7) (Figure 5.5).

Full glacial conditions (AZ1 and AZ6) are characterised by high relative abundances of Brigantedinium spp. and relatively low abundances of Impagidinium spp. (maximum 20\%). Spiniferities mirabilis group is occasionally abundant, particularly in the shallowest site, while S. ramosus and I. sphaericum are absent and rare, respectively. Nematosphaeropsis labyrinthus is common.

The early stages of de-glaciation ( $A Z 2$ and AZ7) are characterised by a notable decrease in the relative, and absolute, abundance of Brigantedinium spp., which in turn is replaced by an increase in Impagidinium aculeatum and $N$. labyrinthus. In MD06-2989, S. mirabilis forms up to $20 \%$ of assemblages in the upper part of AZ7. The lowest sample examined in AZ2 in the offshore MD06-2987 contained unusually 
Chapter 5

high concentration of Impagidinium, with $58 \%$ I. aculeatum and $36 \%$ I. patulum (Figure 5.5).

The three MIS11 interglacial assemblage zones (AZ3-5) are characterised by increased abundances of $I$. aculeatum, I. patulum, and S. mirabilis, and common occurrences of $N$. labyrinthus in variable abundances. In the early phases, (AZ3) infrequent Selenopemphix spp. and Echnidinium spp. are recognised. Several species were recorded only in the interglacial assemblage; including Bitectatodinium tepikiense, Dalella chathamensis, Impagidinium striatulum, and Impagidinium variaseptum. The lower AZ3 is characterised by a rapid decrease in N. labyrinthus, low relative abundances of Brigantedinum spp. $(<5 \%)$, an absence of $S$. quanta, and high relative abundances of $I$. aculeatum. The highest abundances of $I$. aculeatum were observed in MD06-2987, the most off-shore site. Zone AZ4 is characterised by a peak of $N$. labyrinthus, and moderate abundances of $I$. aculeatum and I. patulum, and this zone contains the lowest absolute cyst abundances (Figure 5.4). In AZ4, the concentrations of Brigantedinium spp. remain low, but concentrations fluctuate and progressively increase up section to a maximum abundance of 20\% in MD06-2989. This increase is accompanied by the more frequent occurrence of other peridinoid cysts, along with an increase in the absolute abundance of dinocysts. The final interglacial zone, AZ5, has declining relative abundances of $I$. aculeatum and $I$. patulum, which is replaced by increases in N. labyrinthus and Brigantedinium spp.

Other taxa were observed to have no obvious change in presence or abundance throughout the cores. These include the cool water taxa Impagidinium pallidum, open ocean species Pyxidinopsis reticulata, and Impagidinium paradoxum, and the temperate water species Operculodinium janduchenei (Figure 5.5) Although the cool water taxa Selenopemphix antarctica was not observed in the early part of AZ4, it was present throughout the rest of the studied interval.

\subsubsection{SST models}

Three SST models, WA-PLS, MAT, and ANN, were applied to the dinocyst assemblages produced comparable results, but with several interesting differences (Figures 5.6A-C, Supplementary Material S5.2). When the fossil assemblages were 


\section{Chapter 5}

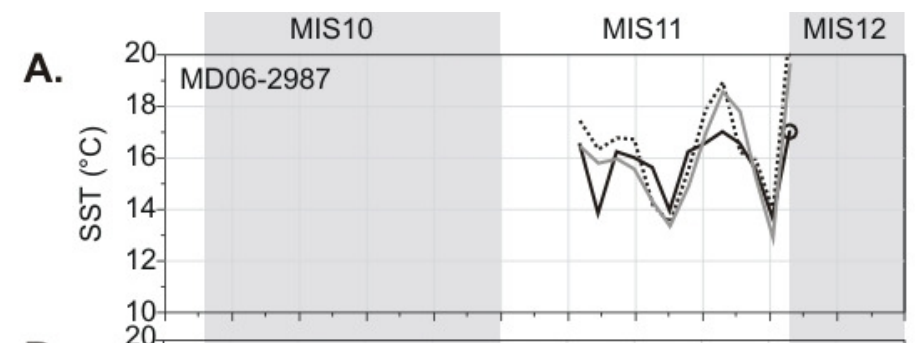

B.

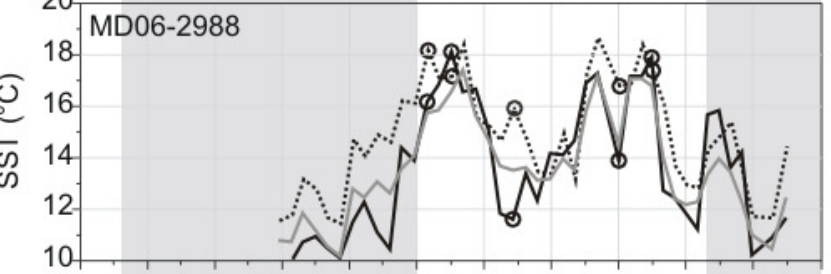

C.

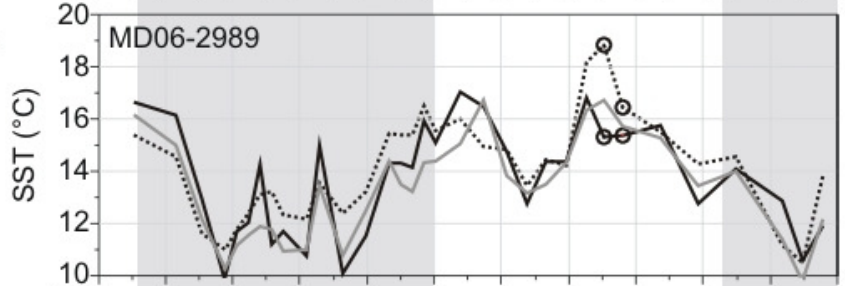

D.

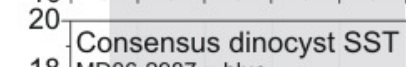

18-MD06-2987 = blue

O $16-\begin{aligned} & \text { MD06-2988 }=\text { green } \\ & \text { MD06-2989 }=\text { yellow }\end{aligned}$

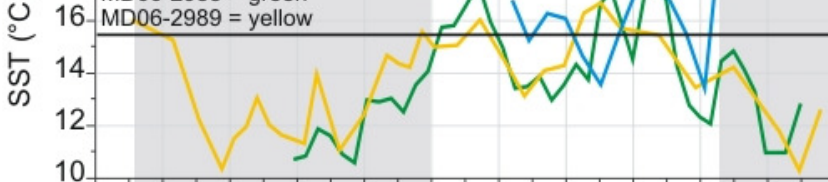

E.
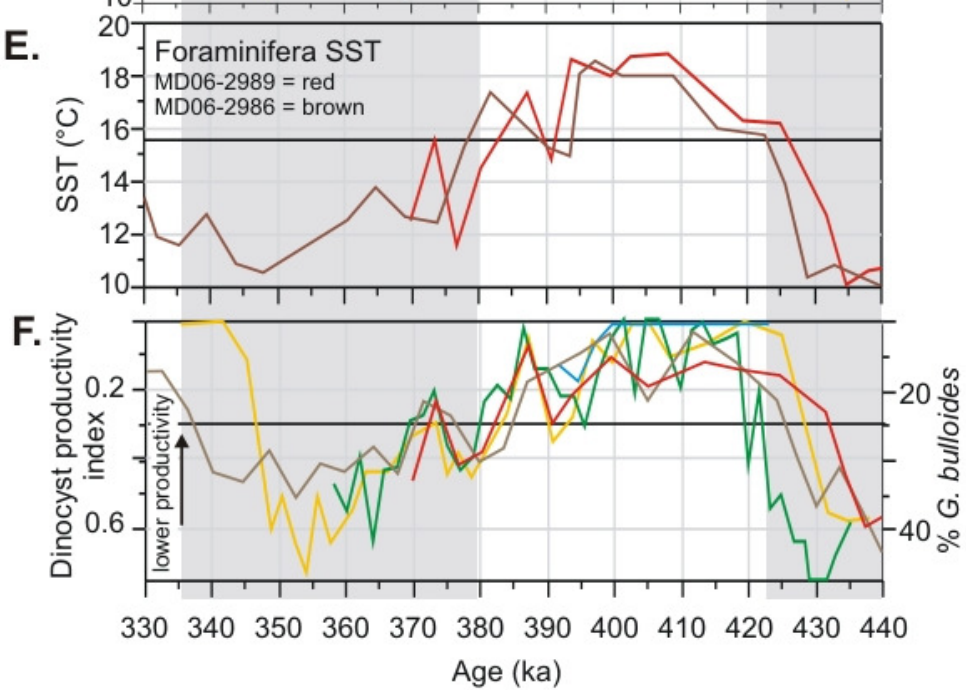

Figure 5.6. A - C. SST model results using dinocyst assemblages. Black line $=$ WA-PLS model, grey line $=$ MAT model, dashed line $=$ ANN model. Circles indicate samples with a squared chord dissimilarity value to the nearest analogue sample $>$ 99th percentile of modern training set, and are excluded from the consensus dinocyst SST estimates D. Consensus SST estimates using the average of three model outputs shown above. MD06-2987 = blue , MD06-2988 = green, MD06-2989 = yellow. E. SST estimates from two cores in the study area based on foraminifera assemblages and an ANN model (Hayward et al., 2012). F. Productivity indices based on dinocyst assemblages and foraminifera assemblages (Hayward et al., 2012). Colour coding as for panels D and E. 
included passively in a detrended correspondence ordination of the SH-311 seafloor dinocyst training set, all the fossil assemblages plotted within the area occupied by the modern training set, indicating fossil assemblage are similar to those in the training set. In the MAT model, eight fossil samples had a dissimilarity score to the nearest modern analogue sample greater than $99^{\text {th }}$ percentile (0.41). These samples (highlighted in Figure 5.6) were often those with large differences in SST estimates between the three models, with the difference of estimated SSTs between the MAT and ANN particularly large, and these samples are those for which the MAT and ANN estimates are discarded to form the 'consensus SST' estimate in Figure 5.6D. The ANN model generally returned the warmest SST estimates, a characteristic observed by other multi-model faunal transfer function reconstructions in the region (Barrows et al., 2007; Hayward et al., 2012).

The dinocyst-based transfer functions indicate a SST range of $7-8^{\circ} \mathrm{C}$ for glacial MIS12 to interglacial MIS11, which is remarkably similar to that estimated from the foraminifera assemblages (Figure 5.6D-E). Glacial SSTs for both MIS12 and MIS10 were $10-11^{\circ} \mathrm{C}$, while peak MIS11 SSTs were $17-18^{\circ} \mathrm{C}$. There is broad agreement between the three dinocyst and two foraminifera records on both timing and magnitude of SST variation over MIS11.

Variation between core sites has been noted above, particularly in the timing of mass flux mimima, but there is less variation in the relative timing of SST events. We explored possible regional relationships between SST and productivity and the mixing index by examination of a regional stack of records. Available SST results from dinocysts and foraminifera from MD06-2986, -2987, -2988, and -2989 are averaged in $2 \mathrm{kyr}$ bins centred on odd-numbered millennia between $355 \mathrm{ka}$ and $439 \mathrm{ka}$ (Figure 5.8C, Supplementary Material S5.3). Two stacked SST records are complied: (i) ANN estimates from dinocyst and foraminifera assemblages from four cores MD06-2986, 2987, -2988, -2989, and (ii) the "dinocyst consensus" SST estimates from cores MD06-2987, -2988, and -2989 (Figure 5.8C). Of the 40 composite SST estimates between $355-439 \mathrm{ka}$, the average number of model results per bin in the 'dinocyst-only' compilation is 2.3 , with 10 containing a single model result, while the 
average number of estimates per bin in the ANN composite is 2.7. For the ANN composite, the range of SST estimates are shown for the bins where multiple SST estimates are available (Figure 5.8C), and generally shows good agreement between the estimates, with the main exception between $405-395 \mathrm{ka}$, where there is up to $5^{\circ} \mathrm{C}$ range in estimates. This range is due to warm SST estimates from the foraminifera assemblages persisting until ca. 395ka, while the dinocyst SST estimates show a decrease from peak warmth $\sim 405 \mathrm{ka}$. This stacked time series produces a clearer regional picture of MIS11 development in the east Tasman Sea

SSTs started to warm between 435-430ka, and reached approximately modern-day SSTs $\left(\sim 15.5^{\circ} \mathrm{C}\right)$ by $\sim 428 \mathrm{ka}$. SSTs fluctuated about slightly cooler than modern conditions for the following $\sim 10 \mathrm{kyr}$, with a pronounced SST minima at $\sim 420 \mathrm{ka}$ in the dinocyst composite records. Maximum SSTs occurred between 415ka and 405$400 \mathrm{ka}$. Peak SST estimates were $\sim 18^{\circ} \mathrm{C}, \sim 2.5^{\circ} \mathrm{C}$ warmer than present mean annual SST in the study area, or $1^{\circ} \mathrm{C}-4.5^{\circ} \mathrm{C}$ warmer than present when the RMSE calibration errors of the transfer function models are considered.

The end of peak warmth occurs between 405-395ka, when SSTs rapidly declined. A brief warming is recorded at $\sim 385 \mathrm{ka}$. In the MD06-2989 foraminifera record, a brief rise of $\sim 2^{\circ} \mathrm{C}$ occurs over not more than $5 \mathrm{ka}$, but in the dinocyst models a SST rise of $\sim 4^{\circ} \mathrm{C}$ over a similar period of time is inferred. Following the $\sim 385 \mathrm{ka}$ SST peak, the SSTs declined into MIS10 and reach a minima at 350ka.

\subsubsection{Productivity indices}

The productivity indices all suggest that eutrophic conditions and productivity were higher during the MIS12 and MIS10 glacials, than during the intervening MIS11 interglacial (Figure 5.6F).

Within MD06-2989, the timing of change is synchronous for the dinocyst and foraminifera productivity indices, with productivity declining from $\sim 435 \mathrm{ka}$ and a minima recorded at 425ka. In MD06-2988, productivity decreases c.10ky later than at MD06-2989, reaching the lowest values (inferred productivity minima) at c. 420ka. All indices suggest low productivity until ca. 400ka, and a productivity increase between 395-390ka. Two productivity minima occur in all three records 
covering the MIS11-10 transition, at c. 387ka and 373ka, which coincide with peaks in the foraminifera SST record (Figure 6F).

A consensus of the "dinocyst productivity index" was calculated for 2 kyr bins in the same way as for the SST estimates, to create a regional dinocyst productivity index (Figure 5.8E, Supplementary Material S5.3).

The "dinocyst productivity index" is the ratio of selected peridinioid cysts to oceanic gonyaulaucoid cysts (Section 5.3.5). Peridinioid cysts are more susceptible to oxidation in seafloor depositional settings than gonyaulaucoid (Zonneveld et al., 1997; Zonneveld et al., 2008), raising the possibility that variation in the "productivity index" may reflect varying sea-floor or post-depositional oxygen levels rather than a true reflection of nutrient availability in surface waters and cyst production. In this setting, however, oxidation is unlikely to have altered the productivity index significantly, as the foraminifera-based productivity index, resistant to the effects of oxidation, is well aligned to variation in the dinocyst index. Moreover, the absolute abundance of peridinioid cysts, also shown to be a robust indicator of productivity (Reichart and Brinkhuis, 2003) exhibits a very similar pattern to the index explored in more detail here (Figure 5.4).

\subsubsection{Water mass affinities}

Dinocyst water mass indicators prior to 430ka are mainly of SAW, with some indications of STF front assemblages (Figure 5.7). The first indication of dinocyst assemblages clearly indicative of STW during the MIS12-11 transition occurred at 425ka in MD06-2989, although SAW indicators are also present in all three records until 418ka (Figure 5.7). In a stacked record of all three cores (Figure 5.7C), the MIS $12 / 11$ glacial termination is shown to be punctuated by a brief return of SAW over the area between $422-418 \mathrm{ka}$, which is preceded by a period of mixed assemblages containing features indicative of both SAW and STW masses.

There are no dinocyst-based SAW indicators between 418-400ka in the three cores. SAW indicators return in the two southern-most cores between 400-390ka, although mixed assemblages, similar to those observed during the termination, are a feature of that period. The return of regional warmth during MIS11c (ca. 385ka) is 


\section{Chapter 5}
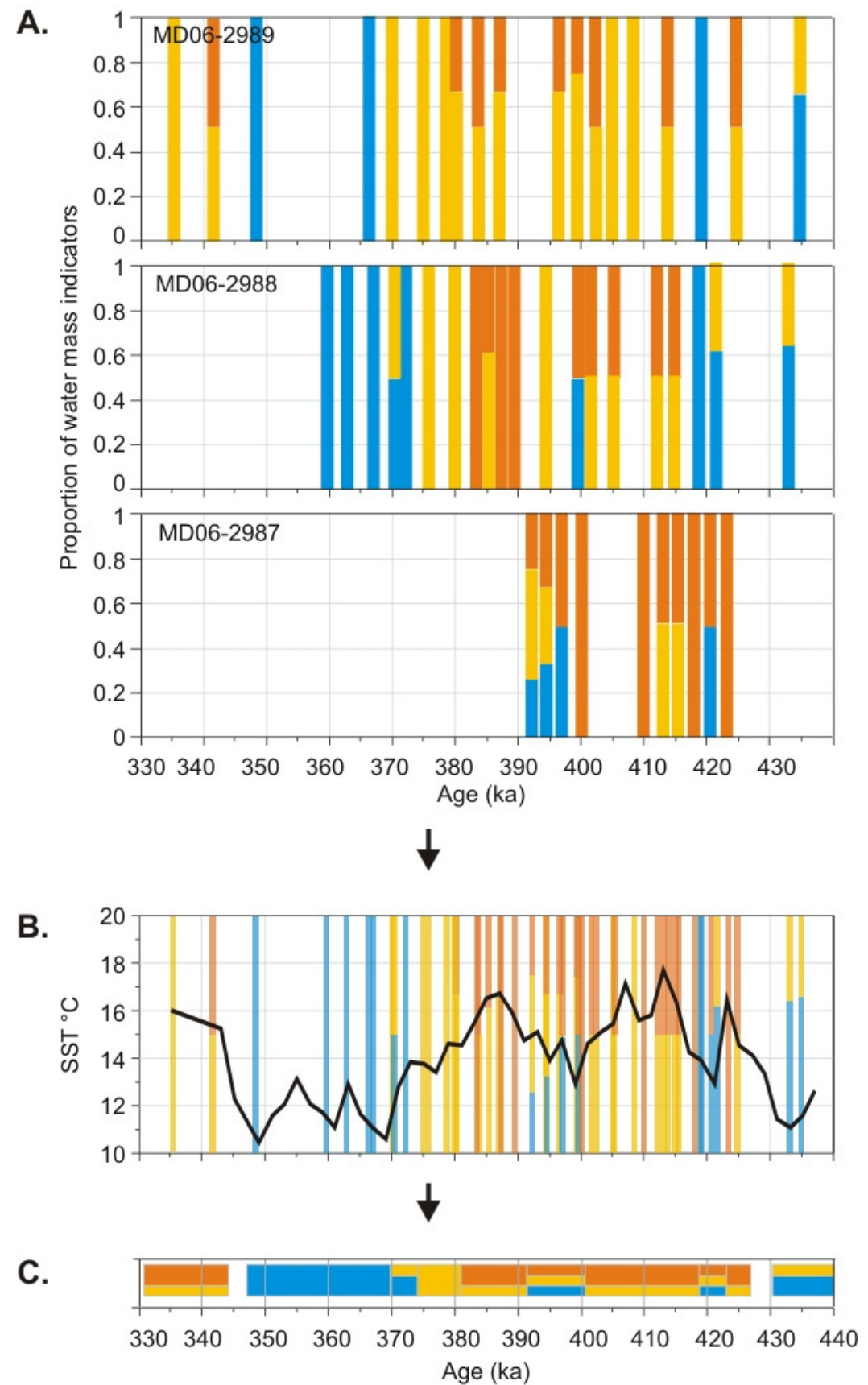

Figure 5.7. A. Dinocyst based estimates of water mass overlying three east Tasman Sea core sites (MD06-2987, MD06-2988, MD06-2989) during MIS12-MIS10. Coloured bars denote the proportion of water mass criteria from Table 4.1 present in each sample (samples with no water mass-diagnostic criteria are omitted): orange = STW, yellow $=$ STW, but with a southern range up to $5^{\circ}$ latitude south of the STF, blue $=$ SAW. B. Water mass criteria from each core are combined into a single timescale, overlain by regional dinocyst-based SST compilation from Figure 4.8. C. Qualitative summary of regional water mass properties. 
accompanied by an absence of SAW assemblages, with assemblages most strongly indicative of STW in the entire MD06-2988 record occurring during this interval.

During the MIS11-10 transition, the last clear indicator of STW is observed at 380ka, which is followed by $7 \mathrm{ka}$ of assemblages found within, and north of, the STF. Dinocyst assemblage SAW indicators dominate the cores between $368-c a$. $345 \mathrm{ka}$ in MIS10.

\subsection{Discussion}

\subsubsection{Duration and relative warmth of MIS11: comparison with other records}

The broad features of the MIS11 SST record identified in the east Tasman Sea (Figure 5.8C), of a prolonged interglacial lasting at least $28 \mathrm{kyr}$, divided into two phases with peak warmth occurring during the later phase, is similar to other global records. Other Southern Hemisphere marine records point to a relatively long interglacial with climatic optima 425 - 405ka in the South Atlantic Ocean Drilling Program (ODP) Site 1089 (Cortese et al., 2007), while peak SSTs at another South Atlantic site (ODP 1085 ) were identified at 425-390ka with peak light planktic $\delta^{18} \mathrm{O}$ between 411-404ka (Dickson et al., 2010).

In the New Zealand region, the site with sufficient sampling resolution south of the STF, DSDP Site 594, has MIS11 interglacial SSTs during 420-400ka, with peak warmth at 405-403ka (Weaver et al., 1998; Hayward et al., 2008). In contrast, SST at ODP Site 1123 north of the STF, (Figure 5.1) exhibits a smooth SST peak between 417394ka, with peak warmth at 405ka (Crundwell et al., 2008).

Likewise, a prolonged, two-phase interglacial with maximum warmth during the later phase of MIS11 is recorded in European and Greenland pollen records (Kühl and Litt, 2007; deVernal and Hillaire-Marcel, 2008; Koutsodendris et al., 2010), and in SST observations in the northeast Atlantic (Kandiano and Bauch, 2005; Voelker et al., 2010), however offshore from the Iberian Margin (Desprat et al., 2005), and Greece (Muller and Pross, 2007) warmer forest pollen assemblages are recorded during the 


\section{Chapter 5}

early part of MIS11.

There is less consensus on the relative warmth of MIS11 compared to the present day. North Atlantic and European records suggest peak SSTs were similar to, or cooler than, average Holocene conditions (Bauch et al., 2000; de Abreu et al., 2005), while Siberian pollen records suggest warmer and wetter continental temperatures

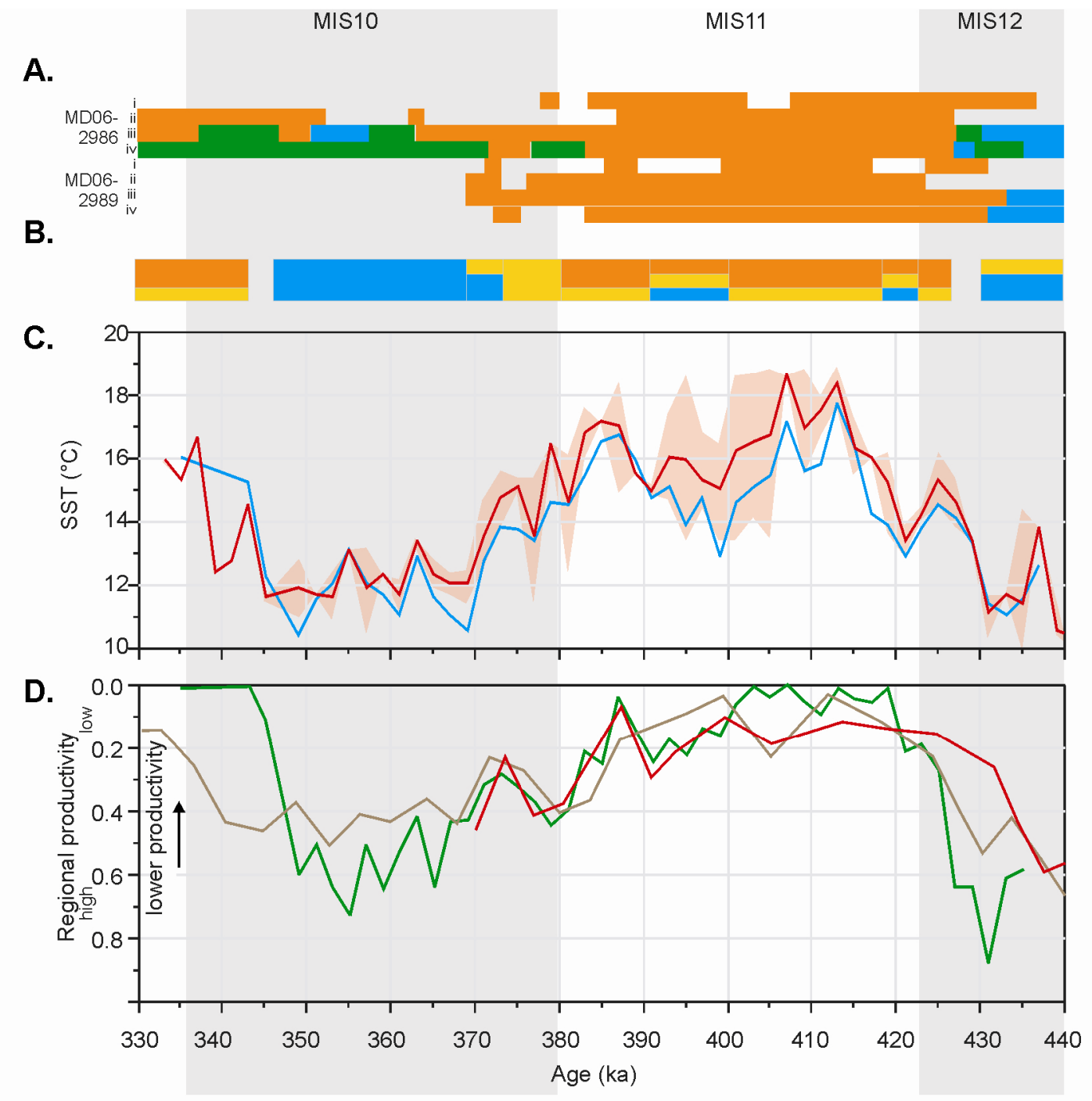

Figure 5.8. A. Foraminifera based water mass estimates from MD06-2986 and MD06-2989 summarised from Hayward et al (2012). Orange $=S T W$, green $=S T F$, blue $=S A W,(i)=G$. inflata: $G$. bulloides index, (ii) $=$ incompta:pachyderma index, (iii) $=\%$ G. ruber index, (iv) $=\% O$. universa index. B. Dinocyst based water mass estimates from Figure 4.6. Water masses are represented as: orange $=S T W$, yellow $=S T F$ and north, blue $=$ SAW. C. Regional SST estimates for east Tasman Sea, obtained from the average of multiple faunal models, in $2 y r s$ bins. Red = average of ANN results from MD06-2987, MD06-2988 (dinocyst), MD06-2989 (dinocyst and foraminifera), MD06-2986 (foraminifera); light red = maximum and minimum SST estimates from each $2 \mathrm{kyr}$ bin; blue = average of dinocyst composite model SST estimates only. D. Productivity indices. Green = average of dinocyst productivity index from MD06-2987, MD06-2988, MD06-2989, in 2kyr bins; red = \% G. bulloides from MD062989 and brown = MD06-2986 (Hayward et al., 2012). 
(Prokopenko et al., 2010). In the South Atlantic, some records suggest MIS11 temperatures were similar to the late Holocene (Hodell et al., 2000; Kunz-Pirrung et al., 2002). SSTs in a South Atlantic record from beneath the Benguela Current were $\sim 1^{\circ} \mathrm{C}$ warmer than present (Dickson et al., 2010), while the estimates of temperature from the EPICA Dome C Antarctic ice core (Jouzel et al., 2007) suggests MIS11 was warmer than any time in the Holocene, but comparable to other Late Quaternary interglacials. In the east Pacific Ocean, warm molluscan assemblages off Chile were identified almost $10^{\circ}$ latitude south of their present range (Ortlieb et al., 1996), suggesting MIS11 SSTs along the coast of Chile were substantially warmer than today.

Marine records from the SW Pacific Ocean suggest the region was warmer than the Holocene during the peak of MIS11. The consensus SST estimates of the present study suggest the east Tasman Sea was $\sim 2-3^{\circ} \mathrm{C}$ warmer than present, while peak SST at DSDP Site 594 (Figure 5.1) was $\sim 3^{\circ} \mathrm{C}$ warmer than present (Hayward et al., 2008), although dinocyst results from DSDP 594 suggest warmth of this level was not sustained (Chapter 6). North of the STF, SSTs during MIS11 at ODP Site 1123 were $\sim 3^{\circ} \mathrm{C}$ warmer than modern, although with SSTs similar to those of MIS7 and MIS9 (Crundwell et al., 2008; Hayward et al., 2008).

\subsubsection{Water mass estimates}

Four foraminifera-based proxies that trace the relative position of the STF in the east Tasman Sea over MIS11, have been published for cores MD06-2986 and MD06-2989 (Hayward et al., 2012). These proxies are: a ratio of Neogloboquadrina incompta to N. pachyderma; a ratio of Globorotalia inflata to Globigerina bulloides; and the presence of two warm water species in sufficient abundance (Globigerinoides ruber and Orbulina universa) (Hayward et al., 2012 and references therein). The results of these estimates are summarised graphically in Figure 5.8A.

Cumulatively, the four foraminifera proxies suggest that SAW entered the region briefly during MIS12 and MIS10, but that the region was bathed in STW for much of the remaining period. There is reasonable agreement between the foraminifera and dinocyst-based water-mass proxies on the timing of SAW replacement with STW 
during the MIS12-11 transition, between 434-427ka, although the foraminifera index “\% Orbulina universa" in MD06-2986 suggests STW reached the study area as early as 437ka. There is little indication in the foraminifera-based indices of the brief incursions of SAW inferred from dinocyst assemblages during stadials centred on 420ka and 395ka, except for fluctuations in "\% Orbulina universa" at MD06-2989, that drop below the "STW threshold" during those times (Figure 5.8A). The foraminifera-based indices also suggest the return of SAW to the region was delayed during the inception of glacial MIS10, compared to that suggested by the dinocystbased indices. The first foraminifera-based proxy indicative of SAW is at c. $357 \mathrm{ka}$, almost 10ka after the dinocyst-based proxies indicate SAW returned to this part of the east Tasman Sea.

In the modern east Tasman Sea, the STF is positioned south of the study area (Figure 5.1A). The dinocyst water mass indicators are consistent with SAW over the study area during MIS10, while the foraminifera water mass indicators suggest the STF remained near to the study area. The proxy signals are slightly different during MIS12, with the dinocyst water mass indicators indicative of a more proximal STF than inferred from the foraminiferal indicators (Figure 5.8). These differences may relate reflect variability that is recorded in a different way by the two proxies, either as seasonal variability, or contrasting depth preferences of the proxies which could result in a different picture of frontal location. During both glacials, it is likely that the STF in the east Tasman Sea was located within or near to the study area, as suggested by Hayward et al. (2012). The northwards migration of the STF is well documented during the LGM in the Tasman Sea (Sikes et al., 2009), accompanied by a similar northwards migration of the Tasman Front (Martinez, 1994). All the water mass estimates point to the STF south of the study area during MIS11: how far south is more difficult to constrain with the current data.

\subsubsection{Productivity in the east Tasman Sea MIS12-10}

Based on the relationship observed between the "dinocyst productivity index" and satellite derived chlorophyll- $a$ in the modern east Tasman Sea, chlorophyll- $a$ concentrations in the region are likely to have ranged between $0.4 \mathrm{mg} . \mathrm{m}^{-3}$ (index values $>0.6$ ) during glacial periods and $0.2-0.3 \mathrm{mg} \cdot \mathrm{m}^{-3}$ during MIS11 (index 
values <0.2) (Figure 5.2). At present, the calibration dataset is not sufficient to resolve the smaller changes in the index values observed during the peak of MIS11 (Figure 5.8E), although no variability similar to the ca. 6ka periodicity in the SST record is observed in the dinocyst productivity record. The foraminifera-based proxy used here is consistent with the dinocyst index. The "\% G. bulloides" varies between $12-22 \%$ during MIS11, with minima at $410 \mathrm{ka}$ and $\sim 400 \mathrm{ka}$, and also a minimum at 385ka. The minima values suggest that both MD06-2986 and MD06-2989 were, at least briefly, beneath the "high intermediate" chlorophyll- $a$ biome during MIS11.

In contrast, dinocyst-based productivity indices during glacials MIS12 and MIS10 ranged between 0.4 and 0.9 , with average values $\sim 0.6$. These values suggest a range of glacial chlorophyll- $a$ concentrations of $0.3-0.5 \mathrm{mg} \cdot \mathrm{m}^{-3}$. The range of "\% $G$. bulloides" during glacials, of $40 \%$ to $60 \%$, supports surface waters of the "high" chlorophyll-a biome (Figure 5.3, 5.8E), but cannot exclude the "high intermediate" biome.

The increased productivity during glacials MIS12 and MIS10 inferred from the dinocyst and foraminifera proxies is most likely due to a northwards shift in the zone of elevated productivity associated with the STF, consistent with the interpretation of the water mass indicators in Section 5.5.3. In addition, lower sea level resulting in river discharge close to the canyon heads may also have increased the incidence of nutrient-laden plumes of suspended sediment, extending the zone of "coastal" productivity into the Tasman Sea, similar to that inferred during the Last Glacial Maximum (LGM) in STW to the east of New Zealand (Carter et al., 2002; Carter and Manighetti, 2006). Productivity in the micronutrient-limited SAW in the study area during glacial times may also have been more susceptible to the input of terrestrial nutrients than STW off the east Coast of New Zealand. In other Tasman Sea records, strong anti-phased correlations are observed over the last ca. 400kyr between SST and various proxies for productivity on glacial/interglacial scales, frequently linked with increased dust flux during glacial times (e.g. Nees, 1997; Calvo et al., 2004; Nürnberg and Groeneveld, 2006).

Productivity during the interglacial MIS11 appears to have been lower, and was also 
probably less than the Holocene. During MIS11, the lowest productivity is restricted to times where water mass indicators show an absence of SAW influence. The minima in productivity proxies in the MIS11 records presented here are consistent with oligotrophic surface waters of the central Tasman Sea entering the study area. Although there is a broad correlation during the MIS11 interglacial of lowest productivity during periods of elevated SST (Figure 5.8), samples with lowest productivity are not confined to those with elevated SSTs: the first minimum in the dinocyst-based productivity index occurs at ca. 418ka, ca. 5ka prior to the peak SSTs.

Observations of the modern ocean/climate system provide insights into possible oceanic circulation that could give rise to the productivity response observed during MIS11. Over the last decade of ocean warming, the rate of circulation in the South Pacific Gyre, the western limb of which drives circulation of the East Australian Current (EAC) and the Tasman Front (Figure 5.1), has increased, attributed to an increase in westerly winds (Roemmich et al., 2007). Increase in gyre flow affects transport within the EAC. Over the last $\sim 60$ years, the intensification of the gyre has resulted in a $\sim 350 \mathrm{~km}$ southwards extension of the EAC along the eastern margin of Tasmania (Hill et al., 2008), while transport along the Tasman Front has declined (Hill et al., 2011). The South Pacific Gyre has shifted south in concert with the zonal westerly winds (Roemmich et al., 2007; Cai, 2006; Hill et al., 2008; 2011). A reduction in east Tasman Sea productivity might therefore arise from southward migration of the STF.

\subsubsection{A different productivity regime during MIS11?}

The broad correlation on orbital timescales between water mass, SST and productivity observed in this study is consistent with what might be expected given observations of modern oceanography and other proxy reconstructions of the east Tasman Sea from the late Quaternary. However, the interaction of SST, nutrient availability and productivity in the east Tasman Sea during MIS11 may have differed from the modern setting. This suggestion is based on observations of the relationship between productivity proxies and SST during MIS12-11, compared to later times. 


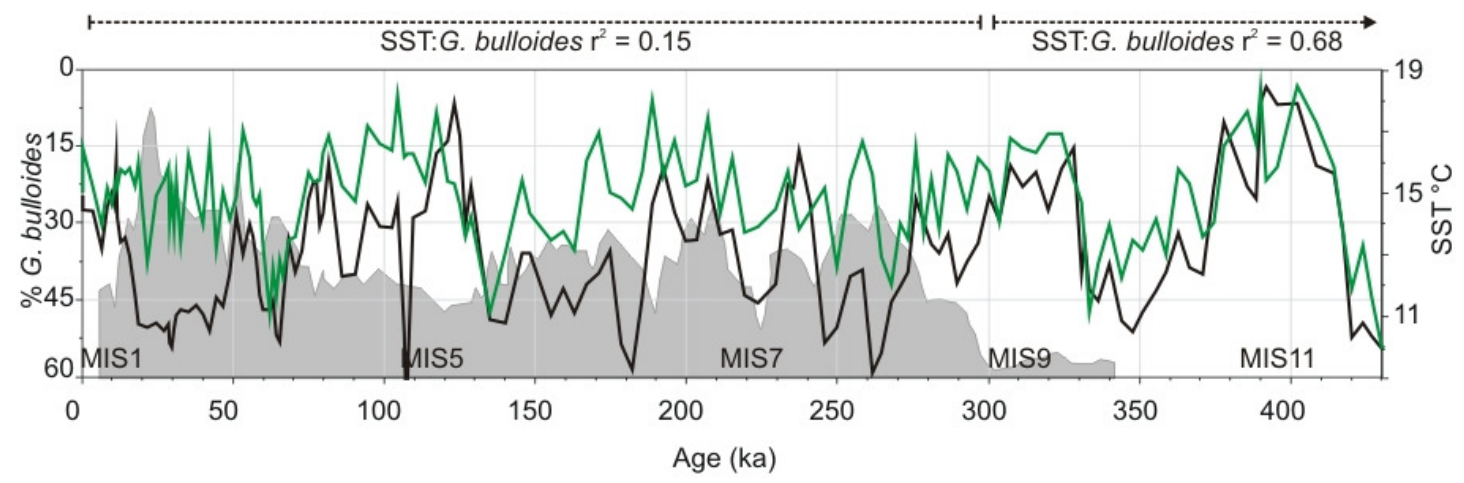

Figure 5.9. \% G. bulloides (green, reversed axes) and foraminifera based SST (black) over the last 440ka at MD062986 (Hayward et al., 2012), underlain by \% aeolian content at site E26.1 immediately to the north of the study area (Figure 5.1) (grey shading, scale is maximum of $12 \%$ aeolian content at $25 \mathrm{ka}$ ) (Hesse, 1994), showing: (i) relatively strong, anti-phased correlation between SST and \% G. bulloides prior to $300 \mathrm{ka}$, and (ii) a much weaker correlation following the inception of Australian-derived dust accumulation around MIS9.

Prior to 300ka (MIS10), a strong (anti-phased) correlation is observed between the foraminifera-based SST and the foraminiferal productivity indicator \% G. bulloides (Pearson correlation coefficient $=-0.82, r^{2}=0.68$ ) (Figure 5.9) (Hayward et al., 2012). Although the relationship remains anti-phased after 340ka, the correlation is lower in samples between 340ka and the present (correlation coefficient $=-0.39, r^{2}=0.15$ ). Assuming the ecological niche represented by \% G. bulloides has remained constant over time, it appears that although the lowest rates of productivity occurred during MIS11, productivity and SST were also more strongly correlated during the interval.

Care has been taken to compare correlations of 'full' glacial cycles, as the degree of coupling may vary within a cycle, but another way to document the correlation between SST and \% G. bulloides is to do so in sections of the time series. Thus, correlations of each transition from full glacial to peak warmth, i.e. 40-0ka, 165125ka, 280-240ka, and 440-400ka are considered in turn. When considered in this way, the correlation between SST and \% G. bulloides is much stronger in the MIS1211 termination (correlation coefficient $=-0.89, r^{2}=0.8$ ) than the later four terminations, where the next highest correlations are observed during the MIS10-9 and MIS6-5 transitions strength (correlation coefficients $\sim-0.65, r^{2} \sim 0.43$ ). A similar relationship is observed in the overlapping core MD06-2989, that extends from 386ka - 1084ka (Hayward et al., 2012). There, a strong antiphased correlation is also observed between SST and \% G. bulloides during 546 - 386ka (MIS14) (correlation coefficient $\left.=-0.81, r^{2}=0.66\right)$, although it reduces slightly when the correlation is 
extended to $564 k$ a to compare two entire cycles $\left(-0.73, r^{2}=0.54\right)$.

Given the close proximity of the study area to New Zealand, and to the STF, the shift in strength of correlation between SST and \% G. bulloides is most likely to reflect some change in the relative influence of terrestrial input and water mass migrations around 300-350ka. Alternatively, such a shift in correlation may simply be a feature of the relatively prolonged deglacial during MIS12-11 compared to later transitions (e.g. Tzedakis, 2010), reflect other unique factors associated with the end of the Mid Pleistocene transition (e.g. Clark et al., 2006), or change in the ecology of $G$. bulloides. Another possibility, given that the timing of this shift coincides approximately with the increase of Australian aridity (Pillans and Bourman, 2001; Kershaw et al., 2003) and the inception of trans-Tasman transport of Australianderived dust (Hesse, 1994; Hesse and McTainsh, 1999), is that the resulting increase of iron flux allowed higher rates of primary productivity over a greater area of the east Tasman Sea than was possible during MIS14-10 (Figure 5.9).

We explore the final possibility in more detail here, although the present data are insufficient to determine whether one, or a combination, of factors caused the change in the relationship between this productivity proxy and SST. Indeed, additional proxies for productivity are also required to determine whether the observations made here are repeatable.

Modern STW in the Tasman Sea is enriched in iron relative to the "high nutrient-low chlorophyll' SAW to the south (Boyd et al., 2005; Bowie et al., 2009). Iron is inferred to enter the modern Tasman Sea off Australia via entrainment of shelf sediments and atmospheric dust input (Bowie et al., 2009; Lannuzel et al., 2011; Mongin et al., 2011a; 2011b). Inspection of ocean colour satellite imagery for the east Tasman Sea study area suggests coastal waters are seeded by direct fluvial discharge, and under modern conditions Ekman transport of the W to SW winds would favour offshore transport of sediment-laden water towards the core sites (Brown et al., 1998). The flux of Australian dust directly into the study area, and onto the South Island, must also contribute a proportion of the iron to reach the study area. The accumulation rate of Australian dust at a South Island tarn during the Holocene was 
0.2-1.6 g/ $\mathrm{m}^{2} /$ year (Marx et al., 2009). At this rate, Australian derived dust could form $1-4 \%$ of the sediment accumulation in cores of the study area, using accumulation rate to mass relationships observed on the east of New Zealand (Carter et al., 2001). Australian dust is enriched in iron, ( $10-25 \%$ iron) (Douglas et al., 1999; Radhi et al., 2010a, 2010b, 2011) compared to the sediment load of West Coast rivers of the South (Kautz and Martin, 2007) and North Island (Goldsmith et al., 2008) (range 2-10\% iron).

Australian aridity appears to have increased progressively during the Mid Pleistocene Transition (MPT) (Pillans and Bourman, 2001; Kershaw et al., 2003), with initiation of terrestrially derived dust flux into Tasman Sea recorded from 400-300ka (Hesse, 1994; Calvo et al., 2004), with a strong pattern of increased flux during glacial times. The easternmost core included in the study of Hesse (1994), E26-1 slightly north of the present study region (Figure 5.1A), recorded the first aeolian dust flux after MIS9 (300ka) (Figure 5.9).

Using the rates quoted above, the effect of Australian dust deposition into the study region during MIS9-10 could have increased the flux of elemental iron to surface waters of the east Tasman Sea by $5-20 \%$. In addition, the new flux may also have contained more soluble forms of iron from ash, and also been deposited to surface waters during times of the year that could complement the input of iron from the New Zealand landmass. Although bio-utilisation of iron is complicated by timing, bioavailability and rates of flux (e.g., Boyd et al., 2005; Bowie et al., 2009; Lannuzel et al., 2011), an increase of iron flux into the Tasman Sea of this magnitude after MIS11 was possibly sufficient to alter the nutrient limitation regimes of primary productivity in the study area, particularly if it also had the effect of enriching STW of the entire Tasman Sea, which could be transported into the study area by the East Tasman Drift.

To return to the original observation, of variable correlation between SST and productivity; one possible explanation for this pattern is that in the iron-limited east Tasman Sea prior to $340 \mathrm{ka}$, productivity in the study area was influenced primarily by the proximity of the STF and the magnitude of terrestrial derived nutrient input 
from the South Island. During later times, in waters that were not iron limited, additional influences on productivity, such as windiness/ mixing intensity, may have resulted in a productivity regime less coupled to the glacial/interglacial scale changes in water mass that was apparently the dominant influence between MIS14-10. Further observations of productivity and variations in dust flux and other productivity drivers in the Tasman Sea between MIS10-1 are required to test this hypothesis.

Notwithstanding the cause of the shift in strength of correlation between SST and \% G. bulloides at 300ka, the observation that one occurs has implications for interpretation of faunal proxies used to infer MIS11 environments in the east Tasman Sea. Whether due to variation in ecological niche or productivity regime (i) the faunal environmental proxies, used to determine the relative position of water masses and frontal systems, and to reconstruct SST, should be treated with more caution as good modern analogues may not be available, and (ii) the biological response to elevated warmth inferred from MIS11 may differ from that which might occur in the modern ocean.

\subsection{Conclusions}

1. The MIS12-11 transition in the east Tasman Sea featured a two-stage warming, with (i) a period between ca. 428-415ka when SST fluctuated around slightly below modern levels, and (ii) a sustained period of SSTs $>16.5^{\circ} \mathrm{C}\left(\sim 1^{\circ} \mathrm{C}\right.$ above modern) between $415-405 k$ with peak SSTs $>18^{\circ} \mathrm{C}$ present during $413-407 \mathrm{ka}$.

2. In the east Tasman Sea, these fluctuations in SST were accompanied by dinocyst and foraminifera assemblage changes indicative of an increased influence of SAW during glacial periods, inferred to correspond with a northward migration of the STF.

3. Productivity indices during MIS12-10 are anti-phased with SST. The productivity minima associated with peak SSTs in MIS11 was likely lower than modern productivity in the east Tasman Sea. These 
variations in productivity on glacial-interglacial timescales are inferred to arise from migration of the STF, interacting with terrestrially derived nutrients from the adjacent New Zealand landmass.

4. A strong correlation is observed between SST and a qualitative foraminifera-based proxy for productivity, (\% G. bulloides) between MIS14-MIS9, with a particularly strong correlation during the MIS12-11 transition. In contrast, the correlation during later times (MIS9 - present) is much weaker. The stronger correlation prior to $345 \mathrm{ka}$ may reflect the prolonged MIS12-11 deglacial compared to later transitions, an increase in the variability of the STF or New Zealand -derived terrigenous input after this time, or may reflect a primary productivity regime that was occasionally iron limited prior to the initiation of Australian aridity and enhanced trans-Tasman dust transport after MIS10-9.

\subsection{Acknowledgements}

Bruce Hayward provided additional unpublished foraminifera counts for MD06-2989. George Scott performed SSTs estimations for the additional foraminifera counts. Ruzica Dadic processed raw Hardman-Mountjoy et al. (2008) biome data to .txt format for Figure 3. Thanks to the Crew and Science party of 2006 Marion Dufresne cruise. Sonja Fry at GNS Science assisted with palynological processing. Oxygen isotopes and age model from Helen Neil at NIWA, including the initial compilation of the 'mixing index'.

\section{Supplementary Material}

The following data tables are included at the end of this thesis:

S5.1. Dinocyst census counts from MIS11 east Tasman Sea samples

S5.2. SST and productivity index values from MIS11 east Tasman Sea samples

S5.3. Stacked SST and productivity index values from MIS11 east Tasman Sea samples 


\title{
6. Marine-terrestrial climate during Marine Isotope Stage 11, South Island, New Zealand.
}

\begin{abstract}
Marine and terrestrial conditions in the eastern New Zealand region during Marine Isotope Stage 11 (MIS11, 423ka - 380ka) are determined from assemblages of dinoflagellate cysts (dinocysts) and pollen from Deep Sea Drilling Project Site 594 (DSDP594). The dinocyst assemblages are used to infer sea surface temperatures (SSTs), using a selection of transfer function models and a 311-sample training set of modern sea-floor samples. The pollen record, combined with earlier work at DSDP594, is the longest continuous Mid-Late Quaternary pollen record in the region ( 3 - 446ka, average resolution $3 \mathrm{ka}$ ), recording variation of vegetation along the eastern margin of New Zealand's South Island, ca. $250 \mathrm{~km}$ west of the core site.

Two distinct phases were recognised during MIS11 in both dinocysts and pollen assemblages. During the early phase (ca. 430 - 415ka), dinocyst assemblages suggest surface water productivity conditions varied on sub-millennial timescales, while more stable dinocyst assemblages are a feature of the later phase of MIS11 (ca. $415-400 \mathrm{ka}$ ). The dinocyst assemblages of the early phase are most similar to those observed at the Site during MIS5e, while the assemblages of later MIS11 are similar to, but qualitatively represent waters warmer than, the Holocene. Estimates from transfer functions indicate SSTs during late MIS11 were likely warmer than the present, but they do not appear to have been as warm as during MIS5e.
\end{abstract}

The succession of pollen assemblages during MIS12-11 is similar to that observed in MIS2-1 and MIS6-5. However the transitions between pollen assemblages during the MIS12-11 deglacial occurred more slowly, and includes a ca. 10ky period with high abundances of pollen of Coprosma, that is not observed during later deglacials. The duration of the pollen assemblages that represent maximum extent of the warmest forest type, Podocarpus/Prumnopitys, is ca. 15ky during MIS11. This is 
longer than this pollen assemblage is observed during MIS5e (ca.6.1ky) or during the early climatic optimum of the Holocene (ca. 6.3ky duration).

During MIS11, changes in the pollen record at DSDP594 correlate more closely to SST variation in the east Tasman Sea than to variations in marine conditions at DSDP594, suggesting that marine conditions from the east coast have only limited influence of conditions on the adjacent landmass.

\subsection{Introduction}

Climatic conditions during Late Quaternary interglacials illustrate the natural variability of the Earth system under pre-anthropogenic atmospheric carbon dioxide concentrations. In addition, some interglacials of the Late Quaternary were warmer than present day, at least in some parts of the globe, and aspects of those environments may serve as analogues for projected future warming. Two such phases are Marine Isotope Stage (MIS) 5e (peak warmth ca. 125ka) and MIS11 (peak warmth ca. 405ka) (Lisiecki and Raymo, 2005; Jouzel et al., 2007).

In the Southwest (SW) Pacific, environmental conditions during MIS5e are becoming increasingly well documented by a range of proxies from both marine (e.g., Nelson et al., 1993; Wells and Okada, 1997; Marret et al., 2001; Kawahata, 2002; Pahnke et al., 2003; Neil et al., 2004; Pelejero et al., 2006; Pahnke and Sachs, 2006; Barrows et al., 2007; Hayward et al., 2008, 2012; Lueer et al., 2009) and terrestrial environmental reconstructions (Heusser and van der Geer, 1994; Mildenhall, 1995; Newnham et al., 2007, 2011; Vandergoes et al., 2005; Ryan et al., in press). MIS11 records in the region are less common, with available marine records indicating sea surface temperatures (SST) warmer than the Holocene (Calvo et al., 2003; Pelejero et al., 2006; Hayward et al., 2008, 2012). There are no continuous records documenting terrestrial environments of MIS11 in the region.

In this chapter, we describe dinoflagellate cyst (dinocyst) and spore/pollen assemblages from MIS11 in Deep Sea Drilling Project (DSDP) Site 594 to the east of the South Island of New Zealand (Figure 6.1). The purpose of this study is threefold: 
1. to document the climate response in Subantarctic Surface Water (SAW) during MIS11 by examining dinocyst assemblages, comparing with existing records from warm periods MIS 1 and MIS 5e; and estimating SST from the dinocyst assemblages using a faunal transfer function;

2. to compare the MIS11 pollen record to those found in younger interglacial sections of DSDP594; and place terrestrial vegetation changes during MIS11 in a continuous, well dated sequence; and

3. to explore the relationships between terrestrial and marine environmental conditions during MIS11.

\subsection{Oceanographic setting}

A key oceanographic feature of the New Zealand region is the Subtropical Front (STF) (Figure 6.1). This feature separates Subtropical from Subantarctic surface water masses and it also forms the boundary between two contrasting circulation systems.

North of the STF, water of the counter-clockwise South Pacific Subtropical Gyre (Roemmich, 2007; Roemmich et al., 2007) travels east across the Tasman Sea as the Tasman Front centred on ca. $30^{\circ} \mathrm{S}$ (Chiswell et al., 1997). This current system then flows southeastwards along the eastern continental margin of the North Island as the East Auckland and East Cape currents (Stanton et al., 1997; Tilburg et al., 2001). The flow is subsequently steered eastwards along the northern flank of Chatham Rise, where it may help constrain the STF which resides along the east-west rise crest (Chiswell, 1994; Uddstrom and Oien, 1999).

South of the STF, circulation is dominated by the eastward flowing Antarctic Circumpolar Current (ACC) (Carter et al., 1998; Morris et al., 2001; Sokolov and Rintoul, 2009). As the flow approaches New Zealand, the dominant frontal systems that form the northern part of the ACC, namely the Subantarctic (SAF) and Polar (PF) fronts are forced north by the western boundary of the Campbell Plateau to around $50^{\circ} \mathrm{S}$ before returning to an eastward flow (Figure 6.1). Part of the SAF flow passes northwestward though a gap in the plateau to form the clockwise Bounty Gyre, some components of which flow along southern Chatham Rise and the STF. 


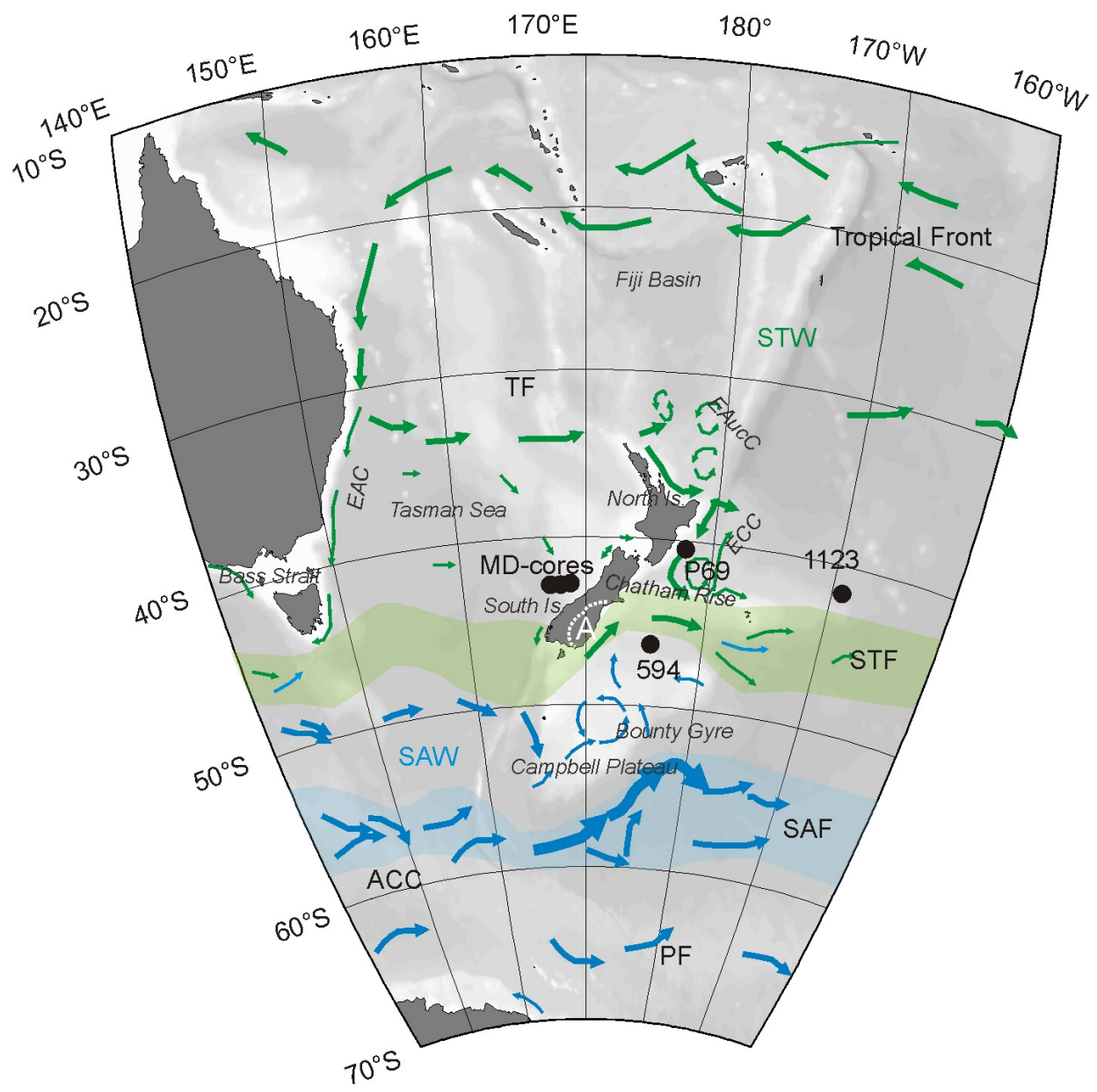

Figure 6.1. Location map showing surface water circulation in the New Zealand sector of the southwest Pacific, with sample sites mentioned in text shown. TF = Tasman Front, EAucC = East Auckland Current, STW = subtropical water, STF = Subtropical Front, SAW = Subantarctic Water, ACC = Antarctic Circumpolar Current. Polygon marked " $A$ " on the south Island is the inferred source of much of the Quaternary pollen observed at DSDP 594.

The surface water masses separated by the fronts have distinct physical and biophysical properties. The latitudinal transition from tropical to polar waters is characterized by a change in mean annual SST from $28^{\circ} \mathrm{C}$ at $15^{\circ} \mathrm{S}$ to $-0.5^{\circ} \mathrm{C}$ at $65^{\circ} \mathrm{S}$ (Locarnini et al., 2010). The highest surface salinities in this region, 35.7 psu, are found in the STW of the central Tasman Sea, falling to 34.3 psu south of the STF, and 33.9 psu south of the PF. Nitrate and phosphate are virtually absent from STW north of the STF, and increase in concentrations to a regional maximum at $63^{\circ} \mathrm{S}$, while dissolved silica is only found in high concentrations south of the PF (Garcia et al., 2010). Levels of productivity vary over this region, and are generally highest near to land and at frontal zones (Behrenfeld and Falkowski, 1997). Regional productivity is 
highest along the STF to the east of New Zealand, where mean annual productivity is over $1000 \mathrm{mgC} / \mathrm{m}^{2} /$ day (Bradford-Grieve et al., 1997; Murphy et al., 2001).

\subsection{Warm interglacials in the SW Pacific}

The two warmest interglacials following the Mid Pleistocene Transition (MPT) (e.g. Clark et al., 2006; Tzedakis et al., 2009) are MIS5e and MIS11, and are discussed here in relation to the Holocene (MIS1).

In the New Zealand region of the SW Pacific, numerous proxy reconstructions suggest warmer SSTs during MIS5e (peak warmth 125ka) than any time during the Holocene (Marret et al., 2001; Pahnke et al., 2003, Pahnke and Sachs, 2006; Pelejero et al., 2006; Barrows et al., 2007; Hayward et al., 2008, 2012; Lüer et al., 2008). This is also reflected in the a record based on the marine fossil group that is the focus of the present study, dinocyst assemblages from DSDP594 (Marret et al., 2001), where Holocene assemblages are very different, and suggest cooler SSTs, to those of MIS5e. The New Zealand terrestrial response to a warm climate during MIS5e is documented by a continuous pollen record from a near-shore marine core off western South Island, that suggests more extensive forest cover, reflecting warmer temperatures than present (Ryan et al., in press). However, the presence of subalpine shrub pollen in an equivalent on-shore record from nearby Okarito Bog points to relatively cool temperatures during MIS5e (Newnham et al., 2007, 2011). Discontinuous MIS5 terrestrial records from New Zealand contain pollen assemblages indicative of conditions similar to the present (e.g., Bussel, 1990; Newnham and Alloway, 2004), although it is not clear the peak warmth of MIS5e is sampled. Other records report assemblages indicative of warmer-than-present conditions (e.g., Mildenhall, 1995). The published pollen record from distal marine core DSDP594, provides a broad picture of terrestrial conditions from ca. 350ka to present (Heusser and Van der Geer, 1994). Despite the poor preservation, low diversity, and different relative abundances in contrast to assemblages from terrestrial sites (e.g., Wilmshurst et al., 1999; Soons et al., 2002; Crouch et al., 2010), Heusser and van der Geer (1994) suggest the vegetation was similar during MIS1 and MIS5e. 
For MIS11 (423-380ka), foraminifera-based transfer functions (Hayward et al., 2008, 2012) and a recently developed dinocyst transfer function applied to east Tasman Sea assemblages (Chapter 5, this study) both indicate peak MIS11 SSTs west and east of New Zealand were $2-3^{\circ} \mathrm{C}$ warmer than the present, and $1-2^{\circ} \mathrm{C}$ warmer than the Holocene optimum. In contrast, an alkenone $U^{K}{ }_{37}$-based SST record from south of Tasmania indicates peak MIS11 temperatures there were similar to present, and cooler than the Holocene Optimum (Pelejero et al., 2006), although regional-scale climate changes may be obscured in the record due to sensitivity of this site to variability in the East Australian Current extension (e.g. Hill et al., 2008). The only terrestrial pollen assemblages spanning MIS11 in the NZ region are three samples from the Wanganui Basin (Figure 6.1) (Bussell, 1987), and 10 samples from the distal marine Ocean Drilling Programme (ODP) Site 1123 (Mildenhall, 2003; Mildenhall et al., 2004). Bussell (1987) interpreted the Wanganui Basin assemblages as representing a climate warmer than present, as several pollen types were recognised from species south of their modern range, while a MIS11 sample from Site 1123 contained the highest concentration of Podocarpus/Prumnopitys pollen of the last four glacial/interglacials.

In summary, all available marine records from STW west of New Zealand, and in SAW to the east of New Zealand indicate that SSTs during MIS5e were the warmest of the previous 4 interglacials (MIS1-9). For MIS11, most proxy records in the region suggest SSTs were generally warmer than the Holocene, with most records indicating peak SSTs during the later part of MIS11.

Coeval pollen on the West Coast of the South Island and at DSDP594 suggest a general coupling of South Island vegetation with SST during interglacials MIS1 and MIS5, in that most (but not all) proxies suggest terrestrial and marine conditions were warmer during MIS5e than the Holocene. For MIS11, the few proxy records in the region suggest generally warmer SSTs than the Holocene, but no continuous pollen records are available to confirm whether there is a consistent vegetative response to warm interglacials in the eastern South Island. 


\subsection{Methods}

\subsubsection{DSDP594}

Site 594 was drilled during DSDP Leg 90 in 1983 (Nelson, 1986). The site is located on the southern margin of the Chatham Rise in $1400 \mathrm{~m}$ water depth, approximately $250 \mathrm{~km}$ east the South Island, at about the latitude of Dunedin at $45^{\circ} 31.41^{\prime} \mathrm{S}$, $174^{\circ} 56.88^{\prime}$ E (Figure 6.1). The core lies in SAW, just south and east of the STF. The Late Quaternary section of the core consists of alternating layers of nannofossilbearing terrigenous clayey silts, and foraminiferal-bearing nannofossil oozes (Nelson, 1986). The silts represent a glacial phase of hemipelagic deposition whereas the pelagic calcareous oozes were deposited in interglacial periods (Nelson et al., 1993).

The core chronology used here is based on matching the $\delta^{18} \mathrm{O}$ of the planktonic foraminifera Globigerina bulloides to the globally-tuned benthic $\delta^{18} \mathrm{O}$ stack, LRO4 (Lisiecki and Raymo, 2005; Ryan, 2010, this study) and all other records from DSDP594 used here are transferred onto the same timescale. Although this should produce a closer fit to the $\mathrm{LRO} 4$ stack than tuning to a combination of $\delta^{18} \mathrm{O}, \mathrm{CaCO}_{3}$, and SST, as previous age models have done (Nelson et al., 1993; Kowalski and Meyers, 1997; Wilson et al., 2005; Schafer et al., 2005; Hayward et al., 2008, 2011), the relatively low resolution of the $G$. bulloides $\delta^{18} \mathrm{O}$ record compared to the other environmental proxies used to establish tie points effectively results in a similar average error. However, it allows more rigorous comparison between cores collected at different locations, particularly those separated by frontal systems that may not necessarily have temporally aligned SST histories. In practice, the age model over MIS12-10 is very similar to that used by Hayward et al., (2008), with the most significant difference in the timing of peak foraminiferal SST. In the Hayward et al. (2008) model, peak foraminifera assemblage-based SSTs occur at 405ka. However, this SST peak is later than isotopic minima in both G.bulloides and the benthic Uvigerina spp., strongly suggesting this point is younger than $402 \mathrm{ka}$. Thus, in the present age model, this point is $401 \mathrm{ka}$. Observations of offsets between benthic and planktic isotopes from the region (ODP 1123, Crundwell, pers. comm.) suggest ages are still likely to be offset ca. 2-3ky (younger) when compared with chronologies derived using benthic stable isotopes. 
Limited support for the age model comes from the presence of the Rangitawa tephra at $36.5 \mathrm{~m}$ at DSDP594, which has an age of 340ka $\pm 7 \mathrm{ka}$ (MIS10), with the error derived from orbital tuning of marine records (Pillans, 1996; Alloway et al., 2005; Holt et al., 2010). The present age model assigns an age of 339ka to this depth. This age model differs from the interpretation of Soons et al. (2002), who suggested that the interval $32-34 \mathrm{~m}$ represented deposition during MIS7 based on their interpretation of the pollen assemblages. Their interpretation implies that the MIS11 section presented here could be MIS9. Although they are correct in their observation that the pollen assemblage over that interval is unusual, it is insufficient reason to adjust an age model well supported by tephra, isotopes and other environmental proxies (e.g. $\mathrm{CaCO}_{3}$, foraminiferal SST estimates, Nelson et al. 1993; Hayward et al., 2008).

\subsubsection{Sample processing and counting}

52 samples were processed for palynology between $36.86 \mathrm{~m}$ and $49.32 \mathrm{~m}$ (343ka 446ka). All samples were processed using standard Quaternary marine palynological techniques. Cold $33 \% \mathrm{HCl}$ was added to a dried sample to remove carbonate, while silicate was removed by 24 hours in cold $40 \% \mathrm{HF}$. This was followed by a second cold $33 \% \mathrm{HCl}$ wash, brief ultrasonic treatment, removal of fines with $6 \mu \mathrm{m}$ filter and mounting on glass coverslips in glycerine jelly (Crouch et al., 2010). A single Lycopodium tablet (batch number 938934) was added to each sample for determination of absolute abundances.

Census counts of dinocysts were made for each sample, following taxonomy in Zonneveld (1997), Rochon et al. (1999), Marret and Zonneveld (2003), and references therein. Census counts stopped at 300 specimens, or when two slides had been examined. Dinocysts were sparse in some intervals. Samples at seven intervals were combined to achieve adequate census counts (Supplementary Material S6.1), with combinations restricted to samples nearer than $30 \mathrm{~cm}$ depth in the core ( 2 ky time assuming a constant accumulation rate), and constituent samples inspected for similarity before combination. Observations from an additional eight samples were discarded as counts were too low. Hence, 37 dinocyst census counts are included, with an average count of 317 cysts, and average 
sampling resolution of $2.7 \mathrm{ka}$ between MIS12-MIS10. This is slightly coarser ( $1 \mathrm{ky})$ than the existing sampling resolution from MIS1-6 (Marret et al., 2001). All dinocyst count data are included in Supplementary Material S6.1.

Census counts of pollen were made on the same samples that were examined for dinocysts. Pollen abundance was generally lower than dinocysts, and processing techniques designed to maximise dinocyst preservation do not result in ideal pollen slides. Taxonomy followed Pocknall (1981a, b, c), Large and Braggins (1991), and Moar (1993). The dry-land pollen sum is calculated in a consistent way to Heusser and Van der Geer (1994), and proportions are thus directly comparable in DSDP594, although some aspects of the assemblages, including the frost-intolerant Ascarina lucida, are grouped into a category of 'undifferentiated angiosperms'. Division within the podocarps followed Heusser and Van der Geer (1994), with Dacrydium cupressinum, Dacrycarpus dacrydioides, Halocarpus sp., and Phyllocladus spp. differentiated, while Prumnopitys spp. and Podocarpus spp. were grouped. Nothofagus fusca pollen, N. menzeisii, and N. brassii were separated. Cyathea spp., other trilete, and monolete spores were counted outside of the dryland sum. Cyperaceae spp. were also counted, but were identified in much lower numbers than Heusser and Van der Geer (1994) where sampling overlapped. Although Cyperaceae spp. were a significant component of glacial assemblages from the younger part of the core, very few were identified from MIS10 or MIS12. The cause of this discrepancy has not been investigated, as the primary focus here is comparison of interglacial climates. Census counts stopped when 300 dryland specimens were reached, or two slides were inspected. Pollen samples with insufficient counts were combined using the same methodology as for dinocysts, resulting in 28 pollen samples included in this study. The pollen samples had an average dryland pollen sum of 260 specimens (average 490 specimens including spores), and an average sample resolution of $3.7 \mathrm{ka}$, compared to an average resolution of $2.9 \mathrm{ka}$ for the interval 350-0ka (Heusser and Van der Geer, 1994). Pollen count data are included in Supplementary Material S6.2. 


\subsubsection{Dinocyst water mass indicators}

In the New Zealand region, the most significant change in modern sea-floor dinocyst assemblages is observed across the STF (Chapter 2, this study), reflecting the contrasting properties of water masses either side of the front, including temperature, salinity, kinetic energy, and nutrients (Bradford-Grieve et al., 1997; Boyd et al., 1999; Murphy et al., 2001). In modern sediments, the relative abundances of 19 dinocyst taxa are observed to change in a consistent way across the STF (Table 2.3, Chapter 2). The presence of these taxa is used here to infer similarity to dinocyst assemblages that are today characteristic of SAW or STW in the New Zealand region. The dinocyst counts for each sample are plotted in the following way: the relative abundance of every taxon that fulfilled the criteria in Table $\mathbf{2 . 3}$ are plotted, less the threshold value shown in the table. For example, the dinocyst assemblage sample at $441.4 \mathrm{ka}$ contained $78 \%$ Selenopemphix antarctica relative to the entire dinocyst assemblage. The threshold value for this taxon in SAW is $1 \%$, thus $77 \%$ of the assemblage is shown to contain characteristics of assemblages presently found in SAW. Other samples contain components of dinocyst assemblages that are today characteristic of both SAW and STW. While these are interpreted here to reflect a degree of mixing of surface water masses greater than is observed at present, it is possible that the conditions required to generate these apparently "mixed" assemblages could arise by other processes.

\subsubsection{SST transfer functions}

For this study, a 311-sample, 39 taxon training set of dinocyst census counts of seafloor samples from the Southern Hemisphere is compiled (Marret et al., 1997; Harland et al., 1998; Vink et al. 2000; Zonneveld et al., 2001; Holwarth et al., 2007; Esper and Zonneveld, 2002; 2007; Crouch et al., 2010; Verleye and Louwye, 2010; Laurijssen and Zonneveld, unpublished; Chapter 2, this study). Ordination of this dataset indicates that SST correlated most strongly to the dinocyst distribution, and accounted for $37 \%$ of the species-environmental relationship after removal of covarying gradients. SST was twice as strongly correlated with dinocyst distribution than the secondary environmental gradients (Chapter 2, this study). On the basis of this ordination, and observations of the importance of water temperature as a direct and/or indirect control of dinoflagellate growth rate and cyst formation (e.g., 
Grzebyk and Berland, 1996; Jensen and Moestrup, 1997; Hwang and Lu, 2000; Juhl, 2005; Navarro et al., 2006; Guerrini et al., 2007; Laabir et al., 2011), SST is inferred to be an appropriate target for quantitative estimation using fossil dinocyst assemblages.

SSTs were estimated from dinocyst assemblages for each sample using three methods: weighted averaging with partial least squares (WA-PLS) (ter Braak and Juggins, 1993), the modern analogue technique (MAT) (Hutson, 1980; Guiot and de Vernal, 2007) and an artificial neural network (ANN) (Malmgren and Nordlund, 1997; Malmgren et al., 2001). The results of all three models are considered, as modern cross validations experiments show each to have contrasting strengths (Chapter 4, this study). Selection of optimum components in WA-PLS was guided by a randomized t-test of the equality of predictions from each component (van der Voet, 1994), included in the C2 software 1.4.2 used for this analysis (Juggins, 2005). For the MAT, a chord dissimilarity was used to select the five nearest analogues, using the MAT routine in $\mathrm{C} 2$. ANNs were trained using the program Tiberius (www.tiberius.biz). This software contains a single hidden layer, with one fixed linear neuron, and variable numbers of non-linear neurons containing tan- $h$ functions. Optimal training was achieved using 10 non-linear neurons. The training regime followed Hayes et al. (2005) and Kucera et al. (2005).

In a "leave-one-out" cross validation, root mean square error (RMSE) of the SH-311 database were $1.2^{\circ} \mathrm{C}(\mathrm{ANN}), 1.5^{\circ} \mathrm{C}(\mathrm{MAT})$, and $1.8^{\circ} \mathrm{C}$ (WA-PLS) between $7-17^{\circ} \mathrm{C}$. For SST $<7^{\circ} \mathrm{C}$ the MAT and ANN models have a RMSE $\sim 2-2.5^{\circ} \mathrm{C}$, while the WA-PLS model appears to have no predictive power over this interval. The SH-311 training set is spatially autocorrelated using the tests of Telford and Birks (2009). One way to assess the effects of spatial autocorrelation on apparent model performance is to assess prediction errors using spatially independent test sets (Birks at al., 2010). Although it is difficult to obtain appropriate balance in a relatively small training set such as has been assembled here, a 68-sample test set of samples around the New Zealand region was split from the training set and separated by $>1000 \mathrm{~km}$ from the nearest training set samples. Model performance of this spatially independent test 
set was 1.3 times (WA-PLS) and 2 times (ANN and MAT) poorer than leave-one-out cross validation.

High dissimilarity values in MAT are often used to identify non analogue situations (e.g., Gersonde et al., 2005; deVernal et al., 2005; Marret et al., 2008; Sikes et al., 2009). We have used a dissimilarity score higher than the $99^{\text {th }}$ percentile of those observed within the modern training set to identify fossil samples with poor modern assemblages (a chord distance of 0.41 ). Another test of suitability of fossil assemblages for quantitative reconstruction used here is inspection of the mutual distribution of both the training and fossil assemblages in ordination plots.

\subsubsection{Interpreting the pollen record}

Transport to DSDP594 potentially complicates vegetation and climatic interpretation based on the pollen assemblages, due to three main factors: 1) the large, and possibly variable, source area; 2) alteration of the assemblages by winnowing, compared to terrestrial counterparts; and 3) physical damage to pollen during transport to the site. Each factor is considered briefly here, before describing the groups of pollen used here to infer vegetation and climate.

In their interpretation of the DSDP594 record, Heusser and Van der Geer (1994) provided no specific analysis of the likely source area of the pollen and spores, interpreting the pollen to represent vegetation changes across the "South Island", and inferring that a significant proportion of pollen was likely transported to the site via water rather than wind. Most of the pollen found in sediment traps and sea-floor sediments to the east of New Zealand are of anemophilous plants (Crouch et al., 2010; Chapter 3, this study), and eastwards aeolian dispersal of such pollen from the New Zealand landmass over great distances $(<750 \mathrm{~km})$ has been established (Mildenhall, 1976; Holt et al., 2010). However, there is an order-of-magnitude decrease in the average pollen concentration in sea-floor sediments within $100 \mathrm{~km}$ of the New Zealand landmass (Crouch et al., 2010, Chapter 3, this study), suggesting that most pollen entering the ocean east of New Zealand is either via rivers, or by a near-shore pollen rain, an observation consistent with other ocean margin settings (e.g. Traverse, 2007). 
Inspection of modern currents (Figure 6.1), including the trajectories of drifters from the global Drifter Programme (Chiswell and Rickard, 2006) suggests that much of the pollen reaching the site under the present interglacial circulation regime is likely to be sourced from South Canterbury and eastern Otago (area " $A$ " on Figure 6.1). Inferred glacial circulation patterns (Neil et al., 2004) also favour a similar pollen source, although enhanced circulation and counter-surface currents may have extended the distance travelled for water-borne pollen, while variation of westerly wind intensity or frequency may have led to more extensive aerial transport of pollen during glacials (Mildenhall, 2003; Mildenhall et al., 2004; Shulmeister et al., 2004; Lorrey et al., 2012).

Discrepancies between the MIS7 assemblages at DSDP594 and a single pollen sample in a fragmentary record from on-shore Banks Peninsula (near Christchurch) led Soons et al. (2002) to suggest that the DSDP594 record was a poor record of South Island vegetation. Although this observation largely ignored the possibility that the Banks Peninsula core site may itself reflect local rather than regional vegetation, it does highlight the value in linking terrestrial with near-shore pollen records prior to interpreting the assemblages from more distal marine settings.

In preparation for the present study, we inspected the pollen assemblage from a recently-collected marine core close to the Canterbury coast (Integrated Ocean Drilling Programme [IODP] 1352, water depth 340m) (Figure 6.1), as a "bridging" near-shore east coast record. Although comparison of IODP 1352 with the DSDP594 record is complicated by a poorly developed IODP 1352 age model, it is possible to match up the broad and distinctive patterns of pollen succession observed during MIS9 and MIS11. Since the sediment source of the upper-slope IODP 1352 is interpreted to be largely from South Canterbury and East Otago rivers (Land et al., 2010; Fulthorpe et al., 2010), the similarity of pollen succession observed at the two sites lends support to a southeastern South Island source for much of the pollen at DSDP594, although these data await more robust age constraint.

Winnowing, the preferential transport of some pollen types over others, has long been recognised as an influence on pollen assemblages in lacustrine and marine 
settings (Traverse, 2007). The effects have been observed in modern New Zealand oceanic settings (Crouch et al., 2010), and broadly result in over representation of large saccate pollen and spores (e.g. Podocarpus, Cyathea) with increasing transport distance at the expense of smaller grains such as Kunzea spp., Poaceae, Coprosma spp., Dacrydium spp., Colobanthus spp.. While this means distal marine assemblages can never be compared directly to those from terrestrial settings, overall patterns and large signals can be compared, and the assemblages within the core may be compared, provided similar transport pathways are assumed through time (e.g. Mildenhall, 2003; Mildenhall et al., 2004).

Poor preservation of pollen in marine settings can preclude divisions that are made routinely in better preserved terrestrial sequences (e.g., Mildenhall 2003; Mildenhall et al., 2004; Crouch et al., 2010): for example identification of Podocarpus spp. and Prumnopitys spp. to specific level, identification of ferns and fern allies, and many wetland taxa.

For interpretation of the DSDP594 pollen record, we have collated the pollen assemblage into a number of functional groups and individual taxa, following the quantitative ordination of New Zealand pre-deforestation pollen spectra against modern mean annual air temperature and precipitation (Wilmshurst et al., 2007) (Table 6.1).We use the succession and relative abundance of these functional groups to compare the timing of vegetation developments during MIS11, and compare these to subsequent interglacial periods at the site.

\subsection{Results}

\subsubsection{Dinocyst assemblages}

Dinocyst assemblages examined in this study are of comparable diversity to that reported for the MIS6-1 part of the core (Marret et al., 2001). We recorded 32 taxa, 
Table 6.1. Vegetation associations and qualitative climatic indicators used to interpret the pollen record in this thesis

\begin{tabular}{|l|c|c|}
\hline Pollen & Vegetation & Climate indicators \\
\hline & & \\
\hline Poaceae, Chenopodiaceae, Asteraceae & Herbfield, low shrubs & Cold \\
\hline Phyllocladus, Halocarpus & Alpine shrubland & Cold, wet \\
\hline Coprosma & & Cool, dry \\
\hline Cyathea & Forest margin & Warmer, wet \\
\hline Prumnopitys/Podocarpus & Hard wood forest & Warm \\
\hline Dacrycarpus dacrydioides & Forest margin, swamp & Warm \\
\hline Dacrydium cupressinum & Lowland forest & Warm, wet \\
\hline Nothofagus fuscospora & Forest, open forest & Cool \\
\hline Nothofagus menzeisii & Forest, open forest & Cool, wet \\
\hline
\end{tabular}

23 of which were recognised in more than one sample. The most dominant taxa were Nematosphaeropsis labyrinthus, Selenopemphix antarctica and Brigantedinium spp., while large numbers of Spiniferites mirabilis, S. hyperacanthus, S. ramosus and Selenopemphix quanta were occasionally observed (Figure 6.2). Average abundance was 1200 cysts. $\mathrm{g}^{-1}$ (2200 cysts. $\mathrm{g}^{-1}$ with the inclusion of a single outlier dominated by Spiniferites hyperacanthus at 348ka), and was generally higher in interglacial samples. Abundance was particularly high between 421 - 418ka (average 5500 cysts. $\mathrm{g}^{-1}$ ) and 348-345ka (average 2200 cysts. $\mathrm{g}^{-1}$ ). The overall concentrations and patterns documented here are similar to those observed in the younger part of the core (Marret et al., 2001) where an average abundance of 1700 cysts.g ${ }^{-1}$ was observed, with a peak of 10,000 cysts. ${ }^{-1}$ during MIS5e.

A clear progression of assemblages indicative of glacial to interglacial conditions was observed between MIS12 and 10. For interpretation, the succession was qualitatively divided into seven assemblages zones (Figure 6.2).

The oldest assemblage zone (AZ1), (>438ka during the peak of MIS12) is dominated by S. antarctica (70\%), relatively low concentrations of Brigantedinium spp. (10$15 \%)$, traces of other peridinoid cysts including S. quanta, and occasional Impagidinium pallidum. A dramatic transition occurs between 438ka - 431ka (where there is a 7ky sample gap), from the AZ1 zone into the AZ2 zone. In AZ2 (431-423ka), S. antarctica is less than $10 \%$ of the assemblage, and is frequently absent, and the 


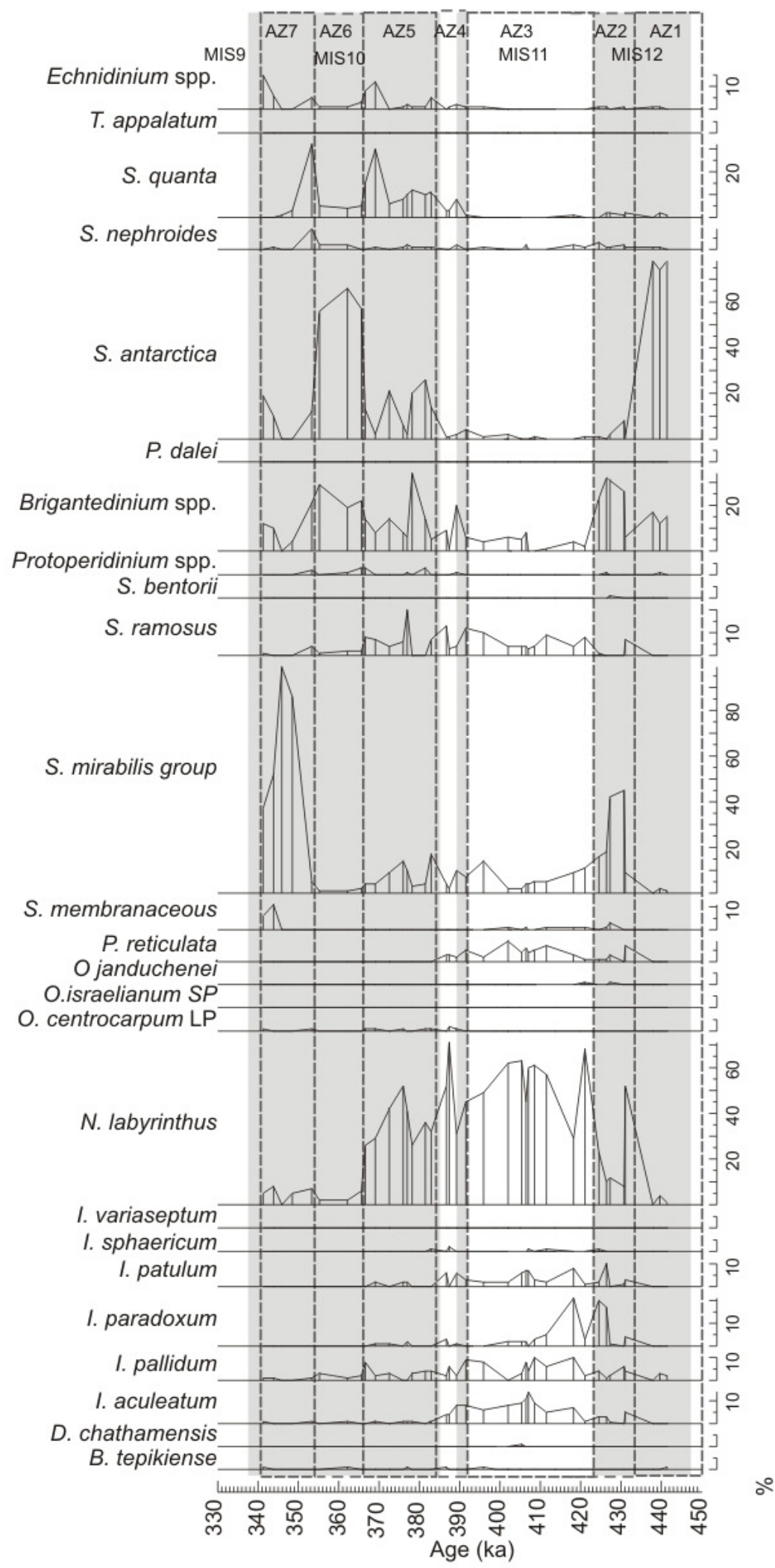

Figure 6.2. Percentage diagram of main dinoflagellate cyst taxa from MIS12-10 section of DSDP 594. Composition of Assemblage Zones AZ1-AZ7 are discussed in text. Marine Isotope Stage boundaries shown are the mid-point of each isotopic variation from Lisiecki and Raymo (2005). 


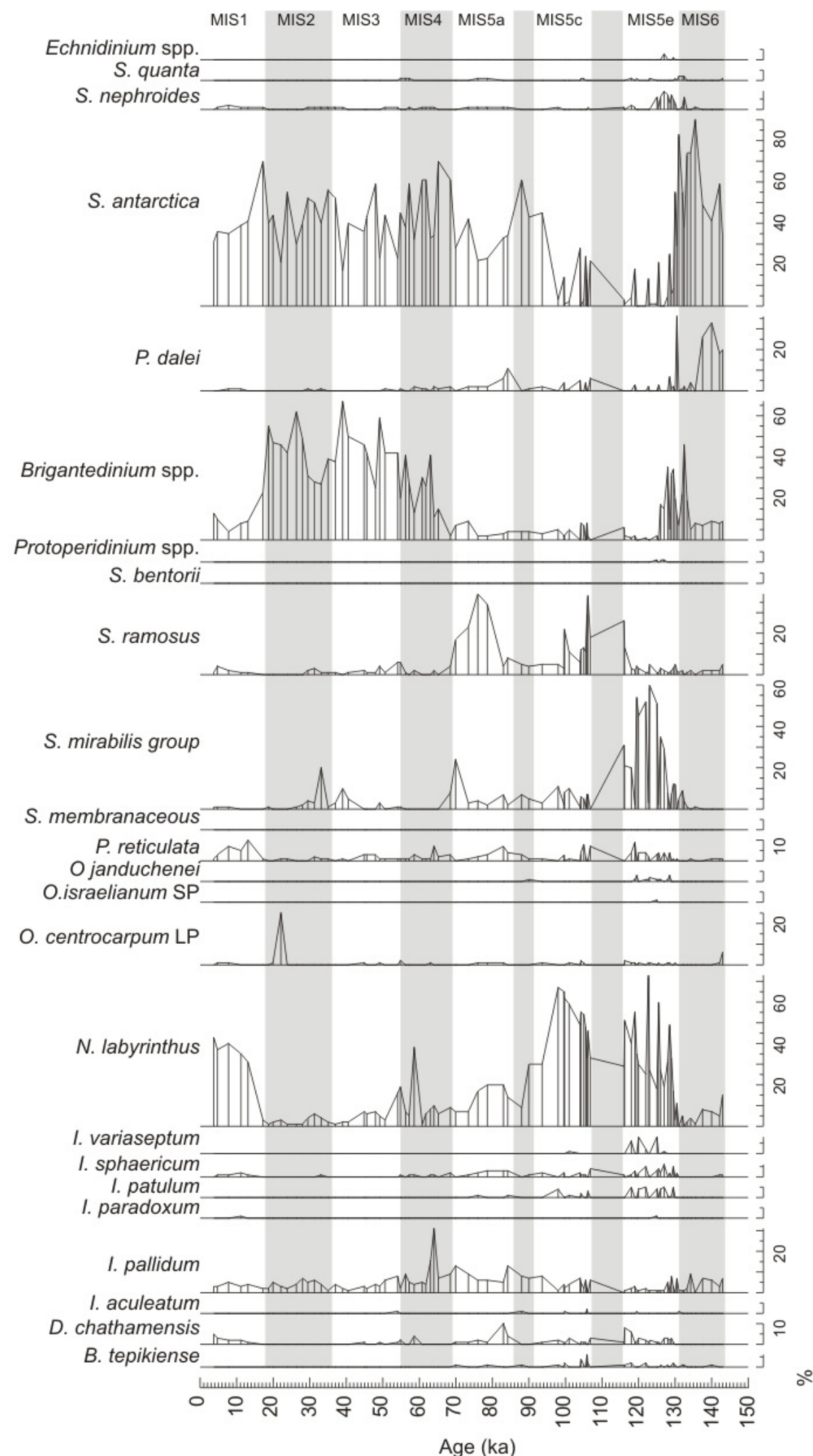

Figure 6.3. Percentage diagram of main dinoflagellate cyst taxa from MIS1-6 section of DSDP 594. All data from Marret et al. (2001). 
assemblages are dominated alternately by N. labyrinthus and S. mirabilis group (S. mirabilis sensu stricto and S. hyperacanthus), with elevated concentrations of Brigantedinium spp. (up to $30 \%$ ). The zone includes the first presence of four Impagidinium taxa (I. aculeatum, I paradoxum, I. patulum and I. sphaericum), with the proportion of total Impagidinium spp. increasing up through the zone, particularly I. paradoxum and I. patulum (Figure 6.2). The zone also includes the first presence of Pyxidinopsis reticulata and Spiniferites membranaceus. AZ3 (423ka $392 \mathrm{ka}$ ) is characterised by the lowest concentration of peridinoid cysts in the section, high relative abundances of $N$. labyrinthus, and common presence (up to 10\%) of $S$. ramosus, and a single occurrence of Operculodinium janduchenei. The brief AZ4 $(392 \mathrm{ka}-384 \mathrm{ka})$ is a transitional zone, defined by the reintroduction of peridinoid cysts, including Selenopemphix quanta and Echinidinium spp., with a small increase in S. antarctica and the last appearance of P. reticulata, while AZ5 (366-384ka) contains still higher, but fluctuating concentrations of S. antarctica and S. quanta, declining abundances of $N$. labyrinthus, the last presence of $I$. paradoxum and $I$. patulum accompanied by a marked decrease in I. aculeatum. Assemblages of AZ6 (366ka - 354ka) are very similar to the glacial AZ1 zone. The overlying AZ7 (341ka $354 \mathrm{ka}$ ) has some similarities to AZ2, in the high abundance of S. mirabilis group, but differs from AZ2 by the near-absence of warmer water Impagidinium spp. taxa, and greater frequency of peridinoid cysts including S. quanta and Echinidinium spp..

Similar assemblages to those observed in MIS11 are recognised in the MIS6 - 5 record (Figure 6.3) of Marret et al. (2001). The glacial assemblages of MIS6 have a similar composition to AZ1 and AZ6 (although the older part of the MIS6 section contains cysts of Pentapharsodinium dalei up to 30\%). MIS5e has similar composition to upper AZ2 and AZ3, with relatively low S. antarctica (although up to 20\%), and a domination by alternating N. labyrinthus and S. mirabilis group, along with up to $30 \%$ Brigantedinium spp. A notable difference between the MIS5e and MIS11 assemblages is the presence of two taxa (Impagidinium variaseptum and Operculodinium israelianum) during MIS5e in concentrations that are today found in waters north of the STF. 
When comparing dinocyst assemblages of MIS12/11, MIS6/5e and MIS2/1, the last glacial-deglacial transition and MIS1 assemblages are markedly different to those of MIS6/5e and MIS12/11. With the exception of an increase in $N$. labyrinthus and $P$. reticulata at $c a .15 \mathrm{ka}$, the Holocene assemblages are similar to the underlying glacial stages, with low diversity and relatively high (up to 40\%) relative abundances of $S$. antarctica. The diverse Impagidinium spp. and Spiniferites spp. components characteristic of MIS5e and early MIS11 are not observed in MIS1. But for the high relative abundances of $S$. antarctica, and slightly less common Spiniferities spp., the Holocene dinocyst assemblages are also similar to those of the later part of MIS11 (AZ3) (Figures 6.2 and 6.3).

\subsubsection{Water mass indicators}

During peak glacial times at DSDP594 (MIS 2-4, 6, 10, and 12) the water mass properties interpreted from dinocyst assemblages show clear indications of SAW, and no components of the assemblage are indicative of water from north of the STF (Figure 6.4). Assemblages during the interglacial periods MIS11, MIS5a and MIS5e have components indicative of possible STW influence, and the SAW influences are much reduced when compared to the glacial assemblages. In MIS11, components indicative of possible STW influence are present, between 430 - 410ka (Figure 6.4). There are also intermittent, but muted, indications of possible STW influence for the following 40ka, until full glacial assemblages with a strong SAW signal are observed after 370ka.

Assemblage components that are unequivocal indicators of STW are restricted to samples from MIS5e (Figure 6.4). Interestingly, MIS1 (Holocene) assemblages have no components indicative of STW, and the water mass indicators do not change across the MIS2-MIS1 deglacial transition.

\subsubsection{SST models}

The first approach used here to assess the quality of transfer function models (dissimilarity scores to the nearest analogue sample) indicates $80 \%$ of the fossil samples have adequate modern analogues within the training set for the MIS12-10 sequence. Eight samples have a dissimilarity score $>0.41$ between MIS12-11 

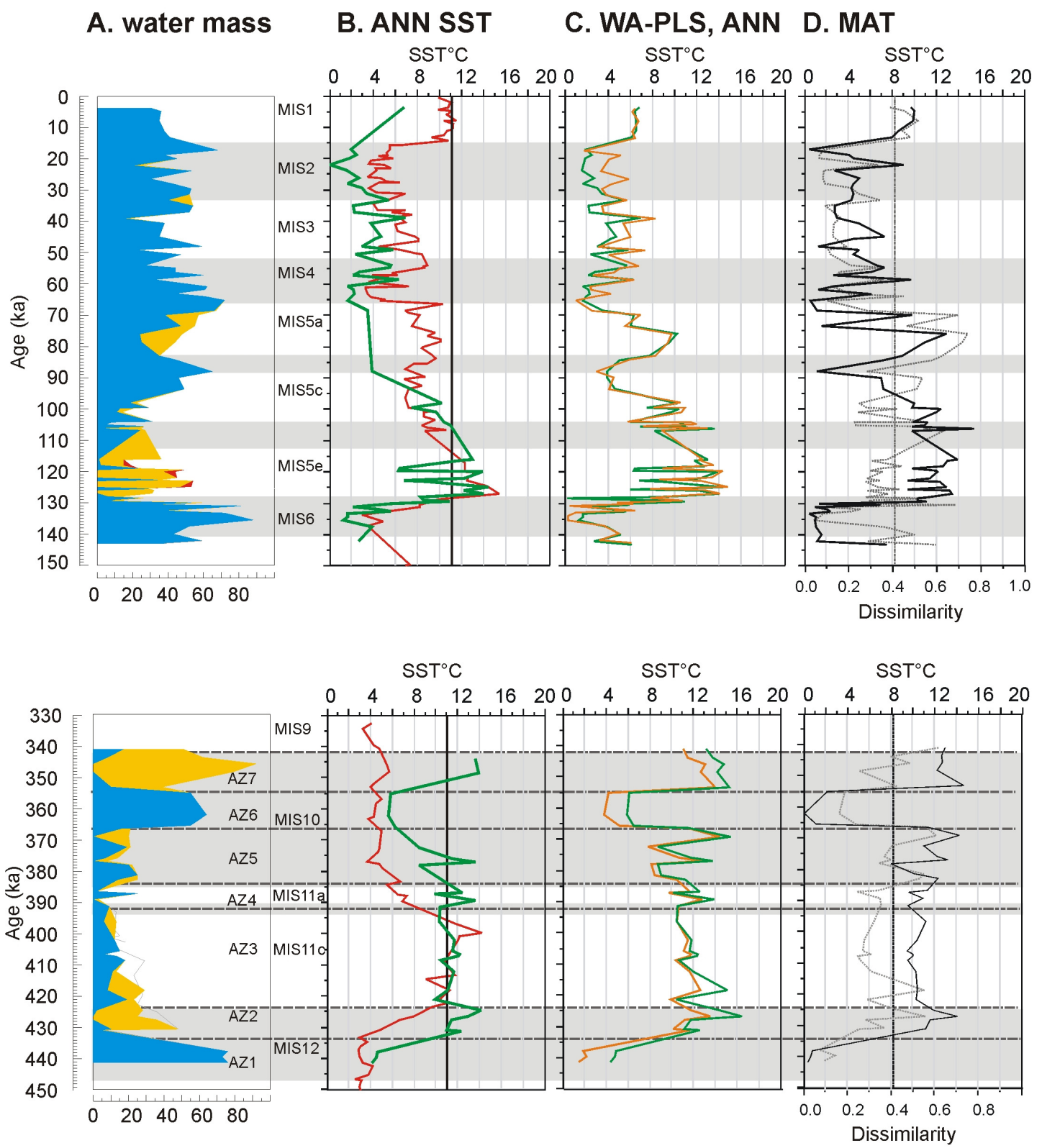

Figure 6.4. DSDP 594, water mass indicators and SST estimates. A. Water mass indicators are as follows: blue $=$ portion of assemblages similar to modern SAW; yellow $=$ portion of assemblages similar to those observed within modern waters north of $5^{\circ}$ south of the STF; red = portion of assemblages similar to modern STW. B. red = foraminifera-based SST estimates using an ANN model (Hayward et al., 2008), green = dinocyst-based SST estimates using an ANN model, samples with a dissimilarity score $>0.41$ to the nearest modern sample are excluded. . green = dinocyst-based SST estimates using an ANN model, orange = dinocyst-based SST estimates using a WA-PLS model. D. black = dinocyst-based SST estimates using a MAT model, black dashed = square chord dissimilarity to nearest modern analogue sample.

(Figure 6.4), while a similar proportion (77\%) crossed this dissimilarity threshold in the MIS6-1 succession (Figure 6.4). However, while all of the MIS12-10 samples plot within the distribution of the modern training set in ordination space (Figure 6.5), a proportion of those from MIS6-1 do not. Model errors are likely to be greater for 


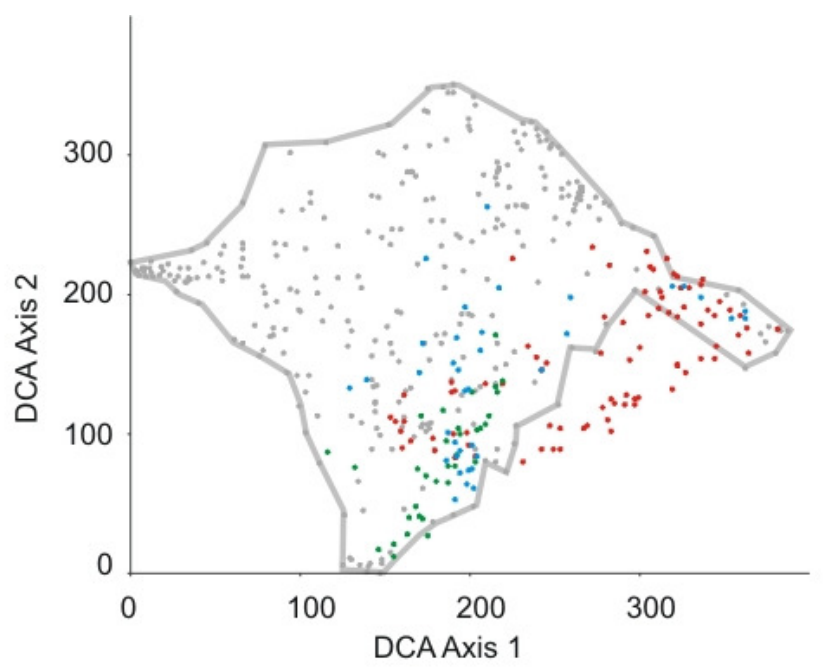

Figure 6.5. Biplot of the first two axes of a detrended correspondence analysis (DCA) of modern and fossil dinocyst assemblages from the Southern Hemisphere, using the PAST software (Hammer et al., 2001). Data include: the modern SH-311 dinocyst training set (grey dots, with extent of scatter shown by grey line), samples of MIS12-10 age from east Tasman Sea core MD06-2989 (green dots), samples of MIS12-10 age from DSDP 594 (blue dots), and samples of MIS6-1 age from DSDP 594 (red dots).

these samples, particularly for MAT and ANN models. These samples are distributed throughout the succession, but are most common in the Holocene, MIS4, and MIS5b, and are less common in MIS5e assemblages (Figure 6.4).

The SST models produced for the MIS6-1 part of the core are very similar to the seasonal SST results of Marret et al. (2001), which showed peak SST during MIS5e to be $\sim 3^{\circ} \mathrm{C}$ warmer than the present. Although a few SST estimates remain that plot outside the ordination range of the modern training set (Figure 6.5), when those with high dissimilarity scores are removed from the ANN model (Figure 6.4), the succession is remarkably coherent with the equivalent foraminifera-based SST model (except for sample gaps in the Holocene and MIS5a) (Figure 6.4B). In particular, the timing and magnitude of SST rise during the MIS6-5 transition are very similar. Of the three models, only the MAT estimates accurately reconstruct the modern core top mean annual SST of $11^{\circ} \mathrm{C}$. The ANN and WA-PLS models indicate SSTs of $5-6^{\circ} \mathrm{C}$ during the Holocene.

In the MIS12-10 succession, SST models show a warming from MIS12 glacial conditions between 440 - 430ka, with peak MIS11 warmth at 423ka (Figure 6.4). From that peak, the ANN model shows a fluctuating decline in SSTs between 410ka 366ka. In contrast, both the MAT and WA-PLS models suggest a more sustained 
period of stable interglacial SSTs between $423 \mathrm{ka}$ - 385ka, followed by a period of increased variability in SSTs until 366ka. All three models show a stable ca. $11 \mathrm{ky}$ period of low SSTs during MIS10, between 366ka - 355ka, coinciding with AZ6, and a rapid warming to interglacial SSTs between 355ka - 353ka. The ANN model produced the warmest estimates, consistent with other multi-model transfer function studies in the region (Barrows et al., 2007; Hayward et al., 2008, 2012), with SST estimates of three samples with good modern analogues being $>14 \pm 1.2^{\circ} \mathrm{C}(1.8-$ $4.2^{\circ} \mathrm{C}$ above present SST). The MAT and WA-PLS model SST estimates were much lower, with no samples with good analogues warmer than $14 \pm 1.5 / 1.8^{\circ} \mathrm{C}$ (MAT/WAPLS RMSE, respectively) during MIS11.

While the magnitude of glacial to interglacial SST change between the foraminifera and dinocyst based estimates is similar during MIS12-11 $\left(8-9^{\circ} \mathrm{C}\right)$, the timing of events varies markedly between the two proxies. Although the dinocyst sampling gap between $440 \mathrm{ka}-430 \mathrm{ka}$ means that the commencement of warming may have been synchronous between the two proxies, the dinocyst-based models suggest much faster warming than that depicted by the foraminifera-based models. The dinocyst models suggest SSTs similar to the present day was attained by $430 \mathrm{ka}$, while the foraminifera models suggest this occurred 13ky later, at $417 \mathrm{ka}$ (Figure 6.4). This discrepancy is explored further in Section 6.6.1, and may be due to poor SST estimates associated with the distinctive dinocyst assemblages of AZ2. Peak SST in the foraminifera model $\left(3^{\circ} \mathrm{C}\right.$ above present SST) is represented by a single sample late in MIS11C, about 298ka, which is followed by a relatively rapid decline to nearglacial SSTs.

In summary, there are multiple samples during MIS5e with SST estimates $>13^{\circ} \mathrm{C}$ $\left(>2^{\circ} \mathrm{C}\right.$ above present SSTs) that have good modern analogues, and consensus between model estimates. There is less evidence for a sustained period of SST $>13^{\circ} \mathrm{C}$ during MIS11, as there is poorer agreement between the dinocyst-based models, and between the best dinocyst-based models and the foraminifera-based SST estimates. 


\subsubsection{Pollen assemblages}

A clear glacial-interglacial pollen succession is observed in the sampled interval from 448ka - 355ka (Figure 6.6). This pollen record has been qualitatively divided into seven pollen zones (PZ), many of which coincide with the dinocyst-based zone boundaries identified in Figure 6.2. The youngest samples examined here overlap with those of Heusser and Van der Geer (1994) between 355ka - 350ka. The relative abundance counts for the overlapping samples are consistent (within $5-10 \%$ ) between the two studies (Figures 6.6-6.7).

Pollen concentrations ranged from $\sim 100-3000$ grains. $\mathrm{g}^{-1}$ and were highest in interglacial and deglacial samples, with the average concentration over the $425-$ 418ka interval almost four times the average of the remaining samples. For the overlapping section in MIS10, pollen concentrations in the present study are lower (average 140 grains. $^{-1}$ ) than those reported by Heusser and Van der Geer (1994) (430 grains grains. $\mathrm{g}^{-1}$ ). Although pollen concentrations in the two studies were calculated using the same marker-grain method, the different processing methods employed may be the source of this discrepancy. Processing in the present study has been optimised for recovery of dinocysts, average abundances of which are very similar to those reported by Marret et al. (2001).

The glacial assemblage PZ1 (>434ka, MIS12) is dominated by abundant Asteraceae, Phyllocladus spp., grasses, and Chenopodiaceae (Figure 6.6, Table 6.1). The first vegetative changes associated with the deglacial (PZ2, 434ka - 425ka) are a rapid increase in Cyathea (tree fern) spores and Coprosma pollen. Between $425 \mathrm{ka}-419 \mathrm{ka}$ (PZ3), herb pollen notably decreased and the abundance of Podocarpus/Prumnopitys pollen begins to increase, while high abundances of Coprosma remain. The relative abundance of Podocarpus/Prumnopitys pollen doubles between 424ka - 419ka (PZ4), and remains high ( 70\%) until 404ka. PZ4 also contains elevated Dacrycarpus dacrydioides and Asteraceae is absent. Towards the top of the PZ4, the relative abundance of Nothofagus fuscospora gradually increases while D. dacrydioides decreases. After 404ka, until 398ka, Nothofagus pollen abundance increases further (PZ5), and replaces Podocarpus/Prumnopitys. At the top of the zone, the proportion of Phyllocladus spp. and Halocarpus spp. pollen increases, and is accompanied by 


\section{Chapter 6}

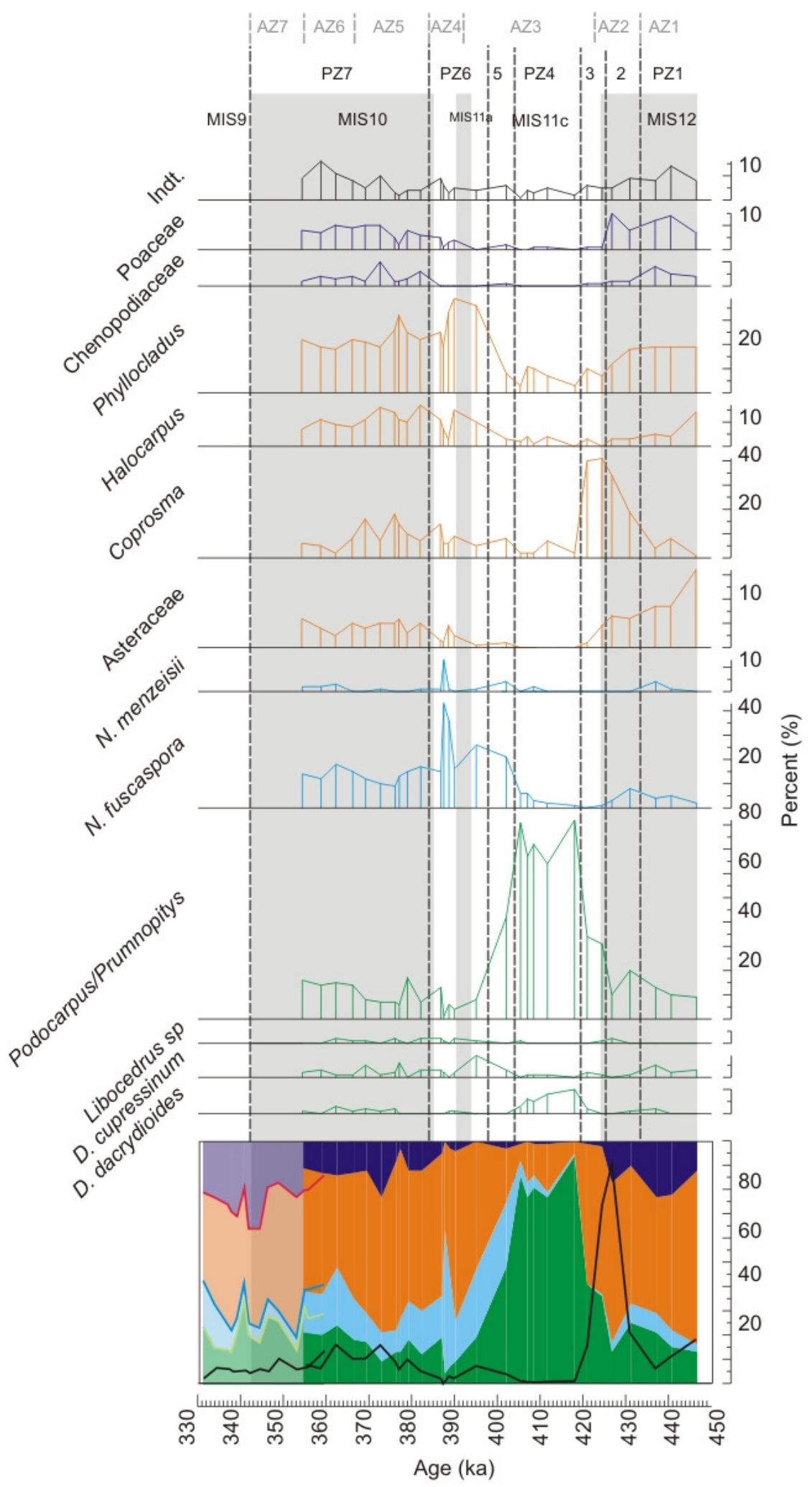

Figure 6.6. Summary percentage pollen diagram of MIS12-10 from DSDP 594. Composite diagram shows the proportion of hardwood conifer pollen (green), Nothofagus pollen (light blue), small trees and shrubs (red) and grass/herbs (blue). The proportion of Cyathea to the dry land pollen sum is shown by the black line (maximum at $425 \mathrm{ka}$ is $3 \mathrm{x}$ dryland sum). Composition of Pollen Zones PZ1-PZ7 are discussed in the text. Composite diagram between 330-355ka is drawn from data from Heusser and Van der Geer (1994). 


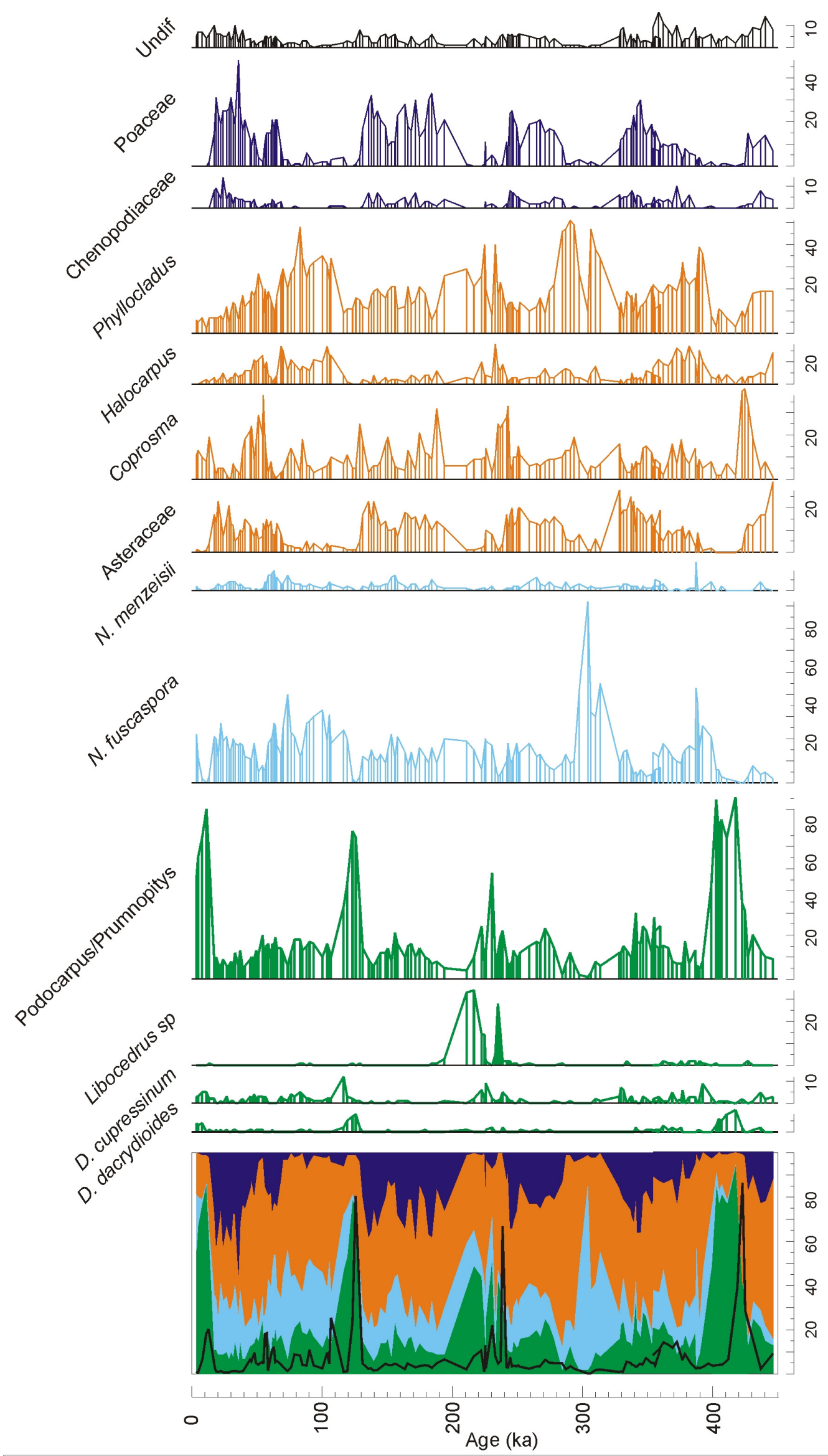

Figure 6.7. Summary percentage pollen diagram of MIS12-1 from DSDP 594. Data from 0-355ka are from Heusser and Van der Geer (1994), 355-450ka this study. Composite diagram same as for Figure 5.6. 
a peak (10\%) of Dacrydium cupressinum. Zone PZ6 (398ka - 384ka) contains a gradual increase of pollen characteristic of cool glacial periods, including Asteraceae and Poaceae, punctuated by a brief spike of Nothofagus spp., both N. fuscospora and N. menzeisii, centered on $\sim 388 \mathrm{ka}$. The Nothofagus peak is mainly at the expense of Phyllocladus spp. and Halocarpus spp.. The MIS10 glacial pollen spectrum is stable for the 40ka following 380ka (PZ7), with an assemblage dominated by small trees and shrubs, such as Asteraceae, Phyllocladus spp., grasses, and Chenopodiaceae. A forest component, of both hardwoods and particularly Nothofagus spp., remained throughout MIS10 in higher proportions than MIS12.

\subsection{Discussion}

MIS11 evolved differently to later interglacials of the Quaternary, with a protracted deglaciation, followed by an interstadial that persisted over two insolation peaks (Tzedakis et al., 2009; 2012). In contrast, MIS5e (ca. 125ka), MIS7e (ca. 237ka), MIS9 (ca. 324ka) had rapid deglaciations, coinciding with early peaks in Antarctic temperatures, atmospheric $\mathrm{CO}_{2}$ and $\mathrm{CH}_{4}$, followed by monotonic declines. The MIS21 glacial termination (18-10ka) and the following Holocene display a mixture of both patterns, with a relatively rapid deglaciation, and early Holocene maxima in Antarctic temperatures and greenhouse gas (GHG) concentrations that are not followed by monotonic declines (Jouzel et al., 2007; Tzedakis et al., 2012). The long interstadial, along with the fact that MIS1 and the early part of MIS11 share similar orbital parameters of muted insolation due to an eccentricity minimum (Loutre and Berger, 2003), has led to studies exploring MIS11 as a possible analogue for the development of the Holocene under pre-anthropogenic conditions (Muller and Pross, 2007; Bowen, 2010; Tzedakis, 2010; Koutsodendris et al., 2010). However, two main factors complicate the use of MIS11 as a direct analogue for the Holocene.

1. The relative influence of insolation between the two interglacials has slight differences in the phasing of precession and obliquity, resulting in nonunique patterns of insolation (Dickson et al., 2009; Tzedakis, 2010; Rohling et al., 2010): although MIS11 is a close match, it is not an exact match 
2. Although apparently modulated by orbital variation, the nature of interglacials is also likely to be influenced by the environments that preceeded them. MIS11, for example, follows the most intense glaciation of the past 1My (MIS12) (e.g. as measured by benthic oxygen isotopes; Lisiecki and Raymo, 2005, or relative sea level; Rohling et al., 2009) and is the first fully developed quasi-100ka cycle following the climate reorganisation of the Mid-Pleistocene Transition (Clark et al., 2006; Kandiano and Bauch, 2007; Voelker et al., 2010; Holden et al., 2011). Moreover, possible perturbations in carbon cycling associated with the Mid-Brunhes Dissolution Event may also have influenced marine conditions (Wang et al., 2002; Barker et al., 2006).

Notwithstanding the variations described above, both the dinocyst and the pollen assemblages at DSDP594 during parts of MIS11 have many similarities to Holocene counterparts. The succession of pollen assemblages during the protracted MIS11 deglacial mirrors the succession seen in the more rapid deglacials of MIS6-5 and MIS2-1, while the dinocyst and pollen assemblages of the later part of MIS11 are similar to, although qualitatively warmer than, that observed in the Holocene. The combination of the east Tasman Sea marine records (Hayward et al., 2012; Chapter 5, this study) and the dinocyst and pollen records from DSDP594 suggest that conditions in the New Zealand region in the later part of MIS11 were similar to those of the early Holocene climatic optimum, or slightly warmer.

\subsubsection{Comparison of dinocyst records from MIS11, MIS5 and MIS1 east of New Zealand}

At DSDP594, different dinocyst assemblages are observed during the early (430ka 423ka) and late (423ka - 390ka) phases of MIS11. The early phase has most similarity to the succession observed in MIS5e, while the late phase has some similarity to assemblages of MIS1 (Holocene). The assemblages of the early and late phases are discussed in turn, under the following themes:

1. There are two 'modes' of dinocyst succession observed during late Quaternary interglacials at DSDP594, one of variable assemblages during MIS5e and the early part of MIS11, and another of stable assemblages during 
MIS1, and late MIS11. The cause of the different modes is hypothesised to relate to variable versus stable nutrient and productivity regimes.

2. Previous reconstructions suggest warm STW crossed the STF to reach DSDP594 during MIS5e and MIS11 (Hayward et al., 208; 2012). The warmwater taxonomic indicators established here indicate that significant southward incursion of STW was restricted to the variable assemblage mode of MIS5e, and that even during the variable assemblage mode of early MIS11, STW incursions were sufficiently infrequent that they were not recorded in the dinocyst record.

1. Following the Selenopemphix antarctica-dominated glacial assemblages of MIS12 and MIS6, MIS5e and early MIS11 are characterised by samples with assemblage that are alternately dominated by either Nematosphaeropsis labyrinthus or Spiniferites mirabilis group, with Brigantedinium spp. also common with both (Figures 6.2 - 6.3). Where sampling resolution is sufficient, the transitions between $N$. labyrinthus and $S$. miribilis dominance are seen to occur in $<500$ years during both time intervals. These rapidly alternating assemblages, is the 'variable' mode introduced above. Assemblages dominated by $N$. labyrinthus are common in the modern ocean and high relative abundances are generally characteristic of the waters between the STF and SAF (Chapter 2, this study), which are cool and generally oligotrophic. There are no local modern analogues for high concentrations of S. miribilis, which has not yet been observed to exceed $25 \%$ of a modern Southern Hemisphere sample (Chapter 2, this study). However, it is occasionally dominant in samples off the Iberian Peninsula (Marret and Zonneveld, 2003), a region of intense seasonal upwelling (Dickson et al., 1988; Haynes et al., 1993; Lemos and Pires, 2004). While high abundances of $S$. miribilis during MIS5e and early MIS11 do not necessarily reflect transient Iberianstyle upwelling, and S. miribilis is not observed in similar concentrations in other regions where upwelling occurs (Marret and Zonneveld, 2003), the alternation of $N$. labyrinthus and S. miribilis may be due to variations in the nature of primary productivity in SAW. In the modern SAW setting of DSDP594, variation in productivity can result from increased southward incursions of warmer, micro nutrient-rich STW across the STF, variation in strength or timing of mixing of surface 
waters, or variations in nutrient-rich dust input (e.g., Greig and Gilmour, 1992; Shaw and Vennell, 2000; Boyd et al., 2004). All are potential mechanisms for the variability in the dinocyst record observed during MIS5e and early MIS11 (ca. $430-415 \mathrm{ka}$ ), although Australian-derived dust flux was likely lower during MIS11 (Hesse, 1994).

In contrast, the MIS1 dinocyst assemblage at DSDP594 is dominated by relatively stable assemblages of N. labrynthis and S. antarctica (Figures 6.2-6.3), the 'stable' mode. But for the high relative abundances of $S$. antarctica, and slightly less common Spiniferities spp., the Holocene dinocyst assemblages are also similar to those of the later part of MIS11 (AZ3) (Figures 6.2 and 6.3).

2. The presence of samples with high abundances of S. miribilis, along with a paucity of modern analogue samples with SSTs between $5-10^{\circ} \mathrm{C}$ (Chapters 2 and 4 , this study) may explain the divergent SST estimates from foraminifera and dinocyst based models between 430ka - 415ka at DSDP594 (Figure 6.4), which is a feature restricted to $A Z 2$ in the present study.

Dinocyst water mass indicators point to a southwards migration of STW across the STF to DSDP594 only during MIS5e (Figure 6.4). This interpretation, is consistent with the circulation reconstruction of Hayward et al. $(2008,2012)$, although there is no evidence for the subsequent formation of an eddy circulation near DSDP594, either in the paleo record or in modern observations of periodic southwards incursions of STW through the Mernoo Gap on the western Chatham Rise (Grieg and Gilmour, 1992; Shaw and Vennell, 2000). In contrast to the circulation reconstruction of Hayward et al. $(2008,2012)$, the dinocyst-based proxies do not support a similar southward jet of warm STW water at any time during MIS11. The brief peak in SST estimates from the foraminifera-based models at $\sim 401 \mathrm{ka}$ is not observed in the dinocyst record (Figure 6.4), and none of the MIS11 dinocyst assemblages have characteristics of modern STW. While early MIS11 assemblages contain elements indicative of relative warmth in this SAW setting (e.g., Operculodinium janduchenei, Impagidinium aculeatum), MIS5e contains additional indicators of warmth (e.g., Operculodinium israelianum and Impagidinium variaseptum), which are present in greater abundance. 
Early MIS11 in this region appears to have STW influence of intermediate intensity between the Holocene and MIS5e. The assemblages of the Holocene and late MIS11 are similar, but may be distinguished by the much lower concentrations of $S$. antarctica, and a higher 'background' abundance of both S. miribilis and S. ramosus. Qualitatively, the lower concentration of S. antarctica during late MIS11 suggests warmer conditions than during the Holocene, and possibly less productive surface waters.

\subsubsection{Pollen record of MIS11}

The general structure of the MIS11 pollen succession at DSDP594 is more similar to that observed in MIS5 and the Holocene, than the intervening MIS7 and MIS9 (Figure 6.7). The similarities between the Holocene, MIS5 and MIS11 lie in the broad succession of pollen and spore taxa, from the early spread of Cyathea spp., followed by a dominance of Podocarpus/Prumnopitys and Dacrycarpus spp., which are then replaced by Nothofagus spp. and Phyllocladus spp./Halocarpus spp., before a return to glacial grass and shrubs. In contrast, MIS7 and MIS9 are each missing aspects of this pattern: the Podocarpus/Prumnopitys abundance alternates with Phyllocladus/Halocarpus throughout MIS7 before being replaced by Libocedrus spp., while MIS9 is dominated by Nothofagus spp., with Podocarpus/Prumnopitys barely exceeding average glacial concentrations. The vegetation associations during MIS7 and MIS9 are not discussed further here.

As in the succession of dinocyst assemblages, there are also significant differences between the MIS11 pollen succession and those of MIS 1 and MIS5. The two most notable differences are:

1. the nature of the MIS12-11 deglacial succession, which is much slower (ca. $10 \mathrm{ky})$ than all later deglacial successions, (ca. 5-6ky), and

2. the duration of the hardwood-conifer Podocarpus/Prumnopitys pollen assemblages, which represents maximum extent of the warmest forest type, is ca. $15.8 \mathrm{ky}$ long during MIS11, compared with ca. 6.1ky during MIS5e and ca. $6.3 \mathrm{ky}$ during the early Holocene climatic optimum. The pollen assemblage 
during the entire $c a .15 .8 \mathrm{ky}$ of late MIS11 is most similar to that of the early Holocene climatic optimum.

Each are discussed in turn below.

\subsubsection{The MIS12-11 deglacial pollen succession}

In the last two glacial terminations at DSDP594 (MIS2-1 and MIS6-5), the first change in pollen assemblages following glacial grasses and herbs, is a brief increase in the relative abundance of Coprosma. This is then followed within 3-6ky by a large spike of Cyathea spores (Figure 6.7). The MIS12-11 deglacial succession also has the same early increase of Coprosma (from $\sim 430 \mathrm{ka}$ ), that is followed by a large Cyathea spike within $\sim 5 \mathrm{ky}$. However, in contrast to the later deglacials, the increase of Cyathea spp. is not followed by the rapid dominance of Podocarpus/Prumnopitys. Instead, the relative abundance of Coprosma continued to rise, and was not replaced by high abundances of Podocarpus/Prumnopitys, along with low abundances of Cyathea and Coprosma typical of later interglacials, until $\sim 418 \mathrm{ka}$. This pollen assemblage (PZ3, Figure 6.6) is unique in the $450 \mathrm{ky}$-long record at DSDP594. Two possible biogeographical explanations are considered for this unusual association:

1. The source area during this time may have been larger than inferred for the majority of the record (Figure 6.1), possibly sampling pollen from what are today contrasting climatic regions of Southland and Canterbury, or possibly North Island sources (Kidson, 2000; Lorrey et al., 2007), due to the unique combination of lower sea levels (20-60m below present, Rohling et al., 2009, 2010) and Holocene-like temperatures during this interval (Hayward et al., 2012, Chapter 5, This Study). Alternatively, this unusual scenario may have resulted in greater climatic heterogeneity along the eastern South Island than the present, or

2. the Coprosma vegetation may have occupied an exposed continental shelf, and this genus displayed a decline due to flooding of the shelf as sea level rose, while the area covered by Podocarpus/ Prumnopitys forest remained unchanged between $425-400 k a$. 
The second scenario can be discounted by inspection of absolute abundance data, and the accessory pollen types during each interval. Podocarpus/Prumnopitys pollen concentrations (measured in grains per gram of non-carbonate sediment) were 2-5 times higher between 400-420ka than the preceding 420-430ka interval (Figure 6.8), suggesting that the rise in relative abundance of Podocarpus/Prumnopitys at $420 \mathrm{ka}$ was due to an expansion in source vegetation, rather than flooding of suggested Coprosma spp. growing on the exposed continental shelf, assuming the transport to the site remained unchanged. In addition, other aspects of the pollen spectra indicate that source vegetation was likely different between 420-400ka and the preceding 430-420ka interval: the later assemblages feature peaks of Dacrycarpus spp., while Asteraceae and Chenopodiaceae are absent.
A.
B.
C.

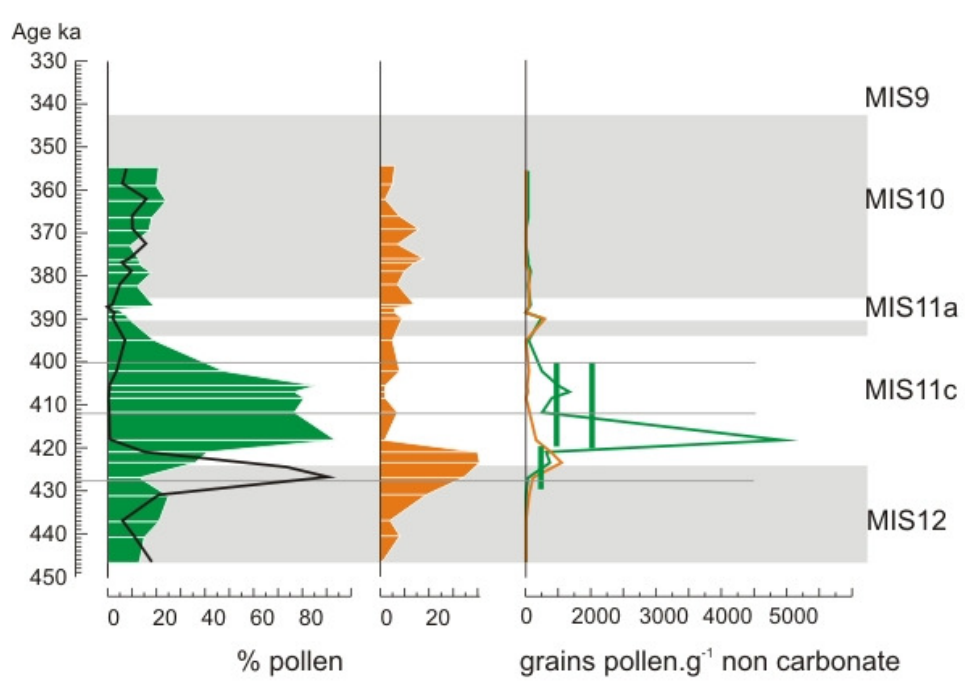

Figure 6.8. A. \% Podocarpus/ Prumnopitys pollen, overlain by \% Cyathea outside the dryland pollen sum (same scale at Figure 6.6). B. \% Coprosma pollen. $\mathrm{C}$ green $=$ Podocarpus $/$ Prumnopitys grains. $\mathrm{g}^{-1}$, orange $=$ Coprosma grains. $\mathrm{g}^{-1}$. Vertical green bars show average concentration of Podocarpus/Prumnopitys over each time period, dual green bars in the 420-400ka interval show effect of exclusion of the very abundant outlier at 418ka.

The different geographies resulting from lower sea level during the period 430-420ka (e.g., the connection of Stewart Island to the mainland and closure of Cook Strait) would have resulted in different coastal currents thus affecting pollen and sources of transport, while the STF was probably further north along the western South Island margin potentially transporting pollen from more northerly sources. A more northerly position of the STF during glacial times is documented for the Indian Ocean (Howard and Prell, 1992), South Tasman Rise (Sikes et al., 2009), and Tasman Sea 
(Martinez, 1994) with subsequent southerly migration during the deglaciation. In addition, there is evidence for SAW influence at $42^{\circ} \mathrm{S}$ along the South Island west coast as late as $420 \mathrm{ka}$ during MIS11, suggesting a slower southwards migration of the frontal system than during the later deglacials (Hayward et al., 2012; Chapter 5, this study, Figure 6.9). Concurrently, the different geographies resulting from lower sea level may also have increased the heterogeneity of Canterbury climate during this protracted deglacial.

Increased southwards transport of STW across the STF inferred by Hayward et al. $(2008,2012)$ would have the potential to increase the source area of pollen to include eastern North Island sources. However, as discussed above, the dinocyst proxies do not support significant southwards transport during MIS11, while the major changes in pollen assemblages do not coincide with the peak of foraminiferabased SST estimates, suggesting that variations in a North Island pollen component are an unlikely cause of the unusual PZ3 pollen assemblage.

\subsubsection{Duration of peak terrestrial warmth during MIS11}

Turning to the observation of the duration of peak warmth during MIS11. Benthic oxygen isotopes indicate MIS11 was longer than those following, with exception of MIS 1 which is incomplete (e.g., Droxler et al., 2003; Lisiecki and Raymo, 2005). SSTs of the oceans surrounding the South Island were similar to, or exceeded, Holocene levels for an extended (up to 40ky) period of time (Hayward et al., 2012; Chapter 5; this study). Two aspects of the pollen assemblage from DSDP594 indicate that interglacial conditions on the South Island were also likely longer that subsequent interglacials, and an early-Holocene-like vegetation persisted for much of MIS11.

At DSDP594, the pollen data show an early-Holocene peak in the relative abundance of Podocarpus/Prumnopitys pollen, where it exceeds $60 \%$ of the dry-land pollen assemblage in two samples, at $7.8 \mathrm{ka}$ and $11.1 \mathrm{ka}$ (maximum duration is $9.1 \mathrm{ky}$, with bounding samples at $4.6 \mathrm{ka}$ and $13.7 \mathrm{ka}$ ) (Figure 6.7). This peak coincides with a twopeak early Holocene climatic optima recorded by New Zealand terrestrial proxies between 11600 and 6500 cal. yr BP (Alloway et al., 2007), while marine proxies show SST was $1-2^{\circ} \mathrm{C}$ higher than the Holocene average within this period (Pahnke and 
Sachs, 2003; Hayward et al., 2012). Podocarpus/Prumnopitys pollen exceeds $60 \%$ relative abundance at DSDP594 during two other interglacials: MIS5e and late MIS11 (Figure 6.7). This occurred in two samples during MIS5e, at $123.3 \mathrm{ka}$ and $125.8 \mathrm{ka}$ (minimum/maximum duration arising from sampling resolution $2.5 \mathrm{ky}-9.7 \mathrm{ky}$ ), and five samples during MIS11 between 405.6ka and 418.2ka (minimum/maximum duration $12.6 \mathrm{ky}-19 \mathrm{ky})$.

Another way to compare the relative length of the three interglacials is the length of time the relative abundance of Podocarpus/Prumnopitys pollen exceeded the abundance observed in the youngest sample at DSDP594. The youngest pollen sample at DSDP594 is at ca. 3.5ka, which has 45\% Podocarpus/ Prumnopitys (Heusser and van der Geer, 1994). The oldest Holocene sample to exceed this criterion is $13.6 \mathrm{ka}$, (age of next oldest sample is $17.1 \mathrm{ka}$ ). This is older than the 11-11.7ka onset of Holocene conditions inferred from the increase in the proportion of $D$. cupressinum pollen from West Coast South Island records (Ryan et al., in press), but is nearer to the onset of terrestrial warming inferred from more northerly records (Newnham et al., 2003), and air-temperature estimates from the West Coast derived from pollen assemblages (Newnham et al., 2011). The relative abundance of Podocarpus/Prumnopitys pollen during MIS5e exceeded $45 \%$ in samples between 119.2ka and 125.8ka (minimum/maximum duration 6.6ky - 12.4ky) and during MIS11 in samples between 405.6ka and 418.2ka (minimum/maximum duration $12.6 \mathrm{ky}-19 \mathrm{ky})$.

These qualitative comparisons of interglacial duration paint contrasting pictures on the relative length of MIS1, 5 e and 11, although these conclusions, based only on the relative abundance of a single pollen group must be treated cautiously given the sampling resolution, transport, preservation and source area considerations outlined in Section 6.4.4.

MIS1 thus far has hardwood forest of similar persistence to that observed during MIS11. However, the pollen record at DSDP594 suggests the hardwood forest during all of MIS11 (405.6ka and 418.2ka) was as extensive as that of the early Holocene climatic optimum (3.4-9.1ky). 


\subsubsection{East-west comparison of marine records during MIS11}

Our dinocyst record at DSDP594 can be compared with coeval east Tasman Sea records (Chapter 5, this study), forming a transect across the South Island (and the STF, as the east Tasman Sea study area is within modern STW) (Figures 6.1 and 6.9).

Within the limitations of sample resolution and age control (benthic isotopes in the west vs planktic in the east), we explore the synchronicity and intensity of events during MIS11. While there are similarities in the SST records either side of the South Island, variation in the DSDP594 pollen record coincides most frequently with changes in the east Tasman Sea SST record.

SST during MIS11 in the east Tasman Sea exhibits more large variations than at DSDP594.

Initiation of the MIS12-11 deglaciation occurred between 435-430ka on both coasts, (Hayward et al., 2012; Chapter 5, this study) with indicators of SAW absent from the east Tasman Sea by $425 \mathrm{ka}$, and dinocyst based estimates of SSTs near to modern levels. This is coincident with the rise in Cyathea spores at DSDP594.

A ca. 6ky long cooling occurred at between $\sim 425 \mathrm{ka}-419 \mathrm{ka}$ in the east Tasman Sea, accompanied by the reintroduction of elements of a SAW-like assemblage in this area (Figure 6.9). This cooling coincides with the prolonged deglacial Coprosmadominated pollen assemblage observed at DSDP594. SST exceeded modern temperatures by $415 \mathrm{ka}$ in the east Tasman Sea, $\sim 5 \mathrm{ky}$ after the foraminifera based SST estimates attaining modern temperatures at DSDP594 (Hayward et al., 2008, Figure 6.9). While the SSTs at DSDP594 remained high for $\sim 15 \mathrm{ky}$, until $\sim 400 \mathrm{ka}$, SSTs in the east Tasman Sea were more variable, with a 10ky long period of maximum warmth, followed by cooling from $\sim 405 \mathrm{ka}$. The $\sim 405 \mathrm{ka}$ decrease from peak SST in the east Tasman Sea coincides with the increase of Nothofagus spp. pollen at DSDP594, replacing Podocarpus/ Prumnopitys. The $\sim 400$ ka decrease of foraminiferabased SSTs at DSDP594 coincides with another incursion of dinocyst assemblages 
Figure 6.9. Comparison of sea surface conditions during MIS11. A. Water mass indicators from the east Tasman Sea (Chapter 4): blue $=$ SAW, yellow $=$ STF and north, orange $=$ STW. Note that the cores are today located north of the STF. B. east Tasman Sea composite SST record, red = ANN composite model of dinocysts and foraminifera, blue = dinocyst-based model,Chapter 4. C. DSDP 594 composite pollen diagram from Figure 5.6. D. DSDP 594 SST: red = foraminifera-based ANN model, green = dinocyst-based ANN model. E. DSDP 594 dinocyst-based water mass indicators from Figure 5.4 .

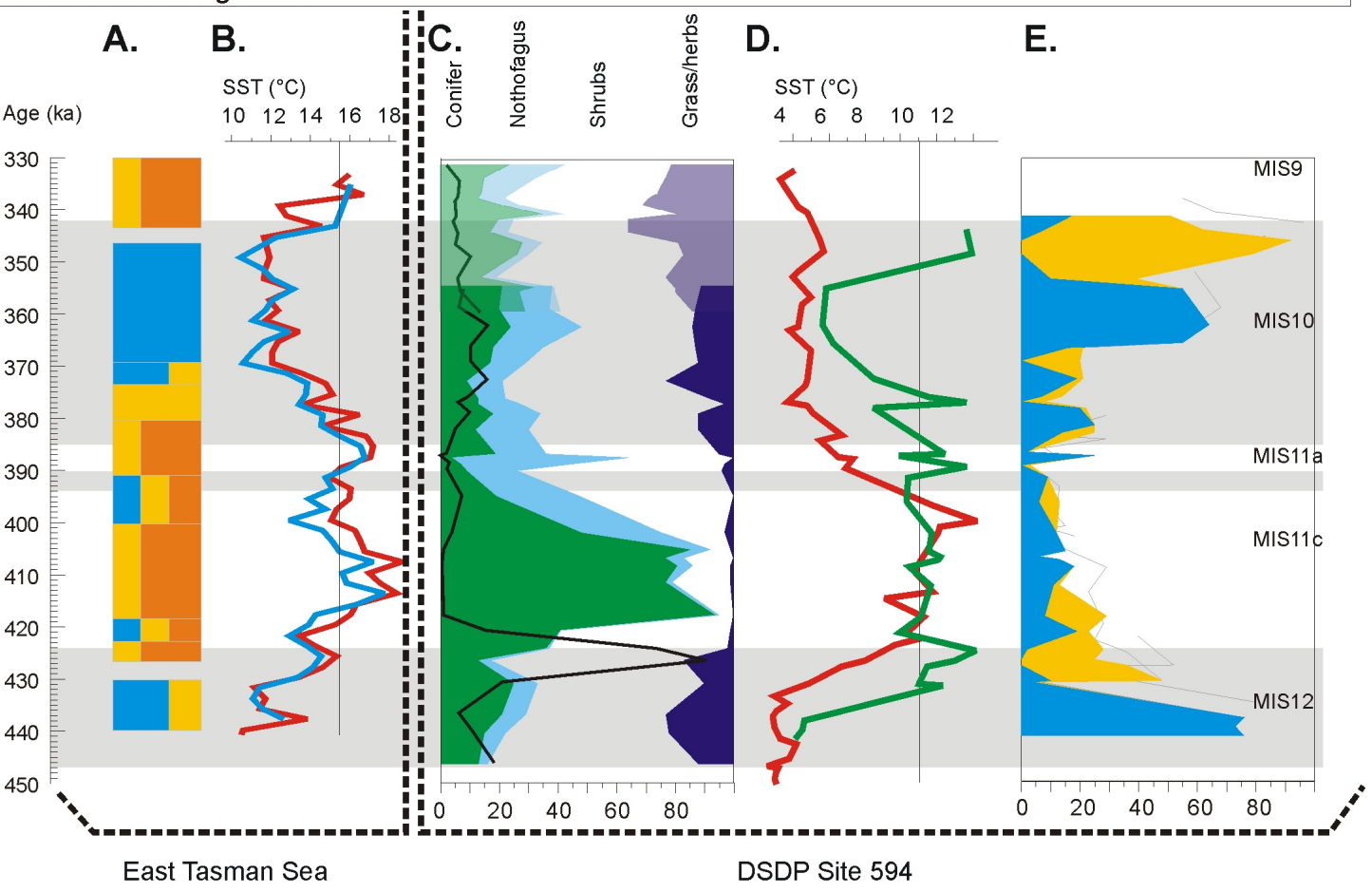

indicative of SAW into the east Tasman Sea, and a further cooling in the east Tasman Sea SST.

Finally, a pronounced warming in the east Tasman Sea at $~ 387 \mathrm{ka}$ is accompanied by a spike in Nothofagus, including N. menzeisii, in the DSDP594 pollen record, with the Nothofagus mainly replacing herb and shrub vegetation. No clear signs of increased SSTs, or variation in water mass indicators, are present in the DSDP594 record at that time.

The correlation of east Tasman Sea SST variation with the eastern South Islandderived pollen record at DSDP594, compared to the record of marine variability from the same samples is not unexpected, given the sensitivity of New Zealand climate to variation in the prevailing westerly winds (Salinger, 1980; Sturman and Tapper, 1996; Shulmeister et al., 2004; Lorrey et al., 2007). Given the likely wide source area of the DSDP594 pollen assemblage, however, precise vegetation changes, and concomitant local climatic effects, are difficult to determine. If the pattern of correlation between low precipitation, low Tasman Sea SST, and higher windiness observed 
during the $20^{\text {th }}$ Century (Ummenhofer and England, 2007; Ummenhofer et al., 2009) was the same for MIS11, the relatively cool SST in the east Tasman Aea during the early part of MIS11 may have led to vegetation changes due to water stress in the Canterbury region.

\subsection{Conclusions}

1) At DSDP594, distinct dinocyst assemblages characteristic of early and late phases of MIS11 are identified. The early phase, characterised by rapidly alternating dominance of $N$. labyrinthus and S. mirabilis, is interpreted to represent fluctuations in primary productivity. In contrast, the late phase is characterised by stable assemblages dominated by $N$. labyrinthus. The early phase is similar to the assemblage succession observed at the site during MIS5e, while the later stable phase is similar to assemblages of the Holocene (MIS1).

2) SST estimates using dinocyst assemblages suggest that MIS11 was an extended period of warmth similar to present conditions, although dinocyst-based SST estimates from the early phase may be compromised due to insufficient modern analogue samples. There are multiple samples during MIS5e with SST estimates $>13^{\circ} \mathrm{C}\left(>2^{\circ} \mathrm{C}\right.$ above present SSTs) that have good modern analogues, and consensus between model estimates. There is less evidence for a sustained period of SST $>13^{\circ} \mathrm{C}$ during MIS11, as there is poorer agreement between the dinocyst-based models, and between the best dinocyst-based models and the foraminifera-based SST estimates.

3) The dinocyst assemblage during MIS5e has characteristics of assemblages found north of the STF in modern sea-floor samples. Thus, some southward migration of STW to DSDP594 may have occurred during MIS5e. In contrast, while there are indications from dinocyst assemblages that the early phase of MIS11 shared a 
similar regime of variable productivity to MIS5e, neither MIS11 or Holocene dinocyst assemblages contain similar indications of southward migration of STW.

4) The MIS11 pollen record at DSDP594 shows a vegetation succession similar to MIS5 and MIS1, but the deglacial succession was slower than younger transitions, with a two-step expansion of Podocarpus/Prumnopitys hardwood forest. The maximum relative abundance of Podocarpus/Prumnopitys pollen from 420 ka was similar to that observed at the site during the early Holocene climatic optimum. Such high abundances persisted for $\sim 15 \mathrm{ky}$, about twice as long as during MIS5e and MIS1.

5) Changes in the pollen record at DSDP594 during MIS11 correlate more closely to SST variation in the east Tasman Sea than to variation in marine conditions at DSDP594, suggesting that the eastern ocean had only limited influence on the eastern South Island

\subsection{Acknowledgements}

Sonja Fry and Xun Li at GNS Science assisted with processing of palynological samples. Thanks to Matt Ryan, Linda Heusser and Fabienne Marret for raw palynological and age data from the younger part of DSDP594.

\section{Supplementary Material}

The following data tables are included at the end of this thesis

S6.1. DSDP594 MIS11 dinocyst counts

S6.2. DSDP594 MIS11 pollen counts 


\section{Conclusion}

The three aims of this thesis were to:

- Better understand the distribution of modern dinocysts in the SW Pacific and the environmental factors that control their distribution.

- Develop models from the modern dinocyst data to quantify past climatic conditions with the focus on MIS 11.

- Use these models in conjunction with pollen records both during MIS11 and other Quaternary interglacials in order to compare sea surface and terrestrial signal, thus illustrating a range of past responses to warm environments in the New Zealand region

In this chapter, the key results relating to each aim are reviewed, and areas that would benefit from further research are identified.

\subsection{Controls on the modern distribution of dinocysts}

As in other parts of the globe, dinocyst assemblages from sea-floor sediments vary across the SW Pacific.

Ordination shows that of the environmental variables gathered the gradient most strongly correlated to variation in dinocyst assemblages is sea surface temperature (SST).

Although there are good physiological reasons why dinoflagellate growth and cyst formation should be influenced by SST, more detailed exploration of the controls of sea surface conditions and productivity suggests that in certain settings SST is likely to have almost an incidental influence on the composition of sea floor dinocyst assemblages in some instances. Dinocyst assemblages are a product of the 
ecosystem and biogeographical province, which frequently and fortuitously vary along meridional gradients.

The clustering analysis in Chapter 2 illustrated the influence of regional ecosystems on sea floor assemblages, while the sediment trap study in Chapter 3 reveals, on shorter timescales, some of the complexity of these regional variations. Within the two small zones of SST sampled by each sediment trap, different combinations of the timing and intensity of mixing, availability of nutrient and light, and the interactions with other organisms and trophic levels, all contribute to the composition of the dinocyst assemblage preserved in sea floor sediments.

Areas for further research into the modern distribution and sedimentary processes undertaken in this thesis include improved coverage of under-sampled areas, both around New Zealand (e.g. the Tasman Sea) and the wider Southern Hemisphere (e.g. Southern Ocean, Indian Ocean), while the addition of well constrained short sediment cores could further refine late Holocene flux and transport pathways of dinocyst and pollen into ocean sediments. The absence of a significant part of the sea floor dinocyst assemblage from the sediment trap study also requires further investigation, both for general understanding of dinocyst ecology and sedimentary processes in the region, but also because the disconnect could have significant implications for the assumptions made in quantitative reconstructions.

Given their organic-walled composition and ecology, dinocysts are preserved in depositional settings where assemblages of other marine micro-fossil groups can be poorly preserved, thus they may at times be unique archives of environmental information. However, given the complexity of oceanographic systems, the greatest potential for understanding past environments lies in the use of dinocysts along side other micro-fossil groups and proxies. For example, integration of multiple fossil groups should better identify modern biogeographical provinces, which should result in more accurate paleoenvironmental interpretations. There has been much progress towards documentation of the modern distribution of most oceanic 
microfossil groups in the New Zealand region in recent years, which raises the exciting prospect of multi-group reconstructions for key time slices in the region.

\subsection{Estimating SST from dinocyst assemblages}

Given the importance and complexity of biogeography described above, it seems an almost impossible undertaking to attempt to reduce all this variability into a single parameter, SST. However, if any parameter is to be extracted from the dinocyst abundance data, the work in Chapter $\mathbf{4}$ demonstrates that SST is the most reasonable; ecologically, physiologically and mathematically.

The real value of a transfer function lies in the robust demonstration of how accurately the estimations of the target variable are, along with the identification of instances where those error estimates are likely to be exceeded. Both these aspects in SW Pacific transfer functions have been explored in this project. The way that accuracy is measured has a large influence on the apparent performance of a transfer function model. When accuracy is measured using frequently employed, but simpler methods (leave-one-out cross validation), the performance of the dinocyst training set assembled for this thesis is comparable to the performance of other marine micro-fossil groups used in the region.

However, simple methods of error assessment may underestimate the true errors (of all faunal training sets), as they do not account for spatial inter-connectedness (autocorrelation) between samples. The effects of this omission has been previously demonstrated using artificial data; and experiments in this project using only 'real' assemblage data also show autocorrelation is likely to have a significant effect on the accuracy of predictions, although the effects are possibly not as severe in the SW Pacific as in other regions.

The more important outcome of the experiments undertaken above is an appreciation of the strengths and assumptions of various transfer function models. Of the models considered, WA-PLS appears to be most successful at extracting 
information accurately from unfamiliar assemblages. This does not mean the other models considered (MAT and ANN) should be dismissed, as they are very accurate when assemblages are familiar. Moreover, they have other advantages, particularly the MAT, as a tool suitable for reconstruction of an entire ocean system, i.e. it could be used for identification of entire biogeographic zones, which can be as useful as isolating single environmental gradients.

It has been observed that faunal training sets are occasionally "datasets of necessity": a collation of samples for which availability is the principal selection criterion. In an area as large and relatively understudied as the SW Pacific, and indeed the Southern Hemisphere, such a criticism can carry some weight. This is not necessarily a bad thing: one has to start somewhere, but with the caveat that periodic reviews are undertaken of the data that have been allowed into the training set. Such reviews should ensure that the best available, rather than the greatest number, of samples are included from a given region, based on various criteria (e.g. quality of sampling and processing, age control, count size, and alignment of taxonomic determinations). In the collation of the SH311 training set for this thesis, such decisions resulted in the exclusion of many published samples, but also the retention of others that can be excluded as higher quality data becomes available. The same is true of the abiotic data assigned to each sample. Satellite observations continually improve, along with extrapolation methodologies that contribute to generate climatological datasets. Such periodic review should progressively reduce prediction errors.

\subsection{MIS 11 in the SW Pacific}

The warm interglacial MIS11 in the New Zealand region was selected for study in this thesis both because of its orbital similarity to the Holocene, and the availability of published oceanic reconstructions indicative of greater warmth than present. MIS11 can serve both as an illustration of the regional variability possible under very similar 
boundary conditions to the Holocene, but also can provide some insight into a world that is very similar to our own, but slightly warmer (and a third the $\mathrm{CO}_{2}$ ).

The SST estimates from dinocysts examined from two sites, on the western and eastern side of the South Island, show uneven warming across the oceans of the southern New Zealand region during the peak of MIS11. The east Tasman Sea was 2$3^{\circ} \mathrm{C}$ warmer than present for ca. 10ky. In contrast, warmth in SAW east of New Zealand was more variable, and it is likely SSTs did not exceed $1-2^{\circ} \mathrm{C}$ above modern conditions for a sustained period of time.

Two faunal productivity proxies, along with dinocyst indicators of water mass, suggest that the peak warmth of MIS11 in the east Tasman Sea was accompanied by productivity levels that were likely below those of the present day, with oligotrophic oceanic water entering the study area, possibly accompanied by a southwards movement of the STF. However, the observation that one of the faunal productivity proxies is more strongly correlated to SST during MIS11 than later times raises the possibility that the productivity regime in east Tasman Sea surface waters differed from present.

The same dinocyst-based indicators of water mass used in the east Tasman Sea do not show any firm indications of STW leaking past the STF east of New Zealand during MIS11 (DSDP594), and thus a circulation similar to the late Holocene is implied for that area. In contrast, there is strong evidence from the dinocyst record of STW assemblages south of the STF during MIS5e at DSDP594.

A pollen record preserved in ocean sediments off eastern New Zealand is inferred to have sampled vegetation growing on the eastern South Island, and is the first continuous record of regional vegetation from MIS11 of this resolution. The pollen record shows a relatively long period of full-interglacial vegetation (ca. 15kyr) compared to later interglacials. Moreover, the composition of the pollen assemblages during the peak of MIS11 is most similar to those of the early Holocene climatic optimum. The timing of changes in the pollen assemblage are closer to the 
timing of SST variation on the east Tasman Sea than variation in the ocean to the east of New Zealand, suggest that the climate of the eastern South Island was more closely linked to conditions in the east Tasman Sea than to oceanic conditions east of New Zealand during MIS11.

The interpretation of these records, and their value as windows on previously warm worlds, would be significantly enhanced by the addition of younger records for comparison. Given that one immediate response to warming in the modern ocean appears to be the pronounced southward migration of warm currents in the western Tasman Sea, potentially associated with reduced eastward flow of the Tasman Current (Roemmich et al., 2007; Hill et al., 2008, 2011), high resolution oceanographic records, including dinocysts, from the east Tasman Sea, south Tasman Sea, and north of New Zealand for the early Holocene, and the last interglacial (MIS5e) might provide a valuable insight of the sensitivity on this part of the SW Pacific ocean to warming.

In summary, this study has added significantly to what is known of MIS11 in the SW Pacific region. There were many differences between MIS11 and the Holocene, heat appears to have been distributed differently across the region, with warming and oceanographic response concentrated to the west, while terrestrial vegetation reflected the warmer conditions observed to the west of the South Island. 


\section{References}

\section{References}

Abelmann, A., Brathauer, U., Gersonde, R., Sieger, R., Zielinski, U., 1999. Radiolarian-based transfer function for the estimation of sea surface temperatures in the Southern Ocean (Atlantic sector). Palaeoceanography, 18(2): 8-1.

Acker, J.G., Leptoukh, G., 2007. Online Analysis Enhances Use of NASA Earth Science Data. Eos, Trans. AGU, 88(2 ): 14-17.

Alheit, J., Bakun, A., 2010. Population synchronies within and between ocean basins: apparent teleconnections and implications as to physical-biological linkage mechanisms. Journal of Marine Systems, 79: 267-285.

Alloway, B.V., Lowe, D.J., Barrell, D.J.A., Newnham, R.M., Almond, P.C., Augustinus, P.C., Bertler, N.A.N. and NZ-INTIMATE Members, 2007, Towards a climate event stratigraphy for New Zealand over the past 30000 years (NZ-INTIMATE project). Journal of Quaternary Science, 22, p. 9-35.

Alloway, B.V., Pillans, B.J., Carter., L., Naish, T.R., Westgate, J.A., 2005. Onshore-offshore correlation of Pleistocene rhyolitic eruptions from New Zealand: implications for TVZ eruptive history and paleoenvironmental construction. Quaternary Science Reviews, 24: 1601-1622.

Andersen, D.M., Keafer, B.A., 1987. An endogenous annual clock in the toxic marine dinoflagellate Gonyaulax tamarensis. Nature, 325(6105): 616-617.

Anderson, D.M., Chisholm, S.W., Watras, C.J., 1983. Importance of life cycle events in the population dynamics of Gonyaulax tamarensis. Marine Biology, 76(2): 179-189.

Antonov, J.I., Seidov, D., Boyer, T.P., Locarnini, R.A., Mishonov, A.V., Garcia, H.E., Baranova, O.K., Zweng, M.M., Johnson, D.R., 2010. World Ocean Atlas 2009, Volume 2: Salinity. NOAA Atlas NESDIS 69. U.S. Government Printing Office, Washington, D.C., 184 pp.

Armstrong, R.A., Lee, C., Hedges, J.I., Honjo, S., Wakeham, S.G., 2001. A new, mechanistic model for organic carbon fluxes in the ocean based on the quantitative association of POC with ballast minerals. Deep Sea Research II, 49: 219-236. 


\section{References}

Ayón, P., Purca, S., Guevara-Carrasco, R., 2004. Zooplankton volume trends off Peru between 1964 and 2001. ICES Journal of Marine Science, 61(4): 478-484.

Barbini, R., Colao, F., Fantoni, R., Fiorani, L., Okladnikov, I.G., Palucci, A., 2005. Lidar calibrated satellite sensed primary production in the Southern Ocean. Journal of Optoelectronics and Advanced Materials, 7(2): 1091-1101.

Barker, S., Archer, D., Booth, L., Elderfield, H., Henderiks, J., Rickaby, R. E. M., 2006. Globally increased pelagic carbonate production during the Mid-Brunhes dissolution interval and the $\mathrm{CO}_{2}$ paradox of MIS 11. Quaternary Science Reviews, 25: 3278-3293.

Barrows, T.T., Juggins, S., 2005. Sea-surface temperatures around the Australian margin and Indian Ocean during the Last Glacial Maximum. Quaternary Science Reviews, 24: 1017-1047.

Barrows, T.T., Juggins, S., De Deckker, P., Calvo, E., Pelejero, C., 2007. Long-term sea surface temperature and climate change in the Australian-New Zealand region. Palaeoceanography, 22: PA2215, doi:10.1029/2006PA001328.

Barrows, T.T., Juggins, S., De Dekker, P., Thiede, J. Martinez, J.I., 2000. Sea-surface temperatures of the SW Pacific Ocean during the Last Glacial Maximum. Paleoceanography, 15: 95-109.

Bauch, H.A., Erlenkeuser, H., Helmke, J.P., Struck, U., 2000. A paleoclimatic evaluation of marine oxygen isotope stage 11 in the high-northern Atlantic (Nordic Seas). Global and Planetary Change, 24(1): 27-39.

Beardall, J., Stojkovic, S., Larsen, S., 2009. Living in a high CO2 world: Impacts of global climate change on marine phytoplankton. Plant Ecology and Diversity, 2(2): 191-205.

Behrenfeld, M. and Falkowski, P., 1997. Photosynthetic rates derived from satellite-based chlorophyll concentration. Limnology and Oceanography, 42: 1-20.

Behrenfeld, M. J., O'Malley, R.T., Siegel, D.A., McClain, C.R., Sarmiento, J.L., Feldman, G.C., Milligan, A.J., Falkowski, P.G., Letelier, R.M., Boss, E.S. 2006, Climate-driven trends in contemporary ocean productivity. Nature, 444(7120), 752-755.

Birks, H.J.B., 1995. Quantitative palaeoenvironmental reconstructions. In: D. Maddy, Brew, J.S. (Editor), Statistical Modelling of Quaternary Science Data. Technical Guide 5. Quaternary Research Association, Cambridge, pp. 161-254. 


\section{References}

Birks, H.J.B., Heiri, O., Seppä, H., Bjune, A.E., 2010. Strengths and Weaknesses of Quantitative Climate Reconstructions Based on Late-Quaternary Biological Proxies. The Open Ecology Journal, 3: 68-110.

Bonnet, S., de Vernal, A., Gersonde, R., Lembke-Jene, L., 2012. Modern distribution of dinocysts from the North Pacific Ocean $\left(37-64^{\circ} \mathrm{N}, 144^{\circ} \mathrm{E}-148^{\circ} \mathrm{W}\right)$ in relation to hydrographic conditions, sea-ice and productivity. Marine Micropalentology, 84-85: 87-113.

Bonnet, S., de Vernal, A., Hillaire-Marcel, C., Radi, T., Husum, K., 2010. Variability of seasurface temperature and sea-ice cover in the Fram Strait over the last two millennia. Marine Micropalaeontology, 74: 59-74.

Bopp, L., Monfray, P., Aumont, O., Dufresne, J.-L., Le Treut, H., Madec, G., Terray, L., Orr, J.C., 2001. Potential impact of climate change on marine export production. Global Biogeochemical Cycles 15 (1), 81-99.

Bow, S.-T., 1984. Pattern recognition. Marcel Dekker, New York.

Bowen, D.Q., 2010. Sea level 400000 years ago (MIS 11): analogue for present and future sea-level? Climate of the Past, 6: 19-29.

Bowie, A.R., Lannuzel, D., Remenyi, T.A., Wagener, T., Lam, P.J., Boyd, P.W., Guieu, C., Townsend, A.T., Trull, T.W., 2009. Biogeochemical iron budgets of the Southern Ocean south of Australia: Decoupling of iron and nutrient cycles in the subantarctic zone by the summertime supply. Global Biogeochemical Cycles, 23(4): art. no. GB4034.

Boyd, P., LaRoche, J., Gall, M., Frew, R., McKay, R.M.L., 1999. Role of iron, light, and silicate in controlling algal biomass in subantarctic waters SE of New Zealand. Journal of Geophysical Research C: Oceans 104(C6): 13395-13408

Boyd, P., Trull, T., 2006. Understanding the export of marine biogenic particles: is there consensus? Progress in Oceanography, 4: 276-312, doi:10.1016/j.pocean.2006.10.007.

Boyd, P.W., Law, C.S., Hutchins, D.A., Abraham, E.R., Croot, P.L., Ellwood, M., Frew, R.D., Hadfield, M., Hall, J., Handy, S., Hare, C., Higgins, J., Hill, P., Hunter, K.A., LeBlanc, K., Maldonado, M.T., McKay, R.M., Mioni, C., Oliver, M., Pickmere, S., Pinkerton, M., Safi, K., Sander, S., Sanudo-Wilhelmy, S.A., Smith, M., Strzepek, R., Tovar-Sanchez, A., Wilhelm, S.W., 2005. FeCycle: Attempting an iron biogeochemical budget from a mesoscale SF6 tracer 


\section{References}

experiment in unperturbed low iron waters. Global Biogeochemical Cycles 19(4): art. no.GB4S20, doi:10.1029/2005GB002494.

Boyd, P.W., McTainsh, G., Sherlock, V., Richardson, K., Nichol, S., Ellwood, M., Frew, R., 2004, Episodic enhancement of phytoplankton stocks in New Zealand subantarctic waters: Contribution of atmospheric and oceanic iron supply. Global Biogeochemical Cycles, v. 18, p. GB1029 1-23.

Bradford, J. M., 1983. Physical and chemical oceanography of the west coast of the South Island, New Zealand. New Zealand Journal of Marine and Freshwater Research, 17, 71-81.

Bradford, J.M., Chang, F.H., 1987. Standing stocks and productivity of phytoplankton off Westland, New Zealand, February 1982. New Zealand Journal of Marine and Freshwater Research, 21: 71-90.

Bradford, J.M., Heath, R.A., Chang, F.H., Hay, C.H., 1982. The effect of warm-core eddies on oceanic productivity off northeastern New Zealand. Deep Sea Research II, 29(12): 15011516.

Bradford-Grieve, J.M., Boyd, P.W., Chang, F.H., Chiswell, S., Hadfield, M., Hall, J.A., James, M.R., Nodder, S.D., Shushkina, E.A., 1999. Pelagic ecosystem structure and functioning in the Subtropical Front region east of New Zealand in austral winter and spring 1993. Journal of Plankton Research, 21(3): 405-428.

Bradford-Grieve, J.M., Chang, F. H., Gall, M., Pickmere, S., Richards, F., 1997. Sizefractionated phytoplankton standing stocks and primary production during austral winter and spring 1993 in the Subtropical Convergence region near New Zealand. New Zealand Journal of Marine and Freshwater Research, 31: 201 - 224.

Bradford-Grieve, J.M., Murdoch, R.C., James, M.R., Oliver, M., Hall, J., 1996. Vertical distribution of zooplankton $>39 \mu \mathrm{m}$ in relation to the physical environment off the west coast of South Island, New Zealand. New Zealand Journal of Marine and Freshwater Research, 30: 285-300.

Breiman, L., 2001. Random forests. Machine Learning, 45: 5-32.

Brooks, S.J., Bennion, H., Birks, J.B., 2001. Tracing lake trophic history with a chironomidtotal phosphorus inference model. Freshwater Biology, 46: 513-533. 


\section{References}

Brown, J., Colling, A., Park, D., Phillips, J., Rothery, D., Wright, J., 1998. Ocean Circulation. The Open University, Milton Keynes. 238pp.

Bussell, M.R., 1987. Palynological evidence for upper Putikian (middle Pleistocene) interglacial and glacial climates at Rangitawa Stream, South Wanganui Basin, New Zealand. New Zealand Journal of Geology and Geophysics 29: 471-479.

Bussell, M.R., 1990. Palynology of oxygen isotope stages 6 and 5e from the coverbeds of a marine terrace, Taranaki, New Zealand. Quaternary Research, 34: 86-100.

Calvo, E., Pelejero, C., Logan, G.A., De Deckker, P., 2004. Dust-induced changes in phytoplankton composition in the Tasman Sea during the last four glacial cycles. Palaeoceanography, 19: PA2020, doi:10.1029/2003PA000992.

Carter, L., Alloway, B.V., Shane, P.A., 2004. Deep-ocean records of major rhyolitic eruptions and dispersal from the Coromandel and Taupo Volcanic Zones of New Zealand. New Zealand Journal of Geology and Geophysics, 47: 481-500.

Carter, L., Carter, R.M., 1988. Late Quaternary deveopment of left-bank-dominant levees in the Bounty Trough, New Zealand. Marine Geology, 78: 185-197.

Carter, L., Garlick, R. D., Sutton, P., Chiswell, S., Oien, N. A., Stanton, B. R., 1998. Ocean Circulation New Zealand. . NIWA Chart Miscellaneous Series No. 76, Wellington.

Carter, L., Neil, H.L., McCave, I.N., 2000. Glacial to interglacial changes in non-carbonate and carbonate accumulation in the SW Pacific Ocean, New Zealand. Palaeogeography, Palaeoclimatology, Palaeoecology, 162: 333-356.

Carter, R.M., Carter, L., 1996. The abyssal Bounty Fan and lower Bounty Channel: evolution of a rifted-margin sedimantary system. Marine Geology, 130: 181-202.

Chang, F.H., 1988. Distribution, abundance, and size composition of phytoplankton off Westland, New Zealand, February 1982. New Zealand Journal of Marine and Freshwater Research, 22: 345-367.

Chang, F.H., Bradford, J. M., 1985. Standing stocks and productivity of phytoplankton off Westland, New Zealand, June 1979. New Zealand Journal of Marine and Freshwater Research, 19: 193-211. 


\section{References}

Chang, F.H., Bradford-Grieve, J.M., Vincent, W.F., Woods, P.H., 1995. Nitrogen uptake by the summer size-fractionated phytoplankton assemblages in the Westland, New Zealand, upwelling system. New Zealand Journal of Marine and Freshwater Research, 29(2): 147-161.

Chang, F.H., Gall, M, 1998. Phytoplankton assemblages and photosynthetic pigments during winter and spring in the Subtropical Convergence region near New Zealand. New Zealand Journal of Marine and Freshwater Research, 32: 515-530.

Chang, F.H., Zeldis, J., Gall, M., Hall, J., 2003. Seasonal and spatial variation of phytoplankton assemblages, biomass and cell size from spring to summer across the north-eastern New Zealand continental shelf. Journal of Plankton Research, 25(7): 737 - 758.

Chiswell, S.M., 1994. Acoustic doppler current profiler measurements over the Chatham Rise. New Zealand Journal of Marine and Freshwater Research, 28(167-178).

Chiswell, S. M., 1996, Variability in the Southland Current, New Zealand, New Zealand. Journal of Marine and Freshwater Research, 30, 1-17.

Chiswell, S.M., 2001. Eddy energetics in the Subtropical Front over the Chatham Rise, New Zealand. New Zealand Journal of Marine and Freshwater Research, 35: 1-15.

Chiswell, S.M., 2003. Circulation within the Wairarapa Eddy, New Zealand. New Zealand Journal of Marine and Freshwater Research 37(4): 691-704.

Chiswell, S.M., 2005. Mean and variability in the Wairarapa and Hikurangi Eddies, New Zealand. New Zealand Journal of Marine and Freshwater Research, 39: 121-134.

Chiswell, S.M., 2011. Annual cycles and spring blooms on phytoplankton: don't abandon Sverdrup complety. Marine Ecology Progress Series, 443: 39-50.

Chiswell, S.M., Rickard, G.J., 2006. Comparison of model and observational ocean circulation climatologies for the New Zealand region. Journal of Geophysical Research C: Oceans, 111: doi:10.1029/2006JC003489.

Chiswell, S.M., Roemmich, D., 1998. The East Cape Current and two eddies: a mechanism for larval retention? New Zealand Journal of Marine and Freshwater Research, 32: 385-397. 


\section{References}

Chiswell, S.M., Toole, J., Church, J., 1997. Transports across the Tasman Sea from WOCE repeat sections: the East Australian Current 1990-94. New Zealand Journal of Marine and Freshwater Research, 31: 469-467.

Clark, P.U., Archer, D., Pollard, D., Blum, J.D., Rial, J.A., Brovkin, V., Mix, A.C., Pisias, N.G., Roy, M., 2006, The middle Pleistocene transition: characteristics, mechanisms, and implications for long-term changes in atmospheric pCO2: Quaternary Science Reviews, v. 25, p. 3150-3184.

Cloern, J.E., Jassby, A.D., 2008. Complex seasonal patterns of primary producers at the landsea interface. Ecology Letters, 11: 1294-1303.

Cloern, J.E., Jassby, A.D., 2010. Patterns and Scales of Phytoplankton Variability in EstuarineCoastal Ecosystems. Estuaries and Coasts, 33: 230-241.

Cochran, U., Neil, H., 2010. Diatom $(<63 \mu \mathrm{m})$ distribution offshore of eastern New Zealand: Surface sediment record and temperature transfer function. Marine Geology, 2010(270): 257-271, DOI: 10.1016/j.margeo.2009.11.003.

Cortese, G., Abelmann, A., 2002. Radiolarian-based paleotemperatures during the last 160 kyr at ODP Site 1089 (Southern Ocean, Atlantic Sector). Palaeogeography, Palaeoclimatology, Palaeoecology, 182: 259-286.

Cortese, G., Abelmann, A., Gersonde, R., 2007. The last five glacial-interglacial transitions: A high-resolution 450,000-year record from the subantarctic Atlantic. Palaeoceanography, 22 : article number: PA4203, doi:10.1029/2007PA001457.

Cronin, T.M., 1991. Pliocene shallow water paleoceanography of the North Atlantic ocean based on marine ostracodes. Quaternary Science Reviews, 10(2-3): 175-188.

Crouch, E.M., Mildenhall, D.C., Neil, H.L., 2010. Distribution of organic-walled marine and terrestrial palynomorphs in surface sediments, offshore eastern New Zealand. Marine Geology, 270: 235-256. doi: 10.1016/j.margeo.2009.11.004.

Crundwell, M., Scott, G., Naish, T., Carter, L., 2008. Glacial-interglacial ocean climate variability from planktonic foraminifera during the Mid-Pleistocene transition in the temperate Southwest Pacific, ODP Site 1123. Palaeogeography, Palaeoclimatology, Palaeoecology, 260: 202-229. 


\section{References}

Dale, B., 1996. Dinoflagellate cyst ecology: modeling and geological applications. In: J. Jansonius, McGregor, D.C. (Editor), Palynology: Principles and Applications. American Association of Stratigraphic Palynologists Foundation, pp. 1249-1275.

de Abreu, L., Abrantes, F.F., Shackleton, N.J., Tzedakis, P.C., McManus, J.F., Oppo, D.W., Hall, M.A., 2005. Ocean climate variability in the eastern North Atlantic during interglacial marine isotope stage 11: A partial analogue to the Holocene? Palaeoceanography, 20(3): art. no. PA3009.

De Schepper, S., Fischer, E.I., Groeneveld, J., Head, M.J., Matthiessen, J., 2011. Deciphering the palaeoecology of Late Pliocene and Early Pleistocene dinoflagellate cysts. Palaeogeography, Palaeoclimatology, Palaeoecology, 309: 17-32.

de Vernal, A., Henry, M., Matthiessen, J., Mudie, P.J., Rochon, A., Boessenkool, K.P., Eynaud, F., Grøsfjeld, K., Guiot, J., Hamel, D., Harland, R., Head, M.J., Kunz-Pirrung, M., Levac, E., Loucheur, V., Peyron, O., Pospelova, V., Radi, T., Turon, J.-L., and Voronina, E., 2001. Dinoflagellate cyst assemblages as tracers of sea-surface conditions in the northern North Atlantic, Arctic and sub-Arctic seas: the new $n=677$ data base and its application for quantitative paleoceanographic reconstruction. Journal of Quaternary Science, 16(7): 681698.

de Vernal, A., Eynaud, F., Henry, M., Hillaire-Marcel, C., Londeix, L., Mangin, S., Matthiessen, J., Marret, F., Radi, T., Rochon, A., Soligna, S., Turon, J.-L., 2005. Reconstruction of seasurface conditions at middle to high latitudes of the Northern Hemisphere during the Last Glacial Maximum (LGM) based on dinoflagellate cyst assemblages. Quaternary Science Reviews, 24: 897-924.

de Vernal, A., Hillaire-Marcel, C., 2008. Natural variability of Greenland climate, vegetation, and ice volume during the past million years. Science, 320(5883): 1622-1625.

de Vernal, A., Marret, F., 2007. Organic-walled dinoflagellate cysts: tracers of sea surface conditions. In: C. Hillaire-Marcel, de Vernal, A. (Editors), Developments in Marine Geology. Elsevier, pp. 371-408.

Demarcq, H., 2009. Trends in primary production, sea surface temperature and wind in upwelling systems (1998-2007). Progress in Oceanography, 83(1-4): 376-385. 


\section{References}

Desprat, S., Sánchez-Goñi, M.F., Turon, J.-L., McManus, J.F., Loutre, M.F., Duprat, J., Malaize, B., Peyron, O., Peypouquet, J.-P., 2005. Is vegetation responsible for glacial inception during periods of muted insolation changes? Quaternary Science Reviews, 24: 1361-1374.

Dickson, A.J., Beer, C.J., Dempsey, C., Maslin, M.A.,Bendle, J.A., McClymont, E.L., Pancost, R.D., 2009. Oceanic forcing of the Marine Isotope Stage 11 Glacial. Nature Geoscience, 2: 428-433.

Dickson, A.J., Leng, M.J., Maslin, M.A., Sloane, H.J., Green, J., Bendle, J.A., McClymont, E.L., Pancost, R.D., 2010. Atlantic overturning circulation and Agulhas leakage influences on southeast Atlantic upper ocean hydrography during marine isotope stage 11. Paleoceanography, 25(3): Article number PA3208.

Dickson, A.J., Leng, M.J., Maslin, M.A., Sloane, H.J., Green, J., Bendle, J.A., McClymont, E.L., Pancost, R.D., 2010. Atlantic overturning circulation and Agulhas leakage influences on southeast Atlantic upper ocean hydrography during Marine Isotope Stage 11. Palaeoceanography, 25(3): Article number PA3208.

Dickson, R.R., Kelly, P.M., Colebrook, J.M., Wooster, W.S., Cushing, D.H., 1988, North winds and production in the eastern North Atlantic. Journal of Plankton Research, 10: 151-169.

Dieffenbacher-Krall, A.C., Vandergoes, M.J., Denton, G.H., 2007. An inference model for mean summer air temperatures in the Southern Alps, New Zealand, using subfossil chironomids. Quaternary Science Reviews, 26: 2487-2504.

Dodge, J.D., Harland, R., 1991. The distribution of planktonic dinoflagellates and their cysts in the eastern and northeastern Atlantic Ocean. New Phycologist, 118(4): 593-603.

Douglas, G.B., Hart, B.T., Beckett, R., Gray, C.M., Oliver, R.L., 1999. Geochemistry of suspended particulate matter (SPM) in the Murray-Darling River system: A conceptual isotopic/geochemical model for the fractionation of major, trace and rare earth elements. Aquatic Geochemistry, 5(2): 167-194.

Droxler, A.W., Alley, R.B., Howard, W.R., Poore, R.Z., Burkle, L.H., 2003. Unique and exceptionally long interglacial Marine Isotope Stage 11: window into Earth warm future climate. AGU Geophysical Monograph, 137: 1-14. 


\section{References}

Dudley, W.C., Nelson, C.S., 1994. The influence of non-equilibrium isotope fractionation on the Quaternary calcareous nannofossil stable isotope signal in the southwest Pacific Ocean, DSDP Site 594. Marine Micropaleontology, 24: 3-27.

Ellegaard, M., Daugbjerg, N., Rochon, A., Lewis, J., Harding, I., 2003. Morphological and LSU rDNA sequence variation within the Gonyaulax spinifera-Spiniferites group (Dinophyceae) and proposal of G. elongata comb. nov. and G. membranacea comb. nov. Phycologia 42(2): 151-164.

Ellegaard, M., Lewis, J., Harding, I., 2002. Cyst-theca relationship, life cycle, and effects of temperature and salinity on the cyst morphology of Gonyaulax baltica sp. nov. (Dinophyceae) from the Baltic Sea area. Journal of Phycology, 38(4): 775-789.

Esper, O., Versteegh, G.J.M., Zonneveld, K.A.F., Willems, H., 2004. A palynological reconstruction of the Agulhas Retroflection (South Atlantic Ocean) during the Late Quaternary. Global and Planetary Change, 41: 31-62.

Esper, O., Zonneveld, K.A.F., 2002. Distribution of organic-walled dinofagellate cysts in surface sediments of the Southern Ocean (eastern Atlantic sector) between the Subtropical Front and the Weddell Gyre. Marine Micropaleontology, 46: 177 - 208.

Esper, O., Zonneveld, K.A.F., 2007. The potential of organic-walled dinoflagellate cysts for the reconstruction of past sea-surface conditions in the Southern Ocean. Marine Micropaleontology, 65: 185 - 212.

Falkowski, P.G., Barber, R.T., Smetacek, V., 1998. Biogeochemical Controls and Feedbacks on Ocean Primary Production. Science, 281: 200-206.

Fensome, R.A., Riding, J.B., Taylor, F.J.R., 1996. Dinoflagellates. In: J. Jansonius, McGregor, D.C. (Editor), Palynology: Principles and Applications. American Association of Stratigraphic Palynologists Foundation, pp. 107-169.

Fensome, R.A., Williams, G.L., 2004. The Lentin and Williams index of fossil dinoflagellates, 2004 edition. Am. Assoc. Stratigr. Palynol. Contrib. Ser., 42: 909 pp.

Figueroa, R.I., Garces, E., Bravo, I., 2007. Comparative study of the life cycles of Alexandrium tamutum and Alexandrium minutum (Gonyaulacales, Dinophyceae) in culture. Journal of Phycology, 43: 1039-53. 


\section{References}

Fiorani, L., Okladnikov, I.G., Palucci, A., 2007. Lidar-calibrated regional models for satellite retrieval of primary productivity in the Southern Ocean. Journal of Optoelectronics and Advanced Materials, 9(12): 3939-3945.

Frew, R.D., Hutchins, D. A., Nodder, S., Sanudo-Wilhelmy, S., Tovar-Sanchez, A., Leblanc, K., Hare, C.E., Boyd. P.W., 2006. Particulate iron dynamics during FeCycle in subantarctic waters southeast of New Zealand. Global Biogeochemical Cycles, 20: GB1S93, doi:10.1029/2005GB002558.

Fuji, R., Matsuoka, K., 2006. Seasonal change of dinoflagellates cyst flux collected in a sediment trap in Omura Bay, West Japan. Journal of Plankton Research, 28(2): 131-147.

Fulthorpe, C.S., Hoyanagi, K., Blum, P., Guèrin, G., Slagle, A.L., Blair, S.A., Browne, G.H., Carter, R.M., Ciobanu, M.-C., Claypool, G.E., Crundwell, M.P., Dinarès-Turell, J., Ding, X., George, S.C., Hepp, D.A., Jaeger, J., Kawagata, S., Kemp, D.B., Kim, Y.-G., Kominz, M.A., Lever, H., Lipp, J.S., Marsaglia, K.M., McHugh, C.M., Murakoshi, N., Ohi, T., Pea, L., Richaud, M., Suto, I., Tanabe, S., Tinto, K.J., Uramoto, G., Yoshimura, T., 2010. Integrated ocean drilling program expedition 317 preliminary report canterbury basin sea level global and local controls on continental margin stratigraphy. Integrated Ocean Drilling Program: Preliminary Reports 317: 1-333.

Garcia, H.E., Locarnini, R. A., Boyer, T. P., Antonov, J. I., Baranova, O. K., Zweng, M. M., Johnson, D. R. , 2010. World Ocean Atlas 2009, Volume 3: Dissolved Oxygen, Apparent Oxygen Utilization, and Oxygen Saturation. NOAA Atlas NESDIS 70. U.S. Government Printing Office, Washington, D.C., 344 pp. pp.

Garcia, H.E., Locarnini, R. A., Boyer, T.P., Antonov, J.I., Zweng, M.M., Baranova, O.K., Johnson, D.R., 2010. World Ocean Atlas 2009, Volume 4: Nutrients (phosphate, nitrate, silicate). NOAA Atlas NESDIS 71. U.S. Government Printing Office, Washington, D.C., 398 pp. pp.

Gardner, W.D., 1985. The effect of tilt on sediment trap efficiency. Deep-Sea Research, 32: 349-361.Goring, D.G., Bell, R.G., 1999. El Niño and decadal effects on sea-level variability in northern New Zealand: a wavelet analysis. New Zealand Journal of Marine and Freshwater Research, 33(4): 587 - 598. 


\section{References}

Gersonde, R., Crosta, X., Abelmann, A., Armand, L., 2005. Sea-surface temperature and sea ice distribution of the Southern Ocean at the EPILOG Last Glacial Maximum - a circumAntarctic view based on siliceous microfossil records. Quaternary Science Reviews, 24: 869896.

Gibson, C.H., Thomas, W.H., 1995. Effects of turbulence intermittency on growth inhibition of a red tide dinoflagellate, Gonyaulax polyedra Stein. Journal of Geophysical Research C: Oceans, 100(C12): 24,841-24.

Goldsmith, S.T., Carey, A.E., Lyons, W.B., Hicks, D.M. , 2008. Geochemical fluxes and weathering of volcanic terrains on high standing islands: Taranaki and Manawatu-Wanganui regions of New Zealand. Geochimica et Cosmochimica Acta, 72(9): 2248-2267.

Goring, D.G., Bell, R.G., 1999. El Nino and decadal effects on sea-level variability in northern New Zealand: a wavelet analysis. New Zealand Journal of Marine and Freshwater Research, 33(4): 587 - 598.

Gouretski, V.V., Koltermann, K. P., 2004. WOCE Global Hydrographic Climatology: A Technical Report, Berichte des Bundesamtes für Seeschifffahrt und Hydrographie, Hamburg.

Govin, A., Holzwarth, U., Heslop, D., Ford Keeling, L., Zabel, M., Mulitza, S., Collins, J.A., Chiessi, C.M., 2012. Distribution of major elements in Atlantic surface sediments $\left(36^{\circ} \mathrm{N}-\right.$ $\left.49^{\circ} \mathrm{S}\right)$ : Imprint of terrigenous input and continental weathering. Geochemistry, Geophysics, Geosystems, 13(1): art. no. Q01013.

Greig, M. J., Ridgway, N.M., Shakespeare, B.S., 1988. Sea surface temperature variations at coastal sites around New Zealand, New Zealand Journal of Marine and Freshwater Research, 22, 391-400.

Greig, M.J., Gilmour, A.E., 1992. Flow through the Mernoo Saddle, New Zealand. New Zealand Journal of Marine and Freshwater Research, 26(2): 155-165.

Grzebyk, D., Berland, B., 1996. Influences of temperature, salinity and irradiance on growth of Prorocentrum minimum (Dinophyceae) from the Mediterranean Sea. Journal of Plankton Research, 18(10): 1837-1849.

Guerrini, F., Ciminiello, P., Dell'Aversano, C., Tartaglione, L., Fattorusso, E., Boni, L., Pistocchi, R., 2007. Influence of temperature, salinity and nutrient limitation on yessotoxin production 


\section{References}

and release by the dinoflagellate Protoceratium reticulatum in batch-cultures. Harmful Algae, 6(5): 707-717.

Guiot, J., 2011. Transfer Functions. IOP Conference Series: Earth and Environmental Science, 14(1): art. no. 012008.

Guiot, J., de Vernal, A., 2007. Transfer functions: methods for quantative paleoecology based on microfossils. In: Hillaire-Marcel, C., de Vernal, A. (Editors), Proxies in Late Cenezoic paleooceanography. Elsevier, 523 - 563.

Guiot, J., de Vernal, A., 2011a. Is spatial autocorrelation introducing biases in the apparent accuracy of paleo-climatic reconstructions? Quaternary Science Reviews, 30(15-16): 19651972.

Guiot, J., de Vernal, A., 2011b. QSR Correspondence "Is spatial autocorrelation introducing biases in the apparent accuracy of palaeoclimatic reconstructions?" Reply to Telford and Birks. Quaternary Science Reviews, 30(21-22): 3214-3216.

Gutiérrez, D., Bouloubassi, I., Sifeddine, A., Purca, S., Goubanova, K., Graco, M., Field, D., Méjanelle, L., Velazco, F., Lorre, A., Salvatteci, R., Quispe, D., Vargas, G., Dewitte, B., Ortlieb, L., 2011. Coastal cooling and increased productivity in the main upwelling zone off Peru since the mid-twentieth century. Geophysical Research Letters, 38(7): art. no. L07603.

Hadfield, M. G., 2000. Atmospheric effects on upper-ocean temperature in the southeast Tasman Sea, Journal of Physical Oceanography, 30(12), 3239-3248.

Hadfield, M. G., Sharples, J., 1996. Modelling mixed layer depth and plankton biomass off the west coast of South Island, New Zealand, Journal of Marine Systems, 8, 1-29.

Hae, J.J., Yeong, D.Y., Kyeong, A.S., Jong, H.K., Jae, Y.P., Kim, S., Seung, H.L., Won, H.Y., 2005. Feeding by the mixotrophic red-tide dinoflagellate Gonyaulax polygramma: Mechanisms, prey species, effects of prey concentration, and grazing impact. Aquatic Microbial Ecology, 38(3): 249-257.

Hall, B.L., Henderson, G.M., Baroni, C., Kellogg, T.B., 2010. Constant Holocene SouthernOcean $14 C$ reservoir ages and ice-shelf flow rates Earth and Planetary Science Letters, 296(12): $115-123$. 


\section{References}

Hall, J., Safi, K., Cumming, A. , 2004. Role of microzooplankton grazers in the subtropical and subantarctic waters to the east of New Zealand. New Zealand Journal of Marine and Freshwater Research, 38(1): 91-101.

Hall, J.A., James, M.R., Bradford-Grieve, J.M., 1999. Structure and dynamics of the pelagic microbial food web of the Subtropical Convergence region east of New Zealand. Aquatic Microbial Ecology, 20(1): 95-105.

Hamilton, L. J., 2006. Structure of the Subtropical Front in the Tasman Sea, Deep-Sea Research Part I: Oceanographic Research Papers, 53(12), 1989-2009.

Hammer, Ø., Harper, D.A.T., Ryan, P.D., 2001. PAST: Paleontological Statistics Software Package for Education and Data Analysis. Palaeontologia Electronica 4(1): 9pp.

Hansen, P.J., 2011. The role of photosynthesis and food uptake for the growth of marine mixotrophic dinoflagellates. The Journal of Eukaryotic Microbiology, 58(3): 203-214.

Hardman-Mountford, N.J., Hirata, T., Richardson. K.A., Aiken, J., 2008. An objective methodology for the classification of ecological pattern into biomes and provinces for the pelagic ocean. Remote Sensing of Environment, 112: 3341-3352.

Harland, R., Pudsey, C.J., 1999. Dinoflagellate cysts from sediment traps deployed in the Bellingshausen, Weddell and Scotia seas, Antarctica. Marine Micropalaeontology, 37: 77-99.

Harland, R., Pudsey, C.J., Howe, J.A., Fitzpatrick, M.E.J., 1998. Recent dinoflagellate cysts in a transect from the Falkland Trough to the Weddell Sea, Antarctica. Palaeontology, 41: 10931131.

Hayes, A., Kucera, M., Kallel, N., Sbaffi, L., Rohling, E. J., 2005. Glacial Mediterranean sea surface temperatures based on planktonic foraminiferal assemblages. Quaternary Science Reviews, 24: 999-1016.

Haynes, R., Barton, E.D., Pilling, I., 1993, Development, persistence, and variability of upwelling filaments off the Atlantic coast of the Iberian Peninsula: Journal of Geophysical Research C: Oceans, v. 98, p. 22,681-22,692.

Hayward, B.W., Scott, G.H., Crundwel, M.P., Kennett, J.P., Carter, L., Neil, H.L., Sabaa, A.T., Wilson, K., Rodger, J.S., Schaefer, G., Grenfell, H.R., Li, Q., 2008. The effect of submerged 


\section{References}

plateaux on Pleistocene gyral circulation and sea-surface temperatures in the Southwest Pacific. Global and Planetary Change: doi: 10.1016/j.gloplacha.2008.07.003.

Hayward, B.W., Sabaa, A.T., Kolodziej, A., Crundwell, M.P., Steph, S., Scott, G.H., Neil, H.L., Bostock, H., Carter, L., Grenfell, H.R., 2012. Planktic foraminifera-based sea-surface temperature record in the Tasman Sea and history of the Subtropical Front around New Zealand, over the last one million years Marine Micropalentology, 82-83: 13-27

Head, M., 1996. Modern dinoflagellate cysts and their biological affinities. In: Jansonius, J., McGregor, D.C. (Editors), Palynology: principles and applications. American Association of Stratigraphic Palynologists Foundation, Dallas, Texas, pp. 1197-1248.

Heath, R. A., 1985. A review of the physical oceanography of the seas around New Zealand - 1982. New Zealand Journal of Marine and Freshwater Research, 19, 79-124.

Heath, R. A., Gilmour, A.E., 1987. Flow and hydrological variability in the Kahurangi Plume off north-west South Island, New Zealand. New Zealand Journal of Marine and Freshwater Research, 21, 125-140.

Heiskanen, A.S., 1993. Mass encystment and sinking of dinoflagellates during a spring bloom. Marine Biology, 116: 161-167.

Henson, S. A., Sarmiento, J.L., Dunne, J.P., Bopp, L., Lima, I., Doney, S.C., John, J., Beaulieu, C., 2010. Detection of anthropogenic climate change in satellite records of ocean chlorophyll and productivity. Biogeosciences, 7(2), 621-640.

Heslop, D., De Schepper, S., Proske, U., 2011. Diagnosing the uncertainty of taxa relative abundances derived from count data. Marine Micropalentology, 79: 114-120.

Hesse, P., 1994. The record of continental dust from Australia in Tasman Sea sediments. Quaternary Science Reviews, 13: 257-272.

Hesse, P.P., McTainsh, G.H., 1999. Last glacial maximum to early Holocene wind strength in the mid-latitudes of the Southern Hemisphere from Aeolian Dust in the Tasman Sea. Quaternary Research, 52(3): 343-349.

Heusser, L., van der Geer, G., 1994. Direct correlation of terrestrial and marine paleoclimate records from four glacial-interglacial cycles - DSDP 594 southwest Pacific. Quaternary Science Reviews, 13: 273 - 282. 


\section{References}

Hicks, D. M., Hill, J., Shankar, U., 1996. Variation of suspended sediment yields around New Zealand: The relative importance of rainfall and geology. IAHS-AISH Publication., 149-156 pp. Hicks, D.M., Shankar, U., Mckerchar, A.I., Basher, L., Lynn, I., Page, M., Jessen, M, 2011. Suspended sediment yields from New Zealand rivers. Journal of Hydrology (NZ), 50(1): 81142.

Hill, K.L., Rintoul, S.R., Coleman, R., Ridgway, K.R., 2008. Wind forced low frequency variability of the East Australia Current. Geophysical Research Letters, 35(8): art. no. L08602.

Hill, K.L., Rintoul, S.R., Ridgway, K.R., Oke, P.R., 2011. Decadal changes in the South Pacific western boundary current system revealed in observations and ocean state estimates. Journal of Geophysical Research C: Oceans, 116(1): art. no. C01009.

Hillaire-Marcel, C., de Vernal, A., 2007. Methods in Late Cenozoic paleoceanography: Introduction. In: Hillaire-Marcel, C., de Vernal, A. (Editors), Proxies in Late Cenozoic paleoceanography. Elsevier, Amsterdam, pp. 1-14.

Hiscock, M.R., Marra, J., Smith Jr., W.O., Goericke, R., Measures, C., Vink, S., Olson, R.J., Sosikf, H.M., Barber, R.T., 2003. Primary productivity and its regulation in the Pacific Sector of the Southern Ocean. Deep-Sea Research II, 50: 533-558.

Hodell, D.A., Charles, C.D., Ninnemann, U.S., 2000. Comparison of interglacial stages in the South Atlantic sector of the southern ocean for the past $450 \mathrm{kyr}$ : implications for Marine Isotope Stage MIS/11. Global and Planetary Change, 24: 7 - 26.

Hodell, D.A., Channeil, J.E.T., Curtis, J.H., Romero, O.E., Röhl, U., 2008. Onset of "Hudson Strait" Heinrich events in the eastern North Atlantic at the end of the middle Pleistocene transition ( 640 ka)?. Paleoceanography, 23(4): art. no. PA4218.

Hoegh-Guldberg, O., Bruno, J.F., 2010. The impact of climate change on the world's marine ecosystems, Science, 328(5985), 1523-1528.

Holden, P.B., Edwards, N.R., Wolff, E.W., Valdes, P.J., Singarayer, J.S., 2011, The Mid-Brunhes Event and West Antarctic ice sheet stability: Journal of Quaternary Science, v. 26, p. 474477. 


\section{References}

Hollis, C.J., Neil, H.N., 2005. Sedimentary record of radiolarian biogeography, offshore eastern New Zealand. New Zealand Journal of Marine and Freshwater Research, 39: 165192.

Holt, K.A., Wallace, R.C., Neall, V.E., Kohn, B.P., Lowe, D.J., 2010. Quaternary marker beds and their potential for palaeoenvironmental reconstruction on Chatham Island, east of New Zealand, southwest Pacific Ocean. Journal of Quaternary Science, 25(7): 1169-1178.

Holzwarth, U., Esper, O., Zonneveld, K.A.F., 2007. Distribution of organic-walled dinoflagellate cysts in shelf surface sediments of the Benguela upwelling system in relationship to environmental conditions. Marine Micropaleontology, 64(1-2): 91-119

Holzwarth, U., Esper, O., Zonneveld, K.A.F., 2010. Organic-walled dinoflagellate cysts as indicators of oceanographic conditions and terrigenous input in the NW African upwelling region. Review of Palaeobotany and Palynology, 159: 35-55.

Honjo, S., Manganini, S.J., Krishfield, R.A., Francois, R., 2008. Particulate organic carbon fluxes to the ocean interior and factor controlling the biological pump: A synthesis of global sediment trap programmes since 1983. Progress in Oceanography, 76: 217-285.

Hopkins, J., Shaw, A.G.P., Challenor, P., 2010. The Southland Front, New Zealand: Variability and ENSO correlations. Continental Shelf Research, 30: 1535-1538.

Howard, W.R., Prell, W.L., 1992, Late Quaternary surface circulation of the southern Indian Ocean and its relationship to orbital variations: Palaeoceanography, 7 (1): doi:10.1029/91PA02994

Hutson, W.H., 1980. The Agulhas current during the late Pleistocene: Analysis of modern faunal analogs. Science, 207: 64-66.

Hwang, D.F., Lu, Y.H., 2000. Influence of environmental and nutritional factors on growth, toxicity, and toxin profile of dinoflagellate Alexandrium minutum. Toxicon, 38(11): 14911503.

Imbrie, J., Kipp, N.G., 1977. A new micropaleontological method for quantitative paleoclimatology: application to a Late Pleistocene core. In: K.K. Turekian (Editor), The Late Cenozoic glacial ages. Yale University Press, New Haven. 


\section{References}

Jacobson, D.M., 1999. A brief history of dinoflagellate feeding research. Journal of Eukaryotic Microbiology, 46(4): 376-381.

Jacobson, D.M., Anderson, D. M., 1986. Thecate heterotrophic dinoflagellates: feeding behaviour and mechanisms. Journal of Phycology, 22: 249-58.

James, M.R., Hall, J.A., 1998. Microzooplankton grazing in different water masses associated with the Subtropical Convergence round the South Island, New Zealand. Deep-Sea Research Part I: Oceanographic Research Papers, 45(10): 1689-1707.

Jensen, M.Ø., Moestrup, Ø., 1997. Autecology of the toxic dinoflagellate Alexandrium ostenfeldii: Life history and growth at different temperatures and salinities. European Journal of Phycology, 32(1): 9-18.

Ji, J., Ge, Y., Balsam, W., Damuth, J.E., Chen, J., 2009. Rapid identification of dolomite using a Fourier Transform Infrared Spectrophotometer (FTIR): A fast method for identifying Heinrich events in IODP Site U1308. Marine Geology 258, 258(1-4): 60-68.

Jouzel, J., Masson-Delmotte, V., Cattani, O., Dreyfus, G., Falourd, S., Hoffmann, G., Minster, B., Nouet, J., Barnola, J.M., Chappellaz, J., Fischer, H., Gallet, J.C., Johnsen, S., Leuenberger, M., Loulergue, L., Luethi, D., Oerter, H., Parrenin, F., Raisbeck, G., Raynaud, D., Schilt, A., Schwander, J., Selmo, E., Souchez, R., Spahni, R., Stauffer, B., Steffensen, J. P., Stenni, B., Stocker, T.F., Tison, J.L., Werner, M., Wolff, E.W., 2007. Orbital and millennial Antarctic climate variability over the past 800,000 years. Science, 317-793.

Juggins, S. 2005. C2 User Guide. Software for ecological and palaeoecological data analysis and visualisation. University of Newcastle, Newcastle-upon-Tyne.

Juhl, A.R., 2005. Growth rates and elemental composition of Alexandrium monilatum, a redtide dinoflagellate. Harmful Algae, 4(2): 287-295

Kandiano, E.S., Bauch, H.A., 2007. Phase relationship and surface water mass change in the Northeast Atlantic during Marine Isotope Stage 11 (MIS 11). Quaternary Research, 68: 445455.

Kautz, C.Q., Martin, C.E., 2007. Chemical and physical weathering in New Zealand's Southern Alps monitored by bedload sediment major element composition. Applied Geochemistry, 22(8): 1715-1735. 


\section{References}

Kawahata, H., 2002. Shifts in oceanic and atmospheric boundaries in the Tasman Sea (Southwest Pacific) during the Late Pleistocene: evidence from organic carbon and lithogenic fuxes. Palaeogeography, Palaeoclimatology, Palaeoecology, 184: 225-249.

Kershaw, P., Moss, P., Van der Kaars, S., 2003. Causes and consequences of long-term climatic variability on the Australian continent. Freshwater Biology, 48: 1274-1283.

Kessler, W.S., Gourdeau, L., 2007. The Annual Cycle of Circulation of the Southwest Subtropical Pacific, Analyzed in an Ocean GCM. Journal of Physical Oceanography, 37: 16101627 DOI: 10.1175/JPO3046.1.

Kidson, J.W., 2000. An analysis of New Zealand synoptic types and their use in defining weather regimes. International Journal of Climatology, 20(3): 299-316.

King, A.L., Howard, W.R., 2001. Seasonality of foraminiferal flux in sediment traps at Chatham Rise, SW Pacific: implications for palaeotemperature estimates. Deep-Sea Research I, 48: 1687-1708.

Koc, N., Jansen, E., Haflidason, H., 1993. Paleoceanographic reconstructions of surface ocean conditions in the Greenland, Iceland and Norwegian Seas through the last 14 ka based on diatoms. Quaternary Science Reviews, 12: 115-140.

Kolodziej, A., 2010. Planktic foraminifera-based sea surface temperature estimates and Late Quaternary oceanography off New Zealand's West Coast, Unpublished MSc Thesis, Victoria University of Wellington, New Zealand.

Koutsodendris, A., Müller, U.C., Pross, J., Brauer, A., Kotthoff, U., Lotter, A.F., 2010. Vegetation dynamics and climate variability during the Holsteinian interglacial based on a pollen record from Dethlingen (northern Germany). Quaternary Science Reviews, 29(23-24): 3298-3307.

Kowalski, E.A., Meyers, P.A., 1997. Glacial-interglacial variations in Quaternary production of marine organic matter at DSDP Site 594, Chatham Rise, southeastern New Zealand. Marine Geology, 140: 249-263.

Kremp, A., Rengefors, K., Montresor, M. , 2009. Species-specific encystment patterns in three Baltic cold-water dinoflagellates: The role of multiple cues in resting cyst formation Limnology and Oceanography, 54(4): 1125-1138 


\section{References}

Kucera, M., 2007. Planktonic foraminifera as tracers of past oceanic environments. In: Hillaire-Marcel, C. de Vernal, A. (Editors), Developments in Marine Geology. Elsevier, pp. 213-262.

Kucera, M., Weinelt, M., Kiefer, T., Pflaumann, U., Hayes, A., Weinelte, M., Chen, M-T., Mix, A.C., Barrows, T.T., Cortijo, E., Duprat, J., Juggins, S., Waelbroeck, C., 2005. Reconstruction of sea-surface temperatures from assemblages of planktonic foraminifera: multi-technique approach based on geographically constrained calibration data sets and its application to glacial Atlantic and Pacific Oceans. Quaternary Science Reviews, 24: 951-998.

Kühl, N., Litt, T., 2007. Quantitative time-series reconstructions of Holsteinian and Eemian temperatures using botanical data. Developments in Quaternary Science, 7(C): 239-254.

Kunz-Pirrung, M., Gersonde, R., Hodell, D.A., 2002. Mid-Brunhes century-scale diatom sea surface temperature and sea ice records from the Atlantic sector of the Southern Ocean (ODP Leg 177, sites 1093, 1094 and core PS2089-2). Palaeogeography, Palaeoclimatology, Palaeoecology, 182(3-4): 305-328.

Laabir, M., Jauzein, C., Genovesi, B., Masseret, E., Grzebyk, D., Cecchi, P., Vaquer, A., Collos, Y., 2011. Influence of temperature, salinity and irradiance on the growth and cell yield of the harmful red tide dinoflagellate Alexandrium catenella colonizing Mediterranean waters. Journal of Plankton Research, 33(10): 1550-1563.

Land, M., Wust, R.A.J., Robert, C., Carter, R.M., 2010. Plio-Pleistocene paleoclimate in the Southwest Pacific as reflected in clay mineralogy and particle size at ODP Site 1119, SE New Zealand. Marine Geology, 274: 165-176.

Lannuzel, D., Bowie, A.R., Remenyi, T., Lam, P., Townsend, A., Ibisanmi, E., Butler, E., Wagener, T., Schoemann, V., 2011. Distributions of dissolved and particulate iron in the subAntarctic and Polar Frontal Southern Ocean (Australian sector). Deep Sea Research Part II, 58(21-22): 2094-2112.

Large, M.F., Braggins, J.E., 1991. Spore atlas of New Zealand ferns and fern allies. SIR Publishing, A supplement to the New Zealand Journal of Botany, Wellington.

Laskar, J., Robutel, P., Joutel, F., Gastineau, M., Correia, A.C.M., Levrard, B. 2004. A longterm numerical solution for the insolation quantities of the Earth. Astronomy and Astrophysics, 428 (1), pp. 261-285. 


\section{References}

Lemos, R.T., Pires, H.O., 2004, The upwelling regime off the West Portuguese Coast, 19412000: International Journal of Climatology, v. 24, p. 511-524.

Lewis, J., Hallett, R., 1997. Lingulodnium polyedrum (Gonyaulax polyedra) a blooming dinoflagellate. Oceanography and Marine Biology: an annual review, 35: 97-161.

Lewis, J., Rochon, A., Ellegaard, M., Mudie, P.J., Harding, I., 2001. The cyst-theca relationship of Bitectatodinium tepikiense (Dinophyceae). European Journal of Phycology, 36: 137-146.

Limoges, A., Kielt, J-F., Radi, T., Ruíz-Fernandez, A.C., de Vernal, A., 2010. Dinoflagellate cyst distribution in surface sediments along the south-western Mexican coast $\left(14.76^{\circ} \mathrm{N}\right.$ to 24.75N). Marine Micropalentology, 76(3-4): 104-123.

Lisiecki, L.E., Raymo, M.E., 2005. A Pliocene-Pleistocene stack of 57 globally distributed benthic $\delta 180$ records. Paleoceanography, 20: 1003-1020.

Little, T. A., Cox, S., Vry, J.K., Batt, G., 2005. Variations in exhumation level and uplift rate along the oblique-slip Alpine fault, central Southern Alps, New Zealand, Bulletin of the Geological Society of America, 117(5-6), 707-723.

Locarnini, R.A., Mishonov,A. V., Antonov, J. I., Boyer, T. P., Garcia, H. E., Baranova, O. K., Zweng, M. M., Johnson, D. R., 2010. . World Ocean Atlas 2009, Volume 1: Temperature. NOAA Atlas NESDIS 68. U.S. Government Printing Office, Washington, D.C., 184 pp.

Longhurst, A., 1995. Seasonal cycles of pelagic production and consumption. Progress in Oceanography, 36: 77-167.

Lorrey, A., Fowler, A.M., Salinger, J., 2007. Regional climate regime classification as a qualitative tool for interpreting multi-proxy palaeoclimate data spatial patterns: A New Zealand case study. Palaeogeography, Palaeoclimatology, Palaeoecology, 3-4: 407-433.

Lorrey, A.M., Vandergoes, M., Almond, P., Renwick, J., Stephens, T., Bostock, H., Mackintosh, A., Newnham, R., Williams, P.W., Ackerley, D., Neil, H., Fowler, A.M., 2012. Palaeocirculation across New Zealand during the last glacial maximum at $\sim 21 \mathrm{ka}$. Quaternary Science Reviews, 36: 189-213.

Loutre, M.F., Berger, A., 2003. Marine Isotope Stage 11 as an analogue for the present interglacial. Global and Planetary Change, 36: 209-217. 


\section{References}

Lu, H., Wu, N., Liu, K., Zhu, L., Yang, X., Yao, T., Wang, L., Li, Q., Liu, X., Shen, C., Li, X., Tong, G., Jiang, H., 2011. Modern pollen distributions in Qinghai-Tibetan Plateau and the development of transfer functions for reconstructing Holocene environmental changes. Quaternary Science Reviews, 30: 947-966.

Lüer, V., Cortese, G., Neil, H.N., Hollis, C.J., Willems, H., 2009. Radiolarian-based sea surface temperatures and paleoceanographic changes during the Late Pleistocene-Holocene in the subantarctic southwest Pacific. Marine Micropalentology, 70: 151-165.

Mackas, D.L., Beaugrand, G., 2010. Comparison of zooplankton time-series. Journal of Marine Systems, 79: 286-304.

Malmgren, B.A., Kucera, M., Nyberg, J., Waelbroeck, C., 2001. Comparison of statistical and artificial neural network techniques for estimating past sea surface temperatures from planktonic foraminifer census data. Paleoceanography, 16: 520-530.

Malmgren, B.A., Nordlund, U., 1997. Application of artificial neural networks to paleoceanographic data. Palaeogeography, Palaeoclimatology, Palaeoecology, 136: 59-373.

Mantua, N.J., Hare, S.R., 2002. The Pacific Decadal Oscillation. Journal of Oceanography, 58(1): 35-44.

Marr, J.P., Baker, J.A., Carter, L., Allan, A.S.R., Dunbar, G.B., Bostock, H.C., 2011. Ecological and temperature controls on $\mathrm{Mg} / \mathrm{Ca}$ ratios of Globigerina bulloides from the SW Pacific Ocean. Paleoceanography, 26(2): PA2209.

Marret, F., 2007. Relative abundance of organic-walled dinoflagellate cysts in surface sediments, Pangea.de. doi:10.1594/PANGAEA.603739

Marret, F., de Vernal, A., Benderra, F., Harland, R., 1997. Dinoflagellate cyst distribution in surface sediments of the southern Indian Ocean. Marine Micropalentology 29: 367-392.

Marret, F., de Vernal, A., Benderra, F., Harland, R., 2001. Late Quaternary sea-surface conditions at DSDP Hole 594 in the southwest Pacific Ocean based on dinoflagellate cyst assemblages. Journal of Quaternary Science, 16(7): 739-751.

Marret, F., Scourse, J., Kennedy, H., Ufkes, E., Jansen, F., 2008. Marine production in the Congo-influenced SE Atlantic over the past 30,000 years: A novel dinoflagellate-cyst based transfer function approach. Marine Micropalaeontology, 68: 198-222. 


\section{References}

Marret, F., Zonneveld, K.A.F., 2003. Atlas of modern organic-walled dinoflagellate cyst distribution. Review of Palaeobotany and Palynology, 125: 1-200.

Martinez, J.I., 1994, Late Pleistocene paleoceanography of the Tasman Sea: implications for the dynamics of the warm pool in the western Pacific: Palaeogeography, Palaeoclimatology, Palaeoecology, v. 112, p. 19-62.

Marx, S.K., Kamber, B.S., McGowan, H.A., 2005a. Estimates of Australian dust flux into New Zealand: Quantifying the eastern Australian dust plume pathway using trace element calibrated 210Pb as a monitor. Earth and Planetary Science Letters, 239(3-4): 336-351.

Marx, S.K., Kamber, S.B., McGowan, H.A., 2005b. Provenance of long-travelled dust determined with ultra-trace-element composition: a pilot study with samples from New Zealand glaciers. Earth Surface Processes and Landforms, 30: 699-716.

Masson-Delmotte, V., Stenni, B. Pol, K. Braconnot, P., Cattani, O. Falourd, S., Kageyama, M., Jouzel, J., Landais, A., Minster, B., Barnola, J.M., Chappellaz, J., Krinner, G., Johnsen, S., Rothlisberger, R., Hansen, J., Mikolajewicz, U., Otto-Bliesner, B. , 2010. EPICA Dome C record of glacial and interglacial intensities. Quaternary Science Reviews, 29(1-2): 113-128.

McGlone, M.S., Wilmshurst, J.M., 1999. Dating initial Maori environmental impact in New Zealand. Quaternary International, 59: 17-26.

McKenzie, C.H., Cox, E.R., 1991. Spatial and seasonal changes in the species composition of armored dinoflagellates in the southwestern Atlantic Ocean. Polar Biology, 11: 139-144.

McManus, J., Oppo, D. W., and Cullen, J. L., 1999. A 0.5-million-year record of millennialscale climate variability in the North Atlantic. Science, 283: 971-975.

McMinn, A., 1990. Recent dinoflagellate cyst distribution in eastern Australia. Review of Palaeobotany and Palynology, 65: 305-310.

McMinn, A., 1992. Recent and Late Quaternary Dinoflagellate Cyst Distribution on the Continental Shelf and Slope of Southeastern Australia. Palynology, 16: 13-24.

Mertens, K.N., Verhoeven, K., Verleye, T., Louwye, S., Amorim, A., Ribeiro, S., Deaf, A.S., Harding, I.C., De Schepper, S., González, C., Kodrans-Nsiah, M., De Vernal, A., Henry, M., Radi, T., Dybkjaer, K., Poulsen, N.E., Feist-Burkhardt, S.E., Chitolie, J., Heilmann-Clausen, C., Londeix, L., Turon, J-L., Marret, F., Matthiessen, J., McCarthy, F.M.G., Prasad, V., Pospelova, 


\section{References}

V., Kyffin Hughes, J.E., Riding, J.B., Rochon, A., Sangiorgi, F., Welters, N., Sinclair, N., Thun, C., Soliman, A., Van Nieuwenhove, N., Vink, A., Young, M., 2009. Determining the absolute abundance of dinoflagellate cysts in recent marine sediments: The Lycopodium marker-grain method put to the test. Review of Palaeobotany and Palynology. 157 (3-4): 238-252

Mertens, K.N., Dale, B., Ellegaard, M., Jansson, I.-M., Godhe, A., Kremp, A., Louwye, S., 2011. Process length variation in cysts of the dinoflagellate Protoceratium reticulatum, from surface sediments of the Baltic-Kattegat-Skagerrak estuarine system: A regional salinity proxy. Boreas, $40(2):$ 242-255

Mildenhall, D.C., 1976. Exotic pollen rain on the Chatham Islands during the Late Pleistocene. New Zealand Journal of Geology and Geophysics, 19(3): 327-333.

Mildenhall, D.C., 1995. Pleistocene palynology of the Petone and Seaview drillholes, Petone, Lower Hutt Valley, North Island, New Zealand. Journal of the Royal Society of New Zealand, 25(2): 207-262.

Mildenhall, D.C., 2003. Deep-sea record of Pliocene and Pleistocene terrestrial palynomorphs from offshore eastern New Zealand (ODP Site 1123, Leg 181). New Zealand Journal of Geology and Geophysics, 46: 343-361.

Mildenhall, D.C., Hollis, C.J., Naish, T.R., 2004. Orbitally-infuenced vegetation record of the Mid-Pleistocene Climate Transition, offshore eastern New Zealand (ODP Leg 181, Site 1123). Marine Geology, 205: 87-111.

Miller, A.J., Kuehl, S.A., 2010. Shelf sedimentation on a tectonically active margin: a model sediment budget for the Poverty contintental shelf, New Zealand. Marine Geology, 270: 175187.

Mix, A.C., Morey, A.E., Pisias, N.G., Hostetler, S.W., 1999. Foraminiferal faunal estimates of paleotemperature: circumventing the no-analog problem yields cool ice-age tropics. Paleoceanography, 14: 350-359.

Moar, N., 1993. Pollen grains of New Zealand dicotyledonous plants. Manaaki Whenua Press, Christchurch, 200 pp.

Mongin, M., Matear, R., Chamberlain, M, 2011a. Simulation of chlorophyll and iron supplies in the Sub Antarctic Zone South of Australia. Deep Sea Research Part II, 58: 2126-2134. 


\section{References}

Mongin, M., Matear, R., Chamberlain, M, 2011b. Seasonal and spatial variability of remotely sensed chlorophyll and physical fields in the SAZ-Sense region. Deep-Sea Research II, 58: 2082-2093.

Monterey, G., Levitus, S., 1997. Seasonal variability of mixed layer depth for the world ocean. NOAA Atlas NESDIS 14. U.S. Government Printing Office, Washington, D.C.

Moore, M.I., Murdoch, R.C., 1993. Physical and biological observations of coastal squirt nonupwelling conditions. Journal of Geophysical Research, 98: 20043-20041.

Morey, A.E., Mix, A.C., Pisias, N.G., 2005. Planktonic foraminiferal assemblages preserved in surface sediments correspond to multiple environment variables. Quaternary Science Reviews, 24: 925-950.

Morris, M., Stanton, B., Neil, H., 2001. Subantarctic oceanography around New Zealand: preliminary results from an ongoing survey. New Zealand Journal of Marine and Freshwater Research, 35: 499-519.

Muller, U.C., Pross, J., 2007. Lesson from the past: present insolation minimum holds potential for glacial inception. Quaternary Science Reviews, 26: 3025-3029.

Murphy, R.J., Pinkerton, R.J., Richardson, K.M., Bradford-Grieve, J.M., Boyd, P., 2001. Phytoplankton distributions around New Zealand derived from SeaWiFS remotely-sensed ocean colour data. New Zealand Journal of Marine and Freshwater Research, 35: 343-362.

Naish, T., Powell, R., Levy, R., Wilson, G., Scherer, R., Talarico, F., Krissek, L., Niessen, F., Pompilio, M., Wilson, T., Carter, L., DeConto, R., Huybers, P., McKay, R., Pollard, P. Ross, J., Winter, D. and 39 members of the Science Team 2009. Obliquity-paced Pliocene West Antarctic ice sheet oscillations. Nature, 458: 233-327.

Navarro, J.M., Muñoz, M.G., Contreras, A.M., 2006. Temperature as a factor regulating growth and toxin content in the dinoflagellate Alexandrium catenella. Harmful Algae, 5(6): 762-769.

Nees, S., 1997. Late Quaternary palaeoceanography of the Tasman Sea: the benthic foraminiferal view. Palaeogeography, Palaeoclimatology, Palaeoecology, 131: 365-389.

Nelson, C., 1986. Lithostratigraphy of Deep Sea Drilling Project Leg 90 drill sites in the southwest Pacific: an overview. In: J.C. Kennett, von der Borch, C.C., Barker, P.A. (Editor), 


\section{References}

Initial Reports of the Deep Sea Drilling Project Leg 90. US Government Printing Office, Washington DC, pp. 1471-1491.

Nelson, C.S., Cooke, P.J., Hendy, C.H., Cuthbertson, A.M., 1993. Oceanographic and climatic changes ocean the past 160000 years at deep-Sea Drilling Project site 594 off south eastern New Zealand, south west Pacific Ocean. Paleoceanography, 8(4): doi:10.1029/93PA01162 P8, 435-458.

Newnham, R., Alloway, B., 2004. A terrestrial record of Last Interglacial climate preserved by voluminous debris avalanche inundation in Taranaki, New Zealand. Journal of Quaternary Science, 19(3): 299-314.

Newnham, R.M., Vandergoes, M.J., Hendy, C.H., Lowe, D.J., Preusser, F., 2007. A terrestrial palynological record for the last two glacial cycles from southwestern New Zealand. Quaternary Science Reviews, 26: 517-535.

Newnham, R.M., Vandergoes, M. J., Sikes, E., Carter, L., Wilmhurst, J. M., Lowe, D. J., McGlone, M. S., Sandiford, A., 2011, Does the bipolar seesaw extend to the terrestrial southern mid-latitudes?: Quaternary Science Reviews, DOI: 10.1016/j.qua .scirev.2011.04.013.

Niebler, H.-S.H., Arz, W., Donner, B., Mulitza, S., Patzold, J., Wefer, G., 2003. Sea surface temperatures in the equatorial and South Atlantic Ocean during the Last Glacial Maximum (23-19 ka). Palaeoceanography, 18(3): 1069, doi:10.1029/2003PA000902.

NOAA, 2011: Southern Isolation Index raw data, website accessed January 2011. http://www.cpc.ncep.noaa.gov/data/indices/soi.3m.txt.

Nodder, S., Gall, M., 1998. Pigment fluxes from the Subtropical Convergence region, east of New Zealand: Relationships to planktonic community structure. New Zealand Journal of Marine and Freshwater Research, 32(3): 441-465.

Nodder, S.D., Boyd, P.W., Chiswell, S.M., Pinkerton, M.H., Bradford-Grieve, J.M., Greig, M.J.N, 2005. Temporal coupling between surface and deep ocean biogeochemical processes in contrasting subtropical and subantarctic water masses, southwest Pacific Ocean. Journal of Geophysical Research C: Oceans, 110: doi:10.1029/2004JC002833. 


\section{References}

Nodder, S.D., Northcote, L.C., 2001. Episodic particulate fuxes at southern temperate midlatitudes (420-45oS) in the Subtropical Front region, east of New Zealand. Deep-Sea Research I, 48: 833 - 864.

Norris, R. J., Cooper, A.F., 2001. Late Quaternary slip rates and slip partitioning on the Alpine Fault, New Zealand. Journal of Structural Geology, 23 (2-3), 507-520.

Northcote, L.C., Neil, H.L., 2005. Seasonal variations in foraminiferal flux in the Southern Ocean, Campbell Plateau, New Zealand. Marine Micropaleontology, 56(3-4): 122-137.

Nürnberg, D., Groeneveld, J., 2006. Pleistocene variability of the Subtropical Convergence at East Tasman Plateau: Evidence from planktonic foraminiferal Mg/Ca (ODP Site 1172A). Geochemistry, Geophysics, Geosystems, 7(4): art. no. Q04P11.

Olson, S.L., Hearty, P.J., 2009. A sustained +21 m sea-level highstand during MIS 11 (400 ka): direct fossil and sedimentary evidence from Bermuda. Quaternary Science Reviews, 28: 271 $-285$.

Orsi, A. and Harris, U. (2001, updated 2008) Locations of the various fronts in the Southern Ocean, Australian Antarctic Data Centre - CAASM Metadata (http://gcmd.nasa.gov/KeywordSearch/Metadata.do?Portal=amd_ au\&MetadataView=Full\&MetadataType=0\&KeywordPath=\&OrigMetadataNode=AADC\&Entr yld=southern_ocean_fronts)

Orsi, A.H., Whitworth III, T., Nowlin Jr, W.D., 1995. On the meridional extent and fronts of the Antarctic Circumpolar Current. Deep-Sea Research, 42(5): 641-673.

Ortlieb, L., Diaz, A., Guzman, N., 1996. A warm interglacial episode during oxygen isotope stage 11 in northern Chile. Quaternary Science Reviews, 15(8-9): 857-871.

Pahnke, K., Sachs, J.P., 2006. Sea surface temperatures of southern midlatitudes 0-160 kyr B.P. Paleoceanography, 21(doi:10.1029/2005PA001191).

Pahnke, K., Zahn, R., Elderfield, H., Schulz, M., 2003. 340,000-Year Centennial-Scale Marine Record of Southern Hemisphere Climatic Oscillation. Science, 301: 948-952.

Passow, U., De La Rocha, C.L., 2006. Accumulation of mineral ballast on organic aggregates. Global Biogeochemical Cycles, 20(1): art. no. GB1013 


\section{References}

Pelejero, C., Calvo, E., Barrows, T.T., Logan, G.A., De Deckker, P., 2006. South Tasman Sea alkenone palaeothermometry over the last four glacial/interglacial cycles. Marine Geology, 230: 73-86.

Peyron, O., de Vernal, A., 2001. Application of artificial neural networks (ANN) to high latitude dinocyst assemblages for the reconstruction of part sea-surface conditions in Arctic and sub-Arctic Seas. Journal of Quaternary Science, 16(7): 699-710.

Pfiester, L., Anderson, D. M. , 1987. Dinoflagellate reproduction. In: F. Taylor (Editor), The Biology of Dinoflagellates. Blackwell Scientific, Oxford, pp. 611-648.

Pflaumann, U., Duprat, J., Pujol, C., Labeyrie, L., 1996. SIMMAX: A modern analog technique to deduce Atlantic sea surface temperatures from planktonic foraminifera in deep-sea sediments. Paleoceanography, 11: 15-35.

Pillans, B., Bourman, R., 2001. Mid Pleistocene arid shift in southern Australia, dated by magnetostratigraphy. Australian Journal of Soil Research, 39(1): 89-98.

Pillans, B., Froggatt, P., Kohn, B.P., Berger, G., Walter, R.C., Duller, G., Alloway, B.V., Hesse, P., 1996. Multi-method dating comparison for mid-Pleistocene Rangitawa Tephra, New Zealand. Quaternary Science Reviews (Quaternary Geochronology), 15: 641-653.

Pitcher, G.C., Joyce, L.B., 2009. Dinoflagellate cyst production on the southern Namaqua Shelf of the Benguela upwelling system. Journal of Plankton Research, 31(8): 865-875.

Pocknall, D., 1981a. Pollen morphology of Phyllocladus LC et A. Rich. New Zealand Journal of Botany, 19: 259-266.

Pocknall, D., 1981b. Pollen morphology of the New Zealand species of Dacrydium Solander, Podocarpus L'Heritier, and Dacrycarpus Endlicher (Podocarpaceae). New Zealand Journal of Botany, 19: 67-95.

Pocknall, D., 1981c. Pollen morphology of the New Zealand species of Libocedrus Endlicher (Cupressaceae) and Agathis Salisbury (Araucariaceae). New Zealand Journal of Botany, 19: 67-95

Pospelova, V., de Vernal, A., Pedersen, T.F., 2008. Distribution of dinoflagellate cysts in surface sediments from the northeastern Pacific Ocean $\left(43-25^{\circ} \mathrm{N}\right)$ in relation to sea-surface 


\section{References}

temperature, salinity, productivity and coastal upwelling. Marine Micropalentology, 68: 2148.

Pospelova, V., Esenkulova, S., Johannessen, S.C., O'Brien, M.C., Macdonald, R.W., 2010. Organic-walled dinoflagellate cyst production, composition and flux from 1996 to 1998 in the central Strait of Georgia (BC, Canada): A sediment trap study. Marine Micropalaeontology, 75: 17-37.

Power, S., Casey, T., Folland, C., Colman, A., Mehta, V., 1999. Inter-decadal modulation of the impact of ENSO on Australia. Climate Dynamics, 15(5): 319-324.

Price, A.M., Pospelova, V., 2011. High-resolution sediment trap study of organic-walled dinoflagellate cyst production and biogenic silica flux in Saanich Inlet (BC, Canada). Marine Micropalentology, 80: 18-43.

Prokopenko, A.A., Bezrukova, E.V., Khursevich, G.K., Solotchina, E.P., Kuzmin, M.I., Tarasov, P.E., 2010. Climate in continental interior Asia during the longest interglacial of the past 500 000 years: The new MIS 11 records from Lake Baikal, SE Siberia. Climate of the Past, 6(1): 3148.

Proust, J.-N., Lamarche, G., Migeon, S., Neil, H., Shipboard Scientific Party (2006), MD 152/MATCORE (24 January- 7 February 2006) on RV Marion-Dufresne Rep., 107pp, ISSN : $1246-7375$

Racca, J.M.J., Philibert, A., Racca, R., Prairie, Y.T., 2001. A comparison between diatom-based $\mathrm{pH}$ inference models using artificial neural networks (ANN), weighted averaging (WA) and weighted averaging partial least squares (WA-PLS) regressions. Journal of Paleolimnology, 26: 411-422.

Radhi, M., Box, M.A., Box, G.P., Keywood, M.D., Cohen, D.D., Stelcer, E., Mitchell, R.M, 2011. Size-resolved chemical composition of Australian dust aerosol during winter. Environmental Chemistry, 8(3): 248-262.

Radhi, M., Box, M.A., Box, G.P., Mitchell, R.M., Cohen, D.D., Stelcer, E., Keywood, M.D., 2010a. Size-resolved mass and chemical properties of dust aerosols from Australia's Lake Eyre Basin. Atmospheric Environment, 44(29): 3519-3528. 


\section{References}

Radhi, M., Box, M.A., Box, G.P., Mitchell, R.M., Cohen, D.D., Stelcer, E., Keywood, M.D., 2010b. Optical, physical and chemical characteristics of Australian continental aerosols: Results from a field experiment. Atmospheric Chemistry and Physics, 10(3): 5925-5942.

Radi, T., de Vernal, A., 2004. Dinocyst distribution in surface sediments from the northeastern Pacific margin $\left(40-60^{\circ} \mathrm{N}\right)$ in relation to hydrographic conditions, productivity and upwelling. Review of Palaeobotany and Palynology, 128: 169-193.

Radi, T., de Vernal, A., 2008. Dinocysts as proxy of primary productivity in mid-high latitudes of the Northern Hemisphere. Marine Micropaleontology, 68(1-2): 84-114.

Radi, T., de Vernal, A., Peyron, O, 2001. Relationships between dinoflagellate cyst assemblages in surface sediment and hydrographic conditions in the Bering and Chukchi seas Journal of Quaternary Science, 16(7): 667-680.

Radi, T., Pospelova, V. de Vernal, A., Barrie J.V., 2007. Dinoflagellate cysts as indicators of water quality and productivity in British Columbia estuarine environments. Marine Micropalaeontology 62: 269-297. doi:10.1016/j.marmicro.2006.09.002.

Rahmstorf, S., 1992. Modelling ocean temperatures and mixed-layer depths in the Tasman Sea off the South Island, New Zealand. New Zealand Journal of Marine and Freshwater Research, 26, 37-51.

Reichart, G.J., Brinkhuis, H., 2003. Late Quaternary Protoperidinium cysts as indicators of productivity in the northern Arabian Sea. Marine Micropalaeontology, 49: 303-315.

Ribeiro, S., Amorim, A., 2008. Environmental drivers of temporal succession in recent dinoflagellate cyst assemblages from a coastal site in the North-East Atlantic (Lisbon Bay, Portugal). Marine Micropalaeontology, 68: 156-178.

Ridgway, K. R., Dunn, J. R., 2003. Mesoscale structure of the mean East Australian Current system and its relationship with topography. Progress in Oceanography, 56, 189-222.

Ridgway, K.R., 2007. Long-term trend and decadal variability of the southward penetration of the East Australian Current. Geophysical Research Letters, 34: L13613, doi:10.1029/2007GL030393. 


\section{References}

Riveiros, N.V., Waelbroeck, C., Skinner, L., Roche, D.M., Duplessy, J.-C., Michel, E., 2010. Response of South Atlantic deep waters to deglacial warming during Terminations $V$ and I Earth and Planetary Science Letters, 298(3-4): 323-333.

Rochon, A., de Vernal, A., 1994. Palynomorph distribution in Recent sediments from the Labrador sea. Canadian Journal of Earth Sciences, 31: 115-127.

Rochon, A., de Vernal, A., Turon, J.-L., Matthiessen, J., Head, M.J., 1999. Distribution of Recent dinoflagellate cysts in surface sediments from the North Atlantic Ocean and adjacent seas in relation to sea-surface parameters. American Association of Stratigraphic Palynologists Contribution Series, 35: 152pp.

Rochon, A., Lewis, J., Ellegaard, M., Harding, I.C., 2009. The Gonyaulax spinifera (Dinophyceae) "complex": Perpetuating the paradox?. Review of Palaeobotany and Palynology, 155(1-2): 52-60.

Roemmich, D., 2007. Physical oceanography: Super spin in the southern seas. Nature, 449(7158): 34-35.

Roemmich, D., Gilson, J., Davis, R., Sutton, P., Wijffels, S., Riser, S., 2007. Decadal spinup of the south pacific subtropical gyre. Journal of Physical Oceanography, 37(2): 162-173.

Rohling, E.J., Grant K., Bolshaw, M., Roberts, A.P., Siddall, M., Hemleben, C., Kucera, M., 2009. Antarctic temperature and global sea level closely coupled over the past five glacial cycles. Nature Geosciences, 2: 500-504.

Rohling, E.J., Braun, K., Grant, K., Kucera, M., Roberts, A.P., Siddall, M., Trommer, G., 2010. Comparison between Holocene and Marine Isotope Stage-11 sea-level histories. Earth and Planetary Science Letters, 291: 97-105.

Ryan, M., 2010. A palynological record of the vegetation and climate of Westland since 210 ka, Unpublished MSc Thesis, Victoria University of Wellington, Wellington, 176 pp.

Ryan, M.T., Dunbar, G.B., Vandergoes, M.J., Neil, H.L., Hannah, M., Newnham, R.M., Bostock, H., Alloway, B.V., 2012. Vegetation and climate in Southern Hemisphere mid-latitudes since 210 ka: new insights from marine and terrestrial pollen records from New Zealand: Quaternary Science Reviews, 48: 80-98 


\section{References}

Saba, V.S., Friedrichs, M.A.M., Antoine, D., Armstrong, R.A., Asanuma, I., Behrenfeld, M.J., Ciotti, A.M., Dowell, M., Hoepffner, N., Hyde, K.J.W., Ishizaka, J., Kameda, T., Marra, J., Mlin, F., Morel, A., O'Reilly, J., Scardi, M., Smith Jr., W.O., Smyth, T.J., Tang, S., Uitz, J., Waters, K., Westberry, T.K., 2011. An evaluation of ocean color model estimates of marine primary productivity in coastal and pelagic regions across the globe. Biogeosciences, 8(2): 498-503.

Sachs, J.P., Anderson, R.F., 2005. Increased productivity in the subantarctic ocean during Heinrich events. Nature, 434: 1118-1121.

Salinger, M.J., 1980. New Zealand climate: I. precipitation patterns. Monthly Weather Review, 108: 1892-1904.

Sarmiento, J. L., Slater, R., Barber, R., Bopp, L., Doney, S.C., Hirst, A.C., Kleypas, J., Stouffer, R., 2004. Response of ocean ecosystems to climate warming. Global Biogeochemical Cycles, 18(3), 1-23.

Sathyendranath, S., Longhurst, A. R., Caverhill, C. M., Platt, T., 1995. Regionally and seasonally differentiated primary production in the North Atlantic. Deep Sea Research. 42: 1773-1802.

Schaefer, G., Rodger, J.S., Hayward, B.W., Kennett, J.P., Sabaa, A.T., Scott, G.H., , 2005. Planktic foraminiferal and sea surface temperature record during the last $1 \mathrm{Myr}$ across the Subtropical Front, Southwest Pacific. Marine Micropaleontology 54: 191-212.

Scherer, R.P., 2003. Quaternary interglacials and the West Antarctic Ice Sheet, in Earth's Climate and Orbital Eccentricity: The Marine Isotope Stage 11 Question,. In: A.W. Droxler, Poore, R. (Editors), Geophysical Monograph Series Washington, D. C., pp. 103-112.

Schiebel, R., Waniek, J., Bork, M., Hemleben, C., 2001. Planktic foraminiferal production stimulated by chlorophyll redistribution and entrainment of nutrients. Deep Sea Research. 48: 721-740.

Schlitzer, R., 2002. Interactive analysis and visualization of geoscience data with Ocean Data View. Computers and Geosciences, 28(10): 1211-1218.

Schlitzer, R., 2011, Ocean Data View, http://odv.awi.de 


\section{References}

Shaw, A.G.P., Vennell, R., 2000. Variability of water masses through the Mernoo Saddle, South Island, New Zealand. New Zealand Journal of Marine and Freshwater Research, 34(1): 103-116.

Shaw, P.J.A., 2003. Multivariate statistics for the environmental sciences. Hodder, London, $233 \mathrm{pp}$.

Sherr, E.B., Sherr, B.F., 2007. Heterotrophic dinoflagellates: a significant component of microzooplankton biomass and major grazers of diatoms in the sea. Marine Ecology Progress Series, 352: 187-197

Shulmeister, J., Goodwin, I., Renwick, J., Harle, K., Armand, L., McGlone, M.S., Cook, E., Dodson, J., Hesse, P.P., Mayewski, P., Curran, M., 2004. The Southern Hemisphere westerlies in the Australasian sector over the last glacial cycle: A synthesis. Quaternary International, 118-119: 23-53.

Siddall, M., Chappell, J., Potter, E.K., 2007. Chapter 7: Eustatic Sea Level During Past Interglacials. In: F. Sirocko, Claussen, A., Sanchez Goni, M.F., Litt, T. (Editors), The Climate of Past Interglacials. Elsevier.

Siegenthaler, U., Stocker, T.F., Monnin, E., Luthi,D., Schwander, J., Stauffer, B., Raynaud, D., Barnola, J-M, Fischer, H., Masson-Delmotte, V-M, Jouzel, J., 2005. Stable Carbon CycleClimate Relationship during the Late Pleistocene. Science, 310: 1313-1317.

Sikes, E.L., Howard, W.R., Samson, C.R., Mahan, T.S., Robertson, L.G., Volkman, J.K., 2009. Southern Ocean seasonal temperature and Subtropical Front movement on the South Tasman Rise in the late Quaternary. Palaeoceanography, 24: doi:10.1029/2008PA001659.

Sikes, E.L., Samson, C.R., Guilderson, T.P., Howard, W.R., 2000. Old radiocarbon ages in the southwest Pacific Ocean during the last glacial period and deglaciation. Nature, 405(6786): 555-559.

Simpson, G.L., 2007. Analogue methods in palaeoecology: using the analogue package. Journal of Statistical Software, 22: 1-29.

Smayda, T.J., Reynolds, C.S., 2003. Strategies of marine dinoflagellate survival and some rules of assembly. Journal of Sea Research, 49: 95-106. 


\section{References}

Sokolov, S., Rintoul, S.R., 2009. Circumpolar structure and distribution of the Antarctic Circumpolar Current fronts: 1 . Mean circumpolar paths. Journal of Geophysical Research C: Oceans, 114: C11018 doi:10.1029/2008JC005108

Soons, J.M., Moar, N.T., Shulmeister, J., Wilson, H.D., Carter, J.A., 2002. Quaternary vegetation and climate changes on Banks Peninsula, South Island, New Zealand. Global and Planetary Change, 33: 301-314.

Stanton, B.R., 1976. Circulation and hydrology off the west coast of the South Island, New Zealand. New Zealand Journal of Marine and Freshwater Research, 10: 445-467.

Stanton, B.R., 1998. Ocean Surface Winds off the West Coast of New Zealand: A Comparison of Ocean Buoy, ECMWF Model, and Land-Based Data. Journal of Atmospheric and Oceanic Technology, 15: 1164-1170.

Stanton, B.R., Moore, M.I., 1992. Hydrographic observations during the Tasman Boundary Experiment off the west coast of South Island, New Zealand. New Zealand Journal of Marine and Freshwater Research, 26: 339-358.

Stanton, B.R., Sutton, P.J.H., Chiswell, S.M., 1997. The East Auckland Current, 1994-95. New Zealand Journal of Marine and Freshwater Research, 31: 537-549.

Steinacher, M., Joos, F., Frölicher, T.L., Bopp, L., Cadule, P., Cocco, V., Doney, S.C., Segschneider, J., 2010. Projected 21st century decrease in marine productivity: a multimodel analysis. Biogeosciences, 7(3), 979-1005.

Stoecker, D., 1999. Mixotrophy among dinoflagellates. Journal of Eukaryotic Microbiology, 46(4): 397-401.

Sturman, A., Tapper, N., 1996. The weather and climate of Australia and New Zealand. Oxford University Press, Melbourne, 476 pp.

Sun, X., McMinn, A., 1994. Recent dinoflagellate cyst distribution associated with the Subtropical Convergence on the Chatham Rise, east of New Zealand. Marine Micropalaeontology, 23: 345-356.

Sutton, P. J. H., 2003. The Southland Current: A Subantarctic current. New Zealand Journal of Marine and Freshwater Research, 37(3), 645-652. 


\section{References}

Sutton, P.J.H., Bowen, M., Roemmich, D., 2005. Decadal temperature changes in the Tasman Sea New Zealand Journal of Marine and Freshwater Research, 39(6): 1321-1329.

Sutton, P.J.H., Roemmich, D., 2001. Ocean temperature climate off north-east New Zealand. New Zealand Journal of Marine and Freshwater Research, 35: 553-565.

Telford, R.J., 2006. Limitations of dinoflagellate cyst transfer functions. Quaternary Science Reviews, 25: 1375-1382.

Telford, R.J., Andersson, C., Birks, H.J.B., Juggins, S., 2004. Biases in the estimation of transfer function prediction errors. Paleoceanography, 19: PA4014.

Telford, R.J., Birks, H.J.B., 2005. The secret assumption of transfer functions: problems with spatial autocorrelation in evaluating model performence. Quaternary Science Reviews, 24: 2173-2179.

Telford, R.J., Birks, H.J.B., 2009. Design and evaluation of transfer functions in spatially structured environments. Quaternary Science Reviews, 28: 1309-1316.

Telford, R.J., Birks, H.J.B., 2009. Design and evaluation of transfer functions in spatially structured environments. Quaternary Science Reviews, 28: 1309-1316.

Telford, R.J., Birks, H.J.B., 2011a. A novel method for assessing the statistical significance of quantitative reconstructions inferred from biotic assemblages. Quaternary Science Reviews, 30: $1272-1278$.

Telford, R.J., Birks, H.J.B., 2011b. QSR Correspondence "Is spatial autocorrelation introducing biases in the apparent accuracy of palaeoclimatic reconstructions?". Quaternary Science Reviews, 30(21-22): 3210-3213.

ter Braak, C.J.F., 1994. Canonical community ordination. Part 1: Basic theory and linear methods. Ecoscience, 1 (2): 127-140.

ter Braak, C.J.F., Juggins, S., 1993. Weighted Averaging Partial Least-Squares regression (WAPLS) - an improved method for reconstructing environmental variables from species assemblages. Hydrobiologia, 269: 485-502. 


\section{References}

ter Braak, C.J.F., Juggins, S., 1993. Weighted Averaging Partial Least-Squares Regression (WA-PLS) - an improved method for reconstructing environmental variables from species assemblages. Hydrobiologia, 269: 485-502.

ter Braak, C.J.F., Looman, C.W.N., 1986. Weighted averaging, logit regression and the Gaussian response model. Vegetatio, 65: 3-11.

ter Braak, C.J.F., Smilauer, P., 2002. CANOCO Reference manual and CanoDraw for Windows User's Guide: Software for Canonical Community Ordination (Version 4.5). Microcomputer Power. New York. 500pp.

ter Braak, C.J.F., van Dam, H., 1989. Inferring pH from diatoms - a comparison of old and new calibration methods. Hydrobiologia, 178: 209-223.

Thompson, E.M., Baisea, L.G., Kayenb, R.E., 2007. Spatial correlation of shear-wave velocity in the San Francisco Bay Area sediments. Soil Dynamics and Earthquake Engineering. 27(2): 144-152.

Tilburg, C. E., Hurlburt, H.E., O'Brien, J.J., Shriver, J.F., 2001. The dynamics of the East Australian Current system: the Tasman Front, the East Auckland Current, and the East Cape Current. Journal of Physical Oceanography, 31, 2917-2943.

Tilburg, C.E., Subrahmanyam, B., O'Brien, J.J., 2002. Ocean color variability in the Tasman Sea. Geophysical Research Letters, 29(10): 1487, 10.1029/2001GL014071.

Toggweiler, J.R., Russel, J., 2008. Ocean circulation in a warming climate. Nature, 451: 286288.

Traverse, A., 2007. Paleopalynology, 2nd Edition. Topics in Geobiology, 28. Springer, 813 pp.

Tzedakis, P.C., 2010. The MIS 11 - MIS 1 analogy, southern European vegetation, atmospheric methane and the "early anthropogenic hypothesis". Climate of the Past, 6(2): 131-144.

Tzedakis, P.C., Channell, J.E.T., Hodell, D.A., Kleiven, H.F., Skinner, L.C., 2012. Determining the natural length of the current interglacial. Nature Geoscience, 5(2): 138-142.

Tzedakis, P.C., Raynaud, D., McManus, J.F., Berger, A., Brovkin, V., Kiefer, T., 2009. Interglacial diversity. Nature Geosciences, 2: 751. 


\section{References}

Uddstrom, M.J., Oien, N.A., 1999. On the use of high resolution satellite data to describe the temporal and spatial variability of sea surface temperatures in the New Zealand region. Journal of Geophysical Research, 104(20): 729-751.

Ummenhofer, C.C., England, M.H., 2007. Interannual extremes in New Zealand precipitation linked to modes of Southern Hemisphere climate variability. Journal of Climate, 20: 54185440.

Ummenhofer, C.C., Gupta, A.S., England, M.H., 2009. Causes of late twentieth-century trends in New Zealand precipitation. Journal of Climate, 22: 3-19.

van der Voet, H., 1994. Comparing the predictive accuracy of models using a simple randomization test. Chemometrics and Intelligent Laboratory Systems, 25: 313-323.

Vandergoes, M.J., Newnham, R.M., Hendy, C.H., Lovell, T.V., Preusser, F., Fitzsimons, S.J., Hogg, A., Kasper, H.U., Schluchter, C., 2005. Regional insolation forcing of late Quaternary climate change in the Southern Hemisphere. Nature, 436: 242-245.

Vantrepotte, V., Mélin, F., 2011. Inter-annual variations in the SeaWiFS global chlorophyll a concentration (1997-2007). Deep-Sea Research I, 58(4): 429-441.

Verity, P., Stoecker, D.K., Sieracki, M.E., Burkiel, P.H., Edwards, E.S., Tronzo, C.R., 1993. Abundance, biomass and distribution of heterotrophic dinoflagellates during the North Atlantic spring bloom. Deep-Sea Research II, 40(1/2): 227-244.

Verleye, T., Louwye, S., 2010. Recent geographical distribution of organic-walled dinoflagellate cysts in the southeast Pacific $\left(25-53^{\circ} \mathrm{S}\right)$ and their relation to the prevailing hydrographical conditions. Palaeogeography, Palaeoclimatology, Palaeoecology, 298: 319340.

Verleye, T.J., Louwye, S., 2010. Late Quaternary environmental changes and latitudinal shifts of the Antarctic Circumpolar Current as recorded by dinoflagellate cysts from offshore Chile (41오. Quaternary Science Reviews, 29: 1025-1039.

Verleye, T., Pospelova, V., Mertens, K.N., Louwye, S., 2011. The geographical distribution and (palaeo)ecology of Selenopemphix undulata sp. nov., a new late Quaternary dinoflagellate cyst from the Pacific Ocean. Marine Micropalentology, 78: 65 - 83. 


\section{References}

Verleye, T.J., Mertens, K.N., Young, M.D., Dale, B., McMinn, A., Scott, L., Zonneveld, K.A.F., Louwye, S., 2012. Average process length variation of the marine dinoflagellate cyst Operculodinium centrocarpum in the tropical and Southern Hemisphere Oceans: Assessing its potential as a palaeosalinity proxy. Marine Micropalentology, 86-87: 45-58.

Vink, A., Zonneveld, K.A.F. and Willems, H., 2000. Organic-walled dinoflagellate cysts in western equatorial Atlantic surface sediments: distribution and their relation to environment. Review of Palaeobotany and Palynology, 112: 247-286.

Voelker, A.H.L., Rodrigues, T., Billups, K., Oppo, D., McManus, J., Stein, R., Hefter, J., Grimalt, J.O. , 2010. Variations in mid-latitude North Atlantic surface water properties during the mid-Brunhes (MIS 9-14) and their implications for the thermohaline circulation Climate of the Past, 6: 531-532.

Waelbroeck, C., Labeyrie, L., Duplessy, J.-C., Guiot, J., Labracherie, M., Leclaire, H., Duprat, J., 1998. Improving past sea surface temperature estimates based on planktonic fossil faunas. Paleoceanography, 13: 272-283.

Waite, A.M., Safi, K.A., Hall, J.A., Nodder, S.D., 2000. Mass sedimentation of picoplankton embedded in organic aggregates. Limnology and Oceanography, 45: 87-97.

Wang, P., Tian, J., Cheng, X., Liu, C., Xu, J., , 2002. Carbon reservoir changes preceded major ice-sheet expansion at the mid-Brunhes event. Geology, 31(3): 239-242.

Wasmund, N., Tuimala, J., Suikkanen, S., Vandepitte, L., Kraberg, A., 2011. Long-term trends in phytoplankton composition in the western and central Baltic Sea. Journal of Marine Systems, 87: 145-159.

Watras, C.J., Chisholm, S.W., Anderson, D.M., 1982. Regulation of growth in an estuarine clone of Gonyaulax tamarensis Lebour: Salinity-dependent temperature responses. Journal of Experimental Marine Biology and Ecology, 62(1): 25-37.

Waugh, D. W., Abraham, E.R., Bowen, M.M., 2006. Spatial variations of stirring in the surface ocean: A case study of the Tasman Sea, Journal of Physical Oceanography, 36(3), 526-542.

Weaver, P.P.E., Carter, L., Neil, H.L., 1998. Response of surface water masses and circulation to late Quaternary climate change east of New Zealand. Palaeoceanography, 13(1): 70-83. 


\section{References}

Weaver, P.P.E., Neil, H., Carter, L., 1997. Sea surface temperature estimates from the Southwest Pacific based on planktonic foraminifera and oxygen isotopes. Palaeogeography, Palaeoclimatology, Palaeoecology, 131: 241-256.

Wells P, O.H., Okada, H., 1997. Response of nannoplankton to major changes in sea-surface temperature and movements of hydrological fronts over site DSDP 594 (south Chatham Rise, southeastern New Zealand), during the last 130 kyr. Marine Micropalentology, 32: 341-363.

Wilmshurst, J.M., Eden, D.N., Froggatt, P.C., 1999. Late Holocene forest disturbance in Gisborne, New Zealand: A comparison of terrestrial and marine pollen records. New Zealand Journal of Botany, 37: 523-540.

Wilmshurst, J.M., McGlone, M.S., Leathwick, J.R., Newnham, R.N., 2007. A pre-deforestation pollen-climate calibration model for New Zealand and quantitative temperature reconstructions for the past 18000 years BP. Journal of Quaternary Science, 22(5): 535-547.

Wilson, K., Hayward, B.W., Sabaa, A., Scott, G.H., Kennett, J.P., 2005. A one-million year history of a north-south segment of the Subtropical Front, east of New Zealand. Palaeoceanography 20: doi:10.1029/2004PA001080 PA2004.

Winder, M., Cloern, J.E., 2010. The annual cycles of phytoplankton biomass. Philosophical Transactions of the Royal Society B, 365: 3215-3226.

Wright, I.C., McGlone, M.S., Nelson, C.S., Pillans, B.J., 1995. An integrated latest Quaternary (Stage 3 to present) paleoclimatic and paleoceanographic record from offshore northern New Zealand. Quaternary Research, 44: 283-293.

Xu, Q., Li, Y., Bunting, M.J., Tian, F., Liu, J., 2010. The effects of training set selection on the relationship between pollen assemblages and climate parameters: Implications for reconstructing past climate. Palaeogeography, Palaeoclimatology, Palaeoecology, 289: 123133.

Zaric, S., Donner, T.B., Fischer, G., Mulitza, S., Wefer, G., 2005. Sensitivity of planktic foraminifera to sea surface temperature and export production as derived from sediment trap data. Marine Micropalentology, 55: 75-105. 


\section{References}

Zonneveld, K.A.F. 1997. New species of organic walled dinoflagellate cysts from modern sediments of the Arabian Sea (Indian Ocean). Review of Palaeobotany and Palynology, 97: 319-337.

Zonneveld, K.A.F., Versteegh, G.J.M., de Lange, G.J., 1997. Preservation of organic-walled dinoflagellate cysts in different oxygen regimes: a 10,000 year natural experiment. Marine Micropalentology, 29: 393-405.

Zonneveld, K.A.F., Brummer, G-J.A., 2000. (Palaeo-)ecological significance, transport and preservation of organic-walled dinoflagellate cysts in the Somali Basin, NW Arabian Sea. Deep-Sea Research II, 47: 2229-2256.

Zonneveld, K.A.F., Hoek, R.P., Brinkhuis, H., Willems, H., 2001. Geographical distributions of organic-walled dinoflagellate cysts in surficial sediments of the Benguela upwelling region and their relationship to upper ocean conditions. Progress in Oceanography, 48: 25-72.

Zonneveld, K.A.F., Versteegh, G.J.M., de Lange, G.J., 2001. Palaeoproductivity and postdepositional aerobic organic matter decay reflected by dinofagellate cyst assemblages of the Eastern Mediterranean S1 sapropel. Marine Geology, 172: 181-195.

Zonneveld, K.A.F., Versteegh, G., Kodrans-Nsiah, M., 2008. Preservation and organic chemistry of Late Cenozoic organic-walled dinoflagellate cysts: A review. Marine Micropalentology, 68: 179-197.

Zonneveld, K.A.F., Susek, E., Fischer, G., 2010. Seasonal variability of the organic walled dinoflagellate cyst production in the coastal upwelling region off Cape Blank (Mauritania): a five-year survey Journal of Phycology, 46: 202-215. 


\section{Supplementary Material}

The following data tables are included here.

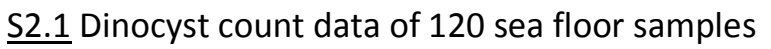

S2.2 NZ-98 count and environmental data 301

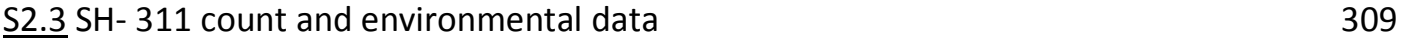

S3.1. Raw dinocyst counts from sediment trap samples 327

S5.1. Dinocyst census counts from MIS11 east Tasman Sea samples 339

S5.2. SST and productivity index values from MIS11 east Tasman Sea samples 345

S5.3. Stacked SST and productivity index values from MIS11 east Tasman Sea samples 347

S6.1. DSDP 594 MIS11 dinocyst counts 349

S6.2. DSDP 594 MIS11 pollen counts 352 


\begin{tabular}{|c|c|c|c|c|c|c|c|c|c|c|c|c|c|c|c|c|}
\hline 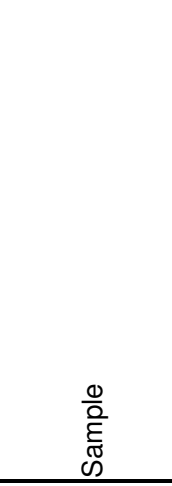 & 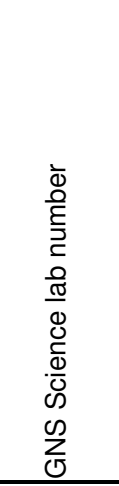 & $\begin{array}{l}E \\
\overline{5} \\
\omega \\
\Phi \\
\stackrel{5}{5} \\
\stackrel{\sigma}{\Sigma}\end{array}$ & 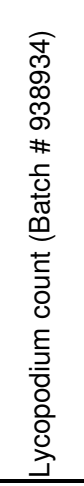 & 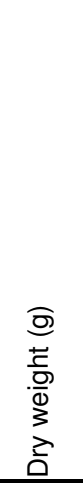 & 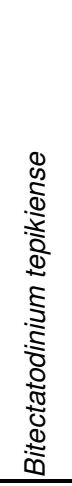 & 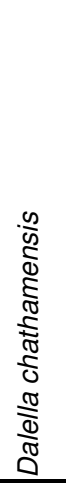 & 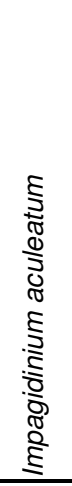 & 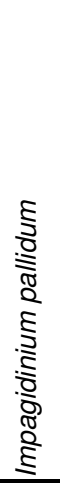 & 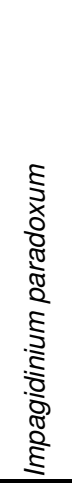 & 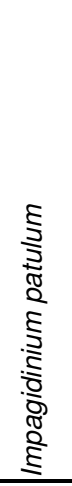 & 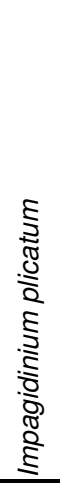 & 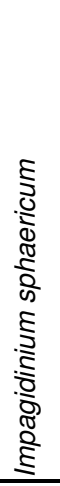 & 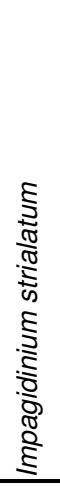 & 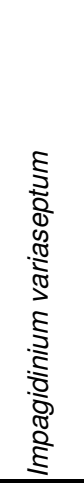 & 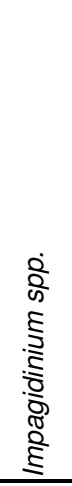 & 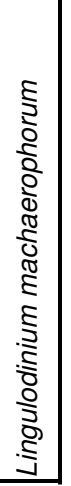 \\
\hline $1172 \mathrm{C}$ & L24193 & 292.5 & 1548 & 3.5 & & 2 & 36 & & 4 & 4 & 2 & 12 & & 11.5 & 3 & \\
\hline $593 \mathrm{~A}$ & L24194 & 301.5 & 1039 & 3.17 & 2 & 4.5 & 135 & 0.5 & 6 & 1.5 & 6 & & 5.5 & 22.5 & 2 & \\
\hline $588 \mathrm{~B}$ & L24195 & 164.75 & 3782 & 2.94 & & & 94 & & 28.5 & 3 & 2 & & 16 & 2 & & \\
\hline 592 & L24196 & 340.25 & 1610 & 3.11 & & & 125 & & 4.5 & 8.5 & $1 \ldots$ & 5 & 2 & 41. & 3 & \\
\hline $1170 \mathrm{C}$ & L24197 & 58.5 & 3508 & 2 & & 3 & 7 & & & 1 & & & 1 & 3 & 2 & \\
\hline $1169 \mathrm{~A}$ & L24198 & 180.5 & 4901 & 3.82 & & 1 & 9 & 5 & 1 & 1 & & & 3 & 2 & & \\
\hline $1171 \mathrm{C}$ & L24199 & 171 & 6402 & 3.69 & & & 6 & & & & & 1 & 3 & & & \\
\hline 590-B & L24200 & 110.25 & 2532 & 3.23 & & & 39 & & 11 & 9 & 6 & & 10 & 3.5 & 1.5 & \\
\hline $1168 \mathrm{C}$ & L24201 & 333.25 & 772 & 3.68 & 10.5 & & 18 & 2 & & 2 & & 18 & & & 2.5 & 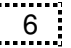 \\
\hline 587 & L24202 & 142.25 & 4650 & 2.52 & 5 & & 38.5 & & 7 & 2 & 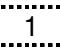 & 2 & 7 & 1 & 3 & $\ddot{4}$ \\
\hline $01 \mathrm{BC}$ & L24203 & 224.25 & 2096 & 2.87 & 13 & 10 & 2 & 3 & & 6.5 & & & & & 6 & \\
\hline $11 \mathrm{BC}$ & L24204 & 16 & 2038 & 1.12 & & 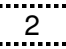 & 13 & "9...". & & & & & & & & \\
\hline 10MC1 & L24205 & 180.75 & 7062 & 1.54 & & 9 & 18 & 5 & 7 & 7 & 13... & & & & & \\
\hline $7 \mathrm{BC}$ & L24206 & 0 & 225 & 2.82 & & & & & & & & & & & & \\
\hline $9 \mathrm{BC}$ & L24207 & 0 & 2100 & 2.87 & & & & & & & & & & & & \\
\hline $02 \mathrm{BC}$ & L24208 & 4.25 & 252 & 1.34 & & & & & & & & & 1 & & 1 & \\
\hline $820 \mathrm{~B}$ & L24209 & 89.5 & 2340 & 1.94 & & & & & & & & & & & & \\
\hline $830 \mathrm{~A}$ & L24210 & 14.5 & 1251 & 1.97 & & & 1 & & & & & & & & 1 & \\
\hline $1119 \mathrm{C}$ & L24211 & 101.25 & 3663 & 2.35 & & 1 & & & 11 & & & & & & 1.25 & \\
\hline $1121 \mathrm{~A}$ & L24212 & 0 & 295 & 1.73 & & & & & & & & & & & & \\
\hline TAN0803-27 & L24213 & 196.25 & 1215 & 1.49 & & 3 & 30.5 & 3.5 & & 2 & & 2 & 1.5 & 2 & 2.5 & \\
\hline TAN0803-9 & L24214 & 302.25 & 579 & 1.67 & … & 1.5 & 14 & & 2 & & & 2 & 3 & & 2 & \\
\hline Q633 & L24215 & 321 & 291 & 1.98 & 2.5 & & 3 & & 3 & & & 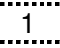 & 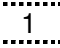 & 8 & 4.5 & \\
\hline H555 & L24216 & 330.25 & 2345 & 3.68 & ............... & 8.5 & 8.5 & 6 & 6 & 4 & & 21 & & & 8.5 & \\
\hline J39 & L24217 & 321.5 & 770 & 5.74 & & ...... & 205 & & 21 & 6.5 & 11. & 6 & 6 & 25 & 6 & \\
\hline $\mathrm{J} 1037$ & L24218 & 114.5 & 1983 & 3.59 & & & & & & & & 2 & & 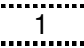 & 1.5 & \\
\hline F150 & L24219 & 367.25 & 276 & 5.2 & & 0.5 & & & 7 & 1. & & -1... & & & 2.25 & \\
\hline $\mathrm{J} 668$ & L24220 & 198.5 & 2420 & 5.72 & & & 13 & & 5 & 9.5 & & 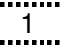 & & 0.5 & & \\
\hline G944 & L24221 & 224.75 & 552 & 4.87 & & & 39 & & 7 & 15 & & 2 & 2 & 2 & 2 & \\
\hline J484 & L24222 & 313.25 & 684 & 3.97 & & & 1 & 29 & & & & 5 & & & 4.25 & \\
\hline J1049 & L24223 & 303 & 898 & 5.07 & & 10 & 3 & 1 & 5 & 5 & & 2 & & & 2.75 & \\
\hline S569 & L24224 & 2.25 & 2070 & 3.18 & & & 31 & & & 1 & & & & & 0.25 & \\
\hline S0136-11 & L24225 & 312.5 & 305 & 3.45 & & 2 & 70 & & 11 & & 1 & 71 & & 3 & 1.5 & \\
\hline Q703 & L24226 & 300.5 & 1139 & 3.31 & & 0.25 & 2 & & 5 & & 1 & & & 6.5 & & \\
\hline Q722 & L24227 & 324.5 & 940 & 4.22 & & & 0.5 & & & & & & & 2 & 1 & \\
\hline SR223 & L24286 & 3 & 321 & 1.24 & & & .....". & & & & & 1 & & & 11 & \\
\hline SR177 & L24287 & 5.25 & 270 & 1.33 & & & & & & & 1 & ב1.... & & & & \\
\hline SR167 & L24288 & 6.25 & 93 & 1.41 & & & (1...". & & & & & & & & & \\
\hline SR156 & L24289 & 51 & 789 & 1.09 & & & 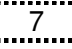 & & 3 & 2.5 & & '13. & & 1 & & \\
\hline 06BC & L24290 & 0.5 & 1220 & 1.96 & & & & & & & & & & & & \\
\hline $08 \mathrm{MC} 1$ & L24291 & 9 & 3464 & 0.34 & & 1 & 2 & 1 & & & & & & & & \\
\hline $05 \mathrm{MC1}$ & L24292 & 1.5 & 1685 & 0.37 & & & & & & & & & & & & \\
\hline $07 \mathrm{MC} 1$ & L24293 & 53.5 & 2695 & 0.45 & & 1 & & 1 & 2 & & & & & & & \\
\hline $4 \mathrm{BC}$ & L24294 & 0.5 & 474 & 1.99 & & & & & & & & & & & 0.5 & \\
\hline $10 \mathrm{BC}$ & L24295 & 2 & 947 & 1.03 & & & & 2 & & & & & & & & \\
\hline $1120 \mathrm{C}$ & L24296 & 208 & 2000 & 1.45 & & 2 & & 7 & & 2 & & 2 & & 1 & 4.25 & \\
\hline $834 \mathrm{~B}$ & L24297 & 15 & 2518 & 0.67 & & & 4 & & 1 & 1 & & 2 & 4.5 & & & \\
\hline $813 \mathrm{~A}$ & L24298 & 0 & & 1.58 & & & & & & & & & & & & \\
\hline $824 \mathrm{~B}$ & L24299 & 7 & 617 & 1.54 & & & 1 & & & & & & & & & \\
\hline $1124 \mathrm{~A}$ & L24300 & 9 & 292 & 1.31 & & & 3 & & & & & & & & 1 & \\
\hline
\end{tabular}




\begin{tabular}{|c|c|c|c|c|c|c|c|c|c|c|c|c|c|c|c|}
\hline 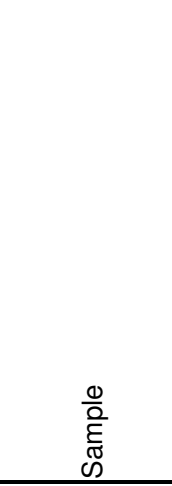 & 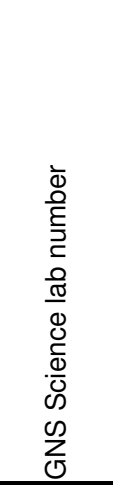 & 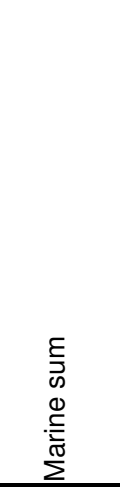 & 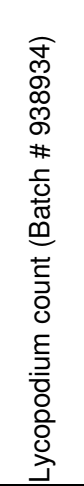 & 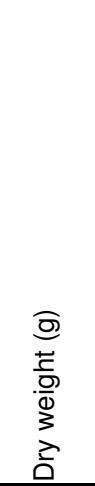 & 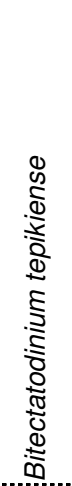 & 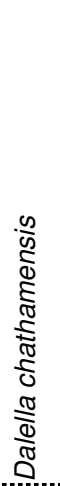 & 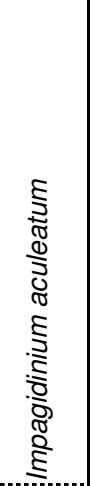 & 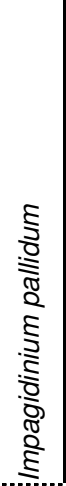 & 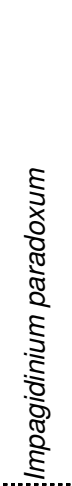 & 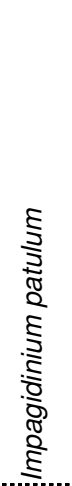 & 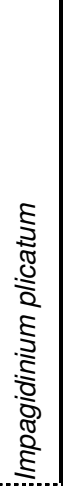 & 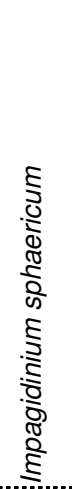 & 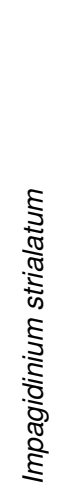 & 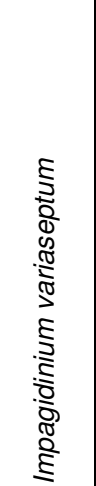 & 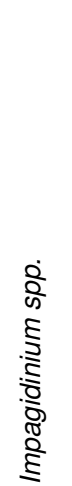 \\
\hline $1122 \mathrm{C}$ & L24301 & 14 & 237 & 1.84 & & & & & & & & & & & 0.5 \\
\hline $823 \mathrm{~B}$ & L24302 & 5.5 & 191 & 1.78 & & & 31 & & & & & & & & \\
\hline $840 \mathrm{~B}$ & L24303 & 28.5 & 3332 & 1.91 & & & 6 & & 3 & & & & 2 & & \\
\hline $822 \mathrm{~A}$ & L24304 & 15.5 & 337 & 1.34 & & & 11 & & & & & & & & \\
\hline 1123B & L24305 & 10.5 & 377 & 0.98 & & & 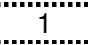 & & & & & & 1 & & \\
\hline TAN803-127 & L24307 & 5 & 1401 & 0.49 & & & 11 & & & 1 & & & & & \\
\hline TAN803-40 & L24308 & 92.25 & 2323 & 1.03 & & 1 & 12 & & & 3 & & 2 & & & 2.75 \\
\hline SO136-003 & L24309 & 195 & 377 & 3.2 & & 5 & 62.5 & & & 3 & & & 1 & 8 & 2 \\
\hline Q723 & $\mathrm{L} 24310$ & 235.75 & 318 & 3.51 & & & 39 & & & 2 & & 4.25 & 2 & 12 & \\
\hline Q699 & L24311 & 248.75 & 250 & 4.33 & & 3 & 167.5 & & & 1.5 & 0.5 & & & 3.5 & \\
\hline J50 & L24312 & 203 & 751 & 2.89 & 2 & & 117 & & 2 & 7 & & ב1... & 3.5 & 21 & 5 \\
\hline $\mathrm{J} 51$ & L24313 & 176.25 & 927 & 3.48 & & & 107.5 & & 5 & & & & 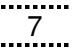 & 8.5 & 3 \\
\hline $\mathrm{X} 250$ & L24314 & 117 & 1026 & 2.48 & & & 33 & & 111 & 111.5 & & 3 & & 3.5 & 7 \\
\hline Q636 & L24315 & 91.75 & 134 & 2.64 & & & 5 & & & 1.5 & 1. & & & ....." & ..... \\
\hline S631 & L24316 & 31.25 & 167 & 3.82 & & 13... & 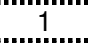 & & & & & & & & \\
\hline U203 & L24317 & 137.65 & 2697 & 2.45 & & & 48.9 & & 31 & 3 & 1. & & 14.5 & 6 & 3 \\
\hline P933 & L24318 & 318.25 & 2638 & 2.6 & & & 102 & & & 5.5 & 4.5 & 2 & ...... & 13.5 & 2.5 \\
\hline G820 & L24319 & 210.75 & nil & 3.65 & & 1. & 72.5 & & 12 & 12.5 & 11 & & 8.5 & 10.25 & 3 \\
\hline F88 & L24320 & 24.75 & 163 & 3.07 & & & & & & & & & & & \\
\hline $\mathrm{J} 21$ & L24321 & 246.5 & 273 & 2.42 & & & 25 & & 4 & & & & & 16.5 & 5.75 \\
\hline 1168 & L24322 & 86.25 & 7900 & 2.79 & & & 47 & & 5 & & & 1 & 15.5 & 1 & 5.25 \\
\hline U614 & L24323 & 16.25 & 1158 & 2.07 & & & 4. & & 4 & 2 & ㄲ... & & 3 & & \\
\hline G977 & L24324 & 10.5 & 3.34 & 3.35 & & & 5 & & & 2 & & & & & \\
\hline 1171 & L24325 & 2 & 2110 & 1.9 & & & & & & 13 & & & & & \\
\hline Z3230 & L24326 & 0 & 3190 & 1.31 & & & & & & & & & & & \\
\hline P937 & L24327 & 207.5 & 2163 & 2.31 & & 3 & 128 & 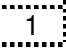 & 5 & 1.5 & & 1 & 3 & 10 & 3 \\
\hline $21-209 A$ & L24328 & 0 & 1212 & 2.39 & & & & & & & & & & & \\
\hline $70 \mathrm{PC}$ & L24329 & 0 & 336 & 0.87 & & & & & & & & & & & \\
\hline $59 P C$ & L24330 & 10.5 & 3840 & 0.94 & & & 5 & & 3.5 & & & & & & \\
\hline 57PC & L24331 & 18 & 2475 & 1.44 & & & 11 & & & 3 & & & 2 & & \\
\hline $54 \mathrm{PC}$ & L24332 & 0 & & 0.5 & & & & & & & & & & & \\
\hline 1125B & L24506 & 210 & 419 & 1.66 & & & 2 & & & & & & & & \\
\hline $\mathrm{H} 347$ & L24575 & 279 & 251 & 14.16 & & & 2 & & & & & & & & \\
\hline H534 & L24576 & 35.5 & 156 & 6.64 & & 2 & 2 & 1 & & & & & & & 0.5 \\
\hline H562 & L24577 & 103.75 & 112 & 14.34 & & & & 1 & & & & & & & \\
\hline A811 & L24578 & 213 & 175 & 16.71 & & & & & & & & & & & \\
\hline A812 & L24579 & 109.75 & 98 & 14.11 & & & & & & & & & & & \\
\hline H531 & L24580 & 18 & 35 & 21.27 & & & & & & & & & & & \\
\hline $\mathrm{H} 533$ & L24581 & 118.5 & 203 & 15.24 & & an.". & '1..." & & 6 & & & -1.... & & & 1.5 \\
\hline S632 & L24582 & 145 & 544 & 11.2 & & 7 & 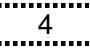 & 2 & 9 & & & 4 & & & 2 \\
\hline G678 & L24583 & 202.75 & 145 & 18.59 & 2 & & 1 & 1. & 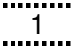 & & & 1. & & & \\
\hline C169 & L24584 & 361.75 & 86 & 18.35 & & & 11.5 & & 2 & & & 3 & & 4 & 2 \\
\hline$\overline{C 266}$ & L24585 & 8 & 3 & 18.99 & & & & & & & & & & & \\
\hline $\mathrm{C} 275$ & L24586 & 0 & & 17.49 & & & & & & & & & & & \\
\hline C293 & L24587 & 65.25 & 66 & 17.62 & & & & & & & & & & & \\
\hline E405 & L24588 & 421.75 & 618 & 16.89 & & & 2 & 3.5 & & & & 4 & & & 4.25 \\
\hline$\overline{E 411}$ & L24589 & 214.75 & 283 & 14.91 & & 4.5 & 5.5 & 6.5 & 1 & & & 7 & & & 2.25 \\
\hline$\overline{E 441}$ & L24590 & 29.25 & 27 & 17.19 & & & 2 & 4 & & & & & & & \\
\hline E453 & L24591 & 332.25 & 73 & 15.04 & an." & & 29 & & 2 & 0.25 & 1.5 & 2 & 5 & 11 & 0.5 \\
\hline E544 & L24592 & 379 & 554 & 7.05 & & & 9 & & 11.5 & 12.5 & 2 & 2 & 2 & 6.5 & 0.25 \\
\hline
\end{tabular}




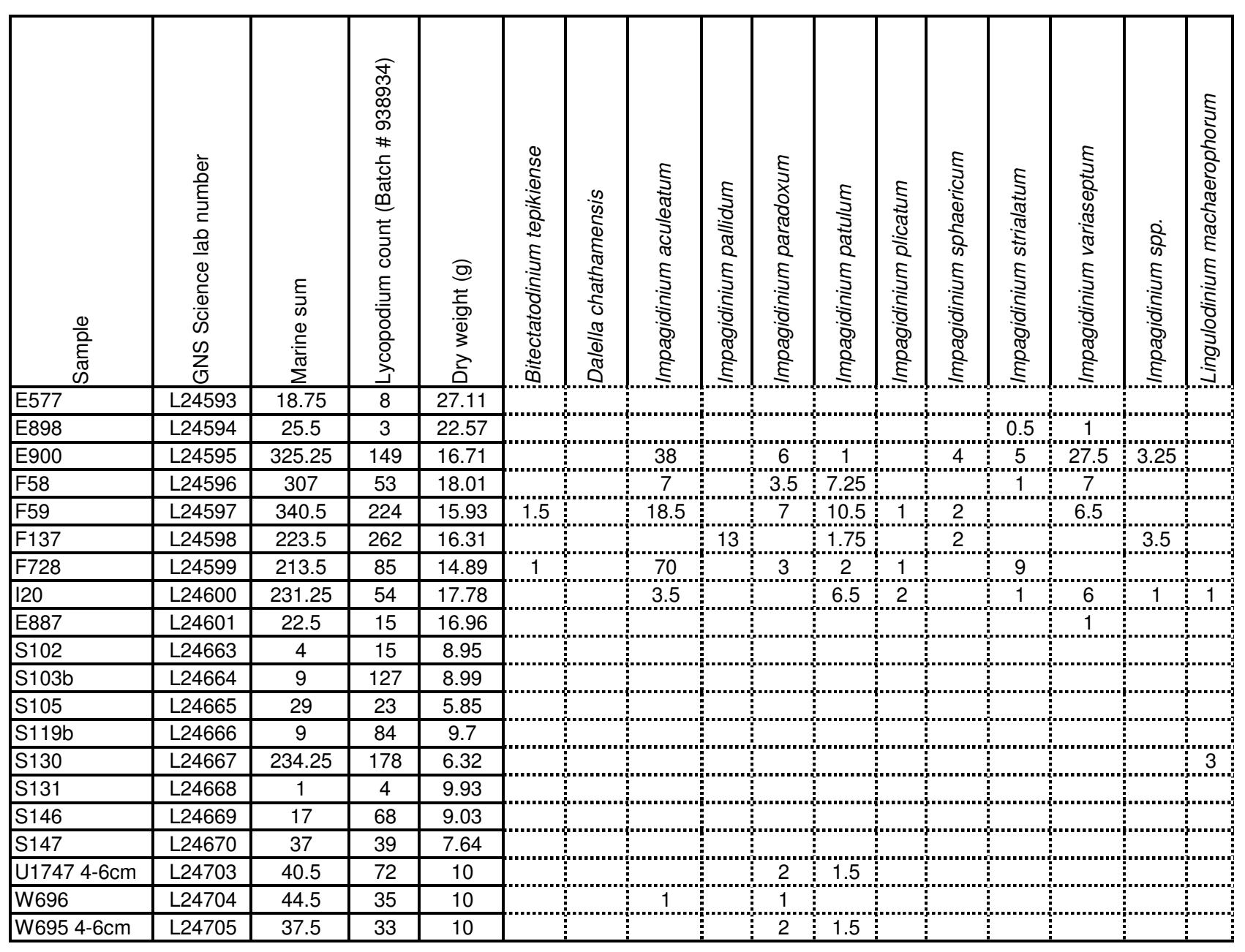




\begin{tabular}{|c|c|c|c|c|c|c|c|c|c|c|c|c|c|c|c|c|c|c|}
\hline $\begin{array}{l}\frac{0}{O} \\
\stackrel{\tilde{E}}{\mathbb{N}} \\
\stackrel{\infty}{0}\end{array}$ & 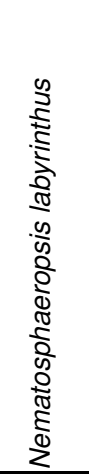 & 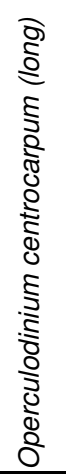 & 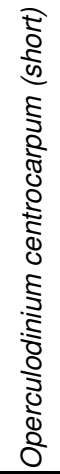 & 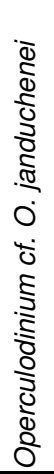 & 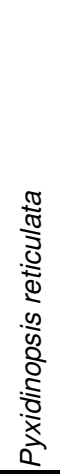 & 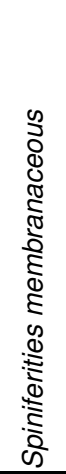 & 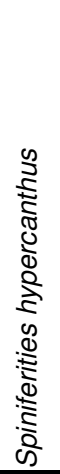 & 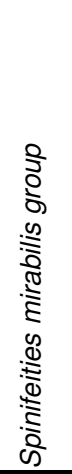 & 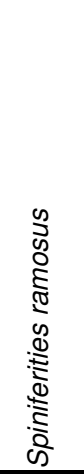 & 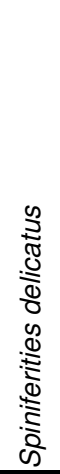 & 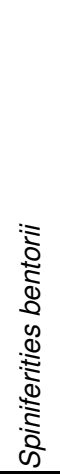 & 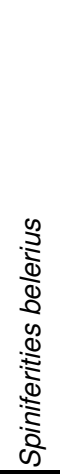 & 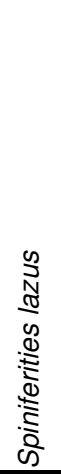 & 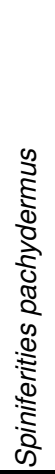 & 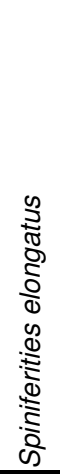 & 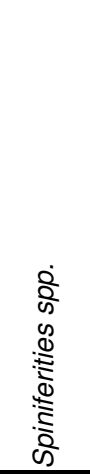 & 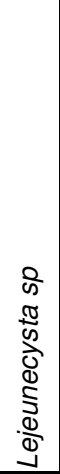 & 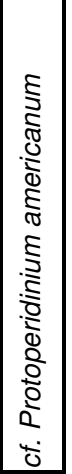 \\
\hline $1172 \mathrm{C}$ & 98 & 38 & & & 15 & & & 7.5 & 12 & & & & & & & 3.5 & & \\
\hline $593 \mathrm{~A}$ & 100 & 1 & & & 4 & & 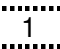 & 2 & 0.5 & & & & & & & 5 & & \\
\hline $588 \mathrm{~B}$ & 4. & 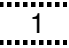 & & '.1... & 6 & & & $\ldots$. & 6 & & & & & & & & & \\
\hline 592 & 69 & 16 & & 13 & 6 & & 5 & 28.5 & 5 & & 3 & & & & & 13.75 & & \\
\hline $1170 \mathrm{C}$ & 33 & 2 & & & 5.5 & & & & & & & & & & & & & \\
\hline $1169 \mathrm{~A}$ & 141 & 4.5 & 1 & & 5 & & & 1 & & & & & & 1 & & 4 & & \\
\hline $1171 \mathrm{C}$ & 153.5 & 1 & & & 1 & & & 1 & & & & & & & & 2 & & \\
\hline 590-B & 9 & 7.5 & 1. & & 2 & & & 3 & & & & & & & & 2.75 & & \\
\hline $1168 \mathrm{C}$ & 46 & 1 & & & 8 & 1 & & 12 & 59.5 & & & 2 & & & 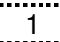 & 6.75 & & \\
\hline 587 & & 8 & 2 & 1 & & 1 & 1 & 5 & 29 & & & & & 4 & & 5.25 & & \\
\hline $01 \mathrm{BC}$ & 146.5 & & & & 1 & & & & 1 & & & & & & & 0.25 & & \\
\hline $11 \mathrm{BC}$ & ?...". & & & & & & & & '.."' & & & & & & & $\cdots$ & & \\
\hline $10 \mathrm{MC} 1$ & 41. & "3...". & & & ?....... & & 31 & 2 & 1.5 & & & & & & & 2.75 & & \\
\hline $7 \mathrm{BC}$ & & & & & & & & & & & & & & & & & & \\
\hline $9 \mathrm{BC}$ & & & & & & & & & & & & & & & & & & \\
\hline $02 \mathrm{BC}$ & 1 & & & & & & & & (n....... & & & & & & & 0.25 & & \\
\hline $820 \mathrm{~B}$ & $\cdots$. & 8.5 & & & & 8 & & 1 & 41. & & & & & & 1. & 2 & & \\
\hline $830 \mathrm{~A}$ & & & & & & & & & 3 & & & & & & & .... & & \\
\hline $1119 \mathrm{C}$ & 6 & 1.5 & & & 1 & & & & 11 & & & & & & & 1 & & \\
\hline $1121 \mathrm{~A}$ & & & & & & & & & & & & & & & & & & \\
\hline TAN0803-27 & 85 & $\dddot{1}$ & & & 1 & & & 1 & 6.5 & & & & & & & 2.75 & 1 & \\
\hline TAN0803-9 & 79 & 7 & $\cdots$ & 1. & 2 & & & & 29 & 1 & 1. & & & & & 5.75 & $\cdots$ & \\
\hline Q633 & (3.... & 31 & & 13 & 1. & 2 & 2 & 15.5 & 125.5 & & & & & & & 38.5 & 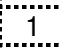 & \\
\hline $\mathrm{H} 555$ & 128 & 77 & ..... & & 7 & & & 27 & ?...".... & & & & & & & 17.75 & & \\
\hline $\mathrm{J} 39$ & 19 & 8 & 0.5 & 11 & 1 & & 1 & 6 & 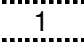 & & & & & & & 6.5 & & \\
\hline $\mathrm{J} 1037$ & 1 & 18 & 3 & & & 1 & & & 20 & & & & & & & ;.…… & 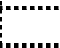 & \\
\hline $\mathrm{F} 150$ & 73 & 113 & & 5.5 & '?'" & 13 & 3 & 8 & 6 & & 3 & & & & & 30 & 13. & \\
\hline J668 & 1 & 6 & & & 1 & & 5.5 & 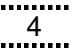 & 17 & & 1. & & & & & 12 & & \\
\hline G944 & 58 & 74 & 1.5 & & .... & 1 & & 2 & 2 & & 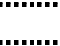 & & & & 2 & 11.25 & & \\
\hline $\mathrm{J} 484$ & 236.5 & & & & 2 & & & 1.5 & & & 4 & & & & & 9 & & \\
\hline J1049 & 148 & 21 & & & 3 & 0.5 & 1 & 15 & 11.5 & & 4 & & & & & 9.25 & & \\
\hline S569 & & & & & & & & & & & & & & & & .... & & \\
\hline S0136-11 & 51 & 3 & 1 & 1 & 1 & & & & 1 & & & & & & & 0.5 & 1 & \\
\hline Q703 & 24 & 72 & 1 & & & 8 & & 2.25 & 88.5 & & & & & & 3 & 36.5 & & \\
\hline Q722 & 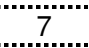 & 60 & 5 & & & 2 & & 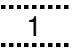 & 165 & & 6 & & & & 1 & 7 & & \\
\hline SR223 & & & & & & & & & & & & & & & & & & \\
\hline SR177 & & 31. & & & & & & & 2 & & & & & & & 0.25 & & \\
\hline SR167 & & 1.5 & & & & & & & 3.25 & & & & & & & 0.5 & & \\
\hline SR156 & & 7 & & & & 2 & ....2. & 2 & 12.5 & 1 & & & & & & 5 & & \\
\hline $06 \mathrm{BC}$ & & & & & & & & & & & & & & & & & & \\
\hline $08 \mathrm{MC} 1$ & 1 & & & & & & & & & & & & & & & & & \\
\hline $05 \mathrm{MC} 1$ & & & & & & & & & & & & & & & & & & \\
\hline $07 \mathrm{MC1}$ & 1 & & & & & & & & & & & & & & & & & \\
\hline $4 \mathrm{BC}$ & & & & & & & & & & & & & & & & & & \\
\hline $10 \mathrm{BC}$ & & & & & & & & & & & & & & & & & & \\
\hline $1120 \mathrm{C}$ & 108 & & & & 13 & 0.5 & 8 & 4.75 & 2 & & 4. & & & & & 32.5 & & \\
\hline $834 \mathrm{~B}$ & & & & & & & & & $\ldots$ & & & & & & & & & \\
\hline $813 \mathrm{~A}$ & & & & & & & & & & & & & & & & & & \\
\hline $824 \mathrm{~B}$ & & 13. & & & & & & & 2 & & & & & & & & & \\
\hline $1124 \mathrm{~A}$ & & & & & & & & & & & & & & & & & & \\
\hline
\end{tabular}




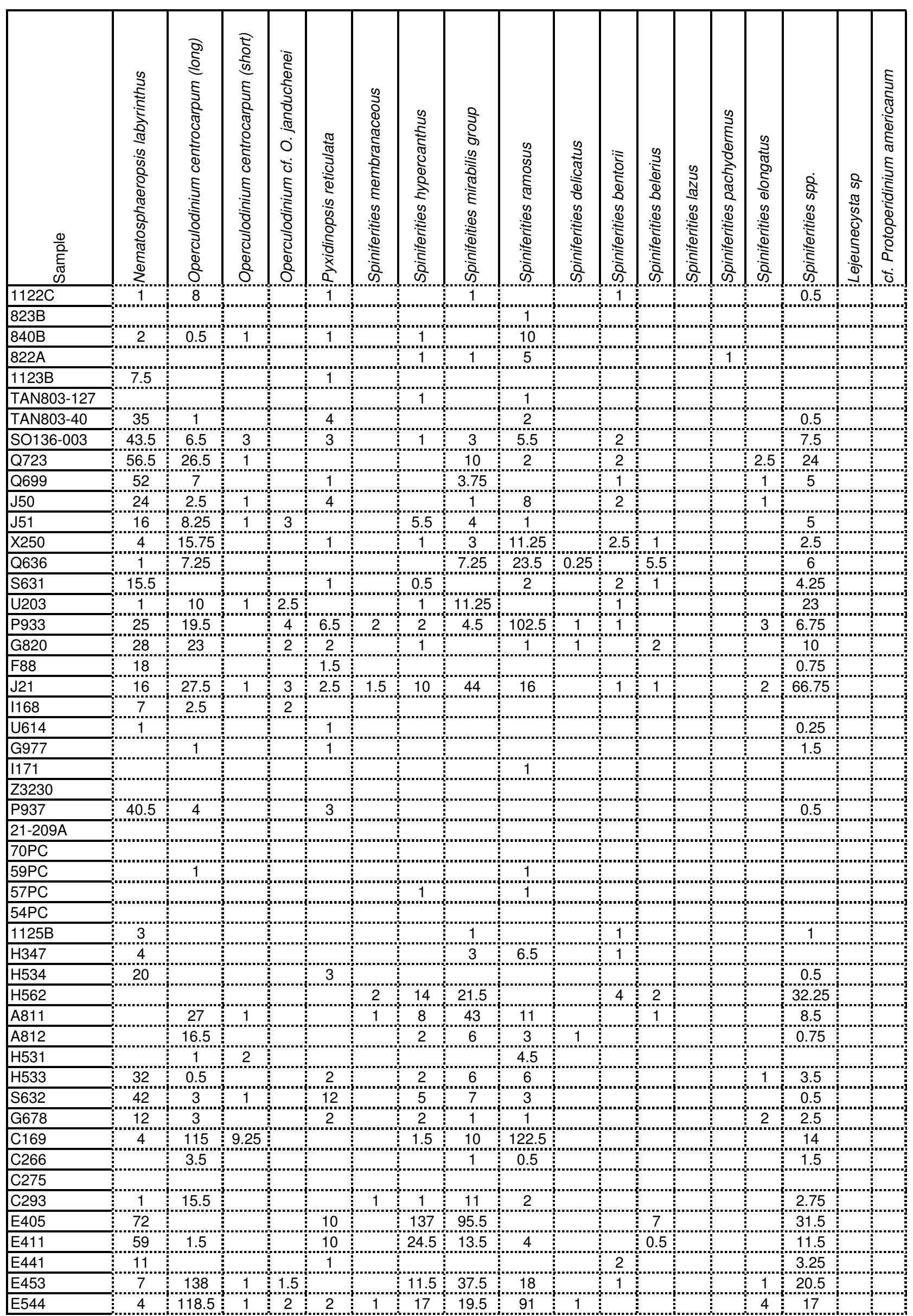




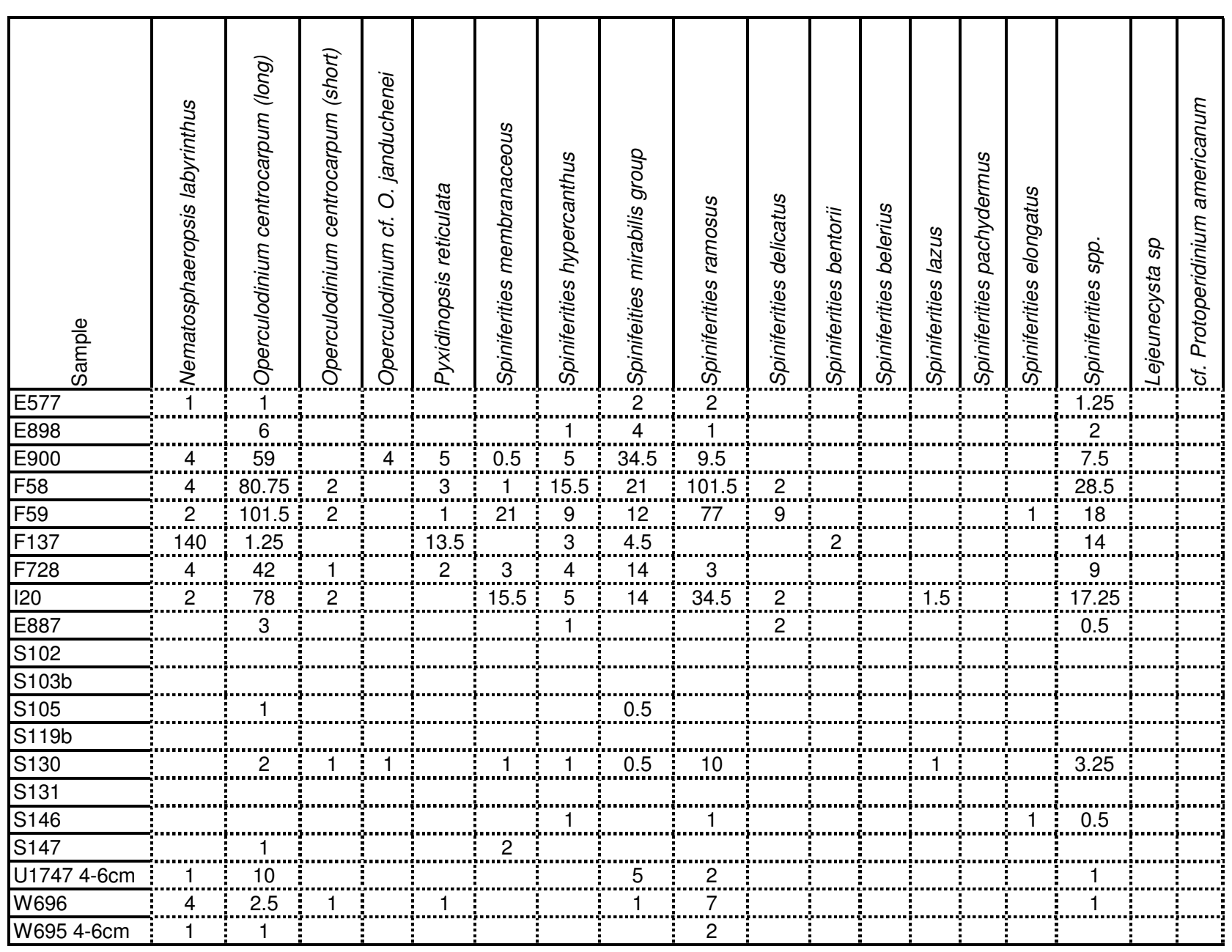




\begin{tabular}{|c|c|c|c|c|c|c|c|c|c|c|c|c|c|c|c|c|c|c|c|}
\hline$\frac{\frac{0}{O}}{\stackrel{\Xi}{E}}$ & 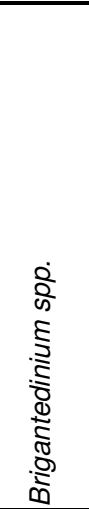 & 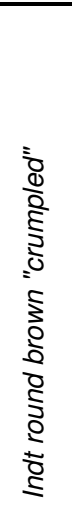 & 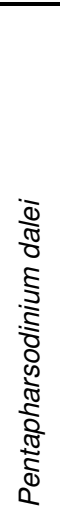 & 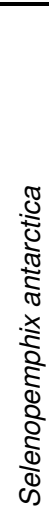 & 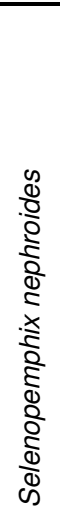 & 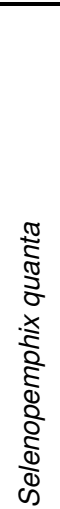 & $\begin{array}{l}\frac{2}{2} \\
\text { d } \\
\frac{x}{2} \\
\frac{2}{2} \\
\frac{1}{d} \\
\frac{0}{2} \\
\frac{D}{d} \\
\frac{d}{d}\end{array}$ & 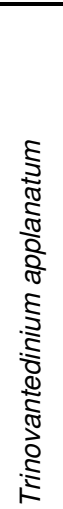 & 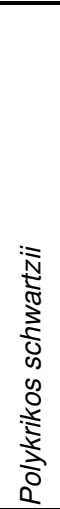 & 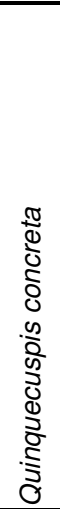 & 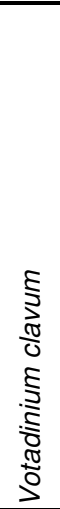 & 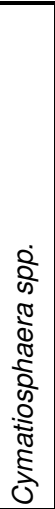 & 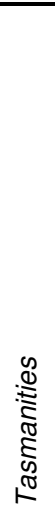 & 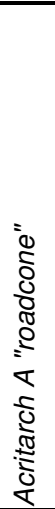 & 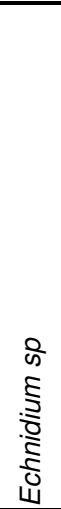 & 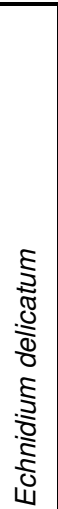 & 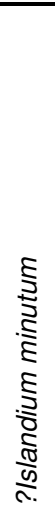 & 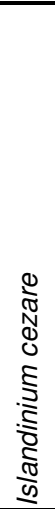 & 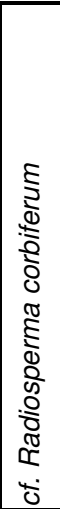 \\
\hline $1172 \mathrm{C}$ & 31 & & & & & 11 & & & 1 & 1 & & & & & & & & & \\
\hline $593 \mathrm{~A}$ & 0.5 & & $\cdots$ & & & & 1 & & & & & & & & & & & & \\
\hline $588 \mathrm{~B}$ & & & 1.25 & & & & & & & & & & & & & & & & \\
\hline 592 & 2 & & & & 1 & & & & & & & & & & & & & & \\
\hline $1170 \mathrm{C}$ & 1 & & & & & & & & & & & & & & & & & & \\
\hline $1169 \mathrm{~A}$ & & & & & & & & & & & & & & & & & & & \\
\hline $1171 \mathrm{C}$ & 1.5 & & & & 1 & & & & & & & & & & & & & & \\
\hline 590-B & 5 & & & & & & & & & & & & & & & & & & \\
\hline $1168 \mathrm{C}$ & 125 & & & 1 & 1 & 1 & & 3 & & & & & & & & 6 & & & \\
\hline 587 & 3.5 & & & & & & & & & & & 2 & & & & & & & \\
\hline $01 \mathrm{BC}$ & 32 & & & 3 & & & & & & & & & & & & & & & \\
\hline $11 \mathrm{BC}$ & & & & ......... & & & & & & & & & & & & & & & \\
\hline $10 \mathrm{MC1}$ & 28.5 & & & 6 & & & 31 & & & & & & & & & & & & \\
\hline $7 \mathrm{BC}$ & & & & & & & , & & & & & & & & & & & & \\
\hline $9 \mathrm{BC}$ & & & & & & & $\ldots$ & & & & & & & & & & & & \\
\hline 02BC & & & & & & & 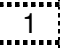 & & & & & ..... & & & & & & & \\
\hline $820 \mathrm{~B}$ & 24 & & $\ldots$ & & & & & & & & & 2 & & 1 & & & & & \\
\hline $830 \mathrm{~A}$ & 6.5 & & & & & & & & & & & 2 & & 1 & & & & & \\
\hline $1119 \mathrm{C}$ & 43 & & & & 1 & 29 & & 1.5 & & & & 2 & & 1 & & & & & \\
\hline $1121 \mathrm{~A}$ & & & & & & ......... & & & & & & & & $\cdots \cdot$ & & & & & \\
\hline TAN0803-27 & 42 & & & & & 6 & 1 & & & & & & & 1 & & 1 & & & \\
\hline TAN0803-9 & 90.5 & 10 & & 2 & 4. & 8.5 & & 8 & 2 & & & & 1 & 1 & & 6 & 15 & & \\
\hline Q633 & 41 & & & & 8.5 & 13 & & $\cdots$ & & & & 2 & & ...... & & & 1 & & \\
\hline H555 & 7 & & & & & & & $\cdots$ & & & & & 13 & & & & & & \\
\hline J39 & & & & & & & & ... & & & & & & (..... & & & & & \\
\hline J1037 & 53 & & & & 9 & & & $\cdots$ & & & & $\cdots$ & & 2 & 2 & & & & \\
\hline F150 & 60 & & & & ...." & $\cdots 4$ & & 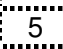 & & & & & & 19 & 5 & & & & \\
\hline J668 & 78 & 13.5 & & & 14.5 & 3 & & 3 & 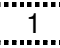 & 4. & & & & & 5 & & & & \\
\hline G944 & 1 & & & & & & & 2 & & & & & & & & & & & \\
\hline J484 & 8 & 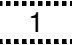 & & & & & & ;... & & & & & & 12 & & & & & \\
\hline J1049 & 45 & 12 & & & & & & & & & & & & 4 & & & & & \\
\hline S569 & & & & & & & & & & & & & & & & & & & \\
\hline S0136-11 & 160.5 & 6 & & & 3 & & & 2 & 1 & & & & & & 1 & & & & \\
\hline Q703 & 26.5 & & & & 6 & 2 & & 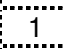 & & & & & & 3 & & & 12 & & \\
\hline Q722 & 32.5 & 10 & & & 2 & & & 2.5 & & ................ & 3 & & & & 12 & 2 & & & 1 \\
\hline SR223 & & & & & & & & & & & & & & & & & & & \\
\hline SR177 & & & & & & & & & & & & & & & & & & & \\
\hline SR167 & & & & & & & & & & & & & & & & & & & \\
\hline SR156 & & & '"3.". & & & & & 3 & & & & & & & & & & & \\
\hline 06BC & 0.5 & & & & & & & & & & & & & & & & & & \\
\hline $08 \mathrm{MC} 1$ & & & & 4 & & & & & & & & & & & & & & & \\
\hline $05 \mathrm{MC1}$ & & & & 1.5 & & & & & & & & & & & & & & & \\
\hline $07 \mathrm{MC1}$ & 13.5 & & & 35 & & & & & & & & & & & & & & & \\
\hline $4 \mathrm{BC}$ & & & & & & & & & & & & & & & & & & & \\
\hline $10 \mathrm{BC}$ & & & & & & & & & & & & & & & & & & & \\
\hline $1120 \mathrm{C}$ & 10 & 3 & & 1 & & & & & & & & & & 3 & & & & & \\
\hline $834 \mathrm{~B}$ & 0.5 & & & & & & & & & & & $\cdots$ & & & & & & & \\
\hline $813 \mathrm{~A}$ & & & & & & & & & & & & & & & & & & & \\
\hline $824 \mathrm{~B}$ & 1.5 & & 0.5 & & & & & & 13 & & & & & & & & & & \\
\hline $1124 \mathrm{~A}$ & 5 & & & & & & & & & & & & & & & & & & \\
\hline
\end{tabular}




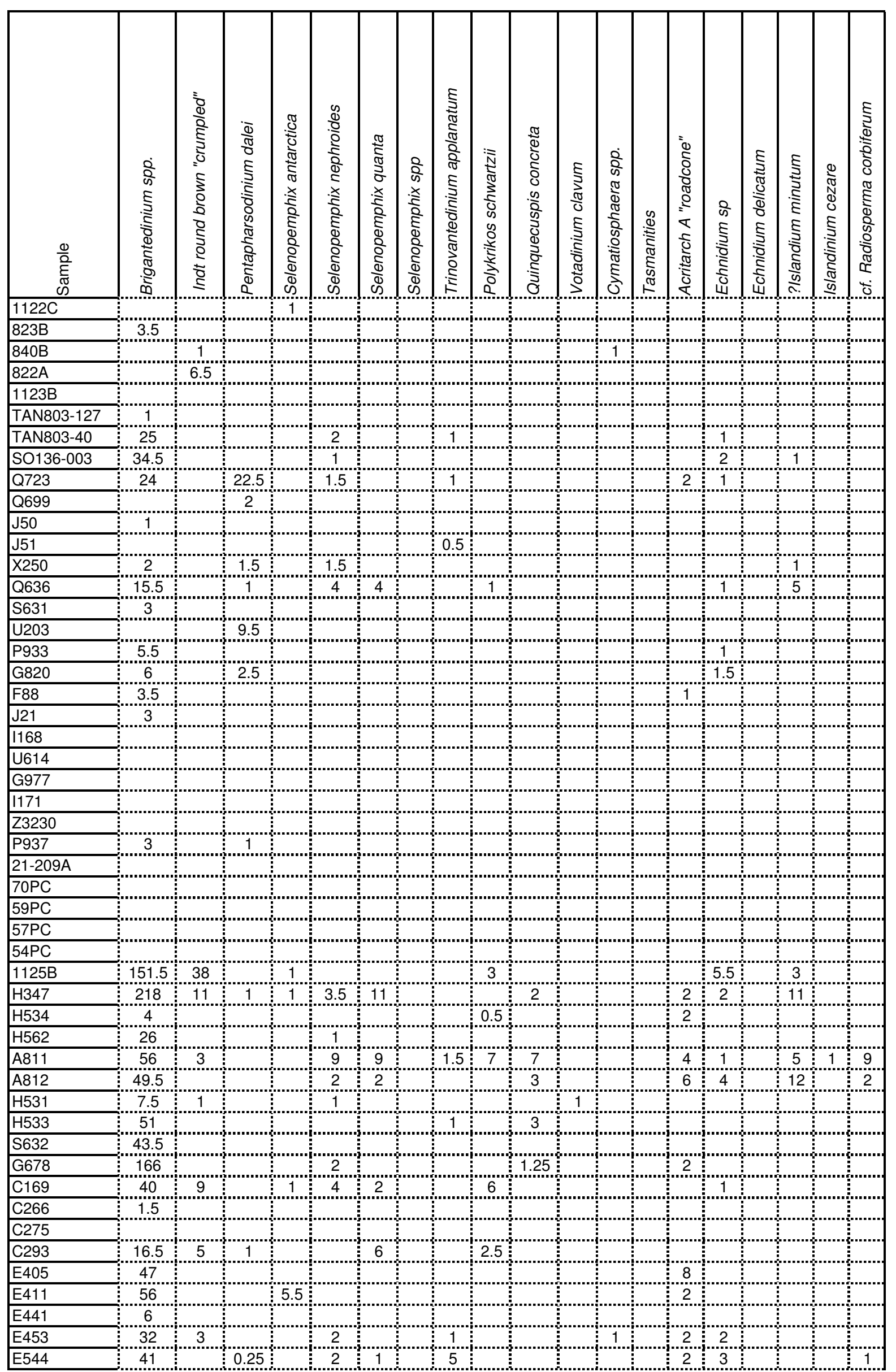




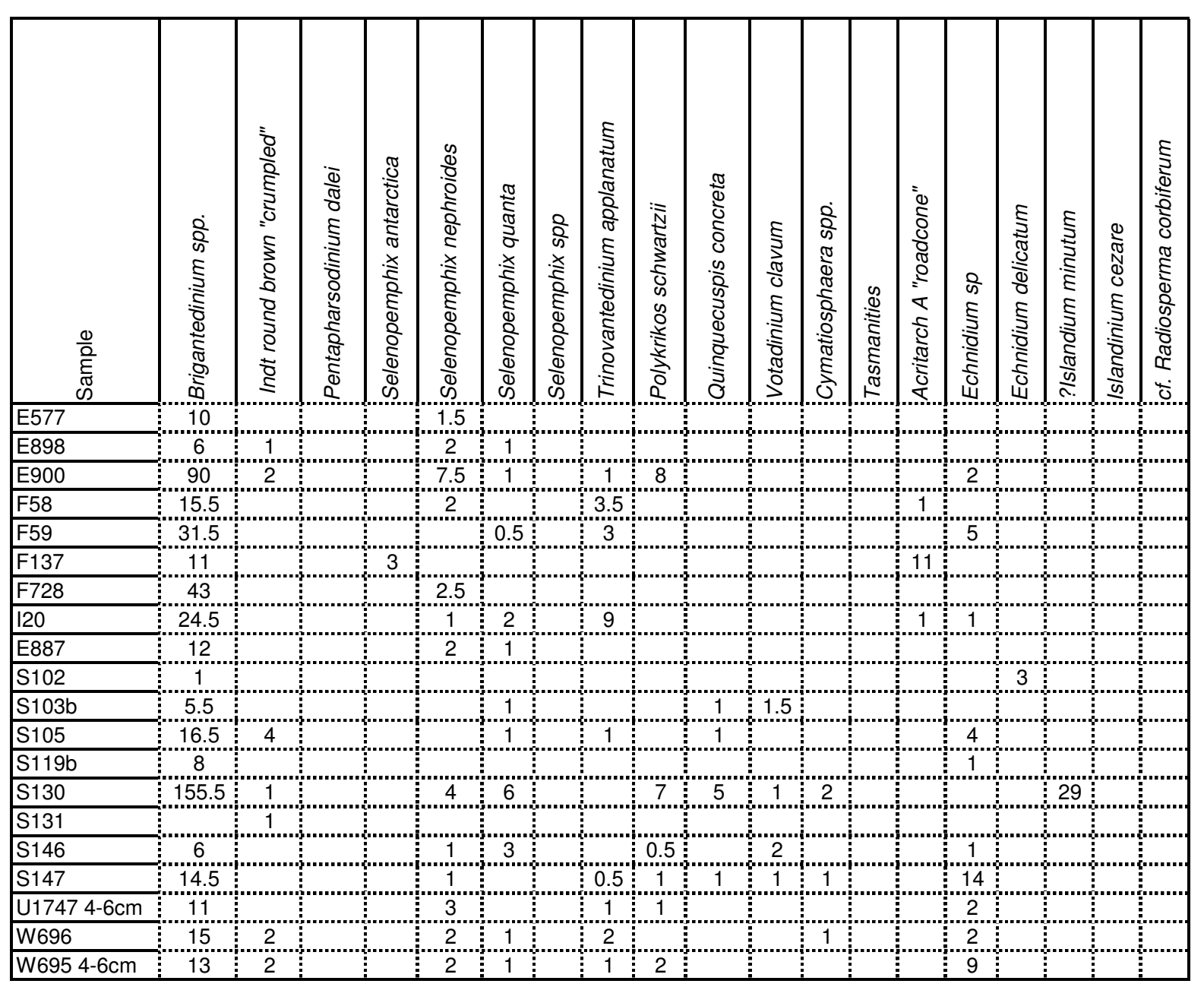




\begin{tabular}{|c|c|c|c|c|c|c|c|c|c|c|c|c|c|c|c|c|c|}
\hline $\begin{array}{l}\stackrel{0}{E} \\
\stackrel{\pi}{z}\end{array}$ & 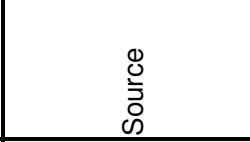 & 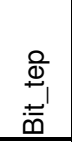 & $\begin{array}{l}\frac{\pi}{\tilde{T}} \\
\frac{\bar{U}}{1} \\
\frac{\pi}{\widetilde{\sigma}} \\
\end{array}$ & $\begin{array}{l}\overline{\bar{D}} \\
\tilde{\sigma}_{1} \\
\stackrel{\varrho}{\underline{\xi}} \\
\end{array}$ & 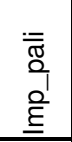 & $\begin{array}{l}\frac{\pi}{\pi} \\
\stackrel{0}{\Omega} \\
\stackrel{0}{E} \\
\underline{\underline{E}}\end{array}$ & 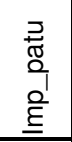 & $\begin{array}{l}\frac{\text { 음 }}{2} \\
\text { 을 } \\
\underline{\underline{E}}\end{array}$ & $\begin{array}{l}\frac{\widetilde{c}}{c} \\
\frac{0}{\infty} \\
\stackrel{0}{\mid} \\
\underline{\underline{E}}\end{array}$ & 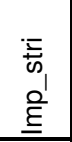 & 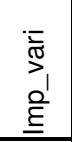 & 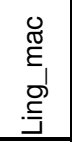 & $\begin{array}{l}\frac{\widehat{a}}{\sigma} \\
\frac{\varepsilon}{\varepsilon} \\
\frac{0}{z}\end{array}$ & $\begin{array}{l}- \\
+ \\
\mathbb{D}_{0} \\
0 \\
0 \\
0\end{array}$ & $\begin{array}{l}\infty \\
D_{1} \\
\tau_{0}^{\prime} \\
0 \\
0 \\
0\end{array}$ & $\begin{array}{l}\bar{\Phi} \\
\frac{\pi}{\bar{n}} \\
\overline{.}\end{array}$ & 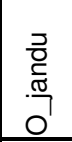 \\
\hline 2_Cro & ouch et al. 2010 & 0.00 & 0.00 & 0.08 & 0.00 & 0.00 & 0.07 & 0.00 & 0.01 & 0.00 & 0.01 & 0.00 & 0.10 & 0.00 & 0.00 & 0.00 & 0.00 \\
\hline 3_Cro & rouch et al. 2010 & 0.00 & 0.00 & 0.12 & 0.00 & 0.01 & 0.04 & 0.00 & 0.02 & 0.03 & 0.03 & 0.00 & 0.11 & 0.19 & 0.00 & 0.00 & 0.00 \\
\hline 8_Cro & Crouch et al. 2010 & 0.00 & 0.00 & 0.20 & 0.00 & 0.00 & 0.05 & 0.02 & 0.05 & 0.00 & 0.04 & 0.00 & 0.06 & 0.18 & 0.02 & 0.00 & 0.00 \\
\hline 9_Cro & rouch et al. 2010 & 0.00 & 0.00 & 0.00 & 0.00 & 0.01 & 0.00 & 0.00 & 0.01 & 0.00 & 0.00 & 0.00 & 0.01 & 0.27 & 0.02 & 0.00 & 0.00 \\
\hline 11_Cro & Črouch et al. 2010 & 0.00 & 0.00 & 0.18 & 0.00 & 0.05 & 0.06 & 0.00 & 0.10 & 0.02 & 0.05 & 0.00 & 0.24 & 0.16 & 0.03 & 0.00 & 0.00 \\
\hline 12_Cro & Crouch et al.:2010 & 0.00 & 0.00 & 0.07 & 0.00 & 0.01 & 0.02 & 0.00 & 0.01 & 0.00 & 0.00 & 0.00 & 0.18 & 0.12 & 0.01 & 0.00 & 0.00 \\
\hline 13_Cro & Crouch et al. 2010 & 0.00 & 0.00 & 0.12 & 0.00 & 0.05 & 0.03 & 0.01 & 0.03 & 0.01 & 0.00 & 0.01 & 0.13 & 0.11 & 0.00 & 0.00 & 0.00 \\
\hline 15_Cro & Crouch et al. 2010 & 0.00 & 0.00 & 0.06 & 0.00 & 0.03 & 0.01 & 0.00 & 0.02 & 0.00 & 0.00 & 0.00 & 0.30 & 0.21 & 0.00 & 0.00 & 0.00 \\
\hline 16_Cro & Crouch et al. 2010 & 0.00 & 0.00 & 0.03 & 0.00 & 0.00 & 0.01 & 0.00 & 0.01 & 0.00 & 0.00 & 0.00 & 0.17 & 0.27 & 0.01 & 0.00 & 0.00 \\
\hline 17_Cro & Crouch et al. 2010 & 0.00 & 0.00 & 0.08 & 0.00 & 0.00 & 0.00 & 0.00 & 0.01 & 0.00 & 0.01 & 0.00 & 0.07 & 0.29 & 0.04 & 0.00 & 0.00 \\
\hline 18_Cro & et al. 2010 & .00 & 0.00 & 01 & 0.00 & 0.00 & 0.01 & 0.00 & 0.01 & 0.00 & 0.00 & 0.00 & 0.16 & 0.35 & 0.01 & 00 & 0.00 \\
\hline 20_Cro & et al. 201 & 0.00 & 0.00 & 0.00 & 0.00 & 0.00 & 0.00 & 0.00 & 0.00 & 0.00 & 0.00 & 0.00 & 0.08 & 0.14 & 0.01 & 00 & 0.00 \\
\hline 21_Cro & Crouch et al. 2010 & 0.00 & 0.00 & 0.00 & 0.00 & 0.00 & 0.00 & 0.00 & 0.00 & 0.00 & 0.00 & 0.00 & 0.01 & 0.14 & 0.01 & 0.00 & 0.00 \\
\hline 22_Cro & Črouch et al. 2010 & 0.04 & 0.01 & 0.01 & 0.02 & 0.01 & 0.01 & 0.00 & 0.01 & 0.00 & 0.00 & 0.00 & 0.43 & 0.23 & 0.01 & 0.00 & 0.00 \\
\hline 24_Cro & Crouch et al. 2010 & 0.01 & 0.00 & 0.00 & 0.00 & 0.00 & 0.00 & 0.00 & 0.07 & 0.00 & 0.00 & 0.00 & 0.12 & 0.03 & 0.00 & 00 & 0.00 \\
\hline 25_Cro & et al. 2010 & 00 & 0.00 & 0.00 & 0.01 & 0.00 & 0.00 & 0.00 & 0.02 & 0.00 & 0.00 & 0.00 & 0.23 & 0.15 & 0.00 & 00 & 0.00 \\
\hline 26_Cro & Crouch et al. 2010 & 0.00 & 0.00 & 0.00 & 0.00 & 0.00 & 0.00 & 0.00 & 0.00 & 0.00 & 0.00 & 0.00 & 0.02 & 0.15 & 0.00 & 0.00 & 0.00 \\
\hline 28_Cro & Crouch et al. 2010 & 0.00 & 0.01 & 0.04 & 0.03 & 0.00 & 0.00 & 0.00 & 0.08 & 0.00 & 0.00 & 0.00 & 0.30 & 0.32 & 0.02 & 0.00 & 0.00 \\
\hline 32_Cro & CCrouch et al. 2010 & 0.00 & 0.08 & 0.03 & 0.03 & 0.01 & 0.00 & 0.00 & 0.03 & 0.00 & 0.00 & 0.00 & 0.50 & 0.01 & 0.00 & 0.00 & 0.00 \\
\hline 33_Cro & et al.:2010 & 0.02 & 0.04 & 0.06 & 0.03 & 0.00 & 0.00 & 0.00 & 0.02 & 0.00 & 0.00 & 0.00 & 0.49 & 0.24 & 0.03 & 00 & 0.00 \\
\hline 37_Cro & et al. 2010 & 0.00 & 0.01 & 0.01 & 0.05 & 0.00 & 0.00 & 0.00 & 0.05 & 0.00 & 0.00 & 0.00 & 0.69 & 0.00 & 0.00 & 0.00 & 0.00 \\
\hline 38_Pre & This Study & 0.00 & 0.01 & 0.13 & 0.00 & 0.01 & 0.01 & 0.01 & 0.04 & 0.00 & 0.04 & 0.00 & 0.35 & 0.13 & 0.00 & 0.00 & 0.00 \\
\hline 39_Pre & This Study & 0.01 & 0.02 & 0.47 & 0.00 & 0.02 & 0.00 & 0.02 & 0.00 & 0.02 & 0.08 & 0.00 & 0.35 & 0.00 & 0.00 & 0.00 & 0.00 \\
\hline 41_Pre & This Study & 0.00 & 0.00 & 0.39 & 0.00 & 0.01 & 0.03 & 0.00 & 0.02 & 0.01 & 0.13 & 0.00 & 0.22 & 0.05 & 0.00 & 0.00 & 0.00 \\
\hline 46_Pre & This S & 03 & 0.00 & 0.06 & 0.01 & 0.00 & 0.01 & 0.00 & 0.06 & 0.00 & 0.00 & 0.02 & 0.14 & 0.00 & 0.00 & 000 & 0.00 \\
\hline 48_Pre & This Study & 0.06 & 0.05 & 0.01 & 0.01 & 0.00 & 0.03 & 0.00 & 0.00 & 0.00 & 0.00 & 0.00 & 0.68 & 0.00 & 0.00 & 00 & 100 \\
\hline 50_Pre & This Study & 0.00 & 0.05 & 0.10 & 0.03 & 0.04 & 0.04 & 0.01 & 0.00 & 0.00 & 0.00 & 0.00 & 0.23 & 0.27 & 0.00 & 0.00 & 0.00 \\
\hline 58_Pre & This Study & 0.00 & 0.02 & 0.17 & 0.02 & 0.00 & 0.01 & 0.00 & 0.01 & 0.01 & 0.01 & 0.00 & 0.46 & 0.00 & 0.00 & 0.00 & 0.00 \\
\hline 59_Pre & This Study & 0.00 & 0.00 & 0.05 & 0.00 & 0.01 & 0.00 & 0.00 & 0.01 & 0.01 & 0.00 & 0.00 & 0.28 & 0.02 & 0.00 & 0.00 & 0.00 \\
\hline 60_Pre & This Study & 01 & 0.00 & 0.03 & 0.00 & 0.01 & 0.00 & 0.00 & 0.00 & 0.00 & 0.03 & 0.00 & 0.01 & 0.11 & 0.00 & 000 & 0.00 \\
\hline 62_Pre & This Study & 0.00 & 0.00 & 0.68 & 0.00 & 0.07 & 0.02 & 0.00 & 0.02 & 0.02 & 0.08 & 0.00 & 0.06 & 0.03 & 0.00 & 0.00 & 0.00 \\
\hline 64_Pre & This Study & 0.00 & 0.00 & 0.00 & 0.00 & 0.02 & 0.00 & 0.00 & 0.00 & 0.00 & 0.00 & 0.00 & 0.23 & 0.36 & 0.00 & 0.00 & 0.02 \\
\hline 66_Pre & This Study & 0.00 & 0.00 & 0.19 & 0.00 & 0.03 & 0.07 & 0.00 & 0.01 & 0.01 & 0.01 & 0.00 & 0.28 & 0.35 & 0.01 & 0.00 & 0.00 \\
\hline 67_Pre & This Study & 00 & 0.00 & 0.00 & 0.10 & 0.00 & 0.00 & 0.00 & 0.02 & 0.00 & 0.00 & 0.00 & 0.83 & 0.00 & 0.00 & 0.00 & 0.00 \\
\hline 68_Pre & This Study & 0.00 & 0.04 & 0.01 & 0.00 & 0.02 & 0.02 & 0.00 & 0.01 & 0.00 & 0.00 & 0.00 & 0.52 & 0.07 & 0.00 & 0.00 & 0.00 \\
\hline 70_Pre & This Study & 0.00 & 0.01 & 0.23 & 0.00 & 0.00 & 0.00 & 0.00 & 0.00 & 0.00 & 0.01 & 0.00 & 0.17 & 0.01 & 0.00 & 0.00 & 0.00 \\
\hline 71_Pre & This Study & 0.00 & 0.00 & 0.01 & 0.00 & 0.02 & 0.00 & 0.00 & 0.00 & 0.00 & 0.03 & 0.00 & 0.09 & 0.28 & 0.00 & 0.00 & 0.00 \\
\hline 72_Pre & This Study & 0.00 & 0.00 & 0.00 & 0.00 & 0.00 & 0.00 & 0.00 & 0.00 & 0.00 & 0.01 & 0.00 & 0.02 & 0.19 & 0.02 & 0.00 & 0.00 \\
\hline 83_Pre & This Study & 0.00 & 0.01 & 0.00 & 0.04 & 0.00 & 0.01 & 0.00 & 0.01 & 0.00 & 0.00 & 0.00 & 0.65 & 0.00 & 0.00 & 0.00 & 0.00 \\
\hline 96_Pre & This Study & 0.00 & 0.00 & 0.19 & 0.00 & 0.00 & 0.01 & 0.00 & 0.02 & 0.01 & 0.06 & 0.00 & 0.27 & 0.13 & 0.00 & 0.00 & 0.00 \\
\hline 97_Pre & This Study & 0.00 & 0.01 & 0.70 & 0.00 & 0.00 & 0.01 & 0.00 & 0.00 & 0.00 & 0.01 & 0.00 & 0.22 & 0.03 & 0.00 & 0.00 & 0.00 \\
\hline 98_Pre & This Study & 0.01 & 0.00 & 0.61 & 0.00 & 0.01 & 0.04 & 0.00 & 0.00 & 0.02 & 0.11 & 0.00 & 0.12 & 0.01 & 0.00 & 0.00 & 0.00 \\
\hline 104_Pre & This Study & 100 & 0.00 & 0.33 & 0.00 & 0.00 & 0.02 & 0.01 & 0.01 & 0.01 & 0.04 & 0.00 & 0.08 & 0.06 & 0.00 & 0.00 & 0.01 \\
\hline \begin{tabular}{|l}
105 Pre \\
\end{tabular} & This Study & 0.00 & 0.00 & 0.37 & 0.00 & 0.06 & 0.06 & 0.06 & 0.00 & 0.04 & 0.05 & 0.00 & 0.14 & 0.12 & 0.00 & 0.00 & 0.01 \\
\hline 107_Pre & This Study & 0.00 & 0.00 & 0.15 & 0.00 & 0.02 & 0.00 & 0.00 & 0.00 & 0.00 & 0.10 & 0.00 & 0.09 & 0.16 & 0.00 & 0.00 & 0.02 \\
\hline 113_Pre & This Study & 0.00 & 0.01 & 0.64 & 0.00 & 0.02 & 0.01 & 0.00 & 0.00 & 0.01 & 0.05 & 0.00 & 0.20 & 0.02 & 0.00 & 0.00 & 0.00 \\
\hline 119_Pre & This Study & 0.00 & 0.00 & 0.01 & 0.00 & 0.00 & 0.00 & 0.00 & 0.00 & 0.00 & 0.00 & 0.00 & 0.01 & 0.00 & 0.00 & 0.00 & 0.00 \\
\hline 120_Pre & This Study & 0.00 & 0.00 & 0.01 & 0.00 & 0.00 & 0.00 & 0.00 & 0.00 & 0.00 & 0.00 & 0.00 & 0.01 & 0.00 & 0.00 & 0.00 & 0.00 \\
\hline 123_Pre & This Study & 0.00 & 0.00 & 0.00 & 0.00 & 0.00 & 0.00 & 0.00 & 0.00 & 0.00 & 0.00 & 0.00 & 0.00 & 0.14 & 0.00 & 0.00 & 0.00 \\
\hline 128_Pre & This Study & 0.01 & 0.00 & 0.00 & 0.00 & 0.00 & 0.00 & 0.00 & 0.00 & 0.00 & 0.00 & 0.00 & 0.06 & 0.02 & 0.00 & 0.00 & 0.00 \\
\hline 129_Pre & This Study & 0.00 & 0.00 & 0.03 & 0.00 & 0.01 & 0.00 & 0.00 & 0.01 & 0.00 & 0.01 & 0.00 & 0.01 & 0.34 & 0.03 & 0.00 & 0.00 \\
\hline 133_Pre & This Study & 0.00 & 0.00 & 0.00 & 0.01 & 0.00 & 0.00 & 0.00 & 0.01 & 0.00 & 0.00 & 0.00 & 0.19 & 0.00 & 0.00 & 0.00 & 0.00 \\
\hline 134_Pre & This Study & 0.00 & 0.02 & 0.03 & 0.03 & 0.00 & 0.00 & 0.00 & 0.04 & 0.00 & 0.00 & 0.00 & 0.30 & 0.01 & 0.00 & 0.00 & 0.00 \\
\hline 136_Pre & This Study & 0.00 & 0.00 & 0.10 & 0.00 & 0.01 & 0.00 & 0.00 & 0.01 & 0.02 & 0.04 & 0.00 & 0.02 & 0.46 & 0.00 & 0.00 & 0.00 \\
\hline 137_Pre & This Study & 0.00 & 0.00 & 0.03 & 0.00 & 0.03 & 0.04 & 0.01 & 0.01 & 0.01 & 0.02 & 0.00 & 0.01 & 0.33 & 0.00 & 0.00 & 0.01 \\
\hline 140_Pre & This Study & 0.00 & 0.00 & 0.12 & 0.00 & 0.02 & 0.00 & 0.00 & 0.01 & 0.02 & 0.09 & 0.00 & 0.01 & 0.19 & 0.00 & 0.00 & 0.01 \\
\hline 141_Pre & This Study & 0.00 & 0.00 & 0.03 & 0.00 & 0.01 & 0.03 & 0.00 & 0.00 & 0.00 & 0.03 & 0.00 & 0.01 & 0.29 & 0.01 & 0.00 & 0.00 \\
\hline 142_Pre & This Study & 0.00 & 0.00 & 0.06 & 0.00 & 0.02 & 0.03 & 0.00 & 0.01 & 0.00 & 0.02 & 0.00 & 0.0 & $\cdots$ & 0.01 & 0.00 & 0.00 \\
\hline
\end{tabular}




\begin{tabular}{|c|c|c|c|c|c|c|c|c|c|c|c|c|c|c|c|c|c|}
\hline $\begin{array}{l}\stackrel{0}{E} \\
\stackrel{\pi}{Z}\end{array}$ & 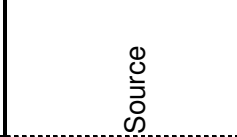 & $\begin{array}{l}\stackrel{0}{\Phi} \\
\stackrel{ \pm}{ \pm}\end{array}$ & $\begin{array}{l}\overline{\widetilde{\sigma}} \\
\frac{\bar{U}}{0} \\
\overline{\widetilde{\sigma}}\end{array}$ & 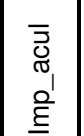 & $\begin{array}{l}\overline{\bar{\sigma}} \\
\stackrel{\sigma}{Q} \\
\stackrel{Q}{\underline{\xi}}\end{array}$ & $\begin{array}{l}\frac{\widetilde{\sigma}}{\widetilde{\sigma}} \\
\stackrel{1}{0} \\
\stackrel{\varrho}{\underline{\xi}}\end{array}$ & 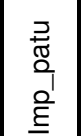 & $\begin{array}{l}\frac{0}{0} \\
\stackrel{0}{\underline{\xi}} \\
\underline{\underline{g}}\end{array}$ & 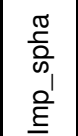 & 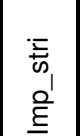 & 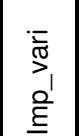 & 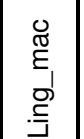 & $\frac{\frac{\overrightarrow{0}}{\sigma}}{\frac{\varepsilon}{\underline{\theta}}}$ & $\begin{array}{l}- \\
\beth^{\prime} \\
\vec{D}_{0} \\
\bigcup_{1} \\
0\end{array}$ & $\begin{array}{l}\infty \\
D_{1} \\
\vec{\Phi}_{0} \\
\bigcup_{1} \\
0\end{array}$ & $\begin{array}{l}\bar{\Phi} \\
\frac{\pi}{\omega} \\
\frac{\pi}{0}\end{array}$ & $\begin{array}{l}\frac{2}{0} \\
\frac{0}{\pi} \\
\frac{\pi}{7} \\
0\end{array}$ \\
\hline 143_Pre & This Study & 0.00 & 0.00 & 0.00 & 0.07 & 0.00 & 0.01 & 0.00 & 0.01 & 0.00 & 0.00 & 0.00 & 0.72 & 0.01 & 0.00 & 0.00 & 0.00 \\
\hline 144_Pre & This Study & 0.00 & 0.00 & 0.35 & 0.00 & 0.01 & 0.01 & 0.00 & 0.00 & 0.04 & 0.00 & 0.00 & 0.02 & 0.21 & 0.00 & 0.00 & 0.00 \\
\hline 45_Pre & This Study & 0.00 & 0.00 & 0.02 & 0.00 & 0.00 & 0.03 & 0.01 & 0.00 & 0.00 & 0.03 & 0.00 & 0.01 & 0.38 & 0.01 & 0.00 & 0.00 \\
\hline 151_Pre & This Study & 0.00 & 0.00 & 0.00 & 0.00 & 0.00 & 0.00 & 0.00 & 0.00 & 0.00 & 0.00 & 0.01 & 0.00 & 0.01 & 0.00 & 0.00 & 0.00 \\
\hline 1875_Mar & Marret et al. 2003 & 0.00 & 0.02 & 0.06 & 0.00 & 0.00 & 0.00 & 0.00 & 0.02 & 0.00 & 0.03 & 0.00 & 0.53 & 0.18 & 0.00 & 0.00 & 0.00 \\
\hline 1879_Mar & Märet et al. 2003 & 0.00 & 0.03 & 0.13 & 0.05 & 0.01 & 0.00 & 0.00 & 0.01 & 0.00 & 0.02 & 0.00 & 0.71 & 0.00 & 0.00 & 0.00 & 0.00 \\
\hline 1883_Mar & Marret et al. 2003 & 0.00 & 0.02 & 0.08 & 0.04 & 0.02 & 0.00 & 0.00 & 0.03 & 0.02 & 0.04 & 0.00 & 0.29 & 0.06 & 0.00 & 0.00 & 0.00 \\
\hline 1887_Mar & Marret et al. 2003 & 0.00 & 0.03 & 0.19 & 0.16 & 0.01 & 0.04 & 0.00 & 0.04 & 0.01 & 0.00 & 0.00 & 0.42 & 0.04 & 0.00 & 0.00 & 0.00 \\
\hline 1888_Mar & Marret et al. 2003 & 0.01 & 0.04 & 0.12 & 0.05 & 0.04 & 0.01 & 0.00 & 0.02 & 0.00 & 0.00 & 0.00 & 0.54 & 0.01 & 0.00 & 0.00 & 0.00 \\
\hline 1889_Mar & Marret et al. 2003 & 0.00 & 0.12 & 0.05 & 0.10 & 0.02 & 0.00 & 0.00 & 0.06 & 0.02 & 0.00 & 0.00 & 0.44 & 0.01 & 0.00 & 0.00 & 0.00 \\
\hline 1893_Mar & Marret et al. 2003 & 0.03 & 0.00 & 0.00 & 0.00 & 0.00 & 0.00 & 0.00 & 0.00 & 0.00 & 0.07 & 0.00 & 0.12 & 0.09 & 0.00 & 0.00 & 0.00 \\
\hline 1894_Mar & tal. 20 & 0.00 & 0.00 & 0.00 & 0.00 & 0.00 & 0.00 & 0.00 & 0.00 & 0.00 & 0.04 & 0.00 & 0.11 & 0.04 & 0.00 & 0.00 & 0.00 \\
\hline 1895_Mar & tal. 2003 & 0.02 & 0.00 & 0.00 & 0.00 & 0.00 & 0.00 & 0.00 & 0.00 & 0.00 & 0.00 & 0.00 & 0.00 & 0.00 & 0.00 & 0.00 & 0.00 \\
\hline 1896_Mar & Marret et al. 2003 & 0.00 & 0.00 & 0.00 & 0.00 & 0.00 & 0.00 & 0.00 & 0.00 & 0.00 & 0.02 & 0.00 & 0.00 & 0.07 & 0.00 & 0.00 & 0.00 \\
\hline 1897_Mar & †Marret et al. 2003 & 0.03 & 0.00 & 0.00 & 0.00 & 0.00 & 0.00 & 0.00 & 0.00 & 0.00 & 0.03 & 0.00 & 0.02 & 0.03 & 0.00 & 0.00 & 0.00 \\
\hline 1898_Mar & Marret et al. 2003 & 0.03 & 0.00 & 0.03 & 0.00 & 0.00 & 0.00 & 0.00 & 0.00 & 0.00 & 0.04 & 0.00 & 0.05 & 0.05 & 0.00 & 0.00 & 0.00 \\
\hline 1899_Mar & al. 2003 & 0.06 & 0.00 & 0.05 & 0.00 & 0.00 & 0.00 & 0.00 & 0.00 & 0.00 & 0.06 & 0.00 & 0.13 & 0.25 & 0.00 & 0.00 & 0.00 \\
\hline 1900_Mar & Marret et al. 2003 & 0.00 & 0.00 & 0.06 & 0.00 & 0.00 & 0.00 & 0.00 & 0.00 & 0.00 & 0.05 & 0.00 & 0.18 & 0.21 & 0.00 & 0.00 & 0.00 \\
\hline 1901_Mar & Märet et al. 2003 & 0.00 & 0.00 & 0.04 & 0.00 & 0.00 & 0.00 & 0.00 & 0.00 & 0.00 & 0.03 & 0.00 & 0.09 & 0.26 & 0.00 & 0.00 & 0.00 \\
\hline 1952_Mar & Marret et al. 2003 & 0.00 & 0.03 & 0.06 & 0.03 & 0.00 & 0.00 & 0.00 & 0.00 & 0.00 & 0.00 & 0.00 & 0.43 & 0.00 & 0.00 & 0.00 & 0.00 \\
\hline 1953_Mar & Marret et al.2003 & 0.00 & 0.05 & 0.12 & 0.05 & 0.03 & 0.01 & 0.00 & 0.00 & 0.00 & 0.00 & 0.00 & 0.51 & 0.00 & 0.00 & 0.01 & 0.00 \\
\hline 1954_Mar & Marret et al. 2003 & 0.00 & 0.04 & 0.05 & 0.03 & 0.01 & 0.01 & 0.00 & 0.05 & 0.00 & 0.00 & 0.00 & 0.18 & 0.00 & 0.00 & 0.00 & 0.00 \\
\hline 1955_Mar & Marret et al. 2003 & 0.00 & 0.00 & 0.00 & 0.12 & 0.00 & 0.00 & 0.00 & 0.00 & 0.00 & 0.00 & 0.00 & 0.01 & 0.00 & 0.00 & 0.00 & 0.00 \\
\hline 1993_Mar & Marret et al. 2003 & 0.00 & 0.05 & 0.06 & 0.06 & 0.00 & 0.02 & 0.00 & 0.06 & 0.00 & 0.00 & 0.00 & 0.38 & 0.11 & 0.00 & 0.00 & 0.00 \\
\hline 1994_Mar & al. 2003 & 0.00 & 0.00 & 0.00 & 0.04 & 0.02 & 0.00 & 0.00 & 0.03 & 0.00 & 0.00 & 0.00 & 0.39 & 0.03 & 0.00 & 0.00 & 0.00 \\
\hline 1995_Mar & al. 2003 & 0.02 & 0.00 & 0.02 & 0.00 & 0.03 & 0.00 & 0.00 & 0.00 & 0.00 & 0.00 & 0.00 & 0.52 & 0.22 & 0.00 & 0.00 & 0.00 \\
\hline 1996_Mar & |Marret et al. 2003 & 0.00 & 0.00 & 0.13 & 0.00 & 0.03 & 0.00 & 0.00 & 0.03 & 0.02 & 0.00 & 0.00 & 0.25 & 0.13 & 0.00 & 0.00 & 0.00 \\
\hline 1998_Mar & Marret et al. 2003 & 0.00 & 0.00 & 0.16 & 0.02 & 0.03 & 0.01 & 0.00 & 0.03 & 0.01 & 0.00 & 0.00 & 0.58 & 0.10 & 0.00 & 0.00 & 0.00 \\
\hline 1999_Mar & Marret et al. 2003 & 0.00 & 0.03 & 0.06 & 0.00 & 0.00 & 0.00 & 0.00 & 0.02 & 0.00 & 0.02 & 0.00 & 0.38 & 0.10 & 0.00 & 0.00 & 0.00 \\
\hline 00_Mar & Märret et al. 2003 & 0.00 & 0.00 & 0.00 & 0.00 & 0.00 & 0.00 & 0.00 & 0.03 & 0.00 & 0.07 & 0.00 & 0.23 & 0.05 & 0.00 & 0.00 & 0.00 \\
\hline 2001_Mar & Marret et al. 2003 & 0.00 & 0.00 & 0.10 & 0.00 & 0.00 & 0.00 & 0.00 & 0.00 & 0.00 & 0.09 & 0.00 & 0.47 & 0.07 & 0.00 & 0.00 & 0.00 \\
\hline 2002_Mar & Märet et al. 2003 & 0.00 & 0.00 & 0.09 & 0.00 & 0.03 & 0.00 & 0.00 & 0.03 & 0.00 & 0.10 & 0.00 & 0.39 & 0.10 & 0.00 & 0.00 & 0.00 \\
\hline 2003_Mar & Märet et al.2003 & 0.00 & 0.03 & 0.02 & 0.02 & 0.02 & 0.00 & 0.00 & 0.03 & 0.00 & 0.04 & 0.00 & 0.46 & 0.09 & 0.00 & 0.00 & 0.00 \\
\hline 2004_Mar & Marret et al. 2003 & 0.00 & 0.00 & 0.00 & 0.02 & 0.00 & 0.00 & 0.00 & 0.00 & 0.00 & 0.03 & 0.00 & 0.22 & 0.08 & 0.00 & 0.00 & 0.00 \\
\hline 2005_Mar & Marret et al. 2003 & 0.00 & 0.00 & 0.00 & 0.00 & 0.00 & 0.00 & 0.00 & 0.00 & 0.00 & 0.07 & 0.00 & 0.23 & 0.09 & 0.00 & 0.00 & 0.00 \\
\hline 2006_Mar & Marret et al. 2003 & 0.00 & 0.03 & 0.04 & 0.00 & 0.00 & 0.00 & 0.00 & 0.00 & 0.00 & 0.04 & 0.00 & 0.40 & 0.12 & 0.00 & 0.00 & 0.00 \\
\hline 2007_Mar & Marret et al. 2003 & 0.00 & 0.00 & 0.02 & 0.00 & 0.00 & 0.00 & 0.00 & 0.02 & 0.00 & 0.04 & 0.00 & 0.45 & 0.13 & 0.00 & 0.00 & 0.00 \\
\hline 2008_Mar & Marret et al. 2003 & 0.02 & 0.00 & 0.00 & 0.06 & 0.00 & 0.03 & 0.00 & 0.02 & 0.00 & 0.00 & 0.00 & 0.17 & 0.08 & 0.00 & 0.00 & 0.00 \\
\hline 2009_Mar & Marret et al. 2003 & 0.00 & 0.02 & 0.04 & 0.02 & 0.00 & 0.00 & 0.00 & 0.00 & 0.00 & 0.05 & 0.00 & 0.34 & 0.14 & 0.00 & 0.00 & 0.00 \\
\hline 2012_Mar & Marret et al. 2003 & 0.00 & 0.00 & 0.00 & 0.00 & 0.00 & 0.00 & 0.00 & ...1... & 0.0 & =0 & 0.00 & 0.23 & 0.31 & 0.00 & 0.00 & 0.00 \\
\hline
\end{tabular}




\begin{tabular}{|c|c|c|c|c|c|c|c|c|c|c|c|c|c|c|c|c|c|c|c|}
\hline $\begin{array}{l}\stackrel{0}{E} \\
\stackrel{\pi}{Z}\end{array}$ & 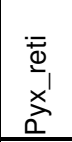 & 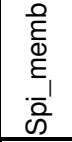 & $\begin{array}{l}\overline{\bar{E}} \\
\overline{\sigma_{1}} \\
\overline{0}\end{array}$ & $\begin{array}{l}\frac{\varepsilon}{\sqrt{0}} \\
\overline{0} \\
\overline{0} \\
0\end{array}$ & $\begin{array}{l}\overline{\overline{0}} \\
\overline{0} \\
\overline{0} \\
\overline{0}\end{array}$ & $\begin{array}{l}\frac{\pi}{0} \\
\frac{0}{0} \\
-\frac{1}{0} \\
\overline{0}\end{array}$ & $\begin{array}{l}\bar{N} \\
\frac{\pi}{0} \\
\overline{0} \\
\overline{0}\end{array}$ & $\begin{array}{l}\frac{\overline{0}}{0} \\
\overline{0} \\
\overline{0}\end{array}$ & 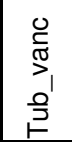 & $\begin{array}{l}\text { 응 } \\
\text { o! } \\
\circ \\
\text { 은 }\end{array}$ & $\begin{array}{l}\text { की } \\
\text { 임 } \\
\text { 음 }\end{array}$ & $\begin{array}{l}\overline{\widetilde{\pi}} \\
\overline{0} \\
\vec{D}_{0} \\
0 \\
0\end{array}$ & 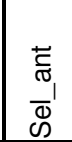 & 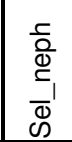 & 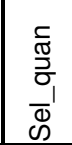 & 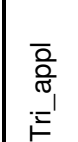 & $\begin{array}{l}\text { 등 } \\
\text { क् } \\
\text { ते } \\
0\end{array}$ & $\begin{array}{l}\frac{0}{0} \\
\text { के } \\
\frac{5}{0} \\
\text { ये }\end{array}$ & م) \\
\hline 2_Cro & 0.00 & 0.00 & 0.21 & 0.24 & 0.00 & 0.00 & 0.00 & 0.00 & 0.00 & 0.00 & 0.22 & 0.00 & 0.00 & 0.02 & 0.00 & 0.02 & 0.00 & 0.03 & 174.15 \\
\hline Cro & 00 & .02 & 0.08 & 0.31 & 0.00 & .00 & 0.00 & 0.00 & 0.00 & 0.00 & 0.01 & 0.00 & 0.00 & 0.00 & 0.00 & 0.01 & 0.00 & 0.00 & 173.51 \\
\hline Cro & 00 & 0.00 & 0.06 & 0.06 & 0.00 & 0.00 & 0.00 & 0.00 & 0.00 & 0.00 & 0.19 & 0.02 & 0.00 & 0.06 & 0.00 & 0.01 & 0.00 & 0.00 & 76.80 \\
\hline Cro & 00 & 0.01 & 0.12 & 0.32 & 0.00 & 0.00 & 0.00 & 0.00 & 0.00 & 0.00 & 0.13 & 0.01 & 0.00 & 0.00 & 0.03 & 0.06 & 0.00 & 0.01 & 176.24 \\
\hline 1_Cro & 01 & 0.00 & 0.00 & 0.00 & 0.00 & 0.00 & 0.00 & 0.00 & 0.00 & 0.00 & 0.03 & 0.00 & 0.01 & 0.01 & 0.00 & 0.02 & 0.00 & 0.01 & 181.51 \\
\hline 2_Cro & 00 & 0.01 & 0.01 & 0.01 & 0.00 & 0.00 & 0.00 & 0.00 & 0.00 & 0.01 & 0.40 & 0.00 & 0.00 & 0.03 & 0.05 & 0.01 & 0.00 & 0.05 & 79.99 \\
\hline 3_Cro & 01 & 0.00 & 0.01 & 0.04 & 0.00 & 00 & 0.00 & 0.00 & 0.00 & 0.00 & 0.22 & 0.00 & 0.00 & 0.02 & 0.08 & 0.02 & 0.00 & 0.10 & 177.99 \\
\hline 5_Cro & 00 & 0.00 & 0.10 & 0.00 & 0.00 & 0.00 & 0.00 & 0.00 & 0.00 & 0.00 & 0.19 & 0.01 & 0.00 & 0.00 & 0.01 & 0.02 & 0.00 & 0.03 & 86.00 \\
\hline 16_Cro & 0.00 & 0.00 & 0.10 & 0.01 & 0.00 & 0.00 & 0.00 & 0.00 & 0.00 & 0.02 & 0.20 & 0.00 & 0.00 & .01 & 0.06 & 0.04 & 0.00 & .04 & 181.51 \\
\hline 17_Cro & .01 & 0.00 & 0.06 & 0.01 & 0.00 & 0.00 & 0.00 & 0.00 & 0.00 & 0.01 & 0.30 & 0.00 & 0.00 & 02 & 0.03 & 0.04 & 0.00 & .03 & 179.36 \\
\hline 8_Cro & 00 & 0.03 & 14 & 0.00 & 0.00 & 00 & 0.00 & 0.00 & 0.00 & 0.01 & 0.13 & 0.00 & 0.01 & $\dddot{10}$ & 0.04 & 08 & .00 & .01 & \\
\hline 0 Cro & 00 & 00 & 02 & 02 & 0.00 & .00 & 0.00 & 0.00 & 0.00 & 0.01 & 0.45 & 0.01 & 0.00 & .01 & 0.15 & 05 & 0.01 & 05 & 50 \\
\hline 1_Cro & 00 & .02 & 03 & .03 & 0.00 & 100 & 0.00 & 0.00 & 0.00 & 0.01 & 0.39 & 0.00 & 0.00 & 001 & 0.27 & 02 & 0.01 & 03 & 36 \\
\hline 22_Cro & .02 & 0.01 & .07 & 0.07 & 0.00 & 0.00 & 0.00 & 0.00 & 0.00 & 0.00 & 0.03 & .00 & 0.01 & .00 & 0.00 & .01 & .00 & .00 & 5.92 \\
\hline 4_Cro & 00 & 0.02 & 0.16 & 0.03 & 0.00 & 0.00 & 0.00 & 0.00 & 0.00 & 0.00 & 0.51 & 0.00 & 0.00 & 02 & 0.03 & .02 & 0.00 & 000 & 78.00 \\
\hline 25_Cro & .00 & 0.00 & 0.03 & 0.02 & 0.00 & .00 & 0.00 & 0.00 & 0.00 & 0.01 & 0.40 & 0.00 & 0.00 & 01 & 0.06 & 0.03 & 0.00 & .03 & .98 \\
\hline 6_Cro & 00 & .00 & .03 & 0.06 & 0.00 & 0.00 & 0.00 & 0.00 & 0.00 & 0.03 & 0.41 & 0.00 & 0.00 & .01 & 0.22 & 0.01 & 0.01 & 0.06 & 65 \\
\hline 28_Cro & .04 & .00 & 0.05 & 0.00 & 0.00 & 0.00 & 0.00 & 0.00 & 0.00 & 0.00 & 0.09 & 0.00 & 0.00 & .00 & 0.00 & 0.01 & 0.00 & .00 & .".." \\
\hline 32_Cro & .03 & 0.00 & 01 & 0.00 & 0.00 & 0.00 & 0.00 & 0.00 & 0.00 & 0.00 & 0.25 & .00 & 0.01 & 100 & 0.00 & 00 & .00 & 00 & 4.08 \\
\hline 33_Cro & .00 & 0.00 & 0.05 & 0.00 & 0.00 & 0.00 & 0.00 & 0.00 & 0.00 & 0.00 & 0.00 & 0.00 & 0.00 & 00 & 0.00 & .02 & 1.00 & .00 & 82.01 \\
\hline 7_Cro & 0.5 & 00 & 00 & 00 & 0.00 & $: 00$ & 0.00 & 0.00 & 0.00 & 0.00 & 0.15 & 0.00 & 0.00 & 0.00 & 0.00 & 0.00 & 0.00 & ...00 & 83 \\
\hline 38_Pre & 0.05 & 0.00 & .03 & 0.04 & .00 & .00 & 0.00 & 0.00 & 0.00 & 0.00 & 0.11 & 0.00 & 0.00 & 00 & 0.04 & 00 & 1.00 & 100 & .93 \\
\hline 39_Pre & 01 & 0.00 & .01 & 0.00 & .00 & .00 & 0.00 & 0.00 & 0.00 & .00 & 0.00 & .00 & 0.00 & .00 & 0.00 & .00 & .00 & .00 & 7.68 \\
\hline 41_Pre & 02 & 0.00 & 0.11 & 0.02 & 0.00 & 0.01 & 0.00 & 0.00 & 0.00 & 0.00 & 0.01 & 0.00 & 0.00 & 000 & 0.00 & 0.00 & 0.00 & 0.00 & .44 \\
\hline 46_Pre & 03 & 01 & .04 & 19 & 0.00 & 00 & 0.00 & .0 & 0.00 & 00 & 0.39 & 0.00 & 0.00 & .00 & 0.00 & .01 & 0.00 & 02 & 41 \\
\hline 8_Pre & .00 & .00 & .00 & .00 & 0.00 & $: 00$ & 0.00 & 0.00 & 0.00 & 0.00 & 0.15 & 0.00 & 0.01 & 0.00 & 0.00 & 0.00 & 0.00 & 00 & .73 \\
\hline 50_Pre & 01 & .00 & 02 & 010 & 0.00 & 00 & 0.00 & 0.00 & 0.00 & 0.00 & 0.16 & 0.00 & 0.03 & 0.00 & 0.00 & .00 & .00 & .00 & 4.69 \\
\hline 58_Pre & 00 & 0.00 & .00 & 0.04 & 0.00 & 0.00 & 0.00 & 0.00 & 0.00 & .00 & 0.23 & 0.00 & 0.00 & .00 & 0.03 & .00 & .00 & .00 & .61 \\
\hline 59_Pre & 0.01 & 0.00 & 0.00 & 0.10 & 0.00 & 0.00 & 0.00 & 0.00 & 0.00 & 0.00 & 0.36 & 0.00 & 0.01 & 0.01 & 0.03 & 0.03 & 0.01 & 0.07 & 66.06 \\
\hline 60_Pre & 00 & 0.01 & 0.07 & 0.46 & 0.00 & 0.00 & 0.00 & 0.00 & 0.00 & 0.00 & 0.15 & 0.00 & 0.00 & .03 & 0.07 & 0.00 & 0.00 & 0.00 & 8.89 \\
\hline 62_Pre & 00 & .00 & .02 & 0.00 & 0.00 & .00 & 0.00 & 0.00 & 0.00 & 0.00 & 0.00 & 0.00 & 0.00 & 0.00 & 0.00 & 0.00 & 0.00 & 0.00 & 00 \\
\hline 64_Pre & .000 & 1.04 & 1.04 & 0.02 & 0.00 & 01 & 0.00 & 0.00 & 0.00 & 0.00 & 0.19 & 0.00 & 0.00 & 0.02 & 0.01 & 0.02 & 0.00 & 0.02 & 4.47 \\
\hline 66_Pre & .00 & 0.00 & .01 & 0.01 & 0.00 & 0.00 & 0.00 & 0.01 & 0.00 & 0.00 & 0.00 & 0.00 & 0.00 & .00 & 0.00 & .01 & 0.00 & .00 & 79.99 \\
\hline 67_Pre & 0.01 & 0.00 & 0.00 & 0.00 & 0.00 & 0.01 & 0.00 & 0.00 & 0.00 & 0.00 & 0.03 & 0.00 & 0.00 & 100 & 0.00 & 00 & 0.00 & 0.00 & 68.99 \\
\hline 68_Pre & 01 & 00 & .05 & 0.04 & 0.00 & .01 & 0.00 & 0.00 & 0.00 & 0.00 & 0.20 & 0.00 & 0.00 & 00 & 0.00 & .00 & 0.00 & 00 & 8.73 \\
\hline 70_Pre & 00 & 00 & 1.00 & 0.00 & 0.00 & 0.00 & 0.00 & 0.00 & 0.00 & 0.00 & 0.55 & 0.00 & 0.00 & 0.01 & 0.00 & 0.01 & 0.00 & 00 & 0.00 \\
\hline 71_Pre & 00 & 0.03 & 01 & 0.34 & 00 & 0.00 & 0.00 & 0.01 & 0.00 & 0.00 & 0.10 & 0.00 & 0.00 & .02 & 0.01 & .00 & 0.00 & .05 & .92 \\
\hline 72_Pre & .00 & 01 & 0.00 & 0.53 & 0.00 & 0.02 & 0.00 & 0.00 & 0.00 & 0.02 & 0.13 & 0.00 & 0.00 & 01 & 0.00 & 01 & 0.00 & .05 & 70.92 \\
\hline 83_Pre & 08 & 0.00 & 0.08 & 0.01 & 0.00 & 0.02 & 0.00 & 0.00 & 0.00 & 0.00 & 0.08 & 0.00 & 0.00 & .00 & 0.00 & .00 & 0.00 & 0.00 & 73.37 \\
\hline 6_Pre & 00 & 00 & .05 & 01 & 0.00 & 01 & 0.00 & 0.01 & 0.00 & 0.00 & 0.12 & 0.11 & 0.00 & .01 & 0.00 & 0.00 & 0.00 & 0.00 & 170.50 \\
\hline 97_Pre & 00 & 0.00 & 0.02 & 0.00 & 0.00 & 0.00 & 0.00 & 0.00 & 0.00 & 0.00 & 0.00 & 0.01 & 0.00 & 000 & 0.00 & 0.00 & 0.00 & 0.00 & 170.34 \\
\hline 98_Pre & 0.02 & 0.00 & .00 & 0.04 & 0.00 & 0.01 & 0.00 & 0.00 & 0.00 & 0.00 & 0.00 & 0.00 & 0.00 & 0.00 & 0.00 & 0.00 & 0.00 & 0.00 & 170.65 \\
\hline 104_Pre & .02 & 0.01 & 0.02 & 0.33 & 0.00 & 0.00 & 0.00 & 0.01 & 0.00 & 0.00 & 0.02 & 0.00 & 0.00 & 00 & 0.00 & 0.00 & 0.00 & 0.00 & 165.22 \\
\hline 105_Pre & 01 & 01 & 1.00 & 0.00 & 0.00 & 0.00 & 0.00 & 0.00 & 0.00 & 0.00 & 0.03 & 0.01 & 0.00 & .00 & 0.00 & 0.00 & 0.00 & 0.01 & 62.60 \\
\hline 107_Pre & oị & .01 & 32 & 0.09 & 0.00 & 00 & 0.00 & 0.01 & 0.00 & 0.00 & 0.02 & 0.00 & 0.00 & 00 & 0.00 & 00 & 0.00 & ....". & 169.65 \\
\hline 113_Pre & .01 & 1.00 & 0.00 & 0.00 & 0.00 & 0.00 & 0.00 & 0.00 & 0.00 & 0.00 & 0.01 & 0.00 & 0.00 & 0.00 & 0.00 & 0.00 & 0.00 & .00 & 166.46 \\
\hline 119_Pre & 0.00 & 00 & .00 & 0.00 & 0.00 & 0.00 & 0.00 & 0.00 & 0.00 & 0.00 & 0.92 & 0.00 & 0.00 & 00 & 0.00 & 0.00 & 0.01 & 0.04 & 178.17 \\
\hline 120_Pre & 00 & 0.00 & 01 & 0.02 & 0.00 & 0.00 & 0.00 & 0.00 & 0.00 & 0.01 & 0.84 & 0.00 & 0.00 & 0.01 & 0.04 & 0.00 & 0.00 & 0.05 & 173.42 \\
\hline 123_Pre & 00 & .00 & .27 & 0.06 & 0.00 & 0.00 & 0.00 & 0.00 & 0.00 & 0.04 & 0.32 & 0.00 & 0.00 & .05 & 0.05 & 0.01 & 0.04 & .03 & 171.36 \\
\hline 128_Pre & .01 & 100 & 0.01 & 0.00 & 0.00 & 0.00 & 0.00 & 0.01 & 0.00 & 0.01 & 0.86 & 0.00 & 0.00 & 0.01 & 0.00 & 0.00 & 0.00 & 0.00 & 171.42 \\
\hline 129_Pre & 0.00 & 0.00 & 0.03 & 0.36 & 0.00 & 0.00 & 0.00 & 0.00 & 0.00 & 0.00 & 0.15 & 0.00 & 0.00 & 0.01 & 0.01 & 0.00 & 0.02 & 0.00 & 172.42 \\
\hline 133_Pre & 03 & 0.02 & 61 & 0.00 & 0.00 & 0.00 & 0.00 & 0.00 & 0.00 & 0.00 & 0.13 & 0.00 & 0.00 & 100 & 0.00 & 0.00 & 0.00 & 0.00 & 169.92 \\
\hline 134_Pre & .05 & 0.00 & 19 & 0.02 & 0.00 & 0.00 & 0.00 & 0.00 & 0.00 & 0.00 & 0.28 & 0.00 & 0.03 & 0.00 & 0.00 & 0.00 & 0.00 & 0.00 & 170.98 \\
\hline 136_Pre & 100 & 0.00 & 0.17 & 0.06 & 0.00 & 0.00 & 0.00 & 0.00 & 0.00 & 0.00 & 0.12 & 0.00 & 0.00 & 0.01 & 0.00 & 0.00 & 0.00 & 0.01 & 173.83 \\
\hline 137_Pre & 01 & 0.00 & 0.11 & 0.26 & 0.00 & 0.00 & 0.00 & 0.01 & 0.00 & 0.00 & 0.12 & 0.00 & 0.00 & 0.01 & 0.00 & 0.01 & 0.00 & 0.01 & 175.39 \\
\hline 140_Pre & 0.02 & 0.00 & 0.13 & 0.03 & 0.00 & 0.00 & 0.00 & 0.00 & 0.00 & 0.00 & 0.30 & 0.00 & 0.00 & 0.02 & 0.00 & 0.00 & 0.03 & 0.01 & 173.63 \\
\hline 141_Pre & 01 & 0.00 & 0.14 & 0.37 & 0.01 & 0.00 & 0.00 & 0.00 & 0.00 & 0.00 & 0.06 & 0.00 & 0.00 & 0.01 & 0.00 & 0.01 & 0.00 & 0.00 & 175.32 \\
\hline 142_Pre & .00 & 0.07 & 0.07 & 0.24 & 0.03 & 0.00 & 0.00 & 0.00 & 0.00 & 0.00 & 0.10 & 0.00 & 0.00 & 0.00 & 0.00 & 0.01 & 0.00 & 0.02 & 175.39 \\
\hline
\end{tabular}




\begin{tabular}{|c|c|c|c|c|c|c|c|c|c|c|c|c|c|c|c|c|c|c|c|}
\hline $\begin{array}{l}\stackrel{0}{E} \\
\stackrel{\pi}{z}\end{array}$ & 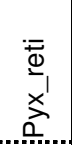 & 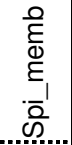 & 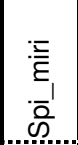 & 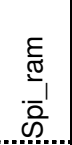 & $\begin{array}{l}\overline{\overline{0}} \\
\overline{0} \\
\overline{0} \\
\overline{2}\end{array}$ & 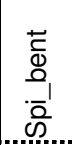 & 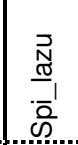 & 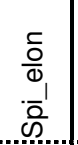 & 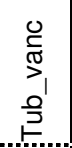 & $\begin{array}{l}\frac{0}{0} \\
0 \\
\circ \\
\circ \\
\frac{0}{0}\end{array}$ & $\begin{array}{l}\text { की } \\
\text { गू } \\
\text {.ू }\end{array}$ & $\begin{array}{l}\overline{\bar{\pi}} \\
\bar{O} \\
\overline{\bar{D}} \\
0\end{array}$ & 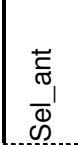 & 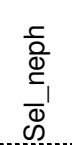 & $\begin{array}{l}\frac{c}{\widetilde{D}} \\
\frac{\partial}{\sigma} \\
\bar{D} \\
\bar{D}\end{array}$ & $\begin{array}{l}\overline{0} \\
\overline{2} \\
\bar{\sigma} \\
\bar{\Xi}\end{array}$ & $\begin{array}{l}\text { टे } \\
\infty \\
\text { । } \\
\text { ते } \\
0\end{array}$ & 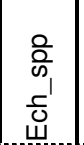 & ס્ \\
\hline 43_Pre & 0.07 & 0.00 & 0.04 & 0.00 & 0.00 & 0.01 & 0.00 & 0.00 & 0.00 & 0.00 & 0.06 & 0.00 & 0.02 & 0.00 & 0.00 & 0.00 & 0.00 & 0.00 & 71.52 \\
\hline 44_Pre & 01 & 01 & 0.09 & 0.01 & 0.00 & 0.00 & 0.00 & 0.00 & 0.00 & 0.00 & 0.21 & 0.00 & 0.00 & 0.01 & 0.00 & 0.00 & 0.00 & 0.00 & 171.80 \\
\hline 45_Pre & 0.00 & .07 & 09 & 0.17 & 0.01 & 0.00 & 0.01 & 0.00 & 0.00 & .00 & 0.12 & .00 & 0.00 & 0.00 & 0.01 & 0.04 & 0.00 & 0.00 & 175.21 \\
\hline 51_Pre & 0.00 & 00 & 0.00 & 0.04 & 0.00 & 0.00 & 0.00 & 0.00 & 0.00 & 0.02 & 0.70 & 0.00 & 0.00 & 0.02 & 0.03 & 0.00 & 0.03 & 0.13 & 178.20 \\
\hline 1875_Mar & 0.04 & 0.00 & 00 & 0.00 & 0.00 & 0.00 & 0.00 & 0.00 & 0.00 & 0.00 & 0.12 & 0.00 & 0.00 & 0.00 & 0.00 & 0.00 & 0.00 & 0.00 & 147.23 \\
\hline 1879_Mar & 0.03 & 0.00 & 00 & 0.00 & 0.00 & 0.00 & 0.00 & 0.00 & 0.00 & 0.00 & 0.01 & 0.00 & 0.00 & 0.00 & 0.00 & 0.00 & 0.00 & 0.00 & 9.94 \\
\hline 1883_Mar & 0.06 & .00 & 0.00 & 0.02 & 0.00 & 0.00 & 0.00 & 0.00 & 0.00 & 0.00 & 0.30 & 0.00 & 0.02 & 0.00 & 0.02 & 0.00 & 0.00 & 0.00 & .05 \\
\hline 1887_Mar & 0.05 & 0.00 & 0.02 & 0.01 & 0.00 & 0.00 & 0.00 & 0.00 & 0.00 & 0.00 & 0.00 & .00 & 0.00 & 0.00 & 0.00 & 0.00 & 0.00 & 0.00 & 175.13 \\
\hline 1888_Mar & 0.03 & 0.00 & 0.00 & 0.08 & 0.00 & 0.00 & 0.00 & 0.00 & 0.00 & 0.00 & 0.04 & 0.00 & 0.02 & 0.00 & 0.00 & 0.00 & 0.00 & 0.00 & 165.06 \\
\hline 1889_Mar & 0.10 & 0.00 & 0.00 & 0.01 & 0.00 & 0.00 & 0.00 & 0.00 & 0.00 & 0.00 & 0.01 & 0.00 & 0.07 & 0.00 & 0.00 & 0.00 & 0.00 & 0.00 & .35 \\
\hline 1893_Mar & 0.00 & 00 & 23 & 0.30 & 0.00 & 0.00 & 0.00 & 00 & 0.00 & 00 & 0.14 & .00 & 0.00 & 0.00 & 0.00 & .03 & 0.00 & 00 & .51 \\
\hline 1894_Mar & 0.02 & 00 & 20 & 0.29 & 0.00 & 00 & 0.00 & 00 & 0.00 & .00 & 0.22 & .00 & 0.00 & 0.02 & 0.03 & 0.03 & .00 & .00 & .52 \\
\hline 1895_Mar & 0.00 & 0.17 & .04 & 0.12 & 0.00 & 0.00 & 0.00 & .00 & 0.00 & .00 & 0.56 & 0.00 & 0.00 & 0.03 & 0.04 & 0.02 & .00 & 0.00 & 142.01 \\
\hline 1896_Mar & 0.00 & 0.06 & 0.07 & 0.11 & 0.00 & 0.00 & 0.00 & 0.00 & 0.04 & 0.00 & 0.55 & 0.00 & 0.00 & 0.03 & 0.03 & 0.00 & 0.00 & 0.00 & 141.12 \\
\hline 1897_Mar & 0.00 & 0.12 & 0.04 & 0.22 & 0.00 & 0.00 & 0.00 & 0.00 & 0.03 & 0.00 & 0.40 & 0.00 & 0.00 & 0.03 & 0.03 & 0.02 & 0.00 & 0.00 & 141.12 \\
\hline 1898_Mar & 0.04 & 17 & .07 & 0.15 & .00 & 0.00 & 0.00 & 00 & 0.00 & .00 & 0.31 & 00 & 0.00 & 0.03 & 0.00 & 0.04 & 0.00 & 0.00 & .06 \\
\hline 1899_Mar & 0.03 & 0.16 & 13 & 0.13 & 0.00 & 00 & 0.00 & 00 & 0.00 & .00 & 0.00 & 00 & 0.00 & 0.00 & 0.00 & 0.00 & 00 & 0.00 & 99 \\
\hline 1900_Mar & 0.00 & 0.21 & 0.14 & 0.15 & 0.00 & 0.00 & 0.00 & 0.00 & 0.00 & 00 & 0.00 & 0.00 & 0.00 & 0.00 & 0.00 & 0.00 & 0.00 & 0.00 & 140.68 \\
\hline 1901_Mar & 0.00 & 0.12 & 0.22 & 0.20 & 0.00 & 0.00 & 0.00 & 0.00 & 0.00 & 0.00 & 0.03 & 0.00 & 0.00 & 0.00 & 0.00 & 0.00 & 0.00 & 0.00 & 140.39 \\
\hline 1952_Mar & 0.06 & 00 & 00 & 0.00 & 0.00 & .00 & 0.00 & $0.00:$ & 0.00 & 00 & 0.34 & 1.0 & 0.05 & 0.00 & 0.00 & 0.00 & 0.00 & o...0. & 145.80 \\
\hline 1953_Mar & 0.02 & 00 & 00 & 0.00 & .00 & 00 & 0.00 & 00 & 0.00 & 0.00 & 0.16 & 0.00 & 0.05 & 0.00 & 0.00 & 0.00 & 0.00 & 0.00 & .48 \\
\hline 1954_Mar & 0.02 & 0.00 & .00 & 0.00 & 0.00 & 0.00 & 0.00 & 00 & 0.00 & 00 & 0.39 & 00 & 0.21 & 0.00 & 0.00 & 0.00 & 0.00 & 0.00 & 147.16 \\
\hline 1955_Mar & 0.01 & 0.00 & .00 & 0.00 & 0.00 & 0.00 & 0.00 & 0.00 & 0.00 & .00 & 0.07 & .02 & 0.78 & 0.00 & 0.00 & 0.00 & 0.00 & 0.00 & 144.58 \\
\hline 1993_Mar & 0.10 & 0.00 & 0.02 & 0.01 & 0.00 & 0.00 & 0.00 & 0.00 & 0.00 & 0.00 & 0.09 & 0.01 & 0.03 & 0.00 & 0.00 & 0.00 & 0.00 & 0.00 & 177.99 \\
\hline 1994_Mar & 04 & 00 & 05 & $\dddot{0} 0$ & 00 & 00 & 0.00 & $00:$ & 0.00 & 00 & 0.32 & 0.02 & 0.03 & 0.00 & 0.00 & 00 & 0.00 & 00 & 99 \\
\hline 1995_Mar & 0.00 & 0.00 & 13 & 0.04 & 0.00 & 0.00 & 0.00 & 00 & 0.00 & 0.00 & 0.03 & 0.00 & 0.00 & 0.00 & 0.00 & 0.00 & 0.00 & 0.00 & -174.08 \\
\hline 1996_Mar & 0.02 & 0.00 & 0.06 & 0.00 & 0.00 & 0.00 & 0.00 & 0.00 & 0.00 & 0.00 & 0.31 & 0.00 & 0.00 & 0.00 & 0.00 & 0.03 & 0.00 & 0.00 & 179.40 \\
\hline 1998_Mar & 0.04 & 0.00 & 0.01 & 0.00 & 0.00 & 0.00 & 0.00 & 0.00 & 0.00 & 0.00 & 0.00 & 0.00 & 0.00 & 0.00 & 0.00 & 0.00 & 0.00 & 0.00 & -171.50 \\
\hline 1999_Mar & 0.03 & 0.00 & 0.04 & 0.01 & 0.00 & 0.00 & 0.00 & 0.00 & 0.00 & 0.00 & 0.25 & 0.00 & 0.00 & 0.00 & 0.05 & 0.00 & 0.00 & 0.00 & 145.21 \\
\hline 2000_Mar & 0.00 & 0.05 & 0.16 & 0.07 & 0.00 & 0.00 & 0.00 & 00 & 0.00 & 00 & 0.35 & 0.00 & 0.00 & 0.00 & 0.00 & 0.00 & 0.00 & 0.00 & 144.23 \\
\hline 2001_Mar & 0.03 & 0.00 & 0.09 & 0.05 & 0.00 & 0.00 & 0.00 & 0.00 & 0.00 & 0.00 & 0.10 & 0.00 & 0.00 & 0.00 & 0.00 & 0.00 & 0.00 & 0.00 & 142.53 \\
\hline 2002_Mar & 0.04 & 0.04 & 0.07 & 0.04 & 0.00 & 0.00 & 0.00 & 0.00 & 0.00 & 0.00 & 0.09 & 0.00 & 0.00 & 0.00 & 0.00 & 0.00 & 0.00 & 0.00 & 142.88 \\
\hline 2003_Mar & 0.03 & 0.03 & 0.07 & 0.06 & 0.00 & 0.00 & 0.00 & 0.00 & 0.00 & 0.00 & 0.09 & 0.00 & 0.00 & 0.00 & 0.00 & 0.00 & 0.00 & 0.00 & 144.41 \\
\hline 2004_Mar & 0.02 & 0.07 & 17 & 0.05 & 0.00 & 0.02 & 0.00 & 0.00 & 0.00 & 0.00 & 0.33 & 0.00 & 0.00 & 0.00 & 0.00 & 0.00 & 0.00 & 0.00 & 144.68 \\
\hline 2005_Mar & 0.03 & 0.04 & 0.16 & 0.12 & 0.00 & 0.00 & 0.00 & 0.00 & 0.00 & 0.00 & 0.19 & 0.00 & 0.00 & 0.00 & 0.04 & 0.02 & 0.00 & 0.00 & 144.34 \\
\hline 2006_Mar & 0.00 & 0.00 & 0.13 & 0.10 & 0.00 & 0.00 & 0.00 & 0.00 & 0.00 & 0.00 & 0.10 & 0.00 & 0.00 & 0.00 & 0.03 & 0.00 & 0.00 & 0.00 & 144.29 \\
\hline 2007_Mar & 0.00 & 0.04 & 0.07 & 0.10 & 0.00 & 0.00 & 0.00 & 0.00 & 0.00 & 0.00 & 0.13 & 0.00 & 0.00 & 0.00 & 0.00 & 0.00 & 0.00 & 0.00 & 144.22 \\
\hline 2008_Mar & 0.02 & 0.26 & 0.03 & 0.19 & 0.00 & 0.00 & 0.00 & 0.00 & 0.00 & 0.00 & 0.09 & 0.00 & 0.00 & 0.00 & 0.02 & 0.00 & 0.00 & 0.00 & 144.10 \\
\hline 2009_Mar & 0.03 & 0.07 & 0.13 & 0.10 & 0.00 & 0.00 & 0.00 & 0.00 & 0.00 & 0.00 & 0.06 & 0.00 & 0.00 & 0.00 & 0.00 & 0.00 & 0.00 & 0.00 & 143.83 \\
\hline 012_Mar & 00 & 00 & 24 & 00 & 00 & 0.00 & .00 & 0.00 & .00 & 0.00 & 0.0 & .00 & 0.00 & 0.00 & 0.04 & 0.09 & 0.00 & 0.00 & -176.91 \\
\hline
\end{tabular}




\begin{tabular}{|c|c|c|c|c|c|c|c|c|c|c|c|c|c|c|c|}
\hline $\begin{array}{l}\stackrel{0}{E} \\
\stackrel{\mathbb{N}}{Z}\end{array}$ & 苂 & ס & స్తు & $\begin{array}{l}\overline{\tilde{a}} \\
\text { ص̆ }\end{array}$ & 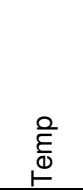 & 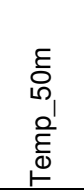 & 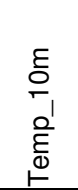 & 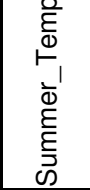 & 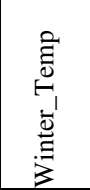 & 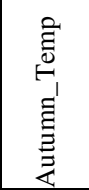 & 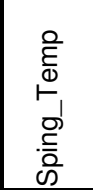 & 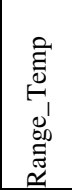 & 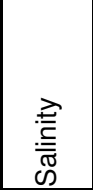 & 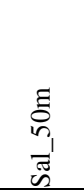 & $\begin{array}{l}\text { O } \\
\stackrel{c}{\alpha}\end{array}$ \\
\hline 2_Cro & -33.65 & $740923 E$ & $33876 \mathrm{~S}$ & 2133 & 19.03 & 17.93 & 18.71 & 21.50 & 16.89 & 19.12 & 18.24 & 4.61 & 35.57 & 35.60 & 0.29 \\
\hline 3_Cro & -34.02 & $1733060 \mathrm{E}$ & $340105 \mathrm{~S}$ & 2036 & 18.86 & 17.59 & 18.39 & 21.33 & 16.72 & 18.92 & 18.04 & 4.61 & 35.55 & 35.57 & 0.29 \\
\hline 8_Cro & -36.32 & $17764813 \mathrm{E}$ & $361920 S$ & 2411 & 17.96 & 17.45 & 18.06 & 20.30 & 15.68 & 17.61 & 17.31 & 4.62 & 35.45 & 35.54 & 0.27 \\
\hline 9_Cro & -36.69 & $1761431 \mathrm{E}$ & $364160 \mathrm{~S}$ & 430 & 17.78 & 17.45 & 18.07 & 20.13 & 15.49 & 17.39 & 17.13 & 4.64 & 35.43 & 35.53 & 0.27 \\
\hline 11_Cro & -39.94 & $1813060 \mathrm{E}$ & $395640 \mathrm{~S}$ & 3654 & 15.67 & 15.25 & 16.00 & 18.22 & 13.13 & 15.41 & 15.23 & 5.09 & 35.19 & 35.30 & 0.27 \\
\hline 12_Cro & -40.33 & $1795940 \mathrm{E}$ & $401980 S$ & 3003 & 15.53 & 15.36 & 16.08 & 18.01 & 13.16 & 15.16 & 15.16 & 4.85 & 35.18 & 35.36 & 0.28 \\
\hline 13_Cro & -40.40 & $1775940 \mathrm{E}$ & $402400 S$ & 2195 & 15.50 & 15.63 & 16.32 & 17.97 & 13.16 & 15.12 & 15.08 & 4.81 & 35.17 & 35.46 & 0.29 \\
\hline 15_Cro & -43.20 & $1860000 \mathrm{E}$ & $431200 \mathrm{~S}$ & 1128 & 13.79 & 13.38 & 13.99 & 16.08 & 11.54 & 13.36 & 13.34 & 4.54 & 34.90 & 35.00 & 0.35 \\
\hline 16_Cro & -42.53 & $1813060 \mathrm{E}$ & $423180 S$ & 1408 & 14.22 & 13.59 & 14.34 & 16.55 & 11.90 & 13.77 & 13.72 & 4.65 & 34.95 & 35.01 & 0.34 \\
\hline 17_Cro & -42.22 & $1792160 \mathrm{E}$ & $421320 S$ & 2540 & 14.03 & 13.59 & 14.38 & 16.73 & 11.77 & 13.95 & 13.63 & 4.97 & 34.97 & 35.03 & 0.34 \\
\hline 18_Cro & -42.72 & 176 & 424 & 850 & 13.60 & 13.10 & 13.88 & 16.31 & 11.44 & 13.61 & 13.10 & 4.87 & 34.88 & 34.96 & 0.39 \\
\hline 20_Cro & -43.00 & 174 & 430 & 854 & 13.40 & 12.05 & 12.91 & 16.07 & 11.35 & 13.40 & 12.77 & 4.72 & 34.83 & 34.78 & 0.43 \\
\hline 21_Cro & -43.33 & $1732160 \mathrm{E}$ & $431980 \mathrm{~S}$ & 79 & 13.19 & 11.38 & 12.29 & 15.82 & 11.19 & 13.17 & 12.53 & 4.63 & 34.79 & 34.66 & 0.46 \\
\hline 22_Cro & -45.33 & $1855520 \mathrm{E}$ & $451980 \mathrm{~S}$ & 4680 & 12.56 & 12.10 & 12.69 & 14.68 & 10.55 & 12.03 & 11.98 & 4.13 & 34.73 & 34.80 & 0.46 \\
\hline 24_Cro & -44.13 & 178 & $440780 \mathrm{~S}$ & 1080 & 12.42 & 11.50 & 12.44 & 15.28 & 10.35 & 12.70 & 11.86 & 4.92 & 34.71 & 34.64 & 0.47 \\
\hline 25_Cro & -44.29 & 174 & 441 & 580 & 12.28 & 10.72 & 11.83 & 15.04 & 10.34 & 12.55 & 11.64 & 4.70 & 34.66 & 34.53 & 0.52 \\
\hline 26_Cro & -44.35 & 172 & 442 & 100 & 12.35 & 10.08 & 11.27 & 14.98 & 10.49 & 12.49 & 11.65 & 4.49 & 34.67 & 34.43 & 0.54 \\
\hline 28_Cro & -46.60 & $1820480 \mathrm{E}$ & $463600 \mathrm{~S}$ & 4440 & 11.59 & 10.45 & 11.22 & 13.66 & 9.78 & 11.20 & 10.71 & 3.88 & 34.54 & 34.47 & 0.58 \\
\hline 32_Cro & -47.04 & 1740 & $470240 S$ & 1429 & 10.41 & 9.16 & 10.01 & 12.89 & 8.78 & 10.80 & 9.73 & 4.11 & 34.43 & 34.32 & 0.70 \\
\hline 33_Cro & -49.67 & 18 & 49 & 4500 & 9.79 & 8.86 & 9.37 & 11.51 & 8.21 & 9.35 & 8.95 & 3.30 & 34.35 & 34.29 & 0.81 \\
\hline 37_Cro & -51.72 & 167 & 512 & 629 & 8.46 & 8.96 & 9.00 & 9.78 & 7.18 & 7.95 & 8.12 & 2.60 & 34.33 & 34.45 & 0.96 \\
\hline 38_Pre & -43.96 & 1495 & 435 & 2622 & 12.82 & 13.05 & 13.34 & 14.58 & 11.01 & 12.22 & 12.33 & 3.57 & 34.96 & 35.10 & 0.56 \\
\hline 39_Pre & -40.51 & $1674050 \mathrm{E}$ & $403048 S$ & 1068 & 15.60 & 14.95 & 15.60 & 18.04 & 13.46 & 14.97 & 14.72 & 4.58 & 35.21 & 35.26 & 0.35 \\
\hline 41_Pre & -36.47 & $1652651 \mathrm{E}$ & $362838 S$ & 1088 & 17.92 & 16.89 & 17.62 & 20.37 & 15.73 & 17.45 & 17.06 & 4.64 & 35.47 & 35.48 & 0.29 \\
\hline 46_Pre & -42.61 & 144 & 42 & 2464 & 13.11 & 12.94 & 13.33 & 14.81 & 11.39 & $\begin{array}{l}12.77 \\
\end{array}$ & 12.54 & 3.42 & 34.98 & 35.04 & 0.48 \\
\hline 48_Pre & -48.73 & 173 & 484 & 638 & 9.56 & 8.67 & 9.24 & 11.70 & 8.10 & 9.79 & 8.93 & 3.60 & 34.37 & 34.30 & 0.79 \\
\hline 50_Pre & -53.04 & $1744128 \mathrm{~W}$ & 530 & 5470 & 8.00 & & & 7.73 & 6.41 & 7.38 & 7.73 & 1.33 & 34.24 & & 1.05 \\
\hline 58_Pre & -49.52 & $1643651 \mathrm{E}$ & $493141 S$ & 3250 & 9.64 & 9.66 & 10.06 & 111.11 & 8.26 & 9.18 & 9.26 & 2.85 & 34.47 & 34.54 & 0.87 \\
\hline 59_Pre & -47.00 & $1660366 \mathrm{E}$ & 465980 & 1648 & 11.11 & 11.69 & 11.95 & 12.95 & 9.52 & 10.74 & 10.64 & 3.43 & 34.62 & 34.75 & 0.70 \\
\hline 60_Pre & -38.46 & 148 & 3827 & 2350 & 16.37 & 15.92 & 16.81 & 18.45 & 14.01 & 15.47 & 15.95 & 4.44 & 35.39 & 35.43 & 0.30 \\
\hline 62_Pre & -37.00 & 170 & 370 & 2096 & 17.46 & 16.35 & 17.07 & 19.97 & 15.31 & 17.19 & 16.52 & 4.66 & 35.41 & 35.40 & 0.30 \\
\hline 64_Pre & -49.47 & $1742800 \mathrm{E}$ & $492800 \mathrm{~S}$ & 501 & 9.18 & 8.32 & 8.78 & 11.23 & 7.78 & 9.36 & 8.54 & 3.45 & 34.33 & 34.27 & 0.83 \\
\hline 66_Pre & -40.12 & $1795910 \mathrm{E}$ & $400700 \mathrm{~S}$ & 2890 & 15.69 & 15.54 & 16.25 & 18.14 & 13.31 & 15.30 & 15.30 & 4.83 & 35.19 & 35.39 & 0.27 \\
\hline 67_Pre & -50.58 & 168 & $503460 S$ & 575 & 9.01 & 9.34 & 9.37 & 10.49 & 7.69 & 8.64 & 8.59 & 2.80 & 34.38 & 34.47 & 0.88 \\
\hline 68_Pre & -44.50 & 178 & 44 & 1339 & 12.14 & 11.30 & 12.25 & 15.03 & 10.09 & 12.47 & 11.56 & 4.95 & 34.67 & 34.59 & 0.48 \\
\hline 70_Pre & -42.00 & 170 & 42 & 1000 & 14.67 & 14.55 & 15.42 & 17.05 & 12.49 & 14.03 & 14.03 & 4.56 & 35.04 & 35.19 & 0.39 \\
\hline 71_Pre & -41.40 & $1705500 \mathrm{E}$ & $412400 \mathrm{~S}$ & 202 & 14.63 & 14.50 & 15.38 & 17.01 & 12.46 & 13.99 & 14.00 & 4.55 & 35.04 & 35.18 & 0.39 \\
\hline 72_Pre & -42.38 & $1693600 \mathrm{E}$ & $421200 \mathrm{~S}$ & 167 & 14.55 & 14.41 & 15.29 & 16.92 & 12.39 & 13.89 & 13.93 & 4.53 & 35.03 & 35.17 & 0.40 \\
\hline 83_Pre & -50.06 & $1732231 E$ & 500 & 546 & 8.98 & 8.31 & 8.66 & 10.83 & 7.63 & 9.01 & 8.40 & 3.20 & 34.33 & 34.30 & 0.86 \\
\hline 96_Pre & -41.88 & & & 507 & 14.54 & 14.40 & 15.28 & 16.90 & 12.37 & 13.88 & 13.92 & 4.53 & 35.03 & 35.17 & 0.40 \\
\hline 97_Pre & -41.15 & & & 698 & 14.65 & 14.53 & 15.41 & 17.04 & 12.48 & 14.02 & 14.02 & 4.55 & 35.04 & 35.18 & 0.39 \\
\hline 98_Pre & -36.67 & $1703900 \mathrm{E}$ & $364000 \mathrm{~S}$ & 2112 & 17.62 & 16.45 & 17.22 & 20.13 & 15.47 & 17.39 & 16.70 & 4.66 & 35.43 & 35.41 & 0.30 \\
\hline 104_Pre & -41.66 & $1651310 \mathrm{E}$ & $413970 S$ & 4421 & 14.87 & 14.22 & 14.84 & 17.25 & 12.81 & $\begin{array}{l}14.18 \\
148\end{array}$ & 14.06 & 4.44 & 35.13 & 35.18 & 0.40 \\
\hline 105_Pre & -33.15 & $1623600 \mathrm{E}$ & $330900 \mathrm{~S}$ & 793 & 20.01 & 19.31 & 20.02 & 22.38 & 17.67 & 19.35 & 19.39 & 4.71 & 35.60 & 35.63 & 0.23 \\
\hline 107_Pre & -39.00 & $1693900 \mathrm{E}$ & $390000 \mathrm{~S}$ & 560 & 16.42 & 15.60 & 16.26 & 18.92 & 14.26 & 15.96 & 15.48 & 4.66 & 35.30 & 35.31 & 0.31 \\
\hline 113_Pre & $\begin{array}{l}-41.32 \\
\end{array}$ & $1662790 \mathrm{E}$ & $411920 S$ & 3253 & 15.11 & 14.43 & 15.08 & 17.51 & 13.01 & 14.43 & 14.29 & 4.50 & 35.15 & 35.20 & 0.38 \\
\hline 119_Pre & -42.55 & $1780996 \mathrm{~W}$ & $423300 \mathrm{~S}$ & 1366 & 14.21 & 13.60 & 14.34 & 13.76 & 11.89 & 13.76 & 13.71 & 1.86 & 34.95 & 35.02 & 0.34 \\
\hline 120_Pre & -44.54 & $1732500 \mathrm{E}$ & $443250 \mathrm{~S}$ & 543 & 12.13 & 9.94 & 11.41 & 14.81 & 10.27 & 12.37 & 11.44 & 4.54 & 34.64 & 34.40 & 0.55 \\
\hline 123_Pre & -44.40 & $1712148 \mathrm{E}$ & $442398 \mathrm{~S}$ & 22 & 12.46 & 10.22 & 11.21 & 14.98 & 10.60 & 12.45 & 11.79 & 4.37 & 34.70 & 34.46 & 0.55 \\
\hline 128_Pre & -45.72 & $1712500 \mathrm{E}$ & $454300 \mathrm{~S}$ & 1400 & 11.38 & 9.55 & 10.40 & 13.85 & 9.70 & 11.59 & 10.65 & 4.15 & 34.56 & 34.36 & 0.64 \\
\hline 129_Pre & -39.67 & $1722520 \mathrm{E}$ & $394020 \mathrm{~S}$ & 234 & 16.02 & 15.22 & 15.85 & 18.51 & 13.81 & 15.56 & 15.15 & 4.70 & 35.22 & 35.23 & 0.30 \\
\hline 133_Pre & -47.33 & $1695520 \mathrm{E}$ & $471980 \mathrm{~S}$ & 1004 & 10.55 & 9.74 & 10.34 & 12.62 & 9.02 & 10.58 & 9.93 & 3.60 & 34.50 & 34.45 & 0.72 \\
\hline 134_Pre & -46.64 & $1705880 \mathrm{E}$ & $463840 S$ & 1244 & 10.82 & 9.47 & 10.13 & 13.12 & 9.24 & 11.01 & 10.13 & 3.88 & 34.51 & 34.37 & 0.69 \\
\hline 136_Pre & -38.00 & $1734980 \mathrm{E}$ & $380000 \mathrm{~S}$ & 794 & 16.99 & 15.99 & 16.91 & 19.46 & 14.75 & 16.60 & 16.16 & 4.71 & 35.34 & 35.28 & 0.28 \\
\hline 137_Pre & -35.33 & $1752340 \mathrm{E}$ & $351980 \mathrm{~S}$ & 797 & 18.33 & 17.37 & 18.13 & 20.75 & 16.12 & 18.18 & 17.60 & 4.63 & 35.50 & 35.54 & 0.29 \\
\hline 140_Pre & -38.02 & $1733780 \mathrm{E}$ & $380120 \mathrm{~S}$ & 974 & 16.97 & 15.96 & 16.87 & 19.45 & 14.74 & 16.59 & 16.13 & 4.71 & 35.34 & 35.28 & 0.29 \\
\hline 141_Pre & -35.23 & $1751920 \mathrm{E}$ & $351380 \mathrm{~S}$ & 922 & 18.37 & 17.40 & 18.16 & 20.79 & 16.17 & $\begin{array}{l}18.24 \\
\end{array}$ & 17.63 & 4.63 & 35.51 & 35.54 & 0.29 \\
\hline 142_Pre & 35.13 & 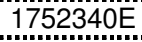 & $50 / 8$ & 1176 & 18.41 & 17.45 & .18 .22 & 20.84 & 16.21 & 2 & 17.6 & 4.62 & 35.51 & 35.55 & 0.29 \\
\hline
\end{tabular}




\begin{tabular}{|c|c|c|c|c|c|c|c|c|c|c|c|c|c|c|c|}
\hline $\begin{array}{l}\stackrel{0}{E} \\
\stackrel{\pi}{z}\end{array}$ & . & 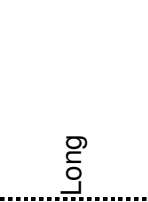 & . & 苂 & $\stackrel{\stackrel{2}{E}}{\stackrel{0}{0}}$ & 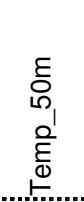 & 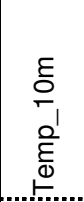 & 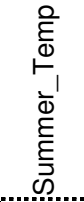 & 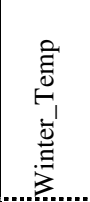 & 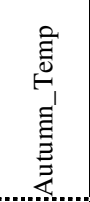 & 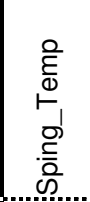 & 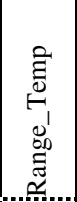 & 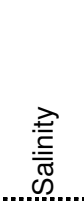 & 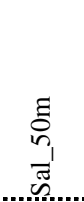 & $\begin{array}{l}\text { on } \\
\text { o요. }\end{array}$ \\
\hline 143_Pre & -51.70 & $1713120 \mathrm{E}$ & $14200 \mathrm{~S}$ & 519 & 8.36 & 8.22 & 8.43 & 9.83 & 7.10 & 8.03 & 7.94 & 2.73 & 34.30 & 34.33 & 0.94 \\
\hline 144_Pre & -38.63 & $1714800 \mathrm{E}$ & $383780 \mathrm{~S}$ & 1233 & 16.61 & 15.71 & 16.44 & 19.12 & 14.42 & 16.20 & 15.69 & 4.70 & 35.30 & 35.29 & 0.30 \\
\hline 145_Pre & -35.42 & $1751260 \mathrm{E}$ & $352520 \mathrm{~S}$ & 514 & 18.29 & 17.34 & 18.10 & 20.71 & 16.08 & 18.13 & 17.55 & 4.63 & 35.50 & 35.54 & 0.29 \\
\hline 151_Pre & -38.94 & $1781195 \mathrm{E}$ & $385630 \mathrm{~S}$ & 128 & 16.50 & 16.32 & 17.04 & 18.87 & 14.16 & 16.03 & 15.96 & 4.72 & 35.29 & 35.51 & 0.27 \\
\hline 1875_Mar & -45.07 & $1471368 \mathrm{E}$ & $450401 \mathrm{~S}$ & 3589 & 11.85 & 12.00 & 12.25 & 13.41 & 10.22 & 11.42 & 11.36 & 3.19 & 34.81 & 34.92 & 0.67 \\
\hline 1879_Mar & -51.37 & "1595640E" & $512208 S$ & 3928 & 8.23 & & & 9.60 & 6.99 & 7.91 & 7.83 & 2.62 & 34.31 & & 1.10 \\
\hline 1883_Mar & -47.89 & $1500318 \mathrm{E}$ & $475321 \mathrm{~S}$ & 2545 & 10.03 & 10.09 & 10.23 & 11.48 & 8.64 & 9.74 & 9.60 & 2.84 & 34.56 & 34.62 & 0.94 \\
\hline 1887_Mar & -54.82 & $1750780 \mathrm{~W}$ & 5449085 & 5214 & 6.82 & 7.12 & 7.24 & 6.69 & 5.29 & 6.32 & 6.69 & 1.40 & 34.16 & 34.19 & 1.21 \\
\hline 1888_Mar & -51.26 & $1650330 \mathrm{E}$ & $511541 S$ & 3808 & 8.65 & 14.74 & 15.39 & 9.98 & 7.36 & 8.15 & 8.31 & 2.62 & 34.36 & 35.37 & 0.98 \\
\hline 1889_Mar & -51.97 & $1612081 \mathrm{E}$ & $515820 \mathrm{~S}$ & 5704 & 7.94 & 14.74 & 15.39 & 9.29 & 6.72 & 7.59 & 7.55 & 2.57 & 34.28 & 35.37 & 1.11 \\
\hline 1893_Mar & -39.34 & $0 \mathrm{E}$ & 392 & 1702 & 14.69 & 14.33 & 15.00 & 16.54 & 12.83 & 14.52 & 14.00 & 3.71 & 35.22 & 35.33 & 0.34 \\
\hline 1894_Mar & -39.31 & 1423 & $60 \mathrm{~S}$ & 1336 & 14.70 & 14.33 & 15.00 & 16.56 & 12.84 & 14.54 & 14.01 & 3.71 & 35.22 & 35.33 & 0.34 \\
\hline 1895_Mar & -38.88 & 1420 & $385250 \mathrm{~S}$ & 686 & 14.83 & 14.37 & 15.02 & 16.71 & 12.99 & 14.74 & 14.11 & 3.72 & 35.24 & 35.34 & 0.33 \\
\hline 1896_Mar & -38.61 & $1410710 \mathrm{E}$ & $383680 \mathrm{~S}$ & 732 & 14.86 & 14.53 & 15.20 & 16.73 & 13.03 & 14.83 & 14.13 & 3.70 & 35.24 & 35.36 & 0.33 \\
\hline 1897_Mar & -38.67 & 1410 & $384020 \mathrm{~S}$ & 1345 & 14.84 & 14.51 & 15.17 & 16.70 & 13.01 & 14.80 & 14.11 & 3.70 & 35.24 & 35.36 & 0.33 \\
\hline 1898_Mar & -38.85 & $0 \mathrm{E}$ & $385120 \mathrm{~S}$ & 2348 & 14.75 & 14.41 & 15.06 & 16.60 & 12.92 & 14.70 & 14.03 & 3.68 & 35.23 & 35.34 & 0.33 \\
\hline 1899_Mar & -39.68 & 140 & $394080 \mathrm{~S}$ & 3984 & 14.36 & 14.13 & 14.73 & 16.17 & 12.56 & 14.24 & 13.70 & 3.61 & 35.17 & 35.28 & 0.36 \\
\hline 1900_Mar & -39.83 & 1404 & $394980 \mathrm{~S}$ & 4319 & 14.26 & 14.02 & 14.60 & 16.05 & 12.47 & 14.14 & 13.60 & 3.58 & 35.15 & 35.25 & 0.37 \\
\hline 1901_Mar & -40.07 & ${ }^{\prime} 1402320 \mathrm{E}$ & 4003905 & 4703 & 14.11 & 13.80 & 14.33 & 15.89 & 12.34 & 14.00 & 13.46 & 3.56 & 35.13 & 35.20 & 0.38 \\
\hline 1952_Mar & -47.15 & $1454780 \mathrm{E}$ & 4708865 & 2890 & 10.29 & 10.23 & 10.39 & 11.67 & 8.90 & 10.06 & 9.89 & 2.76 & 34.59 & 34.64 & 0.89 \\
\hline 1953_Mar & -49.15 & 148 & OS & 3885 & 8.99 & 7.81 & 7.90 & 10.34 & 7.74 & 8.88 & 8.61 & 2.60 & 34.42 & 34.28 & 1.07 \\
\hline 1954_Mar & -50.59 & 147 & $60 \mathrm{~S}$ & 4350 & 7.76 & 1.42 & 1.64 & 9.07 & 6.64 & 7.89 & 7.34 & 2.43 & 34.27 & 33.86 & 1.22 \\
\hline 1955_Mar & -57.95 & $1443503 \mathrm{E}$ & 575686S & 3740 & 2.12 & -1.50 & -1.38 & 4.00 & 1.18 & 3.48 & 1.31 & 2.81 & 33.88 & 34.18 & 1.73 \\
\hline 1993_Mar & -45.39 & $1775940 \mathrm{E}$ & $452340 \mathrm{~S}$ & 0 & 11.46 & 10.37 & 11.36 & 14.32 & 9.51 & 11.89 & 10.80 & 4.81 & 34.57 & 34.43 & 0.56 \\
\hline 1994_Mar & -45.02 & 1745 & $20 \mathrm{~S}$ & 1122 & 11.71 & 10.23 & 11.34 & 14.46 & 9.84 & 12.08 & 11.05 & 4.62 & 34.58 & 34.45 & 0.57 \\
\hline 1995_Mar & -45.33 & $1740480 \mathrm{~W}$ & 451 & 4808 & 12.56 & 12.10 & 12.69 & 12.03 & 10.55 & 12.03 & 11.98 & 1.48 & 34.73 & 34.80 & 0.46 \\
\hline 1996_Mar & -40.24 & $1792400 \mathrm{E}$ & $401440 S$ & 3010 & 15.61 & 15.45 & 16.16 & 18.07 & 13.24 & 15.22 & 15.23 & 4.83 & 35.19 & 35.38 & 0.28 \\
\hline 1998_Mar & -41.58 & $1713000 \mathrm{~W}$ & $413480 \mathrm{~S}$ & 3556 & 14.52 & 14.00 & 14.68 & 14.35 & 12.11 & 14.35 & 14.10 & 2.24 & 34.98 & 35.06 & 0.30 \\
\hline 1999_Mar & -44.33 & $1451260 \mathrm{E}$ & $441980 S$ & 2270 & 12.14 & 12.07 & 12.35 & 13.71 & 10.52 & 11.78 & 11.62 & 3.20 & 34.84 & 34.93 & 0.61 \\
\hline 2000_Mar & -41.39 & $1441380 \mathrm{E}$ & $412340 S$ & 814 & 13.83 & 13.47 & 13.96 & 15.60 & 12.01 & 13.47 & 13.25 & 3.59 & 35.09 & 35.12 & 0.41 \\
\hline 2001_Mar & -42.25 & $1423180 \mathrm{E}$ & $421500 \mathrm{~S}$ & 4103 & 13.12 & 12.82 & 13.21 & 14.81 & 11.43 & 12.88 & 12.53 & 3.38 & 34.97 & 35.01 & 0.47 \\
\hline 2002_Mar & -42.23 & $1425280 \mathrm{E}$ & 4213805 & 3715 & 13.17 & 12.86 & 13.26 & 14.86 & 11.47 & 12.91 & 12.57 & 3.40 & 34.98 & 35.02 & 0.47 \\
\hline 2003_Mar & -42.20 & $1442460 \mathrm{E}$ & $421200 \mathrm{~S}$ & 2360 & 13.36 & 13.01 & 13.42 & 15.09 & 11.60 & 13.01 & 12.78 & 3.49 & 35.01 & 35.05 & 0.46 \\
\hline 2004_Mar & -42.18 & $1444080 \mathrm{E}$ & 421080S & 765 & 13.41 & 13.03 & 13.44 & 15.14 & 11.63 & 13.04 & 12.83 & 3.51 & 35.02 & 35.06 & 0.45 \\
\hline 2005_Mar & -41.52 & $1442040 \mathrm{E}$ & $413120 \mathrm{~S}$ & 838 & 13.77 & 13.42 & 13.90 & 15.53 & 11.95 & 13.40 & 13.19 & 3.58 & 35.08 & 35.11 & 0.42 \\
\hline 2006_Mar & -41.51 & $1441740 \mathrm{E}$ & $413060 \mathrm{~S}$ & 1081 & 13.77 & 13.42 & 13.90 & 15.53 & 11.95 & 13.41 & 13.18 & 3.58 & 35.08 & 35.11 & 0.42 \\
\hline 2007_Mar & -41.52 & $1441320 \mathrm{E}$ & $413120 \mathrm{~S}$ & 1557 & 13.75 & 13.42 & 13.90 & 15.51 & 11.94 & 13.40 & 13.17 & 3.57 & 35.07 & 35.11 & 0.42 \\
\hline 2008_Mar & -41.50 & 14400600 & $413000 \mathrm{~S}$ & 1703 & 13.75 & 13.42 & 13.90 & 15.51 & 11.94 & 13.40 & 13.16 & 3.57 & 35.07 & 35.11 & 0.42 \\
\hline 2009_Mar & -41.12 & $1434980 \mathrm{E}$ & $410720 \mathrm{~S}$ & 1265 & 13.94 & 13.58 & 14.09 & 15.71 & 12.11 & 13.61 & 13.34 & 3.60 & 35.10 & 35.16 & 0.40 \\
\hline 2012_Mar & -42.68 & $1765460 \mathrm{w}$ & 4240805 & 1000 & 14.13 & 13.6 & 14.35 & 13.68 & 11.83 & 13.68 & 13.64 & 1.85 & 34.94 & 35.04 & 0.34 \\
\hline
\end{tabular}




\begin{tabular}{|c|c|c|c|c|c|c|c|c|c|}
\hline $\begin{array}{l}\text { E } \\
\text { ত } \\
Z\end{array}$ & 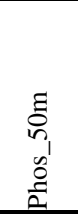 & 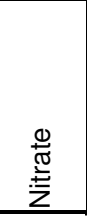 & 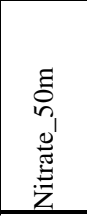 & 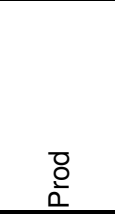 & $\begin{array}{l}\overline{0} \\
\text { o } \\
x^{\prime} \\
\stackrel{\alpha}{\Sigma}\end{array}$ & 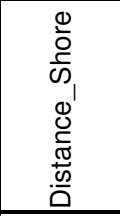 & 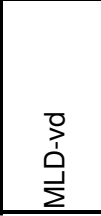 & 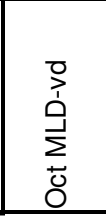 & 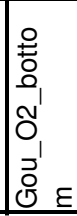 \\
\hline 2_Cro & 0.39 & 1.25 & 2.86 & 477.77 & 633.91 & 131.00 & 72.46 & 108.37 & 3.56 \\
\hline 3_Cro & 0.41 & 1.27 & 3.18 & 614.20 & 817.22 & 60.00 & 69.53 & 106.04 & 3.71 \\
\hline 8_Cro & 0.36 & 1.17 & 2.16 & 610.90 & 856.57 & 81.00 & 57.32 & 30.06 & 3.78 \\
\hline 9_Cro & 0.36 & 1.19 & 2.22 & 873.52 & 1163.89 & 38.00 & 52.32 & 26.06 & 4.65 \\
\hline 11_Cro & 0.27 & 1.10 & 1.78 & 631.85 & 961.48 & 191.00 & 67.02 & 27.17 & 4.56 \\
\hline 12_Cro & 0.26 & 1.27 & 1.96 & 715.60 & 1139.72 & 211.00 & "70.48 & 27.75 & 4.17 \\
\hline 13_Cro & 0.24 & 1.38 & 1.55 & 792.33 & $\begin{array}{l}1204.99 \\
\end{array}$ & 98.00 & 73.64 & 29.45 & 4.13 \\
\hline 15_Cro & 0.36 & 2.11 & 2.74 & 624.06 & 924.85 & 259.00 & 59.46 & 4.40 & 4.18 \\
\hline 16_Cro & 0.38 & 2.17 & 3.58 & 756.27 & 1171.28 & 287.00 & 59.69 & 39.32 & 3.85 \\
\hline 17_Cro & 0.37 & 2.16 & 3.94 & 802.59 & 1233.69 & 297.00 & 70.83 & 43.12 & 3.97 \\
\hline 18_Cro & 0.40 & 2.64 & 4.67 & 849.83 & 1287.90 & 174.00 & 66.48 & 51.00 & 4.60 \\
\hline 20_Cro & 0.49 & 2.95 & 6.30 & 983.84 & 1431.91 & 92.00 & 63.94 & 18.63 & 4.85 \\
\hline 21_Cro & 0.51 & 3.28 & 6.90 & 1252.06 & 1827.74 & 35.00 & 58.66 & 10.45 & 5.77 \\
\hline 22_Cro & 0.48 & 3.67 & 4.46 & 559.43 & 872.13 & 292.00 & 66.68 & 3.55 & 4.76 \\
\hline 24_Cro & 0.56 & 3.92 & 6.97 & 653.40 & 1136.74 & 395.00 & 58.88 & 58.79 & 5.04 \\
\hline 25_Cro & 0.63 & 4.29 & 8.65 & 881.96 & 1486.97 & 159.00 & 51.70 & 22.75 & 5.39 \\
\hline 26_Cro & 0.70 & 4.44 & 9.96 & 1026.79 & 1743.93 & 60.00 & 33.08 & 10.05 & 5.87 \\
\hline 28_Cro & "0.71" & 6.07 & "8.30" & 427.52 & "707.68 & 616.00 & 62.77 & 8.45 & 4.82 \\
\hline 32_Cro & "än' & 8.09 & 12.03 & 338.95 & "595.94 & 284.00 & 53.43 & "14.11" & 4.28 \\
\hline 33_Cro & 0.95 & 10.35 & 12.22 & 293.45 & "495.11 & 806.00 & 90.22 & "11.91" & 4.80 \\
\hline 37_Cro & 0.83 & 13.42 & 11.64 & 244.77 & "391.48' & 139.00 & 130.89 & 134.69 & 5.56 \\
\hline 38_Pre & 0.50 & 5.55 & 4.81 & 726.04 & 1162.04 & 185.00 & 46.24 & 21.71 & 4.25 \\
\hline 39_Pre & 0.34 & 1.56 & 2.01 & 588.84 & 770.31 & 356.00 & 73.28 & 133.48 & 4.13 \\
\hline 41_Pre & 0.33 & 0.86 & 1.07 & 559.09 & 748.50 & 830.00 & 69.99 & 62.22 & 3.75 \\
\hline 46_Pre & 0.40 & 4.66 & 3.41 & 717.98 & 1040.92 & 66.00 & 46.64 & 15.89 & 4.47 \\
\hline 48_Pre & 0.90 & 10.45 & 13.45 & 273.26 & 443.20 & 392.00 & 62.81 & 29.51 & 5.14 \\
\hline 50_Pre & & 14.38 & & 239.05 & 423.20 & 1307.00 & 108.64 & 6.46 & 4.84 \\
\hline 58_Pre & 0.84 & 10.57 & 9.04 & 357.24 & 611.22 & 361.00 & 127.92 & 55.31 & 4.31 \\
\hline 59_Pre & 0.57 & 7.41 & 5.39 & 661.07 & 1267.02 & 102.00 & 39.18 & 11.00 & 4.49 \\
\hline 60_Pre & 0.31 & 1.82 & 2.60 & 850.49 & 1219.81 & 66.00 & 100.37 & 151.02 & 4.44 \\
\hline 62_Pre & 0.33 & 1.05 & 1.94 & 516.17 & 756.26 & 382.00 & 59.60 & 127.17 & 3.63 \\
\hline 64_Pre & 0.93 & 11.53 & 14.48 & 266.28 & 408.80 & 487.00 & 107.53 & 99.54 & 5.33 \\
\hline 66_Pre & 0.25 & 1.21 & 1.82 & 708.39 & 1135.22 & 200.00 & 69.98 & 27.28 & 4.20 \\
\hline 67_Pre & 0.77 & 12.06 & 11.06 & 246.62 & 367.18 & 380.00 & 114.26 & 12.28 & 5.76 \\
\hline 68_Pre & 0.58 & 4.24 & 7.19 & 493.61 & 968.80 & 458.00 & 57.30 & 58.87 & 4.34 \\
\hline 70_Pre & 0.34 & 2.16 & 2.68 & 671.43 & 1017.46 & 113.00 & 38.13 & 82.68 & 4.58 \\
\hline 71_Pre & 0.35 & 2.19 & 2.83 & 674.50 & 1003.34 & 121.00 & 44.75 & 96.50 & 5.06 \\
\hline 72_Pre & 0.36 & 2.29 & 3.07 & 687.41 & 975.29 & 139.00 & 30.46 & 71.01 & 4.28 \\
\hline 83_Pre & 0.91 & 12.20 & 14.46 & 258.44 & 394.26 & 477.00 & 138.43 & 233.28 & 5.78 \\
\hline 96_Pre & 0.36 & 2.30 & 3.10 & 687.41 & 975.29 & 115.00 & 29.90 & 69.96 & 4.26 \\
\hline 97_Pre & 0.34 & 2.17 & 2.73 & 674.50 & 1003.34 & 110.00 & 26.87 & 62.80 & 4.16 \\
\hline 98_Pre & 0.34 & 1.10 & 2.21 & 512.86 & 739.57 & 292.00 & 56.17 & 104.83 & 3.65 \\
\hline 104_Pre & 0.38 & 2.29 & 2.40 & 612.94 & 827.34 & 350.00 & 41.35 & 42.22 & 4.50 \\
\hline 105_Pre & 0.25 & 0.63 & 0.65 & 543.99 & 677.20 & 931.00 & 58.22 & 59.40 & 4.22 \\
\hline 107_Pre & 0.31 & 1.13 & 1.62 & 525.81 & 708.20 & 302.00 & 74.74 & 137.84 & 4.64 \\
\hline 113_Pre & 0.36 & 2.00 & 2.35 & 634.09 & 839.09 & 331.00 & 49.72 & 85.97 & 4.31 \\
\hline 119_Pre & 0.37 & 2.15 & 3.51 & 761.56 & 1191.88 & 493.00 & 59.38 & 39.03 & 3.93 \\
\hline 120_Pre & 0.72 & 4.65 & 10.29 & 772.52 & 1516.67 & 80.00 & 43.09 & 10.18 & 5.51 \\
\hline 123_Pre & 0.71 & 4.51 & 9.64 & 0.00 & 0.00 & 6.00 & 20.55 & 10.04 & 6.19 \\
\hline 128_Pre & 0.83 & 6.24 & 10.82 & 469.15 & 808.75 & 49.00 & 25.72 & 10.00 & 4.99 \\
\hline 129_Pre & 0.32 & 1.21 & 1.03 & 745.36 & 1059.24 & 92.00 & 55.50 & 52.53 & 5.15 \\
\hline 133_Pre & 0.82 & 8.20 & 11.29 & 358.04 & 576.05 & 87.00 & 40.36 & 10.00 & 5.18 \\
\hline 134_Pre & 0.85 & 7.43 & 11.43 & 387.70 & 644.62 & 80.00 & 33.00 & 10.00 & 4.81 \\
\hline 136_Pre & 0.36 & 1.13 & 1.44 & 699.07 & 961.68 & 75.00 & 49.11 & 26.14 & 4.77 \\
\hline 137_Pre & 0.47 & 1.30 & 3.83 & 605.77 & 805.57 & 81.00 & 60.30 & 40.85 & 4.39 \\
\hline 140_Pre & 0.35 & 1.13 & 1.42 & 696.79 & 978.15 & 91.00 & 48.53 & 27.39 & 4.38 \\
\hline 141_Pre & 0.46 & 1.31 & 3.73 & 631.18 & 848.50 & 79.00 & 61.34 & 47.91 & 4.30 \\
\hline 142_Pre & 0.45 & 1.30 & 3.60 & 587.23 & 773.89 & 90.00 & 62.75 & 54.77 & 4.08 \\
\hline
\end{tabular}




\begin{tabular}{|c|c|c|c|c|c|c|c|c|c|}
\hline $\begin{array}{l}\stackrel{0}{E} \\
\stackrel{\pi}{Z}\end{array}$ & 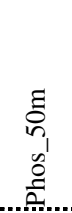 & 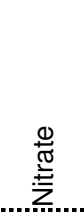 & 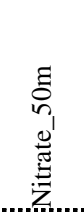 & ס. & 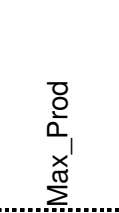 & $\begin{array}{l}0 \\
\frac{0}{0} \\
\frac{0}{\omega} \\
0 \\
0 \\
\frac{0}{0} \\
\frac{\pi}{0} \\
0 \\
0.0\end{array}$ & م) & 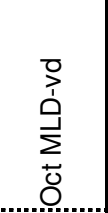 & 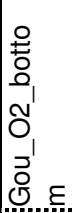 \\
\hline 43_Pre & 0.90 & 13.98 & 14.40 & 233.44 & 389.57 & 576.00 & 98.17 & 518.16 & 5.95 \\
\hline 44_Pre & 32 & 1.10 & 1.43 & 620.35 & 920.95 & 181.00 & 56.24 & 76.57 & 3.84 \\
\hline 45_Pre & 47 & 31 & 3.93 & 664.45 & 907.02 & 61.00 & 59.83 & 40.43 & 4.62 \\
\hline 51_Pre & 21 & 1.07 & 1.23 & 197.27 & 479.05 & 34.00 & 63.78 & 25.19 & 4.90 \\
\hline 875_Mar & 6.61 & 7.31 & 6.48 & 616 & 1038.48 & 138.00 & 46.33 & 14.54 & 4.46 \\
\hline 1879_Mar & & 14.28 & & 257.88 & 483.51 & 667.00 & 102.58 & 166.47 & 4.67 \\
\hline 1883_Mar & 94 & 11.49 & 11.02 & 366.53 & 641.48 & 531.00 & 88.14 & 289.21 & 4.23 \\
\hline 1887_Mar & 1.26 & 17.31 & 17.37 & 20 & 336.56 & 1309.00 & 103.76 & 27.35 & 4.83 \\
\hline 1888_Mar & 0.29 & 12.86 & 1.33 & 293.49 & 540.37 & 65.00 & 137.30 & 321.87 & 4.70 \\
\hline 1889_Mar & 0.29 & 14.72 & 1.33 & 233.77 & 411.41 & 662.00 & 110.43 & 246.52 & 4.66 \\
\hline 1893_Mar & 31 & 2.45 & 1.91 & 59 & 818.42 & 85.00 & 77.48 & 199.67 & 4.66 \\
\hline 894_Mar & 31 & 2.44 & 1.91 & 61 & 836.76 & 85.00 & 76.77 & 197.09 & 4.74 \\
\hline 1895_Mar & 32 & 2.32 & 2.00 & & 819.67 & 51.00 & 65.32 & 133.85 & 4.82 \\
\hline 1896_Mar & 0.31 & 2.25 & 1.88 & 58 & 748.82 & 21.00 & 67.26 & 124.07 & 4.91 \\
\hline 897_Mar & 0.3 & 2.27 & 1.90 & $5 /$ & 770.57 & 34.00 & 67.03 & 93 & 4.79 \\
\hline 1898_Mar & 0.32 & 2.35 & 2.03 & 56 & 771.30 & 56.00 & 67.42 & 128.84 & 4.42 \\
\hline 1899_Mar & 34 & 2.76 & 2.44 & 57 & 741.13 & 137.00 & 72.40 & 123.92 & 4.61 \\
\hline 1900_Mar & 0.36 & 2.88 & 2.64 & 57 & 740.55 & 167.00 & 71.63 & 118.46 & 4.72 \\
\hline 1901_Mar & 0.38 & 3.06 & 3.04 & 574.28 & 750.43 & 203.00 & 69.93 & 111.52 & 4.81 \\
\hline 1952_Mar & 0.90 & 10.97 & 10.70 & 35 & 593.13 & 375.00 & 91.83 & 82.51 & 4.37 \\
\hline 1953_Mar & 1.26 & 13.96 & 15.85 & 28 & 484.69 & 601.00 & 113.12 & 209.28 & 4.68 \\
\hline 1954_Mar & 1.84 & 16.73 & 27.36 & & 463.57 & 745.00 & 103.73 & 143.20 & 4.73 \\
\hline 1955_Mar & 2.13 & 26.05 & 31.01 & & 191.40 & 1575.00 & 26.47 & 29.73 & 5.02 \\
\hline 1993_Mar & 0.69 & 5.4 & 8.93 & 43 & 812.21 & 418.00 & 50.74 & 64.33 & 4.40 \\
\hline 994_Mar & 0 & 5.2 & 9.5 & 79 & 38 & 0 & 06 & 22.22 & 4.77 \\
\hline 1995_Mar & 48 & 3.67 & 4.46 & 43 & 872.13 & 00 & 66.68 & 3.55 & 4.76 \\
\hline 1996_Mar & 0.26 & 1.27 & 1.87 & & 1181.55 & 205.00 & 71.16 & 27.87 & 4.25 \\
\hline 1998_Mar & 0.30 & 1.36 & 1.47 & 532.99 & 767.94 & 924.00 & 56.01 & 44.69 & 4.60 \\
\hline 1999_Mar & 0.56 & 6.60 & 6.03 & 642.97 & 1082.12 & 87.00 & 41.65 & 11.54 & 4.46 \\
\hline 2000_Mar & 0.36 & 3.53 & 2.74 & 71 & 1014.70 & 40.00 & 93.35 & 26.04 & 4.91 \\
\hline 2001_Mar & 0.46 & 4.59 & 4.47 & 57 & 888.25 & 211.00 & 68.67 & 35.96 & 4.78 \\
\hline 2002_Mar & 0.45 & 4.51 & 4.25 & 609.23 & 927.38 & 185.00 & 66.43 & 31.86 & 4.73 \\
\hline 2003_Mar & 0.40 & 4.25 & 3.39 & 715.37 & 1066.96 & 62.00 & 55.42 & 18.67 & 4.61 \\
\hline 004_Mar & 0.40 & 4.20 & 3.30 & 85 & 1201.70 & 30.00 & 55.47 & 18.29 & 4.85 \\
\hline 2005_Mar & 0.37 & 3.63 & 2.83 & 773.34 & 1165.55 & 36.00 & 97.17 & 24.19 & 5.02 \\
\hline 2006_Mar & 0.37 & 3.63 & 2.83 & 701.95 & 1002.99 & 36.00 & 96.40 & 24.64 & 4.91 \\
\hline 2007_Mar & 0.37 & 3.65 & 2.85 & 70 & 1002.99 & 44.00 & 95.15 & 25.29 & 4.73 \\
\hline 2008_Mar & 0.37 & 3.64 & 2.85 & 667.58 & 945.36 & 53.00 & 93.06 & 26.56 & 4.49 \\
\hline 09_Mar & 0.3 & 3.3 & 2.50 & & 841.06 & 62.00 & 78.72 & 37.19 & 4.87 \\
\hline 012_Mar & 0.37 & 2.10 & 3.1 & 7 & 1074.62 & 592.00 & 58.89 & 22.11 & 4.2 \\
\hline
\end{tabular}




\begin{tabular}{|c|c|c|c|c|c|c|c|c|c|c|c|c|c|c|c|c|}
\hline 节 & 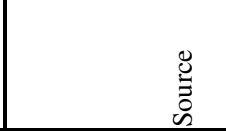 & 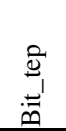 & 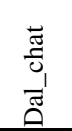 & 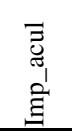 & 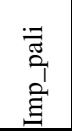 & 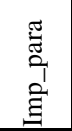 & 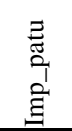 & 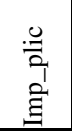 & $\begin{array}{l}\frac{\pi}{2} \\
\text { के } \\
\text { है } \\
\text { ह् }\end{array}$ & 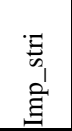 & 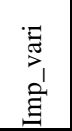 & 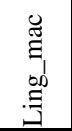 & $\begin{array}{l}\overrightarrow{0} \\
\text { ज्ञ } \\
\tilde{\Xi} \\
\text { z }\end{array}$ & $\begin{array}{l}J^{\prime} \\
\vec{J}^{\prime} \\
0_{0}^{\prime} \\
0\end{array}$ & $\begin{array}{l}n_{1} \\
\vec{J}_{0} \\
U_{1} \\
0\end{array}$ & $\begin{array}{l}\overline{\mathbb{E}} \\
\bar{w} \\
0^{\prime} \\
0\end{array}$ \\
\hline 2_Cro & Crouch et al. 2010 & 0.00 & 0.00 & 0.08 & 0.00 & 0.00 & 0.07 & 0.00 & 0.01 & 0.00 & 0.01 & 0.00 & 0.10 & 0.00 & 0.00 & 0.00 \\
\hline 3_Cro & Crouch et al. 2010 & 0.00 & 0.00 & 0.12 & 0.00 & 0.01 & 0.04 & 0.00 & 0.02 & 0.03 & 0.03 & 0.00 & 0.11 & 0.19 & 0.00 & 0.00 \\
\hline 8_Cro & Crouch et al. 2010 & 0.00 & 0.00 & 0.20 & 0.00 & 0.00 & 0.05 & 0.02 & 0.05 & 0.00 & 0.04 & 0.00 & 0.06 & 0.18 & 0.02 & 0.00 \\
\hline 9_Cro & Crouch et al. 2010 & 0.00 & 0.00 & 0.00 & 0.00 & 0.01 & 0.00 & 0.00 & 0.01 & 0.00 & 0.00 & 0.00 & 0.01 & 0.27 & 0.02 & 0.00 \\
\hline 11_Cro & Crouch et al. 2010 & 0.00 & 0.00 & 0.18 & 0.00 & 0.05 & 0.06 & 0.00 & 0.10 & 0.02 & 0.05 & 0.00 & 0.24 & 0.16 & 0.03 & 0.00 \\
\hline 12_Cro & Crouch et al. 2010 & 0.00 & 0.00 & 0.07 & 0.00 & 0.01 & 0.02 & 0.00 & 0.01 & 0.00 & 0.00 & 0.00 & 0.18 & 0.12 & 0.01 & 0.00 \\
\hline 13_Cro & Crouch et al. 2010 & 0.00 & 0.00 & 0.12 & 0.00 & 0.05 & 0.03 & 0.01 & 0.03 & 0.01 & 0.00 & 0.01 & 0.13 & 0.11 & 0.00 & 0.00 \\
\hline 15_Cro & Crouch et al. 2010 & 0.00 & 0.00 & 0.06 & 0.00 & 0.03 & 0.01 & 0.00 & 0.02 & 0.00 & 0.00 & 0.00 & 0.30 & 0.21 & 0.00 & 0.00 \\
\hline 16_Cro & Crouch et al. 2010 & 0.00 & 0.00 & 0.03 & 0.00 & 0.00 & 0.01 & 0.00 & 0.01 & 0.00 & 0.00 & 0.00 & 0.17 & 0.27 & 0.01 & 0.00 \\
\hline 17_Cro & Crouch et al. 2010 & 0.00 & 0.00 & 0.08 & 0.00 & 0.00 & 0.00 & 0.00 & 0.01 & 0.00 & 0.01 & 0.00 & 0.07 & 0.29 & 0.04 & 0.00 \\
\hline 18_Cro & Crouch et al. 2010 & 0.00 & 0.00 & 0.01 & 0.00 & 0.00 & 0.01 & 0.00 & 0.01 & 0.00 & 0.00 & 0.00 & 0.16 & 0.35 & 0.01 & 0.00 \\
\hline 20_Cro & Crouch et al. 2010 & 0.00 & 0.00 & 0.00 & 0.00 & 0.00 & 0.00 & 0.00 & 0.00 & 0.00 & 0.00 & 0.00 & 0.08 & 0.14 & 0.01 & 0.00 \\
\hline 21_Cro & Crouch et al. 2010 & 0.00 & 0.00 & 0.00 & 0.00 & 0.00 & 0.00 & 0.00 & 0.00 & 0.00 & 0.00 & 0.00 & 0.01 & 0.14 & 0.01 & 0.00 \\
\hline 22_Cro & Crouch et al. 2010 & 0.04 & 0.01 & 0.01 & 0.02 & 0.01 & 0.01 & 0.00 & 0.01 & 0.00 & 0.00 & 0.00 & 0.43 & 0.23 & 0.01 & 0.00 \\
\hline 24_Cro & Crouch et al. 2010 & 0.01 & 0.00 & 0.00 & 0.00 & 0.00 & 0.00 & 0.00 & 0.07 & 0.00 & 0.00 & 0.00 & 0.12 & 0.03 & 0.00 & 0.00 \\
\hline 25_Cro & Crouch et al. 2010 & 0.00 & 0.00 & 0.00 & 0.01 & 0.00 & 0.00 & 0.00 & 0.02 & 0.00 & 0.00 & 0.00 & 0.23 & 0.15 & 0.00 & 0.00 \\
\hline 26_Cro & Crouch et al. 2010 & 0.00 & 0.00 & 0.00 & 0.00 & 0.00 & 0.00 & 0.00 & 0.00 & 0.00 & 0.00 & 0.00 & 0.02 & 0.15 & 0.00 & 0.00 \\
\hline 28_Cro & Crouch et al. 2010 & 0.00 & 0.01 & 0.04 & 0.03 & 0.00 & 0.00 & 0.00 & 0.08 & 0.00 & 0.00 & 0.00 & 0.30 & 0.32 & 0.02 & 0.00 \\
\hline 32_Cro & Crouch et al. 2010 & 0.00 & 0.08 & 0.03 & 0.03 & 0.01 & 0.00 & 0.00 & 0.03 & 0.00 & 0.00 & 0.00 & 0.50 & 0.01 & 0.00 & 0.00 \\
\hline 33_Cro & Crouch et al. 2010 & 0.02 & 0.04 & 0.06 & 0.03 & 0.00 & 0.00 & 0.00 & 0.02 & 0.00 & 0.00 & 0.00 & 0.49 & 0.24 & 0.03 & 0.00 \\
\hline 37_Cro & Crouch et al. 2010 & 0.00 & 0.01 & 0.01 & 0.05 & 0.00 & 0.00 & 0.00 & 0.05 & 0.00 & 0.00 & 0.00 & 0.69 & 0.00 & 0.00 & 0.00 \\
\hline 38_Pre & This Study & 0.00 & 0.01 & 0.13 & 0.00 & 0.01 & 0.01 & 0.01 & 0.04 & 0.00 & 0.04 & 0.00 & 0.35 & 0.13 & 0.00 & 0.00 \\
\hline 39_Pre & This Study & 0.01 & 0.02 & 0.47 & 0.00 & 0.02 & 0.00 & 0.02 & 0.00 & 0.02 & 0.08 & 0.00 & 0.35 & 0.00 & 0.00 & 0.00 \\
\hline 41_Pre & This Study & 0.00 & 0.00 & 0.39 & 0.00 & 0.01 & 0.03 & 0.00 & 0.02 & 0.01 & 0.13 & 0.00 & 0.22 & 0.05 & 0.00 & 0.00 \\
\hline 46_Pre & This Study & 0.03 & 0.00 & 0.06 & 0.01 & 0.00 & 0.01 & 0.00 & 0.06 & 0.00 & 0.00 & 0.02 & 0.15 & 0.00 & 0.00 & 0.00 \\
\hline 48_Pre & This Study & 0.06 & 0.05 & 0.01 & 0.01 & 0.00 & 0.03 & 0.00 & 0.00 & 0.00 & 0.00 & 0.00 & 0.68 & 0.00 & 0.00 & 0.00 \\
\hline 58_Pre & This Study & 0.00 & 0.02 & 0.17 & 0.02 & 0.00 & 0.01 & 0.00 & 0.01 & 0.01 & 0.01 & 0.00 & 0.46 & 0.00 & 0.00 & 0.00 \\
\hline 59_Pre & This Study & 0.00 & 0.00 & 0.05 & 0.00 & 0.01 & 0.00 & 0.00 & 0.01 & 0.01 & 0.00 & 0.00 & 0.28 & 0.03 & 0.00 & 0.00 \\
\hline 60_Pre & This Study & 0.01 & 0.00 & 0.03 & 0.00 & 0.01 & 0.00 & 0.00 & 0.00 & 0.00 & 0.03 & 0.00 & 0.01 & 0.12 & 0.00 & 0.00 \\
\hline 62_Pre & This Study & 0.00 & 0.00 & 0.68 & 0.00 & 0.07 & 0.02 & 0.00 & 0.02 & 0.02 & 0.08 & 0.00 & 0.06 & 0.03 & 0.00 & 0.00 \\
\hline 64_Pre & This Study & 0.00 & 0.00 & 0.00 & 0.00 & 0.02 & 0.00 & 0.00 & 0.00 & 0.00 & 0.00 & 0.00 & 0.22 & 0.34 & 0.00 & 0.00 \\
\hline 66_Pre & This Study & 0.00 & 0.00 & 0.19 & 0.00 & 0.03 & 0.07 & 0.00 & 0.01 & 0.01 & 0.01 & 0.00 & 0.28 & 0.35 & 0.01 & 0.00 \\
\hline 67_Pre & This Study & 0.00 & 0.00 & 0.00 & 0.10 & 0.00 & 0.00 & 0.00 & 0.02 & 0.00 & 0.00 & 0.00 & 0.80 & 0.00 & 0.00 & 0.00 \\
\hline 68_Pre & This Study & 0.00 & 0.03 & 0.01 & 0.00 & 0.02 & 0.02 & 0.00 & 0.01 & 0.00 & 0.00 & 0.00 & 0.51 & 0.07 & 0.00 & 0.00 \\
\hline 70_Pre & This Study & 0.00 & 0.01 & 0.23 & 0.00 & 0.00 & 0.00 & 0.00 & 0.00 & 0.00 & 0.01 & 0.00 & 0.17 & 0.01 & 0.00 & 0.00 \\
\hline 71_Pre & This Study & 0.00 & 0.00 & 0.01 & 0.00 & 0.02 & 0.00 & 0.00 & 0.00 & 0.00 & 0.02 & 0.00 & 0.09 & 0.28 & 0.00 & 0.00 \\
\hline 72_Pre & This Study & 0.00 & 0.00 & 0.00 & 0.00 & 0.00 & 0.00 & 0.00 & 0.00 & 0.00 & 0.01 & 0.00 & 0.02 & 0.19 & 0.02 & 0.00 \\
\hline 83_Pre & This Study & 0.00 & 0.01 & 0.00 & 0.04 & 0.00 & 0.01 & 0.00 & 0.01 & 0.00 & 0.00 & 0.00 & 0.64 & 0.00 & 0.00 & 0.00 \\
\hline 96_Pre & This Study & 0.00 & 0.00 & 0.19 & 0.00 & 0.00 & 0.01 & 0.00 & 0.02 & 0.01 & 0.06 & 0.00 & 0.27 & 0.13 & 0.00 & 0.00 \\
\hline 97_Pre & This Study & 0.00 & 0.01 & 0.70 & 0.00 & 0.00 & 0.01 & 0.00 & 0.00 & 0.00 & 0.01 & 0.00 & 0.22 & 0.03 & 0.00 & 0.00 \\
\hline 98_Pre & This Study & 0.01 & 0.00 & 0.61 & 0.00 & 0.01 & 0.04 & 0.00 & 0.00 & 0.02 & 0.11 & 0.00 & 0.12 & 0.01 & 0.00 & 0.00 \\
\hline 104_Pre & This Study & 0.00 & 0.00 & 0.33 & 0.00 & 0.00 & 0.02 & 0.01 & 0.01 & 0.01 & 0.04 & 0.00 & 0.08 & 0.06 & 0.00 & 0.00 \\
\hline 105_Pre & This Study & 0.00 & 0.00 & 0.37 & 0.00 & 0.06 & 0.06 & 0.06 & 0.00 & 0.04 & 0.05 & 0.00 & 0.14 & 0.12 & 0.00 & 0.00 \\
\hline 107_Pre & This Study & 0.00 & 0.00 & 0.15 & 0.00 & 0.02 & 0.00 & 0.00 & 0.00 & 0.00 & 0.10 & 0.00 & 0.09 & 0.16 & 0.00 & 0.00 \\
\hline 113_Pre & This Study & 0.00 & 0.01 & 0.64 & 0.00 & 0.02 & 0.01 & 0.00 & 0.00 & 0.01 & 0.05 & 0.00 & 0.20 & 0.02 & 0.00 & 0.00 \\
\hline 119_Pre & This Study & 0.00 & 0.00 & 0.01 & 0.00 & 0.00 & 0.00 & 0.00 & 0.00 & 0.00 & 0.00 & 0.00 & 0.01 & 0.00 & 0.00 & 0.00 \\
\hline 120_Pre & This Study & 0.00 & 0.00 & 0.01 & 0.00 & 0.00 & 0.00 & 0.00 & 0.00 & 0.00 & 0.00 & 0.00 & 0.01 & 0.00 & 0.00 & 0.00 \\
\hline 123_Pre & This Study & 0.00 & 0.00 & 0.00 & 0.00 & 0.00 & 0.00 & 0.00 & 0.00 & 0.00 & 0.00 & 0.00 & 0.00 & 0.14 & 0.00 & 0.00 \\
\hline 128_Pre & This Study & 0.01 & 0.00 & 0.00 & 0.00 & 0.00 & 0.00 & 0.00 & 0.00 & 0.00 & 0.00 & 0.00 & 0.06 & 0.02 & 0.00 & 0.00 \\
\hline 129_Pre & This Study & 0.00 & 0.00 & 0.03 & 0.00 & 0.01 & 0.00 & 0.00 & 0.01 & 0.00 & 0.01 & 0.00 & 0.01 & 0.34 & 0.03 & 0.00 \\
\hline 133_Pre & This Study & 0.00 & 0.00 & 0.00 & 0.01 & 0.00 & 0.00 & 0.00 & 0.01 & 0.00 & 0.00 & 0.00 & 0.19 & 0.00 & 0.00 & 0.00 \\
\hline 134_Pre & This Study & 0.00 & 0.02 & 0.03 & 0.03 & 0.00 & 0.00 & 0.00 & 0.04 & 0.00 & 0.00 & 0.00 & 0.30 & 0.01 & 0.00 & 0.00 \\
\hline 136_Pre & This Study & 0.00 & 0.00 & 0.10 & 0.00 & 0.01 & 0.00 & 0.00 & 0.01 & 0.02 & 0.04 & 0.00 & 0.02 & 0.46 & 0.00 & 0.00 \\
\hline 137_Pre & This Study & 0.00 & 0.00 & 0.03 & 0.00 & 0.03 & 0.04 & 0.01 & 0.01 & 0.01 & 0.02 & 0.00 & 0.01 & 0.33 & 0.00 & 0.00 \\
\hline 140_Pre & This Study & 0.00 & 0.00 & 0.12 & 0.00 & 0.02 & 0.00 & 0.00 & 0.01 & 0.02 & 0.09 & 0.00 & 0.01 & 0.19 & 0.00 & 0.00 \\
\hline 141_Pre & This Study & 0.00 & 0.00 & 0.03 & 0.00 & 0.01 & 0.03 & 0.00 & 0.00 & 0.00 & 0.03 & 0.00 & 0.01 & 0.29 & 0.01 & 0.00 \\
\hline 142_Pre & This Study & 0.00 & 0.00 & 0.06 & 0.00 & 0.02 & 0.03 & 0.00 & 0.01 & 0.00 & 0.02 & 0.00 & 0.01 & 0.32 & 0.01 & 0.00 \\
\hline 143_Pre & This Study & 0.00 & 0.00 & 0.00 & 0.06 & 0.00 & 0.01 & 0.00 & 0.01 & 0.00 & 0.00 & 0.00 & 0.68 & 0.01 & 0.00 & 0.00 \\
\hline 144_Pre & This Study & 0.00 & 0.00 & 0.35 & 0.00 & 0.01 & 0.01 & 0.00 & 0.00 & 0.04 & 0.00 & 0.00 & 0.02 & 0.21 & 0.00 & 0.00 \\
\hline
\end{tabular}




\begin{tabular}{|c|c|c|c|c|c|c|c|c|c|c|c|c|c|c|c|c|}
\hline $\begin{array}{l}\text { E్ } \\
\text { z̆ }\end{array}$ & : & $\begin{array}{l}\vec{D}_{1} \\
. \\
.\end{array}$ & 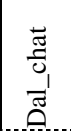 & 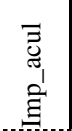 & 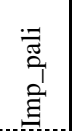 & 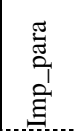 & 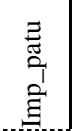 & 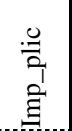 & 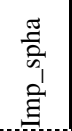 & 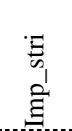 & 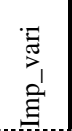 & $\begin{array}{c}\mathscr{\Xi} \\
\mathscr{\Xi}_{1} \\
\infty \\
\Xi\end{array}$ & 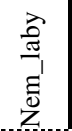 & $\begin{array}{l}\vec{J}^{\prime} \\
\vec{D}^{\prime} \\
\mathrm{U}^{\prime}\end{array}$ & $\begin{array}{l}n \\
\vec{J}_{1} \\
\overrightarrow{0}^{\prime} \\
0 \\
0\end{array}$ & 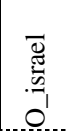 \\
\hline 145_Pre & is Study & 0.00 & 0.00 & 0.02 & 0.00 & 0.00 & 0.03 & 0.01 & 0.00 & 0.00 & 0.03 & 0.00 & 0.01 & 0.38 & 0.01 & 0.00 \\
\hline 151_Pre & is Study & 0.00 & 0.00 & 0.00 & 0.00 & 0.00 & 0.00 & 0.00 & 0.00 & 0.00 & 0.00 & 0.01 & 0.00 & 0.01 & 0.00 & 0.00 \\
\hline \begin{tabular}{|l|}
1393 Vin \\
\end{tabular} & nk et al. 2004 & 0.00 & 0.19 & 0.00 & 0.00 & 0.00 & 0.00 & 0.00 & 0.00 & 0.00 & 0.28 & 0.00 & 0.19 & 0.07 & 0.00 & 0.00 \\
\hline 1394_Vin & nk et al. 2004 & 0.00 & 0.12 & 0.00 & 0.00 & 0.00 & 0.00 & 0.00 & 0.00 & 0.00 & 0.52 & 0.00 & 0.17 & 0.00 & 0.00 & 0.00 \\
\hline 1395_Vin & nk et al. 2004 & 0.00 & 0.09 & 0.00 & 0.00 & 0.00 & 0.00 & 0.00 & 0.00 & 0.00 & 0.38 & 0.00 & 0.11 & 0.00 & 0.00 & 0.00 \\
\hline 1396_Vin & al. 2004 & 0.00 & 0.00 & 0.00 & 0.00 & 0.00 & 0.00 & 0.00 & 0.00 & 0.00 & 0.05 & 0.02 & 0.16 & 0.77 & 0.00 & 0.00 \\
\hline 1399_Vin & ik et al. 2004 & 0.00 & 0.00 & 0.00 & 0.00 & 0.00 & 0.00 & 0.00 & 0.00 & 0.00 & 0.00 & 0.00 & 0.03 & 0.92 & 0.00 & 0.00 \\
\hline 1400_Vin & al. 2004 & 0.00 & 0.16 & 0.00 & 0.00 & 0.00 & 0.00 & 0.00 & 0.00 & 0.00 & 0.00 & 0.00 & 0.21 & 0.16 & 0.00 & 0.00 \\
\hline 1402_Vin & 1.2004 & .00 & 0.00 & 0.00 & 0.00 & 0.00 & 0.00 & 0.00 & 0.00 & 0.00 & 0.00 & 0.06 & 0.04 & 10 & 0.00 & 0.00 \\
\hline 1403_Vin & nk et al. 2004 & 0.00 & 0.00 & 0.00 & 0.00 & 0.00 & 0.00 & 0.00 & 0.00 & 00 & 0.00 & 0.03 & 0.03 & .09 & 0.00 & 0.00 \\
\hline 1404_Vin & al. 2004 & 0.00 & 0.00 & 0.00 & 0.00 & 0.00 & 0.00 & 0.00 & 0.00 & 0.00 & 0.00 & 0.01 & 0.00 & 0.17 & 0.00 & 0.00 \\
\hline \begin{tabular}{|l|}
$1405 \_V i n$ \\
\end{tabular} & nk et al. 2004 & 0.00 & 0.00 & 0.00 & 0.00 & 0.00 & 0.00 & 0.00 & 0.00 & 0.00 & 0.00 & 0.00 & 0.01 & 0.15 & 0.00 & 0.00 \\
\hline 1406_Vin & 1.. 2004 & 0.00 & 0.00 & 0.00 & 0.00 & 0.00 & 0.00 & 0.00 & 0.00 & 0.00 & 0.00 & 0.04 & 0.03 & 0.19 & 0.00 & 0.00 \\
\hline 1407_Vin & 1. 2004 & 0.00 & 0.00 & 0.00 & 0.00 & 0.00 & 0.00 & 0.00 & 0.00 & 0.00 & 0.00 & 0.06 & 0.01 & 0.13 & 0.00 & 0.00 \\
\hline 1875_Mar & al. 2004 & 0.00 & 0.02 & 0.06 & 0.00 & 0.00 & 0.00 & 0.00 & 0.02 & 0.00 & 0.03 & 0.00 & 0.53 & 0.18 & 0.00 & 0.00 \\
\hline 1876_Mar & et al. 2003 & 0.00 & 0.00 & 0.00 & 0.00 & 0.00 & 0.00 & 0.00 & 0.00 & 0.00 & 0.00 & 0.00 & 0.00 & 0.00 & 0.00 & 0.00 \\
\hline 1883_Mar & 20 & 00 & 0.02 & 0.08 & 0.04 & 0.02 & 0.00 & 0.00 & 0.03 & 0.02 & 04 & 0.00 & 0.29 & .06 & 00 & .00 \\
\hline 1887_Mar & 20 & .00 & 0.03 & 0.19 & 0.16 & 0.01 & 0.04 & 0.00 & 0.04 & 0.01 & 0.00 & 0.00 & 0.42 & 0.04 & 0.00 & 0.00 \\
\hline 1890_Mar & 1.20 & 0.00 & 0.00 & 0.06 & 0.00 & 0.00 & 0.00 & 0.00 & 0.00 & 0.00 & 0.06 & 0.00 & 0.05 & 0.43 & 0.00 & 0.00 \\
\hline 1891_Mar & al. 2003 & 0.00 & 0.00 & 0.02 & 0.00 & 0.00 & 0.00 & 0.00 & 0.00 & 0.00 & 0.07 & 0.00 & 0.09 & 0.47 & 0.00 & 0.00 \\
\hline 1892_Mar & 1.20 & 0.00 & 0.00 & 0.05 & 0.00 & 0.00 & 0.00 & 0.00 & 0.00 & 0.00 & 0.04 & 0.00 & 0.14 & 0.55 & 0.00 & 0.00 \\
\hline 1893_Mar & 2 & 03 & 0.00 & 0.00 & 0.00 & 0.00 & 0.00 & 0.00 & 0.00 & 0.00 & 0.07 & 0.00 & 0.12 & 0.09 & 0.00 & 0.00 \\
\hline 1894_Mar & 20 & .00 & 0.00 & 0.00 & 0.00 & 0.00 & 0.00 & 0.00 & 0.00 & 0.00 & 0.04 & 0.00 & 0.11 & 0.04 & 0.00 & .00 \\
\hline 1895_Mar & 22 & 0.02 & 0.00 & 0.00 & 0.00 & 0.00 & 0.00 & 0.00 & 0.00 & 0.00 & 0.00 & 0.00 & 0.00 & 0.00 & 0.00 & 0.00 \\
\hline 1896_Mar & al. 2003 & 0.00 & 0.00 & 0.00 & 0.00 & 0.00 & 0.00 & 0.00 & 0.00 & 0.00 & 0.02 & 0.00 & 0.00 & 0.07 & 0.00 & 0.00 \\
\hline \begin{tabular}{|l|}
$1897 \_M a r$ \\
\end{tabular} & 1.20 & 0.03 & 0.00 & 0.00 & 0.00 & 0.00 & 0.00 & 0.00 & 0.00 & 0.00 & 0.03 & 0.00 & 0.02 & 0.03 & 0.00 & 0.00 \\
\hline 1898_Mar & 1.28 & 03 & 0.00 & 0.03 & 0.00 & 0.00 & 0.00 & 0.00 & 0.00 & 0.00 & 0.04 & 0.00 & 0.05 & 0.05 & 0.00 & 0.00 \\
\hline 1899_Mar & 2 & 0.06 & 0.00 & 0.05 & 0.00 & 0.00 & 0.00 & 0.00 & 0.00 & 0.00 & 0.06 & 0.00 & 0.13 & 0.25 & 0.00 & .00 \\
\hline 1900_Mar & 24 & 0.00 & 0.00 & 0.06 & 0.00 & 0.00 & 0.00 & 0.00 & 0.00 & 0.00 & 0.05 & 0.00 & 0.18 & 0.21 & 0.00 & 0.00 \\
\hline 1901_Mar & 20 & 0.00 & 0.00 & 0.04 & 0.00 & 0.00 & 0.00 & 0.00 & 0.00 & 0.00 & 0.03 & 0.00 & 0.09 & 0.26 & 0.00 & 0.00 \\
\hline 1902_Mar & 20 & 0.00 & 0.00 & 0.05 & 0.00 & 0.00 & 0.00 & 0.00 & 0.00 & 0.00 & 0.05 & 0.00 & 0.11 & 0.38 & 0.00 & 0.00 \\
\hline 1903_Mar & 120 & 0.00 & 0.00 & 0.00 & 0.00 & 0.00 & 0.00 & 0.00 & 0.00 & 0.00 & 0.00 & 0.00 & 0.00 & 0.47 & 0.00 & .00 \\
\hline 1904_Mar & 1. 2 & 0.00 & 0.00 & 0.14 & 0.00 & 0.00 & 0.00 & 0.00 & 0.07 & 0.00 & 0.05 & 0.00 & 0.07 & 0.29 & 0.00 & .00 \\
\hline 1905_Mar & 20 & 0.00 & 0.00 & 0.14 & 0.00 & 0.02 & 0.00 & 0.00 & 0.05 & 0.04 & 0.05 & 0.00 & 0.08 & 0.31 & 0.00 & 0.00 \\
\hline 1907_Mar & .20 & 0.00 & 0.00 & 0.00 & 0.00 & 0.00 & 0.00 & 0.00 & 0.00 & 0.00 & 0.00 & 0.00 & 0.05 & 0.71 & 0.00 & 0.00 \\
\hline \begin{tabular}{|l|} 
1909_Mar \\
\end{tabular} & 3 & 0.00 & 0.00 & 0.13 & 0.00 & 0.07 & 0.00 & 0.00 & 0.04 & 0.03 & 0.46 & 0.00 & 0.05 & 0.02 & 0.00 & 0.00 \\
\hline 1912_Mar & 1.2 & 0.00 & 0.00 & 0.00 & 0.00 & 0.00 & 0.00 & 0.00 & 0.00 & 0.00 & 0.00 & 0.00 & 0.00 & 0.51 & 0.00 & 0.00 \\
\hline 1913_Mar & 1.2003 & 0.00 & 0.00 & 0.02 & 0.00 & 0.00 & 0.00 & 0.00 & 0.00 & 0.00 & 0.00 & 0.00 & 0.00 & 0.58 & 0.00 & 0.00 \\
\hline 1914_Mar & 1.20 & 0.00 & 0.00 & 0.04 & 0.00 & 0.00 & 0.00 & 0.00 & 0.00 & 0.00 & 0.00 & 0.00 & 0.00 & 0.66 & 0.00 & 0.00 \\
\hline 1915_Mar & 20 & 00 & 0.00 & 0.00 & 0.00 & 0.00 & 0.00 & 0.00 & 0.00 & 0.00 & 0.00 & 0.00 & 0.08 & 0.76 & 0.00 & 0.00 \\
\hline 1916_Mar & 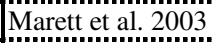 & 00 & 0.00 & 0.00 & 00 & 0.00 & 0.00 & 0.00 & 0.00 & 0.00 & 0.00 & 0.00 & 0.00 & 1.00 & 0.00 & 00 \\
\hline 1917_Mar & 1.20 & 0.00 & 0.04 & 0.54 & 0.00 & 0.06 & 0.00 & 0.02 & 0.07 & 0.06 & 0.06 & 0.00 & 0.04 & 0.04 & 0.00 & 0.02 \\
\hline 1918_Mar & 1.20 & 0.00 & 0.02 & 0.45 & 0.00 & 0.00 & 0.02 & 0.03 & 0.21 & 0.09 & 0.10 & 0.00 & 0.03 & 0.00 & 0.00 & 0.02 \\
\hline 1919_Mar & 20 & .00 & 0.02 & 0.44 & 0.00 & 0.02 & 0.00 & 0.00 & 0.18 & 0.14 & 0.08 & 0.00 & 0.03 & 0.00 & 0.00 & 0.02 \\
\hline 1920_Mar & 20 & 00 & 0.00 & 0.00 & 0.00 & 0.00 & 0.00 & 0.00 & 0.03 & 0.00 & 0.00 & 0.00 & 0.12 & 0.03 & 0.00 & 0.00 \\
\hline 1921_Mar & 17 & .00 & 0.00 & 0.00 & 0.00 & 0.00 & 0.00 & 0.00 & 0.00 & 0.00 & 0.00 & 0.00 & 0.12 & 0.00 & 0.00 & 0.00 \\
\hline 1922_Mar & 1.2003 & .00 & 0.00 & 0.00 & 0.00 & 0.00 & 0.00 & 0.00 & 0.00 & 0.00 & 0.00 & 0.00 & 0.08 & 0.00 & 0.00 & 0.00 \\
\hline 1923_Mar & 1.20 & 0.00 & 0.00 & 0.00 & 0.00 & 0.00 & 0.00 & 0.00 & 0.00 & 0.00 & 0.00 & 0.00 & 0.08 & 0.00 & 0.00 & 0.00 \\
\hline 1924_Mar & 1.2003 & 0.00 & 0.00 & 0.06 & 0.00 & 0.00 & 0.04 & 0.00 & 0.00 & 0.00 & 0.13 & 0.00 & 0.28 & 0.06 & 0.00 & 0.00 \\
\hline 1925_Mar & 1.20 & 0.00 & 0.00 & 0.14 & 0.00 & 0.00 & 0.05 & 0.00 & 0.03 & 0.05 & 0.11 & 0.00 & 0.25 & 0.23 & 0.00 & 0.00 \\
\hline 1926_Mar & al. 2003 & 0.00 & 0.00 & 0.13 & 0.00 & 0.00 & 0.00 & 0.00 & 0.00 & 0.00 & 0.19 & 0.00 & 0.26 & 0.21 & 0.00 & 0.00 \\
\hline 1927_Mar & arett et al. 2003 & 0.00 & 0.00 & 0.06 & 0.00 & 0.00 & 0.00 & 0.00 & 0.00 & 0.00 & 0.35 & 0.00 & 0.10 & 0.07 & 0.00 & 0.00 \\
\hline 1928_Mar & 1. 2003 & .00 & 0.00 & 0.19 & 0.00 & 0.00 & 0.07 & 0.00 & 0.06 & 0.04 & 0.12 & 0.00 & 0.14 & 0.06 & 0.00 & 0.00 \\
\hline 1929_Mar & 20 & 00 & 0.00 & 0.13 & 0.00 & 0.00 & 0.07 & 0.00 & 0.00 & 0.04 & 0.31 & 0.00 & 0.14 & 0.05 & 0.00 & 0.00 \\
\hline 1930_Mar & al. 2003 & 0.00 & 0.00 & 0.21 & 0.00 & 0.00 & 0.07 & 0.00 & 0.04 & 0.05 & 0.10 & 0.00 & 0.11 & 0.04 & 0.00 & 0.02 \\
\hline 1931_Mar & 1. 2003 & 0.00 & 0.00 & 0.33 & 0.00 & 0.02 & 0.11 & 0.00 & 0.09 & 0.14 & 0.19 & 0.00 & 0.04 & 0.02 & 0.00 & 0.02 \\
\hline 1932_Mar & arett et al. 2003 & 0.00 & 0.00 & 0.31 & 0.00 & 0.00 & 0.07 & 0.00 & 0.13 & 0.20 & 0.18 & 0.00 & 0.11 & 0.00 & 0.00 & 0.00 \\
\hline 1933_Mar & 1.20 & .00 & 0.00 & 0.42 & 0.00 & 0.00 & 0.13 & 0.00 & 0.08 & 0.11 & 0.08 & 0.00 & 0.07 & 0.00 & 0.00 & 0.00 \\
\hline 937_Mar & Marett et al. 2003 & 0.0 & 0.05 & 0.0 & 00 & 0.00 & 0.0 & 0.00 & 0.28 & 0.00 & .0 & 0.00 & 0.09 & 0.04 & 0.00 & 0.00 \\
\hline
\end{tabular}




\begin{tabular}{|c|c|c|c|c|c|c|c|c|c|c|c|c|c|c|c|c|}
\hline $\begin{array}{l}\text { E్ } \\
\text { z̆ }\end{array}$ & 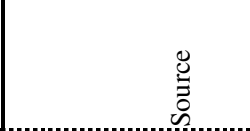 & $\begin{array}{l}\vec{D}_{1} \\
. \\
.\end{array}$ & 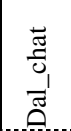 & 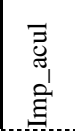 & 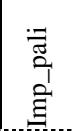 & 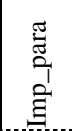 & 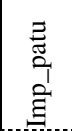 & $\begin{array}{l}\frac{0}{2} \\
\frac{1}{1} \\
\text { है। }\end{array}$ & 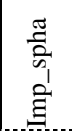 & 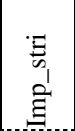 & 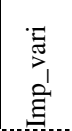 & 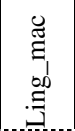 & 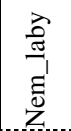 & $\begin{array}{l}-1 \\
\vec{\Xi} \\
\vec{J}^{\prime} \\
0^{\prime}\end{array}$ & $\begin{array}{l}n_{1} \\
\vec{J}^{\prime} \\
\tilde{D}_{1} \\
0\end{array}$ & 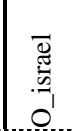 \\
\hline 938_Mar & arett et al. 2003 & 0.00 & 0.01 & 0.00 & 0.00 & 0.00 & 0.00 & 0.00 & 0.00 & 0.00 & 0.00 & 0.00 & 0.00 & 0.00 & 0.00 & 0.00 \\
\hline 1939_Mar & arett et al. 2003 & 00 & 0.04 & 0.00 & 0.02 & 0.00 & 0.01 & 0.00 & 0.11 & 0.00 & 0.00 & 0.00 & 0.02 & 0.00 & 0.00 & 0.00 \\
\hline 940_Mar & arett et al. 2003 & 00 & 0.03 & 0.00 & 0.04 & 0.00 & 0.00 & 0.00 & 0.12 & 0.00 & 0.00 & 0.00 & 0.03 & 0.00 & 0.00 & 0.00 \\
\hline 1941_Mar & al. 2003 & 0.00 & 0.00 & 0.00 & 0.00 & 0.00 & 0.00 & 0.00 & 0.09 & 0.00 & 0.00 & 0.00 & 0.00 & 0.00 & 0.00 & 0.00 \\
\hline 1942_Mar & tal. 2003 & 0.00 & 0.00 & 0.00 & 0.00 & 0.00 & 0.00 & 0.00 & 0.06 & 0.00 & 0.00 & 0.00 & 0.00 & 0.00 & 0.00 & 0.00 \\
\hline 1943_Mar & 1.2003 & 0.00 & 0.00 & 0.00 & 0.00 & 0.00 & 0.00 & 0.00 & 0.04 & 0.00 & 0.00 & 0.00 & 0.00 & 0.00 & 0.00 & 0.00 \\
\hline 945_Mar & 1.2003 & .00 & 0.00 & 0.00 & 0.00 & 0.00 & 0.00 & 0.00 & 0.02 & 0.00 & 0.00 & 0.00 & 0.00 & 0.00 & 0.00 & 0.00 \\
\hline 1947_Mar & 1.. 2003 & .00 & 0.06 & 0.00 & 0.00 & 0.00 & 0.00 & 0.00 & 0.48 & 0.00 & 0.00 & 0.00 & 0.19 & 0.00 & 0.00 & 0.00 \\
\hline 1948_Mar & 1.20 & 00 & 0.00 & 0.11 & 0.03 & 0.03 & 0.01 & 0.00 & 0.08 & 0.00 & 0.00 & 0.00 & 0.04 & 0.00 & 0.00 & 0.00 \\
\hline 1949_Mar & et al. 200 & 00 & 0.00 & 0.04 & 0.00 & 0.00 & 0.00 & 0.00 & 0.09 & 0.00 & 0.00 & 0.00 & 0.08 & .00 & 0.00 & 0.00 \\
\hline 1950_Mar & 1.2003 & 00 & 0.02 & 0.05 & 0.04 & 0.03 & 0.00 & 0.00 & 0.04 & 0.00 & 0.00 & 0.00 & 0.11 & 0.00 & 0.00 & 0.00 \\
\hline 951_Mar & al. 2003 & 00 & 0.01 & 0.02 & 0.03 & 0.02 & 0.00 & 0.00 & 0.03 & 0.00 & 0.00 & 0.00 & 0.04 & 0.00 & 0.00 & 0.00 \\
\hline 1952_Mar & 1.200 & .00 & 0.03 & 0.05 & 0.03 & 0.00 & 0.00 & 0.00 & 0.00 & 0.00 & 0.00 & 0.00 & 0.42 & 0.00 & 0.00 & 0.00 \\
\hline 1954_Mar & 1. 200 & .00 & 0.04 & 0.05 & 0.03 & 0.01 & 0.01 & 0.00 & 0.05 & 0.00 & 0.00 & 0.00 & 0.18 & 0.00 & 0.00 & 0.00 \\
\hline 1955_Mar & 1.. 200 & 0.00 & 0.00 & 0.00 & 0.12 & 0.00 & 0.00 & 0.00 & 0.00 & 0.00 & 0.00 & 0.00 & 0.01 & 0.00 & 0.00 & 0.00 \\
\hline 1958_Mar & al. 2003 & 0.00 & 0.00 & 0.00 & 0.02 & 0.00 & 0.00 & 0.00 & 0.00 & 0.00 & 0.00 & 0.00 & 0.00 & 00 & 0.00 & 0.00 \\
\hline 959_Mar & 20 & 00 & 0.00 & 0.00 & 0.18 & 0.00 & 0.00 & 0.00 & 0.00 & 0.00 & 0.00 & 0.00 & 0.00 & 00 & 00 & 100 \\
\hline 1962_Mar & 20 & 00 & 0.04 & 0.00 & 0.02 & 0.00 & 0.00 & 0.00 & 0.00 & 0.00 & 0.00 & 0.00 & 0.06 & 00 & 0.00 & 0.00 \\
\hline 1963_Mar & 1.200 & 0.00 & 0.02 & 0.00 & 0.04 & 0.00 & 0.00 & 0.00 & 0.01 & 0.00 & 0.00 & 0.00 & 0.00 & 0.01 & 0.00 & 0.00 \\
\hline 1968_Mar & 1.2003 & 0.00 & 0.00 & 0.01 & 0.00 & 0.00 & 0.00 & 0.00 & 0.01 & 0.00 & 0.00 & 0.00 & 0.00 & 0.00 & 0.00 & 0.00 \\
\hline 1969_Mar & 20 & 01 & 0.00 & 0.00 & 0.00 & 0.00 & 0.00 & 0.00 & 0.02 & 0.00 & 0.00 & 0.00 & 0.00 & 0.00 & 0.00 & 0.00 \\
\hline 1970_Mar & 20 & 00 & 0.00 & 0.00 & 0.00 & 0.00 & 0.00 & 0.00 & 0.00 & 0.00 & 0.00 & 0.00 & 0.03 & 0.00 & 0.00 & 0.00 \\
\hline 1971_Mar & 20 & 00 & 0.00 & 0.00 & 0.00 & 0.00 & 0.00 & 0.00 & 0.00 & 0.00 & 0.00 & 0.00 & 0.00 & 1.00 & 0.00 & 0.00 \\
\hline 1972_Mar & 200 & 00 & 0.00 & 0.00 & 0.00 & 0.00 & 0.00 & 0.00 & 0.00 & 0.00 & 0.00 & 0.00 & 0.00 & 0.00 & 0.00 & 100 \\
\hline 1973_Mar & 1.2003 & 0.00 & 0.00 & 0.00 & 0.00 & 0.00 & 0.00 & 0.00 & 0.00 & 0.00 & 0.00 & 0.00 & 0.02 & 0.02 & 0.00 & 0.00 \\
\hline 974_Mar & 20 & 0.00 & 0.00 & 0.00 & 0.00 & 0.00 & 0.00 & 0.00 & 0.00 & 0.00 & 0.01 & 0.00 & 0.00 & 0.00 & 0.00 & 0.00 \\
\hline 1975_Mar & .20 & 0.00 & 0.00 & 0.00 & 0.00 & 0.00 & 0.00 & 0.00 & 0.00 & 0.00 & 0.00 & 0.00 & 0.00 & 0.00 & 0.00 & 0.00 \\
\hline 1987_Mar & 20 & .00 & 0.00 & 0.00 & 0.00 & 0.00 & 0.00 & 0.00 & 0.00 & 0.00 & 0.00 & 0.00 & 0.00 & .00 & 0.00 & .00 \\
\hline 1988_Mar & 20 & 00 & 0.00 & 0.01 & 0.00 & 0.00 & 0.00 & 0.00 & 0.00 & 0.00 & 0.00 & 0.00 & 0.02 & 00 & 0.00 & 100 \\
\hline 1989_Mar & 200 & 0.00 & 0.00 & 0.00 & 0.00 & 0.00 & 0.00 & 0.00 & 0.00 & 0.00 & 0.00 & 0.00 & 0.04 & 0.00 & 0.00 & 0.00 \\
\hline 90_Mar & 200 & 00 & 0.00 & 0.00 & 0.00 & 0.00 & 0.00 & 0.00 & 0.00 & 0.00 & 0.00 & 0.00 & 0.00 & 0.00 & 0.00 & 0.00 \\
\hline 1991_Mar & 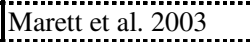 & 0.00 & 0.00 & 0.00 & 0.00 & 0.00 & 0.00 & 0.00 & 0.00 & 0.00 & 0.00 & 0.00 & 0.02 & 0.00 & 0.00 & 0.00 \\
\hline 1992_Mar & .20 & 0.00 & 0.00 & 0.00 & 0.00 & 0.00 & 0.00 & 0.00 & 0.00 & 0.00 & 0.00 & 0.00 & 0.06 & 0.00 & 0.00 & .00 \\
\hline 1993_Mar & 200 & .00 & 0.05 & 0.06 & 0.06 & 0.00 & 0.02 & 0.00 & 0.06 & 0.00 & 0.00 & 0.00 & 0.38 & 0.11 & 0.00 & 0.00 \\
\hline 1994_Mar & 200 & 1.00 & 0.00 & 0.00 & 0.04 & 0.02 & 0.00 & 0.00 & 0.03 & 0.00 & 0.00 & 0.00 & 0.39 & 0.03 & 0.00 & 0.00 \\
\hline 995_Mar & 20 & 02 & 0.00 & 0.02 & 0.00 & 0.03 & 0.00 & 0.00 & 0.00 & 0.00 & 0.00 & 0.00 & 0.52 & 0.22 & 0.00 & 0.00 \\
\hline 1996_Mar & 20 & 0.00 & 0.00 & 0.13 & 0.00 & 0.03 & 0.00 & 0.00 & 0.03 & 0.02 & 0.00 & 0.00 & 0.25 & 0.13 & 0.00 & 0.00 \\
\hline 1998_Mar & 1. 2003 & 0.00 & 0.00 & 0.16 & 0.02 & 0.03 & 0.01 & 0.00 & 0.03 & 0.01 & 0.00 & 0.00 & 0.58 & 0.10 & 0.00 & 0.00 \\
\hline 1999_Mar & 2003 & 0.00 & 0.03 & 0.06 & 0.00 & 0.00 & 0.00 & 0.00 & 0.02 & 0.00 & 0.02 & 0.00 & 0.38 & 0.10 & 0.00 & 0.00 \\
\hline 2000_Mar & 20 & 00 & 0.00 & 0.00 & 0.00 & 0.00 & 0.00 & 0.00 & 0.03 & 0.00 & 0.07 & 0.00 & 0.23 & 0.05 & 0.00 & 0.00 \\
\hline 2001_Mar & 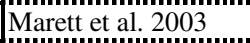 & 00 & 0 & 0.10 & 00 & 0.00 & 0.00 & 0.00 & 0.00 & 0.00 & 0.09 & 0.00 & 0.47 & 0.07 & 0.00 & 0.00 \\
\hline 2002_Mar & 200 & 00 & 0.00 & 0.09 & 0.00 & 0.03 & 0.00 & 0.00 & 0.03 & 0.00 & 0.10 & 0.00 & 0.39 & 10 & 0.00 & 0.00 \\
\hline 2003_Mar & 1.2003 & 0.00 & 0.03 & 0.02 & 0.02 & 0.02 & 0.00 & 0.00 & 0.03 & 0.00 & 0.04 & 0.00 & 0.46 & 0.09 & 0.00 & 0.00 \\
\hline 2004_Mar & 200 & 00 & 0.00 & 0.00 & 0.02 & 0.00 & 0.00 & 0.00 & 0.00 & 0.00 & 0.03 & 0.00 & 0.22 & 0.08 & 0.00 & 0.00 \\
\hline 05_Mar & 20 & 00 & 0.00 & 0.00 & 00 & 0.00 & 0.00 & 0.00 & 0.00 & 0.00 & 0.07 & 0.00 & 0.23 & 0.09 & 0.00 & 0.00 \\
\hline 2006_Mar & 200 & 00 & 0.03 & 0.04 & 0.00 & 0.00 & 0.00 & 0.00 & 0.00 & 0.00 & 0.04 & 0.00 & 0.40 & 0.12 & 0.00 & 0.00 \\
\hline 2007_Mar & 2003 & 00 & 0.00 & 0.02 & 0.00 & 0.00 & 0.00 & 0.00 & 0.02 & 0.00 & 0.04 & 0.00 & 0.45 & 0.13 & 0.00 & 0.00 \\
\hline 2008_Mar & 2003 & 0.02 & 0.00 & 0.00 & 0.06 & 0.00 & 0.03 & 0.00 & 0.02 & 0.00 & 0.00 & 0.00 & 0.17 & 0.08 & 0.00 & 0.00 \\
\hline 2009_Mar & 2003 & 0.00 & 0.02 & 0.04 & 0.02 & 0.00 & 0.00 & 0.00 & 0.00 & 0.00 & 0.05 & 0.00 & 0.34 & 0.14 & 0.00 & 0.00 \\
\hline 2012_Mar & 200 & 0.00 & 0.00 & 0.00 & 0.00 & 0.00 & 0.00 & 0.00 & 0.00 & 0.00 & 0.00 & 0.00 & 0.23 & 0.31 & 0.00 & 0.00 \\
\hline 2013_Hol & Holwarth et al., 20 & 0.00 & 0.00 & 0.00 & 0.00 & 0.00 & 0.00 & 0.00 & 0.00 & 0.00 & 0.00 & 0.00 & 0.00 & 0.60 & 0.00 & 0.01 \\
\hline 2014_Hol & $\mathrm{t}$ al.., 2007 & .00 & 0.00 & 0.00 & 0.00 & 0.00 & 0.00 & 0.00 & 0.00 & 0.00 & 0.00 & 0.00 & 0.00 & 0.37 & 0.00 & 0.00 \\
\hline 2015_Hol & al.,., & 00 & 0.00 & 0.00 & 0.00 & 0.00 & 0.00 & 0.00 & 0.00 & 0.00 & 0.00 & 0.00 & 0.00 & 0.21 & 0.00 & 0.00 \\
\hline _Hol & $1 . ., 2$ & 0.00 & 0.00 & 0.00 & 0.00 & 0.00 & 0.00 & 0.00 & 0.00 & 0.00 & 0.00 & 0.00 & 0.00 & 0.02 & 0.00 & 0.00 \\
\hline 2017_Hol & tal., 20 & 0.00 & 0.00 & 0.00 & 0.00 & 0.00 & 0.00 & 0.00 & 0.00 & 0.00 & 0.00 & 0.00 & 0.00 & 0.04 & 0.00 & 0.00 \\
\hline 2018_Hol & al., 200 & 0.00 & 0.00 & 0.00 & 0.00 & 0.00 & 0.00 & 0.00 & 0.00 & 0.00 & 0.00 & 0.00 & 0.00 & 0.53 & 0.00 & 0.00 \\
\hline 2019_Hol & olwarth et al., 2007 & 0.00 & 0.00 & 0.00 & 0.00 & 0.00 & 0.00 & 0.00 & 0.00 & 0.00 & 0.00 & 0.00 & 0.02 & 0.53 & 0.00 & 0.00 \\
\hline 20_Hol & al., 2 & .00 & 0.00 & 0.00 & 0.00 & 0.00 & 0.00 & 0.00 & 0.00 & 0.00 & 0.00 & 0.00 & 0.01 & 0.86 & 0.00 & 0.01 \\
\hline $21 \_\mathrm{Hol}$ & Holwarth et al., 2007 & 0.00 & 0.00 & 0.00 & 0.00 & 0.00 & 0.0 & 0.00 & 0.00 & 0.0 & & 0.0 & 0.01 & 0.84 & 0.00 & "20 \\
\hline
\end{tabular}




\begin{tabular}{|c|c|c|c|c|c|c|c|c|c|c|c|c|c|c|c|c|}
\hline $\begin{array}{c}\text { छ్ } \\
\text { Zू }\end{array}$ & 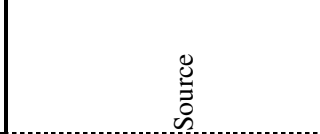 & 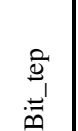 & 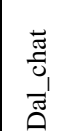 & 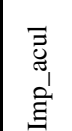 & 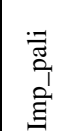 & 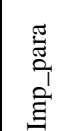 & 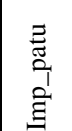 & 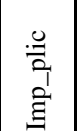 & $\begin{array}{l}\frac{\pi}{2} \\
\frac{1}{n} \\
\frac{1}{\xi}\end{array}$ & $\begin{array}{l}\Xi_{0} \\
\vdots \\
\text { a }\end{array}$ & 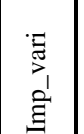 & 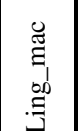 & 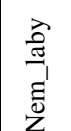 & $\begin{array}{l}-1 \\
\vec{J} \\
\vec{\Xi}^{\prime} \\
U^{\prime}\end{array}$ & $\begin{array}{l}n \\
\overrightarrow{1} \\
\overrightarrow{0} \\
0 \\
0 \\
0\end{array}$ & $\begin{array}{l}\overline{\mathbb{W}} \\
\frac{\pi}{2} \\
0 \\
0\end{array}$ \\
\hline 2022_Hol & lowarth et al., 2007 & 0.00 & 0.00 & 0.00 & 0.00 & 0.00 & 0.00 & 0.00 & 0.00 & 0.00 & 0.00 & 0.00 & 0.00 & 0.66 & 0.00 & 0.03 \\
\hline 2023_Hol & llwarth et al., 2007 & 0.00 & 0.00 & 0.00 & 0.00 & 0.00 & 0.00 & 0.00 & 0.00 & 0.00 & 0.00 & 0.00 & 0.00 & 0.47 & 0.00 & 0.02 \\
\hline 24_Hol & al., 2007 & 0.00 & 0.00 & 0.00 & 0.00 & 0.00 & 0.00 & 0.00 & 0.00 & 0.00 & 0.00 & 0.00 & 0.00 & 0.05 & 0.00 & 0.00 \\
\hline 25_Hol & il.,.,2007"in & .00 & 0.00 & 0.00 & 0.00 & 0.00 & 0.00 & 0.00 & 0.00 & 0.00 & 0.00 & 0.00 & 0.00 & 0.61 & 0.00 & 0.00 \\
\hline 026_Hol & $1 ., 200$ & 00 & 0.00 & 0.00 & 0.00 & 0.00 & 0.00 & 0.00 & 0.00 & 0.00 & 0.00 & 0.00 & 0.10 & 66 & 0.00 & 0.00 \\
\hline 2027_Hol & 200 & 00 & 0.00 & 0.00 & 0.00 & 0.00 & 0.00 & 0.00 & 0.00 & 0.00 & 0.00 & 0.00 & 0.03 & 84 & 0.00 & 0.01 \\
\hline 2028_Hol & al., 2007 & 00 & 0.00 & 0.00 & 0.00 & 0.00 & 0.00 & 0.00 & 0.00 & 0.00 & 0.00 & 0.00 & 0.03 & 80 & 0.00 & 0.01 \\
\hline 2029_Hol & ., 2007 & 0.00 & 0.00 & 0.00 & 0.00 & 0.00 & 0.00 & 0.00 & 0.00 & 0.00 & 0.00 & 0.00 & 0.02 & .05 & 0.00 & 0.00 \\
\hline 31_Hol & .2007 & \%̈̈ & 0.00 & 0.00 & 0.00 & 0.00 & 0.00 & 0.00 & 0.00 & 0.00 & 0.00 & 0.00 & 0.04 & ... & 0.00 & 0.01 \\
\hline 2033_Hol & $1 ., 20$ & 00 & 0.00 & 0.00 & 0.00 & 0.00 & 0.00 & 0.00 & 0.00 & 0.00 & 0.00 & 0.00 & 0.00 & 03 & 0.00 & 0.00 \\
\hline 2034_Hol & $1 ., 20$ & 00 & 0.00 & 0.00 & 0.00 & 0.00 & 0.00 & 0.00 & 0.00 & 0.00 & 0.00 & 0.00 & 0.00 & 16 & 0.00 & .00 \\
\hline 2035_Hol & $1 . ., 200$ & .00 & 0.00 & 0.00 & 0.00 & 0.00 & 0.01 & 0.00 & 0.00 & 0.00 & 0.00 & 0.00 & 0.03 & 811 & 0.00 & .00 \\
\hline 2036_Hol & l., 2007 & 0.00 & 0.00 & 0.00 & 0.00 & 0.00 & 0.00 & & 0.00 & 0.00 & 0.00 & 0.00 & 0.03 & 0.77 & 0.00 & .00 \\
\hline 037_Hol & 1.., 2007 & .00 & 0.00 & 0.00 & 0.00 & 0.00 & 0.00 & 0.00 & 0.00 & 0.00 & 0.00 & 0.00 & 0.04 & 0.16 & 0.00 & 0.01 \\
\hline 2038_Hol & $1 ., 20$ & 00 & 0.00 & 0.00 & 0.00 & 0.00 & 0.00 & 0.00 & 0.00 & 0.00 & 0.00 & 0.00 & 0.01 & 0.43 & 0.00 & 0.00 \\
\hline 2039_Hol & .20 & 00 & 0.00 & 0.00 & 0.00 & 0.00 & 0.00 & 0.00 & 0.00 & 0.00 & 0.00 & 0.00 & 0.02 & 08 & 0.00 & .00 \\
\hline 2040_Hol & 200 & 00 & 0.00 & 0.00 & 0.00 & 0.00 & 0.00 & 0.00 & 0.00 & 0.00 & 0.00 & 0.00 & 0.00 & 00 & 0.00 & 00 \\
\hline 042_Hol & 200 & mö & 0.00 & 0.00 & 0.00 & 0.00 & 0.00 & 0.00 & 0.00 & 00 & 0.00 & 00 & 0.00 & 01 & .00 & 00 \\
\hline 2043_Hol & 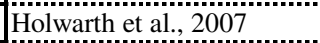 & 00 & .00 & 0.00 & 00 & 0.00 & 0.00 & 0.00 & 0.00 & 0.00 & 0.00 & 0.00 & 0.08 & 43 & $0.00 \vdots$ & 00 \\
\hline 2044_Hol & $\cdots$ & $\dddot{00}$ & 0.00 & 0.00 & 0.00 & 0.00 & 0.00 & 0.00 & 0.00 & 0.00 & 0.00 & 0.00 & 0.00 & 22 & 0.00 & .00 \\
\hline 2045_Hol & 2 & 00 & 0.00 & 0.00 & 0.00 & 0.00 & .00 & 0.00 & .00 & 00 & .00 & 0.00 & 0.07 & 21 & 0.00 & .00 \\
\hline 2047_Hol & ,.,2007 & 0.00 & 0.00 & 0.00 & 0.00 & 0.00 & 0.00 & 0.00 & 0.00 & 0.00 & 0.00 & 0.00 & 0.11 & 0.22 & 0.00 & 0.00 \\
\hline 2048_Hol & 2 & 00 & 0.00 & 0.00 & 0.00 & 0.00 & 0.00 & 0.00 & 0.00 & 0.00 & 0.00 & 0.00 & 0.04 & .73 & 0.00 & 0.00 \\
\hline 2049_Hol & 20 & $\dddot{00}$ & a... & 0.01 & 0.00 & 0.00 & 0.01 & 0.00 & 0.01 & 0.00 & 0.00 & 0.00 & 0.19 & 41 & 0.00 & 0.01 \\
\hline 2050_Hol & ".". & 0 & 0.00 & 0.02 & 0.00 & 0.00 & 0.01 & 0.00 & 0.03 & 0.00 & 0.00 & 00 & 0.18 & .57 & 0.00 & .00 \\
\hline 2051_Hol & 20 & 000 & 0.00 & 0.00 & 0.00 & 0.00 & 0.00 & 0.00 & 0.00 & 00 & 0.00 & 0.00 & 0.06 & 64 & 0.00 & 01 \\
\hline 2052_Hol & 2007 & 0.00 & 0.00 & 0.00 & 0.00 & 0.01 & 0.00 & 0.00 & 0.00 & 0.00 & 0.00 & 0.00 & 0.13 & 0.21 & 0.00 & 0.01 \\
\hline 2053_Hol & 200 & 00 & 0.00 & 0.00 & 0.00 & 0.00 & 0.00 & 0.01 & 0.00 & 0.00 & 0.00 & 0.00 & 0.04 & 0.36 & 0.00 & 0.00 \\
\hline 54_Hol & & 00 & 0.00 & 0.00 & 0.00 & 0.00 & 0.00 & 0.00 & 0.00 & 0.00 & 0.00 & 0.00 & 0.02 & 25 & 0.00 & .00 \\
\hline 2055_Hol & & $00:$ & 0.00 & 0.00 & 0.00 & 0.00 & 00 & 0.00 & 00 & 0.00 & .00 & 00 & 0.32 & 42 & 0.00 & .01 \\
\hline 2056_Hol & 20 & 00 & 0.00 & 0.00 & 0.00 & 0.00 & 0.00 & 0.00 & 0.00 & 0.00 & 0.00 & 0.00 & 0.13 & 40 & 0.00 & .00 \\
\hline 57_Hol & 2007 & 00 & 0.00 & 0.00 & 0.00 & 0.00 & 0.00 & 0.00 & 0.00 & 0.00 & .00 & 0.00 & 0.08 & 18 & 0.00 & 01 \\
\hline 59_Hol & & 4 & 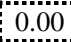 & 0.00 & 0.00 & 0.00 & 0.00 & 0.00 & 0.00 & 0.00 & .00 & 0.00 & 0.03 & 0.12 & .00 & 0.00 \\
\hline 560_Hol & $\mathrm{i}$ & $\dddot{070}:$ & 0.00 & 0.00 & 0.00 & 0.00 & 0.00 & 0.00 & 0.00 & 0.00 & 0.00 & 0.00 & 0.07 & 26 & 0.00 & 0.00 \\
\hline 2061_Hol & & .00 & 0.00 & 0.00 & 0.00 & 0.00 & .00 & 0.00 & .00 & 0.00 & .00 & 0.00 & 0.02 & 23 & 0.00 & .00 \\
\hline 2063_Hol & 2007 & 0.00 & 0.00 & 0.00 & 0.00 & 0.00 & 0.00 & 0.00 & 0.00 & 0.00 & 0.00 & 0.00 & 0.00 & 0.01 & 0.00 & 0.00 \\
\hline 2064_Hol & 20 & 00 & 0.00 & 0.00 & 0.00 & 0.00 & 0.00 & 0.00 & 0.00 & 0.00 & 0.00 & 0.00 & 0.00 & .07 & 0.00 & 0.00 \\
\hline 2065_Hol & 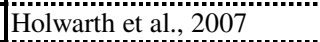 & ב" & 0.00 & 0.00 & 0.00 & 0.00 & 0.00 & 0.00 & 0.00 & 0.00 & 0.00 & 0.00 & 0.00 & 0.79 & 0.00 & 0.00 \\
\hline 2066_Hol & S & 00 & 0.00 & 0.00 & 0.00 & 0.00 & 0.00 & 0.00 & 0.00 & 0.00 & 0.00 & 0.00 & 0.04 & 0.21 & 0.00 & 0.01 \\
\hline 2067_Hol & 2007 & .00 & 0.00 & 0.00 & 0.00 & 0.00 & 0.00 & 0.00 & 0.00 & 0.00 & 0.00 & 0.00 & 0.01 & 0.35 & 0.00 & 0.00 \\
\hline 2068_Hol & 2007 & $0.00 \vdots$ & 0.00 & 0.00 & 0.00 & 0.00 & 0.00 & 0.00 & 0.00 & 0.00 & 0.00 & 0.00 & 0.03 & 0.01 & 0.00 & 0.00 \\
\hline 669_Hol & & 0.00 & 0.00 & 0.00 & 0.00 & 0.00 & 0.00 & 0.00 & 0.00 & 0.00 & .00 & 0.00 & 0.00 & 12 & 0.00 & 0.00 \\
\hline 070_Hol & ..... & Oa: & 0.00 & 0.00 & 0.00 & 0.00 & 0.00 & 0.00 & 0.00 & 0.00 & 00 & 0.00 & 0.00 & 46 & 0.00 & 0.00 \\
\hline 2071_Ver & reye, & 00 & 0.00 & 0.00 & 0.00 & 0.00 & 0.00 & 0.00 & 0.00 & 0.00 & .00 & 0.00 & 0.00 & .00 & 0.00 & 0.00 \\
\hline 2072_Ver & we & 00 & 0.00 & 0.00 & 0.00 & 0.00 & 0.00 & 0.00 & 0.00 & 0.00 & 1.00 & 0.00 & 0.00 & 0.00 & 0.00 & 0.00 \\
\hline 573_Ver & $\mathrm{i}$ & $00 \vdots$ & 0.00 & 0.00 & 0.00 & 0.00 & 0.00 & 0.00 & 0.00 & 0.00 & 0.00 & 0.00 & 0.00 & 0.00 & 0.00 & 0.00 \\
\hline 774_Ver & & & & 0.00 & 0.00 & 0.00 & 0.00 & 0.00 & 0.00 & 0.00 & .00 & 0.00 & 0.00 & 0.00 & 00 & 0.00 \\
\hline 2075_Ver & & .00 & 0.00 & 0.00 & 0.00 & 0.00 & 0.00 & 0.00 & 0.00 & 0.00 & 0.00 & 0.00 & 0.00 & 0.00 & 0.00 & 0.00 \\
\hline 2076_Ver & d Leweye, 2 & .00 & 0.00 & 0.18 & 0.00 & 0.01 & 0.00 & 0.00 & 0.01 & 0.00 & 0.00 & 0.00 & 0.31 & 0.03 & 0.00 & 0.01 \\
\hline 2077_Ver & rle & .00 & 0.00 & 0.00 & 0.00 & 0.00 & 0.00 & 0.00 & 0.00 & 0.00 & 0.00 & 0.00 & 0.03 & 0.02 & 0.00 & 0.00 \\
\hline 2078_Ver & & 00 & 0.00 & 0.00 & 0.00 & 0.00 & 0.00 & 0.00 & 0.00 & 0.00 & .00 & 0.00 & 0.00 & 0.00 & 0.00 & 0.00 \\
\hline 2079_Ver & & $100:$ & 0.00 & 0.00 & 0.00 & 0.00 & 0.00 & 0.00 & 0.00 & 0.00 & 0.00 & 0.00 & 0.00 & 0.00 & 0.00 & 0.00 \\
\hline 2080_Ver & ye, 2 & 0.00 & 0.00 & 0.00 & 0.00 & 0.01 & 0.00 & 0.00 & 0.00 & 0.00 & 0.00 & 0.00 & 0.00 & 0.01 & 0.00 & 0.00 \\
\hline 2081_Ver & Leweye, 20 & 0.01 & 0.00 & 0.32 & 0.00 & 0.07 & 0.00 & 0.00 & 0.02 & 0.01 & 0.00 & 0.00 & 0.13 & 0.11 & 0.00 & 0.00 \\
\hline 2082_Ver &, 2 & $.00 \mathrm{:}$ & 0.00 & 0.12 & 0.00 & 0.04 & 0.00 & 0.00 & 0.01 & 0.01 & 0.00 & 0.00 & 0.14 & 0.31 & 0.00 & 0.00 \\
\hline 2083_Ver & & & 0.0 & 0.06 & 0.0 & 0.03 & 0.0 & 0.0 & 0.0 & & 0.00 & 0.00 & 0.04 & 00 & .00 & 0.00 \\
\hline 2084_Ver & V vieyc aru Le & 0.00 & 0.00 & 0.00 & 0.00 & 0.02 & 0.00 & 0.00 & 0.00 & 0.00 & 0.00 & 0.00 & 0.05 & 0.05 & 0.00 & 0.00 \\
\hline 885_Ver & eye, 20 & 0.00 & 0.00 & 0.11 & 0.00 & 0.01 & 0.00 & 0.00 & 0.04 & 0.01 & 0.00 & 0.00 & 0.17 & 0.09 & 0.00 & 0.00 \\
\hline 886_Ver & Verleye and Leweye, 2011 & 0.00 & 0.00 & 0.03 & 0.00 & 0.01 & 0.00 & 0.00 & 0.01 & 0.00 & 0.00 & 0.00 & 0.27 & 0.09 & 0.00 & 0.00 \\
\hline
\end{tabular}




\begin{tabular}{|c|c|c|c|c|c|c|c|c|c|c|c|c|c|c|c|c|}
\hline 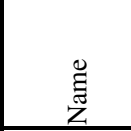 & $\stackrel{\mathscr{U}}{\Xi}$ & 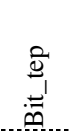 & $\begin{array}{l}\frac{\pi}{\tilde{J}} \\
\frac{\pi}{0} \\
\frac{1}{\pi}\end{array}$ & $\begin{array}{l}\overline{\bar{z}} \\
\tilde{\tilde{\sigma}} \\
\overline{\tilde{\Xi}}\end{array}$ & 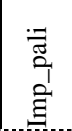 & 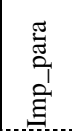 & 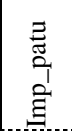 & 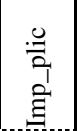 & 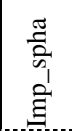 & $\begin{array}{l}\Xi_{0} \\
1_{1} \\
\stackrel{1}{\Xi}\end{array}$ & 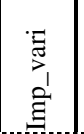 & 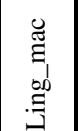 & 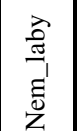 & $\begin{array}{l}J^{\prime} \\
\overrightarrow{0} \\
\overrightarrow{0}^{\prime} \\
0^{\prime}\end{array}$ & $\begin{array}{l}n_{1} \\
\vec{z} \\
\overrightarrow{0}_{1} \\
0\end{array}$ & $\begin{array}{l}\overline{\mathbb{J}} \\
\stackrel{\tilde{W}}{2} \\
0 \\
0\end{array}$ \\
\hline 87_Ver & rleye and Leweye, 2011 & 000 & 0.01 & : & 0.00 & 0.00 & 0.00 & 0.00 & 0.00 & 0.00 & 0.00 & 0.00 & 0.11 & 0.05 & 0.00 & 0.00 \\
\hline 088_Ver & rleye and Lewey & .00 & 0.00 & 0.02 & 0.00 & 0.00 & 0.00 & 0.00 & 0.01 & 0.00 & 0.00 & 0.00 & 0.19 & 0.03 & 0.00 & 0.00 \\
\hline 089_Ver & de...... & 0.00 & 0.00 & 0.04 & 0.00 & 0.00 & 0.00 & 0.00 & 0.01 & 0.00 & 0.00 & 0.00 & 0.21 & 0.04 & 0.00 & 0.01 \\
\hline 90_Ver & di.... & 00 & 0.00 & 0.02 & 0.00 & 0.00 & 0.00 & 0.00 & 0.01 & 0.00 & 0.00 & 0.00 & 0.14 & .". & 0.00 & 0.00 \\
\hline $91 \_$Ver & diev & 00 & 0.00 & 0.02 & 0.00 & 0.00 & 0.00 & 0.00 & 0.02 & 0.00 & 0.00 & 0.00 & 0.19 & .05 & 0.00 & 0.01 \\
\hline 2092_Ver & d Lev & 00 & 0.00 & 0.02 & 0.00 & 0.00 & 0.00 & 0.00 & 0.00 & 0.00 & 0.00 & 0.00 & 0.13 & 05 & 0.00 & 00 \\
\hline 2093_Ver & id Leweye, & .00 & 0.00 & 0.02 & 0.00 & 0.00 & 0.00 & 0.00 & 0.00 & 0.00 & 0.00 & 0.00 & 0.05 & 03 & 0.00 & 0.00 \\
\hline 2094_Ver & dev & 0.00 & 0.00 & 0.01 & 0.00 & 0.02 & 0.00 & 0.00 & 0.01 & 0.00 & 0.00 & 0.00 & 0.04 & 03 & 0.00 & 0.02 \\
\hline 95_Ver & i..." & 00 & 0.00 & 0.00 & 0.00 & 0.00 & 0.00 & 0.00 & .00 & 0.00 & 0.00 & 0.00 & 0.01 & 01 & 0.0 & .00 \\
\hline 096_Ver & IIG & 0 & 0.00 & 0.04 & 0.00 & 0.00 & 0.00 & 0.00 & 0.00 & 0.00 & 0.00 & 0.00 & 0.06 & $02:$ & 0.00 & 0.00 \\
\hline 2097_Ver & d Le & 00 & 0.00 & 0.00 & 0.00 & 0.00 & 0.00 & 0.00 & 0.00 & 0.00 & 0.00 & 0.00 & 0.03 & 00 & 0.00 & .00 \\
\hline 2098_Ver & diney & 100 & 0.00 & 0.00 & 0.00 & 0.00 & 0.00 & 0.00 & 0.00 & 0.00 & 0.00 & 0.00 & 0.00 & 00 & 0.00 & 1.00 \\
\hline 2099_Ver & Id Ley & 0.00 & 0.00 & 0.00 & 0.00 & 0.00 & 0.00 & & 0.00 & 0.00 & 0.00 & 0.00 & 0.00 & 00 & 0.00 & 1.00 \\
\hline 100_Ver & $1 \mathrm{Le}$ & 00 & 0.00 & 0.00 & 0.00 & 0.00 & 0.00 & 0.00 & 0.00 & 0.00 & 0.00 & 0.00 & 0.00 & 00 & .00 & 0.00 \\
\hline 101_Ver & III & 00 & 0.00 & 0.02 & 0.00 & 0.00 & 0.00 & 0.00 & 0.00 & 0.00 & 0.00 & 0.00 & 0.02 & 00 & 0.00 & 0.00 \\
\hline 102_Ver & A Le & 00 & 0.00 & 0.02 & 0.00 & 0.01 & 0.01 & 0.00 & 0.00 & 0.00 & 0.00 & 0.00 & 0.04 & 02 & 0.00 & .00 \\
\hline 103_Ver & Le & 00 & 0.01 & 0.00 & 0.03 & 0.00 & 0.00 & 0.00 & 0.06 & 0.00 & 0.00 & 0.00 & 0.53 & 09 & 0.00 & 00 \\
\hline 04_Ver & & mö & 0.00 & 0.00 & 0( & 0.00 & 0.00 & 0.00 & $\cdots$ & 00 & 0.00 & 00 & 0.40 & 08 & $00:$ & .... \\
\hline 05_Ver & & & & 0 & & 0.00 & 30 & & & 0 & 00 & 00 & 0.58 & 03 & $00 \vdots$ & 00 \\
\hline 06_Ver & & & & 0.00 & 00 & 0.00 & 00 & & 00 & 0.00 & .00 & 00 & 0.43 & 04 & .00 & 00 \\
\hline 107_Ver & & 00 & 0.00 & 0.03 & 0.00 & 0.00 & .00 & & 01 & 0.00 & 00 & 00 & 0.38 & 07 & 0.00 & 00 \\
\hline 108_Ver & Le & 00 & 0.00 & 0.05 & 0.01 & 0.01 & 0.00 & 0.00 & 0.02 & 0.00 & 0.00 & 0.00 & 0.58 & .07 & 0.00 & 0.00 \\
\hline 09_Ver & & .00 & 0.00 & 0.00 & 0.00 & 0.00 & 0.00 & 0.0 & 0.8 & 0.0 & 0.00 & 0.00 & 0.02 & 01 & 0.00 & .00 \\
\hline 2110_Ver & & 00 & 0.00 & 0.00 & 0.00 & 0.00 & 0.00 & 0.00 & 0.00 & 0.00 & 0.00 & 0.00 & 0.00 & 00 & .00 & .00 \\
\hline 11_Ver & & .00 & 0.00 & 0.12 & 0.00 & 0.00 & 0.00 & 0.00 & 0.01 & 0.00 & 0.00 & 00 & 0.36 & 05 & 0.00 & .00 \\
\hline 2112_Ver & & 0 & 0.00 & 0.16 & 0.00 & 0.00 & 0.00 & 0 & 0.00 & 0.00 & 0.00 & 0.00 & 0.15 & 04 & 0.00 & .00 \\
\hline 13_Ver & $1 \mathrm{Le}$ & 0.00 & 0.00 & 0.05 & 0.00 & 0.00 & 0.00 & 0.00 & 0.00 & 0.00 & 0.00 & 0.00 & 0.06 & 02 & 0.00 & 0.00 \\
\hline 14_Ver & & ōi & 0.00 & 0.00 & 0.00 & 0.00 & 0.00 & 0.00 & 0.00 & 0.00 & 0.00 & 0.00 & 0.00 & 00 & 0.00 & .... \\
\hline 15_Ver & & i0 & 0.00 & 0.00 & 0.00 & 0.00 & 0.00 & 0.00 & 0.00 & 0.00 & 0.00 & 0.00 & 0.00 & 00 & 00 & .00 \\
\hline 16_Ver & & 00 & & 0.00 & 0.00 & 0.00 & 00 & 0.00 & 00 & 0.00 & .00 & 00 & 0.00 & 00 & 0.00 & 00 \\
\hline 17_Ver & 2 & 00 & 0.00 & 0.00 & 0.00 & 0.00 & 0.00 & 0.00 & 0.00 & 0.00 & 0.00 & 0.00 & 0.00 & $00 \vdots$ & 0.00 & .00 \\
\hline 18_Ver & & $\because$ & $\cdots$ & 0.0 & 0.00 & 0.0 & 0.00 & 0. & 0.00 & 0.0 & .00 & 0.00 & 0 & 02 & .00 & .00 \\
\hline 9_Lau & & & & 0.0 & 00 & 0.00 & 0.00 & 0. & .00 & 0.00 & .00 & 0.00 & 0.00 & 0.79 & .03 & 0.07 \\
\hline 20_Lau & & 00 & 0.00 & 0.00 & 0.00 & 0.00 & 0.00 & 0.00 & 0.00 & 0.00 & 0.00 & 0.00 & 0.00 & 0.86 & .03 & 0.04 \\
\hline 21_Lau & & 00 & 0.00 & 0.00 & 0.00 & 0.00 & 00 & 0.00 & .00 & 0.00 & .00 & 0.00 & 0.00 & 87 & 0.02 & .03 \\
\hline 2122_Lau & ... & 0.00 & 0.00 & 0.00 & 0.00 & 0.00 & 0.00 & 0.00 & 0.00 & 0.00 & 0.00 & 0.01 & 0.00 & 0.84 & 0.01 & 0.06 \\
\hline $23 \_$Lau & & 0 & 0 & 0.02 & 0.00 & 0.00 & 01 & 0.00 & 0.00 & 0.00 & 0.00 & 0.00 & 0.00 & 0.87 & .02 & .04 \\
\hline 24_Lau & 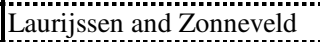 & רo" & 0.00 & 0.00 & 0.00 & 0.01 & 0.00 & 0.00 & 0.00 & 0.00 & 0.00 & 0.00 & 0.00 & 86 & .02 & .07 \\
\hline 25_Lau & & & 0.00 & 0.00 & 0.00 & 0.00 & 00 & 0.00 & 0.00 & 0.00 & 0.00 & 0.01 & 0.00 & 86 & 0.04 & .02 \\
\hline 26_Lau & & 02 & 0.00 & 0.01 & 0.00 & 0.01 & 0.01 & 0.00 & 0.04 & 0.01 & 1.00 & 0.01 & 0.02 & 0.57 & 0.02 & 0.02 \\
\hline 27_Lau & & .00 & 0.00 & 0.00 & 0.00 & 0.00 & 0.00 & 0.00 & 0.00 & 0.00 & 0.01 & 0.00 & 0.00 & 0.85 & 0.03 & 0.05 \\
\hline 8_Lau & & . & N... & 0.0 & 0.00 & 0.01 & 0.00 & 0.00 & 0.00 & 0.00 & .00 & 0.01 & 0.00 & 81 & 0.02 & 0.08 \\
\hline 29_Lau & & & & 0.00 & 0.00 & 0.00 & 0.00 & 0.00 & 0.00 & 0.00 & .00 & 0.00 & 0.00 & 82 & 0.02 & 0.06 \\
\hline 30_Lau & & 00 & & 0.00 & 0.00 & 0.00 & 0.00 & 0.00 & .00 & 00 & .00 & 0.00 & 0.00 & 88 & 0.03 & .02 \\
\hline 31_Lau & & .00 & 0.00 & 0.00 & 0.00 & 0.00 & 0.00 & 0.00 & 0.00 & 0.00 & .00 & 0.00 & 0.00 & 78 & 0.02 & 0.03 \\
\hline 32_Lau & & 00 & 0.00 & 0.00 & 0.00 & 0.00 & 0.00 & 0.00 & 0.00 & 0.00 & 0.00 & 0.00 & 0.02 & 0.60 & 0.02 & 0.08 \\
\hline 3_Lau & & & & 0.00 & $=0.00$ & 0.00 & 0.00 & 0.00 & 0.00 & 0.00 & .00 & 0.00 & 0.02 & 0.77 & 0.01 & 0.00 \\
\hline 34_Lau & & & & 0.00 & 0.00 & 0.00 & 0.00 & 0.00 & 0.00 & 0.00 & .00 & 0.00 & 0.02 & 0.35 & 0.00 & 0.00 \\
\hline 2135_Lau & 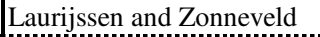 & .00 & 0.00 & 0.00 & 0.00 & 0.00 & 0.00 & 0.00 & 0.01 & 0.00 & 0.00 & 0.00 & 0.01 & 0.69 & 0.03 & 0.01 \\
\hline 36_Lau & 1 & 00 & 0.00 & 0.00 & 0.00 & 0.00 & 0.00 & 0.00 & 0.00 & 0.00 & 0.00 & 0.00 & 0.00 & 0.83 & 0.04 & 0.00 \\
\hline 37_Lau & & 00 & 0.00 & 0.00 & 0.00 & 0.00 & 0.00 & 0.00 & 0.00 & 0.00 & .00 & 0.00 & 0.00 & 86 & .02 & 0.00 \\
\hline 2138_Lau & & .00 & & 0.00 & 0.00 & 0.00 & 0.00 & 0.00 & 0.03 & 0.00 & 0.01 & 0.00 & 0.00 & 0.07 & 0.00 & 0.00 \\
\hline 2139_Lau & & 0.00 & 0.00 & 0.00 & 0.00 & 0.01 & 0.01 & 0.00 & 0.02 & 0.00 & 0.00 & 0.00 & 0.02 & 0.60 & 0.01 & 0.01 \\
\hline 140_Lau & ev & 0.00 & 0.00 & 0.00 & 0.00 & 0.00 & 0.00 & 0.00 & 0.00 & 0.00 & 0.00 & 0.00 & 0.05 & 0.61 & 0.00 & 0.00 \\
\hline 41_Lau & & .00 & 0.00 & 0.00 & 0.00 & 0.00 & 0.00 & 0.00 & 0.01 & 0.00 & 0.00 & 0.00 & 0.03 & 0.76 & 0.01 & 0.00 \\
\hline 2_Lau & & & & 0.0 & 0. & 0.00 & 0.6 & 0.0 & $\therefore$ & 0.0 & 0.00 & 0.0 & 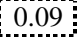 & 42 & $.02:$ & 0.00 \\
\hline 2143_Lau & & 0.00 & 0.00 & 0.01 & 0.00 & 0.00 & 0.00 & 0.00 & 0.01 & 0.00 & 0.00 & 0.00 & 0.01 & 0.39 & 0.00 & 0.00 \\
\hline 44_Lau & $\cdots$ & 0.00 & 0.00 & 0.00 & 0.00 & 0.00 & 0.00 & 0.00 & 0.01 & 0.00 & 0.00 & 0.00 & 0.00 & 0.62 & 0.01 & 0.00 \\
\hline 45_Lau & aurijssen and Zonneveld & 0.00 & 0.00 & 0.00 & 0.00 & 0.00 & 0.00 & 0.00 & 0.01 & 0.00 & 0.00 & 0.00 & 0.00 & 0.56 & 0.02 & 0.00 \\
\hline
\end{tabular}




\begin{tabular}{|c|c|c|c|c|c|c|c|c|c|c|c|c|c|c|c|c|}
\hline Е & 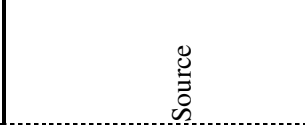 & $\begin{array}{l}\stackrel{\text { ज्ञ }}{.} \\
.\end{array}$ & 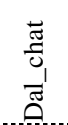 & $\begin{array}{l}\bar{\Xi} \\
\bar{\Xi} \\
\widetilde{\Xi}\end{array}$ & 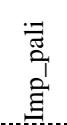 & 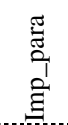 & 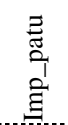 & 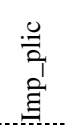 & $\begin{array}{l}\frac{\pi}{2} \\
\frac{2}{n} \\
\frac{1}{\Xi}\end{array}$ & 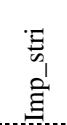 & $\begin{array}{l}\vec{\Xi} \\
\vec{z} \\
\text { Iे }\end{array}$ & 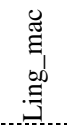 & 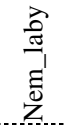 & 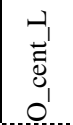 & $\begin{array}{c}\sim \\
\overrightarrow{1} \\
\stackrel{0}{0} \\
0 \\
0\end{array}$ & 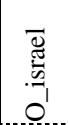 \\
\hline 2146_Lau & Laurijssen and Zonneveld & 0.01 & 0.00 & 0.00 & 0.00 & 0.00 & 0.00 & 0.00 & 0.03 & 0.00 & 0.00 & 0.00 & 0.00 & 0.55 & 0.01 & 0.00 \\
\hline 2147_Lau & Laurijssen and Zonneveld & 0.00 & 0.00 & 0.00 & 0.00 & 0.00 & 0.00 & 0.00 & 0.00 & 0.00 & 0.01 & 0.00 & 0.01 & 0.39 & 0.01 & 0.00 \\
\hline 2148_Lau & Laurijssen and Zonneveld & 0.00 & 0.00 & 0.00 & 0.00 & 0.00 & 0.01 & 0.00 & 0.01 & 0.00 & 0.00 & 0.00 & 0.01 & 0.32 & 0.01 & 0.00 \\
\hline 2149_Lau & Laurijssen and Zonneveld & 0.00 & 0.00 & 0.00 & 0.00 & 0.00 & 0.01 & 0.00 & 0.00 & 0.00 & 0.00 & 0.00 & 0.02 & 0.36 & 0.00 & 0.00 \\
\hline 2150_Lau & Laurijssen and Zonneveld & 0.00 & 0.00 & 0.01 & 0.00 & 0.00 & 0.01 & 0.00 & 0.00 & 0.00 & 0.01 & 0.00 & 0.02 & 0.31 & 0.02 & 0.00 \\
\hline 2151_Lau & Laurijssen and Zonneveld & 0.00 & 0.00 & 0.00 & 0.00 & 0.00 & 0.00 & 0.00 & 0.01 & 0.00 & 0.01 & 0.00 & 0.02 & 0.10 & 0.00 & 0.00 \\
\hline 2152_Lau & Laurijssen and Zonneveld & 0.00 & 0.00 & 0.01 & 0.00 & 0.00 & 0.00 & 0.00 & 0.00 & 0.00 & 0.00 & 0.00 & 0.02 & 0.83 & 0.01 & 0.00 \\
\hline 2153_Lau & Laurijssen and Zonneveld & 0.00 & 0.00 & 0.00 & 0.00 & 0.00 & 0.00 & 0.00 & 0.05 & 0.00 & 0.00 & 0.00 & 0.07 & 0.10 & 0.00 & 0.00 \\
\hline 2154_Lau & Laurijssen and Zonneveld & 0.00 & 0.00 & 0.00 & 0.00 & 0.00 & 0.00 & 0.00 & 0.06 & 0.00 & 0.02 & 0.00 & 0.02 & 0.17 & 0.00 & 0.00 \\
\hline 2155_Lau & Laurijssen and Zonneveld & 0.00 & 0.00 & 0.00 & 0.00 & 0.00 & 0.00 & 0.00 & 0.02 & 0.00 & 0.00 & 0.00 & 0.01 & 0.11 & 0.01 & 0.00 \\
\hline 2156_Lau & Laurijssen and Zonneveld & 0.00 & 0.00 & 0.00 & 0.00 & 0.00 & 0.00 & 0.00 & 0.03 & 0.00 & 0.00 & 0.00 & 0.01 & 0.00 & 0.00 & 0.00 \\
\hline 2157_Lau & Laurijssen and Zonneveld & 0.00 & 0.01 & 0.00 & 0.00 & 0.00 & 0.00 & 0.00 & 0.01 & 0.00 & 0.00 & 0.00 & 0.02 & 0.02 & 0.00 & 0.00 \\
\hline 2158_Lau & Laurijssen and Zonneveld & 0.00 & 0.00 & 0.00 & 0.00 & 0.00 & 0.00 & 0.00 & 0.02 & 0.00 & 0.03 & 0.00 & 0.00 & 0.10 & 0.00 & 0.00 \\
\hline 2159_Lau & Laurijssen and Zonneveld & 0.00 & 0.00 & 0.00 & 0.00 & 0.00 & 0.00 & 0.00 & 0.02 & 0.00 & 0.00 & 0.00 & 0.00 & 0.00 & 0.00 & 0.00 \\
\hline 2160_Lau & Laurijssen and Zonneveld & 0.00 & 0.00 & 0.00 & 0.00 & 0.00 & 0.01 & 0.00 & 0.01 & 0.00 & 0.00 & 0.00 & 0.01 & 0.02 & 0.00 & 0.00 \\
\hline 2161_Lau & Laurijssen and Zonneveld & 0.00 & 0.00 & 0.00 & 0.00 & 0.00 & 0.00 & 0.00 & 0.01 & 0.00 & 0.00 & 0.00 & 0.02 & 0.13 & 0.00 & 0.00 \\
\hline
\end{tabular}




\begin{tabular}{|c|c|c|c|c|c|c|c|c|c|c|c|c|c|c|c|c|c|c|c|c|}
\hline $\begin{array}{l}\text { छ్ } \\
\text { ż }\end{array}$ & 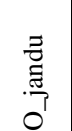 & 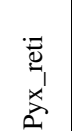 & $\begin{array}{l}\text { है } \\
\text { है } \\
\bar{a}_{1} \\
\overline{2}\end{array}$ & 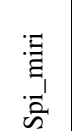 & 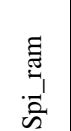 & $\begin{array}{l}\overline{0} \\
\overline{0} \\
\bar{n} \\
\bar{n}\end{array}$ & $\begin{array}{c}\vec{z} \\
\overrightarrow{0} \\
\overrightarrow{\mid} \\
\vec{n} \\
\bar{n}\end{array}$ & $\begin{array}{l}\overline{\tilde{\tilde{U}}} \\
\tilde{L}_{1} \\
\overline{n_{n}}\end{array}$ & $\begin{array}{l}\frac{0}{0} \\
\overline{0} \\
\overline{0} \\
\infty\end{array}$ & 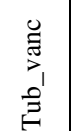 & $\begin{array}{l}\text { مे } \\
\text { के } \\
\text { o } \\
0 \\
0\end{array}$ & 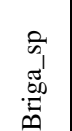 & 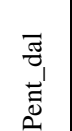 & $\begin{array}{l}\overrightarrow{\tilde{J}_{1}} \\
\overline{\mathbf{D}} \\
\vec{\omega}\end{array}$ & 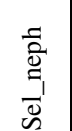 & $\begin{array}{l}\tilde{\Xi} \\
\tilde{\Xi} \\
\bar{\Xi} \\
\tilde{\infty}\end{array}$ & $\begin{array}{l}\overline{\vec{z}} \\
\vec{\Xi} \\
\vec{\Xi} \\
\vec{\xi}\end{array}$ & $\begin{array}{l}\overrightarrow{0} \\
\ddot{1} \\
\frac{1}{0}\end{array}$ & $\begin{array}{l}\frac{5}{0} \\
\text { o } \\
\frac{1}{0} \\
0\end{array}$ & $\begin{array}{l}20 \\
\text { के } \\
\frac{1}{5} \\
\text { in }\end{array}$ \\
\hline 2_Cro & 0.00 & 0.00 & 0.00 & 0.21 & 0.24 & 0.00 & 0.00 & 0.00 & 0.00 & 0.00 & 0.00 & 0.22 & 0.00 & 0.00 & 0.02 & 0.00 & 0.02 & 0.00 & 0.00 & 0.03 \\
\hline 3_Cro & 0.00 & 0.00 & 0.02 & 0.08 & 0.31 & 0.00 & 0.00 & 0.00 & 0.00 & 0.00 & 0.00 & 0.01 & 0.00 & 0.00 & 0.00 & 0.00 & 0.01 & 0.00 & 0.00 & 0.00 \\
\hline 8_Cro & 0.00 & 0.00 & 0.00 & 0.06 & 0.06 & 0.00 & 0.00 & 0.00 & 0.00 & 0.00 & 0.00 & 0.19 & 0.02 & 0.00 & 0.06 & 0.00 & 0.01 & 0.00 & 0.00 & 0.00 \\
\hline Cro & .00 & 0.00 & 0.01 & 0.12 & 0.32 & 0.00 & 0.00 & 0.00 & 0.00 & 0.00 & 0.00 & 0.13 & 0.01 & 0.00 & 0.00 & 0.03 & 0.06 & 0.00 & 0.00 & 0.01 \\
\hline 11_Cro & .00 & 0.01 & 0.00 & 0.00 & 0.00 & 0.00 & 0.00 & 0.00 & 0.00 & 0.00 & 0.00 & 0.03 & 0.00 & 0.01 & 0.01 & 0.00 & 0.02 & 0.00 & 0.00 & 0.01 \\
\hline 12_Cro & .00 & 0.00 & 0.01 & 0.01 & 0.01 & 0.00 & 0.00 & 0.00 & 0.00 & 0.00 & 0.01 & 0.40 & 0.00 & 0.00 & 0.03 & 0.05 & 0.01 & 0.00 & 0.00 & 0.05 \\
\hline 13_Cro & 0.00 & 0.01 & 0.00 & 0.01 & 0.04 & 0.00 & 0.00 & 0.00 & 0.00 & 0.00 & 0.00 & 0.22 & 0.00 & 0.00 & 0.02 & 0.08 & 0.02 & 0.00 & 0.00 & 0.10 \\
\hline 15_Cro & 00 & 0.00 & 0.00 & 0.10 & 0.00 & 0.00 & 0.00 & 0.00 & 0.00 & 0.00 & 0.00 & 0.19 & 0.01 & 0.00 & 0.00 & 0.01 & 0.02 & 0.00 & 0.00 & 0.03 \\
\hline 16_Cro & .00 & 0.00 & 0.00 & 0.10 & 0.01 & 0.00 & 0.00 & 0.00 & 0.00 & 0.00 & 0.02 & 0.20 & 0.00 & 0.00 & 0.01 & 0.06 & 0.04 & 0.00 & 0.00 & 0.04 \\
\hline 17_Cro & .00 & 0.01 & 0.00 & 0.06 & 0.01 & 0.00 & 0.00 & 0.00 & 0.00 & 0.00 & 0.01 & 0.30 & 0.00 & 0.00 & 0.02 & 0.03 & 0.04 & 0.00 & 0.00 & 0.03 \\
\hline 18_Cro & 0.00 & 0.00 & 0.03 & 0.14 & 0.00 & 0.00 & 0.00 & 0.00 & 0.00 & 0.00 & 0.01 & 0.13 & 0.00 & 0.01 & 0.01 & 0.04 & 0.08 & 0.00 & 0.00 & 0.01 \\
\hline 20_Cro & 0.00 & 0.00 & 0.00 & 0.02 & 0.02 & 0.00 & 0.00 & 0.00 & 0.00 & 0.00 & 0.01 & 0.45 & 0.01 & 0.00 & 0.01 & 0.15 & 0.05 & 0.00 & 0.01 & 0.05 \\
\hline 21_Cro & 0.00 & 0.00 & 0.02 & 0.03 & 0.03 & 0.00 & 0.00 & 0.00 & 0.00 & 0.00 & 0.01 & 0.39 & 0.00 & 0.00 & 0.01 & 0.27 & 0.02 & 0.00 & 0.01 & 0.03 \\
\hline 22_Cro & 0.00 & 0.02 & 0.01 & 0.07 & 0.07 & 0.00 & 0.00 & 0.00 & 0.00 & 0.00 & 0.00 & 0.03 & 0.00 & 0.01 & 0.00 & 0.00 & 0.01 & 0.00 & 0.00 & 0.00 \\
\hline 24_Cro & 0.00 & 0.00 & 0.02 & 0.16 & 0.03 & 0.00 & 0.00 & 0.00 & 0.00 & 0.00 & 0.00 & 0.51 & 0.00 & 0.00 & 0.02 & 0.03 & 0.02 & 0.00 & 0.00 & 0.00 \\
\hline 25_Cro & 0.00 & 0.00 & 0.00 & 0.03 & 0.02 & 0.00 & 0.00 & 0.00 & 0.00 & 0.00 & 0.01 & 0.40 & 0.00 & 0.00 & 0.01 & 0.06 & 0.03 & 0.00 & 0.00 & 0.03 \\
\hline 26_Cro & 0.00 & 0.00 & 0.00 & 0.03 & 0.06 & 0.00 & 0.00 & 0.00 & 0.00 & 0.00 & 0.03 & 0.41 & 0.00 & 0.00 & 0.01 & 0.22 & 0.01 & 0.00 & 0.01 & 0.06 \\
\hline 28_Cro & 00 & 0.04 & 0.00 & 0.05 & 0.00 & 0.00 & 0.00 & 0.00 & 0.00 & 0.00 & 0.00 & 0.09 & 0.00 & 0.00 & 0.00 & 0.00 & 0.01 & 0.00 & 0.00 & 0.00 \\
\hline 32_Cro & 00 & 0.03 & 0.00 & 0.01 & 0.00 & 0.00 & 0.00 & 0.00 & 0.00 & 0.00 & 0.00 & 0.25 & 0.00 & 0.01 & 0.00 & 0.00 & 0.00 & 0.00 & 0.00 & 0.00 \\
\hline 33_Cro & 00 & 0.00 & 0.00 & 0.05 & 0.00 & 0.00 & 0.00 & 0.00 & 0.00 & 0.00 & 0.00 & 0.00 & 0.00 & 0.00 & 0.00 & 0.00 & 0.02 & 0.00 & 0.00 & 0.00 \\
\hline 37_Cro & 0.00 & 0.05 & 0.00 & 0.00 & 0.00 & 0.00 & 0.00 & 0.00 & 0.00 & 0.00 & 0.00 & 0.15 & 0.00 & 0.00 & 0.00 & 0.00 & 0.00 & 0.00 & 0.00 & 0.00 \\
\hline 38_Pre & 0.00 & 0.05 & 0.00 & 0.03 & 0.04 & 0.00 & 0.00 & 0.00 & 0.00 & 0.00 & 0.00 & 0.11 & 0.00 & 0.00 & 0.00 & 0.04 & 0.00 & 0.00 & 0.00 & 0.00 \\
\hline 39_Pre & 00 & 0.01 & 0.00 & 0.01 & 0.00 & 0.00 & 0.00 & 0.00 & 0.00 & 0.00 & 0.00 & 0.00 & 0.00 & 0.00 & 0.00 & 0.00 & 0.00 & 0.00 & 0.00 & 0.00 \\
\hline 41_Pre & .00 & 0.02 & 0.00 & 0.10 & 0.02 & 0.00 & 0.01 & 0.00 & 0.00 & 0.00 & 0.00 & 0.01 & 0.00 & 0.00 & 0.00 & 0.00 & 0.00 & 0.00 & 0.00 & 0.00 \\
\hline 46_Pre & 0.00 & 0.03 & 0.00 & 0.04 & 0.20 & 0.00 & 0.00 & 0.00 & 0.00 & 0.00 & 0.00 & 0.40 & 0.00 & 0.00 & 0.00 & 0.00 & 0.01 & 0.00 & 0.00 & 0.00 \\
\hline 48_Pre & 0.00 & 0.00 & 0.00 & 0.00 & 0.00 & 0.00 & 0.00 & 0.00 & 0.00 & 0.00 & 0.00 & 0.15 & 0.00 & 0.01 & 0.00 & 0.00 & 0.00 & 0.00 & 0.00 & 0.00 \\
\hline 58_Pre & 0.00 & 0.00 & 0.00 & 0.00 & 0.04 & 0.00 & 0.00 & 0.00 & 0.00 & 0.00 & 0.00 & 0.23 & 0.00 & 0.00 & 0.00 & 0.03 & 0.00 & 0.00 & 0.00 & 0.00 \\
\hline 9_Pre & 00 & 0.01 & 0.00 & 0.00 & 0.10 & 0.00 & 0.00 & 0.00 & 0.00 & 0.00 & 0.00 & 0.36 & 0.00 & 0.01 & 0.01 & 0.03 & 0.03 & 0.00 & 0.01 & 0.05 \\
\hline 0_Pre & 00 & 0.00 & 0.01 & 0.07 & 0.47 & 0.00 & 0.00 & 0.00 & 0.00 & 0.00 & 0.00 & 0.15 & 0.00 & 0.00 & 0.03 & 0.07 & 0.00 & 0.00 & 0.00 & 0.00 \\
\hline 62_Pre & 0.00 & 0.00 & 0.00 & 0.02 & 0.00 & 0.00 & 0.00 & 0.00 & 0.00 & 0.00 & 0.00 & 0.00 & 0.00 & 0.00 & 0.00 & 0.00 & 0.00 & 0.00 & 0.00 & 0.00 \\
\hline 64_Pre & 0.02 & 0.00 & 0.04 & 0.03 & 0.02 & 0.00 & 0.01 & 0.00 & 0.00 & 0.00 & 0.00 & 0.18 & 0.00 & 0.00 & 0.02 & 0.01 & 0.02 & 0.00 & 0.00 & 0.02 \\
\hline 66_Pre & 00 & 0.00 & 0.00 & 0.01 & 0.01 & 0.00 & 0.00 & 0.00 & 0.01 & 0.00 & 0.00 & 0.00 & 0.00 & 0.00 & 0.00 & 0.00 & 0.01 & 0.00 & 0.00 & 0.00 \\
\hline 67_Pre & 00 & 0.01 & 0.00 & 0.00 & 0.00 & 0.00 & 0.01 & 0.00 & 0.00 & 0.00 & 0.00 & 0.03 & 0.00 & 0.00 & 0.00 & 0.00 & 0.00 & 0.00 & 0.00 & 0.00 \\
\hline 68_Pre & 0.00 & 0.01 & 0.00 & 0.05 & 0.04 & 0.00 & 0.01 & 0.00 & 0.00 & 0.00 & 0.00 & 0.20 & 0.00 & 0.00 & 0.00 & 0.00 & 0.00 & 0.00 & 0.00 & 0.00 \\
\hline 70_Pre & 0.00 & 0.00 & 0.00 & 0.00 & 0.00 & 0.00 & 0.00 & 0.00 & 0.00 & 0.00 & 0.00 & 0.55 & 0.00 & 0.00 & 0.01 & 0.00 & 0.01 & 0.00 & 0.00 & 0.00 \\
\hline 71_Pre & .00 & 0.00 & 0.03 & 0.01 & 0.34 & 0.00 & 0.00 & 0.00 & 0.01 & 0.00 & 0.00 & 0.10 & 0.00 & 0.00 & 0.02 & 0.01 & 0.00 & 0.00 & 0.00 & 0.05 \\
\hline \begin{tabular}{|l|} 
72_Pre \\
\end{tabular} & .00 & 0.00 & 0.01 & 0.00 & 0.53 & 0.00 & 0.02 & 0.00 & 0.00 & 0.00 & 0.02 & 0.14 & 0.00 & 0.00 & 0.01 & 0.00 & 0.01 & 0.00 & 0.00 & 0.04 \\
\hline 83_Pre & 0.00 & 0.08 & 0.00 & 0.08 & 0.01 & 0.00 & 0.02 & 0.00 & 0.00 & 0.00 & 0.00 & 0.08 & 0.00 & 0.00 & 0.00 & 0.00 & 0.00 & 0.00 & 0.00 & 0.00 \\
\hline 96_Pre & 0.00 & 0.00 & 0.00 & 0.05 & 0.01 & 0.00 & 0.01 & 0.00 & 0.01 & 0.00 & 0.00 & 0.11 & 0.11 & 0.00 & 0.01 & 0.00 & 0.00 & 0.00 & 0.00 & 0.00 \\
\hline 97_Pre & 0.00 & 0.00 & 0.00 & 0.02 & 0.00 & 0.00 & 0.00 & 0.00 & 0.00 & 0.00 & 0.00 & 0.00 & 0.01 & 0.00 & 0.00 & 0.00 & 0.00 & 0.00 & 0.00 & 0.00 \\
\hline \begin{tabular}{|l} 
98_Pre \\
\end{tabular} & 0.00 & 0.02 & 0.00 & 0.00 & 0.04 & 0.00 & 0.01 & 0.00 & 0.00 & 0.00 & 0.00 & 0.00 & 0.00 & 0.00 & 0.00 & 0.00 & 0.00 & 0.00 & 0.00 & 0.00 \\
\hline 104_Pre & 01 & 0.02 & 0.01 & 0.02 & 0.33 & 0.00 & 0.00 & 0.00 & 0.01 & 0.00 & 0.00 & 0.02 & 0.00 & 0.00 & 0.00 & 0.00 & 0.00 & 0.00 & 0.00 & 0.00 \\
\hline 105_Pre & 0.01 & 0.01 & 0.00 & 0.00 & 0.01 & 0.00 & 0.00 & 0.00 & 0.00 & 0.00 & 0.00 & 0.03 & 0.01 & 0.00 & 0.00 & 0.00 & 0.00 & 0.00 & 0.00 & 0.01 \\
\hline 107_Pre & 0.02 & 0.01 & 0.01 & 0.32 & 0.09 & 0.00 & 0.00 & 0.00 & 0.01 & 0.00 & 0.00 & 0.02 & 0.00 & 0.00 & 0.00 & 0.00 & 0.00 & $\begin{array}{l}0.00 \\
0\end{array}$ & 0.00 & 0.00 \\
\hline 113_Pre & .00 & 0.01 & 0.00 & 0.00 & 0.00 & 0.00 & 0.00 & 0.00 & 0.00 & 0.00 & 0.00 & 0.01 & 0.00 & 0.00 & 0.00 & 0.00 & 0.00 & 0.00 & 0.00 & 0.00 \\
\hline 119_Pre & 0.00 & 0.00 & 0.00 & 0.00 & 0.00 & 0.00 & 0.00 & 0.00 & 0.00 & 0.00 & 0.00 & 0.92 & 0.00 & 0.00 & 0.00 & 0.00 & 0.00 & 0.00 & 0.01 & 0.04 \\
\hline 120_Pre & 0.00 & 0.00 & 0.00 & 0.01 & 0.02 & 0.00 & 0.00 & 0.00 & 0.00 & 0.00 & 0.01 & 0.83 & 0.00 & 0.00 & 0.01 & 0.04 & 0.00 & 0.00 & 0.00 & 0.05 \\
\hline 123_Pre & 0.00 & 0.00 & 0.00 & 0.26 & 0.06 & 0.00 & 0.00 & 0.00 & 0.00 & 0.00 & 0.04 & 0.30 & 0.00 & 0.00 & 0.05 & 0.05 & 0.01 & 0.00 & 0.04 & 0.03 \\
\hline 128_Pre & 0.00 & 0.01 & 0.00 & 0.01 & 0.00 & 0.00 & 0.00 & 0.00 & 0.01 & 0.00 & 0.01 & 0.85 & 0.00 & 0.00 & 0.01 & 0.00 & 0.00 & 0.00 & 0.00 & 0.00 \\
\hline 129_Pre & 0.00 & 0.00 & 0.00 & 0.03 & 0.36 & 0.00 & 0.00 & 0.00 & 0.00 & 0.00 & 0.00 & 0.14 & 0.00 & 0.00 & 0.01 & 0.01 & 0.00 & 0.00 & 0.02 & 0.00 \\
\hline 133_Pre & 0.00 & 0.03 & 0.00 & 0.61 & 0.02 & 0.00 & 0.00 & 0.00 & 0.00 & 0.00 & 0.00 & 0.12 & 0.00 & 0.00 & 0.00 & 0.00 & 0.00 & 0.00 & 0.00 & 0.00 \\
\hline 134_Pre & 0.00 & 0.05 & 0.00 & 0.19 & 0.02 & 0.00 & 0.00 & 0.00 & 0.00 & 0.00 & 0.00 & 0.28 & 0.00 & 0.03 & 0.00 & 0.00 & 0.00 & 0.00 & 0.00 & 0.00 \\
\hline \begin{tabular}{|l|}
$136 \_P r e$ \\
\end{tabular} & 0.00 & 0.00 & 0.00 & 0.16 & 0.06 & 0.00 & 0.00 & 0.00 & 0.00 & 0.00 & 0.00 & 0.12 & 0.00 & 0.00 & 0.01 & 0.00 & 0.00 & 0.00 & 0.00 & 0.01 \\
\hline 137_Pre & 0.01 & 0.01 & 0.00 & 0.10 & 0.26 & 0.00 & 0.00 & 0.00 & 0.01 & 0.00 & 0.00 & 0.12 & 0.00 & 0.00 & 0.01 & 0.00 & 0.01 & 0.00 & 0.00 & 0.01 \\
\hline 140_Pre & 0.01 & 0.02 & 0.00 & 0.13 & 0.03 & 0.00 & 0.00 & 0.00 & 0.00 & 0.00 & 0.00 & 0.30 & 0.00 & 0.00 & 0.02 & 0.00 & 0.00 & 0.00 & 0.03 & 0.01 \\
\hline 141_Pre & 0.00 & 0.01 & 0.00 & 0.13 & 0.37 & 0.01 & 0.00 & 0.00 & 0.00 & 0.00 & 0.00 & 0.06 & 0.00 & 0.00 & 0.01 & 0.00 & 0.01 & 0.00 & 0.00 & 0.00 \\
\hline 142_Pre & 0.00 & 0.00 & 0.07 & 0.07 & 0.24 & 0.03 & 0.00 & 0.00 & 0.00 & 0.00 & 0.00 & 0.10 & 0.00 & 0.00 & 0.00 & 0.00 & 0.01 & 0.00 & 0.00 & 0.02 \\
\hline 143_Pre & 0.00 & 0.07 & 0.00 & 0.04 & 0.00 & 0.00 & 0.01 & 0.00 & 0.00 & 0.00 & 0.00 & 0.05 & 0.00 & 0.01 & 0.00 & 0.00 & 0.00 & 0.00 & 0.00 & 0.00 \\
\hline 144_Pre & 0.00 & 0.01 & 0.01 & 0.09 & 0.01 & 0.00 & 0.00 & 0.00 & 0.00 & 0.00 & 0.00 & 0.21 & 0.00 & 0.00 & 0.01 & 0.00 & 0.00 & 0.00 & 0.00 & 0.00 \\
\hline
\end{tabular}




\begin{tabular}{|c|c|c|c|c|c|c|c|c|c|c|c|c|c|c|c|c|c|c|c|c|}
\hline 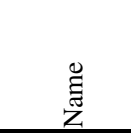 & 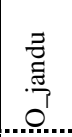 & . & 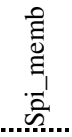 & 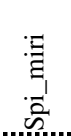 & 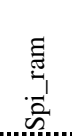 & 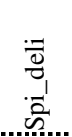 & 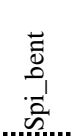 & 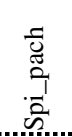 & $\begin{array}{l}\tilde{0} \\
\frac{0}{0} \\
\overline{2} \\
\bar{n}\end{array}$ & 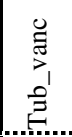 & 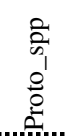 & 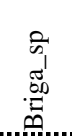 & 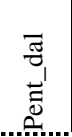 & 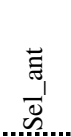 & 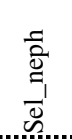 & 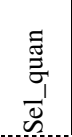 & 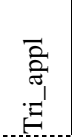 & $\begin{array}{l}\overrightarrow{0} \\
\frac{1}{1} \\
\frac{1}{0}\end{array}$ & $\begin{array}{l}\overline{0} \\
0 \\
\frac{1}{0} \\
\overrightarrow{0}\end{array}$ & 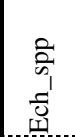 \\
\hline 5_Pre & 0.00 & 0.00 & 0.07 & 0.09 & 0.17 & 0.01 & 0.00 & 0.00 & 0.00 & 0.00 & 0.00 & 0.12 & 0.00 & 0.00 & 0.00 & 0.01 & 0.04 & 0.00 & 0.00 & 0.00 \\
\hline 1_Pre & .00 & 0.00 & 0.00 & 0.00 & 0.05 & 0.00 & 0.00 & 0.00 & 0.00 & 0.00 & 0.02 & 0.70 & 0.00 & 0.00 & 0.02 & 0.03 & 0.00 & 0.00 & 0.03 & 0.13 \\
\hline 93_Vin & ...." & 0.28 & 0.00 & 0.00 & 0.00 & 0.00 & 0.00 & 0.00 & 0.00 & 0.00 & 0.00 & 0.00 & 0.00 & 0.00 & 0.00 & 0.00 & 0.00 & 0.00 & 0.00 & 0.00 \\
\hline 4_Vin & 00 & 0.19 & 0.00 & 0.00 & 0.00 & 0.00 & 0.00 & 0.00 & 0.00 & 0.00 & 0.00 & 0.00 & 0.00 & 0.00 & .00 & 0.00 & 0.00 & .00 & 0.00 & .00 \\
\hline 95 95_Vin & 00 & 0.26 & 0.00 & 0.00 & 0.00 & 0.00 & 0.00 & 0.00 & 0.00 & 0.00 & 0.08 & 0.08 & .00 & 0.00 & 0.00 & 0.00 & .00 & .00 & 0.00 & .00 \\
\hline 396_Vin & 00 & 0.00 & 0.00 & .00 & 0.00 & 0.00 & 0.00 & 0.00 & 0.00 & 0.00 & 00 & 0.00 & .00 & .00 & .00 & .00 & .00 & .00 & 0.00 & 0.00 \\
\hline 1399_Vin & 00 & 0.02 & 0.00 & 1.00 & 0.00 & 0.00 & 0.00 & 0.00 & 0.00 & 0.00 & 0.02 & 0.02 & 0.00 & .00 & 0.00 & .00 & 0.00 & .00 & 0.00 & .00 \\
\hline 400_Vin & 00 & 0.47 & 0.00 & 1.00 & 0.00 & 0.00 & 0.00 & 0.00 & 0.00 & 0.00 & 0.00 & 0.00 & 0.00 & 00 & 0.00 & 00 & .00 & .00 & 0.00 & 0.00 \\
\hline 02_Vin & $\dddot{00}$ & 0.00 & 0.00 & 00 & 0.00 & 0.00 & 0.00 & 0.00 & 1.00 & 0.00 & 0.40 & 0.32 & .00 & 0.00 & .00 & .... & .00 & 00 & .00 & 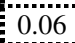 \\
\hline 03_Vin & 00 & 0.02 & 0.00 & 00 & 0.00 & 0.00 & 0.00 & 0.00 & 0.00 & 0.00 & 0.42 & 0.38 & .00 & 0.00 & .00 & j0 & 00 & .00 & . 00 & .03 \\
\hline 1404_Vin & 00 & 0.00 & 0.00 & 00 & 0.00 & .00 & 0.00 & 0.00 & 00 & 0.00 & .42 & 0.37 & .00 & .00 & .00 & 00 & .00 & .00 & 0.00 & .04 \\
\hline 1405_Vin & 00 & 0.00 & 0.00 & 0.00 & 0.00 & 0.00 & 0.00 & 0.00 & 0.00 & 0.00 & 0.43 & 0.32 & 0.00 & 00 & 0.00 & 00 & 0.00 & .00 & 0.00 & .09 \\
\hline 06_Vin & .00 & 0.01 & 0.00 & 0.00 & 0.00 & 0.00 & 0.00 & 0.00 & 0.00 & 0.00 & 0.36 & 0.31 & 0.00 & 0.00 & 0.00 & 0.00 & 0.00 & 00 & 0.00 & .04 \\
\hline 07 OVin & $\dddot{00}$ & 0.02 & 0.00 & 100 & 0.00 & 0.00 & 0.00 & 0.00 & 0.00 & 0.00 & 0.40 & 0.35 & 0.00 & 0.00 & .00 & 1.00 & 00 & 00 & 0.00 & .03 \\
\hline 75_Mar & 00 & 0.04 & 0.00 & 0.00 & 0.00 & 0.00 & 0.00 & 0.00 & 0.00 & 0.00 & 0.00 & 0.12 & 0.00 & 0.00 & 0.00 & 0.00 & 0.00 & 00 & 0.00 & 0.00 \\
\hline 376_Mar & 00 & 0.00 & 0.00 & 0.00 & 0.00 & 0.00 & 0.00 & 0.00 & .00 & 0.00 & .00 & 89 & .00 & .11 & 0.00 & 00 & 0.00 & 00 & 0.00 & .00 \\
\hline 83_Mar & 0.00 & 0.06 & 0.00 & 0.00 & 0.02 & 0.00 & 0.00 & 0.00 & 0.00 & 0.00 & 0.00 & 0.30 & .00 & 02 & 0.00 & 02 & 0.00 & 00 & 0.00 & .00 \\
\hline 37_Mar & 00 & 05 & 0.00 & 02 & 0.0 & 0.00 & .00 & 0.00 & .00 & 0.00 & 00 & 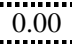 & 00 & 06 & 00 & .0 & 0 & .00 & 0.00 & 0 \\
\hline 90_Mar & 00 & 06 & 0.03 & 13 & 0.13 & .00 & 00 & 0.00 & 00 & 0.00 & 00 & 0.04 & 0 & 00 & 00 & 00 & 00 & 00 & 00 & .00 \\
\hline 391_Mar & 00 & 0.02 & 0.05 & 07 & 13 & 0.00 & 00 & 0.00 & 00 & 0.00 & .00 & 0.06 & 00 & 0.00 & 00 & 00 & 02 & .00 & 00 & .00 \\
\hline 1892_Mar & 00 & 0.00 & 0.00 & 10 & 0.13 & 0.00 & 0.00 & 0.00 & 0.00 & 0.00 & 0.00 & 0.00 & 00 & 00 & 00 & 00 & 0.00 & 00 & 0.00 & .00 \\
\hline 893_Mar & 0.00 & 0.00 & 0.00 & 0.23 & 0.30 & 0.00 & 0.00 & 0.00 & 0.00 & 0.00 & 0.00 & 0.14 & 0.00 & 0.00 & 0.00 & 0.00 & 0.03 & 0.00 & 0.00 & .00 \\
\hline 94_Mar & 00 & 0.02 & 0.00 & 20 & 0.29 & 0.00 & 0.00 & 0.00 & 1.06 & 0.00 & 0.00 & 0 & .00 & 0.0 & .02 & 0.0 & 0.03 & .00 & 0.00 & .00 \\
\hline 5_Mar & 00 & 0.00 & 0.17 & 04 & 0.12 & 0.00 & 0.00 & 0.00 & 00 & 0.00 & .00 & 0.56 & 00 & 0.00 & 33 & 0.04 & 02 & 00 & 1.00 & .00 \\
\hline 1896_Mar & 00 & 0.00 & 0.06 & 07 & 0.11 & 0.00 & 0.00 & 0.00 & .00 & 0.04 & .00 & 0.55 & .00 & 0.00 & 0.03 & 03 & .00 & 00 & 0.00 & .00 \\
\hline 897_Mar & 00 & 0.00 & 0.12 & "3i" & 0.22 & 0.00 & 0.00 & 0.00 & 0.00 & 0.03 & 0.00 & 40 & 0.00 & .00 & 0.03 & 03 & 0.02 & 00 & 0.00 & .00 \\
\hline 98_Mar & 0.00 & 0.04 & 0.17 & 0.07 & 0.15 & 0.00 & 0.00 & 0.00 & 0.00 & 0.00 & 0.00 & 0.31 & 0.00 & 0.00 & 0.03 & .00 & 0.04 & 00 & 0.00 & 0.00 \\
\hline 9_Mar & 00 & 0.03 & 0.16 & 13 & 0.13 & 0.00 & 0.00 & 0.00 & 00 & 0.00 & 0.00 & 0.00 & 0.00 & 0.00 & 00 & 0.00 & 00 & 00 & 00 & 100 \\
\hline 00_Mar & 00 & 0.00 & 0.21 & 14 & 0.15 & 000 & 0.00 & 0.00 & 00 & 0.00 & 0.00 & 0.00 & 0.00 & 0.00 & 00 & 00 & 100 & 00 & 0.00 & 00 \\
\hline 01_Mar & 00 & 0.00 & 0.12 & .22 & 0.20 & 0.00 & 0.00 & 0.00 & .00 & 0.00 & .00 & 0.03 & .00 & .00 & .00 & 00 & 0.00 & .00 & 0.00 & .00 \\
\hline 02_Mar & .00 & 0.00 & 0.00 & 17 & 0.23 & 0.00 & 0.00 & 0.00 & 0.00 & 0.00 & 0.00 & 0.00 & 0.00 & 0.00 & .00 & 00 & .00 & .00 & 0.00 & .00 \\
\hline 3_Mar & 00 & 0.00 & 0.00 & 00 & 0.07 & 0 & .0 & 0. & 0.00 & 0. & 0.00 & 0 & .00 & 0.00 & 00 & 0.00 & 0 & .0 & .0( & .00 \\
\hline 4_Mar & 00 & .00 & 0.00 & 00 & 0.04 & 0.00 & 0 & 0.0 & 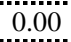 & 0.00 & .00 & 0.2 & 00 & 0.00 & .00 & 0.0 & .00 & 0.00 & .00 & .00 \\
\hline 05_Mar & 00 & 0.03 & 0.00 & 0 & 0.07 & 0.00 & 0.00 & 0.06 & 0.00 & 0.00 & .00 & 0.14 & .00 & 0.00 & .00 & 0.00 & .00 & .00 & 0.00 & .00 \\
\hline 07_Mar & 00 & 0.00 & 0.00 & .06 & 0.14 & 0.00 & 0.00 & 0.00 & 0.00 & 0.00 & 0.00 & 0.00 & .00 & 0.00 & 0.00 & .00 & 0.00 & .04 & 0.00 & .00 \\
\hline 09_Mar & 00 & 0.02 & 0.00 & 0.00 & 0.00 & 0.00 & 0.00 & 0.00 & 0.00 & 0.00 & 0.00 & 0.18 & 0.00 & 0.00 & 0.00 & 0.00 & 0.00 & 0.00 & 0.00 & 0.00 \\
\hline 12_Mar & 00 & 0.00 & 0.00 & .00 & 0.15 & 0.00 & 0.00 & 0.0 & 00 & 0.00 & .00 & 0.34 & 00 & 0.00 & .00 & 0.00 & .00 & 0.00 & 0.00 & .00 \\
\hline 13_Mar & 30 & 0.00 & 0.00 & 03 & 0.15 & 0.00 & 0.00 & 0.08 & 00 & 0.00 & .00 & 0.10 & .00 & 0.00 & .00 & .00 & .03 & 0.00 & 0.00 & .00 \\
\hline 14_Mar & 00 & 0.00 & 0.00 & 0.00 & 0.11 & 0.00 & 0.00 & 0.08 & 0.00 & 0.00 & 0.00 & 0.10 & 0.00 & 0.00 & 0.00 & 0.00 & 0.00 & 0.00 & 0.00 & 0.00 \\
\hline 15_Mar & 00 & 0.00 & 0.00 & 1.00 & 0.12 & 0.00 & 0.00 & 0.03 & 0.00 & 0.00 & 0.00 & 0.00 & 0.00 & 0.00 & 0.00 & 0.00 & 0.00 & 0.00 & 0.00 & 0.00 \\
\hline 6_Mar & D0 & 0.00 & 0.00 & 0. & 0.00 & 0.00 & 0.00 & 0.00 & 0.00 & 0.00 & 0.00 & 0.00 & 0.00 & 0.00 & 0.00 & 0.00 & 0.00 & 0.00 & 0.00 & 0.00 \\
\hline 7_Mar & 0 & 0.06 & 0.00 & 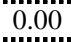 & 0.00 & 0.00 & 0.00 & 0. & 00 & 0.00 & 0.00 & 0.00 & 00 & 0.00 & 00 & 0.00 & .00 & 0.00 & 0.00 & .00 \\
\hline 8_Mar & 00 & 0.04 & 0.00 & .00 & 0.00 & 0.00 & 0.00 & 0.00 & 0.00 & 0.00 & 0.00 & 0.00 & .00 & 0.00 & .00 & 0.00 & .00 & .00 & 0.00 & .00 \\
\hline 19_Mar & 00 & 0.06 & 0.00 & 0.00 & 0.00 & 0.00 & 0.00 & 0.00 & 0.00 & 0.00 & .00 & 0.02 & .00 & .00 & .00 & 0.00 & .00 & .00 & 0.00 & 0.00 \\
\hline 20_Mar & 00 & 0.03 & 0.00 & .00 & 0.00 & 0.00 & 0.00 & 0.00 & 0.00 & 0.00 & 0.00 & 0.80 & .00 & 0.00 & .00 & 0.00 & 0.00 & 0.00 & 0.00 & 0.00 \\
\hline 1_Mar & 00 & 0.00 & 0.00 & 0.00 & 0.00 & 0.00 & 0.00 & 0.00 & 0.00 & 0.00 & 0.00 & 0.88 & 0.00 & 0.00 & 0.00 & 0.00 & .00 & 0.00 & 0.00 & .00 \\
\hline 22_Mar & 00 & 0.00 & 0.00 & 0.00 & 0.00 & 0.00 & 0.00 & 0.00 & 0.00 & 0.00 & 0.00 & 0.92 & 0.00 & 0.00 & 00 & 0.00 & .00 & 0.00 & 0.00 & 0.00 \\
\hline 23_Mar & 0.00 & 0.00 & 0.00 & 0.00 & 0.00 & 0.00 & 0.00 & 0.00 & 0.00 & 0.00 & 0.00 & 0.92 & 0.00 & 0.00 & 0.00 & 0.00 & 0.00 & 0.00 & 0.00 & 0.00 \\
\hline 1924_Mar & 0.00 & 0.00 & 0.00 & 0.00 & 0.00 & 0.00 & 0.00 & 0.00 & 0.00 & 0.00 & 0.00 & 0.41 & 0.00 & 0.00 & 0.00 & 0.00 & 0.00 & 0.00 & 0.00 & 0.00 \\
\hline 25_Mar & 00 & 0.00 & 0.00 & 0.00 & 0.00 & 0.00 & 0.00 & 0.00 & 0.00 & 0.00 & 0.00 & 0.14 & 0.00 & 0.00 & 0.00 & 0.00 & 0.00 & 0.00 & 0.00 & 0.00 \\
\hline 26_Mar & 00 & 0.00 & 0.00 & 0.00 & 0.00 & 0.00 & 0.00 & 0.00 & 0.00 & 0.00 & 0.00 & 0.21 & 0.00 & 0.00 & .00 & 0.00 & 0.00 & 0.00 & 0.00 & 0.00 \\
\hline 1927_Mar & 0.00 & 0.00 & 0.00 & 0.00 & 0.00 & 0.00 & 0.00 & 0.00 & 0.00 & 0.00 & 0.00 & 0.41 & 0.00 & 0.00 & 0.00 & 0.00 & 0.00 & 0.00 & 0.00 & 0.00 \\
\hline 28_Mar & 0.00 & 0.05 & 0.00 & 0.00 & 0.00 & 0.00 & 0.00 & 0.00 & 0.00 & 0.00 & 0.00 & 0.27 & 0.00 & 0.00 & 0.00 & 0.00 & 0.00 & 0.00 & 0.00 & 0.00 \\
\hline 29_Mar & 0.00 & 0.07 & 0.00 & .00 & 0.00 & 0.00 & 0.00 & 0.00 & 0.00 & 0.00 & 0.00 & 0.19 & 0.00 & 0.00 & 0.00 & 0.00 & 0.00 & 0.00 & 0.00 & 0.00 \\
\hline 30_Mar & 0.00 & 0.08 & 0.00 & 0.00 & 0.00 & 0.00 & 0.00 & 0.00 & 0.00 & 0.00 & 0.00 & 0.29 & 0.00 & 0.00 & 0.00 & 0.00 & .00 & 0.00 & 0.00 & 0.00 \\
\hline 31_Mar & .00 & 0.0 & 0.00 & 0.0 & 0.00 & 0.0 & 0.0 & 0.0 & 0. & 0.0 & 0.00 & 0.00 & .00 & 0. & .00 & 0.00 & 00 & 0.00 & .00 & 0.00 \\
\hline 1932_Mar & 0.00 & 0.00 & 0.00 & 0.00 & 0.00 & 0.00 & 0.00 & 0.00 & 0.00 & 0.00 & 0.00 & 0.00 & 0.00 & 0.00 & 0.00 & 0.00 & 0.00 & 0.00 & 0.00 & 0.00 \\
\hline 33_Mar & .00 & 0.08 & 0.00 & 0.00 & 0.00 & 0.00 & 0.00 & 0.00 & 0.00 & 0.00 & 0.00 & 0.02 & 0.00 & 0.00 & 0.00 & 0.00 & 0.00 & 0.00 & 0.00 & 0.00 \\
\hline 37_Mar & 0.00 & 0.00 & 0.00 & 0.00 & 0.03 & 0.00 & 0.00 & 0.00 & 0.00 & 0.00 & 0.00 & 0.32 & 0.00 & 0.16 & 0.00 & 0.00 & 0.00 & 0.00 & 0.00 & 0.00 \\
\hline
\end{tabular}




\begin{tabular}{|c|c|c|c|c|c|c|c|c|c|c|c|c|c|c|c|c|c|c|c|c|}
\hline $\begin{array}{l}\text { ๕్ } \\
\text { Zू }\end{array}$ & 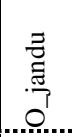 & . & 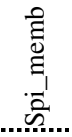 & 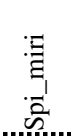 & 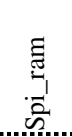 & 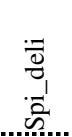 & 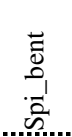 & 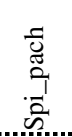 & $\begin{array}{l}\tilde{0} \\
\frac{0}{0} \\
\overline{2} \\
\bar{n}\end{array}$ & 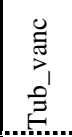 & $\begin{array}{c}\text { 20 } \\
\text { के } \\
0 \\
0 \\
0 \\
0 \\
0.1\end{array}$ & 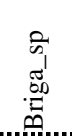 & 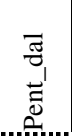 & 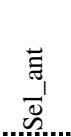 & 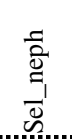 & 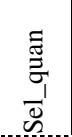 & $\begin{array}{l}\overline{\vec{n}} \\
\text { 志 } \\
\vec{\Xi}\end{array}$ & $\begin{array}{l}\overrightarrow{0} \\
\frac{1}{1} \\
\frac{1}{0}\end{array}$ & $\begin{array}{l}\overline{0} \\
0 \\
\frac{1}{0} \\
\overrightarrow{0}\end{array}$ & 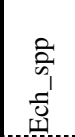 \\
\hline 38_Mar & 0.00 & 0.00 & 0.00 & 0.00 & 0.00 & 0.00 & 0.00 & 0.00 & 0.00 & 0.00 & 0.00 & 0.09 & 0.00 & 0.85 & 0.00 & 0.00 & 0.00 & 0.00 & 0.00 & 0.00 \\
\hline 39_Mar & .00 & 0.00 & 0.00 & 0.00 & 0.00 & 0.00 & 0.00 & 0.00 & 0.00 & 0.00 & 0.00 & 0.03 & 0.00 & 0.77 & 0.00 & 0.00 & 0.00 & 0.00 & 0.00 & 0.00 \\
\hline 40_Mar & ...." & 0.00 & 0.00 & 0.00 & 0.00 & 0.00 & 0.00 & 0.00 & 0.00 & 0.00 & 0.00 & 0.53 & 0.00 & 0.25 & 0.00 & 0.00 & 0.00 & 0.00 & 0.00 & 0.00 \\
\hline 11_Mar & 00 & 0.00 & 0.00 & 0.00 & 0.00 & 0.00 & 0.00 & 0.00 & 0.00 & 0.00 & 0.00 & 0.09 & 0.00 & 0.82 & 0.00 & 0.00 & 0.00 & .00 & 0.00 & "ä" \\
\hline 42_Mar & 00 & 0.00 & 0.00 & 0.00 & 0.00 & 0.00 & 0.00 & 0.00 & 0.00 & 0.00 & 0.13 & 0.03 & .00 & 0.78 & 0.00 & 0.00 & .00 & .00 & 0.00 & .00 \\
\hline 43_Mar & 00 & 0.00 & 0.00 & .00 & 0.00 & .00 & 0.00 & 0.00 & 0.00 & 0.00 & .00 & 0.11 & .00 & 0.85 & .00 & .00 & .00 & .00 & 0.00 & 0.00 \\
\hline 1945_Mar & 00 & 0.00 & 0.00 & 1.00 & 0.00 & 0.00 & 0.00 & 0.00 & 0.00 & 0.00 & 0.00 & 0.07 & 0.00 & 88 & 0.00 & .00 & 0.00 & .00 & 0.00 & .00 \\
\hline 47_Mar & 00 & 0.00 & 0.00 & .00 & 0.00 & 0.00 & 0.00 & 0.00 & 0.00 & 0.00 & 0.00 & 0.23 & 0.00 & 0.05 & 0.00 & 00 & .00 & .00 & .00 & 00 \\
\hline 48_Mar & $\dddot{0} 01$ & 0.01 & 0.00 & 00 & 0.00 & 0.00 & 0.00 & 0.00 & .00 & 0.00 & .0 & 0.63 & .00 & 0.01 & .00 & ... & .00 & $\ddot{0}$ & .00 & 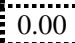 \\
\hline 49_Mar & 00 & 0.02 & 0.00 & 00 & 0.00 & 0.00 & 0.00 & 0.00 & .00 & 0.00 & 0.00 & 0.65 & 00 & 12 & 00 & & 00 & 00 & .00 & .00 \\
\hline 50_Mar & 00 & 0.02 & 0.00 & 00 & 0.00 & .00 & 0.00 & 0.00 & 00 & 0.00 & .00 & 0.46 & .00 & 23 & .00 & 00 & .00 & .00 & 0.00 & .00 \\
\hline 951_Mar & .00 & 0.00 & 0.00 & 0.00 & 0.00 & 0.00 & 0.00 & 0.00 & 1.00 & 0.00 & 0.00 & 47 & 00 & 39 & 0.00 & 00 & 0.00 & 00 & 0.00 & .00 \\
\hline 52_Mar & .00 & 0.06 & 0.00 & 0.00 & 0.00 & 0.00 & 0.00 & 0.00 & 0.00 & 0.00 & 0.03 & 0.33 & 0.00 & 0.05 & 0.00 & 0.00 & 00 & 00 & 0.00 & .00 \\
\hline 54_Mar & 00 & 0.02 & 0.00 & 100 & 0.00 & 0.00 & 0.00 & 0.00 & 0.00 & 0.00 & 0.00 & 0.39 & 0.00 & 0.21 & 00 & . & .00 & . & .00 & .00 \\
\hline 55_Mar & 00 & 0.01 & 0.00 & 0.00 & 0.00 & 0.00 & 0.00 & 0.00 & 0.00 & 0.00 & 0.01 & 0.07 & 0.02 & 0.77 & 0.00 & 0.00 & .00 & .00 & .00 & 0.00 \\
\hline 58_Mar & 00 & 0.00 & 0.00 & 0.00 & 0.00 & 0.00 & 0.00 & 0.00 & .00 & 0.00 & .00 & 0.06 & .00 & .92 & 0.00 & 00 & .00 & 00 & 0.00 & .00 \\
\hline 59_Mar & 0.00 & 0.00 & 0.00 & 0.00 & 0.00 & 0.00 & 0.00 & 0.00 & 0.00 & 0.00 & 0.00 & 0.04 & .00 & 0.78 & 0.00 & 00 & 0.00 & 00 & 0.00 & .00 \\
\hline 62_Mar & 00 & 00 & 00 & 00 & .00 & 00 & 0.00 & 0.00 & .00 & 0.00 & .00 & 0.62 & 0.00 & 26 & 00 & .00 & 00 & .00 & 0.00 & .00 \\
\hline 63_Mar & .00 & 00 & 0.00 & 00 & 00 & .00 & 00 & 0.00 & 00 & 0.00 & .00 & 49 & 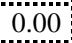 & 42 & 00 & 00 & 00 & 00 & 00 & .00 \\
\hline 968_Mar & "ä" & 0.00 & 0.00 & 00 & 00 & .00 & 00 & 0.00 & 00 & 0.00 & 00 & 0.24 & 00 & 74 & 00 & 00 & .00 & .00 & 00 & .00 \\
\hline 969_Mar & 00 & 0.00 & 0.00 & .00 & 0.00 & 0.00 & 0.00 & 0.00 & .00 & 0.00 & .00 & 31 & .00 & 67 & .00 & 00 & 0.00 & 00 & 0.00 & 00 \\
\hline 70_Mar & 0.00 & 0.00 & 0.00 & 0.00 & 0.00 & 0.00 & 0.00 & 0.00 & 0.00 & 0.00 & 0.00 & 0.78 & 0.00 & 0.19 & 0.00 & .00 & 0.00 & .00 & 0.00 & .00 \\
\hline 1_Mar & 00 & 0.00 & 0.00 & .00 & 0.00 & 0.00 & 0.00 & 0.00 & .00 & 0.00 & .00 & 0.00 & .00 & 0.00 & .00 & 0.00 & .00 & .00 & 0.00 & .00 \\
\hline 2_Mar & 00 & 0.00 & 0.00 & 00 & 0.00 & 0.00 & 0.00 & 0.00 & 00 & 0.00 & 00 & 06 & 00 & 33 & 00 & 00 & 00 & 00 & 0.00 & .00 \\
\hline 73_Mar & 00 & 0.00 & 0.00 & .00 & 0.00 & 0.00 & 0.00 & 0.00 & .00 & 0.00 & .00 & 0.87 & .00 & 0.09 & 0.00 & 00 & .00 & 00 & 0.00 & .00 \\
\hline 1974_Mar & .00 & 0.00 & 0.00 & 00 & 0.00 & 0.00 & 0.00 & 0.00 & 0.00 & 0.00 & 0.00 & 0.74 & 0.00 & 25 & 0.00 & 00 & 0.00 & 00 & 0.00 & .00 \\
\hline 75_Mar & 0.00 & 0.00 & 0.00 & 0.00 & 0.00 & 0.00 & 0.00 & 0.00 & 0.00 & 0.00 & 0.00 & 0.87 & 0.00 & 0.13 & 0.00 & .00 & 0.00 & 00 & 0.00 & .00 \\
\hline 7_Mar & 00 & 0.00 & 0.00 & 00 & 0.00 & 0.00 & 0.00 & 0.00 & 00 & 0.00 & 0.00 & 0.93 & 0.00 & 0.07 & 00 & 0.00 & 0.00 & 00 & 00 & 100 \\
\hline 88_Mar & 00 & 0.00 & 0.00 & 00 & 0.00 & 000 & 0.00 & 0.00 & 00 & 0.00 & 00 & 0.95 & 0.00 & 02 & 0.00 & 00 & 100 & 00 & .00 & 00 \\
\hline 1989_Mar & 00 & 0.00 & 0.00 & 00 & 0.00 & 0.00 & 0.00 & 0.00 & .00 & 0.00 & .00 & 0.96 & .00 & 00 & .00 & 00 & 0.00 & 00 & 0.00 & .00 \\
\hline 90_Mar & .00 & 0.00 & 0.00 & 1.00 & 0.00 & 0.00 & 0.00 & 0.00 & 0.00 & 0.00 & 0.00 & 0.99 & .00 & 0.01 & .00 & 00 & .00 & .00 & 0.00 & .00 \\
\hline 1_Mar & 00 & 0.00 & 0.00 & 00 & 0.00 & 0 & .0 & 0. & 0.00 & 0. & 0.00 & 0.98 & .00 & 0.00 & .00 & 0.00 & .00 & .0 & .0( & .00 \\
\hline 2_Mar & 00 & 0.00 & 0.00 & 00 & 0.00 & 0.00 & 00 & 0.0 & 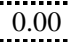 & 0.00 & 00 & 0.94 & 00 & 0.00 & .00 & 0.00 & .00 & 0.00 & .00 & .00 \\
\hline 93_Mar & 00 & 0.10 & 0.00 & $\dddot{70}$ & 0.01 & 0.00 & 0.00 & 0.00 & 0.00 & 0.00 & 00 & 0.09 & 01 & 0.03 & 00 & 0.00 & .00 & 00 & 0.00 & 00 \\
\hline 94_Mar & .00 & 0.04 & 0.00 & .05 & 0.06 & 0.00 & 0.00 & 0.00 & 0.00 & 0.00 & 0.00 & 0.32 & .02 & .03 & 0.00 & .00 & 0.00 & .00 & 0.00 & .00 \\
\hline 95_Mar & 0.00 & 0.00 & 0.00 & 0.13 & 0.04 & 0.00 & 0.00 & 0.00 & 0.00 & 0.00 & 0.00 & 0.03 & 0.00 & 0.00 & 0.00 & 0.00 & 0.00 & .00 & 0.00 & 0.00 \\
\hline 96_Mar & 00 & 0.02 & 0.00 & 0.05 & 0.00 & 0.00 & 0.00 & 0.0 & 00 & 0.0 & 02 & 0.30 & 00 & 0.00 & .00 & 0.00 & .03 & 0.00 & 0.00 & .00 \\
\hline 98_Mar & 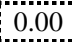 & 0.04 & 0.00 & 0.01 & 0.00 & 0.00 & 0.00 & 0.00 & 00 & 0.00 & 00 & 0.00 & 00 & 0.00 & .00 & .00 & .00 & 00 & 0.00 & .00 \\
\hline 1999_Mar & 00 & 0.03 & 0.00 & 0.04 & 0.01 & 0.00 & 0.00 & 0.00 & 0.00 & 0.00 & 0.00 & 0.25 & 0.00 & 0.00 & 0.00 & 0.05 & 0.00 & 00 & 0.00 & 0.00 \\
\hline 00_Mar & 00 & 0.00 & 0.05 & 16 & 0.07 & 0.00 & 0.00 & 0.00 & 0.00 & 0.00 & 0.00 & 0.35 & 0.00 & 0.00 & 0.00 & 0.00 & 00 & 0.00 & 0.00 & 0.00 \\
\hline 01_Mar & 00 & 0.03 & 0.00 & 0.09 & 0.05 & 0.00 & 0.00 & 0.00 & 0.00 & 0.00 & 0.00 & 0.10 & 0.00 & 0.00 & 0.00 & 0.00 & 0.00 & 0.00 & 0.00 & 0.00 \\
\hline 2_Mar & 00 & 0.04 & 0.04 & 0.07 & 0.04 & 0. & 0.00 & 0.00 & 0.00 & 0.00 & 0.00 & 0.09 & 00 & 0.00 & 00 & 0.00 & .00 & 00 & 0.00 & .00 \\
\hline 03_Mar & 00 & 0.03 & 0.03 & 0.07 & 0.06 & 0.00 & 0.00 & 0.00 & 0.00 & 0.00 & 0.00 & 0.09 & .00 & 0.00 & .00 & 0.00 & .00 & .00 & 0.00 & .00 \\
\hline 2004_Mar & 00 & 0.02 & 0.07 & 0.17 & 0.05 & 0.00 & 0.02 & 0.00 & 0.00 & 0.00 & 0.00 & 0.33 & .00 & .00 & .00 & 0.00 & .00 & .00 & 0.00 & 0.00 \\
\hline 05_Mar & 00 & 0.03 & 0.04 & 16 & 0.12 & 0.00 & 0.00 & 0.00 & 0.00 & 0.00 & 0.00 & 0.19 & .00 & 0.00 & .00 & 0.04 & .02 & 0.00 & 0.00 & 0.00 \\
\hline 06_Mar & 00 & 0.00 & 0.00 & 13 & 0.10 & 0.00 & 0.00 & 0.00 & 0.00 & 0.00 & 0.00 & 0.10 & 0.00 & 0.00 & 0.00 & 0.03 & 0.00 & 0.00 & 0.00 & .00 \\
\hline 07_Mar & 00 & 0.00 & 0.04 & & 0.10 & 0.00 & 0.00 & 0.00 & 0.00 & 0.00 & 0.00 & 0.13 & 00 & 0.00 & 00 & 0.00 & .00 & 0.00 & 0.00 & 0.00 \\
\hline 08_Mar & 0.00 & 0.02 & 0.26 & 0.03 & 0.19 & 0.00 & 0.00 & 0.00 & 0.00 & 0.00 & 0.00 & 0.09 & 0.00 & 0.00 & 0.00 & 0.02 & .00 & 0.00 & 0.00 & 0.00 \\
\hline 2009_Mar & 0.00 & 0.03 & 0.07 & 0.13 & 0.10 & 0.00 & 0.00 & 0.00 & 0.00 & 0.00 & 0.00 & 0.06 & 0.00 & 0.00 & 0.00 & 0.00 & 0.00 & 0.00 & 0.00 & 0.00 \\
\hline 12_Mar & 00 & 0.00 & 0.00 & 24 & 0.00 & 0.00 & 0.00 & 0.00 & 0.00 & 0.00 & 0.00 & 0.09 & 0.00 & 0.00 & 0.00 & .04 & 0.09 & 0.00 & 0.00 & 0.00 \\
\hline 13_Hol & 00 & 0.00 & 0.02 & 0.01 & 0.16 & 0.00 & 0.00 & 0.00 & 0.00 & 0.00 & 0.01 & 0.12 & 0.00 & 0.00 & .00 & 0.02 & .02 & 0.02 & 0.00 & 0.01 \\
\hline 14_Hol & 00 & 0.00 & 0.00 & 0.00 & 0.13 & 0.00 & 0.00 & 0.00 & 0.00 & 0.00 & 0.00 & 0.26 & 0.00 & 0.00 & 0.00 & 0.00 & 0.09 & 0.03 & 0.00 & 0.12 \\
\hline 15_Hol & 00 & 0.00 & 0.00 & 0.00 & 0.04 & 0.00 & 0.00 & 0.00 & 0.00 & 0.00 & 0.00 & 0.49 & 0.00 & 0.00 & 0.00 & 0.02 & 0.01 & 0.02 & 0.00 & 0.21 \\
\hline 16_Hol & 00 & 0.00 & 0.00 & 00 & 0.01 & 0.00 & 0.00 & 0.00 & 0.00 & 0.00 & 0.00 & 0.59 & 0.00 & 0.00 & 0.00 & 0.13 & 0.00 & 0.12 & 0.00 & 0.13 \\
\hline 17_Hol & 0.00 & 0.00 & 0.00 & 0.00 & 0.00 & 0.00 & 0.00 & 0.00 & 0.00 & 0.00 & 0.03 & 0.34 & 0.00 & 0.00 & 0.03 & 0.23 & 0.00 & 0.00 & 0.00 & 0.34 \\
\hline S_Hol & & 0.0 & 0.00 & 0.0 & 0.3 & 0.0 & 0.0 & 0.0 & 0 & 0.0 & 0 . & 0. & 0.00 & 0. & .00 & 0.0 & 00 & 0.02 & .00 & 0.04 \\
\hline 19_Hol & 0.00 & 0.00 & 0.00 & 0.00 & 0.37 & 0.00 & 0.00 & 0.00 & 0.00 & 0.00 & 0.05 & 0.02 & 0.01 & 0.00 & 0.00 & 0.00 & 0.00 & 0.00 & 0.00 & 0.00 \\
\hline 20_Hol & .00 & 0.00 & 0.00 & 0.00 & 0.07 & 0.00 & 0.00 & 0.00 & 0.00 & 0.00 & 0.00 & 0.03 & 0.00 & 0.00 & 0.00 & 0.00 & 0.01 & 0.00 & 0.00 & 0.01 \\
\hline 21_Hol & 0.00 & 0.00 & 0.00 & 0.00 & 0.10 & 0.00 & 0.00 & 0.00 & 0.00 & 0.00 & 0.00 & 0.04 & 0.00 & 0.00 & 0.00 & 0.00 & 0.00 & 0.00 & 0.00 & 0.00 \\
\hline
\end{tabular}




\begin{tabular}{|c|c|c|c|c|c|c|c|c|c|c|c|c|c|c|c|c|c|c|c|c|}
\hline $\begin{array}{l}\stackrel{\Xi}{\Xi} \\
z\end{array}$ & $\frac{\tilde{Z}}{\stackrel{\Xi}{\Xi}}$ & 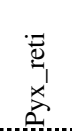 & $\begin{array}{c}\text { है } \\
\bar{\Xi} \\
\Xi \\
\bar{\Xi} \\
\overline{\tilde{z}}\end{array}$ & 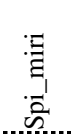 & 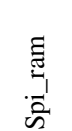 & $\begin{array}{l}\overline{0} \\
\frac{1}{2} \\
\overline{2}\end{array}$ & $\begin{array}{l}\overrightarrow{\overrightarrow{0}} \\
\stackrel{1}{1} \\
\overrightarrow{0} \\
\overrightarrow{0}\end{array}$ & $\begin{array}{l}\overline{0} \\
\tilde{\tilde{\sigma}} \\
. \\
\bar{n}\end{array}$ & $\begin{array}{l}\frac{\tilde{0}}{0} \\
\bar{a} \\
\overline{0}\end{array}$ & 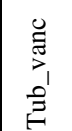 & $\begin{array}{l}2 \\
\text { के } \\
\text { ! } \\
\stackrel{0}{0}\end{array}$ & 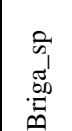 & $\begin{array}{l}\text { ज्ञ } \\
\overrightarrow{0} \\
\overrightarrow{0}\end{array}$ & $\begin{array}{l}\vec{\Xi}_{\bar{J}} \\
\vec{\Xi}_{\tilde{D}}\end{array}$ & 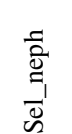 & $\begin{array}{l}\tilde{\Xi} \\
\vec{\sigma}_{1} \\
\bar{\Xi}\end{array}$ & $\begin{array}{l}\overline{\overrightarrow{2}} \\
\text { ज्ञ } \\
\Xi \\
\Xi\end{array}$ & $\begin{array}{l}\text { Oे } \\
\frac{1}{1} \\
\frac{\lambda}{0}\end{array}$ & $\begin{array}{l}\overrightarrow{0} \\
\text { । } \\
\vec{\lambda} \\
0\end{array}$ & $\begin{array}{l}2 \\
0 \\
0 \\
\frac{1}{0}\end{array}$ \\
\hline 22_Hol & "no" & 0.00 & 0.00 & 0.01 & 0.19 & 0.00 & 0.00 & 0.00 & 0.00 & o.t..." & 0.01 & 06 & 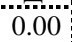 & 000 & 0.00 & 0.00 & 0.02 & 0.00 & 000 & 002 \\
\hline 23_Hol & .00 & 0.00 & 0.01 & 0.00 & 0.34 & 0.00 & 0.00 & 0.00 & 0.00 & 0.00 & 0.01 & 0.08 & 0.00 & 0.00 & 0.00 & 0.02 & 0.03 & 0.01 & 0.00 & 0.01 \\
\hline 24_Hol & 00 & 0.00 & 0.00 & 0.00 & 0.04 & 0.00 & 0.00 & 0.00 & 0.00 & 0.00 & 0.14 & 0.48 & 0.00 & 0.00 & 0.03 & 0.19 & 0.01 & 0.02 & 0.00 & 0.05 \\
\hline$\overline{5 \_\mathrm{Hol}}$ & :30" & 0.00 & 0.00 & 0.00 & 0.03 & .00 & 0.00 & 0.00 & 0.00 & 0.00 & 0.00 & 0.16 & 00 & 0.00 & 0.00 & 0.08 & .00 & .09 & 3.00 & .04 \\
\hline $6 \_\mathrm{Hol}$ & 00 & 0.00 & 0.00 & 0.00 & 0.04 & 00 & 0.00 & 0.00 & 0.00 & 0.00 & 0.00 & 0.13 & .00 & 0.00 & .00 & 0.02 & .02 & .00 & .00 & .03 \\
\hline 27_Hol & 00 & 00 & 0.00 & 0.00 & 0.04 & .00 & 0.00 & 0.00 & 0.00 & 0.00 & 0.00 & 0.03 & 00 & 00 & .00 & 01 & 01 & .00 & .00 & .02 \\
\hline 28_Hol & 01 & 0.00 & 0.00 & 01 & 0.06 & 0.00 & 0.00 & 0.00 & 0.00 & 0.00 & 0.00 & 0.04 & .00 & 00 & .00 & .01 & 01 & .00 & .00 & .02 \\
\hline 29_Hol & 00 & 0.00 & 0.00 & 0.00 & 0.05 & 0.00 & 0.00 & 0.00 & 0.00 & 0.00 & 0.00 & 0.69 & .00 & 00 & 0.00 & 10 & 00 & .00 & & \\
\hline 31_Hol & 00 & 01 & 0.00 & 00 & 0.03 & 00 & 0.00 & 0.00 & 0.00 & 0.00 & 0.01 & 0.10 & .00 & 00 & .00 & .04 & .02 & 00 & .00 & .06 \\
\hline 3_Hol & 00 & 00 & 0.00 & 00 & 0.03 & 00 & 0.00 & 0.00 & 0.00 & 0.00 & 25 & 0.40 & 00 & 00 & 01 & 0.25 & 00 & 01 & .00 & .03 \\
\hline 34_Hol & 00 & 00 & 0.00 & 02 & 0.00 & 00 & 0.00 & 0.00 & 0.00 & 0.00 & .04 & 0.30 & .00 & 00 & .00 & 32 & .00 & 04 & .00 & .12 \\
\hline 35_Hol & 00 & 0.01 & 0.00 & 1.00 & 0.07 & 0.00 & 0.00 & 0.00 & 0.00 & 0.00 & 0.01 & 0.04 & 00 & 00 & 0.00 & 00 & 02 & 00 & .00 & .00 \\
\hline 36_Hol & on' & 0.03 & 0.00 & 0.00 & 0.00 & 0.00 & 0.00 & 0.00 & 0.00 & 0.00 & 0.03 & 0.10 & .00 & .00 & 0.00 & 0.00 & 0.01 & 00 & .00 & .02 \\
\hline 7_Hol & 0.00 & 0.00 & 0.01 & 100 & 0.02 & 00 & 0.00 & 0.00 & 0.00 & 0.00 & 0.00 & 0.30 & 01 & 0.00 & 00 & 118 & 00 & . & .00 & 20 \\
\hline 38_Hol & "'ק" & 0.00 & 0.00 & 0.00 & 0.05 & .00 & 0.00 & 0.00 & 0.00 & 0.00 & 0.00 & 0.26 & .00 & 0.00 & .00 & 0.16 & .00 & .05 & .1...". & .04 \\
\hline 39_Hol & 00 & 0.00 & 0.00 & 0.00 & 0.06 & 0.00 & .00 & 0.00 & .00 & 00 & 0.03 & 39 & .01 & 00 & 0.00 & 34 & .01 & 01 & .00 & .04 \\
\hline 40_Hol & 00 & 0.00 & 0.00 & 0.00 & 0.00 & .00 & 0.00 & 0.00 & 0.00 & 0.00 & 0.11 & 0.85 & 00 & 00 & .00 & 04 & 00 & 00 & 00 & .00 \\
\hline 2_Hol & 00 & 00 & .00 & 00 & $\dddot{00}$ & 00 & 0.00 & 0.00 & 0.00 & $\cdots$ & 0.0 & 0.3 & .00 & 00 & 0.00 & 43 & 1.00 & 15 & 00 & 02 \\
\hline Hol & 00 & 00 & 0.00 & 00 & 0.01 & 0 & 0.00 & 00 & 00 & 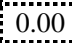 & .01 & 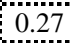 & . & 00 & 0 & 01 & 4 & 02 & 00 & 09 \\
\hline 44_Hol & 00 & 000 & 0.00 & 0.01 & 00 & & 0.00 & 0.00 & 00 & & 01 & & 0 & 00 & 00 & 09 & 04 & 07 & 00 & .15 \\
\hline 45_Hol & 00 & 0.00 & 0.00 & 00 & 0.13 & 00 & 0.00 & 0.00 & .00 & 00 & 0.00 & 00 & .00 & 00 & .00 & 01 & .02 & 28 & 00 & .29 \\
\hline 47_Hol & 00 & 0.00 & 0.00 & 0.00 & 0.00 & 0.00 & 0.00 & 0.00 & 0.00 & 0.00 & 0.00 & 0.56 & 0.00 & 00 & 0.00 & .00 & .00 & 00 & .00 & .11 \\
\hline 8_Hol & 00 & 0.00 & 0.00 & .00 & 0.00 & .00 & 0.00 & 0.00 & 0.00 & 0.0 & 0.0 & 0.1 & 0.00 & 0.00 & 00 & 0.0 & .03 & .00 & .00 & 02 \\
\hline 9_Hol & ח̈ & בij & 0.00 & 00 & 0.00 & 00 & 0.00 & 0.00 & 0 & 0.00 & 0.00 & $\cdots$ & 0 & 00 & 00 & 03 & 04 & 00 & 00 & .05 \\
\hline 50_Hol & 0 & 0 & 0.00 & 00 & 0.00 & .00 & 0.00 & 0.00 & 00 & 0.00 & 00 & 0.07 & 00 & 00 & .00 & 03 & .04 & 00 & .00 & .05 \\
\hline 51_Hol & רi" & 0.01 & 0.00 & "an" & 0.00 & 0.00 & 0.00 & 0.00 & 0.00 & 0.00 & 0.01 & 0.13 & 0.00 & 00 & 0.00 & 07 & 01 & 00 & 0.00 & .05 \\
\hline 52_Hol & 00 & 0.00 & 0.00 & 0.01 & 0.01 & 0.00 & 0.00 & 0.00 & 0.00 & 0.00 & 0.00 & 0.28 & 0.00 & 0.00 & 0.00 & 0.14 & 01 & 03 & .00 & .17 \\
\hline $\mathrm{Hol}$ & :30' & 0.01 & 0.01 & 0.00 & 0.0 & 0.00 & 0.00 & 0.00 & 0.00 & 0.00 & 0.00 & 0.21 & 100 & 0.00 & .00 & 0.09 & 10 & 00 & .00 & 16 \\
\hline 54_Hol & "ז & 0.00 & 0.00 & 0 & 03 & .00 & 0.00 & 0.00 & 00 & 0.00 & .00 & 0.48 & 0 & .00 & .00 & 00 & .00 & 02 & 00 & 20 \\
\hline 55_Hol & & 00 & 0.01 & 0 & 0.02 & 10 & 0.00 & 0.00 & 00 & 0.00 & .01 & 0.06 & 01 & 00 & .00 & 03 & .04 & 04 & .00 & .01 \\
\hline 56_Hol & 00 & 0.00 & 0.01 & 0.00 & 0.03 & 0.00 & 0.00 & 0.00 & 0.00 & 0.00 & .01 & 0.07 & .00 & 00 & .00 & 0.11 & 01 & .05 & .00 & 17 \\
\hline 7_Hol & 00 & 02 & 0.00 & 00 & 0.00 & 0.00 & 0.0 & 0 & 0.00 & 0. & .00 & 0 & .00 & .00 & .00 & 0.11 & .02 & 01 & .00 & .10 \\
\hline 9_Hol & & 00 & 00 & 100 & 0.02 & .00 & .00 & 0.00 & .00 & 0.00 & .00 & 0.36 & .00 & 00 & 02 & 24 & 03 & 07 & .00 & .12 \\
\hline 60_Hol & 00 & 0.00 & 0.01 & .00 & 0.02 & 00 & 0.00 & 0.00 & 0.00 & 0.00 & 01 & 0.35 & .00 & 0.00 & .00 & 12 & 05 & 02 & 00 & 10 \\
\hline 61_Hol & 00 & 0.00 & 0.00 & 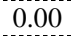 & 0.00 & 0.00 & 0.00 & 0.00 & 0.00 & 0.00 & 0.00 & 0.48 & .00 & .00 & .00 & .12 & .00 & 00 & .00 & .15 \\
\hline 63_Hol & 00 & 0.00 & 0.00 & 0.00 & 0.01 & 0.00 & 0.00 & 0.00 & 0.00 & 0.00 & 0.02 & 0.45 & 0.00 & 0.00 & 0.03 & 0.45 & .00 & .00 & 0.00 & 0.04 \\
\hline 64_Hol & 30 & 0.00 & 0.00 & 00 & 0.05 & 0.00 & 0.00 & 0.0 & 0.00 & 0.0 & .04 & 0.46 & 0.00 & 0.00 & 01 & 0.22 & 00 & 01 & .00 & 0.15 \\
\hline 65_Hol & 11 & 0.01 & 0.01 & 000 & 0.01 & 0.00 & 0.00 & 0.00 & 0.00 & 0.00 & 0.01 & 0.08 & .00 & 0.00 & 00 & 0.05 & 00 & .01 & .00 & .00 \\
\hline 2066_Hol & & 0. & 0.00 & 00 & 0.03 & 0.00 & 0.00 & 0.00 & 0.00 & 0.00 & 00 & 0.18 & 00 & 0.00 & .00 & .07 & .04 & 111 & .00 & 0.32 \\
\hline 67_Hol & 00 & 0.01 & 0.01 & 1.00 & 0.02 & 0.00 & 0.00 & 0.00 & .00 & 0.00 & 0.02 & 0.12 & .00 & 0.00 & 00 & 0.13 & .02 & .08 & 0.00 & 0.23 \\
\hline 68_Hol & . & 0.00 & 0.00 & 0.00 & 0.00 & 0.00 & 0.00 & 0.00 & 0.00 & 0.00 & 0.00 & 0.87 & 0.00 & 00 & 0.00 & 00 & 00 & 07 & 00 & 03 \\
\hline 9_Hol & & 0.00 & 0.00 & .00 & 0.01 & 0.00 & 00 & 0.00 & 0 & 0.00 & 00 & 0.70 & 00 & 00 & .00 & 02 & 01 & 00 & .00 & 13 \\
\hline 770_Hol & & 0.00 & 0.00 & .00 & 0.24 & 0 & 0.00 & 0.00 & 0.00 & 0.00 & .00 & 0.20 & 00 & 0.00 & 00 & .02 & 00 & 00 & .00 & .09 \\
\hline 2071_Ver & 00 & 0.00 & 0.00 & .00 & 0.00 & 0.00 & 0.00 & 0.00 & 0.00 & 0.00 & 0.01 & 0.97 & .01 & 0.00 & .00 & 00 & .00 & 00 & .01 & 0.00 \\
\hline 2072_Ver & 00 & 0.00 & 0.00 & .0 & 0.00 & 0.00 & 0.00 & 0.00 & 0.00 & 0.00 & 00 & 0.82 & .17 & 0.00 & .00 & 100 & .00 & .00 & .01 & 0.00 \\
\hline 73 73er & 00 & 0.00 & 0.00 & 0.00 & 0.00 & 0.00 & 0.00 & 0.00 & 0.00 & 0.00 & 0.01 & 0.97 & 0.00 & 0.00 & 0.00 & 02 & .00 & 00 & 00 & 00 \\
\hline 74_Ver & & 0.0 & 0.00 & & 0.00 & 0.00 & 0.00 & 0.00 & 0.00 & 0.00 & 0.02 & 0.90 & 03 & 0.00 & .00 & 0.03 & 00 & 01 & .02 & 0.00 \\
\hline 2075_Ver & 0.00 & 0.00 & 0.00 & 0.00 & 0.00 & 0.00 & 0.00 & 0.00 & 0.00 & 0.00 & 0.02 & 0.86 & 0.09 & 0.00 & .00 & 0.02 & .00 & .00 & .01 & 0.00 \\
\hline 2076_Ver & 00 & 0.04 & 0.00 & 0.00 & 0.00 & 0.00 & 0.00 & 0.00 & 0.00 & 0.00 & 0.08 & 0.15 & 0.02 & 0.00 & 0.00 & 0.00 & 0.00 & .00 & 0.00 & 0.17 \\
\hline 2077_Ver & 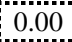 & 0.00 & 0.00 & 0.0 & 0.00 & 0.00 & 0.00 & 0.00 & 0.00 & 0.00 & 111 & 0.75 & .00 & 0.00 & 0.00 & 0.00 & 0.00 & 00 & .00 & 0.09 \\
\hline 78 78_Ver & & 0.00 & 0.00 & 0.00 & 0.00 & 0.00 & 0.00 & 0.00 & 0.00 & 0.00 & 0.26 & 0.66 & 0.01 & 0.00 & 00 & 0.02 & 00 & 0.00 & .00 & 0.05 \\
\hline 2079_Ver & 0.00 & 0.00 & 0.00 & 0.00 & 0.00 & 0.00 & 0.00 & 0.00 & 0.00 & 0.00 & 0.18 & 0.77 & 0.00 & 0.00 & 00 & 0.03 & 0.00 & 0.00 & .00 & 0.01 \\
\hline 2080_Ver & 0.00 & 0.01 & 0.00 & 0.00 & 0.00 & 0.00 & 0.00 & 0.00 & 0.00 & 0.00 & 0.26 & 0.57 & 0.00 & 0.00 & 0.00 & 0.02 & 0.00 & 0.01 & 0.00 & 0.10 \\
\hline 2081_Ver & 00 & 0.14 & 0.00 & 0.00 & 0.17 & 0.00 & 0.00 & 0.00 & 0.00 & 0.00 & 0.01 & 0.00 & 0.01 & 0.00 & 0.00 & 0.00 & 0.00 & 00 & 0.00 & 0.00 \\
\hline 082_Ver & 0.00 & 0.08 & 0.00 & 0.00 & 0.24 & 0.00 & 0.00 & 0.00 & 0.00 & 0.00 & 0.00 & 0.01 & 0.03 & 0.00 & 0.00 & 0.00 & .01 & 0.00 & 00 & 0.00 \\
\hline 83_Ver & & 0.0 & 0.00 & 0.0 & 0.1 & 0.0 & 0.0 & 0.0 & 0. & 0.0 & 0.1 & 0. & 0.01 & 0. & 00 & 0.05 & 00 & .01 & 00 & 0.03 \\
\hline 2084_Ver & 0.00 & 0.03 & 0.00 & 0.00 & 0.24 & 0.00 & 0.00 & 0.00 & 0.00 & 0.00 & 0.13 & 0.27 & 0.05 & 0.00 & 0.00 & 0.05 & 0.00 & 0.01 & 0.00 & 0.10 \\
\hline 855 8er & .00 & 0.19 & 0.00 & 0.0 & 0.17 & 0.00 & 0.00 & 0.00 & 0.00 & 0.00 & 0.03 & 0.01 & 0.13 & 0.00 & 0.00 & 0.00 & 0.00 & 0.00 & 0.00 & 0.03 \\
\hline 866_Ver & 0.00 & 0.02 & 0.00 & 0.00 & 0.02 & 0.00 & 0.00 & 0.00 & 0.00 & 0.00 & 0.12 & 0.31 & 0.01 & 0.00 & 0.00 & 0.00 & 0.00 & 0.00 & 0.00 & 0.12 \\
\hline
\end{tabular}




\begin{tabular}{|c|c|c|c|c|c|c|c|c|c|c|c|c|c|c|c|c|c|c|c|c|}
\hline $\begin{array}{l}\text { Е్ } \\
\text { Z }\end{array}$ & $\frac{\tilde{Z}}{\stackrel{\Xi}{\Xi}}$ & 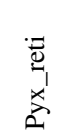 & $\begin{array}{c}\text { है } \\
\text { है } \\
\bar{a} \\
\bar{a}\end{array}$ & 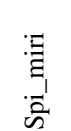 & 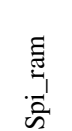 & $\begin{array}{l}\overline{0} \\
\frac{1}{2} \\
\overline{2}\end{array}$ & $\begin{array}{l}\overrightarrow{\overrightarrow{0}} \\
\stackrel{1}{1} \\
\overrightarrow{0} \\
\overrightarrow{0}\end{array}$ & $\begin{array}{l}\overline{0} \\
\tilde{\tilde{\sigma}} \\
. \\
\bar{n}\end{array}$ & $\begin{array}{l}\frac{\tilde{0}}{0} \\
\bar{a} \\
\overline{0}\end{array}$ & 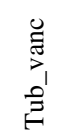 & $\begin{array}{l}0 \\
\hat{n}_{1} \\
0^{\prime} \\
0 \\
0 \\
0\end{array}$ & $\begin{array}{l}\infty \\
\infty \\
\tilde{\infty} \\
\overline{0}\end{array}$ & $\begin{array}{l}\text { ज्ञ } \\
\overrightarrow{0} \\
\overrightarrow{0}\end{array}$ & $\begin{array}{l}\vec{\Xi}_{\bar{J}} \\
\vec{\Xi}_{\tilde{D}}\end{array}$ & 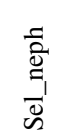 & $\begin{array}{l}\text { ज्ञ } \\
\vec{J}_{J} \\
\bar{\Xi}\end{array}$ & $\begin{array}{l}\overline{\vec{a}} \\
\text { ज्ञ } \\
\vec{\Xi}\end{array}$ & $\begin{array}{l}\overrightarrow{0} \\
\ddot{1} \\
\frac{1}{0}\end{array}$ & 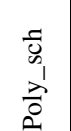 & $\begin{array}{l}2 \\
0 \\
\text { के } \\
\text { in }\end{array}$ \\
\hline 87 8er & (00" & 0.00 & 0.00 & 0.00 & 0.00 & 0.00 & 0.00 & 0.00 & 0.00 & 0.00 & 0.14 & 047 & 0.02 & 0.00 & 0.00 & 0.00 & 0.00 & 0.00 & 0.00 & 0.19 \\
\hline 88_Ver & .00 & 0.02 & 0.00 & 0.00 & 0.00 & 0.00 & 0.00 & 0.00 & 0.00 & 0.00 & 0.14 & 0.43 & 0.02 & 0.00 & 0.00 & 0.02 & 0.01 & 0.00 & 0.00 & 0.11 \\
\hline 89_Ver & ...." & 0.02 & 0.00 & 0.00 & 0.03 & 0.00 & 0.00 & 0.00 & 0.00 & 0.00 & 0.15 & 0.33 & 0.00 & 0.00 & 0.00 & 0.01 & 0.00 & 0.00 & 0.00 & 0.15 \\
\hline $90 \_$Ver & 00 & 0.01 & 0.00 & 0.00 & 0.00 & 0.00 & 0.00 & 0.00 & 0.00 & 0.00 & 0.09 & 0.56 & 0.00 & 0.00 & .00 & 0.01 & 0.00 & 0.00 & 0.00 & 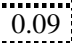 \\
\hline 91_Ver & 00 & 0.01 & 0.00 & 0.00 & 0.01 & 0.00 & 0.00 & 0.00 & 0.00 & 0.00 & .14 & 0.40 & .00 & 0.00 & 0.00 & mas & .00 & .00 & 0.00 & 13 \\
\hline 2092 2Ver & 00 & 0.03 & 0.00 & .00 & 0.00 & .00 & 0.00 & 0.00 & .00 & 0.00 & .21 & 0.35 & 01 & .00 & 1.00 & .00 & .01 & .00 & 0.00 & 18 \\
\hline 2093_Ver & 00 & 0.01 & 0.00 & 1.00 & 0.00 & 0.00 & 0.00 & 0.00 & 0.00 & 0.00 & 0.16 & 0.50 & .01 & 0.00 & 0.00 & 00 & 0.00 & .00 & .00 & 21 \\
\hline 94_Ver & .00 & 0.00 & 0.00 & 0.00 & 0.01 & 0.00 & 0.00 & 0.00 & 0.00 & 0.00 & 0.12 & 0.58 & 00 & 0.00 & 0.00 & 0.04 & 0.01 & .00 & 0.00 & 12 \\
\hline 95_Ver & $0 \mathrm{C}$ & 0.00 & 0.00 & 00 & 0.00 & 0.00 & 0.00 & 0.00 & .00 & 0.00 & 33 & 0.50 & .01 & 0.00 & .00 & 0.02 & .02 & 00 & .00 & 0 \\
\hline 2096_Ver & $\ddot{00}$ & 0.00 & 0.00 & .00 & 0.00 & 0.00 & 0.00 & 0.00 & .00 & 0.00 & 16 & 0.53 & 00 & .00 & 00 & & 00 & .00 & .00 & 18 \\
\hline 2097_Ver & 00 & 0.00 & 0.00 & 00 & 0.00 & 0.00 & 0.00 & 0.00 & .00 & 0.00 & .22 & 0.55 & .00 & 0.00 & .00 & .04 & .01 & .00 & 0.00 & .17 \\
\hline 2098_Ver & .00 & 0.00 & 0.00 & 1.00 & 0.00 & 0.00 & 0.00 & 0.00 & 1.00 & 0.00 & 24 & 0.62 & .01 & .00 & 0.00 & 06 & .02 & 00 & 0.00 & .06 \\
\hline 099_Ver & .00 & 0.00 & 0.00 & 0.00 & 0.01 & 0.00 & 0.00 & 0.00 & 0.00 & 0.00 & 0.27 & 0.59 & 0.01 & 0.00 & 0.00 & 0.00 & 0.00 & 00 & 0.00 & .06 \\
\hline 00_Ver & 00 & 0.00 & 0.00 & 100 & 0.00 & 0.00 & 0.00 & 0.00 & 0.00 & 0.00 & 0.29 & 0.57 & 0.00 & 0.00 & 00 & 0.07 & 0.01 & 00 & .00 & .05 \\
\hline 01_Ver & 00 & 0.00 & 0.00 & 0.00 & 0.02 & 0.00 & 0.00 & 0.00 & 0.00 & 0.00 & 0.23 & 0.54 & 0.01 & 0.00 & 0.00 & 0.05 & 0.00 & .00 & 0.00 & 0.10 \\
\hline 02_Ver & 00 & 0.01 & 0.00 & 0.00 & 0.02 & 0.00 & 0.00 & 0.00 & .00 & 0.00 & .21 & 0.49 & .00 & 0.00 & 0.00 & 04 & .00 & 00 & 0.00 & .13 \\
\hline 103_Ver & 0.00 & 0.01 & 0.00 & 0.00 & 0.05 & 0.00 & 0.00 & 0.00 & 0.00 & 0.00 & 0.01 & 0.18 & 02 & 00 & 0.00 & 01 & 0.00 & 00 & .00 & 00 \\
\hline 04_Ver & 00 & 00 & 0.00 & 00 & 0.07 & 0.00 & .00 & 0.00 & .00 & 0.00 & $0 t_{-}$ & 0.30 & .03 & 00 & 00 & 0.0 & 0.01 & 0.00 & 0.00 & .03 \\
\hline 05 _Ver & 00 & 00 & 0.00 & 00 & 04 & .00 & .00 & 0.00 & 00 & 0.00 & 03 & 0.27 & .02 & .00 & .00 & 00 & .00 & .00 & .00 & .02 \\
\hline 106_Ver & "ä" & 0.00 & 0.00 & 00 & 04 & 0.00 & 0.00 & 0.00 & 00 & 0.00 & .03 & 0.38 & 2 & 0.00 & .00 & 01 & 01 & 00 & 00 & .04 \\
\hline 107_Ver & 00 & 0.03 & 0.00 & .00 & 0.03 & 0.00 & 0.00 & 0.00 & .00 & 0.00 & .05 & 0.28 & .02 & .00 & .00 & 01 & .01 & 00 & .00 & 08 \\
\hline 108_Ver & 0.00 & 0.01 & 0.00 & 0.00 & 0.02 & 0.00 & 0.00 & 0.00 & 0.00 & 0.00 & 0.06 & 0.09 & 0.04 & 0.00 & 0.00 & 00 & 0.01 & .00 & 0.00 & .04 \\
\hline 09_Ver & 00 & 0.00 & 0.00 & .00 & 0.01 & 0.00 & 0.00 & 0.00 & 0.00 & 0.00 & 0.2 & 0.5 & .01 & 0.00 & .00 & 0.01 & 0.01 & .01 & 0.00 & .12 \\
\hline 10_Ver & 00 & 0.00 & 0.00 & 1.00 & 0.00 & 0.00 & 0.00 & 0.00 & 00 & 0.00 & 18 & 0.67 & 0.01 & 0.00 & 00 & .04 & 01 & 00 & 1.00 & .08 \\
\hline 2111_Ver & 00 & 0.05 & 0.00 & 1.00 & 0.01 & 0.00 & 00 & 0.00 & 00 & 0.00 & .02 & 0.25 & 111 & .00 & .00 & 01 & 01 & 00 & 0.00 & 00 \\
\hline 2112_Ver & 0.00 & 0.08 & 0.00 & 0.00 & 0.00 & 0.00 & 0.00 & 0.00 & 0.00 & 0.00 & 0.03 & 0.36 & 16 & .00 & 0.00 & 01 & 0.00 & 00 & 0.00 & 01 \\
\hline 13_Ver & 0.00 & 0.01 & 0.00 & 0.00 & 0.01 & 0.00 & 0.00 & 0.00 & 0.00 & 0.00 & 0.12 & 0.53 & 0.07 & 0.00 & 0.00 & 0.01 & 0.00 & 00 & 0.00 & 0.13 \\
\hline 4_Ver & 00 & 0.00 & 0.00 & .00 & 0.00 & 0.00 & 0.00 & 0.00 & 0.00 & 0.00 & 0.21 & 0.66 & 0.02 & 0.00 & 00 & 0.08 & 0.00 & 00 & 00 & .03 \\
\hline 15_Ver & 00 & 0.00 & 0.00 & .00 & 0.00 & 0.00 & 0.00 & 0.00 & .00 & 0.00 & .20 & 0.72 & .00 & 0.00 & .00 & 0.05 & .01 & .00 & .00 & .03 \\
\hline 16_Ver & 00 & 0.00 & 0.00 & 00 & 0.00 & 0.00 & 0.00 & 0.00 & .00 & 0.00 & 19 & 0.74 & .00 & .00 & .00 & 01 & .00 & 00 & 0.00 & .05 \\
\hline 17_Ver & .00 & 0.00 & 0.00 & 0.00 & 0.00 & 0.00 & 0.00 & 0.00 & 0.00 & 0.00 & 0.15 & 0.76 & 0.00 & 0.00 & .00 & 94 & .00 & .00 & 0.00 & 05 \\
\hline 8_Ver & 00 & 0.07 & 0.00 & 00 & 0.00 & 0 & 0.0 & 0. & 0.00 & 0. & .16 & 0.5 & .06 & 0.00 & .00 & 0.00 & .00 & .00 & .0 & .05 \\
\hline 9_Lau & 00 & 0.00 & 0.00 & .05 & 00 & 0 & .00 & 0. & 0 & 0.00 & 04 & 0.01 & 00 & 0.00 & .00 & 0.00 & .00 & 0.00 & .00 & .00 \\
\hline 20_Lau & 00 & 0.00 & 0.00 & $\dddot{07}$ & 0.00 & 0.00 & 0.00 & 0.00 & .00 & 0.00 & .00 & 0.03 & .00 & 0.00 & .00 & 0.00 & .00 & .00 & 0.00 & .00 \\
\hline 21_Lau & 00 & 0.00 & 0.00 & .04 & 0.03 & 0.00 & 0.00 & 0.00 & 0.00 & 0.00 & 0.00 & 0.01 & .00 & 0.00 & .00 & .00 & 0.00 & .00 & 0.01 & .00 \\
\hline 22_Lau & 00 & 0.00 & 0.00 & 0.05 & 0.01 & 0.00 & 0.00 & 0.01 & 0.00 & 0.00 & 0.00 & 0.01 & 0.00 & 0.00 & 0.01 & 0.00 & 0.00 & .00 & 0.00 & 0.01 \\
\hline 3_Lau & 00 & 0.00 & 0.00 & 0.02 & 0.01 & 0.00 & 0.00 & 0.0 & 0.00 & 0.00 & 00 & 0.02 & 00 & 0.00 & .00 & 0.00 & .00 & 0.00 & 0.00 & .00 \\
\hline 24_Lau & 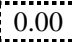 & 0.00 & 0.00 & 02 & 0.00 & 0.00 & 0.00 & 0.00 & 00 & 0.00 & 01 & 0.01 & .00 & 0.00 & .00 & 0.00 & .00 & 0.00 & 0.00 & .00 \\
\hline 125_Lau & 00 & 0.00 & 0.00 & 0.02 & 0.01 & 0.00 & 0.00 & 0.01 & 0.00 & 0.00 & 0.00 & 0.03 & 0.00 & 0.00 & 0.01 & 0.00 & 0.00 & 0.00 & 0.00 & 0.00 \\
\hline 26_Lau & 00 & 0.00 & 0.00 & 03 & 0.04 & 0.00 & 0.00 & 0.00 & 0.00 & 0.00 & 0.00 & 0.18 & 0.00 & 0.00 & 00 & 0.00 & 00 & 0.00 & 0.00 & 0.00 \\
\hline 27_Lau & 00 & 0.00 & 0.00 & 0.0 & 0.02 & 0.00 & 0.00 & 0.00 & 0.00 & 0.00 & 0.00 & 0.00 & 0.00 & 0.00 & 0.00 & 0.00 & 0.01 & 0.00 & 0.00 & 0.00 \\
\hline 8_Lau & ...... & 0 & 0.00 & 0.04 & 0.02 & 0. & 0.00 & 0.00 & 0.00 & 0.00 & 01 & 0.00 & 00 & 0.00 & 00 & 0.00 & 00 & 0.00 & 0.00 & .00 \\
\hline 2129_Lau & 00 & 0.00 & 0.00 & 0.05 & 0.01 & 0.00 & 0.00 & 0.00 & 0.00 & 0.00 & .01 & 0.01 & .00 & 0.00 & .00 & 0.00 & .00 & .00 & 0.01 & .01 \\
\hline 30_Lau & 00 & 0.00 & 0.00 & 0.03 & 0.02 & 0.00 & 0.00 & 0.00 & 0.00 & 0.00 & 0.00 & 0.01 & .00 & .00 & .00 & 0.00 & .00 & .00 & 0.00 & 0.01 \\
\hline 31_Lau & 00 & 0.00 & 0.00 & 10 & 0.02 & 0.00 & 0.00 & 0.01 & 0.00 & 0.00 & 0.00 & 0.01 & .00 & 0.00 & .00 & 0.00 & .00 & 0.00 & 0.02 & 0.01 \\
\hline 32_Lau & 00 & 0.00 & 0.00 & 0.07 & 0.09 & 0.00 & 0.00 & 0.02 & 0.00 & 0.00 & 0.00 & 0.04 & 0.00 & 0.00 & 0.01 & 0.01 & 0.00 & 0.00 & 0.04 & 0.01 \\
\hline 3_Lau & 00 & 0.0 & 0.00 & 0.09 & 0.05 & 0.00 & 0.00 & 0.01 & 0.00 & 0.00 & 0.00 & 0.02 & 0.00 & 0.00 & 00 & 0.00 & 00 & 0.00 & 0.02 & 0.00 \\
\hline 34_Lau & 0.00 & 0.00 & 0.00 & 0.02 & 0.23 & 0.00 & 0.00 & 0.00 & 0.00 & 0.00 & 0.00 & 0.00 & 0.00 & 0.00 & .00 & 0.00 & .00 & 0.00 & 0.01 & 0.00 \\
\hline 2135_Lau & 0.00 & 0.00 & 0.00 & 0.07 & 0.12 & 0.00 & 0.00 & 0.01 & 0.00 & 0.00 & 0.00 & 0.05 & 0.00 & 0.00 & 0.00 & 0.00 & 0.00 & 0.00 & 0.01 & 0.00 \\
\hline 36_Lau & 00 & 0.00 & 0.00 & 0.07 & 0.06 & 0.00 & 0.00 & 0.00 & 0.00 & 0.00 & 0.00 & 0.00 & 0.00 & 0.00 & 0.00 & 0.00 & 0.00 & 0.00 & 0.01 & 0.00 \\
\hline 37_Lau & .00 & 0.00 & 0.00 & 0.07 & 0.03 & 0.00 & 0.00 & 0.00 & 0.00 & 0.00 & 0.00 & 0.00 & 0.00 & 0.00 & .00 & 0.00 & 0.00 & 0.01 & 0.00 & 0.00 \\
\hline 2138_Lau & 0.00 & 0.00 & 0.00 & 0.01 & 0.00 & 0.00 & 0.00 & 0.01 & 0.00 & 0.00 & 0.03 & 0.72 & 0.00 & 0.00 & 0.00 & 0.10 & 0.00 & 0.00 & 0.00 & 0.00 \\
\hline 139_Lau & 0.00 & 0.00 & 0.00 & 0.08 & 0.07 & 0.00 & 0.00 & 0.01 & 0.00 & 0.00 & 0.01 & 0.15 & 0.00 & 0.00 & 0.00 & 0.00 & 0.00 & 0.00 & 0.02 & 0.00 \\
\hline 140_Lau & 0.00 & 0.00 & 0.00 & 0.03 & 0.14 & 0.00 & 0.00 & 0.00 & 0.00 & 0.00 & 0.00 & 0.12 & 0.02 & 0.01 & 0.00 & 0.01 & 0.00 & 0.01 & 0.00 & 0.01 \\
\hline 141_Lau & 0.00 & 0.00 & 0.00 & 0.05 & 0.08 & 0.00 & 0.00 & 0.02 & 0.00 & 0.00 & 0.00 & 0.04 & 0.00 & 0.00 & 0.00 & 0.00 & .00 & 0.00 & 0.00 & 0.00 \\
\hline 2_Lau & .00 & 0.0 & 0.00 & 0.0 & 0.08 & 0.0 & 0.0 & 0.0 & 0. & 0.0 & 0.00 & 0.23 & 00 & 0. & .00 & 0.0 & 00 & 0.00 & 0.04 & 0.00 \\
\hline 2143_Lau & 0.00 & 0.00 & 0.00 & 0.03 & 0.03 & 0.00 & 0.00 & 0.00 & 0.00 & 0.00 & 0.00 & 0.46 & 0.00 & 0.00 & 0.01 & 0.01 & 0.00 & 0.00 & 0.05 & 0.00 \\
\hline 44_Lau & .00 & 0.00 & 0.00 & 0.04 & 0.09 & 0.00 & 0.00 & 0.00 & 0.00 & 0.00 & 0.00 & 0.18 & 0.00 & 0.00 & 0.00 & 0.00 & 0.00 & 0.00 & 0.05 & 0.00 \\
\hline 145_Lau & 0.00 & 0.00 & 0.00 & 0.08 & 0.05 & 0.00 & 0.00 & 0.00 & 0.00 & 0.00 & 0.00 & 0.25 & 0.00 & 0.00 & 0.00 & 0.01 & 0.00 & 0.00 & 0.01 & 0.01 \\
\hline
\end{tabular}




\begin{tabular}{|c|c|c|c|c|c|c|c|c|c|c|c|c|c|c|c|c|c|c|c|c|}
\hline $\begin{array}{l}\stackrel{\Xi}{\Xi} \\
\text { ż }\end{array}$ & 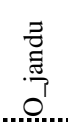 & ..... & 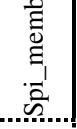 & 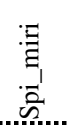 & 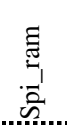 & $\begin{array}{l}\overline{0} \\
\overline{0} \\
\overline{2} \\
\overline{2}\end{array}$ & $\begin{array}{l}\overrightarrow{D_{0}} \\
\overrightarrow{0} \\
\vec{a} \\
\underline{2} .\end{array}$ & 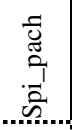 & $\begin{array}{l}\frac{0}{0} \\
0 \\
\frac{2}{2} \\
\text { in... }\end{array}$ & 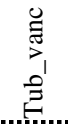 & 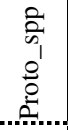 & 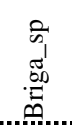 & 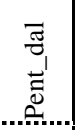 & 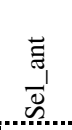 & 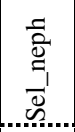 & $\begin{array}{c}\bar{\Xi} \\
\vec{\Xi} \\
\tilde{D}_{1} \\
\tilde{n}\end{array}$ & 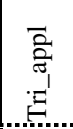 & $\begin{array}{l}\overline{0} \\
\frac{1}{1} \\
\text { 궁 }\end{array}$ & $\begin{array}{l}\frac{5}{0} \\
w_{1} \\
\frac{\lambda}{0} \\
\overline{0}\end{array}$ & 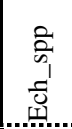 \\
\hline 2146_Lau & 0.00 & 0.00 & 0.00 & 0.01 & 0.06 & 0.00 & 0.00 & 0.00 & 0.00 & 0.00 & 0.00 & 0.28 & 0.00 & 0.00 & 0.00 & 0.01 & 0.01 & 0.01 & 0.04 & 0.00 \\
\hline 2147_Lau & 0.00 & 0.00 & 0.00 & 0.03 & 0.14 & 0.00 & 0.00 & 0.00 & 0.00 & 0.00 & 0.00 & 0.39 & 0.00 & 0.00 & 0.00 & 0.01 & 0.00 & 0.00 & 0.02 & 0.01 \\
\hline 2148_Lau & 0.00 & 0.00 & 0.00 & 0.01 & 0.06 & 0.00 & 0.00 & 0.00 & 0.00 & 0.00 & 0.00 & 0.51 & 0.00 & 0.01 & 0.00 & 0.02 & 0.00 & 0.00 & 0.03 & 0.01 \\
\hline 2149_Lau & 0.00 & 0.00 & 0.00 & 0.02 & 0.06 & 0.00 & 0.00 & 0.00 & 0.00 & 0.00 & 0.00 & 0.51 & 0.00 & 0.00 & 0.00 & 0.00 & 0.00 & 0.00 & 0.02 & 0.00 \\
\hline 2150_Lau & 0.00 & 0.00 & 0.00 & 0.01 & 0.02 & 0.00 & 0.00 & 0.00 & 0.00 & 0.00 & 0.00 & 0.54 & 0.00 & 0.00 & 0.00 & 0.01 & 0.00 & 0.00 & 0.02 & 0.02 \\
\hline 2151_Lau & 0.00 & 0.00 & 0.00 & 0.00 & 0.01 & 0.00 & 0.00 & 0.00 & 0.00 & 0.00 & 0.00 & 0.80 & 0.00 & 0.02 & 0.00 & 0.01 & 0.00 & 0.00 & 0.00 & 0.02 \\
\hline 2152_Lau & 0.00 & 0.00 & 0.00 & 0.01 & 0.09 & 0.00 & 0.00 & 0.00 & 0.00 & 0.00 & 0.00 & 0.04 & 0.00 & 0.00 & 0.00 & 0.00 & 0.00 & 0.00 & 0.00 & 0.00 \\
\hline 2153_Lau & 0.00 & 0.00 & 0.00 & 0.02 & 0.01 & 0.00 & 0.00 & 0.00 & 0.00 & 0.00 & 0.00 & 0.75 & 0.00 & 0.00 & 0.00 & 0.00 & 0.00 & 0.00 & 0.00 & 0.00 \\
\hline 2154_Lau & 0.00 & 0.00 & 0.00 & 0.00 & 0.00 & 0.00 & 0.00 & 0.00 & 0.00 & 0.00 & 0.00 & 0.69 & 0.00 & 0.03 & 0.00 & 0.00 & 0.00 & 0.00 & 0.02 & 0.00 \\
\hline 2155_Lau & 0.00 & 0.00 & 0.00 & 0.00 & 0.01 & 0.00 & 0.00 & 0.00 & 0.00 & 0.00 & 0.00 & 0.83 & 0.00 & 0.02 & 0.00 & 0.00 & 0.00 & 0.00 & 0.00 & 0.00 \\
\hline 2156_Lau & 0.00 & 0.00 & 0.00 & 0.00 & 0.00 & 0.00 & 0.00 & 0.00 & 0.00 & 0.00 & 0.00 & 0.90 & 0.00 & 0.03 & 0.00 & 0.00 & 0.00 & 0.00 & 0.00 & 0.03 \\
\hline 2157_Lau & 0.00 & 0.00 & 0.00 & 0.00 & 0.00 & 0.00 & 0.00 & 0.00 & 0.00 & 0.00 & 0.01 & 0.94 & 0.00 & 0.00 & 0.00 & 0.00 & 0.00 & 0.00 & 0.00 & 0.01 \\
\hline 2158_Lau & 0.00 & 0.00 & 0.00 & 0.00 & 0.01 & 0.00 & 0.00 & 0.00 & 0.00 & 0.00 & 0.01 & 0.83 & 0.00 & 0.00 & 0.00 & 0.00 & 0.00 & 0.00 & 0.00 & 0.01 \\
\hline 2159_Lau & 0.00 & 0.00 & 0.00 & 0.00 & 0.00 & 0.00 & 0.00 & 0.00 & 0.00 & 0.00 & 0.00 & 0.97 & 0.00 & 0.01 & 0.00 & 0.00 & 0.00 & 0.00 & 0.00 & 0.00 \\
\hline 2160_Lau & 0.00 & 0.00 & 0.00 & 0.00 & 0.02 & 0.00 & 0.00 & 0.00 & 0.00 & 0.00 & 0.00 & 0.93 & 0.00 & 0.00 & 0.00 & 0.00 & 0.00 & 0.00 & 0.01 & 0.00 \\
\hline 2161_Lau & 0.00 & 0.00 & 0.00 & 0.00 & 0.02 & 0.00 & 0.00 & 0.00 & 0.00 & 0.00 & 0.00 & 0.78 & 0.01 & 0.01 & 0.00 & 0.01 & 0.00 & 0.00 & 0.03 & 0.00 \\
\hline
\end{tabular}




\begin{tabular}{|c|c|c|c|c|c|c|c|c|c|c|c|c|c|c|c|c|c|c|c|c|c|c|c|}
\hline $\begin{array}{l}\stackrel{\Xi}{\Xi} \\
\text { Ż } \\
\end{array}$ & 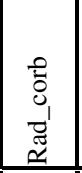 & ס્ડ & 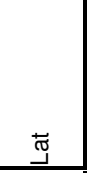 & $\begin{array}{l}\text { 등 } \\
\text { 잉 }\end{array}$ & $\stackrel{\text { 을 }}{\stackrel{E}{E}}$ & 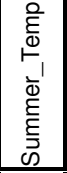 & 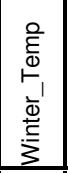 & 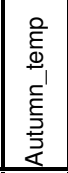 & 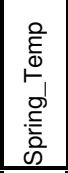 & 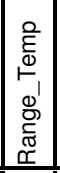 & $\begin{array}{l}\overrightarrow{0} \\
\end{array}$ & $\begin{array}{l}\overrightarrow{0} \\
\dot{D} \\
\vec{J} \\
\vec{J} \\
\Sigma\end{array}$ & 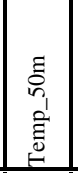 & 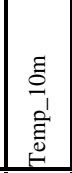 & 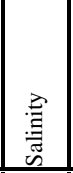 & 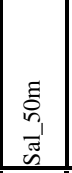 & $\begin{array}{l}\frac{0}{\tilde{J}} \\
\frac{\pi}{0} \\
\frac{0}{0} \\
\frac{c}{2} \\
\end{array}$ & 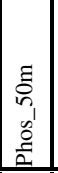 & 节 & 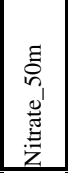 & 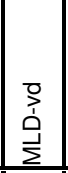 & 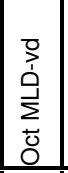 & 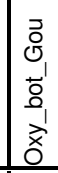 \\
\hline 2_Cro & 0.00 & 174.15 & -33.65 & 2133 & 18.8 & 21.2 & 16.6 & 19.3 & 18.2 & 4.6 & 484 & 834 & 17.9 & 18.7 & 35.6 & 35.6 & 0.3 & 0.4 & 2.1 & 2.9 & 71 & 99 & 3.9 \\
\hline 3_Cro & 0.00 & 173.51 & -34.02 & 2036 & 18.5 & 20.8 & 16.3 & 19.1 & 17.8 & 4.5 & 624 & 1003 & 17.6 & 18.4 & 35.6 & 35.6 & 0.4 & 0.4 & 2.3 & 3.2 & 70 & 105 & 4.0 \\
\hline 8_Cro & 0.00 & 176.80 & -36.32 & 2411 & 18.1 & 20.6 & 15.9 & 18.6 & 17.4 & 4.8 & 610 & 943 & 17.4 & 18.1 & 35.5 & 35.5 & 0.2 & 0.4 & 1.6 & 2.2 & 62 & 36 & 4.1 \\
\hline 9_Cro & 0.00 & 176.24 & -36.69 & ....... & 18.1 & 20.7 & 15.8 & 18.6 & 17.4 & 4.9 & 844 & 1140 & 17.4 & 18.1 & 35.5 & 35.5 & 0.2 & 0.4 & 1.7 & 2.2 & 61 & 33 & 4.3 \\
\hline 11_Cro & 0.00 & 181.51 & -39.94 & 3654 & 16.1 & 18.8 & 13.6 & 16.4 & 15.5 & 5.2 & 652 & 1143 & 15.3 & 16.0 & 35.3 & 35.3 & 0.2 & 0.3 & 0.7 & 1.8 & 67 & 27. & 4.5 \\
\hline 12_Cro & 0.00 & 179.99 & -40.33 & 3003 & 16.1 & 18.8 & 13.7 & 16.5 & 15.6 & 5.1 & 719 & 1274 & 15.4 & 16.1 & 35.4 & 35.4 & 0.2 & 0.3 & 0.9 & 2.0 & 70 & 29 & 4.4 \\
\hline 13_Cro & 0.00 & 177.99 & -40.40 & 2195 & 16.4 & 19.0 & 13.9 & 16.8 & 15.8 & 5.0 & 800 & 1461 & 15.6 & 16.3 & 35.5 & 35.5 & 0.2 & 0.2 & 0.8 & 1.6 & 72 & 31. & 4.4 \\
\hline 15_Cro & 0.00 & 186.00 & -43.20 & 1128 & 14.1 & 16.5 & 12.0 & 14.2 & 13.5 & 4.5 & 621 & 997 & 13.4 & 14.0 & 35.0 & 35.0 & 0.3 & 0.4 & 1.2 & 2.7 & 60 & 5 & 4.4 \\
\hline 16_Cro & 0.00 & 181.51 & -42.53 & 1408 & 14.4 & 17.2 & 12.1 & 14.5 & 13.8 & 5.1 & 743 & 1321 & 13.6 & 14.3 & 35.0 & 35.0 & 0.3 & 0.4 & 1.5 & 3.6 & 59 & 39 & 4.5 \\
\hline 17_Cro & 0.00 & 179.36 & -42.22 & 2540 & 14.4 & 17.2 & 12.0 & 14.6 & 13.9 & 5.2 & 810 & 1499 & 13.6 & 14.4 & 35.0 & 35.0 & 0.3 & 0.4 & 1.7 & 3.9 & 71 & 42 & 4.5 \\
\hline 18_Cro & 0.00 & 176.91 & -42.72 & 850 & 13.9 & 16.6 & 11.6 & 14.1 & 13.5 & 5.0 & 871 & 1475 & 13.1 & 13.9 & 34.9 & 35.0 & 0.3 & 0.4 & 1.6 & 4.7 & 64 & 51 & 4.8 \\
\hline 20_Cro & 0.00 & 174.50 & -43.00 & 854 & 13.0 & 15.6 & 10.8 & 13.0 & 12.7 & 4.8 & 1020 & 1700 & 12.1 & 12.9 & 34.7 & 34.8 & 0.4 & 0.5 & 1.3 & 6.3 & 60 & 13 & 5.0 \\
\hline \begin{tabular}{|l|}
$21 \_C r o$ \\
\end{tabular} & 0.00 & 173.36 & -43.33 & 79 & 12.4 & 15.1 & 10.2 & 12.2 & 12.2 & 4.9 & 1268 & 1983 & 11.4 & 12.3 & 34.6 & 34.7 & 0.4 & 0.5 & 1.2 & 6.9 & 63 & 10 & 5.2 \\
\hline 22_Cro & 0.00 & 185.92 & -45.33 & 4680 & 12.7 & 15.1 & 11.0 & 12.8 & 12.0 & 4.1 & 573 & 1016 & 12.1 & 12.7 & 34.8 & 34.8 & 0.4 & 0.5 & 2.4 & 4.5 & 67 & 4. & 4.7 \\
\hline 24_Cro & 0.00 & 178.00 & -44.13 & 1080 & 12.5 & 15.4 & 10.0 & 12.6 & 11.9 & 5.4 & 632 & 1257 & 11.5 & 12.4 & 34.6 & 34.6 & 0.4 & 0.6 & 3.5 & 7.0 & 61 & 58 & 4.7 \\
\hline 25_Cro & 0.00 & 174.98 & -44.29 & 580 & 11.9 & 14.7 & 9.6 & 11.8 & 11.5 & 5.2 & 889 & 1747 & 10.7 & 11.8 & 34.5 & 34.5 & 0.5 & 0.6 & 3.4 & 8.6 & 55 & 25 & 4.9 \\
\hline \begin{tabular}{|l}
$26 \_C r o$ \\
\end{tabular} & 0.00 & 172.65 & -44.35 & 100 & 11.4 & 14.2 & 9.1 & 11.0 & 11.3 & 5.1 & 1078 & 1881 & 10.1 & 11.3 & 34.4 & 34.4 & 0.6 & 0.7 & 3.4 & 10.0 & 33 & 10 & 5.1 \\
\hline 28_Cro & 0.00 & 182.08 & -46.60 & 4440 & 11.2 & 13.9 & 9.4 & 11.3 & 10.4 & 4.5 & 400 & 729 & 10.4 & 11.2 & 34.5 & 34.5 & 0.6 & 0.7 & 5.7 & 8.3 & 66 & 7 & 4.7 \\
\hline 32_Cro & 0.00 & 174.08 & -47.04 & 1429 & 10.1 & 12.6 & 8.0 & 10.1 & 9.6 & 4.7 & 326 & 599 & 9.2 & 10.0 & 34.3 & 34.3 & 0.7 & 0.8 & 8.2 & 12.0 & 55 & 14 & 4.6 \\
\hline 33_Cro & 0.00 & 182.01 & -49.67 & 4500 & 9.4 & 11.6 & 7.9 & 9.6 & 8.6 & 3.7 & 283 & 496 & 8.9 & 9.4 & 34.3 & 34.3 & 0.8 & 0.9 & 10.4 & 12.2 & 90 & 7 & 4.8 \\
\hline 37_Cro & 0.00 & 167.83 & -51.72 & 629 & 9.0 & 10.1 & 8.2 & 9.3 & 8.4 & 1.9 & 235 & 507 & 9.0 & 9.0 & 34.4 & 34.5 & 0.9 & 0.8 & 11.9 & 11.6 & 136 & 235 & 5.4 \\
\hline 38_Pre & 0.00 & 149.93 & -43.96 & 2622 & 13.4 & 15.5 & 11.7 & 13.8 & 12.7 & 3.8 & 746 & 1381 & 13.0 & 13.3 & 35.0 & 35.1 & 0.5 & 0.5 & 4.1 & 4.8 & 51 & 23 & 4.6 \\
\hline 39_Pre & 0.00 & 167.68 & -40.51 & 1068 & 15.7 & 18.4 & 13.7 & 16.0 & 14.6 & 4.7 & 600 & 1011 & 14.9 & 15.6 & 35.2 & 35.3 & 0.3 & 0.3 & 1.0 & 2.0 & 70 & 127 & 4.2 \\
\hline 41_Pre & 0.00 & 165.44 & -36.47 & 1088 & 17.7 & 20.1 & 15.6 & 18.3 & 16.9 & 4.5 & 570 & 902 & 16.9 & 17.6 & 35.5 & 35.5 & 0.3 & 0.3 & 0.5 & 1.1 & 68 & 61 & 3.8 \\
\hline 46_Pre & 0.00 & 144.41 & -42.61 & 2464 & 13.4 & 14.9 & 12.0 & 14.0 & 12.6 & 2.9 & 727 & 1551 & 12.9 & 13.3 & 35.0 & 35.0 & 0.3 & 0.4 & 2.1 & 3.4 & 43 & 14 & 4.8 \\
\hline 48_Pre & 0.00 & 173.73 & -48.73 & 638 & 9.3 & 11.4 & 7.5 & 9.4 & 8.8 & 3.9 & 264 & 463 & 8.7 & 9.2 & 34.3 & 34.3 & 0.8 & 0.9 & 10.9 & 13.4 & 73 & 33 & 5.0 \\
\hline 58_Pre & 0.00 & 164.61 & -49.52 & 3250 & 10.1 & 11.4 & 9.1 & 10.4 & 9.5 & 2.3 & 364 & 670 & 9.7 & 10.1 & 34.5 & 34.5 & 0.8 & 0.8 & 9.1 & 9.0 & 126 & 63 & 4.7 \\
\hline 59_Pre & 0.00 & 166.06 & -47.00 & 1648 & 12.0 & 13.7 & 10.7 & 12.2 & 11.3 & 3.0 & 716 & 1816 & 11.7 & 12.0 & 34.7 & 34.8 & 0.6 & 0.6 & 5.5 & 5.4 & 34 & 10 & 4.8 \\
\hline 60_Pre & 0.00 & 148.89 & -38.46 & 2350 & 16.9 & 19.6 & 14.6 & 17.4 & 16.2 & 5.1 & 851 & 1257 & 15.9 & 16.8 & 35.5 & 35.4 & 0.3 & 0.3 & 1.5 & 2.6 & 104 & 182 & 4.8 \\
\hline 62_Pre & 0.00 & 170.00 & -37.00 & 2096 & 17.2 & 19.7 & 15.0 & 17.7 & 16.3 & 4.7 & 530 & 977 & 16.3 & 17.1 & 35.4 & 35.4 & 0.3 & 0.3 & 1.0 & 1.9 & 62 & 127 & 3.9 \\
\hline 64_Pre & 0.00 & 174.47 & -49.47 & 501 & 8.8 & 10.8 & 7.2 & 8.9 & 8.3 & 3.5 & 254 & 483 & 8.3 & 8.8 & 34.3 & 34.3 & 0.8 & 0.9 & 12.6 & 14.5 & 110 & 134 & 5.0 \\
\hline 66_Pre & 0.00 & 179.99 & -40.12 & 2890 & 16.3 & 19.0 & 13.9 & 16.7 & 15.7 & 5.1 & 705 & 1197 & 15.5 & 16.3 & 35.4 & 35.4 & 0.2 & 0.3 & 0.8 & 1.8 & 69 & 28 & 4.4 \\
\hline 67_Pre & 0.00 & 168.99 & -50.58 & 575 & 9.4 & 10.6 & 8.4 & 9.7 & 8.8 & 2.2 & 254 & 426 & 9.3 & 9.4 & 34.4 & 34.5 & 0.8 & 0.8 & 10.9 & 11.1 & 115 & 32 & 5.6 \\
\hline 68_Pre & 0.00 & 17 & -44.50 & 1339 & 12.3 & 15.3 & 9.8 & 12.4 & 11.6 & 5.4 & 491 & 1240 & 11.3 & 12.2 & 34.6 & 34.6 & 0.5 & 0.6 & 3.9 & 7.2 & 59 & 59 & 4.7 \\
\hline 70_Pre & $0.00 \vdots$ & 17 & -42.00 & 1000 & 15.5 & 18.4 & 13.3 & 15.8 & 14.4 & 5.0 & 664 & 1113 & 14.6 & 15.4 & 35.1 & 35.2 & 0.3 & 0.3 & 1.1 & 2.7 & 41 & 87 & 4.6 \\
\hline 71_Pre & 0.00 & & -41.40 & 20 & 15 & 18.4 & 13 & 15.8 & 14.4 & 5.0 & 664 & 1124 & 14.5 & 15.4 & 35.1 & 35.2 & 0.3 & 0.3 & 1.2 & 2.8 & 46 & 90 & 4.7 \\
\hline 72_Pre & 0.00 & & & 167 & 15.4 & 18.3 & 13.2 & 15.6 & 14.3 & 5.1 & 689 & 1070 & 14.4 & 15.3 & 35.1 & 35.2 & 0.3 & 0.4 & 1.3 & 3.1 & 35 & 78 & 4.5 \\
\hline 83_Pre & 0.00 & & -50 & 546 & 8.7 & 10.5 & 7.3 & 8.8 & 8.2 & 3.2 & 23 & 418 & 8.3 & 8.7 & 34.3 & 34.3 & 0.8 & 0.9 & 13.0 & 14.5 & 133 & 240 & 5.3 \\
\hline 96_Pre & 0.00 & & -41.88 & 507 & 15.3 & 18.3 & 13.2 & 15.6 & 14.3 & 5.1 & 689 & 1070 & 14.4 & 15.3 & 35.1 & 35.2 & 0.3 & 0.4 & 1.3 & 3.1 & 35 & 77 & 4.5 \\
\hline 97_Pre & 0.00 & 170.34 & -41.15 & 698 & 15.5 & 18.4 & 13.3 & 15.8 & 14.4 & 5.0 & 664 & 1124 & 14.5 & 15.4 & 35.1 & 35.2 & 0.3 & 0.3 & 1.1 & 2.7 & 36 & 76 & 4.4 \\
\hline 98_Pre & 0.00 & 170.65 & -36.67 & 2112 & 17.3 & 19.9 & 15.1 & 17.8 & 16.5 & 4.8 & 531 & 909 & 16.4 & 17.2 & 35.4 & 35.4 & 0.3 & 0.3 & 1.2 & 2.2 & 59 & 109 & 3.8 \\
\hline 104_Pre & 0.00 & 165.22 & -41.66 & 4421 & 14.9 & 17.6 & 13.0 & 15.1 & 14.0 & 4.6 & 639 & 1117 & 14.2 & 14.8 & 35.2 & 35.2 & 0.4 & 0.4 & 1.7 & 2.4 & 46 & 42 & 4.4 \\
\hline 105_Pre & 0.00 & 162.60 & -33.15 & 793 & 20.1 & 22.6 & 17.9 & 20.5 & 19.3 & 4.7 & 535 & 897 & $19.3 \vdots$ & 20.0 & 35.6 & 35.6 & $\begin{array}{c}0.2 \\
0.2\end{array}$ & 0.3 & 0.5 & 0.7 & $59 \vdots$ & 58 & 3.9 \\
\hline 107_Pre & 0.00 & 169.65 & -39.00 & 560 & 16.3 & 19.0 & 14.2 & 16.8 & 15.3 & 4.8 & 520 & 812 & 15.6 & 16.3 & 35.3 & 35.3 & 0.3 & 0.3 & 0.7 & 1.6 & 75 & 137 & 4.3 \\
\hline 113_Pre & 0.00 & 166.46 & -41.32 & 3253 & 15.2 & 17.9 & 13.2 & 15.4 & 14.2 & 4.7 & 651 & 1043 & 14.4 & 15.1 & 35.2 & 35.2 & 0.4 & 0.4 & 1.4 & 2.4 & 51 & 96 & 4.3 \\
\hline 119_Pre & 0.00 & -178.17 & -42.55 & 1366 & 14.4 & 17.2 & 12.1 & 14.5 & 13.8 & 5.1 & 755 & 1392 & 13.6 & 14.3 & 35.0 & 35.0 & 0.3 & 0.4 & 1.5 & 3.5 & 60 & 37. & 4.6 \\
\hline 120_Pre & 0.00 & 173.42 & -44.54 & 543 & 11.5 & 14.3 & 9.2 & 11.2 & 11.3 & 5.1 & 815 & 1993 & .9.9 & 11.4 & 34.5 & 34.4 & 0.6 & 0.7 & 3.4 & 10.3 & 47! & 10 & 5.0 \\
\hline 123_Pre & 0.05 & 171.36 & -44.40 & 22 & 11.3 & 14.1 & 9.1 & 11.0 & 11.2 & 5.1 & 0 & $\begin{array}{l}0 \\
. . .\end{array}$ & $10.2 \vdots$ & 11.2 & 34.4 & 34.5 & 0.7 & 0.7 & 3.6 & 9.6 & 20 & 10 & 5.1 \\
\hline 128_Pre & $0.00 \vdots$ & 171.42 & -45.72 & 1400 & 10.5 & 13.1 & 8.4 & 10.3 & 10.3 & 4.8 & 478 & 928 & $9.6 \vdots$ & 10.4 & 34.3 & 34.4 & $\begin{array}{l}0.8: \\
0 . . .\end{array}$ & 0.8 & 5.3 & 10.8 & $25 \vdots$ & 10 & 4.9 \\
\hline 129_Pre & 0.00 & 172.42 & -39.67 & 234 & 15.9 & 18.7 & 13.7 & 16.3 & 15.0 & 5.0 & 752 & 1206 & 15.2 & 15.9 & 35.2 & 35.2 & 0.2 & 0.3 & 0.4 & 1.0 & 54 & 50 & $\begin{array}{l}4.7 \\
1 . . .\end{array}$ \\
\hline 133_Pre & 0.00 & 169.92 & -47.33 & 1004 & 10.4 & 12.3 & 8.8 & 10.8 & 9.9 & 3.5 & 360 & 712 & 9.7! & 10.3 & 34.5 & 34.4 & $\begin{array}{c}0.7 \\
\ldots . . .\end{array}$ & 0.8 & 7.7 & 11.3 & 43 & 10 & 5.2 \\
\hline 134_Pre & 0.00 & 170.98 & -46.64 & 1244 & 10.2 & 12.5 & 8.3 & 10.2 & 9.8 & 4.3 & 391 & 726 & $9.5 \vdots$ & 10.1 & 34.4 & 34.4 & $\begin{array}{c}0.8 \\
\cdots \ldots .\end{array}$ & 0.9 & 6.7 & 11.4 & 35 & 10 & 4.9 \\
\hline 136_Pre & $0.00 \vdots$ & 173.83 & -38.00 & 794 & 17.0 & 20.0 & 14.5 & 17.4 & 16.1 & 5.4 & 658 & 899 & $16.0 \vdots$ & 16.9 & 35.3 & 35.3 & \begin{tabular}{l}
$0.2:$ \\
\hdashline...
\end{tabular} & 0.4 & 0.9 & $\mid$\begin{tabular}{l}
1.4 \\
\hdashline...... \\
\end{tabular} & $46 \vdots$ & 26 & 4.6 \\
\hline 137_Pre & 0.00 & 175.39 & -35.33 & 797 & 18.2 & 20.6 & 16.0 & 18.6 & 17.6 & 4.6 & 602 & 951 & 17.4 & 18.1 & 35.5 & 35.5 & 0.3 & 0.5 & 2.5 & 3.8 & 60 & 51 & 4.2 \\
\hline 140_Pre & 0.00 & 173.63 & -38.02 & 974. & 17.0 & 19.9 & 14.5 & 17.3 & 16.1 & 5.4 & 650 & 897 & 16.0 & 16.9 & 35.3 & 35.3 & 0.2 & 0.4 & $0.9 \vdots$ & 1.4 & 44 & 26 & 4.5 \\
\hline 141_Pre & 0.00 & 175.32 & -35.23 & 922. & 18.2 & 20.6 & 16.0 & 18.6 & 17.6 & 4.6 & 624 & 1026 & $17.4 \vdots$ & 18.2 & 35.6 & 35.5 & $\begin{array}{c}0.3 \vdots \\
0.3 .\end{array}$ & 0.5 & $2.5 \vdots$ & 3.7 & $61 \vdots$ & 57 & 4.1 \\
\hline 142_Pre & 0.00 & 175.39 & -35.13 & 1176 & 18.3 & 20.7 & 16.0 & 18.7 & 17.7 & 4.6 & 591 & 916 & 17.4 & 18.2 & 35.6 & 35.5 & 0.3 & 0.4 & 2.4 & 3.6 & 62 & 59 & 4.1 \\
\hline 143_Pre & 0.00 & 171.52 & -51.70 & 519 & 8.5 & 9.8 & 7.4 & 8.6 & 8.0 & 2.4 & 211 & 418 & 8.2 & 8.4 & 34.3 & 34.3 & 0.8 & 0.9 & 13.8 & 14.4 & 204 & 545 & 5.6 \\
\hline 144_Pre & 0.00 & 171.80 & -38.63 & 1233 & 16.5 & 19.3 & 14.3 & 16.9 & 15.6 & 5.1 & 610 & 1054 & 15.7 & 16.4 & 35.3 & 35.3 & 0.2 & 0.3 & 0.7 & 1.4 & 56 & 80 & 4.2 \\
\hline
\end{tabular}




\begin{tabular}{|c|c|c|c|c|c|c|c|c|c|c|c|c|c|c|c|c|c|c|c|c|c|c|c|}
\hline $\begin{array}{l}\mathscr{\Xi} \\
\text { Z }\end{array}$ & 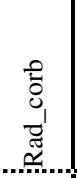 & . & . & 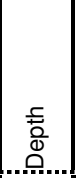 & $\stackrel{\stackrel{\varrho}{E}}{\stackrel{E}{\Phi}}$ & 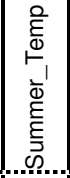 & 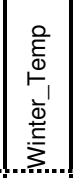 & 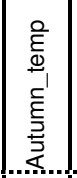 & 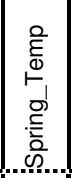 & 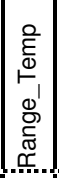 & . & 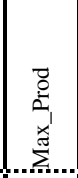 & 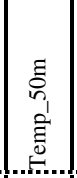 & 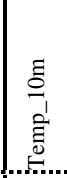 & 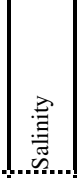 & 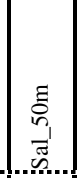 & 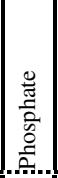 & 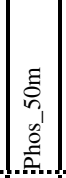 & . & 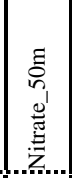 & 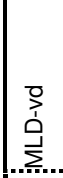 & 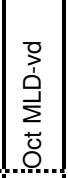 & 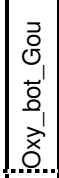 \\
\hline 5_Pre & 0.00 & 175.21 & -35.42 & 514 & 18.1 & 20.6 & 15.9 & 18.5 & 17.6 & 4.6 & 654 & 1029 & 17.3 & 18.1 & 35.5 & 35.5 & 0.3 & 0.5 & 2.6 & 3.9 & 60 & 55 & 4.2 \\
\hline 51_Pre & 0.00 & 178.20 & -38.94 & 128 & 17.1 & 19.8 & 14.6 & 17.7 & 16.5 & 5.2 & 187 & 609 & 16.3 & 17.0 & 35.5 & 35.5 & 0.2 & 0.2 & 0.6 & 1.2 & 65 & 27 & 4.4 \\
\hline 393_Vin & 0.00 & -16.33 & -31.05 & 3470 & 20.4 & 23.2 & 18.2 & 20.8 & 19.3 & 5.0 & 248 & 346 & 19.2 & 20.3 & 35.9 & 35.9 & 0.2 & 0.2 & 0.0 & 0.2 & 36 & 34 & 5.5 \\
\hline 1394_Vin & 0.00 & -16.84 & -31.13 & 3810 & 20.3 & 23.1 & 18.1 & 20.8 & 19.3 & 5.0 & 246 & 353 & 19.1 & 20.2 & 35.9 & 35.8 & 0.2 & 0.2 & 0.0 & 0.2 & 39 & 31. & 5.5 \\
\hline 1395_Vin & 0.00 & -19.76 & -31.62 & 4204 & 20.2 & 23.1 & 18.1 & 20.7 & 19.1 & 5.0 & 258 & 377 & 19.1 & 20.1 & 35.8 & 35.8 & 0.2 & 0.2 & 0.1 & 0.2 & 37 & 32 & 5.4 \\
\hline 1396_Vin & 0.00 & -37.95 & -27.63 & 4273 & 23.0 & 25.5 & 21.0 & 23.7 & 22.0 & 4.5 & 286 & 332 & 22.1 & 22.9 & 36.4 & 36.4 & 0.1 & 0.1 & 0.8 & 0.7 & 33 & 35 & 5.3 \\
\hline 1399_Vin & 0.00 & -38.55 & -25.03 & 3842 & 24.2 & 26.4 & 22.3 & 24.8 & 23.4 & 4.0 & 265 & 321 & 23.3 & 24.2 & 36.6 & 36.7 & 0.1 & 0.1 & 1.1 & 1.2 & 49 & 79 & 5.4 \\
\hline 1400_Vin & 0.00 & -28.11 & -7.47 & 4886 & 27.0 & 27.9 & 26.3 & 27.9 & 26.3 & 1.6 & 194 & 249 & 26.8 & 27.0 & 36.2 & 36.3 & 0.1 & 0.1 & 0.4 & 0.4 & 53 & 63 & 5.2 \\
\hline 1402_Vin & 0.00 & -36.27 & -3.55 & 3174 & 27.2 & 28.0 & 26.5 & 28.0 & 26.7 & 1.6 & 202 & 239 & 26.9 & 27.2 & 36.1 & 36.3 & 0.2 & 0.2 & 0.4 & 0.6 & 42 & 58 & 5.4 \\
\hline 1403_Vin & 0.00 & -36.35 & -4.25 & 2361 & 27.2 & 28.0 & 26.4 & 28.0 & 26.7 & 1.6 & 239 & 303 & 27.0 & 27.2 & 36.2 & 36.4 & 0.1 & 0.1 & 0.3 & 0.4 & 43 & 58 & 5.4 \\
\hline 1404_Vin & 0.00 & -36.64 & -4.61 & 826 & 27.2 & 28.0 & 26.4 & 28.0 & 26.7 & 1.6 & 298 & 351 & 27.0 & 27.2 & 36.2 & 36.4 & 0.1 & 0.1 & 0.3 & 0.4 & 44 & 60 & 5.4 \\
\hline 1405_Vin & 0.00 & -37.72 & -3.67 & 772 & 27.2 & 28.1 & 26.4 & 28.1 & 26.8 & 1.7 & 306 & 344 & 26.9 & 27.2 & 36.1 & 36.3 & 0.2 & 0.2 & 0.5 & 0.8 & 41. & 62 & 5.3 \\
\hline 1406_Vin & 0.0 & -38.31 & -2.90 & 2289 & 27.2 & 28.0 & 26.4 & 28.0 & 26.7 & 1.6 & 214 & 259 & 26.9 & 27.2 & 36.1 & 36.3 & 0.2 & 0.2 & 0.6 & 0.8 & 34. & 50 & 5.3 \\
\hline 1407_Vin & 0.0 & -38.23 & -2.73 & 2461 & 27.2 & 28.0 & 26.5 & 28.0 & 26.7 & 1.6 & 210 & 247 & 26.9 & 27.2 & 36.1 & 36.3 & 0.2 & 0.2 & 0.6 & 0.8 & 34 & 51 & 5.3 \\
\hline 1875_Mar & .. & 147.23 & -45.07 & 3589 & 12.3 & $\begin{array}{l}14.0 \\
14 . .\end{array}$ & 10.8 & 12.8 & 11.6 & 3.1 & 604 & 1087 & 12.0 & 12.2 & 34.9 & 34.9 & 0.6 & 0.6 & 5.7 & 6.5 & 44 & 14 & 4.5 \\
\hline 1876_Mar & 0.00 & 68.67 & -47.97 & 530 & 4.2 & 5.4 & 3.2 & 4.8 & 3.4 & 2.2 & 211 & 368 & 4.0 & 4.2 & 33.8 & 33.8 & 1.6 & 1.7 & 23.5 & 22.5 & 54 & 42 & 5.8 \\
\hline 883_Mar & 0.00 & 150.05 & -47.89 & 2545 & 10.3 & 11.8 & 9.0 & 10.6 & 9.8 & 2.7 & 370 & 696 & 10.1 & 10.2 & 34.6 & 34.6 & 0.9 & 0.9 & 11.1 & 11.0 & 88 & 288 & 4.5 \\
\hline 887_Mar & 0.00 & -175.13 & -54.82 & 5214 & 7.3 & 8.6 & 5.9 & 7.6 & 7.0 & 2.7 & 197 & 488 & 7.1 & 7.2 & 34.2 & 34.2 & 1.2 & 1.3 & 16.7 & 17.4 & 101 & 29 & 4.8 \\
\hline 1890_Mar & 0.00 & 138.51 & -37.99 & 3810 & 15.4 & 17.4 & 13.8 & 16.1 & 14.5 & 3.6 & 539 & 744 & 14.7 & 15.4 & 35.4 & 35.4 & 0.2 & 0.3 & 1.0 & 1.3 & 63 & 117 & 4.9 \\
\hline 1891_Mar & 0.00 & 138.54 & -37.98 & 3614 & 15.4 & 17.4 & 13.8 & 16.1 & 14.5 & 3.6 & 539 & 744 & 14.7 & 15.4 & 35.4 & 35.4 & 0.2 & 0.3 & 1.0 & 1.3 & 63 & 116 & 4.9 \\
\hline 1892_Mar & 0.00 & 137.77 & -38.19 & 5390 & $\begin{array}{l}3.2 \\
15.2\end{array}$ & 17.2 & 13.6 & 15.8 & 14.3 & 3.6 & 547 & 832 & 14.6 & $\begin{array}{l}15.2 \\
15.2\end{array}$ & 35.3 & 35.3 & 0.3 & 0.3 & 1.3 & 1.5 & 66 & 115 & 4.9 \\
\hline 1893_Mar & 0.00 & 142.51 & -39.34 & 1702 & 15.1 & 17.0 & 13.7 & 15.4 & 14.2 & 3.3 & 600 & 930 & 14.3 & 15.0 & 35.4 & 35.3 & 0.2 & 0.3 & 1.2 & 1.9 & 85 & 206 & 4.9 \\
\hline 1894_Mar & 0.00 & 142.52 & -39.31 & 1336 & 15.1 & 17.0 & 13.7 & 15.4 & 14.2 & 3.3 & 625 & 909 & 14.3 & 15.0 & 35.4 & 35.3 & 0.2 & 0.3 & 1.2 & 1.9 & 84 & 204 & 4.9 \\
\hline 1895_Mar & 0.00 & 142.01 & -38.88 & 686 & 15.1 & 17.0 & 13.8 & 15.5 & 14.3 & 3.2 & 627 & 922 & 14.4 & 15.0 & 35.4 & 35.3 & 0.2 & 0.3 & 1.2 & 2.0 & 66 & 111 & 4.9 \\
\hline 1896_Mar & 0.00 & 141.12 & -38.61 & 732 & 15.3 & 17.2 & 14.0 & 15.7 & 14.4 & 3.2 & 602 & 844 & 14.5 & 15.2 & 35.4 & 35.4 & 0.2 & 0.3 & 1.0 & 1.9 & 71 & 121 & 4.8 \\
\hline 1897_Mar & 0.00 & 141.12 & -38.67 & 1345 & 15.3 & 17.1 & 14.0 & 15.7 & 14.4 & 3.2 & 594 & 906 & 14.5 & 15.2 & 35.4 & 35.4 & 0.2 & 0.3 & 1.1 & 1.9 & 71 & 121 & 4.8 \\
\hline 1898_Mar & 0.00 & 141.06 & -38.85 & 2348 & 15.2 & 17.0 & 13.8 & 15.5 & 14.3 & 3.2 & 589 & 966 & 14.4 & 15.1 & 35.4 & 35.3 & 0.3 & 0.3 & 1.2 & 2.0 & 70 & 120 & 4.8 \\
\hline 1899_Mar & 0.00 & 140.99 & -39.68 & 3984 & 14.8 & 16.7 & 13.5 & 15.2 & 14.0 & 3.2 & 608 & 897 & 14.1 & 14.7 & 35.3 & 35.3 & 0.3 & 0.3 & 1.7 & 2.4 & 70 & 116 & 4.8 \\
\hline 1900_Mar & 0.00 & 140.68 & -39.83 & 4319 & 14.7 & 16.5 & 13.3 & 15.0 & 13.9 & 3.2 & 603 & 872 & 14.0 & 14.6 & 35.3 & 35.3 & 0.3 & 0.4 & 1.9 & 2.6 & 67 & 113 & 4.8 \\
\hline 1901_Mar & 0.00 & 140.39 & -40.07 & 4703 & 14.4 & 16.2 & 13.0 & 14.8 & 13.6 & 3.2 & 577 & 913 & 13.8 & 14.3 & 35.2 & 35.2 & 0.3 & 0.4 & 2.3 & 3.0 & 67 & 111 & 4.8 \\
\hline 1902_Mar & 0.00 & 139.70 & -40.10 & 4996 & 14.3 & 16.1 & 12.9 & 14.7 & 13.5 & 3.3 & 568 & 1013 & 13.7 & 14.2 & 35.2 & 35.2 & 0.3 & 0.4 & 2.5 & 3.2 & 64 & 106 & 4.8 \\
\hline 1903_Mar & 0.00 & 16.16 & -31.89 & 520 & 16.9 & 18.6 & 15.4 & 16.9 & 16.9 & 3.2 & 1105 & 1749 & 15.1 & 16.7 & 35.2 & 35.2 & 0.5 & 0.8 & 2.2 & 7.3 & 32 & 33 & 4.8 \\
\hline 1904_Mar & 0.00 & 12.16 & -30.44 & 3906 & 18.3 & 20.6 & 16.3 & 18.5 & 17.7 & 4.4 & 549 & 689 & 17.4 & 18.2 & 35.5 & 35.5 & 0.4 & 0.4 & 0.7 & 1.4 & 55 & 48 & 5.0 \\
\hline 1905_Mar & 0.00 & 11.74 & -31.09 & 4312 & 18.4 & 20.7 & 16.3 & 18.6 & 17.8 & 4.4 & 511 & 621 & 17.6 & 18.3 & 35.5 & 35.5 & 0.4 & 0.3 & 0.5 & 1.1 & 57 & 51 & 5.0 \\
\hline 1907_Mar & 0.00 & 8.27 & -3 & 5067 & 17.2 & 19.3 & 15.1 & 17.5 & 16.7 & 4.2 & 521 & 726 & $16.4 \vdots$ & 17.1 & 35.4 & 35.4 & 0.3 & 0.4 & 1.3 & 1.5 & 35 & 34 & 5.0 \\
\hline 1909_Mar & 0 & -8 & & 3836 & 16.6 & 19. & 14 & 17.1 & 15. & 4.7 & 473 & 750 & $15.5:$ & 16.5 & 35.2 & $35.2:$ & 0.3 & 0.4 & 0.5 & 1.6 & 39 & 24 & 5.3 \\
\hline 1912_Mar & 0.00 & 17.86 & & 94 & 18.2 & 20. & 16.1 & 18.2 & 18 & 4.0 & 1031 & 1527 & 16.8 & 18.1 & 35.4 & 35.3 & 0.5 & 0.7 & 1.6 & 4.9 & 33 & 39 & 5.0 \\
\hline 1913_Mar & 0 & & & 188 & 18. & 20 & 16 & 18. & 18 & 4.1 & 88 & 1075 & 16.8 & 18.2 & 35.4 & 35.4 & 0.5 & .7 & 1.5 & 4.6 & 33 & 39 & 5.0 \\
\hline 1914_Mar & 0.00 & & & 28 & 18 & 20 & 16.4 & 18.5 & 18 & 4.2 & 829 & 1045 & 16.9 & 18.4 & 35.4 & 35.4 & 0.5 & 0.6 & 1.5 & 4.1 & 34. & 40 & 5.0 \\
\hline 1915_Mar & 0.00 & 15.50 & -31.79 & 1510 & 17.2 & 19.0 & 15.5 & 17.2 & 17.1 & 3.5 & 881 & 1261 & 15.6 & 17.0 & 35.3 & 35.3 & 0.5 & 0.8 & 2.0 & 6.1 & 36 & 33 & 4.9 \\
\hline 1916_Mar & 0.00 & 15.30 & -31.45 & 1373 & 17.2 & 19.1 & 15.5 & 17.2 & 17.1 & 3.6 & 846 & 1107 & 15.6 & 17.1 & 35.3 & 35.3 & 0.5 & 0.7 & 2.0 & 5.9 & 37 & 34 & 4.8 \\
\hline 1917_Mar & 0.00 & -16.33 & -31.05 & 3470 & 20.4 & 23.2 & 18.2 & 20.8 & 19.3 & 5.0 & 248 & 346 & 19.2 & 20.3 & 35.9 & 35.9 & 0.2 & 0.2 & 0.0 & 0.2 & 36 & 34 & 5.5 \\
\hline 1918_Mar & 0.00 & -16.84 & -31.13 & 3810 & 20.3 & 23.1 & 18.1 & 20.8 & 19.3 & 5.0 & 246 & 353 & 19.1 & 20.2 & 35.9 & 35.8 & 0.2 & 0.2 & 0.0 & 0.2 . & 39 & 31. & 5.5 \\
\hline 1919_Mar & 0.00 & -19.76 & -31.62 & 4204 & 20.2 & 23.1 & 18.1 & 20.7 & 19.1 & 5.0 & 258 & 377 & 19.1 & 20.1 & 35.8 & 35.8 & 0.2 & 0.2 & 0.1 & 0.2 & 37 & 32 & 5.4 \\
\hline 1920_Mar & 0.00 & -19.50 & -42.04 & 3384 & 11.7 & 13.6 & 10.4 & 12.0 & 10.8 & 3.2 & 502 & 803 & 11.4 & 11.7 & 34.7 & 34.7 & 0.8 & 0.7 & 5.5 & 6.4 & 101 & 189 & 5.0 \\
\hline 1921_Mar & 0.00 & -21.72 & -44.51 & 4296 & 9.4 & 11.4 & 8.1 & 9.8 & 8.4 & 3.4 & 380 & 581 & 9.2 & 9.3 & 34.4 & 34.4 & 1.1 & 1.0 & 10.6 & 11.5 & 94 & 144 & 5.1 \\
\hline 1922_Mar & 0.00 & -17.34 & -44.21 & 3768 & 9.2 & 11.0 & 8.0 & 9.6 & 8.2 & 3.0 & 355 & 570 & 9.0 & 9.1 & 34.3 & 34.3 & 1.1 & 0.9 & 10.5 & 11.0 & 76 & 128 & 4.9 \\
\hline 1923_Mar & 0.00 & -13.07 & -44.00 & 3830 & 9.0 & 10.6 & 7.6 & 9.7 & 7.9 & 3.0 & 388 & 664 & 8.7 & 8.8 & 34.3 & 34.3 & 1.0 & 0.9 & 10.0 & 10.6 & 89 & 135 & 4.9 \\
\hline 1924_Mar & 0.00 & -18.16 & -39.95 & 3525 & 13.6 & 15.8 & 12.1 & 13.9 & 12.7 & 3.7 & 582 & 1020 & 13.1 & 13.6 & 34.9 & 34.9 & 0.6 & 0.5 & 2.1 & 3.0 & 80 & 124 & 5.1 \\
\hline 1925_Mar & 0.00 & -21.04 & -39.09 & 4024 & 14.5 & 16.7 & 12.8 & 15.1 & 13.5 & 4.0 & 583 & 985 & 14.0 & 14.5 & 35.1 & 35.1 & 0.5 & 0.5 & 1.6 & 2.3 & 62 & 145 & 5.1 \\
\hline 1926_Mar & 0.00 & -21.54 & -38.43 & 4126 & 15.1 & 17.4 & 13.3 & 15.7 & 14.1 & 4.1 & 564 & 867 & 14.5 & 15.1 & 35.2 & 35.2 & 0.4 & 0.4 & 1.2 & 1.7 & 49 & 101 & 5.1 \\
\hline 1927_Mar & 0.00 & -21.86 & -37.77 & 3567 & 15.8 & 18.2 & 13.9 & 16.5 & 14.7 & 4.3 & 526 & 777 & 15.1 & 15.7 & 35.3 & 35.3 & 0.4 & 0.4 & 0.8 & 1.2 & 47 & 82 & 5.1 \\
\hline 1928_Mar & 0.00 & -22.45 & -36.45 & 4216 & 16.8 & 19.2 & 14.7 & 17.5 & 15.6 & 4.5 & 511 & 822 & 15.9 & 16.7 & 35.4 & 35.4 & 0.3 & 0.3 & 0.5 & 0.7 & 45 & 42 & 5.2 \\
\hline 1929_Mar & 0.00 & -22.73 & -35.71 & 3972 & 17.4 & 20.0 & 15.3 & 18.2 & 16.3 & 4.6 & 454 & 738 & 16.5 & \begin{tabular}{l}
17.3 \\
\hdashline$\ldots .3$ \\
\end{tabular} & 35.4 & 35.5 & 0.3 & 0.3 & 0.3 & 0.5 & 42 & 39 & 5.2 \\
\hline 1930_Mar & 0.00 & -22.99 & $\begin{array}{l}-35.25 \\
. \cdots\end{array}$ & 3963 & 17.6 & 20.2 & 15.5 & 18.4 & 16.5 & 4.7 & 424 & 634 & $16.7 \vdots$ & 17.5 & 35.5 & 35.5 & 0.3 & 0.3 & 0.3 & 0.4 & 42 & 38 & 5.2 \\
\hline 1931_Mar & 0.00 & -23.59 & -33.83 & 4352 & 18.9 & 21.6 & 16.7 & 19.5 & 17.6 & 4.9 & 315 & 441 & 17.9 & 18.8 & 35.6 & 35.6 & 0.2 & 0.2 & 0.2 & 0.2 & 42 & 35 & 5.2 \\
\hline 1932_Mar & 0.00 & -24.25 & -33.18 & 4491 & 19.2 & 22.0 & 17.1 & 19.8 & 17.9 & 4.9 & 306 & 434 & 18.2 & 19.1 & 35.7 & 35.7 & 0.2 & 0.2 & 0.1 & 0.1 & 43 & 36 & 5.2 \\
\hline 1933_Mar & 0.00 & -24.25 & -31.95 & 4335 & 20.1 & 23.1 & 18.0 & 20.6 & 18.8 & 5.0 & 280 & 424 & 19.1 & 20.0 & 35.8 & 35.8 & 0.2 & 0.2 & 0.1 & 0.1 & 43 & 33 & 5.2 \\
\hline 1937_Mar & 0.00 & -48.34 & -53.87 & 4304 & 3.5 & 5.4 & 2.0 & 3.7 & 3.0 & 3.4 & 220 & 596 & .... & $\begin{array}{l}3.5 \\
3 . . \\
\end{array}$ & 34.0 & 34.0 & 1.5 & 1.7 & 23.0 & 25.1 & 79 & 20 & 4.9 \\
\hline
\end{tabular}




\begin{tabular}{|c|c|c|c|c|c|c|c|c|c|c|c|c|c|c|c|c|c|c|c|c|c|c|c|}
\hline $\begin{array}{l}\mathscr{\Xi} \\
\text { Zू } \\
\end{array}$ & 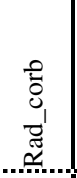 & مْ & . & 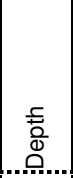 & $\stackrel{\stackrel{O}{E}}{\stackrel{E}{E}}$ & 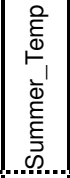 & 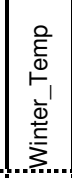 & 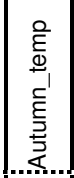 & 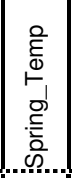 & 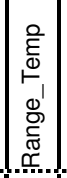 & . & 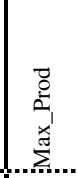 & 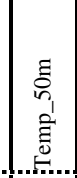 & 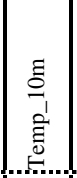 & 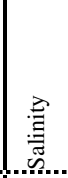 & 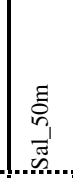 & 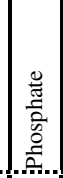 & 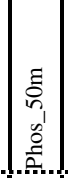 & . & 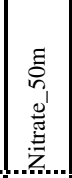 & . & 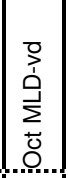 & 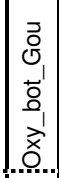 \\
\hline 38_Mar & 0.00 & -41.18 & -52.15 & 0 & 2.8 & 4.7 & 1.3 & 3.2 & 2.2 & 3.4 & 384 & 929 & 2.5 & 2.8 & 33.9 & 33.9 & 1.6 & 1.7 & 22.4 & 24.6 & 51 & 36 & 5.0 \\
\hline 1939_Mar & 0.00 & -45.96 & -52.68 & 3388 & 3.6 & 5.5 & 2.0 & 3.8 & 2.9 & 3.5 & 243 & 741 & 3.2 & 3.5 & 34.0 & 34.0 & 1.5 & 1.6 & 22.7 & 24.6 & 63 & 20 & 4.8 \\
\hline 1940_Mar & 0.00 & -45.02 & -55.55 & 3840 & 1.8 & 3.7 & 0.4 & 2.1 & 1.2 & 3.4 & 194 & 618 & 1.6 & 1.8 & 33.9 & 33.9 & 1.6 & 1.7 & 24.3 & 26.0 & 60 & 20 & 5.1 \\
\hline 1941_Mar & 0.00 & -42.97 & -56.73 & 0 & 1.1 & 2.9 & -0.3 & 1.4 & 0.6 & 3.2 & 190 & 564. & 0.9 & 1.1 & 33.9 & 34.0 & 1.6 & 1.7 & 24.1 & 25.9 & 57 & 20 & 5.2 \\
\hline 1942_Mar & 0.00 & -41.97 & -59.37 & 3900 & -0.1 & 1.3 & -1.3 & -0.1 & -0.4 & 2.6 & 133 & 401. & -0.3 & -0.1 & 34.0 & 34.1 & 1.7 & 1.8 & 24.4 & 26.2 & 36 & 54 & 5.5 \\
\hline 1943_Mar & 0.00 & -43.08 & -59.88 & 0 & -0.4 & 1.0 & -1.4 & -0.5 & -0.6 & 2.5 & 127 & 403 & -0.5 & -0.4 & 34.0 & 34.1 & 1.7 & 1.8 & 24.4 & 26.3 & 31 & 45 & 5.5 \\
\hline 1945_Mar & 0.00 & -41.51 & -51.94 & 3402 & 3.1 & 5.0 & 1.6 & 3.5 & 2.4 & 3.4 & 303 & 831. & 2.7 & 3.1. & 33.9 & 33.9 & 1.6 & 1.7 & 22.1 & 24.3 & 52 & 46 & 4.9 \\
\hline 1947_Mar & 0.00 & -57.02 & -52.85 & 1219 & 6.0 & 7.9 & 4.5 & 5.8 & 5.8 & 3.4 & 306 & 752. & 5.6 & 6.0 & 34.1 & 34.1 & 1.3 & 1.4 & 19.7 & 20.9 & 126 & 98 & 5.2 \\
\hline 1948_Mar & 0.00 & 79.49 & -46.68 & 2925 & 7.4 & 8.3 & 6.4 & 7.9 & 7.0 & 1.8 & 255 & 468 & 7.2 & 7.4 & 34.0 & 34.0 & 1.2 & 1.3 & 18.5 & 16.7 & 36 & 29 & 4.9 \\
\hline 49_Mar & 0.00 & 82.93 & -45.75 & 3480 & 8.8 & 9.5 & 8.1 & 9.3 & 8.5 & 1.4 & 275 & 440 & 8.7 & 8.8 & 34.2 & 34.2 & 1.0 & 1.0 & 15.5 & 14.6 & 59 & 63 & 4.9 \\
\hline 50_Mar & 0.00 & 90.11 & -46.07 & 3400 & 8.6 & 9.4 & 8.1 & 8.7 & 8.3 & 1.3 & 258 & 472 & 8.5 & 8.6 & 34.3 & 34.3 & 1.0 & 1.1 & 14.3 & 14.5 & 99 & 133 & 4.9 \\
\hline 51_Mar & 0.00 & 100.08 & -49.92 & 3350 & 4.8 & 5.9 & 4.0 & 4.9 & 4.4 & 1.9 & 185 & 326 & 4.7 & 4.7 & 34.0 & 34.0 & 1.4 & 1.5 & 18.5 & 19.5 & 77 & 144 & 5.0 \\
\hline 52_Mar & 0.00 & 145 & -47.15 & 2890 & 10.4 & 11.7 & 9.3 & 10.9 & 9.9 & 2.4 & 363 & 615 & 10.2 & 10.4 & 34.6 & 34.6 & 0.9 & 0.9 & 10.7 & 10.7 & 84 & 73 & 4.5 \\
\hline 54_Mar & ... & 147 & -50.59 & 4350 & 8.0 & 9.1 & 7.1 & 8.1 & 7.5 & 2.0 & 252 & 566 & 7.8 & 7.9 & 34.3 & 34.3 & 1.3 & 1.3 & 16.9 & 15.9 & 108 & 135 & 4.7 \\
\hline 55_Mar & 0.0 & 14 & -57.95 & 3740 & 1.6 & 3.5 & 0.3 & 1.7 & 1.1 & 3.2 & 105 & 261 & 1.4 & 1.6 & 33.9 & 33.9 & 1.8 & 1.8 & 26.8 & 27.4 & 25 & 29 & 5.1 \\
\hline 58_Mar & 0.00 & 138 & -65.75 & 615 & -1.3 & -0.2 & -1.9 & -1.5 & -1.6 & 1.7 & 68 & 301 & -1.5 & -1.4 & 34.0 & 34.2 & 2.1 & 2.1 & 30.7 & 31.0 & 11 & 10 & 5.1 \\
\hline 1959_Mar & 0.00 & 115.70 & -64.30 & 2232 & -1.1 & 0.2 & -1.8 & -1.4 & -1.3 & 2.0 & 61 & 297 & -1.4 & -1.1 & 34.1 & 34.2 & 1.7 & 1.9 & 27.2 & 29.8 & 15 & 1 & 5.2 \\
\hline 62_Mar & 0.00 & 86.08 & -45.10 & 3559 & 9.5 & 10.2 & 8.9 & 9.7 & 9.1 & 1.3 & 286 & 485 & 9.4 & 9.5 & 34.4 & 34.4 & 0.9 & 1.0 & 13.8 & 13.6 & 94 & 72 & 4.9 \\
\hline 963_Mar & 0.00 & 90.05 & -50.07 & 4036 & 5.6 & 6.4 & 5.0 & 5.8 & 5.4 & 1.4 & 206 & 391 & 5.5 & 5.6 & 34.0 & 34.0 & 1.3 & 1.4 & 19.3 & 19.4 & 117 & 103 & 5.2 \\
\hline 1968_Mar & 0.00 & 3.81 & -53.75 & 1838 & 0.6 & 1.7 & -0.4 & 1.2 & -0.1 & 2.1 & .99. & 190 & 0.5 & 0.6 & 33.9 & 33.9 & 1.8 & 1.8 & 23.5 & 24.3 & 49 & 35 & 5.2 \\
\hline 1969_Mar & 0.00 & 3.84 & -53.64 & 2089 & 0.7 & 1.8 & -0.3 & 1.2 & -0.1 & 2.1 & 100 & 198 & 0.5 & 0.6 & 33.9 & 33.9 & 1.8 & 1.8 & 23.4 & 24.3 & 50 & 39 & 5.2 \\
\hline 70_Mar & 0.00 & 5.77 & -50.16 & 3763 & 3.1 & 4.1 & 2.2 & 3.5 & 2.5 & 1.9 & 152 & 348 & 3.0 & 3.0 & 33.8 & 33.8 & 1.7 & 1.6 & 21.1 & 21.6 & 79 & 135 & 5.0 \\
\hline 71_Mar & 0.00 & 17.36 & -34.75 & 2578 & 18.2 & 20.2 & 16.1 & 18.3 & 18.3 & 4.0 & 837 & 1090 & 16.8 & 18.1 & 35.4 & 35.4 & 0.5 & 0.7 & 1.5 & 4.6 & 34 & 40 & 5.0 \\
\hline 72_Mar & 0.00 & -5.96 & -51.01 & 2114 & 1.9 & 3.0 & 0.8 & 2.4 & 1.4 & 2.2 & 105 & 211 & 1.8 & 1.9 & 33.8 & 33.8 & 1.5 & 1.6 & 23.4 & 24.2 & 65 & 29 & 4.9 \\
\hline 973_Mar & 0.00 & -6.00 & -49.13 & 3525 & 3.3 & 4.5 & 2.0 & 4.0 & 2.6 & 2.5 & 204 & 498 & 3.1 & 3.2 & 33.8 & 33.8 & 1.5 & 1.5 & 21.3 & 22.6 & 79 & 91 & 4.9 \\
\hline 974_Mar & 0.00 & -6.00 & -54.00 & 2415 & 0.4 & 1.6 & -0.6 & 0.8 & -0.1 & 2.2 & 76 & 153 & 0.3 & 0.4 & 33.8 & 33.8 & 1.6 & 1.8 & 24.8 & 25.5 & 52 & 96 & 5.1 \\
\hline 1975_Mar & 0.00 & -6.00 & -48.57 & 3657 & 3.8 & 5.2 & 2.5 & 4.6 & 3.1 & 2.6 & 202 & 413 & 3.7 & 3.8 & 33.8 & 33.9 & 1.4 & 1.4 & 20.3 & 21.8 & 85 & 115 & 4.9 \\
\hline 987_Mar & 0.00 & -114.89 & -59.21 & 5135 & 3.6 & 4.4 & 3.2 & 3.8 & 3.1 & 1.4 & 127 & 311 & 3.5 & 3.6 & 34.0 & 34.0 & 1.7 & 1.7 & 23.4 & 23.9 & 153 & 191 & 4.9 \\
\hline 1988_Mar & 0.00 & -113.57 & -56.89 & 3896 & 5.0 & 6.0 & 4.4 & 5.1 & 4.6 & 1.5 & 134 & 296 & 4.9 & 5.0 & 34.1 & 34.1 & 1.5 & 1.5 & 20.8 & 20.8 & 158 & 328 & 4.7 \\
\hline 1989_Mar & 0.00 & -93.83 & -57.55 & 4038 & 5.3 & 6.6 & 4.4 & 5.0 & 5.0 & 2.2 & 147 & 335 & 5.2 & 5.3 & 34.1 & 34.1 & 1.5 & 1.5 & 21.2 & 21.6 & 163 & 306 & 4.9 \\
\hline 1990_Mar & 0.00 & -91.16 & -57.65 & 3341 & 5.3 & 6.8 & 4.4 & 5.1 & 5.0 & 2.4 & 153 & 377 & 5.2 & 5.3 & 34.1 & 34.1 & 1.5 & 1.5 & 20.7 & 20.9 & 193 & 322 & 4.9 \\
\hline 1991_Mar & 0.00 & -92.38 & -57.04 & 5026 & 5.5 & 7.0 & 4.6 & 5.3 & 5.2 & 2.3 & 156 & 423 & 5.4 & 5.5 & 34.1 & 34.1 & 1.4 & 1.5 & 20.5 & 20.9 & 183 & 330 & 4.9 \\
\hline 1992_Mar & 0.00 & -93.79 & -56.57 & 5240 & 5.7 & 7.1 & 4.8 & 5.5 & 5.3 & 2.2 & 154 & 400 & 5.6 & 5.7 & 34.1 & 34.1 & 1.4 & 1.5 & 20.2 & 20.7 & 165 & 341 & 4.9 \\
\hline 1993_Mar & 0.00 & 177.99 & -45.39 & 0 & 11.4 & 14.4 & 9.0 & 11.5 & 10.7 & 5.4 & 426 & 878 & 10.4 & 11.4 & 34.4 & 34.4 & 0.6 & 0.7 & 5.5 & 8.9 & 56 & 65 & 4.6 \\
\hline 1994_Mar & 0.00 & & -45.02 & 1122 & 11.4 & 14.3 & 9.1 & 11.3 & 11.0 & 5.2 & 544 & 1213 & 10.2 & 11.3 & 34.5 & 34.4 & 0.6 & 0.7 & 4.6 & 9.6 & 53 & 22 & 4.8 \\
\hline 1995_Mar & 0 & & & 4808 & 12 & 15 & 11.0 & 12.8 & 12 & 4.1 & 573 & 1016 & 12.1 & 12.7 & 34.8 & 3 & 0.4 & 0.5 & 2.4 & 4.5 & 67 & 4 & 4.7 \\
\hline 1996_Mar & .. & & & 3010 & 16.2 & 18 & 13.8 & 16.6 & 15.7 & 5.1 & 730 & 1354 & 15.4 & 16.2 & 35.4 & 35 & 0.2 & & 0.8 & 1.9 & 70 & 28 & 4.4 \\
\hline 1998_Mar & 0 & & & 355 & 14. & 17 & 12 & 15.1 & 14.3 & 5.0 & 537 & 772 & 14.0 & 14.7 & 35.1 & 35 & 0.3 & 0.3 & 0.7 & 1.5 & 54 & 45 & 4.5 \\
\hline 1999_Mar & 0 & & & 2270 & 12 & 14 & 11 & 12. & 11.6 & 2.9 & 650 & 1272 & 12.1 & 12.3 & 34.9 & 34 & 0.5 & 0.6 & 5.1 & 6.0 & 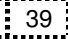 & 12 & 4.6 \\
\hline 2000_Mar & 0.00 & 14 & -41.39 & 814 & 14.0 & 15.6 & 12.7 & 14.5 & 13.2 & 3.0 & 720 & 1187 & 13.5 & 14.0 & 35.1 & 35.1 & 0.3 & 0.4 & 1.4 & 2.7 & 75 & 23 & 5.0 \\
\hline 2001_Mar & 0.00 & 142.53 & -42.25 & 4103 & 13.3 & 14.8 & 11.9 & 13.7 & 12.6 & 2.9 & 584 & 1007 & 12.8 & 13.2 & 35.0 & 35.0 & 0.4 & 0.5 & 3.3 & 4.5 & 73 & 33 & 4.8 \\
\hline 2002_Mar & 0.00 & 142.88 & -42.23 & 3715 & 13.3 & 14.9 & 12.0 & 13.8 & 12.6 & 2.9 & 624 & 1030 & 12.9 & 13.3 & 35.0 & 35.0 & 0.4 & 0.4 & 3.0 & 4.3. & 74 & 30 & 4.8 \\
\hline 2003_Mar & 0.00 & 144.41 & -42.20 & 2360 & 13.5 & 15.0 & 12.1 & 14.1 & 12.7 & 2.9 & 714 & 1217 & 13.0 & 13.4 & 35.0 & 35.1 & 0.3 & 0.4 & 2.1 & 3.4 & 58 & 17 & 4.8 \\
\hline 2004_Mar & 0.00 & 144.68 & -42.18 & 765 & 13.5 & 15.0 & 12.1 & 14.1 & 12.7 & 2.9 & 858 & 1485 & 13.0 & 13.4 & 35.0 & 35.1 & 0.3 & 0.4 & 2.0 & 3.3. & 46 & 15 & 4.9 \\
\hline 2005_Mar & 0.00 & 144.34 & -41.52 & 838 & 13.9 & 15.5 & 12.6 & 14.5 & 13.2 & 2.9 & 755 & 1297 & 13.4 & 13.9 & 35.1 & 35.1 & 0.3 & 0.4 & 1.5 & 2.8 & 88 & 22 & 5.0 \\
\hline 2006_Mar & 0.00 & 144.29 & -41.51 & 1081 & 13.9 & 15.5 & 12.6 & 14.5 & 13.2 & 2.9 & 700 & 1172 & 13.4 & 13.9 & 35.1 & 35.1 & 0.3 & 0.4 & 1.5 & 2.8 & 84 & 22 & 5.0 \\
\hline 2007_Mar & 0.00 & 144.22 & -41.52 & 1557 & 13.9 & 15.5 & 12.6 & 14.5 & 13.2 & 2.9 & 700 & 1172 & 13.4 & 13.9 & 35.1 & 35.1 & 0.3 & 0.4 & 1.5 & 2.9 & 80 & 22 & 4.9 \\
\hline 2008_Mar & 0.00 & 144.10 & -41.50 & 1703 & 13.9 & 15.5 & 12.6 & 14.5 & 13.2 & 2.9 & 668 & 1074 & 13.4 & 13.9 & 35.1 & 35.1 & 0.3 & 0.4 & 1.4 & 2.9 & 73 & 23 & 4.9 \\
\hline 2009_Mar & 0.00 & 143.83 & -41.12 & 1265 & 14.1 & 15.8 & 12.7 & 14.6 & 13.3 & 3.1 & 632 & 960 & 13.6 & 14.1 & 35.1 & 35.2 & 0.3 & 0.4 & 1.4 & 2.5 & 71 & 29 & 4.9 \\
\hline 2012_Mar & 0.00 & -176.91 & -42.68 & 1000 & 14.4 & 17.1 & 12.2 & 14.5 & 13.8 & 4.9 & 714 & 1269 & 13.7 & 14.4 & 35.0 & 35.0 & 0.3 & 0.4 & 1.3 & 3.2 & 60 & 21 & 4.6 \\
\hline 2013_Hol & 0.00 & 17.90 & -32.40 & 105 & 16.5 & 17.8 & 15.2 & 16.5 & 16.5 & 2.6 & 250 & 327 & 14.5 & 16.3 & 35.2 & 35.1 & 0.6 & 1.0 & 2.5 & 9.2 & 28 & 31 & 4.9 \\
\hline 2014_Hol & 0.00 & 17.10 & -32.49 & 295 & 16.7 & 18.2 & 15.3 & 16.7 & 16.7 & 2.8 & 257 & 339 & 14.8 & 16.5 & 35.2 & 35.2 & 0.6 & 1.0 & 2.4 & 8.4 & 30 & 33 & 4.8 \\
\hline 2015_Hol & 0.00 & 18.02 & -31.93 & 116 & 16.4 & 17.7 & 15.1 & 16.2 & 16.4 & 2.6 & 263 & 338 & 14.1 & 16.1 & 35.1 & 35.1 & 0.6 & 1.1 & 2.7 & 9.8 & 28 & 31 & 4.9 \\
\hline 2016_Hol & 0.00 & 18.21 & -31.93 & 84 & 16.3 & 17.6 & 15.1 & 16.2 & 16.4 & 2.5 & 262 & 337 & 14.0 & 16.0 & 35.1 & 35.1 & 0.6 & 1.1 & 2.8 & 9.9 & 30 & 33 & 4.9 \\
\hline 2017_Hol & $0.00 \vdots$ & 17.31 & -30.46 & 56 & 16.5 & 18.2 & 15.0 & 16.2 & 16.7 & 3.2 & 293. & 405 & 14.3 & 16.3 & 35.2 & 35.1 & 0.6 & $0.9 \vdots$ & 2.9 & 8.9 & 24 & 25 & 4.8 \\
\hline 2018_Hol & 0.00 & 16.93 & -30.55 & 180 & 16.5 & 18.3 & 15.0 & 16.2 & 16.7 & 3.2 & 284. & 366 & 14.3 & 16.3 & 35.2 & 35.1 & 0.6 & 0.9 & 2.8 & $\begin{array}{r}8.8 \\
. \cdots .\end{array}$ & 23 & 24 & 4.7 \\
\hline 2019_Hol & 0.00 & 16.55 & -30.57 & 224 & 16.6 & 18.3 & 15.1 & 16.3 & 16.7 & 3.3 & 283 & 355 & 14.4 & 16.4 & 35.2 & 35.1 & 0.6 & 0.9 & 2.8 & 8.6 & 22 & 23 & 4.7 \\
\hline 2020_Hol & 0.00 & 14.60 & -30.10 & 530 & 17.3 & 19.4 & 15.5 & 17.2 & 17.1 & 3.9 & 303 & 394 & 15.7 & 17.1 & 35.3 & 35.3 & 0.5 & 0.7 & 2.2 & 5.6 & 37 & 33 & 4.8 \\
\hline 2021_Hol & 0.00 & $\begin{array}{l}15.42 \\
. . . . . . .\end{array}$ & -29.95 & 205 & $\begin{array}{l}16.8 \\
\end{array}$ & 18.8 & 15.1 & 16.5 & 16.8 & 3.7 & 297 & 393 & 14.9 & 16.6 & $\begin{array}{l}35.2 \\
\cdots \cdots . .\end{array}$ & 35.2 & 0.6 & 0.8 & 3.0 & $\begin{array}{l}7.5 \\
-2 . .\end{array}$ & 28 & 26 & $\begin{array}{l}4.7 \\
\cdots . . .\end{array}$ \\
\hline
\end{tabular}




\begin{tabular}{|c|c|c|c|c|c|c|c|c|c|c|c|c|c|c|c|c|c|c|c|c|c|c|c|}
\hline $\begin{array}{l}\mathscr{\Xi} \\
\text { Zू } \\
\end{array}$ & 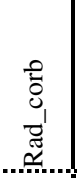 & . & . & 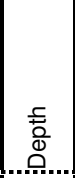 & $\stackrel{\stackrel{\varrho}{E}}{\stackrel{E}{\Phi}}$ & 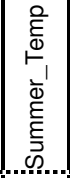 & 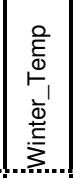 & 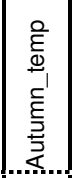 & 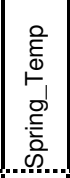 & 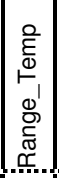 & . & 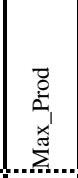 & 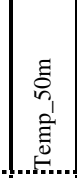 & 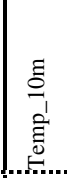 & 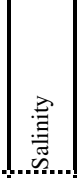 & 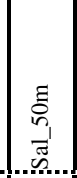 & 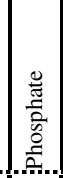 & 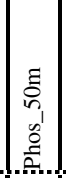 & . & 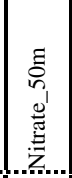 & 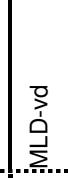 & . & 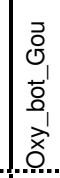 \\
\hline 2022_Hol & 0.00 & 15.83 & -29.78 & 191 & 16.4 & 18.4 & 14.7 & 16.0 & 16.6 & 3.6 & 299 & 396 & 14.2 & 16.2 & 35.1 & 35.1 & 0.6 & 0.9 & 3.6 & 8.9 & 25 & 25 & 4.7 \\
\hline 2023_Hol & 0.00 & 16.42 & -29.63 & 165 & 16.0 & 17.8 & 14.3 & 15.4 & 16.4 & 3.5 & 300 & 365 & 13.4 & 15.7 & 35.0 & 35.0 & 0.6 & 1.0 & 4.2 & 10.6 & 20 & 21 & 4.7 \\
\hline 2024_Hol & 0.00 & 16.93 & -29.63 & 102 & 15.9 & 17.7 & 14.3 & 15.2 & 16.3 & 3.4 & 302 & 385 & 13.2 & 15.6 & 35.0 & 35.0 & 0.7 & 1.1 & 4.3 & 11.0 & 22. & 23 & 4.7 \\
\hline 2025_Hol & 0.00 & 18.12 & -32.73 & 9 & 16.7 & 18.0 & 15.3 & 16.7 & 16.7 & 2.7 & 247 & 312 & 14.7 & 16.4 & 35.2 & 35.2 & 0.6 & 1.0 & 2.4 & 8.7 & 31. & 35 & 4.9 \\
\hline 2026_Hol & 0.00 & 13.40 & -27.20 & 2060 & 17.1 & 19.1 & 15.4 & 17.3 & 16.7 & 3.6 & 321 & 425 & 15.9 & 17.0 & 35.3 & 35.3 & 0.6 & 0.8 & 3.6 & 6.0 & 37 & 39 & 4.6 \\
\hline 2027_Hol & 0.00 & 13.72 & -27.03 & 0 & 16.9 & 18.7 & 15.3 & 17.1 & 16.5 & 3.4 & 330 & 433 & 15.6 & 16.7 & 35.2 & 35.2 & 0.7 & 0.8 & 4.1 & 6.9 & 33 & 37. & 4.5 \\
\hline 2028_Hol & 0.00 & 14.10 & -27.03 & 437 & 16.7 & 18.5 & 15.1 & 16.9 & 16.3 & 3.3 & 347 & 462 & 15.4 & 16.6 & 35.2 & 35.2 & 0.7 & 0.9 & 4.4 & 7.4 & 34 & 36 & 4.4 \\
\hline 2029_Hol & 0.00 & 14.67 & -26.95 & 270 & 16.4 & 18.1 & 14.9 & 16.5 & 16.0 & 3.1 & 357 & 507 & 15.0 & 16.2 & 35.2 & 35.2 & 0.8 & 1.0 & 4.9 & 8.4 & 32 & 39 & 4.4 \\
\hline 2031_Hol & 0.00 & 13.78 & -26.22 & 390 & 16.4 & 18.0 & 15.0 & 16.6 & 16.0 & 3.0 & 356 & 534 & 15.1 & 16.2 & 35.2 & 35.2 & 0.8 & 1.0 & 4.9 & 8.3 & 29 & 34 & 4.3 \\
\hline 2033_Hol & 0.00 & 17.01 & -29.69 & 80 & 15.9 & 17.8 & 14.3 & 15.3 & 16.3 & 3.4 & 303 & 389 & 13.3 & 15.7 & 35.0 & 35.0 & 0.7 & 1.0 & 4.2 & 10.8 & 23 & 24 & 4.7 \\
\hline 2034_Hol & 0.00 & 18.01 & -31.51 & 62 & 16.0 & 17.1 & 14.9 & 15.7 & 16.1 & 2.2 & 273 & 361 & 13.3 & 15.6 & 35.1 & 35.1 & 0.6 & 1.2 & 3.1 & 11.3 & 27 & 30 & 4.8 \\
\hline 2035_Hol & 0.00 & 15.03 & -31.05 & 2035 & 17.3 & 19.3 & 15.6 & 17.3 & 17.2 & 3.7 & 279 & 381 & 15.8 & 17.2 & 35.3 & 35.3 & 0.5 & 0.7 & 1.9 & 5.5 & 38 & 35 & 4.8 \\
\hline 2036_Hol & 0.00 & 13.40 & -24.10 & 304 & 16.5 & 18.3 & 14.9 & 16.6 & 16.0 & 3.4 & 437 & 656 & 14.8 & 16.2 & 35.2 & 35.2 & 0.7 & 1.0 & 4.3 & 9.6 & 26 & 30 & 4.1 \\
\hline 2037_Hol & 0.00 & 14.39 & -22.94 & 40 & 16.6 & 18.7 & 14.8 & 16.6 & 16.3 & 3.9 & 515 & 820 & 14.6 & 16.4 & 35.2 & 35.2 & 0.8 & 1.3 & 5.0 & 13.2 & 21 & 31. & 3.9 \\
\hline 2038_Hol & 0.00 & 14.40 & -23.10 & 38 & 16.5 & 18.6 & 14.8 & 16.5 & 16.2 & 3.8 & 508 & 778 & 14.6 & 16.3 & 35.2 & 35.2 & 0.8 & 1.2 & 4.9 & 12.6 & 21 & 31 & 3.9 \\
\hline 2039_Hol & 0.00 & 16.44 & -28.97 & 123 & 16.3 & 18.3 & 14.6 & 15.8 & 16.5 & 3.7 & 314 & 436 & 14.0 & 16.1 & 35.1 & 35.1 & 0.6 & 1.0 & 4.1 & 9.7 & 18 & 20 & 4.7 \\
\hline 2040_Hol & 0.00 & 16.44 & -28.80 & 50 & 16.4 & 18.4 & 14.6 & 15.9 & 16.6 & 3.8 & 317 & 445 & 14.2 & 16.2 & 35.1 & 35.1 & 0.7 & 0.9 & 4.2 & 9.7 & 18 & 20 & 4.6 \\
\hline 2042_Hol & 0.00 & 16.08 & -28.37 & 43 & 16.4 & 18.5 & 14.6 & 16.0 & 16.6 & 3.9 & 319 & 432 & 14.3 & 16.2 & 35.1 & 35.1 & 0.7 & 1.0 & 4.4 & 9.8 & 20 & 21 & 4.6 \\
\hline 2043_Hol & 0.00 & 11.39 & -17.26 & 198 & 19.3 & 22.0 & 16.6 & 20.1 & 18.4 & 5.5 & 3058 & 6398 & 16.4 & 19.1 & 35.7 & 35.5 & 0.7 & 1.2 & 9.1 & 18.4 & 24 & 25 & 4.4 \\
\hline 2044_Hol & 0.00 & 11.06 & -17.26 & 1485 & 19.3 & 22.0 & 16.6 & 20.1 & 18.4 & 5.4 & 2642 & 6155 & 16.4 & 19.1 & 35.7 & 35.5 & 0.7 & 1.2 & 9.0 & 18.2 & 21 & 23 & 4.6 \\
\hline 2045_Hol & 0.00 & 11.70 & -17.94 & 108 & 18.6 & 21.3 & 16.1 & 19.3 & 17.8 & 5.1 & 1687 & 5877 & 16.2 & 18.5 & 35.6 & 35.5 & 0.8 & 1.3 & 9.6 & 18.2 & 21 & 22 & 4.2 \\
\hline 2047_Hol & 0.00 & 13.61 & -21.25 & 29 & 17.7 & 20.0 & 15.5 & 17.9 & 17.2 & 4.5 & 595 & 932 & 15.7 & 17.5 & 35.3 & 35.3 & 0.8 & 1.3 & 6.3 & 13.1 & 26 & 26 & 3.8 \\
\hline 2048_Hol & 0.00 & 12.58 & -21.25 & 390 & 17.8 & 20.2 & 15.7 & 18.1 & 17.3 & 4.5 & 582 & 1107 & 15.8 & 17.6 & 35.3 & 35.3 & 0.8 & 1.2 & 6.1 & 12.5 & 24 & 24 & 4.0 \\
\hline 2049_Hol & 0.00 & 11.80 & -21.27 & 1502 & 18.0 & 20.4 & 15.9 & 18.4 & 17.4 & 4.5 & 530 & 1208 & 16.1 & 17.9 & 35.3 & 35.4 & 0.7 & 1.2 & 5.9 & 11.6 & 28 & 29 & 4.4 \\
\hline 2050_Hol & 0.00 & 11.63 & -20.92 & 1525 & 18.0 & 20.4 & 15.9 & 18.4 & 17.4 & 4.6 & 544 & 1180 & 16.2 & 17.9 & 35.4 & 35.4 & 0.8 & 1.2 & 6.6 & 12.5 & 29 & 29 & 4.4 \\
\hline 2051_Hol & 0.00 & 12.23 & -20.58 & 339 & 17.6 & 20.0 & 15.4 & 17.9 & 17.1 & 4.6 & 585 & 963 & 15.6 & 17.4 & 35.3 & 35.4 & 0.9 & 1.4 & 7.7 & 14.9 & 25 & 25 & 4.1 \\
\hline 2052_Hol & 0.00 & 11.40 & -17.07 & 140 & 19.5 & 22.2 & 16.7 & 20.3 & 18.7 & 5.5 & 3816 & 6735 & 16.4 & 19.3 & 35.7 & 35.6 & 0.7 & 1.2 & 8.9 & 18.3 & 23 & 25 & 4.4 \\
\hline 2053_Hol & 0.00 & 11.12 & -17.57 & 1502 & 19.1 & 21.8 & 16.4 & 19.9 & 18.2 & 5.4 & 2038 & 5947 & 16.4 & 18.9 & 35.7 & 35.5 & 0.8 & 1.2 & 9.3 & 18.4 & 23 & 24. & 4.6 \\
\hline 2054_Hol & 0.00 & 11.28 & -17.57 & 776 & 19.1 & 21.8 & 16.4 & 19.8 & 18.2 & 5.4 & 2151 & 5612 & 16.3 & 18.9 & 35.7 & 35.5 & 0.8 & 1.2 & 9.3 & 18.5 & 24 & 26 & 4.5 \\
\hline 2055_Hol & 0.00 & 11.45 & -17.57 & 222 & 19.0 & 21.8 & 16.4 & 19.8 & 18.2 & 5.4 & 2376 & 6118 & 16.3 & 18.9 & 35.7 & 35.5 & 0.8 & 1.2 & 9.3 & 18.5 & 24 & 26 & 4.3 \\
\hline 2056_Hol & 0.00 & 11.57 & -17.53 & 130 & 19.1 & 21.8 & 16.4 & 19.8 & 18.2 & 5.4 & 2582 & 6699 & 16.3 & 18.9 & 35.7 & 35.5 & 0.8 & 1.2 & 9.3 & 18.5 & 22 & 24 & 4.3 \\
\hline 2057_Hol & 0.00 & 11.33 & -18.38 & 620 & 18.1 & 20.7 & 15.8 & 18.7 & 17.4 & 4.9 & 1004 & 2428 & 15.9 & 17.9 & 35.6 & 35.5 & 0.9 & 1.4 & 10.2 & 18.9 & 26 & 28 & 4.4 \\
\hline 2059_Hol & 0.00 & 11.87 & -18.40 & 98 & 18.0 & 20.5 & 15.6 & 18.5 & 17.2 & 4.9 & 1174 & 3573 & 15.8 & 17.8 & 35.5 & 35.5 & 1.0 & 1.4 & 10.5 & 19.5 & 20 & 21 & 4.2 \\
\hline 2060_Hol & 0.00 & 11.53 & -1 & 285 & 18.3 & 20.8 & 15.9 & 18.9 & 17.5 & 4.9 & 853 & 2161 & 16.1 & 18.1 & 35.5 & 35.5 & 0.9 & 1.3 & 9.4 & 10.8 & 27 & 28 & 4.3 \\
\hline 2061_Hol & 0.00 & 11.32 & -18.92 & 468 & 18.3 & 20.9 & 16.0 & 18.9 & 17.5 & 4.9 & 802 & 2325 & 16.2 & 18.2 & 35.5 & 35.5 & 0.9 & 1.3 & 9.3 & 16.6 & 27 & 28 & 4.4 \\
\hline 2063_Hol & 0.00 & & & 77 & 16.3 & 18 & 14 & 15. & 16 & 3.8 & 316 & 435 & 14.0 & 16.1 & 35.1 & 35.1 & 0.6 & 1.0 & 4.1 & 8 & 18 & 20 & 4.7 \\
\hline 2064_Hol & 0 & & & 100 & 16.4 & 18 & 14.6 & 16.0 & 16 & 3.9 & 316 & 431 & 14.3 & 16.2 & 35.1 & 35.1 & 0.7 & 0 & 4.4 & 10.0 & 21 & 22 & 4.6 \\
\hline 2065_Hol & 0.0 & & & 25 & 16.6 & 18 & 14. & 16 & 16 & 4.0 & 520 & 775 & 14.4 & 16.3 & 35.2 & 35.2 & 0.8 & 4 & 5.2 & & 21 & 31. & 3.9 \\
\hline 2066_Hol & 0.00 & & & 50 & 18.1 & 20 & 15.8 & 18.6 & 17 & 4.9 & 981 & 2390 & 15.9 & 17.9 & 35.5 & 35.5 & 0.9 & 1.4 & 9.8 & 17.7 & 22 & 22 & 4.0 \\
\hline 2067_Hol & 0.00 & 11.70 & -17.07 & 48 & 19.5 & 22.2 & 16.7 & 20.3 & 18.6 & 5.5 & 3367 & 5901 & 16.3 & 19.3 & 35.7 & 35.6 & 0.7 & 1.2 & 9.0 & 18.5 & 18 & 19 & 4.3 \\
\hline 2068_Hol & 0.00 & 12.67 & -24.15 & 2090 & 16.8 & 18.7 & 15.2 & 17.0 & 16.3 & 3.6 & 394. & 542 & 15.2 & 16.6 & 35.2 & 35.2 & 0.7 & 1.0 & 4.0 & 8.5 & 29 & 31 & 4.4 \\
\hline 2069_Hol & 0.00 & 15.99 & -28.84 & 152 & 16.5 & 18.5 & 14.7 & 16.1 & 16.6 & 3.9 & 314 & 437 & 14.4 & 16.3 & 35.1 & 35.1 & 0.6 & 0.9 & 4.1 & 9.3 & 22 & 23 & 4.6 \\
\hline 2070_Hol & 0.00 & 15.80 & -28.81 & 177 & 16.5 & 18.6 & 14.7 & 16.1 & 16.7 & 3.9 & 314. & 434 & 14.4 & 16.3 & 35.1 & 35.1 & 0.6 & 0.9 & 4.0 & 9.2. & 23 & 24 & 4.6 \\
\hline 2071_Ver & 0.00 & -73.28 & -52.78 & 42 & 8.1 & 9.7 & 6.3 & 8.5 & 7.8 & 3.3 & 636 & 1816 & 7.6 & 7.9 & 33.6 & 33.7 & 1.1 & 1.1 & 12.3 & 14.3 & 6 & 5 & 5.6 \\
\hline 2072_Ver & 0.00 & -73.29 & -52.79 & 60 & 8.1 & 9.7 & 6.3 & 8.5 & 7.7 & 3.3 & 636 & 1819 & 7.6 & 7.9 & 33.6 & 33.7 & 1.1 & 1.1 & 12.3 & 14.3 & 6 & 5 & 5.6 \\
\hline 2073_Ver & 0.00 & -73.26 & -52.75 & 42 & 8.1 & 9.7 & 6.4 & 8.5 & 7.8 & 3.4 & 635 & 1803 & 7.6 & 7.9 & 33.6 & 33.7 & 1.1 & 1.1 & 12.3 & 14.3 & 6 & 5 & 5.6 \\
\hline 2074_Ver & 0.00 & -73.48 & -52.78 & 22 & 8.1 & 9.7 & 6.3 & 8.5 & 7.8 & 3.3 & 630 & 1760 & 7.6 & 7.9 & 33.6 & 33.7 & 1.1 & 1.1 & 12.3 & 14.3 & 6 & 5. & 5.6 \\
\hline 2075_Ver & 0.00 & -73.65 & -52.79 & 46 & 8.1 & 9.7 & 6.4 & 8.5 & 7.8 & 3.3 & 624 & 1719 & 7.6 & 7.9 & 33.6 & 33.7 & 1.1 & 1.1 & 12.4 & 14.3 & 7 & 6 & 5.5 \\
\hline 2076_Ver & 0.00 & -75.90 & -39.88 & 4075 & 13.9 & 16.6 & 11.4 & 14.0 & 13.7 & 5.2 & 769 & 1258 & 12.5 & 13.9 & 33.6 & 33.8 & 0.7 & 0.8 & 3.9 & 7.6 & 19 & 15 & 4.0 \\
\hline 2077_Ver & 0.00 & -74.45 & -41.00 & 844 & 13.3 & 15.8 & 10.9 & 13.2 & 13.3 & 4.9 & 1477 & 2117 & 11.9 & 13.2 & 33.3 & 33.7 & 0.6 & 0.8 & 3.6 & 7.7 & 16 & 8 & 4.1 \\
\hline 2078_Ver & 0.00 & -73.68 & -36.22 & 1019 & 14.0 & 15.8 & 12.3 & 14.0 & 14.0 & 3.5 & 1740 & 3114 & 12.2 & 13.8 & 33.7 & 34.0 & 0.8 & 1.3 & 3.5 & 13.8 & 14 & 23 & 3.7 \\
\hline 2079_Ver & 0.00 & -73.57 & -36.15 & ...... & 14.0 & 15.8 & 12.3 & 14.1 & 14.0 & 3.5 & 1825 & 3264 & 12.2 & 13.8 & 33.7 & 34.0 & 0.7 & 1.3 & 3.5 & 13.7 & 14 & 23 & 3.6 \\
\hline 2080_Ver & 0.00 & -72.72 & $\begin{array}{r}-32.96 \\
-32.96\end{array}$ & 5584 & 15.3 & 17.4 & 13.6 & 15.1 & 15.1 & 3.8 & 1134 & 1787 & 13.2 & 15.1 & 34.2 & 34.2 & 0.6 & 0.9 & 4.4 & 6.7 & 26 & 29 & 3.6 \\
\hline 2081_Ver & 0.00 & -72.63 & -30.57 & 5862 & 15.7 & 18.3 & 13.8 & 15.6 & 15.4 & 4.5 & 1025 & 1423 & 13.9 & 15.6 & 34.3 & 34.2 & 0.5 & 0.5 & 3.6 & 5.6 & 24 & 26 & 3.7 \\
\hline 2082_Ver & $0.00 \vdots$ & -71.93 & $\begin{array}{l}-27.47 \\
-27.4\end{array}$ & 6154 & 16.5 & 19.4 & 14.6 & 16.5 & 15.9 & 4.8 & 915 & 1234 & 14.1 & \begin{tabular}{l}
16.4 \\
\hdashline$\ldots .$. \\
\end{tabular} & 34.5 & 34.4 & 0.5 & 0.8 & 2.2 & 7.5 & 28 & 43 & 3.6 \\
\hline 2083_Ver & 0.00 & -71.54 & -25.70 & 7725 & 17.5 & 20.7 & 15.2 & 17.5 & 16.8 & 5.5 & 871 & 1150 & 14.8 & 17.4 & 34.7 & 34.5 & 0.6 & 0.9 & 1.6 & 3.7 & 29 & 51 & 3.6 \\
\hline 2084_Ver & 0.00 & -72.02 & -27.91 & 6451 & 16.6 & 19.3 & 14.6 & 16.5 & 15.9 & 4.7 & 932 & 1170 & 14.3 & 16.4 & 34.5 & 34.4 & 0.5 & 0.7 & 2.3 & 7.3 & 29 & 42 & 3.6 \\
\hline 2085_Ver & 0.00 & -72.32 & -29.28 & 6442 & 16.1 & 18.6 & 14.2 & 16.1 & 15.6 & 4.4 & 1018 & 1378 & 14.2 & 15.9 & 34.4 & 34.3 & 0.4 & 0.5 & 3.4 & 6.6 & 29 & 35 & 3.7 \\
\hline 2086_Ver & 0.00 & $\begin{array}{l}-75.59 \\
-. . . . . .\end{array}$ & -42.11 & 3847 & 12.9 & 15.6 & 10.5 & 12.9 & 12.7 & 5.1 & 871 & 1437 & 11.8 & 12.9 & 33.4 & 33.7 & 0.6 & 0.8 & 4.2 & 7.8 & 20 & 7 & 4.1 \\
\hline
\end{tabular}




\begin{tabular}{|c|c|c|c|c|c|c|c|c|c|c|c|c|c|c|c|c|c|c|c|c|c|c|c|}
\hline $\begin{array}{l}\mathscr{\Xi} \\
\text { Zू } \\
\end{array}$ & 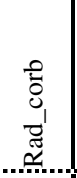 & '. & . & 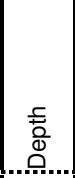 & 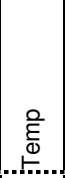 & 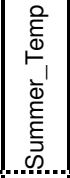 & 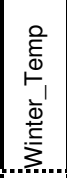 & 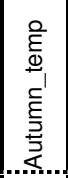 & 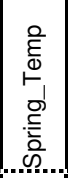 & 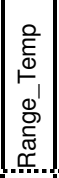 & . & 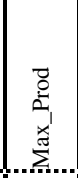 & 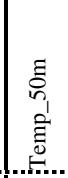 & 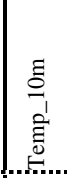 & 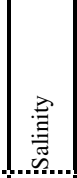 & 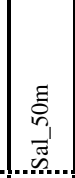 & 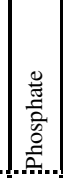 & 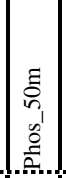 & 莺 & 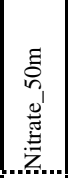 & . & . & 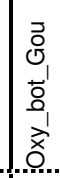 \\
\hline 2087_Ver & 0.00 & -75.45 & -42.07 & 3854 & 12.9 & 15.6 & 10.5 & 13.0 & 12.8 & 5.1 & 932 & 1514 & 11.8 & 12.9 & 33.4 & 33.7 & 0.6 & 0.8 & 4.1 & 7.8 & 20 & 7 & 4.1 \\
\hline 2088_Ver & 0.00 & -75.74 & -42.07 & 3819 & 12.9 & 15.6 & 10.5 & 13.0 & 12.8 & 5.1 & 814 & 1362 & 11.8 & 12.9 & 33.4 & 33.7 & 0.6 & 0.8 & 4.2 & 7.8 & 21 & 7 & 4.1 \\
\hline 2089_Ver & 0.00 & -75.81 & -42.04 & 3810 & 13.0 & 15.6 & 10.5 & 13.0 & 12.8 & 5.1 & 798 & 1339 & 11.9 & 12.9 & 33.4 & 33.7 & 0.6 & 0.8 & 4.3 & 7.8 & 21 & 7 & 4.1 \\
\hline 2090_Ver & 0.00 & -75.68 & -41.97 & 3819 & 13.0 & 15.6 & 10.6 & 13.0 & 12.9 & 5.1 & 836 & 1367 & 11.9 & 13.0 & 33.4 & 33.7 & 0.6 & 0.8 & 4.2 & 7.8 & 20 & 7 & 4.1 \\
\hline 2091_Ver & 0.00 & -75.54 & -42.08 & 3850 & 12.9 & 15.6 & 10.5 & 13.0 & 12.8 & 5.1 & 887 & 1453 & 11.8 & 12.9 & 33.4 & 33.7 & 0.6 & 0.8 & 4.2 & 7.8 & 20 & 7. & 4.1 \\
\hline 2092_Ver & 0.00 & -75.24 & -40.48 & 4101 & 13.5 & 16.1 & 11.1 & 13.5 & 13.5 & 5.0 & 894. & 1251 & 12.1 & 13.5 & 33.4 & 33.8 & 0.6 & 0.8 & 3.8 & 7.4 & 19 & 11. & 4.0 \\
\hline 2093_Ver & 0.00 & -75.15 & -40.50 & 4137 & 13.5 & 16.1 & 11.1 & 13.5 & 13.5 & 5.0 & 928 & 1310 & 12.1 & 13.5 & 33.4 & 33.8 & 0.6 & 0.9 & 3.7 & 7.4 & 18 & 10 & 4.0 \\
\hline 2094_Ver & 0.00 & -75.17 & -39.66 & 4413 & 13.9 & 16.4 & 11.4 & 13.8 & 13.8 & 5.1 & 988 & 1370 & 12.4 & 13.8 & 33.5 & 33.8 & 0.7 & 0.9 & 3.9 & 8.1 & 14 & 13 & 3.9 \\
\hline 2095_Ver & 0.00 & -75.19 & -39.66 & 4307 & 13.9 & 16.5 & 11.4 & 13.8 & 13.8 & 5.1 & 982 & 1370 & 12.4 & 13.8 & 33.5 & 33.8 & 0.7 & 0.9 & 3.9 & 8.0 & 14 & 13 & 3.9 \\
\hline 2096_Ver & 0.00 & -75.25 & -39.67 & 4219 & 13.9 & 16.5 & 11.4 & 13.8 & 13.8 & 5.1 & 962 & 1365 & 12.4 & 13.9 & 33.5 & 33.8 & 0.7 & 0.9 & 3.9 & 8.0 & 14 & 13 & 3.9 \\
\hline 2097_Ver & 0.00 & -74.98 & -39.75 & 4338 & 13.8 & 16.4 & 11.3 & 13.8 & 13.8 & 5.1 & 1060 & 1483 & 12.3 & 13.8 & 33.5 & 33.8 & 0.7 & 0.9 & 3.9 & 8.1 & 13 & 12 & 3.9 \\
\hline 2098_Ver & 0.00 & -74.65 & -36.90 & 4787 & 14.4 & 16.5 & 12.3 & 14.4 & 14.3 & 4.2 & 1181 & 1767 & 12.7 & 14.2 & 33.7 & 33.9 & 0.7 & 1.0 & 3.0 & 11.1 & 15 & 28 & 3.8 \\
\hline 2099_Ver & 0.0 & -74.42 & -36.85 & 4608 & 14.3 & 16.4 & 12.3 & 14.3 & 14.3 & 4.1 & 1248 & 1887 & 12.5 & 14.1 & 33.7 & 33.9 & 0.7 & 1.1 & 3.1 & 11.8 & 15 & 27. & 3.8 \\
\hline 2100_Ver & 0.0 & -74.49 & -36.87 & 4727 & 14.3 & 16.4 & 12.3 & 14.3 & 14.3 & 4.1 & 1225 & 1851 & 12.6 & 14.1 & 33.7 & 33.9 & 0.7 & 1.1 & 3.1 & 11.6 & 15 & 27 & 3.8 \\
\hline 2101_Ver & 0 & -72.70 & -32.52 & 5994 & 15.3 & 17.6 & 13.7 & 15.1 & 15.2 & 4.0 & 1097 & 1682 & 13.2 & 15.2 & 34.2 & 34.2 & 0.6 & 0.8 & 4.6 & 5.8 & 27 & 28 & 3.6 \\
\hline 102_Ver & 0.00 & -72.50 & -33.01 & 4024 & 15.2 & 17.3 & 13.5 & 15.0 & 15.0 & 3.8 & 1217 & 2008 & 13.1 & 15.1 & 34.2 & 34.2 & 0.7 & 0.9 & 4.6 & 7.1 & 26 & 29 & 3.6 \\
\hline 2103_Ver & 0.00 & -76.96 & -50.65 & 3964 & 8.9 & 10.8 & 6.9 & 9.4 & 8.4 & 3.8 & 425 & 894 & 8.7 & 8.7 & 33.5 & 33.8 & 1.1 & 1.1 & 10.8 & 11.1 & 11 & 10 & 4.5 \\
\hline 2104_Ver & 0.00 & -76.60 & -46.88 & 3298 & 10.7 & 13.0 & 8.4 & 10.9 & 10.4 & 4.6 & 813 & 1826 & 10.1 & 10.7 & 33.4 & 33.7 & 0.9 & 0.9 & 7.8 & 10.5 & 15 & 9 & 4.2 \\
\hline 2105_Ver & 0.00 & -76.67 & -46.35 & 3014 & 10.9 & 13.3 & 8.6 & 11.0 & 10.6 & 4.7 & 813 & 1875 & 10.2 & 10.9 & 33.4 & 33.7 & 0.9 & 0.8 & 7.0 & 10.2 & 17 & 7 & 4.1 \\
\hline 2106_Ver & 0.00 & -76.54 & -46.32 & 2879 & 10.9 & 13.3 & 8.6 & 11.0 & 10.6 & 4.7 & 853 & 1863 & 10.2 & 10.9 & 33.4 & 33.7 & 0.9 & 0.8 & 6.9 & 10.2 & 16 & 7 & 4.1 \\
\hline 2107_Ver & 0.00 & -76.25 & -43.42 & 3523 & 12.3 & 14.9 & 9.9 & 12.5 & 12.1 & 5.0 & 843 & 1572 & 11.5 & 12.3 & 33.3 & 33.7 & 0.6 & 0.8 & 4.5 & 8.2 & 18 & 5 & 4.0 \\
\hline 2108_Ver & 0.00 & -76.48 & -43.54 & 3471 & 12.3 & 14.9 & 9.9 & 12.5 & 12.1 & 5.0 & 834 & 1671 & 11.4 & 12.3 & 33.3 & 33.7 & 0.6 & 0.8 & 4.7 & 8.3 & 18 & 5 & 4.0 \\
\hline 2109_Ver & 0.00 & -74.47 & -39.97 & 1055 & 13.7 & 16.2 & 11.2 & 13.6 & 13.7 & 5.0 & 1418 & 2143 & 12.2 & 13.6 & 33.5 & 33.8 & 0.7 & 0.9 & 3.8 & 7.8 & 13 & 10 & 3.9 \\
\hline 2110_Ver & 0.00 & -74.12 & -40.01 & 430 & 13.6 & 16.2 & 11.2 & 13.5 & 13.6 & 4.9 & 1810 & 2796 & 12.1 & 13.6 & 33.4 & 33.8 & 0.7 & 0.9 & 3.7 & 7.7 & 12 & 9 & 4.0 \\
\hline 2111_Ver & 0.00 & -75.92 & -40.48 & 3850 & 13.6 & 16.3 & 11.1 & 13.7 & 13.4 & 5.2 & 723 & 1171 & 12.3 & 13.6 & 33.5 & 33.8 & 0.6 & 0.8 & 4.0 & 7.5 & 21 & 12 & 4.0 \\
\hline 2112_Ver & 0.00 & -75.75 & -37.85 & 4051 & 14.5 & 17.1 & 12.1 & 14.6 & 14.4 & 5.0 & 873 & 1307 & 13.0 & 14.5 & 33.7 & 33.9 & 0.7 & 0.8 & 3.0 & 8.5 & 16 & 29 & 3.9 \\
\hline 2113_Ver & 0.00 & -75.43 & -37.67 & 3946 & 14.5 & 17.0 & 12.1 & 14.5 & 14.4 & 4.9 & 969 & 1358 & 12.9 & 14.4 & 33.7 & 33.9 & 0.7 & 0.8 & 2.8 & 9.2 & 15 & 29 & 3.9 \\
\hline 2114_Ver & 0.00 & -73.45 & -36.53 & 133 & 13.7 & 15.5 & 12.2 & 13.7 & 13.9 & 3.3 & 2549 & 4875 & 11.9 & 13.5 & 33.7 & 34.0 & 0.8 & 1.5 & 3.8 & 15.4 & 14 & 23 & 3.7 \\
\hline 2115_Ver & 0.00 & -73.57 & -36.17 & 510 & 14.0 & 15.8 & 12.3 & 14.0 & 14.0 & 3.5 & 1861 & 3372 & 12.2 & 13.8 & 33.7 & 34.0 & 0.7 & 1.3 & 3.5 & 13.8 & 14 & 23 & 3.6 \\
\hline 2116_Ver & 0.00 & -73.68 & -36.17 & 1028 & 14.0 & 15.9 & 12.3 & 14.1 & 14.1 & 3.5 & 1704 & 2972 & 12.2 & 13.8 & 33.7 & 34.0 & 0.7 & 1.3 & 3.5 & 13.6 & 14 & 23 & 3.6 \\
\hline 2117_Ver & 0.00 & -73.01 & -35.76 & 172 & 13.9 & 15.7 & 12.4 & 14.1 & 13.9 & 3.3 & 2006 & 3900 & 12.2 & 13.8 & 33.9 & 34.0 & 0.7 & 1.4 & 3.4 & 13.3 & 12 & 17 & 3.5 \\
\hline 2118_Ver & 0.00 & -73.53 & -33.28 & 3852 & 15.2 & 17.3 & 13.5 & 15.1 & 15.0 & 3.7 & 1064 & 1377 & 13.3 & 15.1 & 34.1 & 34.2 & 0.6 & 1.0 & 3.9 & 7.5 & 26 & 32 & 3.7 \\
\hline 2119_Lau & 0.00 & -46.43 & -26.67 & 951 & 23.3 & 25.9 & 20.9 & 23.4 & 22.9 & 5.0 & 412 & 544 & 20.9 & 23.2 & 35.7 & 36.2 & 0.2 & 0.4 & 1.4 & 2.6 & 12 & 16 & 5.2 \\
\hline 2120_Lau & 0.00 & -47.17 & -29.08 & 1850 & 22.6 & 25.5 & 20.0 & 22.9 & 22.0 & 5.5 & 422 & 645 & 21.8 & 22.6 & 36.0 & 36.4 & 0.2 & 0.2 & 1.2 & 1.1 & 18 & 30 & 5.2 \\
\hline 2121_Lau & 0.00 & -47.30 & -2 & 1642 & 22.9 & 25.7 & 20.2 & 23.1 & 22.2 & 5.5 & 467 & 705 & 22.1 & 22.9 & 36.1 & 36.4 & 0.1 & 0.2 & 1.1 & 1.2 & 18 & 29 & 5.2 \\
\hline 2122_Lau & 0 & & & 1519 & 22.9 & 25.8 & 20.2 & 23.2 & 22.4 & 5.5 & 491 & 721 & 22.2 & 23.0 & 36.0 & 36.4 & 0.1 & 0.2 & 1.1 & 1.2 & 17 & 29 & 5.2 \\
\hline 2123_Lau & 0 & & & 2165 & 22.4 & 25. & 19.8 & 22.7 & 21. & 5.5 & 381 & 511 & 21.7 & 22.4 & 36.1 & 36.4 & 0.2 & 0.2 & 1.2 & 1.0 & 21 & 34 & 5.3 \\
\hline 2124_Lau & 0 & & & 2714 & 22.0 & 24 & 19.6 & 22.3 & 21.2 & ? & 38 & 551 & 21.3 & 22.0 & 36.1 & 36 & 0.2 & & 1.0 & 0.9 & 27 & 41. & 5.3 \\
\hline 2125_Lau & 0 & & & 2991 & 21.9 & 24 & 19. & 22.2 & 21.0 & 5.2 & 397 & 559 & 21.2 & 21.9 & 36.2 & 36.4 & 0.1 & 0.2 & 0.9 & 0.8 & 30 & 44 & 5.3 \\
\hline 2126_Lau & 0.00 & -45.67 & -31.80 & 3592 & 21.3 & 24.0 & 19.1 & 21.6 & 20.2 & 4.9 & 425 & 596 & 20.5 & 21.2 & 36.2 & 36.3 & 0.1 & 0.1 & 0.7 & 0.6 & 41 & 58 & 5.3 \\
\hline 2127_Lau & 0.00 & -48.15 & -31.75 & 2627 & 21.4 & 24.5 & 18.7 & 21.5 & 20.7 & 5.8 & 435 & 595 & 20.8 & 21.4 & 35.6 & 36.2 & 0.2 & 0.2 & 1.0 & 1.1 & 20 & 21. & 5.3 \\
\hline 2128_Lau & 0.00 & -48.82 & -31.52 & 1925 & 21.4 & 24.7 & 18.4 & 21.4 & 20.9 & 6.2 & 475 & 702 & 20.8 & 21.3 & 35.2 & 36.2 & 0.3 & 0.2 & 1.1 & 1.4 & 16 & 18 & 5.2 \\
\hline 2129_Lau & 0.00 & -50.25 & -32.50 & 1099 & 20.4 & 24.3 & 16.9 & 20.1 & 20.4 & 7.4 & 797 & 1387 & 20.9 & 20.3 & 33.9 & 36.1 & 0.4 & 0.3 & 1.2 & 1.3 & 12 & 11. & 5.1 \\
\hline 2130_Lau & 0.00 & -50.12 & -32.68 & 1348 & 20.5 & 24.2 & 17.0 & 20.2 & 20.3 & 7.2 & 665 & 1086 & 20.8 & 20.3 & 34.0 & 36.1 & 0.4 & 0.3 & 1.1 & 1.2 & 13 & 11. & 5.2 \\
\hline 2131_Lau & 0.00 & -49.57 & -33.17 & 2281 & 20.3 & 23.8 & 17.2 & 20.3 & 20.0 & 6.5 & 485 & 705 & 20.0 & 20.2 & 34.8 & 35.9 & 0.3 & 0.3 & 1.0 & 1.2 & 17 & 13 & 5.2 \\
\hline 2132_Lau & 0.00 & -51.45 & -34.53 & 1889 & 18.9 & 23.0 & 15.0 & 18.8 & 18.8 & 8.0 & 707 & 1433 & 18.1 & 18.8 & 34.1 & 35.2 & 0.4 & 0.6 & 1.6 & 2.4 & 10 & 6 & 5.1 \\
\hline 2133_Lau & 0.00 & -51.23 & -34.62 & 2142 & 19.0 & 23.0 & 15.3 & 18.9 & 18.9 & 7.8 & 627 & 1187 & 18.2 & 18.9 & 34.3 & 35.3 & 0.4 & 0.5 & 1.6 & 2.3 & 11 & 7 & 5.1 \\
\hline 2134_Lau & 0.00 & -51.00 & -34.72 & 2435 & 19.2 & 23.0 & 15.5 & 19.0 & 18.9 & 7.5 & 578 & 1025 & 18.4 & 19.1 & 34.4 & 35.4 & 0.4 & 0.5 & 1.5 & 2.1 & 13 & 8 & 5.1 \\
\hline 2135_Lau & 0.00 & -50.57 & -35.18 & 3230 & 19.0 & 22.6 & 15.8 & 19.0 & 18.7 & 6.8 & 546 & 878 & 18.2 & 19.0 & 34.9 & 35.5 & 0.3 & 0.4 & 1.5 & 2.0 & 17 & 10 & 5.1 \\
\hline 2136_Lau & 0.00 & -49.38 & -33.35 & 2605 & 20.3 & 23.7 & 17.4 & 20.3 & 19.9 & 6.3 & 475 & 701 & 19.9 & 20.3 & 35.0 & 36.0 & 0.3 & 0.3 & 1.0 & 1.1 & 18 & 13 & 5.2 \\
\hline 2137_Lau & 0.00 & -49.22 & -33.55 & 2867 & 20.4 & 23.6 & 17.5 & 20.4 & 19.8 & 6.2 & 484 & 725 & 19.9 & 20.3 & 35.1 & 36.0 & 0.3 & 0.3 & 1.0 & 1.1 & 19 & 14 & 5.2 \\
\hline 2138_Lau & 0.00 & -49.22 & -33.55 & 2867 & 20.4 & 23.6 & 17.5 & 20.4 & 19.8 & 6.2 & ....... & 725 & 19.9 & 20.3 & 35.1 & 36.0 & 0.3 & 0.3 & 1.0 & 1.1 & 19 & 14. & 5.2 \\
\hline 2139_Lau & 0.00 & -49.68 & -35.73 & 4152 & 19.3 & 22.4 & 16.4 & 19.3 & 18.7 & 6.0 & 591 & 993 & 18.5 & 19.2 & 35.4 & 35.7 & 0.3 & 0.3 & 1.2 & 1.4 & 27 & 14. & 5.1 \\
\hline 2140_Lau & 0.00 & -50.22 & -35.40 & 3673 & 19.2 & 22.6 & 16.1 & 19.2 & 18.7 & 6.4 & 557 & 871 & 18.4 & 19.1 & 35.1 & 35.6 & 0.3 & 0.3 & 1.4 & 1.7 & 19 & 11. & 5.1. \\
\hline 2141_Lau & 0.00 & -48.42 & -34.32 & 4000 & 20.0 & 23.0 & 17.6 & 20.2 & 19.3 & 5.4 & 514. & 787 & 19.4 & ...... & 35.7 & 36.0 & 0.2 & 0.2 & 0.8 & 0.9 & 34 & 19 & 5.2 \\
\hline 2142_Lau & 0.00 & -47.90 & -37.15 & 4962 & 18.4 & 21.3 & 16.1 & 18.7 & 17.6 & 5.1 & 635 & 959 & 17.6 & 18.3 & 35.6 & 35.7 & 0.2 & 0.2 & 1.2 & 1.7 & 51 & 32 & 5.2 \\
\hline 2143_Lau & 0.00 & -46.38 & -38.20 & 5034 & 17.4 & 20.3 & 15.0 & 17.7 & 16.5 & 5.2 & 630 & 1060 & 16.4 & 17.3 & 35.4 & 35.5 & 0.3 & 0.3 & 1.8 & 2.8 & 47 & 31 & 5.2 \\
\hline 2144_Lau & 0.00 & -52.65 & -37.20 & 3054 & 16.7 & 20.7 & 13.2 & 16.5 & 16.4 & 7.5 & 836 & 1559 & 14.6 & 16.5 & 34.4 & 34.9 & 0.5 & 0.7 & 3.1 & 5.9 & 12 & 7 & 5.1 \\
\hline 2145_Lau & 0.00 & -51.68 & -37.90 & 4245 & 17.1 & 20.7 & 14.1 & 16.8 & 16.5 & 6.6 & 743 & 1345 & 15.6 & 17.0 & 35.0 & 35.2 & 0.4 & 0.5 & 2.8 & 4.5 & 26 & 13 & 5.1 \\
\hline
\end{tabular}




\begin{tabular}{|c|c|c|c|c|c|c|c|c|c|c|c|c|c|c|c|c|c|c|c|c|c|c|c|}
\hline $\begin{array}{l}\stackrel{\Xi}{\Xi} \\
\text { Ż } \\
\end{array}$ & 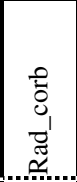 & . & . & 둥 & 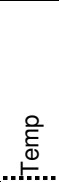 & 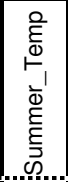 & 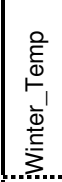 & 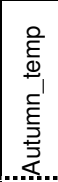 & 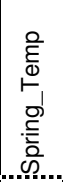 & 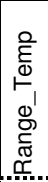 & . & 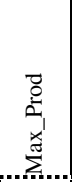 & 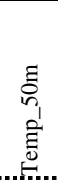 & 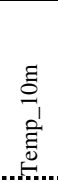 & 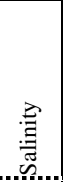 & 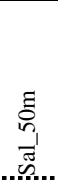 & $\mid$\begin{tabular}{c|}
$\frac{0}{\tilde{J}}$ \\
$\frac{\pi}{2}$ \\
0 \\
0 \\
$\frac{0}{\pi}$ \\
\end{tabular} & 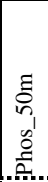 & 节 & 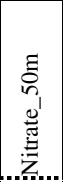 & . & 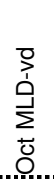 & 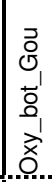 \\
\hline 2146_Lau & 0.00 & -53.02 & -36.98 & 2376 & 16.6 & 20.9 & 12.8 & 16.4 & 16.4 & 8.0 & 1004 & 1917 & 14.3 & 16.4 & 34.0 & 34.7 & 0.5 & 0.7 & 3.0 & 6.4 & 8 & 5 & 5.2 \\
\hline 2147_Lau & 0.00 & -53.13 & -36.90 & 2140 & 16.7 & 21.0 & 12.8 & 16.4 & 16.4 & 8.2 & 1085 & 2087 & 14.2 & 16.4 & 33.8 & 34.6 & 0.5 & 0.8 & 3.0 & 6.5 & 7 & 5 & 5.2 \\
\hline 2148_Lau & 0.00 & -53.83 & -39.40 & 3294 & 14.2 & 18.3 & 10.9 & 13.8 & 13.7 & 7.3 & 1207 & 2143 & 11.8 & 14.0 & 34.4 & 34.6 & 0.6 & 0.8 & 5.8 & 9.9 & 20 & 15 & 5.1 \\
\hline 2149_Lau & 0.00 & -53.97 & -39.30 & 2985 & 14.0 & 18.2 & 10.8 & 13.8 & 13.6 & 7.4 & 1249 & 2331 & 11.6 & 13.9 & 34.4 & 34.5 & 0.6 & 0.9 & 5.8 & 10.2 & 18 & 14 & 5.2 \\
\hline 2150_Lau & 0.00 & -54.15 & -39.17 & 2641 & 14.0 & 18.3 & 10.6 & 13.7 & 13.6 & 7.6 & 1275 & 2493 & 11.4 & 13.8 & 34.3 & 34.5 & 0.6 & 0.9 & 5.8 & 10.5 & 16 & 12 & 5.2 \\
\hline 2151_Lau & 0.00 & -54.32 & -39.05 & 2351 & 14.0 & 18.3 & 10.5 & 13.7 & 13.6 & 7.8 & 1313 & 2537 & 11.2 & 13.8 & 34.2 & 34.4 & 0.6 & 0.9 & 5.6 & 10.7 & 15 & 12 & 5.2 \\
\hline 2152_Lau & 0.00 & -54.63 & -38.82 & 1844 & 14.0 & 18.4 & 10.3 & 13.7 & 13.6 & 8.1 & 1408 & 2794 & 10.9 & 13.8 & 33.9 & 34.3 & 0.6 & 1.0 & 5.3 & 11.0 & 11 & 8 & 5.3 \\
\hline 2153_Lau & 0.00 & -55.25 & -38.35 & 1089 & 13.7 & 18.4 & 9.7 & 13.4 & 13.4 & 8.7 & 1703 & 3285 & 10.1 & 13.4 & 33.6 & 34.1 & 0.7 & 1.1 & 5.3 & 12.2 & 7 & 6 & 5.5 \\
\hline 2154_Lau & 0.00 & -54.60 & -40.08 & 2937 & 13.1 & 17.4 & 9.8 & 12.9 & 12.6 & 7.6 & 1058 & 2529 & 10.4 & 12.9 & 34.3 & 34.4 & 0.7 & 1.0 & 6.9 & 11.8 & 23 & 19 & 5.2 \\
\hline 2155_Lau & 0.00 & -57.55 & -46.15 & 3733 & 8.9 & 12.5 & 6.1 & 8.8 & 8.5 & 6.4 & 849 & 2005 & 7.3 & 8.8 & 34.1 & 34.1 & 1.0 & 1.2 & 12.3 & 15.7 & 41 & 47 & 5.1 \\
\hline 2156_Lau & 0.00 & -58.52 & -46.08 & 2735 & 8.8 & 12.5 & 6.0 & 8.6 & 8.5 & 6.5 & 697 & 1523 & 6.9 & 8.7 & 34.0 & 34.1 & 1.0 & 1.3 & 12.1 & 16.5 & 40 & 44 & 5.1 \\
\hline 2157_Lau & 0.00 & -57.85 & -46.15 & 3439 & 8.8 & 12.4 & 6.0 & 8.7 & 8.5 & 6.4 & 804 & 1796 & 7.1 & 8.7 & 34.1 & 34.1 & 1.0 & 1.2 & 12.3 & 16.0 & 41 & 46 & 5.1 \\
\hline 2158_Lau & 0.00 & -57.77 & -44.85 & 3542 & 9.6 & 13.6 & 6.5 & 9.4 & 9.2 & 7.1 & 935 & 2379 & 7.5 & 9.5 & 34.1 & 34.1 & 0.9 & 1.2 & 11.5 & 15.3 & 5 & 39 & 1 \\
\hline 2159_Lau & 0.00 & -58.38 & -45.15 & 2921 & 9.3 & 13.2 & 6.2 & 9.0 & 8.9 & 7.0 & 804 & 2152 & 7.1 & 9.1 & 34.0 & 34.1 & 1.0 & 1.2 & 11.7 & 16.2 & 36 & 41 & 1 \\
\hline 2160_Lau & 0.00 & -58.10 & -44.92 & 3191 & 9.5 & 13.5 & 6.4 & 9.3 & 9.1 & 7.1 & 906 & 2478 & 7.4 & 9.4 & 34.0 & 34.1 & 0.9 & 1.2 & 11.5 & 15.6 & 35 & 40 & 5.1 \\
\hline 2161_Lau & 0.00 & -57.17 & -44.45 & 4109 & 9.9 & 13.9 & 6.7 & 9.7 & 9.4 & 72 & 977 & 5554 & 7.9 & 9.7 & 341 & 342 & 0.9 & 1.1 & 14 & 14.8 & $=$ & 38 & 5.1 \\
\hline
\end{tabular}


STM counts. ( ) denotes cel contents

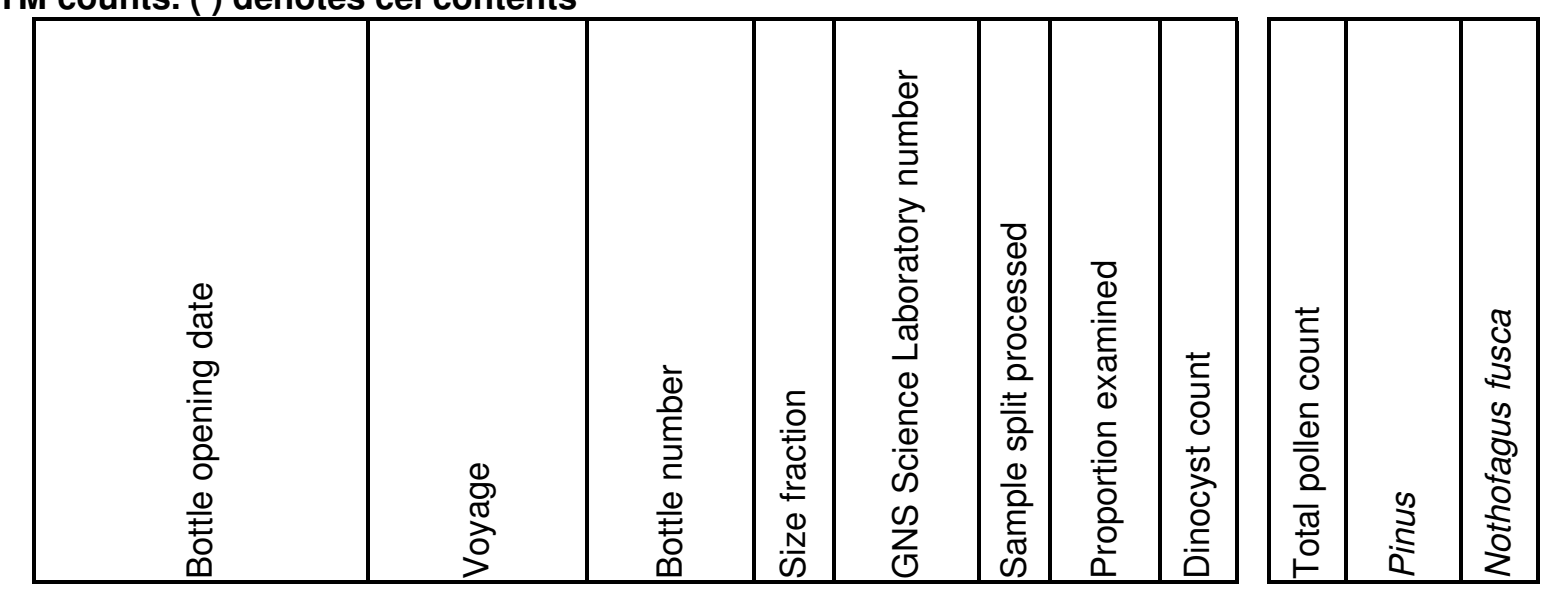

\begin{tabular}{|c|c|c|c|c|c|c|c|c|c|c|c|}
\hline & 3 May 2005 & May-Oct05 & NBM\#1 & $\begin{array}{l}>40 \\
<40\end{array}$ & $\begin{array}{l}R D 3490 \\
25546\end{array}$ & $\begin{array}{l}4 \% \\
4 \%\end{array}$ & $19 \%$ & 0 & 0 & 13 & \\
\hline & 25 May 2005 & "May-Öct05" & NBM\#4" & $>40$ & RD3497 & $4 \%$ & $14 \%$ & 0 & 0 & & \\
\hline & & & & $<40$ & L25553 & $4 \%$ & $50 \%$ & 0 & 3 & 0.5 & \\
\hline & 16 June 2005 & May-Öct05 & NBM\#7" & $>40$ & RD3491 & $4 \%$ & $24 \%$ & 0 & 1 & & \\
\hline & & & & $<40$ & $\mathrm{~L} 25547$ & $4 \%$ & $67 \%$ & 0 & 18 & 7.5 & \\
\hline & 8 July 2005 & May-Oct05 & NBM\#10 & $>40$ & RD3499 & $4 \%$ & $100 \%$ & 0 & 0 & & \\
\hline & & & & $<40$ & L25555 & $4 \%$ & $50 \%$ & 0 & 1 & & \\
\hline & 29 July 2005 & May-Oct05 & NBM\#13 & $>40$ & RD3500 & $4 \%$ & $24 \%$ & 0 & 0 & & \\
\hline & & & & $<40$ & L25556 & $4 \%$ & $100 \%$ & 8 & 44 & & $\cdots$ \\
\hline & 20 August 2005 & May-Oct05 & NBM\#16 & $>40$ & RD3492 & $4 \%$ & $28 \%$ & 0 & 0 & & \\
\hline & & & & $<40$ & L25548 & $4 \%$ & $70 \%$ & 8 & 59 & 32 & 2 \\
\hline & 27 August 2005 & May-Oct05 & NBMA17 & $>40$ & RD3501 & $4 \%$ & $14 \%$ & 0 & 0 & & \\
\hline & & & & $<40$ & $: 25557$ & $4 \%$ & $100 \%$ & 51 & 225 & 115 & 21 \\
\hline & 11 September 2005 & May-Oct05 & NBM\#19 & $>40$ & RD3496 & $4 \%$ & $14 \%$ & 1 & 0 & & \\
\hline & & & & $<40$ & ¿25552 & $4 \%$ & $53 \%$ & 38 & 250 & 185 & 17 \\
\hline & 3 October 2005 & Oct-Apr 06 & "NBMM" & $>40$ & i25982 & $4 \%$ & $100 \%$ & 28 & 321 & 314 & \\
\hline & & & & $<40$ & L25982 & $4 \%$ & $52 \%$ & 8 & 109 & 101 & 2 \\
\hline & 1 November 2005 & Oct -Apr 06 & NBM \#4 & $>40$ & ¿25997 & $4 \%$ & $100 \%$ & 80 & 484 & 469 & 4 \\
\hline & & & & $<40$ & L25997 & $4 \%$ & $100 \%$ & 79 & 490 & 379 & 69 \\
\hline & 1 December 2005 & Oct - Apr 06 & NBM \#7 & $>40$ & L25999 & $4 \%$ & $100 \%$ & 17 & 139 & 118 & 9 \\
\hline & & & & $<40$ & Z25999 & $4 \%$ & $100 \%$ & 13 & 225 & 155 & 32 \\
\hline & 11 December 2005 & Oct-Apro6 & NBMM \#8 & $>40$ & L26004 & $4 \%$ & $100 \%$ & 23 & 104 & 69 & 11 \\
\hline & & & & $<40$ & L26004 & $4 \%$ & $100 \%$ & 16 & 355 & 208 & 93 \\
\hline & 21 December 2005 & Oct-Apr06 & "NBM" \#9" & $>40$ & L25981 & $4 \%$ & $100 \%$ & 14 & 151 & 143 & 1 \\
\hline & & & & $<40$ & L25981 & $4 \%$ & $57 \%$ & 26 & 207 & 159 & 28 \\
\hline & 31 December 2005 & Oct-Apr06 & NBM \# 10 & $>40$ & L26000 & $4 \%$ & $100 \%$ & 15 & 71 & 64 & 2 \\
\hline & & & & $>40$ & $\mathrm{~L} 26000$ & $4 \%$ & $100 \%$ & 31 & 487 & 361 & 49 \\
\hline & 30 January 2006 & Oct-Apr06 & NBM \#13 & $>40$ & [226001 & $4 \%$ & $100 \%$ & 6 & 38 & 28 & 3 \\
\hline & & & & $<40$ & L26001 & $4 \%$ & $100 \%$ & 19 & 130 & & 62 \\
\hline & 1 March 2006 & Oct-Apr06 & NBM \#16 & $>40$ & L26003 & $4 \%$ & $100 \%$ & 4 & 19 & 18 & \\
\hline & & & & $<40$ & L26003 & $4 \%$ & $100 \%$ & 5 & 80 & 40 & 14 \\
\hline & 10 July 2006 & Jul - Jan 07 & NBM \#1 & $>40$ & L25995 & $4 \%$ & $100 \%$ & 1 & 1 & 1 & \\
\hline & & & & $<40$ & L25995 & $4 \%$ & $100 \%$ & 6 & 13 & 5 & 3 \\
\hline & 7 August 2006 & Jul-Jan 07 & NBM" \#4 & $>40$ & L25994 & $4 \%$ & $100 \%$ & 8 & 76 & 61 & 1 \\
\hline$\varepsilon$ & & & & $<40$ & L25994 & $4 \%$ & $100 \%$ & 3 & 13 & 9 & \\
\hline$=$ & 4 September 2006 & Jul -Jan 07 & NBM" \#7" & $>40$ & 125966 & $4 \%$ & $52 \%$ & 6 & 258 & 251 & \\
\hline$\frac{5}{d}$ & & & & $<40$ & Z25966 & $4 \%$ & $100 \%$ & 20 & 249 & 239 & \\
\hline$\underline{E}$ & 2 October 2006 & Jül-Jano7 & NBM"\#10 & $>40$ & L25985 & $4 \%$ & $43 \%$ & 0 & 859 & 855 & 1 \\
\hline $\bar{c}$ & & & & $<40$ & L25985 & $4 \%$ & $100 \%$ & 1 & 196 & 178 & 2 \\
\hline & 30 October 2006 & Jul-Jan07 & NBM \#13 & $>40$ & L25989 & $4 \%$ & $100 \%$ & 5 & 242 & 216 & 11 \\
\hline
\end{tabular}


STM counts. ( ) denotes cel contents

$\sum$ 28 November 2006 Jul-Jan07 NBM \#16 $>40$ L25988 $4 \%$ 14\% 443

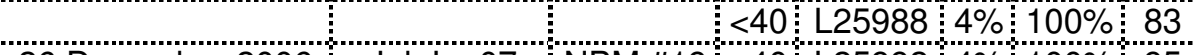
26 December 2006 Jul-Jan07 NBM \#19 >40 L25992 4\% $100 \% 95$

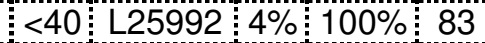
1 February 2007 Jan-Aug 07 NBM \#1 $>40$ L25987 $4 \%$ 100\% 28

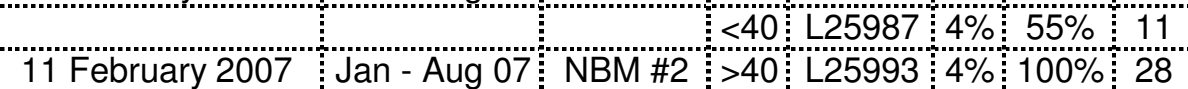
$<0 \quad 2593 \quad 4 \% 100 \% 6$
$-40 \%$ 21 February 2007 Jan-Aug 07 NBM \#3 >40 L25990 4\% $100 \% 3$

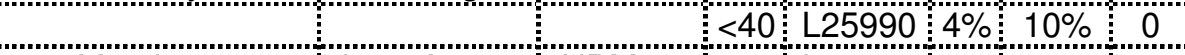
3 March 2007 Jan-Aug 07 NBM $\# 4$ >40 L25986 $4 \%$ 100\% 4

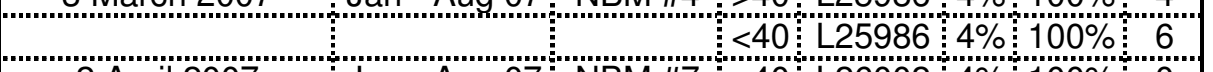

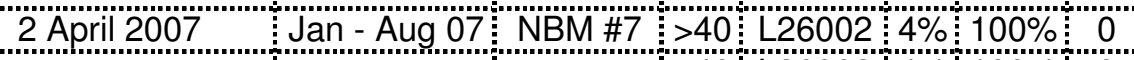
$<40 \quad[26002 \quad 4 \% \quad 100 \%: 0$ 2 May 2007 $\quad J a n-A u g$ 07 NBM \#10 $>40$ L25985 $4 \%$ 100\%

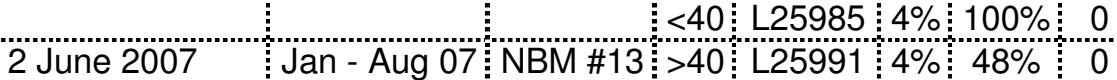

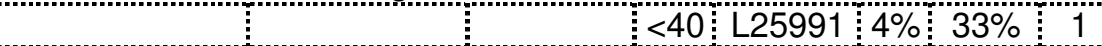

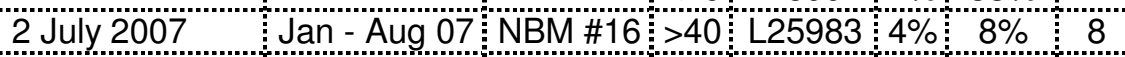
$<40 \quad[25983 \quad 4 \%, 62 \%: 19$ 1 August 2007 - Jan-Aug 07 NBM \#19 >40 L25984 $4 \%$-A00\%:

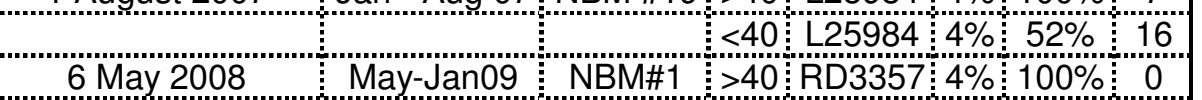

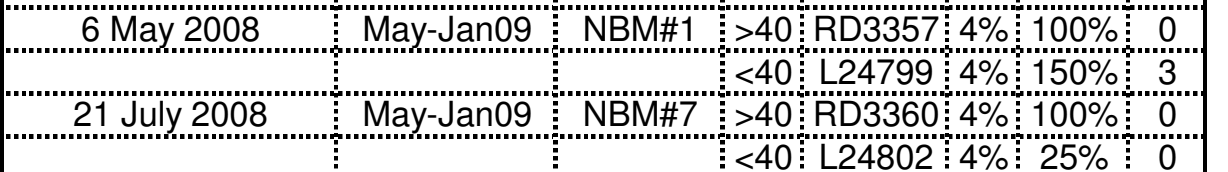

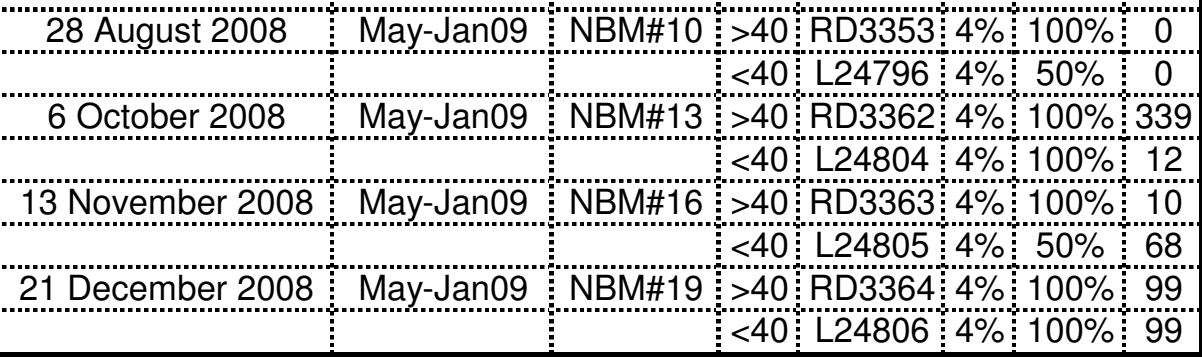

\begin{tabular}{|c|c|c|}
\hline 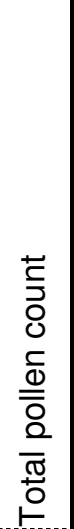 & $\underset{\Sigma}{\stackrel{5}{\Sigma}}$ & 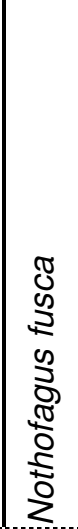 \\
\hline 289 & 232 & 24 \\
\hline 105 & 95 & \\
\hline 128 & 70 & 10 \\
\hline 111 & 91 & \\
\hline 214 & 149 & 11 \\
\hline 87 & 75 & \\
\hline 21 & 4 & 1 \\
\hline 16 & & 1 \\
\hline 15 & & 1 \\
\hline 16 & 9 & \\
\hline 1 & & \\
\hline 10 & 7 & \\
\hline 16 & 12 & \\
\hline 1 & 1 & \\
\hline 1 & 1 & \\
\hline 8 & 7 & \\
\hline 14 & 3 & 1 \\
\hline 7 & 7 & \\
\hline 8 & 7 & 1 \\
\hline 39 & 38 & \\
\hline 70 & 40 & \\
\hline 3 & 2 & \\
\hline 35 & 16 & 3 \\
\hline 1 & & \\
\hline 60 & 8.5 & 9 \\
\hline 0 & & \\
\hline 1 & 1 & \\
\hline 17 & 16 & \\
\hline 6 & 5.5 & \\
\hline 9 & & 3 \\
\hline 74 & 32 & 11 \\
\hline 2 & & 1 \\
\hline 264 & 118 & 107 \\
\hline 20 & & 6 \\
\hline 421 & 126.1 & 184 \\
\hline
\end{tabular}




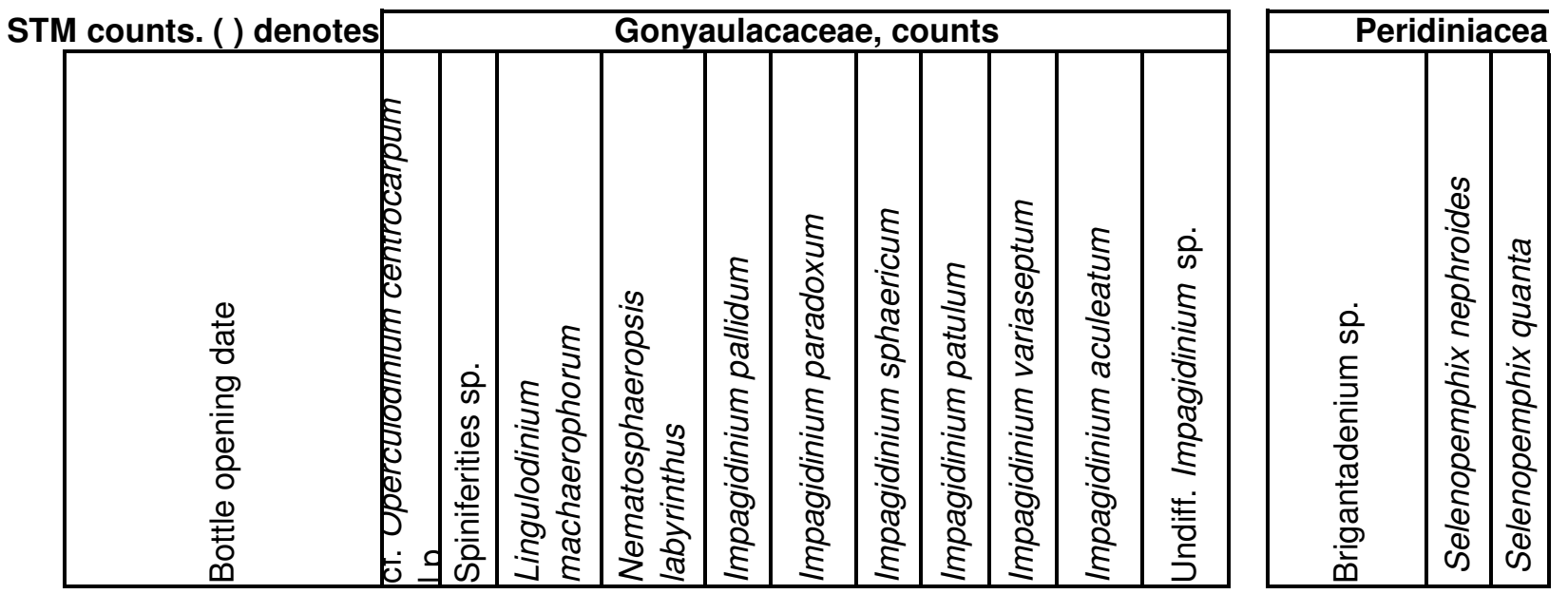

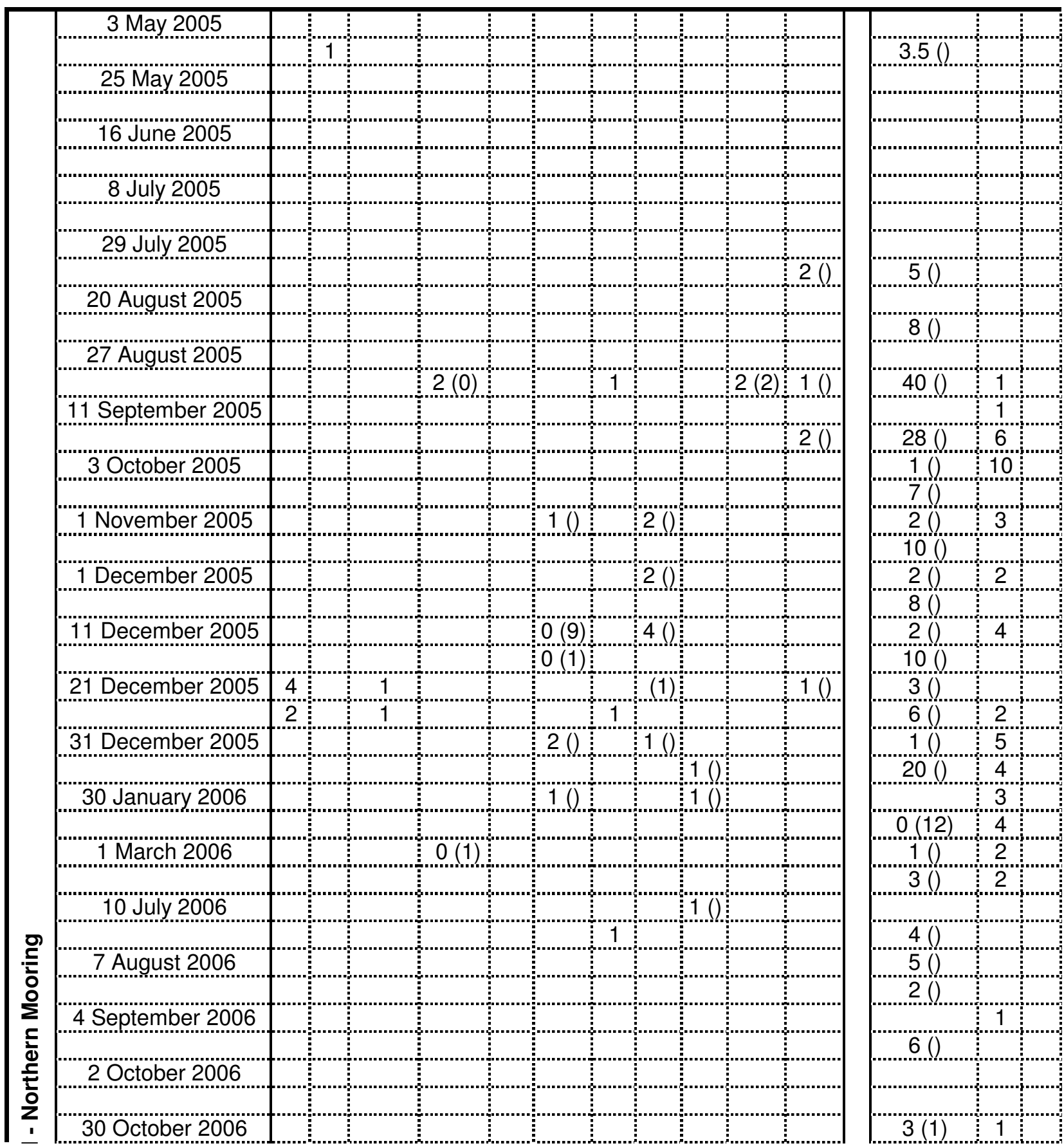




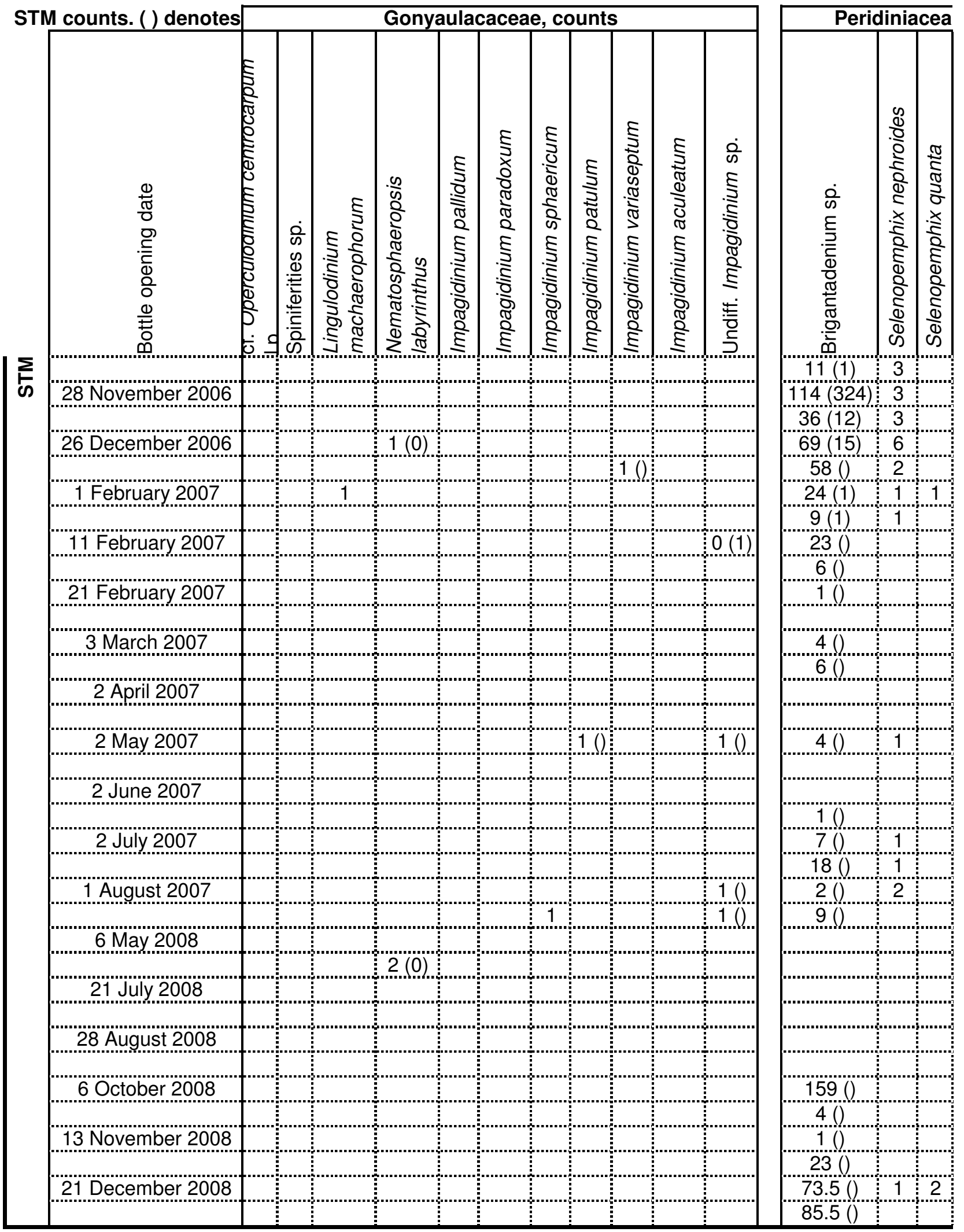


STM counts. () denotese and Polykrikaceae, counts

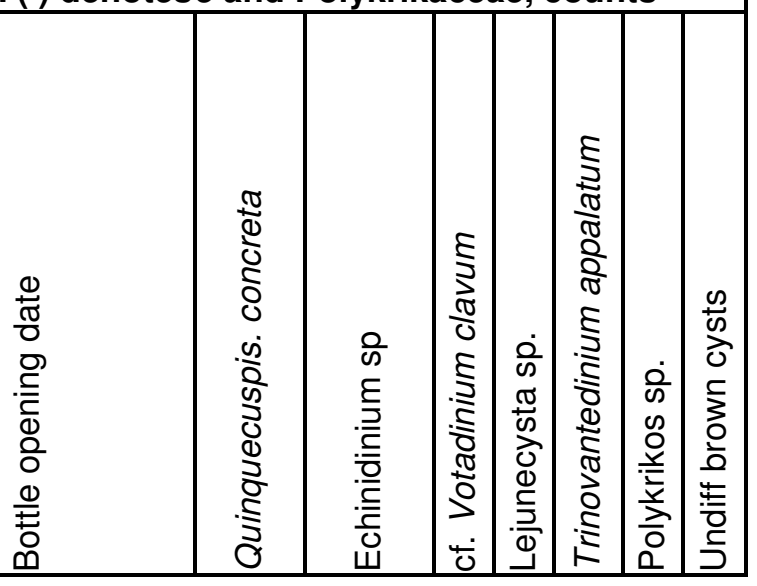

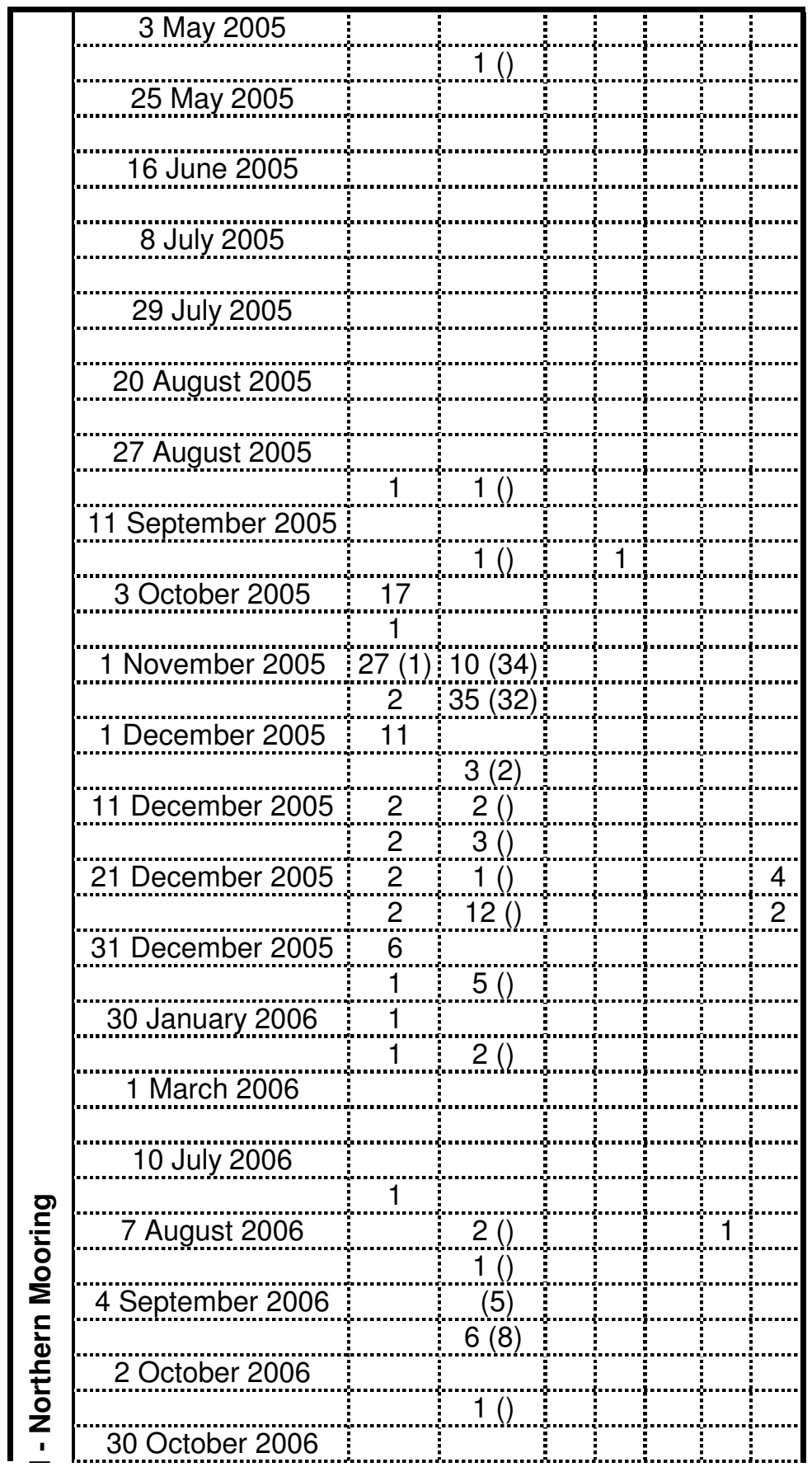




\section{STM counts. () denotese and Polykrikaceae, counts}

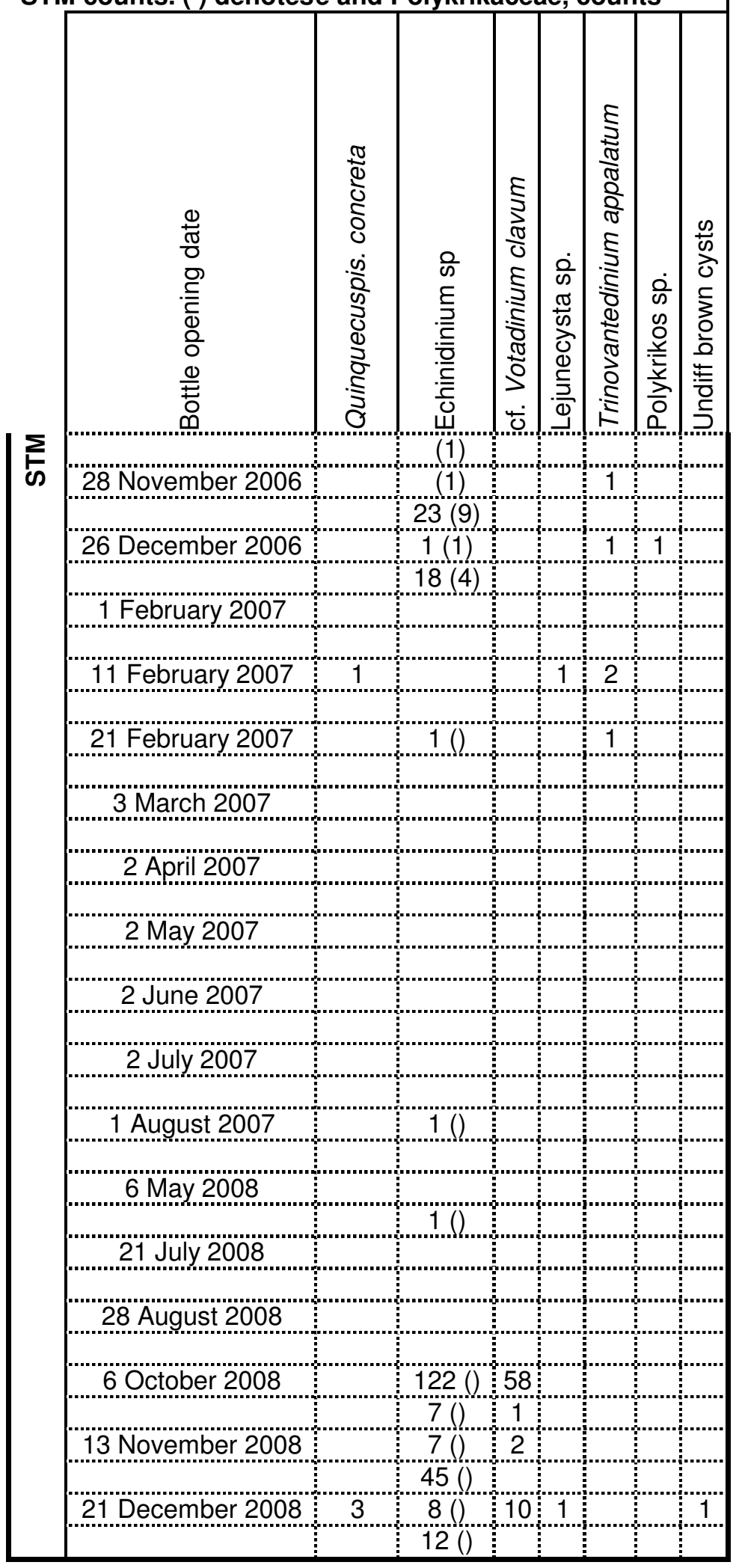


SAM counts. () denotes cel contents

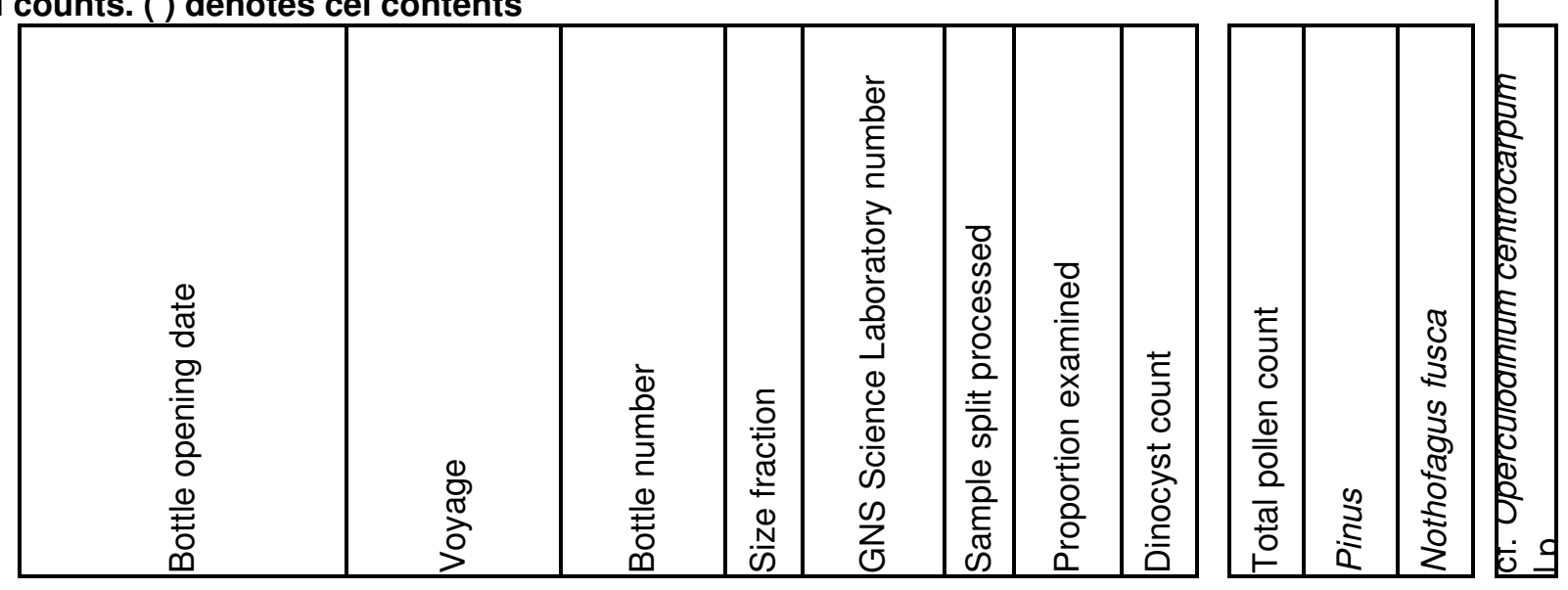

\begin{tabular}{|c|c|c|c|c|c|c|c|c|c|c|c|c|}
\hline & 10 July 2006 & Jul - Jan 07 & SBM \#1 & $>40$ & L25960 & $4 \%$ & $52 \%$ & 0 & 1 & & 1 & \\
\hline & & & & $<40$ & "L25960 & $4 \%$ & $100 \%$ & 16 & 10 & & 4 & \\
\hline & 7 August 2006 & Jül-Jan 07 & SBM \#4 & $>40$ & L25971 & $4 \%$ & $100 \%$ & 3 & 2 & 1 & & \\
\hline & & & & $<40$ & L25971 & $4 \%$ & $100 \%$ & $21 "$ & 20 & 2 & 12 & \\
\hline & 4 September 2006 & Jul-Jan 07 & SBM \#7 & $>40$ & L25968 & $4 \%$ & $100 \%$ & 5 & 48 & 34 & 6 & \\
\hline & & & & $<40$ & L25968 & $4 \%$ & $100 \%$ & 6 & 12 & 3 & 1 & \\
\hline & 13 September 2006 & Jul-Jan 07 & SBM \#8 & $>40$ & L25961 & $4 \%$ & $65 \%$ & $\ddot{8}$ & 4 & 4 & & \\
\hline & & & & $<40$ & L25961 & $4 \%$ & $55 \%$ & 13 & 10 & 5 & 2 & \\
\hline & 2 October 2006 & Jul - Jan 07 & SBM \#10 & $>40$ & L25965 & $4 \%$ & $100 \%$ & 3 & 64 & 61 & & \\
\hline & & & & $<40$ & L25965 & $4 \%$ & $100 \%$ & 1 & 69 & 57 & 2 & \\
\hline & 21 October 2006 & Jul-Jan 07 & SBM \#12 & $>40$ & L25977 & $4 \%$ & $100 \%$ & 6 & 37 & 31 & 3 & \\
\hline & & & & $<40$ & L25977 & $4 \%$ & $100 \%$ & 89 & 108 & 38 & 27 & \\
\hline & 30 October 2006 & Jul-Jan 07 & SBM $\# 13$ & $>40$ & L25975 & $4 \%$ & $100 \%$ & 1 & 14 & 5 & 1 & \\
\hline & & & & $<40$ & L25975 & $4 \%$ & $100 \%$ & 97 & 82 & 24 & 27 & \\
\hline & 18 Noven & Jul-Jan 07 & SBM \#15 & $>40$ & $\mathrm{~L} 25966$ & $4 \%$ & $43 \%$ & 3 & 3 & 3 & & \\
\hline & & & & $<40$ & L25966 & $4 \%$ & $52 \%$ & 30 & 10 & 7 & & \\
\hline & 26 December 2006 & Jul-Jan 07 & SBM \#19 & $>40$ & "L25970 & $4 \%$ & $90 \%$ & 4 & $" 7$ & 5 & & \\
\hline & & & & $<40$ & L25970 & $4 \%$ & $100 \%$ & 101 & 48 & 16 & 9 & \\
\hline & 1 February 2007 & Jan - Aug 07 & SBM\#1 & $>40$ & L25969 & $4 \%$ & $100 \%$ & 2 & 8 & 6 & & \\
\hline & & & & $<40$ & L25969 & $4 \%$ & $100 \%$ & 70 & 48 & 2 & 11 & \\
\hline & 3 March 2007 & Jan - Aug 07 & SBM \#4 & $>40$ & L25963 & $4 \%$ & $100 \%$ & 5 & 7 & 6 & & \\
\hline & & & & $<40$ & $\mathrm{~L} 25963$ & $4 \%$ & $100 \%$ & 138 & 13 & & 1 & \\
\hline & 2 April 2007 & Jan - Aug 07 & SBM\#7 & $>40$ & L25964 & $4 \%$ & $100 \%$ & 6 & 37 & 28 & & \\
\hline & & & & $<40$ & L25964 & $4 \%$ & $100 \%$ & 7 & 11 & 7 & & \\
\hline & 2 May 2007 & Jan - Aug 07 & SBM \#10 & $>40$ & L25976 & $4 \%$ & $100 \%$ & 2 & 13 & 9 & 1 & \\
\hline & & & & $<40$ & L25976 & $4 \%$ & $100 \%$ & 86 & 21 & 7 & 4 & \\
\hline & 13 May 2007 & Jan-Aug 07 & SBM 11 & $>40$ & L25967 & $4 \%$ & $52 \%$ & 12 & 15 & 6 & & \\
\hline & & & & $<40$ & L25967 & $4 \%$ & $100 \%$ & 217 & 17 & 11 & & \\
\hline & 2 June 2007 & Jan-Aug 07 & SBM \#13 & $>40$ & L25978 & $4 \%$ & $100 \%$ & 3 & 5 & 3 & & \\
\hline & & & & $<40$ & L25978 & $4 \%$ & $100 \%$ & 62 & 22 & 10 & 2 & \\
\hline & 2 July 2007 & Jan-Aug 07 & SBM \#16 & $>40$ & L25962 & $4 \%$ & $100 \%$ & 8 & 0 & & & \\
\hline & & & & $<40$ & L25962 & $4 \%$ & $100 \%$ & 167 & 4 & & & \\
\hline & 1 August 2007 & Jan - Aug 07 & SBM \#19 & $>40$ & L25973 & $4 \%$ & $76 \%$ & 1 & 0 & & & \\
\hline & & & & $<40$ & L25973 & $4 \%$ & $100 \%$ & 45 & 17 & 8 & 4 & \\
\hline ఏ & 22 August 2007 & Jan-Aug 07 & SBM \#21 & $>40$ & L25980 & $4 \%$ & $100 \%$ & 7 & 8 & 5 & & \\
\hline 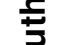 & & & & $>40$ & $\mathrm{~L} 25980$ & $4 \%$ & $100 \%$ & 11 & 0 & & & \\
\hline 웅 & 7 October 2007 & Sept-Apr08 & SBM\#4 & $>40$ & RD3358 & $4 \%$ & $100 \%$ & 6 & 0 & & & \\
\hline 1 & & & & $<40$ & L24800 & $4 \%$ & $100 \%$ & 47 & 29 & 13 & 5 & \\
\hline$\Sigma$ & 11 November 2007 & Sept-Apr08 & SBM\#7 & $>40$ & RD3351 & $4 \%$ & $100 \%$ & 29 & 0 & & & \\
\hline & & & & $<40$ & L42795 & $4 \%$ & $100 \%$ & 42 & 20 & 2 & 8 & \\
\hline & 15 December 2007 & Sept-Apro8 & SBM\#\#10 & $>40$ & RD3361 & $4 \%$ & $100 \%$ & 78 & 4 & & & \\
\hline
\end{tabular}


SAM counts. () denotes cel contents

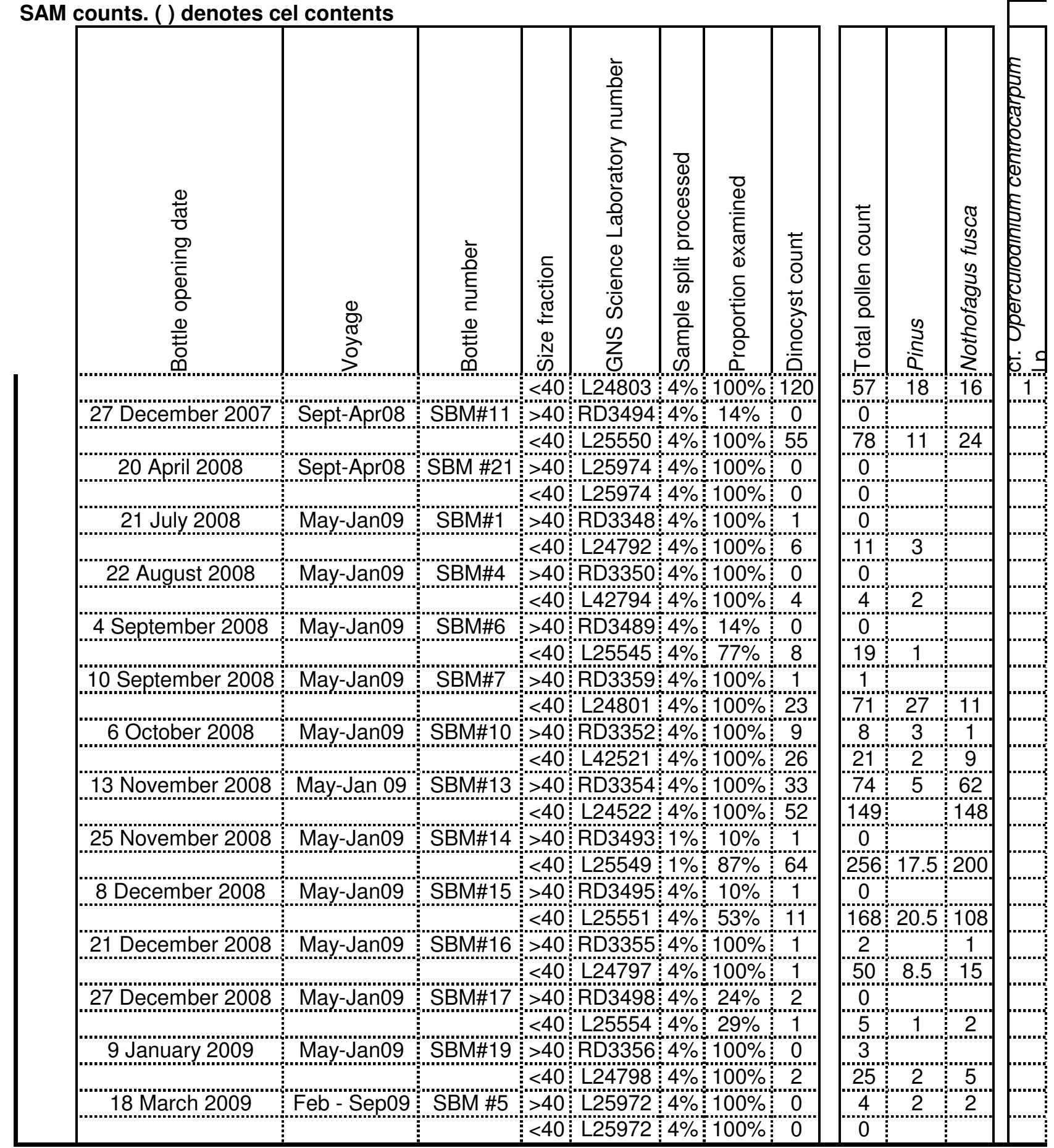


SAM counts. ( ) denotes ci

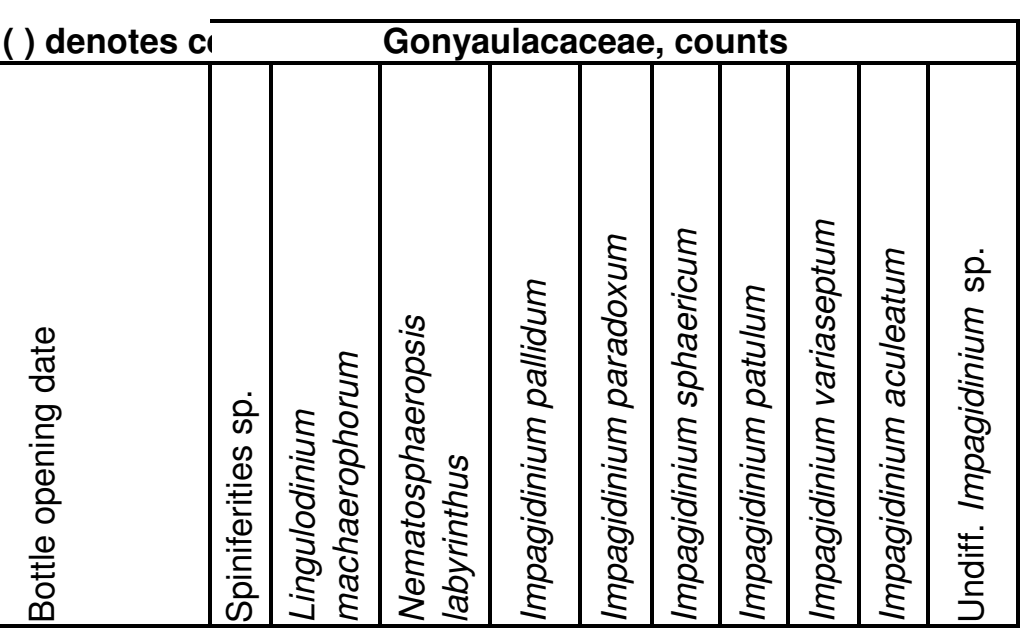

10 July 2006

7 August 2006

\section{September 2006}

13 September 2006

2 October 2006

21 October 2006

30 October 2006

18 November 2006

26 December 2006

1 February 2007

3 March 2007

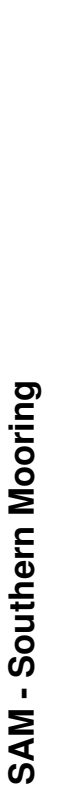

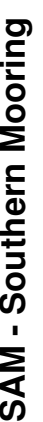

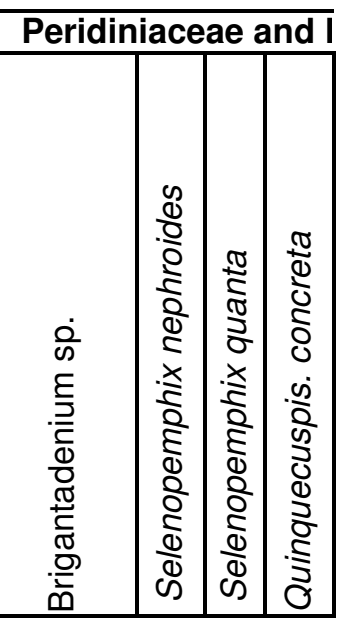

Peridiniaceae and I

\begin{tabular}{|c|c|c|}
\hline 16() & & \\
\hline & & \\
\hline $20(1)$ & & \\
\hline 30 & & \\
\hline 6() & & \\
\hline 2.5() & & \\
\hline 12() & & \\
\hline 20 & 1 & \\
\hline 10 & & \\
\hline 6() & & \\
\hline $86(3)$ & & \\
\hline 10 & & \\
\hline $95(1)$ & & \\
\hline & & \\
\hline 280 & & \\
\hline 20 & & \\
\hline $71(27)$ & & \\
\hline $0(1)$ & & \\
\hline $67(2)$ & & \\
\hline 5() & & \\
\hline 1360 & & \\
\hline $2(1)$ & & \\
\hline 7() & & \\
\hline 10 & & \\
\hline $80(5)$ & & \\
\hline 7() & 1 & \\
\hline $198(13)$ & & \\
\hline 20 & & \\
\hline $58(2)$ & & \\
\hline $7(1)$ & & \\
\hline $162(2)$ & & \\
\hline 10 & & \\
\hline $37(6)$ & & \\
\hline 7() & & \\
\hline 11() & & \\
\hline $6(1)$ & & \\
\hline 42() & & \\
\hline 27() & 1 & \\
\hline 28 (13) & & \\
\hline 74.5() & & \\
\hline
\end{tabular}




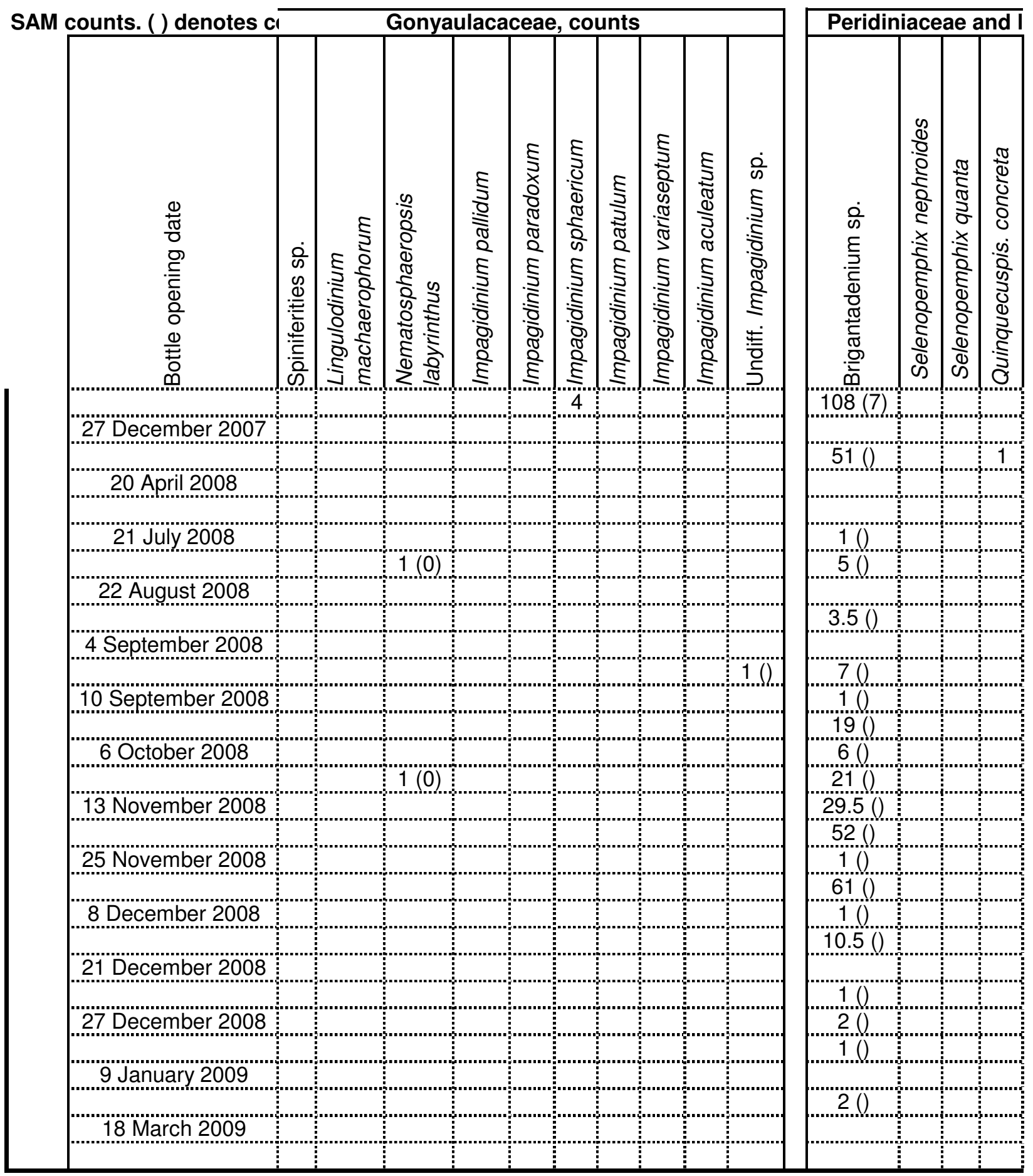


SAM counts. ( ) denotes cPolykrikaceae, counts

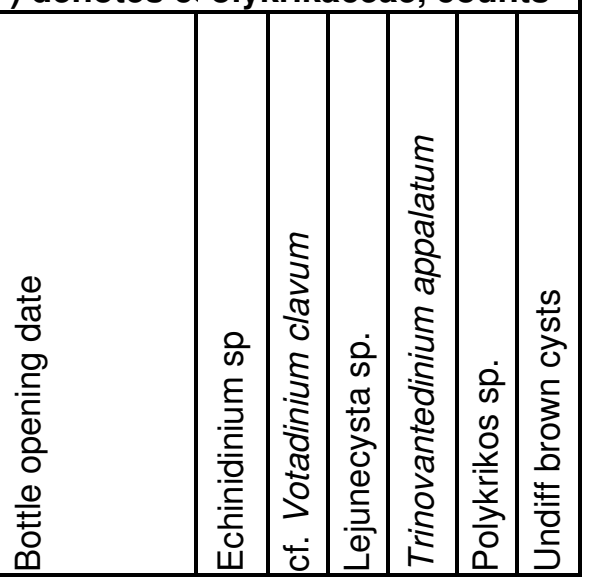

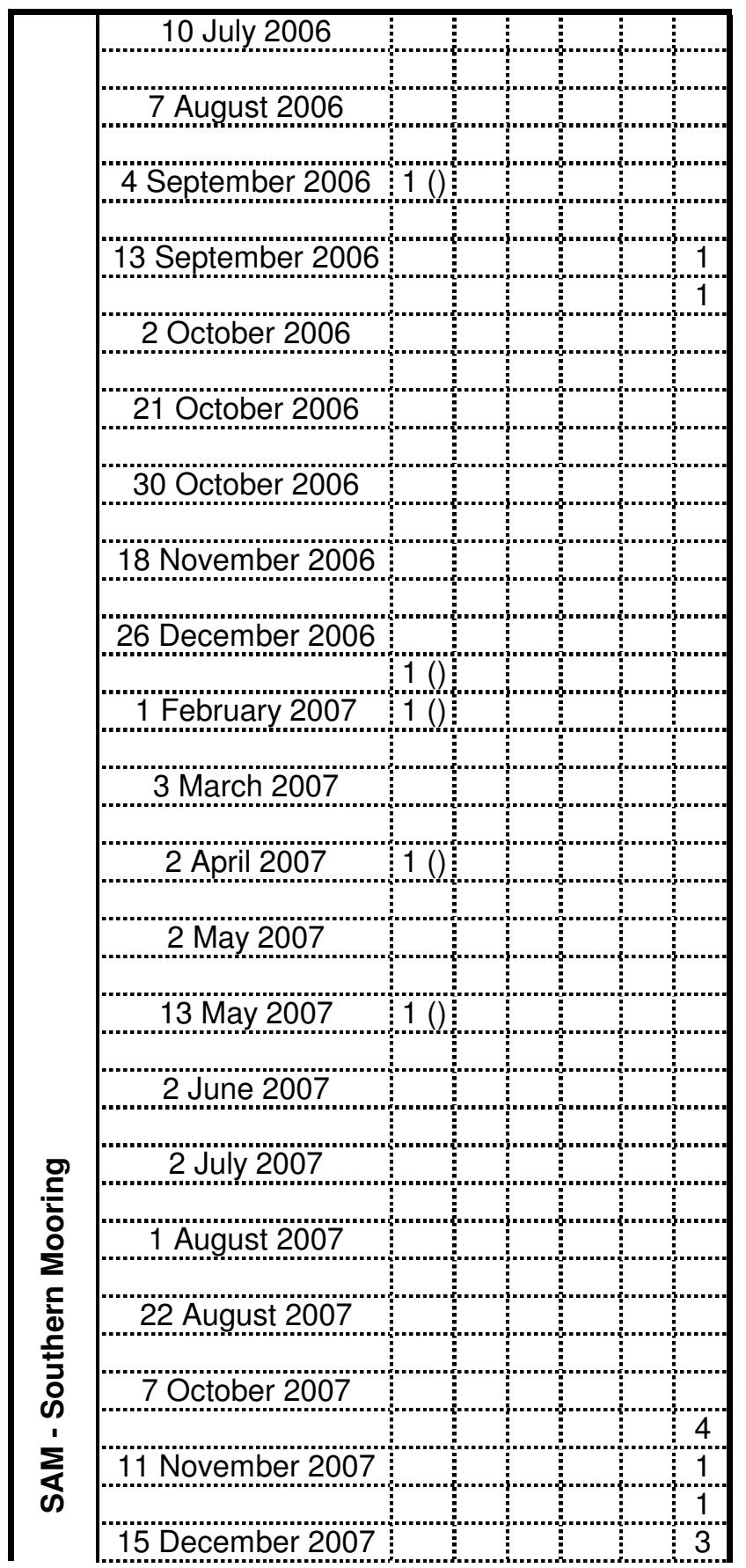


SAM counts. ( ) denotes cPolykrikaceae, counts

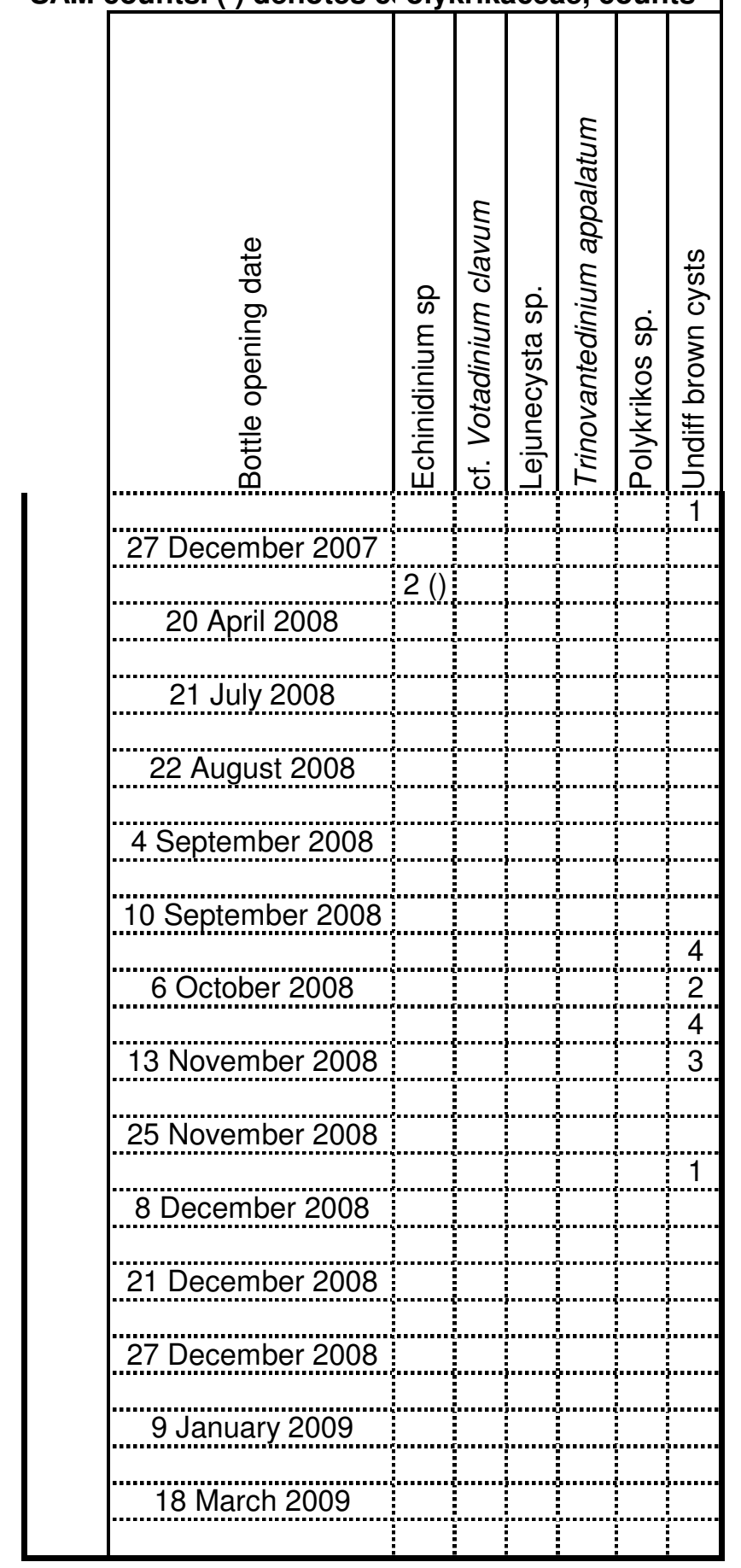




\begin{tabular}{|c|c|c|c|c|c|c|c|c|c|c|c|c|c|c|c|c|c|}
\hline 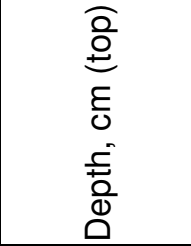 & $\begin{array}{l}\frac{\pi}{2} \\
\frac{0}{0} \\
\frac{8}{\alpha}\end{array}$ & $\begin{array}{l}\overline{0} \\
\frac{\pi}{0} \\
\overline{0} \\
\stackrel{0}{త}\end{array}$ & 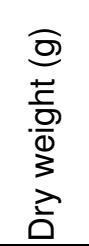 & 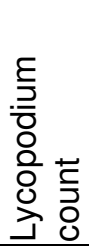 & 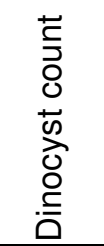 & 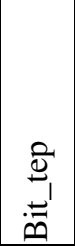 & $\mid \begin{array}{l}\frac{\pi}{\pi} \\
\frac{\pi}{0} \\
\frac{1}{\pi} \\
\tilde{\Omega}\end{array}$ & 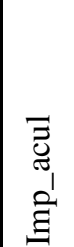 & 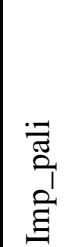 & 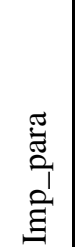 & 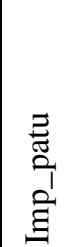 & 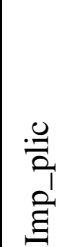 & 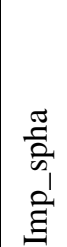 & 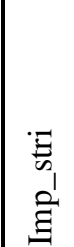 & 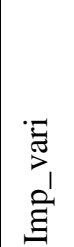 & 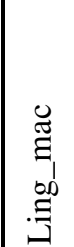 & $\begin{array}{l}\frac{\overrightarrow{0}}{\vec{\sigma}} \\
\frac{\overrightarrow{0}}{\overrightarrow{0}} \\
\vec{z}\end{array}$ \\
\hline & & & & & & & & & & & & & & & & & \\
\hline 6 & 5.3 & 6021 & 32 & 415 & 354 & 00 & 0.00 & 0.29 & 0.00 & 0.00 & 0.04 & 0.00 & 0.06 & 0.00 & 0.00 & 0.00 & \begin{tabular}{|l|l|}
0.15 \\
\end{tabular} \\
\hline & 1.5 & 6022 & 53 & 971 & 339.5 & 00 & 0.01 & 0.30 & 0.01 & 0.00 & 0.02 & 0.00 & 0.08 & 0.00 & 0.00 & 0.00 & 0.22 \\
\hline 7 & 5.4 & 6023 & 5.95 & 115 & 322 & 00 & 0.00 & \begin{tabular}{|l|l|}
0.21 \\
\end{tabular} & \begin{tabular}{|l}
0.01 \\
\end{tabular} & 0.00 & \begin{tabular}{|l|}
0.01 \\
\end{tabular} & 0.00 & 0.05 & \begin{tabular}{|l}
0.00 \\
\end{tabular} & 0.00 & \begin{tabular}{|l|l} 
\\
\end{tabular} & 0.49 \\
\hline 721 & 48.9 & 66024 & 6.48 & 535 & 305.5 & .00 & 0.00 & 0.10 & 0.01 & 0.00 & \begin{tabular}{|l|l|}
0.03 \\
\end{tabular} & 0.00 & 0.02 & 0.00 & 0.00 & 0.00 & 0.52 \\
\hline 726 & 50.6 & 66025 & 7.08 & $\overline{94}$ & 342 & 00 & 0.00 & 0.18 & 0.00 & 0.03 & 0.02 & 0.00 & 0.02 & 0.00 & 0.00 & 0.00 & .46 \\
\hline 731 & 52.3 & 26026 & 5.27 & 525 & 303.5 & 0.00 & 0.00 & 0.15 & 0.01 & 0.02 & 0.04 & 0.00 & 0.00 & 0.00 & 0.00 & 0.00 & 0.33 \\
\hline 736 & 54.1 & 26027 & 6.28 & 419 & 315 & 0.00 & 0.00 & 0.13 & 0.01 & 0.04 & 0.02 & 0.00 & 0.00 & 0.00 & 0.00 & 0.00 & \begin{tabular}{|l|l|} 
\\
\end{tabular} \\
\hline 41 & 55.8 & 26028 & 13.85 & 423 & 331 & 0.00 & \begin{tabular}{|l}
0.00 \\
\end{tabular} & \begin{tabular}{|l}
0.13 \\
\end{tabular} & 0.00 & 0.07 & 0.05 & 0.00 & 0.00 & \begin{tabular}{|l}
0.00 \\
\end{tabular} & 0.00 & 0. & .44 \\
\hline 46 & 357.6 & 26029 & 7.79 & 704 & 370 & 0.00 & 0.00 & 0.12 & 0.01 & 0.03 & 0.03 & \begin{tabular}{|l|}
0.00 \\
\end{tabular} & 0.00 & 0.00 & 0.00 & 0 & 0.42 \\
\hline 756 & 361.1 & 2030 & 8.83 & 273 & 317 & 0.00 & 0.00 & \begin{tabular}{|l|l|}
0.14 \\
\end{tabular} & \begin{tabular}{|l}
0.01 \\
\end{tabular} & 0.04 & \begin{tabular}{|l|l}
0.03 \\
\end{tabular} & 0.00 & 0.00 & 0.00 & 0.00 & 0.00 & 0.48 \\
\hline 761 & 62.8 & 25687 & 6.06 & 440 & 34.5 & 0.00 & 0.00 & 0.23 & 0.01 & 0.02 & 0.04 & 0.00 & 0.00 & 0.00 & 0.00 & 0 & 0.26 \\
\hline 771 & 66.3 & 26031 & 8.29 & 192 & 320 & 0.00 & 0.00 & 0.09 & 0.01 & 0.01 & 0.06 & 0.00 & 0.00 & 0.00 & 0.00 & 0 & 0.69 \\
\hline 781 & 69.8 & 55688 & 89 & 115 & 309 & .00 & 0.00 & \begin{tabular}{|l|l|} 
\\
\end{tabular} & \begin{tabular}{|l}
0.01 \\
\end{tabular} & 0.04 & \begin{tabular}{|l|l}
0.07 \\
\end{tabular} & 0.00 & 0.00 & 0.00 & 0.00 & 0.00 & 0.44 \\
\hline 791 & 73.3 & 25689 & 5.92 & $31 \varepsilon$ & 327 & .00 & 0.00 & \begin{tabular}{|l}
0.32 \\
\end{tabular} & 0.00 & 0.02 & \begin{tabular}{|l|l|}
0.11 \\
\end{tabular} & 0.00 & 0.00 & \begin{tabular}{|l}
0.00 \\
\end{tabular} & 0.00 & \begin{tabular}{|l}
0.00 \\
\end{tabular} & 0.31 \\
\hline 7 & 5.0 & 60032 & 9.16 & - & 301 & 0.00 & 0.00 & \begin{tabular}{|l|l|}
0.24 \\
\end{tabular} & 0.00 & 0.05 & \begin{tabular}{|l|l|}
0.11 \\
\end{tabular} & 0.00 & 0.00 & \begin{tabular}{|l}
0.00 \\
\end{tabular} & 0.00 & \begin{tabular}{|l}
0.00 \\
\end{tabular} & \begin{tabular}{|l|}
0.27 \\
\end{tabular} \\
\hline 801 & 76.8 & L25690 & 7.26 & 126 & 40.75 & 0.00 & 0.00 & \begin{tabular}{|l|l|}
0.18 \\
\end{tabular} & 0.00 & 0.01 & \begin{tabular}{|l|}
0.17 \\
\end{tabular} & \begin{tabular}{|l|}
0.00 \\
\end{tabular} & 0.00 & 0.01 & 0.00 & 0.00 & 0.34 \\
\hline 806 & 8.5 & 66033 & 0.29 & 366 & 15.5 & 00 & 0.00 & 0.23 & 0.00 & 0.03 & \begin{tabular}{|l|}
0.18 \\
\end{tabular} & \begin{tabular}{|l|}
0.00 \\
\end{tabular} & 0.00 & 0.00 & 0.00 & 0.00 & .18 \\
\hline 811 & 30.3 & 25691 & 8.58 & 173 & 39.75 & 00 & 0.00 & 0.32 & 0.00 & 0.05 & \begin{tabular}{|l|l}
0.07 \\
\end{tabular} & 0.00 & 0.00 & 0.00 & 0 & $\overline{0}$ & 0.22 \\
\hline 821 & 83.8 & 25692 & 6.04 & 224 & 06.25 & 0.00 & 0.00 & 0.36 & 0.00 & 0.07 & 0.09 & 0.00 & 0.00 & 0.00 & 0 & 0 & .23 \\
\hline 831 & 87.2 & 25693 & 8.8 & 663 & 16.75 & 0.00 & 0.00 & 0.59 & 0.00 & 0.02 & 0.06 & 0.00 & 0.01 & 0.00 & 0.00 & 0 & .15 \\
\hline 841 & 0.7 & 25694 & 95 & 194 & 54.25 & 0.00 & \begin{tabular}{|l}
0.00 \\
\end{tabular} & \begin{tabular}{|l}
0.27 \\
\end{tabular} & 0.00 & 0.01 & \begin{tabular}{|l|l|}
0.11 \\
\end{tabular} & 0.00 & 0.01 & \begin{tabular}{|l}
0.00 \\
\end{tabular} & 0 & 0 & 29 \\
\hline & 3.7 & 5695 & & 215 & 1.25 & 0 & 0.00 & 0.29 & 01 & 0.01 & 0 & 0 & 1 & 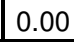 & & & 0.42 \\
\hline 856 & 6.7 & 6034 & 04 & & 31. & 00 & 0.00 & \begin{tabular}{|l}
0.32 \\
\end{tabular} & 0.00 & 0.04 & 0. & 0.00 & 0.00 & 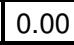 & & & 46 \\
\hline 861 & 99.6 & 25696 & 61 & 962 & 22.75 & 00 & 10 & 0.30 & 0.00 & 0.05 & 0 & \begin{tabular}{|l|}
0.01 \\
\end{tabular} & 0.01 & 0.0 & & & 0.34 \\
\hline 871 & 2.6 & 25697 & 4.66 & 119 & 99.5 & 00 & 0.00 & 0.37 & 0.01 & 0.14 & \begin{tabular}{|l|}
0.14 \\
\end{tabular} & 0.02 & 0.00 & 0.0 & 0 & 0 & 0.26 \\
\hline 876 & 5.2 & 6036 & - & 206 & 187 & 00 & 0.01 & 0.29 & 0.00 & 0.03 & 0.31 & 0.01 & 0.01 & 0.01 & 0.00 & 0 & 0.25 \\
\hline 881 & 8.1 & 25698 & 4 & 686 & 54.75 & 00 & 0.00 & \begin{tabular}{|l}
0.27 \\
\end{tabular} & \begin{tabular}{|l}
0.01 \\
\end{tabular} & 0.06 & \begin{tabular}{|l|l|}
0.17 \\
\end{tabular} & \begin{tabular}{|l|}
0.01 \\
\end{tabular} & 0.00 & 0.00 & 0.00 & \begin{tabular}{|l|l} 
\\
\end{tabular} & 0.23 \\
\hline 886 & 3.7 & 26035 & 5.09 & & 13.25 & 00 & 0.00 & \begin{tabular}{|l|l|}
0.42 \\
\end{tabular} & 0.00 & 0.05 & 0.0 & 0.00 & 0.01 & \begin{tabular}{|l}
0.0 \\
\end{tabular} & 0.00 & 0 & 0.32 \\
\hline 891 & 9.2 & 25699 & 5.73 & 331 & 12.75 & 00 & .01 & 0.28 & 0.00 & 0.00 & 0. & 0.01 & 0.00 & + & 0.00 & 0 & 0.55 \\
\hline$\overline{9}$ & 4.8 & 5700 & 4.56 & 44 & 06.5 & 00 & 01 & 0.32 & 0.00 & .05 & \begin{tabular}{|l|}
0.04 \\
\end{tabular} & 0.00 & 0.01 & 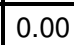 & 0.00 & 0.00 & .44 \\
\hline & 1.7 & 2570 & 5.99 & 37 & 297 & 00 & 0.00 & 0.13 & 0.01 & 0.02 & 0.01 & 0.00 & .05 & 0.00 & 0.00 & 0.00 & 36 \\
\hline 92 & 4.7 & 55702 & 6.94 & & & 00 & 0 & 0.05 & 0.03 & 0.06 & 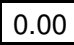 & 0.00 & 03 & 0.00 & 5 & I & 39 \\
\hline & 7.9 & 6037 & - & & & & 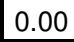 & 0.07 & 00 & 02 & & 0.00 & 00 & .00 & & 0 & 0.32 \\
\hline D06- & & & & & & & & & & & & & & & & & \\
\hline & 9.6 & 6038 & - & & 306.5 & & 0 & \begin{tabular}{|l|l|}
0.14 \\
\end{tabular} & 22 & .03 & ( & & 00 & $t$ & & & .56 \\
\hline & 1.4 & 6039 & - & 22 & & 00 & + & 0.14 & 01 & 0.00 & 0.04 & 5 & 0.00 & .00 & 0.00 & 8 & 0.53 \\
\hline & 3.3 & 6040 & & & & 100 & $t$ & 0.19 & $\overline{00}$ & 0.03 & 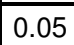 & \begin{tabular}{|l|}
0.00 \\
\end{tabular} & + & 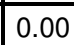 & 0.00 & & 1.52 \\
\hline 46 & 5.1 & 6041 & - & 20 & & 00 & $t$ & 0.12 & 0.00 & 0.02 & 0 & 0. & 0 & $t$ & 0.00 & 0.00 & 1.49 \\
\hline & 6.9 & 26042 & - & 14 & & 0.01 & 0.00 & 0.14 & 0.01 & 0.00 & 0. & 0.00 & 0.00 & I & 0 & 0 & 0.64 \\
\hline 6 & 8.8 & 6043 & & 8 & & 0.00 & 0.0 & 0.11 & 0.02 & 0.00 & 0. & 0.00 & 0.00 & 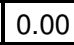 & 0 & 0 & 0.69 \\
\hline & 0.6 & 26044 & & & & .0 & 0.00 & 0.16 & 0.00 & 0.01 & 0.14 & 0.00 & 0.00 & 0.00 & 0.00 & 0.00 & 0.5 \\
\hline & 2.4 & 4046 & - & 114 & 33. & .00 & 0.00 & 0.17 & 0.00 & 0.02 & 0.12 & 0.00 & 0.01 & 0.00 & 0.00 & 0.00 & 0.5 \\
\hline 71 & 4.3 & 6045 & 7 & & 20 & 00 & 0.00 & $\begin{array}{ll}0.21 \\
\end{array}$ & 0.00 & 0.02 & \begin{tabular}{|l|}
0.14 \\
\end{tabular} & 0.01 & 0.00 & 0.00 & 0.00 & 0.00 & .50 \\
\hline 8 & 6.1 & 6047 & & & 33. & 10 & 0.00 & \begin{tabular}{|l|l|}
0.14 \\
\end{tabular} & \begin{tabular}{|l|}
0.01 \\
\end{tabular} & 0.00 & & & 00 & 0.00 & & & 47 \\
\hline & 7.9 & 55670 & 6.22 & & 2 & & & 0.16 & 00 & 0.02 & & & $\overline{00}$ & 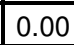 & & & 25 \\
\hline 86 & 9.8 & 6048 & - & & 306 & 0 & 0.00 & 0.17 & 0.00 & 0.00 & 0.20 & 0.00 & 0.00 & 0.00 & 0 & & .27 \\
\hline 91 & 1.6 & 5671 & 8.22 & & 30 & 2 & 0.00 & 0.31 & 0.00 & 0.07 & 0.22 & 0.00 & 00 & 0.00 & 0.00 & 0 & 0.17 \\
\hline 8 & & 604 & & & 44 & & & 0. & 00 & 0.03 & & & 00 & \begin{tabular}{|l}
0.00 \\
\end{tabular} & & & 0.2 \\
\hline 90 & 385.3 & 25672 & 6.02 & 370 & 305 & 0.00 & 0.00 & 0.43 & .00 & .03 & 20 & .00 & 0.00 & 0.00 & 0.00 & \begin{tabular}{|l}
0.00 \\
\end{tabular} & .1 \\
\hline
\end{tabular}




\begin{tabular}{|c|c|c|c|c|c|c|c|c|c|c|c|c|c|c|c|c|c|}
\hline 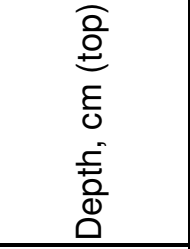 & 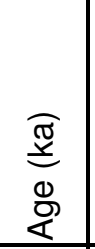 & 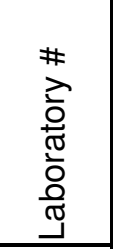 & 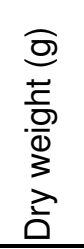 & 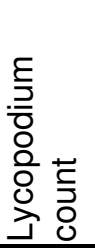 & 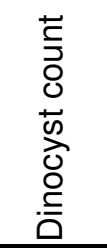 & 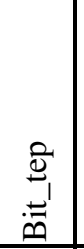 & $\begin{array}{l}\bar{J} \\
\frac{J}{0} \\
\frac{\pi}{J} \\
0\end{array}$ & 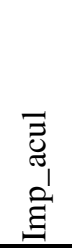 & 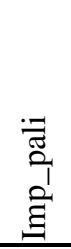 & 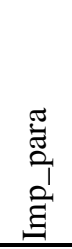 & 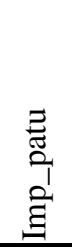 & 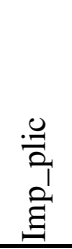 & 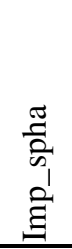 & $\begin{array}{l}\Xi \\
\mathbb{N}_{1} \\
\stackrel{\Xi}{\Xi} \\
\end{array}$ & $\begin{array}{l}\bar{\Xi} \\
> \\
\Xi \\
\Xi \\
\Xi\end{array}$ & 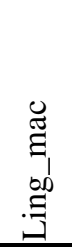 & 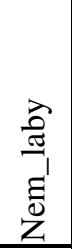 \\
\hline 906 & 37.1 & L26050 & - & 441 & 317 & \begin{tabular}{|l|l|}
0.00 \\
\end{tabular} & 0.00 & 0.56 & 0.00 & 0.02 & 0.19 & 0.00 & 0.01 & 0.00 & 0.00 & 0.00 & 0.16 \\
\hline 911 & 38.9 & L25673 & 7.5 & 26 & 372.5 & .00 & 0.00 & 0.46 & 0.00 & 0.03 & 0.09 & 0.00 & 0.00 & 0.00 & 0.00 & 0.00 & 0.27 \\
\hline 916 & 0.8 & 26051 & - & 94 & 308.5 & \begin{tabular}{|l|}
0.00 \\
\end{tabular} & 0.00 & 0.41 & 0.01 & 0.03 & 0.08 & 0.00 & 0.00 & 0.00 & 0.00 & 0.00 & 0.29 \\
\hline 921 & 2.6 & 5674 & 7.59 & 26 & 316.5 & .00 & 0.00 & 0.24 & 0.00 & 0.03 & 0.12 & 0.00 & 0.00 & 0.00 & 0.00 & 0.00 & 0.39 \\
\hline 926 & 4.4 & L26052 & - & 260 & 11 & .00 & 0.00 & 0.17 & 0.01 & 0.01 & 0.21 & 0.00 & 0.00 & 0.00 & 0.00 & 0.00 & 0.39 \\
\hline 931 & 96.3 & L25675 & 4.85 & 233 & 340 & 0.00 & 0.00 & 0.27 & 0.00 & 0.01 & 0.10 & 0.00 & 0.00 & 0.00 & 0.00 & 0.00 & 0.37 \\
\hline 936 & 8.1 & 6053 & - & r & 330.5 & .00 & 0.00 & 0.28 & 0.00 & 0.02 & 0.07 & 0.00 & 0.00 & 0.00 & 0.00 & 0.00 & 0.49 \\
\hline 941 & 99.9 & L25676 & 4.73 & 53 & 324 & \begin{tabular}{|l|l|}
0.00 \\
\end{tabular} & 0.00 & 0.31 & 0.00 & 0.03 & 0.06 & 0.00 & 0.00 & 0.00 & 0.00 & 0.00 & 0.52 \\
\hline 946 & 1.8 & L26054 & - & 363 & 11.5 & \begin{tabular}{|l|l|}
0.00 \\
\end{tabular} & 0.00 & 0.30 & 0.00 & 0.04 & 0.09 & 0.00 & 0.01 & 0.00 & 0.00 & 0.00 & 0.47 \\
\hline 951 & 3.6 & 77 & 6.58 & 348 & 328.5 & 00 & 0.00 & 0.30 & 0.01 & 0.05 & 0.04 & 0.01 & 0.00 & 0.00 & 0.00 & 0.00 & 0.32 \\
\hline 956 & 5.2 & L26055 & - & 2096 & 229.5 & \begin{tabular}{|l|}
0.00 \\
\end{tabular} & 0.00 & 0.37 & 0.00 & 0.05 & 0.15 & 0.01 & 0.00 & 0.00 & 0.00 & 0.00 & 0.30 \\
\hline 961 & 6.9 & L25678 & 7.87 & 2109 & 350 & \begin{tabular}{|l|}
0.00 \\
\end{tabular} & 0.00 & 0.37 & 0.00 & 0.08 & 0.22 & 0.00 & 0.00 & 0.00 & 0.00 & 0.00 & 0.19 \\
\hline 971 & 0.2 & 79 & 3.11 & 27 & 13 & 00 & 0.01 & 0.22 & 0.00 & 0.06 & 0.15 & 0.00 & 0.00 & 0.00 & 0.00 & 0.00 & 0.32 \\
\hline 976 & 1.8 & L26057 & - & 780 & 314.5 & \begin{tabular}{|l|}
0.00 \\
\end{tabular} & 0.00 & 0.49 & 0.00 & 0.03 & 0.19 & 0.01 & 0.01 & 0.00 & 0.00 & 0.00 & 0.14 \\
\hline 981 & 3.5 & 680 & .67 & 37 & 312.5 & \begin{tabular}{|l|}
0.00 \\
\end{tabular} & 0.00 & 0.44 & 0.00 & 0.07 & 0.20 & 0.00 & 0.00 & 0.00 & 0.01 & 0.00 & 0.19 \\
\hline 986 & 5.1 & & - & & & 0 & 0 & 0.38 & 0.00 & 3 & 0.22 & 0.01 & 0.01 & 0.00 & 0 & 0.00 & 0.19 \\
\hline 991 & 6.8 & L25681 & .31 & 226 & 336.5 & \begin{tabular}{|l|l|}
0.00 \\
\end{tabular} & 0.00 & 0.27 & 0.01 & 0.03 & 0.15 & 0.00 & 0.00 & 0.00 & 0.00 & 0.00 & 0.47 \\
\hline 996 & 8.4 & 59 & - & 94 & 317.5 & \begin{tabular}{l|l|}
0.00 \\
\end{tabular} & 0.00 & 0.21 & 0.00 & 0.02 & 0.09 & 0.00 & 0.00 & 0.00 & 0.00 & 0.00 & 0.61 \\
\hline 1001 & 0.1 & $\angle$ & 61 & & 75 & \begin{tabular}{|l|}
0.00 \\
\end{tabular} & 0.00 & 0.14 & 0.00 & 0.02 & 0.06 & 0.00 & 0.00 & 0.00 & 0.00 & 0.00 & 0.50 \\
\hline 1006 & 21.7 & L26060 & - & 202 & 20.5 & \begin{tabular}{|l|l|}
0.00 \\
\end{tabular} & 0.00 & 0.18 & 0.00 & 0.02 & 0.07 & 0.00 & 0.01 & 0.00 & 0.00 & 0.00 & 0.56 \\
\hline 1011 & 3.4 & 83 & 68 & 425 & 345 & 0.00 & 0.00 & 0.17 & 0.00 & 0.06 & 0.05 & 0.00 & 0.01 & 0.00 & 0.00 & 0.00 & 0.23 \\
\hline 1016 & 5.0 & $\mathrm{~L}$ & - & & & .00 & 0.00 & 0.19 & 0.01 & 0.05 & 0.09 & 0.00 & 0.02 & 0.00 & 0.00 & 0.00 & 0.20 \\
\hline 1021 & 6.7 & 84 & 49 & 260 & 97 & \begin{tabular}{|l|}
0.00 \\
\end{tabular} & 0.00 & 0.11 & 0.00 & 0.06 & 0.06 & 0.00 & 0.00 & 0.00 & 0.00 & .00 & 0.23 \\
\hline 26 & 8.3 & 62 & - & 5 & 329 & \begin{tabular}{|l|l|}
0.00 \\
\end{tabular} & 0.00 & 0.11 & 0.00 & 0.03 & 0.06 & 0.00 & 0.03 & 1.00 & 00 & .00 & 0.30 \\
\hline 1031 & 0.0 & 5 & 5.67 & & & 0.00 & 0.00 & 0.03 & 0.00 & 0.00 & 0.03 & 0.00 & 0.00 & 0.00 & 0.00 & 0.00 & 0.13 \\
\hline 1041 & 2.9 & 86 & 6.7 & 178 & 23.5 & \begin{tabular}{|l|l|}
0.00 \\
\end{tabular} & 0.00 & 0.04 & 0.02 & 0.03 & 0.03 & 0.00 & 0.00 & 0.00 & 0.00 & .00 & 0.37 \\
\hline 1051 & 5.1 & $\mathrm{~L}$ & - & & & 00 & 0 & 0.05 & 0.00 & 5 & 0.06 & 0 & 0.00 & 0 & 0.00 & 0 & 0.37 \\
\hline $0=0$ & & & & & & & & & & & & & & & & & \\
\hline 3761 & 1.8 & L25657 & 1.05 & ${ }_{2}$ & 4.25 & 0.01 & 0.00 & 0.44 & 0.00 & 0.04 & 0.14 & 0.00 & 0.01 & 0.00 & 0.00 & .00 & 0.20 \\
\hline 71 & 4.5 & L25658 & 7.66 & 36 & 325.75 & \begin{tabular}{|l|l|}
0.00 \\
\end{tabular} & 0.00 & 0.39 & 0.00 & 0.03 & 0.10 & 0.00 & 0.00 & 0.00 & 0.00 & 0.00 & 0.25 \\
\hline 3781 & 7.2 & L25659 & 7.66 & & 303.5 & \begin{tabular}{|l|}
0.01 \\
\end{tabular} & 0.00 & 0.46 & 0.00 & 0.01 & 0.13 & 0.00 & 0.01 & 0.00 & 0.01 & 0.00 & 0.29 \\
\hline 91 & 399.8 & L25660 & 9.94 & 5 & 320.5 & \begin{tabular}{|l|l|}
0.00 \\
\end{tabular} & 0.00 & 0.40 & 0.00 & 0.03 & 0.15 & 0.00 & 0.01 & 0.00 & 0.00 & 0.00 & 0.34 \\
\hline 3801 & 402.5 & L25661 & 8 & 1 & 328.5 & \begin{tabular}{|l|}
0.00 \\
\end{tabular} & 0.00 & 0.44 & 0.00 & 0.01 & 0.04 & 0.01 & 0.03 & 0.00 & 0.00 & 0.00 & 0.42 \\
\hline 3811 & 405.2 & L25662 & 85 & 3102 & 318.5 & \begin{tabular}{|l|l|}
0.00 \\
\end{tabular} & 0.00 & 0.35 & 0.00 & 0.02 & 0.03 & 0.01 & 0.03 & 0.00 & 0.00 & 0.00 & 0.47 \\
\hline 3821 & 407.8 & L25663 & 98 & 4400 & 306 & \begin{tabular}{|l|}
0.00 \\
\end{tabular} & 0.00 & 0.41 & 0.00 & 0.02 & 0.08 & 0.01 & 0.00 & 0.00 & 0.01 & 0.00 & 0.40 \\
\hline 3831 & 410.4 & L25664 & 9.69 & 2530 & 315.5 & 0.00 & 0.00 & 0.50 & 0.00 & 0.02 & 0.18 & 0.01 & 0.00 & 0.00 & 0.00 & 0.00 & 0.22 \\
\hline 3841 & 413.0 & L25665 & 9.82 & 1114 & 304.25 & \begin{tabular}{|l|}
0.00 \\
\end{tabular} & 0.00 & 0.61 & 0.00 & 0.08 & 0.18 & 0.00 & 0.00 & 0.01 & 0.00 & 0.00 & 0.06 \\
\hline 3851 & 415.5 & L25666 & 8.36 & 3635 & 310.25 & \begin{tabular}{|l|l|}
0.00 \\
\end{tabular} & 0.00 & 0.60 & 0.00 & 0.02 & 0.18 & 0.00 & 0.00 & 0.00 & 0.00 & 0.00 & 0.11 \\
\hline 3861 & 418.0 & L25667 & 6.88 & 1169 & 319 & \begin{tabular}{|l|l|}
0.00 \\
\end{tabular} & 0.00 & 0.44 & 0.00 & 0.03 & 0.14 & 0.00 & 0.00 & 0.00 & 0.00 & 0.00 & 0.36 \\
\hline 3871 & 420.5 & L25668 & 6.52 & 720 & 317 & \begin{tabular}{|l|}
0.00 \\
\end{tabular} & 0.00 & 0.30 & 0.00 & 0.00 & 0.09 & 0.00 & 0.00 & 0.00 & 0.00 & 0.00 & 0.57 \\
\hline 3881 & 423.0 & L25669 & 4.99 & 912 & 309 & \begin{tabular}{|l|l|}
0.00 \\
\end{tabular} & 0.00 & 0.58 & 0.00 & 0.01 & 0.37 & 0.00 & 0.00 & 0.00 & 0.00 & 0.00 & 0.02 \\
\hline
\end{tabular}




\begin{tabular}{|c|c|c|c|c|c|c|c|c|c|c|c|c|c|c|c|c|c|c|c|}
\hline 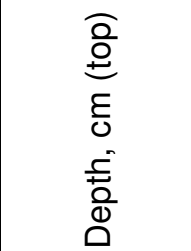 & 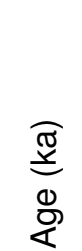 & 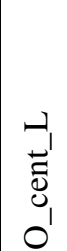 & $\begin{array}{l}n_{1} \\
\overrightarrow{\bar{J}}^{\prime} \\
0_{1}\end{array}$ & 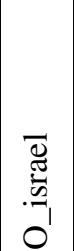 & $\begin{array}{l}\vec{z} \\
\frac{\vec{E}}{0} \\
0\end{array}$ & 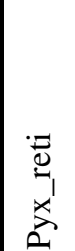 & $\mid \begin{array}{l}\overrightarrow{\vec{\Xi}} \\
\vec{\Xi} \\
\overrightarrow{\omega_{1}} \\
\vec{n}\end{array}$ & $\begin{array}{l}: \vec{\Xi} \\
\stackrel{\Xi}{a_{1}} \\
\overline{\tilde{n}}\end{array}$ & 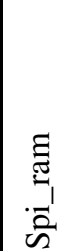 & $\begin{array}{l}\overline{\bar{\theta}} \\
\overline{0} \\
\bar{n}\end{array}$ & 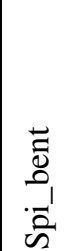 & $\begin{array}{l}\overline{\tilde{E}} \\
\stackrel{\tilde{O}}{1} \\
\bar{n}_{n}\end{array}$ & $\begin{array}{l}\tilde{0} \\
\widetilde{\omega} \\
\tilde{n} \\
\tilde{n}\end{array}$ & 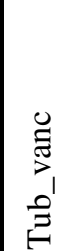 & 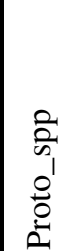 & 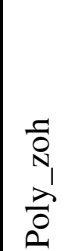 & 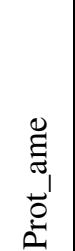 & 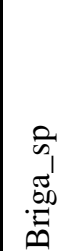 & $\begin{array}{l}\bar{J} \\
\tilde{\sigma} \\
\overrightarrow{0} \\
\tilde{0}\end{array}$ \\
\hline \begin{tabular}{|l|l} 
MD06-2989 \\
\end{tabular} & & & & & & & & & & & & & & & & & & & \\
\hline 691 & 35.3 & 0.25 & 0.00 & 0.00 & 0.01 & 0.01 & 0.00 & \begin{tabular}{|l|}
0.19 \\
\end{tabular} & 0.00 & 0.00 & 0.00 & 0.00 & 0.00 & 0.00 & 0.00 & 0.00 & 0.00 & 0.00 & 0.00 \\
\hline 701 & 341.5 & 0.19 & 0.00 & 0.00 & 0.01 & 0.01 & 0.01 & \begin{tabular}{|l|}
0.15 \\
\end{tabular} & 0.00 & 0.00 & 0.00 & 0.00 & \begin{tabular}{|l|}
0.00 \\
\end{tabular} & 0.00 & 0.00 & 0.00 & 0.00 & 0.00 & 0.00 \\
\hline 711 & 345.4 & 0.11 & 0.00 & 0.00 & 0.01 & 0.00 & 0.01 & \begin{tabular}{|l|}
0.05 \\
\end{tabular} & 0.00 & 0.00 & 0.00 & 0.00 & 0.00 & 0.00 & 0.00 & 0.00 & 0.00 & 0.04 & 0.00 \\
\hline 721 & 348.9 & 0.01 & 0.00 & 0.00 & 0.00 & 0.00 & 0.00 & \begin{tabular}{|l|}
0.03 \\
\end{tabular} & 0.00 & 0.00 & 0.00 & 0.00 & 0.00 & 0.00 & 0.00 & 0.00 & 0.00 & 0.25 & 0.00 \\
\hline 726 & 350.6 & 0.00 & 0.00 & 0.00 & 0.00 & 0.00 & 0.00 & \begin{tabular}{|l|}
0.01 \\
\end{tabular} & 0.00 & 0.00 & 0.00 & 0.00 & 0.00 & 0.00 & 0.00 & 0.00 & 0.00 & 0.25 & 0.00 \\
\hline 731 & 352.3 & 0.00 & 0.00 & 0.00 & 0.00 & 0.02 & 0.00 & \begin{tabular}{|l|}
0.00 \\
\end{tabular} & 0.01 & 0.00 & 0.00 & 0.00 & 0.00 & 0.00 & 0.00 & 0.00 & 0.00 & 0.38 & 0.00 \\
\hline 736 & 354.1 & 0.01 & 0.00 & 0.00 & 0.00 & 0.01 & 0.00 & \begin{tabular}{|l|}
0.00 \\
\end{tabular} & 0.00 & 0.00 & 0.00 & 0.00 & 0.00 & 0.00 & 0.00 & 0.00 & 0.00 & 0.46 & 0.00 \\
\hline 741 & 355.8 & 0.00 & 0.00 & 0.00 & 0.00 & 0.02 & 0.00 & 0.01 & 0.00 & 0.00 & 0.00 & 0.00 & 0.00 & 0.00 & 0.00 & 0.00 & 0.00 & 0.26 & 0.00 \\
\hline 746 & 357.6 & 0.00 & 0.00 & 0.00 & 0.00 & 0.01 & 0.00 & 0.00 & 0.00 & 0.00 & 0.00 & 0.00 & 0.00 & 0.00 & 0.00 & 0.00 & 0.00 & 0.34 & 0.00 \\
\hline 756 & 361.1 & 0.00 & 0.00 & 0.00 & 0.00 & 0.02 & 0.00 & \begin{tabular}{|l|}
0.00 \\
\end{tabular} & 0.00 & 0.00 & 0.00 & 0.00 & 0.00 & 0.00 & 0.00 & 0.00 & 0.00 & 0.26 & 0.00 \\
\hline 761 & 362.8 & 0.10 & 0.00 & 0.00 & 0.01 & 0.00 & 0.00 & 0.09 & 0.00 & 0.00 & 0.00 & 0.00 & 0.00 & 0.00 & 0.00 & 0.00 & 0.00 & 0.23 & 0.00 \\
\hline 771 & 366.3 & 0.00 & 0.00 & 0.00 & 0.00 & 0.02 & 0.00 & \begin{tabular}{|l|l|}
0.00 \\
\end{tabular} & 0.00 & 0.00 & 0.00 & 0.00 & 0.00 & 0.00 & 0.00 & 0.00 & 0.00 & 0.11 & 0.00 \\
\hline 781 & 369.8 & 0.00 & 0.00 & 0.00 & 0.01 & 0.01 & 0.00 & \begin{tabular}{|l|l|}
0.00 \\
\end{tabular} & 0.00 & 0.00 & 0.00 & 0.00 & 0.00 & 0.00 & 0.00 & 0.00 & 0.00 & \begin{tabular}{|l|l}
0.17 \\
\end{tabular} & 0.00 \\
\hline 791 & 373.3 & 0.00 & 0.00 & 0.00 & \begin{tabular}{|l}
0.00 \\
\end{tabular} & 0.02 & 0.00 & \begin{tabular}{|l|}
0.01 \\
\end{tabular} & 0.00 & \begin{tabular}{|l}
0.00 \\
\end{tabular} & 0.00 & 0.00 & 0.00 & \begin{tabular}{|l}
0.00 \\
\end{tabular} & 0.00 & \begin{tabular}{|l}
0.00 \\
\end{tabular} & 0.00 & 0.17 & 0.00 \\
\hline 796 & 375.0 & 0.00 & 0.00 & 0.00 & 0.00 & 0.00 & 0.00 & \begin{tabular}{|l|}
0.01 \\
\end{tabular} & 0.00 & 0.00 & \begin{tabular}{|l|l}
0.00 \\
\end{tabular} & 0.00 & 0.00 & 0.00 & 0.00 & 0.00 & 0.00 & 0.29 & 0.00 \\
\hline 801 & 376.8 & 0.00 & 0.00 & 0.00 & 0.00 & 0.00 & 0.00 & \begin{tabular}{|l|}
0.03 \\
\end{tabular} & 0.00 & 0.00 & 0.00 & 0.00 & \begin{tabular}{|l|}
0.00 \\
\end{tabular} & 0.00 & 0.00 & 0.00 & 0.00 & 0.24 & \begin{tabular}{|l|}
0.00 \\
\end{tabular} \\
\hline 806 & 378.5 & 0.00 & 0.00 & 0.00 & 0.00 & 0.01 & 0.00 & \begin{tabular}{|l|}
0.01 \\
\end{tabular} & 0.00 & 0.00 & 0.00 & 0.00 & 0.00 & 0.00 & 0.00 & 0.00 & 0.00 & 0.32 & \begin{tabular}{|l|}
0.00 \\
\end{tabular} \\
\hline 811 & 380.3 & 0.00 & 0.00 & 0.00 & 0.00 & 0.02 & 0.00 & \begin{tabular}{|l|}
0.00 \\
\end{tabular} & 0.00 & 0.00 & 0.00 & 0.00 & 0.00 & 0.00 & 0.01 & 0.00 & 0.00 & 0.26 & 0.00 \\
\hline 821 & 383.8 & 0.01 & 0.00 & 0.00 & 0.00 & 0.03 & 0.00 & \begin{tabular}{|l|l|}
0.00 \\
\end{tabular} & 0.00 & 0.00 & 0.00 & 0.00 & 0.00 & 0.00 & 0.00 & 0.00 & 0.00 & 0.18 & 0.00 \\
\hline 831 & 387.2 & 0.00 & 0.00 & 0.00 & 0.01 & 0.04 & 0.00 & \begin{tabular}{|l|}
0.09 \\
\end{tabular} & 0.00 & 0.00 & 0.00 & 0.00 & 0.00 & 0.00 & 0.00 & 0.00 & 0.00 & 0.03 & 0.00 \\
\hline 841 & 390.7 & 0.00 & 0.00 & 0.00 & 0.00 & 0.04 & 0.00 & 0.05 & 0.00 & 0.00 & 0.00 & 0.00 & 0.00 & 0.00 & 0.00 & 0.00 & 0.00 & 0.20 & 0.00 \\
\hline 851 & 393.7 & 0.00 & 0.00 & \begin{tabular}{|l|}
0.00 \\
\end{tabular} & 0.00 & 0.05 & \begin{tabular}{|l|l}
0.00 \\
\end{tabular} & \begin{tabular}{|l|}
0.02 \\
\end{tabular} & \begin{tabular}{|l|}
0.01 \\
\end{tabular} & 0.00 & 0.00 & 0.00 & \begin{tabular}{|l|}
0.00 \\
\end{tabular} & \begin{tabular}{|l|l}
0.00 \\
\end{tabular} & \begin{tabular}{|l|l}
0.00 \\
\end{tabular} & \begin{tabular}{|l|}
0.00 \\
\end{tabular} & \begin{tabular}{|l|}
0.00 \\
\end{tabular} & \begin{tabular}{|l|}
0.14 \\
\end{tabular} & \begin{tabular}{|l|}
0.00 \\
\end{tabular} \\
\hline 856 & 396.7 & 0.00 & 0.00 & \begin{tabular}{|l|}
0.00 \\
\end{tabular} & 0.00 & 0.02 & 0.00 & \begin{tabular}{|l|}
0.08 \\
\end{tabular} & 0.00 & 0.00 & 0.00 & 0.00 & \begin{tabular}{|l|}
0.00 \\
\end{tabular} & 0.00 & 0.00 & 0.00 & \begin{tabular}{|l|l|}
0.00 \\
\end{tabular} & \begin{tabular}{|l|l}
0.03 \\
\end{tabular} & 0.00 \\
\hline 861 & 399.6 & 0.00 & 0.00 & 0.00 & 0.01 & 0.05 & 0.00 & \begin{tabular}{|l|}
0.12 \\
\end{tabular} & 0.00 & 0.00 & 0.00 & 0.00 & 0.00 & 0.00 & 0.00 & 0.00 & 0.00 & \begin{tabular}{|l|l}
0.06 \\
\end{tabular} & 0.00 \\
\hline 871 & 402.6 & 0.00 & 0.00 & 0.00 & 0.00 & 0.03 & 0.02 & 0.00 & 0.00 & 0.00 & 0.00 & 0.00 & 0.00 & 0.00 & 0.00 & 0.00 & 0.00 & 0.01 & 0.00 \\
\hline 876 & 405.2 & 0.00 & 0.00 & 0.00 & 0.01 & 0.02 & 0.00 & \begin{tabular}{|l|}
0.05 \\
\end{tabular} & 0.01 & 0.00 & 0.00 & 0.00 & 0.00 & 0.00 & 0.00 & 0.00 & 0.00 & 0.01 & 0.00 \\
\hline 881 & 408.1 & 0.00 & 0.00 & 0.00 & 0.02 & 0.06 & 0.00 & \begin{tabular}{|l|l|}
0.11 \\
\end{tabular} & 0.00 & 0.00 & 0.00 & 0.00 & 0.00 & 0.00 & 0.00 & 0.00 & 0.00 & \begin{tabular}{|l}
0.06 \\
\end{tabular} & 0.00 \\
\hline 886 & 413.7 & 0.00 & 0.00 & 0.00 & \begin{tabular}{|l|l}
0.01 \\
\end{tabular} & 0.05 & 0.00 & \begin{tabular}{|l|}
0.04 \\
\end{tabular} & 0.00 & \begin{tabular}{|l}
0.00 \\
\end{tabular} & \begin{tabular}{|l|l|}
0.00 \\
\end{tabular} & 0.00 & 0.00 & \begin{tabular}{|l}
0.00 \\
\end{tabular} & 0.00 & 0.00 & 0.00 & 0.03 & 0.00 \\
\hline 891 & 419.2 & 0.00 & 0.00 & 0.00 & 0.01 & 0.02 & 0.00 & \begin{tabular}{|l|}
0.02 \\
\end{tabular} & 0.00 & 0.00 & 0.00 & 0.00 & \begin{tabular}{|l|}
0.00 \\
\end{tabular} & 0.00 & 0.00 & 0.00 & 0.00 & 0.00 & \begin{tabular}{|l|}
0.00 \\
\end{tabular} \\
\hline 901 & 424.8 & 0.00 & 0.00 & 0.00 & 0.00 & 0.05 & 0.00 & \begin{tabular}{|l|}
0.05 \\
\end{tabular} & 0.01 & 0.00 & 0.00 & 0.00 & 0.00 & 0.00 & 0.00 & 0.00 & 0.00 & 0.02 & 0.00 \\
\hline 911 & 431.7 & 0.02 & 0.00 & 0.00 & 0.01 & 0.02 & 0.00 & \begin{tabular}{|l|}
0.07 \\
\end{tabular} & 0.00 & 0.00 & 0.00 & 0.00 & 0.00 & 0.00 & 0.00 & 0.00 & 0.00 & 0.28 & 0.00 \\
\hline 921 & 434.7 & 0.02 & 0.00 & 0.00 & 0.00 & 0.01 & 0.00 & \begin{tabular}{|l|}
0.07 \\
\end{tabular} & 0.00 & 0.00 & 0.00 & 0.00 & 0.00 & 0.00 & 0.00 & 0.00 & 0.00 & 0.31 & 0.00 \\
\hline 931 & 437.9 & 0.01 & 0.00 & 0.00 & 0.00 & 0.02 & 0.00 & 0.27 & 0.00 & 0.00 & 0.00 & 0.00 & 0.00 & 0.00 & 0.00 & 0.00 & 0.00 & 0.20 & 0.00 \\
\hline MD06-2988 & & & & & & & & & & & & & & & & & & & \\
\hline 831 & 359.6 & 0.01 & 0.00 & 0.00 & 0.00 & 0.02 & 0.00 & 0.00 & 0.00 & 0.00 & 0.00 & 0.00 & 0.00 & 0.00 & 0.00 & 0.00 & 0.00 & 0.17 & 0.00 \\
\hline 836 & 361.4 & 0.00 & 0.00 & \begin{tabular}{|l|}
0.00 \\
\end{tabular} & 0.00 & 0.01 & 0.00 & \begin{tabular}{|l|}
0.00 \\
\end{tabular} & 0.00 & 0.00 & 0.00 & 0.00 & \begin{tabular}{|l|}
0.00 \\
\end{tabular} & 0.00 & 0.00 & 0.00 & 0.00 & 0.24 & 0.00 \\
\hline 841 & 363.3 & 0.00 & 0.00 & 0.00 & 0.00 & 0.01 & 0.00 & \begin{tabular}{|l|}
0.00 \\
\end{tabular} & 0.00 & 0.00 & 0.00 & 0.00 & 0.00 & 0.00 & 0.00 & 0.00 & 0.00 & 0.16 & 0.00 \\
\hline 846 & 365.1 & 0.00 & 0.00 & 0.00 & 0.00 & 0.02 & 0.00 & \begin{tabular}{|l|}
0.00 \\
\end{tabular} & 0.00 & 0.00 & 0.00 & 0.00 & 0.00 & 0.00 & 0.00 & 0.00 & 0.00 & 0.26 & 0.00 \\
\hline 851 & 366.9 & 0.00 & 0.00 & 0.00 & 0.00 & 0.01 & 0.00 & 0.00 & 0.00 & 0.00 & 0.00 & 0.00 & 0.00 & 0.00 & 0.00 & 0.00 & 0.00 & 0.14 & 0.00 \\
\hline 856 & 368.8 & 0.00 & 0.00 & 0.00 & 0.00 & 0.00 & 0.00 & \begin{tabular}{|l|}
0.00 \\
\end{tabular} & 0.00 & 0.00 & 0.00 & 0.00 & 0.00 & 0.00 & 0.00 & 0.00 & 0.00 & 0.11 & 0.00 \\
\hline 861 & 370.6 & 0.00 & 0.00 & 0.00 & 0.01 & 0.01 & 0.00 & \begin{tabular}{|l|}
0.01 \\
\end{tabular} & 0.00 & 0.00 & 0.00 & 0.00 & 0.00 & 0.00 & 0.00 & 0.00 & 0.00 & 0.11 & 0.00 \\
\hline 866 & 372.4 & 0.00 & 0.00 & 0.00 & 0.00 & 0.01 & 0.00 & \begin{tabular}{|l|}
0.03 \\
\end{tabular} & 0.00 & 0.00 & 0.00 & 0.00 & 0.00 & 0.00 & 0.00 & 0.00 & 0.00 & 0.11 & 0.00 \\
\hline 871 & 374.3 & 0.00 & 0.00 & 0.00 & 0.00 & 0.01 & 0.00 & 0.01 & 0.00 & 0.00 & 0.00 & 0.00 & 0.00 & 0.00 & 0.00 & 0.00 & 0.00 & 0.08 & 0.00 \\
\hline 876 & 376.1 & 0.00 & 0.00 & 0.00 & 0.01 & 0.01 & 0.00 & \begin{tabular}{|l|}
0.01 \\
\end{tabular} & 0.00 & 0.00 & 0.00 & 0.00 & 0.00 & 0.00 & 0.00 & 0.00 & 0.00 & 0.15 & 0.00 \\
\hline 881 & 377.9 & 0.00 & 0.00 & 0.00 & 0.00 & 0.00 & 0.00 & 0.05 & 0.00 & 0.00 & 0.00 & 0.00 & 0.00 & 0.00 & 0.00 & 0.00 & 0.00 & 0.28 & 0.00 \\
\hline 886 & 379.8 & 0.00 & 0.00 & 0.00 & 0.01 & 0.01 & 0.00 & \begin{tabular}{|l|}
0.07 \\
\end{tabular} & 0.00 & 0.00 & 0.00 & 0.00 & 0.00 & 0.00 & 0.00 & 0.00 & 0.00 & 0.21 & 0.00 \\
\hline 891 & 381.6 & 0.00 & 0.00 & 0.00 & 0.00 & 0.00 & 0.00 & 0.01 & 0.00 & 0.00 & 0.00 & 0.00 & 0.00 & 0.00 & 0.00 & 0.00 & 0.00 & 0.17 & 0.00 \\
\hline 896 & 383.4 & 0.0 & 0.00 & 0.00 & \begin{tabular}{|l|l} 
\\
\end{tabular} & \begin{tabular}{|l} 
\\
\end{tabular} & 0.00 & 0.01 & 0.00 & \begin{tabular}{|l}
0.00 \\
\end{tabular} & 0.00 & 0.0 & 0.00 & \begin{tabular}{|l}
0.00 \\
\end{tabular} & 0.00 & \begin{tabular}{|l}
0.00 \\
\end{tabular} & 0.00 & 0.12 & 0.00 \\
\hline 901 & 385.3 & 0.00 & 0.00 & 0.00 & 0.02 & 0.01 & 0.00 & 0.02 & 0.00 & 0.00 & 0.00 & 0.00 & 0.00 & 0.00 & 0.00 & 0.00 & 0.00 & 0.17 & 0.00 \\
\hline
\end{tabular}




\begin{tabular}{|c|c|c|c|c|c|c|c|c|c|c|c|c|c|c|c|c|c|c|c|}
\hline 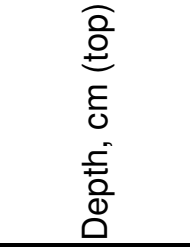 & 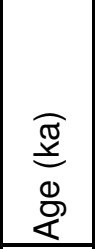 & $\begin{array}{c}-1 \\
-1 \\
0 \\
0 \\
0 \\
0 \\
0\end{array}$ & $\begin{array}{l}n_{1} \\
\vec{U}^{\prime} \\
0 \\
0 \\
0 \\
0\end{array}$ & 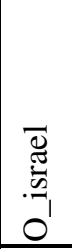 & 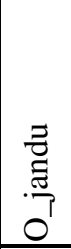 & $\begin{array}{l}\overrightarrow{0} \\
0 \\
0 \\
x_{1} \\
x_{2}^{2}\end{array}$ & 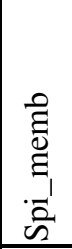 & $\begin{array}{l}\Xi \\
\Xi \\
\Xi_{1} \\
\tilde{n}\end{array}$ & 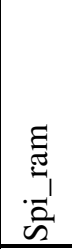 & $\begin{array}{l}\overline{0} \\
\overline{0} \\
\overline{0} \\
\bar{n}\end{array}$ & 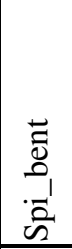 & $\begin{array}{c}\tilde{0} \\
\tilde{z} \\
0 \\
\bar{a} \\
\tilde{n}\end{array}$ & 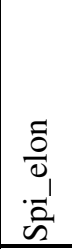 & 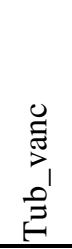 & $\begin{array}{l}0 \\
2 \\
\infty \\
0 \\
0 \\
0 \\
0 \\
0\end{array}$ & $\begin{array}{l}\frac{1}{0} \\
\text { N. } \\
\text { ते } \\
0 \\
0\end{array}$ & 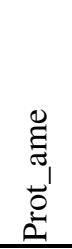 & 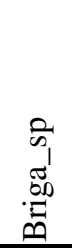 & 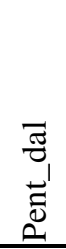 \\
\hline 906 & \begin{tabular}{|l|}
387.1 \\
\end{tabular} & \begin{tabular}{|l|}
0.00 \\
\end{tabular} & 0.00 & 0.00 & 0.00 & \begin{tabular}{|l|}
0.01 \\
\end{tabular} & 0.00 & 0.03 & 0.00 & 0.00 & 0.00 & 0.00 & 0.00 & 0.00 & 0.00 & 0.00 & 0.00 & 0.02 & 0.00 \\
\hline 911 & 388.9 & 0.00 & 0.00 & 0.00 & 0.01 & 0.03 & 0.00 & 0.01 & 0.00 & 0.00 & 0.00 & 0.00 & 0.00 & 0.00 & 0.00 & 0.00 & 0.00 & 0.08 & 0.00 \\
\hline 916 & 390.8 & 0.00 & 0.00 & 0.00 & 0.00 & 0.02 & 0.00 & 0.04 & 0.00 & 0.00 & 0.00 & 0.00 & 0.00 & 0.00 & 0.00 & 0.00 & 0.00 & 0.08 & 0.00 \\
\hline 921 & 392.6 & 0.00 & 0.00 & 0.00 & 0.01 & \begin{tabular}{|l|}
0.04 \\
\end{tabular} & 0.00 & 0.05 & 0.01 & 0.00 & 0.00 & 0.00 & 0.00 & 0.00 & 0.00 & 0.00 & 0.00 & 0.12 & 0.01 \\
\hline 926 & \begin{tabular}{|l|}
394.4 \\
\end{tabular} & 0.00 & 0.00 & 0.00 & 0.01 & 0.00 & 0.00 & 0.08 & 0.00 & 0.00 & 0.00 & 0.00 & 0.00 & 0.00 & 0.00 & 0.00 & 0.00 & 0.10 & 0.00 \\
\hline 931 & 396.3 & 0.00 & 0.00 & 0.00 & 0.00 & 0.03 & 0.00 & 0.02 & 0.00 & 0.00 & 0.00 & 0.00 & 0.00 & 0.00 & 0.00 & 0.00 & 0.00 & 0.17 & 0.00 \\
\hline 936 & 398.1 & 0.00 & 0.00 & 0.00 & \begin{tabular}{|l|}
0.01 \\
\end{tabular} & 0.02 & 0.00 & 0.01 & 0.00 & 0.00 & 0.00 & 0.00 & 0.00 & 0.00 & 0.00 & 0.00 & 0.00 & 0.06 & 0.00 \\
\hline 941 & \begin{tabular}{|l|l}
399.9 \\
\end{tabular} & 0.00 & 0.00 & 0.00 & 0.01 & 0.02 & 0.00 & 0.03 & 0.00 & 0.00 & 0.00 & 0.00 & 0.00 & 0.00 & 0.00 & 0.00 & 0.00 & 0.02 & 0.00 \\
\hline 946 & \begin{tabular}{|l|l}
401.8 \\
\end{tabular} & 0.00 & 0.00 & 0.00 & 0.00 & 0.04 & 0.00 & 0.05 & 0.00 & 0.00 & 0.00 & 0.00 & 0.00 & 0.00 & 0.00 & 0.00 & 0.00 & 0.00 & 0.00 \\
\hline 951 & \begin{tabular}{|l|}
403.6 \\
\end{tabular} & 0.00 & 0.00 & 0.00 & \begin{tabular}{|l|}
0.01 \\
\end{tabular} & \begin{tabular}{|l|}
0.02 \\
\end{tabular} & 0.00 & \begin{tabular}{|l|}
0.12 \\
\end{tabular} & 0.00 & 0.00 & 0.00 & 0.00 & 0.00 & 0.00 & 0.00 & 0.00 & 0.00 & 0.11 & 0.00 \\
\hline 956 & 405.2 & 0.00 & 0.00 & 0.00 & 0.00 & 0.03 & 0.00 & 0.09 & 0.00 & 0.00 & 0.00 & 0.00 & 0.00 & 0.00 & 0.00 & 0.00 & 0.00 & 0.00 & 0.00 \\
\hline 961 & 406.9 & 0.00 & 0.00 & 0.00 & 0.01 & 0.04 & 0.00 & 0.08 & 0.00 & 0.00 & 0.00 & 0.00 & 0.00 & 0.00 & 0.00 & 0.00 & 0.00 & 0.00 & 0.00 \\
\hline 971 & 410.2 & 0.01 & 0.00 & 0.00 & 0.00 & 0.03 & 0.00 & 0.07 & 0.00 & 0.00 & 0.00 & 0.00 & 0.00 & 0.00 & 0.00 & 0.00 & 0.00 & 0.11 & 0.00 \\
\hline 976 & 411.8 & 0.00 & 0.00 & 0.00 & 0.02 & 0.01 & 0.00 & 0.07 & 0.00 & 0.00 & 0.00 & 0.00 & 0.00 & 0.00 & 0.00 & 0.00 & 0.00 & 0.03 & 0.00 \\
\hline 981 & 413.5 & 0.00 & 0.00 & 0.00 & 0.01 & 0.02 & 0.00 & 0.06 & 0.00 & 0.00 & 0.00 & 0.00 & 0.00 & 0.00 & 0.00 & 0.00 & 0.00 & 0.01 & 0.00 \\
\hline 986 & \begin{tabular}{|l|l}
415.1 \\
\end{tabular} & \begin{tabular}{|l|}
0.00 \\
\end{tabular} & 0.00 & 0.00 & \begin{tabular}{|l|}
0.02 \\
\end{tabular} & \begin{tabular}{|l|}
0.03 \\
\end{tabular} & 0.00 & 0.04 & 0.00 & 0.00 & 0.00 & 0.00 & 0.00 & 0.00 & 0.00 & 0.00 & 0.00 & 0.05 & 0.00 \\
\hline 991 & \begin{tabular}{|l|l}
416.8 \\
\end{tabular} & 0.00 & 0.00 & 0.00 & 0.00 & 0.01 & 0.00 & 0.01 & 0.00 & 0.00 & 0.00 & 0.00 & 0.00 & 0.00 & 0.00 & 0.00 & 0.00 & 0.02 & 0.00 \\
\hline 996 & 418.4 & 0.00 & 0.00 & 0.00 & 0.00 & 0.02 & 0.00 & 0.02 & 0.00 & 0.00 & 0.00 & 0.00 & 0.00 & 0.00 & 0.00 & 0.00 & 0.00 & 0.01 & 0.00 \\
\hline 1001 & \begin{tabular}{|l|}
420.1 \\
\end{tabular} & \begin{tabular}{|l|l|}
0.00 \\
\end{tabular} & \begin{tabular}{|l|l}
0.00 \\
\end{tabular} & 0.00 & \begin{tabular}{|l|}
0.01 \\
\end{tabular} & \begin{tabular}{|l|}
0.01 \\
\end{tabular} & 0.00 & 0.04 & 0.00 & 0.00 & 0.00 & 0.00 & 0.00 & 0.00 & 0.02 & 0.00 & 0.00 & 0.17 & 0.00 \\
\hline 1006 & \begin{tabular}{|l}
421.7 \\
\end{tabular} & 0.00 & 0.00 & 0.00 & 0.01 & 0.02 & 0.00 & 0.04 & 0.00 & 0.00 & 0.00 & 0.00 & 0.00 & 0.00 & 0.00 & 0.00 & 0.00 & 0.06 & 0.00 \\
\hline 1011 & 423.4 & 0.00 & 0.00 & 0.00 & 0.01 & 0.01 & 0.00 & 0.04 & 0.00 & 0.00 & 0.00 & 0.00 & 0.00 & 0.00 & 0.00 & 0.00 & 0.00 & 0.31 & 0.01 \\
\hline 1016 & 425.0 & 0.00 & 0.00 & 0.00 & 0.01 & 0.03 & 0.00 & 0.01 & 0.00 & 0.00 & 0.00 & 0.00 & 0.00 & 0.00 & 0.00 & 0.00 & 0.00 & 0.30 & 0.00 \\
\hline 1021 & 426.7 & 0.00 & 0.00 & 0.00 & 0.00 & 0.05 & 0.00 & 0.02 & 0.00 & 0.00 & 0.00 & 0.00 & 0.00 & 0.00 & 0.00 & 0.00 & 0.00 & 0.36 & 0.01 \\
\hline 1026 & \begin{tabular}{|l}
428.3 \\
\end{tabular} & 0.00 & 0.00 & 0.00 & 0.01 & 0.01 & 0.00 & 0.02 & 0.00 & 0.00 & 0.00 & 0.00 & 0.00 & 0.00 & 0.00 & 0.00 & 0.00 & 0.34 & 0.00 \\
\hline 1031 & 430.0 & \begin{tabular}{|l|}
0.01 \\
\end{tabular} & 0.00 & 0.00 & 0.00 & \begin{tabular}{|l|}
0.01 \\
\end{tabular} & 0.00 & 0.02 & 0.01 & 0.00 & 0.00 & 0.00 & 0.00 & 0.00 & 0.00 & 0.00 & 0.00 & 0.67 & 0.01 \\
\hline 1041 & 432.9 & 0.00 & 0.00 & 0.00 & 0.00 & 0.03 & 0.01 & 0.07 & 0.00 & 0.00 & 0.00 & 0.00 & 0.00 & 0.00 & 0.00 & 0.00 & 0.00 & 0.35 & 0.00 \\
\hline 1051 & 435.1 & 0.01 & 0.00 & 0.00 & 0.00 & 0.06 & 0.00 & 0.13 & 0.00 & 0.00 & 0.00 & 0.00 & 0.00 & 0.00 & 0.00 & 0.00 & 0.00 & 0.22 & 0.00 \\
\hline \multicolumn{20}{|l|}{ MD06-2987 } \\
\hline 3761 & 391.8 & 0.00 & 0.00 & 0.00 & 0.00 & 0.04 & 0.00 & 0.01 & 0.02 & 0.00 & 0.00 & 0.00 & 0.00 & 0.00 & 0.00 & 0.00 & 0.00 & 0.07 & 0.00 \\
\hline 3771 & 394.5 & 0.00 & 0.00 & 0.00 & 0.00 & 0.06 & 0.00 & 0.01 & 0.04 & 0.00 & 0.00 & 0.00 & 0.00 & 0.00 & 0.00 & 0.00 & 0.00 & 0.08 & 0.00 \\
\hline 3781 & 397.2 & 0.00 & 0.00 & 0.00 & 0.00 & 0.03 & 0.00 & 0.00 & 0.02 & 0.00 & 0.00 & 0.00 & 0.00 & 0.00 & 0.00 & 0.00 & 0.00 & 0.02 & 0.00 \\
\hline 3791 & 399.8 & 0.00 & 0.00 & 0.00 & 0.00 & 0.02 & 0.00 & 0.03 & 0.03 & 0.00 & 0.00 & 0.00 & 0.00 & 0.00 & 0.00 & 0.00 & 0.00 & 0.00 & 0.00 \\
\hline 3801 & 402.5 & 0.00 & 0.00 & 0.00 & 0.01 & 0.01 & 0.00 & 0.00 & 0.03 & 0.00 & 0.00 & 0.00 & 0.00 & 0.00 & 0.00 & 0.00 & 0.00 & 0.00 & 0.00 \\
\hline 3811 & 405.2 & 0.00 & 0.00 & 0.00 & 0.01 & 0.00 & 0.00 & 0.06 & 0.02 & 0.00 & 0.00 & 0.00 & 0.00 & 0.00 & 0.00 & 0.00 & 0.00 & 0.00 & 0.00 \\
\hline 3821 & \begin{tabular}{|l|l}
407.8 \\
\end{tabular} & 0.00 & 0.00 & 0.00 & 0.00 & 0.01 & 0.00 & 0.02 & 0.03 & 0.00 & 0.00 & 0.00 & 0.00 & 0.00 & 0.00 & 0.00 & 0.00 & 0.00 & 0.00 \\
\hline 3831 & 410.4 & 0.00 & 0.00 & 0.00 & 0.00 & 0.00 & 0.00 & 0.02 & 0.03 & 0.00 & 0.00 & 0.00 & 0.00 & 0.00 & 0.00 & 0.00 & 0.00 & 0.00 & 0.00 \\
\hline 3841 & \begin{tabular}{|l|}
413.0 \\
\end{tabular} & 0.00 & 0.00 & 0.00 & \begin{tabular}{|l|}
0.01 \\
\end{tabular} & 0.00 & 0.00 & 0.03 & 0.01 & 0.00 & 0.00 & 0.00 & 0.00 & 0.00 & 0.00 & 0.00 & 0.00 & 0.00 & 0.00 \\
\hline 3851 & 415.5 & 0.00 & 0.00 & 0.00 & 0.03 & 0.00 & 0.00 & 0.04 & 0.02 & 0.00 & 0.00 & 0.00 & 0.00 & 0.00 & 0.00 & 0.00 & 0.00 & 0.00 & 0.00 \\
\hline 3861 & 418.0 & 0.00 & 0.00 & 0.00 & 0.01 & 0.00 & 0.00 & 0.03 & 0.00 & 0.00 & 0.00 & 0.00 & 0.00 & 0.00 & 0.00 & 0.00 & 0.00 & 0.00 & 0.00 \\
\hline 3871 & 420.5 & 0.00 & 0.00 & 0.00 & 0.00 & 0.00 & 0.00 & 0.04 & 0.00 & 0.00 & 0.00 & 0.00 & 0.00 & 0.00 & 0.00 & 0.00 & 0.00 & 0.00 & 0.00 \\
\hline 3881 & 423.0 & 0.00 & 0.00 & 0.00 & 0.00 & 0.00 & 0.00 & 0.01 & 0.00 & 0.00 & 0.00 & 0.00 & 0.00 & 0.00 & 0.00 & 0.00 & 0.00 & 0.00 & 0.00 \\
\hline
\end{tabular}




\begin{tabular}{|c|c|c|c|c|c|c|c|c|}
\hline 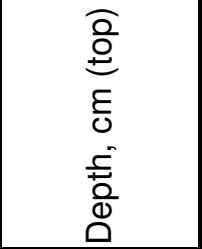 & 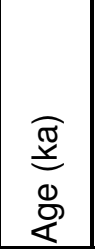 & $\begin{array}{l}\vec{\Xi} \\
\vec{\Xi} \\
\overrightarrow{\tilde{\Xi}}\end{array}$ & 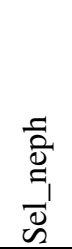 & 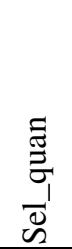 & $\begin{array}{l}\overrightarrow{2} \\
\vec{z} \\
\vec{E} \\
\vec{E}\end{array}$ & $\begin{array}{l}4 \\
0 \\
\frac{0}{1} \\
\frac{\lambda}{0} \\
0\end{array}$ & 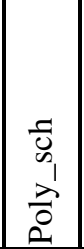 & $\begin{array}{l}2 \\
2 \\
\infty \\
\text { | } \\
\text { I } \\
\text { II }\end{array}$ \\
\hline \multicolumn{9}{|l|}{ MD06-2989 } \\
\hline 691 & 335.3 & 0.00 & 0.00 & 0.00 & 0.00 & 0.00 & 0.00 & 0.00 \\
\hline 701 & 341.5 & 0.00 & 0.00 & 0.00 & 0.00 & 0.00 & 0.00 & 0.00 \\
\hline 711 & 345.4 & 0.01 & 0.00 & 0.00 & 0.00 & 0.00 & 0.00 & 0.00 \\
\hline 721 & 348.9 & 0.01 & 0.01 & 0.00 & 0.00 & 0.00 & \begin{tabular}{|l|}
0.00 \\
\end{tabular} & 0.01 \\
\hline 726 & 350.6 & 0.01 & 0.01 & 0.00 & 0.00 & 0.00 & 0.00 & 0.01 \\
\hline 731 & 352.3 & 0.00 & 0.03 & 0.01 & 0.00 & 0.00 & 0.00 & 0.00 \\
\hline 736 & 354.1 & 0.00 & 0.03 & 0.00 & 0.00 & 0.00 & \begin{tabular}{|l|}
0.00 \\
\end{tabular} & 0.05 \\
\hline 741 & 355.8 & 0.00 & 0.01 & 0.00 & 0.00 & 0.00 & 0.00 & 0.00 \\
\hline 746 & \begin{tabular}{|l|}
357.6 \\
\end{tabular} & 0.00 & 0.03 & 0.00 & 0.00 & 0.00 & 0.00 & 0.01 \\
\hline 756 & 361.1 & 0.00 & 0.02 & 0.00 & 0.00 & 0.00 & \begin{tabular}{|l|}
0.00 \\
\end{tabular} & 0.00 \\
\hline 761 & 362.8 & 0.00 & 0.01 & 0.00 & 0.00 & 0.00 & 0.00 & 0.01 \\
\hline 771 & \begin{tabular}{|l|}
366.3 \\
\end{tabular} & 0.00 & 0.00 & 0.00 & 0.00 & 0.00 & 0.00 & 0.02 \\
\hline 781 & 369.8 & 0.00 & 0.01 & 0.01 & 0.00 & 0.00 & \begin{tabular}{|l|}
0.00 \\
\end{tabular} & 0.00 \\
\hline 791 & 373.3 & 0.00 & 0.01 & 0.02 & 0.00 & 0.00 & 0.00 & 0.00 \\
\hline 796 & \begin{tabular}{|l|}
375.0 \\
\end{tabular} & 0.00 & 0.03 & 0.00 & 0.00 & 0.00 & \begin{tabular}{|l|}
0.00 \\
\end{tabular} & 0.00 \\
\hline 801 & \begin{tabular}{|l|}
376.8 \\
\end{tabular} & 0.00 & 0.00 & 0.00 & 0.00 & 0.00 & \begin{tabular}{|l|}
0.00 \\
\end{tabular} & 0.00 \\
\hline 806 & \begin{tabular}{|l|}
378.5 \\
\end{tabular} & 0.00 & 0.04 & 0.01 & 0.00 & 0.00 & 0.00 & 0.01 \\
\hline 811 & \begin{tabular}{|l|}
380.3 \\
\end{tabular} & 0.00 & 0.02 & 0.02 & 0.00 & 0.00 & \begin{tabular}{|l|}
0.00 \\
\end{tabular} & 0.00 \\
\hline 821 & 383.8 & 0.00 & 0.01 & 0.00 & 0.00 & 0.00 & \begin{tabular}{|l|}
0.00 \\
\end{tabular} & 0.01 \\
\hline 831 & \begin{tabular}{|l|}
387.2 \\
\end{tabular} & 0.00 & 0.00 & 0.00 & 0.00 & 0.00 & 0.00 & 0.00 \\
\hline 841 & \begin{tabular}{|l|}
390.7 \\
\end{tabular} & 0.01 & 0.01 & 0.00 & 0.00 & 0.00 & \begin{tabular}{|l|}
0.00 \\
\end{tabular} & 0.00 \\
\hline 851 & \begin{tabular}{|l|}
393.7 \\
\end{tabular} & 0.00 & 0.00 & 0.00 & 0.00 & 0.00 & 0.00 & 0.00 \\
\hline 856 & \begin{tabular}{|l|}
396.7 \\
\end{tabular} & 0.00 & 0.00 & 0.00 & 0.00 & 0.00 & \begin{tabular}{|l|}
0.00 \\
\end{tabular} & 0.00 \\
\hline 861 & \begin{tabular}{|l|}
399.6 \\
\end{tabular} & 0.00 & 0.00 & 0.00 & 0.00 & 0.00 & \begin{tabular}{|l|}
0.00 \\
\end{tabular} & 0.00 \\
\hline 871 & \begin{tabular}{|l|}
402.6 \\
\end{tabular} & 0.00 & 0.00 & 0.00 & 0.00 & 0.00 & 0.00 & 0.00 \\
\hline 876 & \begin{tabular}{|l|l}
405.2 \\
\end{tabular} & 0.00 & 0.00 & 0.00 & 0.00 & 0.00 & \begin{tabular}{|l|}
0.00 \\
\end{tabular} & 0.00 \\
\hline 881 & \begin{tabular}{|l|}
408.1 \\
\end{tabular} & 0.00 & 0.00 & 0.00 & 0.00 & 0.00 & \begin{tabular}{|l|}
0.00 \\
\end{tabular} & 0.00 \\
\hline 886 & \begin{tabular}{|l|}
413.7 \\
\end{tabular} & 0.00 & 0.01 & 0.00 & 0.00 & 0.00 & 0.00 & 0.00 \\
\hline 891 & \begin{tabular}{|l|l}
419.2 \\
\end{tabular} & 0.00 & 0.00 & 0.00 & 0.00 & 0.00 & \begin{tabular}{|l|}
0.00 \\
\end{tabular} & 0.00 \\
\hline 901 & 424.8 & 0.00 & 0.00 & 0.00 & 0.00 & 0.00 & \begin{tabular}{|l|}
0.00 \\
\end{tabular} & 0.00 \\
\hline 911 & \begin{tabular}{|l|}
431.7 \\
\end{tabular} & 0.00 & 0.00 & 0.00 & 0.00 & 0.00 & \begin{tabular}{|l|}
0.00 \\
\end{tabular} & 0.02 \\
\hline 921 & \begin{tabular}{|l|l}
434.7 \\
\end{tabular} & 0.02 & 0.00 & 0.00 & 0.00 & 0.00 & \begin{tabular}{|l|}
0.00 \\
\end{tabular} & 0.00 \\
\hline 931 & \begin{tabular}{|l|}
437.9 \\
\end{tabular} & 0.00 & 0.00 & 0.00 & 0.00 & 0.00 & 0.00 & 0.01 \\
\hline \multicolumn{9}{|l|}{ MD06-2988 } \\
\hline 831 & 359.6 & 0.00 & 0.02 & 0.00 & 0.00 & 0.00 & 0.00 & 0.00 \\
\hline 836 & \begin{tabular}{|l|}
361.4 \\
\end{tabular} & 0.01 & 0.01 & 0.00 & 0.00 & 0.00 & 0.00 & 0.00 \\
\hline 841 & 363.3 & 0.01 & 0.01 & 0.01 & 0.00 & 0.00 & \begin{tabular}{|l|}
0.00 \\
\end{tabular} & 0.02 \\
\hline 846 & 365.1 & 0.00 & 0.05 & 0.01 & 0.00 & 0.00 & \begin{tabular}{|l|}
0.00 \\
\end{tabular} & 0.00 \\
\hline 851 & 366.9 & 0.00 & 0.01 & 0.00 & 0.00 & 0.00 & 0.00 & 0.00 \\
\hline 856 & 368.8 & 0.00 & 0.02 & 0.00 & 0.00 & 0.00 & 0.00 & 0.00 \\
\hline 861 & 370.6 & 0.00 & 0.02 & 0.00 & 0.00 & 0.00 & \begin{tabular}{|l|}
0.00 \\
\end{tabular} & 0.01 \\
\hline 866 & 372.4 & 0.00 & 0.00 & 0.01 & 0.00 & 0.00 & \begin{tabular}{|l|}
0.00 \\
\end{tabular} & 0.00 \\
\hline 871 & 374.3 & 0.00 & 0.01 & 0.01 & 0.00 & 0.00 & \begin{tabular}{|l|}
0.00 \\
\end{tabular} & 0.00 \\
\hline 876 & 376.1 & 0.00 & 0.02 & 0.01 & 0.00 & 0.00 & 0.00 & 0.00 \\
\hline 881 & 377.9 & 0.01 & 0.02 & 0.00 & 0.00 & 0.00 & \begin{tabular}{|l|}
0.00 \\
\end{tabular} & 0.01 \\
\hline 886 & 379.8 & 0.00 & 0.02 & 0.01 & 0.00 & 0.00 & 0.00 & 0.02 \\
\hline 891 & 381.6 & 0.01 & 0.01 & 0.01 & 0.00 & 0.00 & 0.00 & 0.00 \\
\hline 896 & 383.4 & 0.00 & 0.01 & 0.00 & 0.00 & 0.00 & \begin{tabular}{|l|}
0.00 \\
\end{tabular} & 0.01 \\
\hline 901 & 385.3 & 0.00 & 0.03 & 0.00 & 0.00 & 0.00 & \begin{tabular}{|l|}
0.00 \\
\end{tabular} & 0.00 \\
\hline
\end{tabular}




\begin{tabular}{|c|c|c|c|c|c|c|c|c|}
\hline 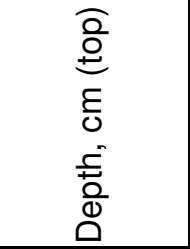 & 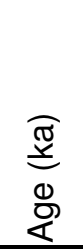 & $\begin{array}{l}\overrightarrow{\tilde{J}_{1}} \\
\overrightarrow{\mathbb{v}^{\prime}}\end{array}$ & $\begin{array}{l}\frac{0}{0} \\
\stackrel{0}{0} \\
\overrightarrow{0} \\
\tilde{\Xi}\end{array}$ & 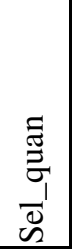 & $\begin{array}{l}\overline{2} \\
\bar{z} \\
\Xi \\
E\end{array}$ & $\begin{array}{l}4 \\
0 \\
\frac{1}{1} \\
\frac{\lambda}{0} \\
0\end{array}$ & 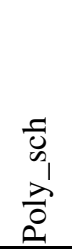 & $\begin{array}{l}\text { है } \\
\text { क } \\
\frac{0}{0} \\
\text { I }\end{array}$ \\
\hline 906 & 387.1 & 0.00 & 0.01 & 0.00 & 0.00 & 0.00 & 0.00 & 0.00 \\
\hline 911 & 388.9 & 0.00 & 0.00 & 0.01 & 0.00 & 0.00 & 0.00 & 0.01 \\
\hline 916 & 390.8 & 0.01 & 0.00 & 0.01 & 0.00 & 0.00 & 0.00 & 0.00 \\
\hline 921 & 392.6 & 0.00 & 0.00 & 0.00 & 0.00 & 0.00 & 0.00 & 0.00 \\
\hline 926 & 394.4 & 0.00 & 0.01 & 0.00 & 0.00 & 0.00 & 0.00 & 0.00 \\
\hline 931 & 396.3 & 0.00 & 0.01 & 0.00 & 0.00 & 0.00 & 0.00 & 0.00 \\
\hline 936 & 398.1 & 0.00 & 0.01 & 0.00 & 0.00 & 0.00 & 0.00 & 0.01 \\
\hline 941 & 399.9 & 0.00 & 0.00 & 0.00 & 0.00 & 0.00 & 0.00 & 0.00 \\
\hline 946 & 401.8 & 0.00 & 0.00 & 0.00 & 0.00 & 0.00 & 0.00 & 0.00 \\
\hline 951 & 403.6 & 0.00 & 0.00 & 0.00 & 0.00 & 0.00 & 0.00 & 0.00 \\
\hline 956 & 405.2 & 0.00 & 0.00 & 0.00 & 0.00 & 0.00 & 0.00 & 0.00 \\
\hline 961 & 406.9 & 0.00 & 0.00 & 0.00 & 0.00 & 0.00 & 0.00 & 0.00 \\
\hline 971 & 410.2 & 0.00 & 0.00 & 0.00 & 0.00 & 0.00 & 0.00 & 0.00 \\
\hline 976 & 411.8 & 0.00 & 0.00 & 0.00 & 0.00 & 0.00 & 0.00 & 0.00 \\
\hline 981 & 413.5 & 0.00 & 0.00 & 0.00 & 0.00 & 0.00 & 0.00 & 0.00 \\
\hline 986 & 415.1 & 0.00 & 0.01 & 0.00 & 0.00 & \begin{tabular}{|l|}
0.00 \\
\end{tabular} & 0.00 & 0.00 \\
\hline 991 & 416.8 & 0.00 & 0.00 & 0.00 & 0.00 & \begin{tabular}{|l|l}
0.00 \\
\end{tabular} & 0.00 & 0.01 \\
\hline 996 & 418.4 & 0.00 & 0.00 & 0.00 & 0.00 & 0.00 & 0.00 & 0.00 \\
\hline 1001 & 420.1 & \begin{tabular}{|l|}
0.00 \\
\end{tabular} & 0.02 & 0.00 & 0.00 & 0.00 & 0.00 & 0.01 \\
\hline 1006 & 421.7 & 0.00 & 0.02 & 0.00 & 0.00 & 0.00 & 0.00 & 0.00 \\
\hline 1011 & 423.4 & 0.00 & 0.01 & 0.00 & 0.00 & 0.00 & 0.00 & 0.09 \\
\hline 1016 & 425.0 & 0.00 & 0.01 & 0.00 & 0.00 & 0.00 & 0.00 & 0.09 \\
\hline 1021 & 426.7 & 0.00 & 0.00 & 0.00 & 0.00 & 0.00 & 0.00 & 0.10 \\
\hline 1026 & 428.3 & 0.00 & 0.02 & 0.01 & 0.00 & 0.00 & 0.00 & 0.07 \\
\hline 1031 & 430.0 & 0.00 & 0.00 & 0.01 & 0.00 & 0.00 & 0.00 & 0.06 \\
\hline 1041 & 432.9 & 0.02 & 0.00 & 0.00 & 0.00 & 0.00 & 0.00 & 0.01 \\
\hline 1051 & 435.1 & 0.00 & 0.00 & 0.00 & 0.00 & 0.00 & 0.00 & 0.03 \\
\hline \multicolumn{9}{|l|}{ MD06-2987 } \\
\hline 3761 & 391.8 & 0.00 & 0.02 & 0.00 & 0.00 & 0.00 & 0.00 & 0.00 \\
\hline 3771 & 394.5 & 0.00 & 0.02 & 0.00 & 0.00 & 0.00 & 0.00 & 0.01 \\
\hline 3781 & 397.2 & 0.00 & 0.01 & 0.00 & 0.00 & 0.00 & 0.00 & 0.00 \\
\hline 3791 & 399.8 & 0.00 & 0.00 & 0.00 & 0.00 & 0.00 & 0.00 & 0.00 \\
\hline 3801 & 402.5 & 0.00 & 0.00 & 0.00 & 0.00 & 0.00 & 0.00 & 0.00 \\
\hline 3811 & 405.2 & 0.00 & 0.00 & 0.00 & 0.00 & 0.00 & 0.00 & 0.00 \\
\hline 3821 & 407.8 & 0.00 & 0.00 & 0.00 & 0.00 & 0.00 & 0.00 & 0.00 \\
\hline 3831 & 410.4 & 0.00 & 0.00 & 0.00 & 0.00 & 0.00 & 0.00 & 0.00 \\
\hline 3841 & 413.0 & 0.00 & 0.00 & 0.00 & 0.00 & 0.00 & 0.00 & 0.00 \\
\hline 3851 & 415.5 & 0.00 & 0.00 & 0.00 & 0.00 & 0.00 & 0.00 & 0.00 \\
\hline 3861 & 418.0 & 0.00 & 0.00 & 0.00 & 0.00 & 0.00 & 0.00 & 0.00 \\
\hline 3871 & 420.5 & 0.00 & 0.00 & 0.00 & 0.00 & 0.00 & 0.00 & 0.00 \\
\hline 3881 & 423.0 & 0.00 & 0.00 & 0.00 & 0.00 & 0.00 & 0.00 & 0.00 \\
\hline
\end{tabular}


S5.2. SST and productivity index values from MIS11 east Tasman Sea samples

\begin{tabular}{|c|c|c|c|c|c|c|c|c|}
\hline 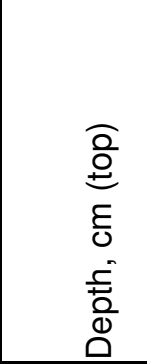 & $\begin{array}{l}\widehat{\mathbb{Q}} \\
\underline{y} \\
0 \\
\mathbb{8}\end{array}$ & $\begin{array}{l}\# \\
\text { \# } \\
\text { త }\end{array}$ & 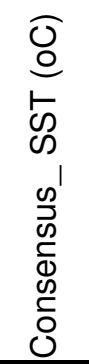 & 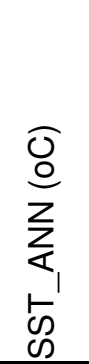 & 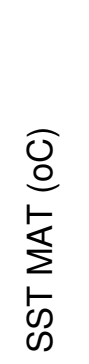 & $\begin{array}{l}\widehat{0} \\
\text { O } \\
\infty \\
\overrightarrow{0} \\
\stackrel{5}{c} \\
\mathscr{\infty}\end{array}$ & 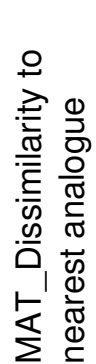 & 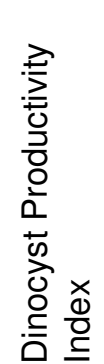 \\
\hline \multicolumn{9}{|c|}{\begin{tabular}{|l|} 
MD06-2989 \\
\end{tabular}} \\
\hline 691 & 335.3 & L26021 & 16.0 & 15.3 & 16.6 & 16.1 & 0.39 & 0.02 \\
\hline 701 & 341.5 & L26022 & 15.2 & 14.5 & 16.1 & 15.0 & 0.34 & 0.01 \\
\hline 711 & 345.4 & L26023 & 12.2 & 11.6 & 12.9 & 12.1 & 0.19 & 0.11 \\
\hline 721 & 348.9 & L26024 & 10.4 & 11.0 & 9.8 & 10.2 & 0.20 & 0.60 \\
\hline 726 & 350.6 & L26025 & 11.5 & 11.7 & 11.7 & 11.1 & 0.19 & 0.51 \\
\hline 731 & 352.3 & L26026 & 12.0 & 12.4 & 12.0 & 11.5 & 0.24 & 0.64 \\
\hline 736 & 354.1 & L26027 & 13.1 & 13.1 & 14.3 & 11.9 & 0.21 & 0.73 \\
\hline 741 & 355.8 & L26028 & 12.0 & 13.2 & 11.2 & 11.7 & 0.28 & 0.51 \\
\hline 746 & 357.6 & L26029 & 11.7 & 12.3 & 11.7 & 10.9 & 0.24 & 0.65 \\
\hline 756 & 361.1 & L22030 & 11.3 & 12.2 & 10.8 & 11.0 & 0.19 & 0.55 \\
\hline 761 & 362.8 & L25687 & 14.0 & 13.5 & 15.0 & 13.4 & 0.20 & 0.44 \\
\hline 771 & 366.3 & L26031 & 11.1 & 12.4 & 10.1 & 10.8 & 0.25 & 0.44 \\
\hline 781 & 369.8 & L25688 & 12.4 & 13.2 & 11.5 & 12.5 & 0.22 & 0.34 \\
\hline 791 & 373.3 & L25689 & 14.7 & 15.4 & 14.3 & 14.3 & 0.35 & 0.29 \\
\hline 796 & 375.0 & L26032 & 14.4 & 15.4 & 14.3 & 13.5 & 0.31 & 0.44 \\
\hline 801 & 376.8 & L25690 & 14.2 & 15.4 & 14.1 & 13.2 & 0.33 & 0.38 \\
\hline 806 & 378.5 & L26033 & 15.6 & 16.5 & 15.9 & 14.3 & 0.34 & 0.45 \\
\hline 811 & 380.3 & L25691 & 15.0 & 15.5 & 15.1 & 14.4 & 0.33 & 0.40 \\
\hline 821 & 383.8 & L25692 & 15.1 & 16.0 & 17.0 & 15.1 & 0.44 & 0.28 \\
\hline 831 & 387.2 & L25693 & 16.0 & 14.9 & 16.5 & 16.7 & 0.29 & 0.05 \\
\hline 841 & 390.7 & L25694 & 14.5 & 14.8 & 14.8 & 13.8 & 0.38 & 0.35 \\
\hline 851 & 393.7 & L25695 & 13.1 & 13.4 & 12.8 & 13.1 & 0.26 & 0.28 \\
\hline 856 & 396.7 & L26034 & 14.1 & 14.4 & 14.4 & 13.5 & 0.32 & 0.06 \\
\hline 861 & 399.6 & L25696 & 14.3 & 14.2 & 14.4 & 14.3 & 0.37 & 0.12 \\
\hline 871 & 402.6 & L25697 & 16.3 & 18.2 & 16.8 & 16.3 & 0.42 & 0.01 \\
\hline 876 & 405.2 & L26036 & 16.7 & 18.8 & 15.3 & 16.7 & 0.51 & 0.01 \\
\hline 881 & 408.1 & L25698 & 15.7 & 16.4 & 15.4 & 15.7 & 0.49 & 0.10 \\
\hline 886 & 413.7 & L26035 & 15.5 & 15.5 & 15.7 & 15.2 & 0.29 & 0.07 \\
\hline 891 & 419.2 & L25699 & 13.5 & 14.2 & 12.7 & 13.4 & 0.33 & 0.00 \\
\hline 901 & 424.8 & L25700 & 14.2 & 14.5 & 14.1 & 14.0 & 0.28 & 0.04 \\
\hline 911 & 431.7 & L25701 & 11.8 & 11.2 & 12.8 & 11.4 & 0.22 & 0.55 \\
\hline 921 & 434.7 & L25702 & 10.3 & 10.5 & 10.6 & 9.8 & 0.17 & 0.58 \\
\hline 931 & 437.9 & L26037 & 12.6 & 13.8 & 11.9 & 12.2 & 0.30 & 0.57 \\
\hline \multicolumn{9}{|c|}{ MD06-2988 } \\
\hline 831 & 359.6 & L26038 & 10.7 & 11.5 & 9.8 & 10.7 & 0.22 & 0.47 \\
\hline 836 & 361.4 & L26039 & 10.8 & 11.8 & 9.8 & 10.7 & 0.17 & 0.56 \\
\hline 841 & 363.3 & L26040 & 11.9 & 13.2 & 10.6 & 11.8 & 0.24 & 0.40 \\
\hline 846 & 365.1 & L26041 & 11.6 & 12.8 & 10.9 & 11.1 & 0.22 & 0.64 \\
\hline 851 & 366.9 & L26042 & 10.9 & 11.7 & 10.4 & 10.5 & 0.21 & 0.44 \\
\hline 856 & 368.8 & L26043 & 10.5 & 11.4 & 10.0 & 10.1 & 0.24 & 0.43 \\
\hline 861 & 370.6 & L26044 & 12.9 & 14.7 & 11.4 & 12.7 & 0.35 & 0.30 \\
\hline 866 & 372.4 & L24046 & 12.9 & 14.0 & 12.2 & 12.4 & 0.30 & 0.28 \\
\hline 871 & 374.3 & L26045 & 13.0 & 14.9 & 11.0 & 13.0 & 0.34 & 0.21 \\
\hline 876 & 376.1 & L26047 & 12.5 & 14.6 & 10.4 & 12.6 & 0.31 & 0.37 \\
\hline 881 & 377.9 & L25670 & 13.5 & 16.2 & 14.3 & 13.5 & 0.41 & 0.44 \\
\hline
\end{tabular}


S5.2. SST and productivity index values from MIS11 east Tasman Sea samples

\begin{tabular}{|c|c|c|c|c|c|c|c|c|}
\hline 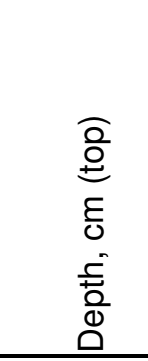 & 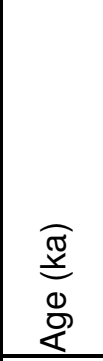 & 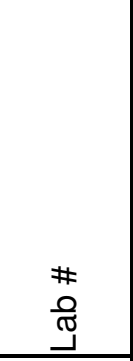 & $\begin{array}{l}\widehat{O} \\
0 \\
5 \\
-5 \\
\infty \\
1 \\
0 \\
0 \\
0 \\
0 \\
0 \\
0 \\
0 \\
0 \\
0\end{array}$ & 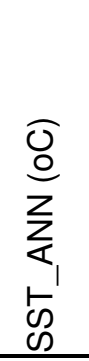 & $\begin{array}{l}0 \\
0 \\
0 \\
上 \\
\Sigma \\
\leftarrow \infty \\
\infty\end{array}$ & 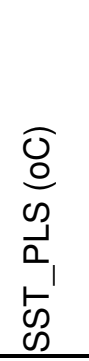 & 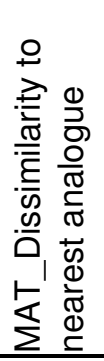 & 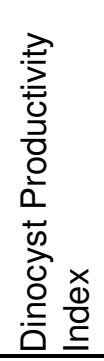 \\
\hline 886 & 379.8 & L26048 & 14.0 & 16.1 & 13.8 & 14.0 & 0.44 & 0.40 \\
\hline 891 & 381.6 & L25671 & 15.7 & 18.2 & 16.1 & 15.7 & 0.55 & 0.24 \\
\hline 896 & 383.4 & L26049 & 15.8 & 17.0 & 16.8 & 15.8 & 0.42 & 0.19 \\
\hline 901 & 385.3 & L25672 & 16.5 & 17.1 & 18.0 & 16.5 & 0.55 & 0.23 \\
\hline 906 & 387.1 & L26050 & 17.4 & 18.4 & 16.5 & 17.3 & 0.33 & 0.03 \\
\hline 911 & 388.9 & L25673 & 15.9 & 15.5 & 16.6 & 15.6 & 0.30 & 0.15 \\
\hline 916 & 390.8 & L26051 & 14.9 & 15.2 & 15.0 & 14.7 & 0.35 & 0.14 \\
\hline 921 & 392.6 & L25674 & 13.4 & 14.7 & 11.8 & 13.7 & 0.38 & 0.22 \\
\hline 926 & 394.4 & L26052 & 13.5 & 15.8 & 11.5 & 13.5 & 0.46 & 0.22 \\
\hline 931 & 396.3 & L25675 & 13.8 & 14.7 & 13.3 & 13.6 & 0.32 & 0.31 \\
\hline 936 & 398.1 & L26053 & 12.9 & 13.4 & 12.3 & 13.1 & 0.33 & 0.16 \\
\hline 941 & 399.9 & L25676 & 13.5 & 13.4 & 14.1 & 13.1 & 0.28 & 0.06 \\
\hline 946 & 401.8 & L26054 & 14.3 & 14.9 & 14.0 & 13.9 & 0.28 & 0.00 \\
\hline 951 & 403.6 & L25677 & 13.7 & 13.1 & 14.6 & 13.5 & 0.40 & 0.22 \\
\hline 956 & 405.2 & L26055 & 16.6 & 17.3 & 16.8 & 15.7 & 0.34 & 0.01 \\
\hline 961 & 406.9 & L25678 & 17.1 & 18.6 & 17.2 & 17.1 & 0.44 & 0.00 \\
\hline 971 & 410.2 & L25679 & 14.5 & 16.7 & 13.8 & 14.5 & 0.46 & 0.20 \\
\hline 976 & 411.8 & L26057 & 17.0 & 16.9 & 17.1 & 17.0 & 0.40 & 0.04 \\
\hline 981 & 413.5 & L25680 & 17.5 & 18.4 & 17.1 & 17.0 & 0.38 & 0.01 \\
\hline 986 & 415.1 & L26058 & 16.7 & 17.3 & 17.8 & 16.7 & 0.45 & 0.08 \\
\hline 991 & 416.8 & L25681 & 14.2 & 16.0 & 12.7 & 14.0 & 0.36 & 0.06 \\
\hline 996 & 418.4 & L26059 & 12.8 & 13.6 & 12.4 & 12.3 & 0.26 & 0.04 \\
\hline 1001 & 420.1 & L25682 & 12.3 & 12.9 & 11.7 & 12.1 & 0.30 & 0.42 \\
\hline 1006 & 421.7 & L26060 & 12.1 & 12.8 & 11.1 & 12.3 & 0.29 & 0.21 \\
\hline 1011 & 423.4 & L25683 & 14.4 & 14.3 & 15.6 & 13.3 & 0.36 & 0.55 \\
\hline 1016 & 425.0 & L26061 & 14.8 & 14.8 & 15.7 & 13.9 & 0.39 & 0.51 \\
\hline 1021 & 426.7 & L25684 & 14.1 & 15.4 & 13.5 & 13.4 & 0.37 & 0.64 \\
\hline 1026 & 428.3 & L26062 & 13.3 & 13.4 & 14.2 & 12.2 & 0.30 & 0.64 \\
\hline 1031 & 430.0 & L25685 & 11.0 & 11.7 & 10.2 & 11.0 & 0.23 & 0.88 \\
\hline 1041 & 432.9 & L25686 & 11.0 & 11.7 & 10.8 & 10.4 & 0.24 & 0.68 \\
\hline 1051 & 435.1 & L26063 & 12.8 & 14.4 & 11.6 & 12.4 & 0.33 & 0.59 \\
\hline \multicolumn{9}{|c|}{ MD06-2987 } \\
\hline 3761 & 391.8 & L25657 & 16.8 & 17.4 & 16.6 & 16.4 & 0.29 & 0.13 \\
\hline 3771 & 394.5 & L25658 & 15.3 & 16.3 & 13.8 & 15.8 & 0.31 & 0.17 \\
\hline 3781 & 397.2 & L25659 & 16.3 & 16.8 & 16.2 & 15.9 & 0.20 & 0.06 \\
\hline 3791 & 399.8 & L25660 & 16.1 & 16.7 & 16.0 & 15.5 & 0.28 & 0.01 \\
\hline 3801 & 402.5 & L25661 & 14.7 & 14.1 & 15.6 & 14.3 & 0.22 & 0.01 \\
\hline 3811 & 405.2 & L25662 & 13.6 & 13.5 & 13.9 & 13.3 & 0.26 & 0.01 \\
\hline 3821 & 407.8 & L25663 & 15.5 & 15.5 & 16.2 & 14.8 & 0.20 & 0.01 \\
\hline 3831 & 410.4 & L25664 & 17.1 & 17.8 & 16.6 & 16.9 & 0.23 & 0.00 \\
\hline 3841 & 413.0 & L25665 & 18.1 & 18.9 & 17.0 & 18.5 & 0.24 & 0.00 \\
\hline 3851 & 415.5 & L25666 & $\begin{array}{ll}16.8 \\
\end{array}$ & 16.2 & 16.6 & 17.7 & 0.27 & 0.00 \\
\hline 3861 & 418.0 & L25667 & 15.5 & 15.9 & 15.5 & 15.2 & 0.22 & 0.00 \\
\hline 3871 & 420.5 & L25668 & 13.5 & 13.9 & 13.6 & 12.8 & 0.26 & 0.00 \\
\hline 3881 & 423.0 & L25669 & 19.7 & 20.7 & 17.0 & 19.7 & 0.42 & 0.00 \\
\hline
\end{tabular}


S5.3. Stacked SST and productivity index values from east Tasman Sea

\begin{tabular}{|c|c|c|c|c|c|c|}
\hline 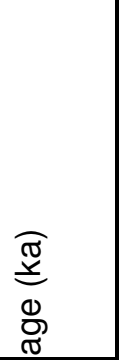 & 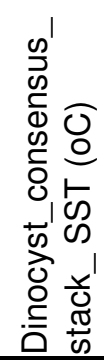 & 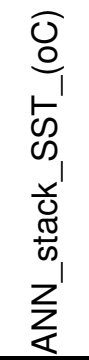 & 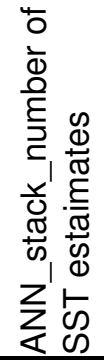 & 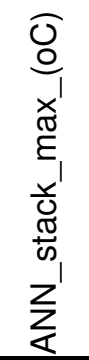 & 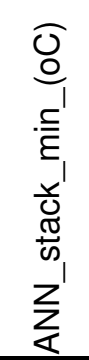 & 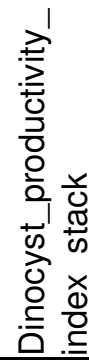 \\
\hline 333 & & 15.9 & 1 & 15.9 & 15.9 & \\
\hline 335 & 16.0 & 15.3 & 1 & 15.3 & 15.3 & 0.02 \\
\hline 337 & & 16.6 & 1 & 16.6 & 16.6 & \\
\hline 339 & & 12.4 & 1 & 12.4 & 12.4 & \\
\hline 341 & & 12.7 & 2 & 12.7 & 12.7 & \\
\hline 343 & 15.2 & 14.5 & 1 & 14.5 & 14.5 & 0.01 \\
\hline 345 & 12.2 & 11.6 & 2 & 11.6 & 11.5 & 0.11 \\
\hline 347 & & & 0 & & & \\
\hline 349 & 10.4 & 11.9 & 2 & 12.8 & 11.0 & 0.60 \\
\hline 351 & 11.5 & 11.7 & 1 & 11.7 & 11.7 & 0.51 \\
\hline 353 & 12.0 & 11.6 & 2 & 12.4 & 10.9 & 0.64 \\
\hline 355 & 13.1 & 13.1 & 1 & 13.1 & 13.1 & 0.73 \\
\hline 357 & 12.0 & 11.9 & 2 & 13.2 & 10.5 & 0.51 \\
\hline 359 & 11.7 & 12.3 & 1 & 12.3 & 12.3 & 0.65 \\
\hline 361 & 11.0 & 11.7 & 4 & 12.2 & 11.2 & 0.53 \\
\hline 363 & 12.9 & 13.4 & 2 & 13.5 & 13.2 & 0.42 \\
\hline 365 & 11.6 & 12.3 & 2 & 12.8 & 11.9 & 0.64 \\
\hline 367 & 11.0 & 12.0 & 2 & 12.4 & 11.7 & 0.44 \\
\hline 369 & 10.5 & 12.0 & 2 & 12.5 & 11.4 & 0.43 \\
\hline 371 & 12.7 & 13.5 & 3 & 14.7 & 12.5 & 0.32 \\
\hline 373 & 13.8 & 14.7 & 4 & 15.6 & 13.8 & 0.29 \\
\hline 375 & 13.7 & 15.1 & 2 & 15.4 & 14.9 & 0.33 \\
\hline 377 & 13.4 & 13.5 & 4 & 15.4 & 11.5 & 0.37 \\
\hline 379 & 14.6 & 16.4 & 2 & 16.5 & 16.2 & 0.45 \\
\hline 381 & 14.5 & 14.6 & 4 & 16.1 & 12.4 & 0.40 \\
\hline 383 & 15.4 & 16.8 & 3 & 17.6 & 16.0 & 0.25 \\
\hline 385 & 16.5 & 17.1 & 1 & 17.1 & 17.1 & 0.23 \\
\hline 387 & 16.7 & 17.0 & 4 & 18.4 & 14.9 & 0.04 \\
\hline 389 & 15.9 & 15.5 & 1 & 15.5 & 15.5 & 0.15 \\
\hline 391 & 14.7 & 14.9 & 3 & 15.2 & 14.8 & 0.25 \\
\hline 393 & 15.1 & 16.0 & 2 & 17.4 & 14.7 & 0.17 \\
\hline 395 & 13.9 & 15.9 & 5 & 18.6 & 13.4 & 0.23 \\
\hline 397 & 14.7 & 15.3 & 3 & 16.8 & 14.4 & 0.14 \\
\hline 399 & 12.9 & 15.0 & 3 & 16.5 & 13.4 & 0.16 \\
\hline 401 & 14.6 & 16.2 & 5 & 18.6 & 13.4 & 0.06 \\
\hline 403 & 15.1 & 16.5 & 4 & 18.7 & 14.1 & 0.01 \\
\hline 405 & 15.4 & 16.7 & 5 & 18.8 & 13.5 & 0.03 \\
\hline 407 & 17.1 & 18.6 & 1 & 18.6 & 18.6 & 0.00 \\
\hline 409 & 15.6 & 16.9 & 3 & 18.8 & 15.5 & 0.06 \\
\hline 411 & 15.8 & 17.5 & 2 & 18.0 & 16.7 & 0.10 \\
\hline 413 & 17.7 & 18.3 & 4 & 18.9 & 17.6 & 0.01 \\
\hline 415 & 16.3 & 16.3 & 3 & $\begin{array}{l}17.3 \\
\end{array}$ & 15.5 & 0.05 \\
\hline 417 & 14.2 & 16.0 & 1 & 16.0 & 16.0 & 0.06 \\
\hline 419 & 13.9 & 15.2 & 5 & 16.2 & 13.6 & 0.01 \\
\hline 421 & 12.9 & 13.4 & 2 & 13.9 & 12.9 & 0.21 \\
\hline 423 & 13.2 & 13.6 & 3 & 13.6 & 13.6 & 0.19 \\
\hline 425 & 14.5 & 15.3 & 4 & 16.2 & 14.5 & 0.28 \\
\hline
\end{tabular}


S5.3. Stacked SST and productivity index values from east Tasman Sea

\begin{tabular}{|c|c|c|c|c|c|c|}
\hline $\begin{array}{l}\underset{\mathbb{J}}{\mathbb{2}} \\
\underset{\mathbb{\sigma}}{\mathbb{\sigma}}\end{array}$ & 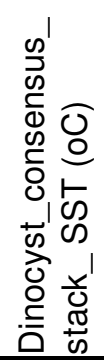 & 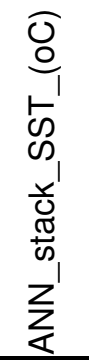 & 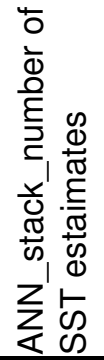 & 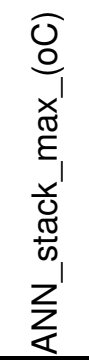 & 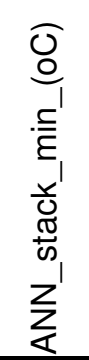 & 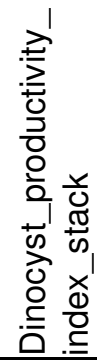 \\
\hline 427 & 14.1 & 14.6 & 2 & 15.4 & 13.8 & 0.64 \\
\hline 429 & 13.3 & 13.4 & 1 & 13.4 & 13.4 & 0.64 \\
\hline 431 & 11.4 & 11.1 & 3 & 11.7 & 10.3 & 0.72 \\
\hline 433 & 11.0 & 11.7 & 1 & 11.7 & 11.7 & 0.68 \\
\hline 435 & 11.5 & 11.4 & & 14.4 & 10.0 & 0.59 \\
\hline 437 & 12.6 & 13.8 & 1 & 13.8 & 13.8 & 0.57 \\
\hline 439 & & 10.5 & 2 & 10.6 & 10.4 & \\
\hline 441 & & 10.3 & 2 & 10.7 & 10.0 & \\
\hline
\end{tabular}




\begin{tabular}{|c|c|c|c|c|c|c|c|c|c|c|c|c|c|c|c|c|c|}
\hline 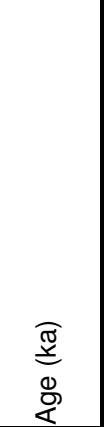 & $\begin{array}{l}\bar{\xi} \\
\overline{\underline{g}} \\
\overline{\overline{0}} \\
\underline{0}\end{array}$ & 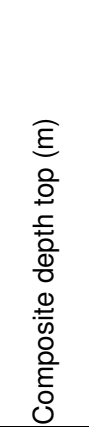 & 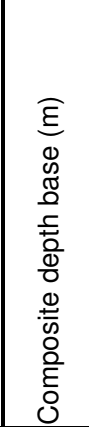 & 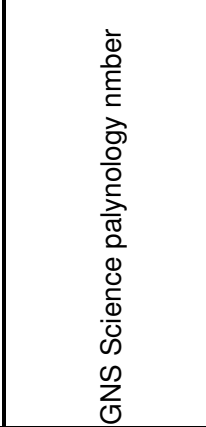 & 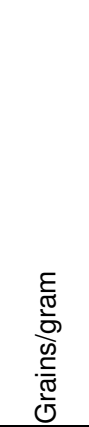 & 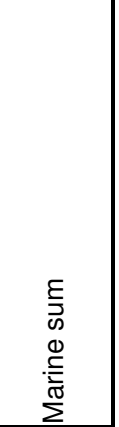 & 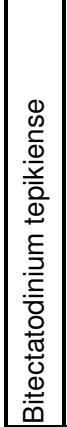 & 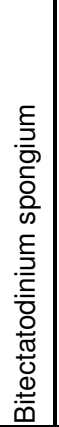 & 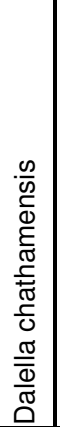 & 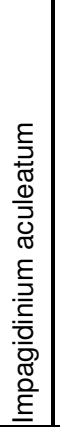 & 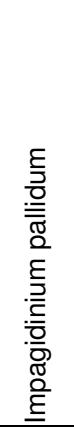 & 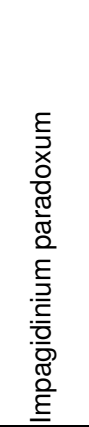 & 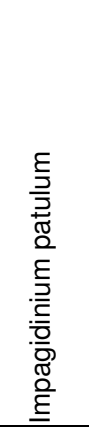 & 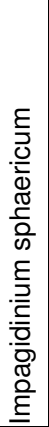 & 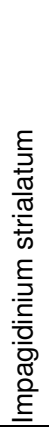 & 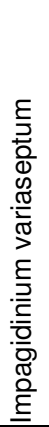 & 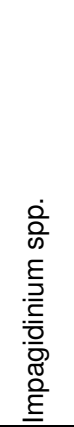 \\
\hline 341.25 & 36.72 & & & L25176 & 536 & 332 & & 2 & & 3 & 4 & 1 & & & & & \\
\hline 344.97 & 37 & & & L25177 & 1071 & 313.75 & & & & 1 & 4 & & & & & & \\
\hline 346.57 & 37.22 & & & L25179 & 39422 & 415 & & & & & & & & & & & \\
\hline 348.61 & 37.5 & & & L25180 & 4724 & 341 & & & & 1 & 1 & & & & & & \\
\hline 353.85 & 38.22 & & & L25182 & 539 & 303.5 & 1 & & & 2 & 4 & 1 & & & & & 0.5 \\
\hline 355.89 & 38.5 & & & L25183 & 197 & 312.5 & & & & 1 & 9 & & 1.5 & & & & \\
\hline 363.18 & 39.5 & & & L25186 & 176 & 166 & 1 & & & 1 & 1 & & & & & & \\
\hline 366.82 & 40 & & & L25188 & 836 & 296.5 & & & & 1 & 5 & & & & & & \\
\hline 367.84 & 40.14 & & & L25189 & 561 & 310 & 1 & & & 1 & 23 & & 1 & & & & \\
\hline 370.46 & 40.5 & & & L25191 & 784 & 339.25 & & & & 2 & 8 & 3 & 5 & 1 & & & 1 \\
\hline 374.10 & 41 & & & L25192 & 613 & 332.5 & & & & 1 & 9 & 2 & & & & & \\
\hline 377.74 & 41.5 & & & L25194 & 584 & 323.25 & & & & 2 & & 1 & 6 & & & & 0.75 \\
\hline 378.76 & 41.64 & & & L25195 & 559 & 307.5 & 2 & & & 4 & & 5 & 7 & & & & \\
\hline 380.08 & 41.82 & & & L25131 & 1236 & 155.25 & & & & 1 & 5 & & & & & & 2 \\
\hline 383.53 & 42.3 & 42.24 & 42.35 & L25134L25135 & 2095 & 136 & 0 & 0 & 0 & 0 & 5 & 0 & 0 & 0 & 0 & 0 & 0 \\
\hline 385.03 & 42.5 & & & L25198 & 283 & 304.25 & & & & 4 & 11 & 1 & & 4 & & & 5 \\
\hline 389.00 & 43.05 & 43.00 & 43.10 & L25200L25137 & 567 & 280.5 & 2 & 0 & 0 & 11 & 5 & 7 & 15.5 & 0 & 0 & 1 & 0 \\
\hline 389.69 & 43.14 & & & L25201 & 304 & 337.5 & & & 1 & 14 & 18 & & & 7 & & & 1.25 \\
\hline 391.65 & 43.41 & 43.32 & 43.50 & L25138L25203 & 649 & 288.75 & 1 & 0 & 0 & 22 & 5 & 3 & 16 & 0 & 0 & 0 & 0 \\
\hline 394.06 & 43.74 & & & L25140 & 329 & 126.5 & & & & 10 & 11 & & 4 & & & & \\
\hline 395.95 & 44 & & & L25204 & 152 & 301 & 4 & & & 16 & 22.5 & 1 & 5 & & & & 2.5 \\
\hline 401.93 & 44.82 & & & L25206 & 358 & 308.5 & & & & 23 & 1 & 6 & 5 & & & & \\
\hline 405.43 & 45.1 & & & L25207 & 717 & 307 & & & 3 & 27 & 10 & 5 & 17.5 & & & & \\
\hline 406.71 & 45.2 & & & L25146 & 441 & 225 & & & 1 & 24 & 18 & 4 & 15 & & & 1 & \\
\hline 407.21 & 45.24 & & & L25147 & 821 & 313.75 & & & 1 & 42 & 13 & & 20.5 & 2 & & & 1 \\
\hline 408.61 & 45.35 & & & L25209 & 999 & 325.75 & & & & 28 & 30 & 8 & 11 & & & & 1.5 \\
\hline 411.79 & 45.6 & 45.60 & 45.60 & L25149L25210 & 1294 & 558.5 & 0 & 0 & 1 & 29 & 33 & 25 & 11 & 3 & 1 & 0 & 3.25 \\
\hline 418.15 & 46.1 & & & L25150 & 4485 & 247.5 & & & & 16 & 24 & 51.5 & 18 & 1 & & & 1 \\
\hline 420.95 & 46.32 & & & L25212 & 6564 & 386.5 & & & & 3 & 9 & 11 & 3 & 1 & & & \\
\hline 424.51 & 46.6 & 46.60 & 46.60 & L25152L25213 & 2318 & 588.25 & 0 & 0 & 0 & 15 & 23 & 105.5 & 13.25 & 4 & 0 & 0 & 7 \\
\hline 426.29 & 46.74 & & & L25153 & 1108 & 324 & & & & 9 & 4 & 50.5 & 31.25 & & & & 3 \\
\hline 427.69 & 46.85 & & & L25215 & 1466 & 424 & & & & 3 & 7 & 4 & & & & & 3 \\
\hline 430.87 & 47.1 & 47.10 & 47.10 & 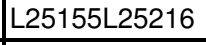 & 3392 & 545 & 0 & 0 & 0 & 0 & 30 & 0 & 3 & 0 & 0 & 0 & 8 \\
\hline 431.07 & 47.12 & & & L25156 & 819 & 230.25 & & & & 10 & 8 & 8 & 7 & & & & 3 \\
\hline 437.91 & 48.1 & & & L25219 & 595 & 230 & & & & & & & 1 & & 1 & & \\
\hline 439.65 & 48.35 & 48.35 & 48.35 & L25161L25221 & 789 & 350.5 & 0 & 0 & 0 & 0 & 10 & 0 & 0 & 0 & 0 & 0 & 0 \\
\hline 441.40 & 48.6 & & & L25222 & 784 & 313.5 & 3 & & & 1 & 5 & 1 & & & & & 0.5 \\
\hline
\end{tabular}




\begin{tabular}{|c|c|c|c|c|c|c|c|c|c|c|c|c|c|c|c|c|c|c|c|c|c|c|}
\hline 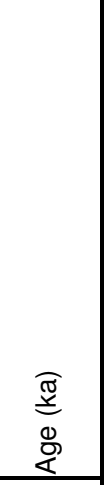 & 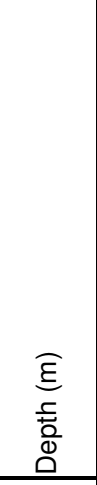 & 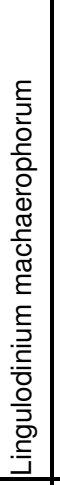 & 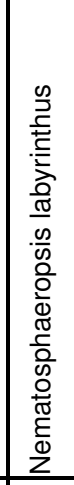 & 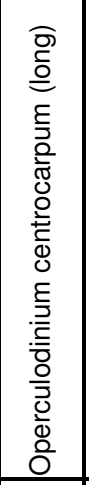 & 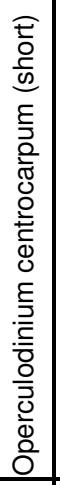 & 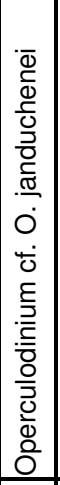 & 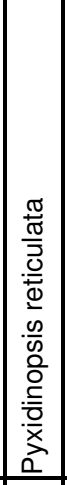 & 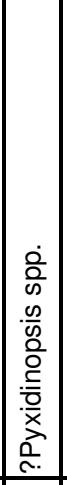 & 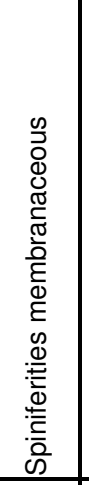 & 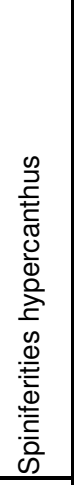 & 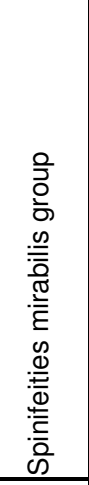 & 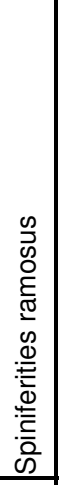 & 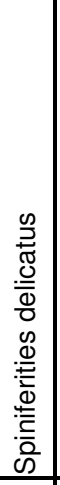 & 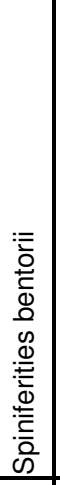 & 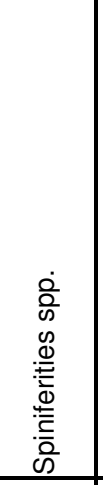 & 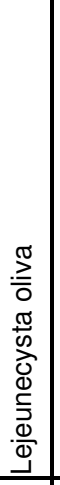 & 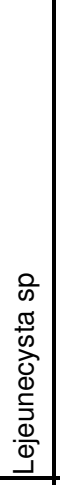 & 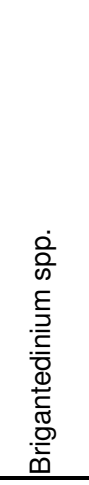 & 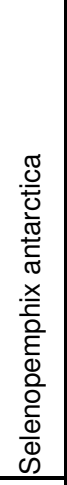 & 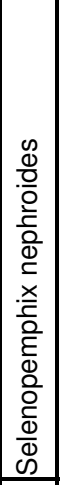 & 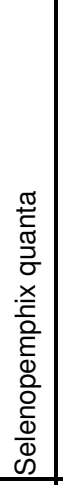 & 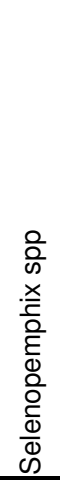 \\
\hline 341.25 & 36.72 & & 16 & 2 & 1 & & & 1 & \begin{tabular}{|c|}
18.5 \\
\end{tabular} & 88 & 25.5 & \begin{tabular}{|l|}
4 \\
\end{tabular} & & & 21 & & & 36 & 59 & 1 & 1 & \\
\hline 344.97 & 37 & 1 & 25 & & & & & & 34 & 121 & 35 & \begin{tabular}{|l|}
1 \\
\end{tabular} & & & 12.75 & & & 29 & 29 & 2 & & \\
\hline 346.57 & 37.22 & & 1 & & & & & & & 300 & 98 & & & & 13 & & & & & & 3 & \\
\hline 348.61 & 37.5 & & 17 & & & & & & & 228 & 44 & & 1 & & 25 & & & 13 & & & 8 & \\
\hline 353.85 & 38.22 & & 22 & 3 & & & & & & 10 & 4 & 13 & & & & & 2 & 63 & 35 & $27 \mid$ & 96 & 4 \\
\hline 355.89 & 38.5 & & 6 & 1.5 & & & & & 1 & & 2 & \begin{tabular}{|l|}
3 \\
\end{tabular} & & & 4.5 & & & 88 & 172 & 5 & 15 & \\
\hline 363.18 & 39.5 & & 4 & \begin{tabular}{|l|}
0.25 \\
\end{tabular} & & & & & & 1 & & 4 & & & 0.7 & & & 31 & 109 & 3 & 7 & 2 \\
\hline 366.82 & 40 & & 17 & 1 & & & & & & 4 & 1 & \begin{tabular}{|l|}
5 \\
\end{tabular} & & & 0.5 & & & 64 & 168 & & 14 & 8 \\
\hline 367.84 & 40.14 & & 76 & 4 & & & & & & & 10.5 & 23 & & & 14 & & & 40.5 & 37 & 1 & 44 & 10 \\
\hline 370.46 & 40.5 & & 97 & 2 & & & & & & 6 & 7 & \begin{tabular}{|l|}
24 \\
\end{tabular} & & & 5.25 & & & 28 & 6 & 3 & 98 & 1 \\
\hline 374.10 & 41 & & \begin{tabular}{|l|}
139 \\
\end{tabular} & & & & & & & 14 & 14 & \begin{tabular}{|l|}
14 \\
\end{tabular} & & & 2.5 & & & 47 & 68 & & 11 & \\
\hline 377.74 & 41.5 & & 168 & 2 & & & 1 & 2 & & 22 & 22 & 19 & & & & & & 25.5 & 20 & 2 & 66 & \\
\hline 378.76 & 41.64 & & \begin{tabular}{|l|}
125 \\
\end{tabular} & 1 & & & 1 & & & 3 & 28 & 62 & & & 2.5 & & & 18 & 6 & 6 & \begin{tabular}{|l|}
29 \\
\end{tabular} & 2 \\
\hline 380.08 & 41.82 & & 40 & & & & & & & 4 & & & & & 0.25 & & & 51 & 31 & 1 & \begin{tabular}{|l|}
18 \\
\end{tabular} & \\
\hline 383.53 & 42.3 & 0 & 49 & 2 & 0 & \begin{tabular}{|l|}
0 \\
\end{tabular} & 0 & 0 & 0 & 5 & 1 & \begin{tabular}{|l|}
0 \\
\end{tabular} & 0 & 0 & 0 & 0 & 0 & 19 & 35 & 2 & 13 & 4 \\
\hline 385.03 & 42.5 & & 92 & 3 & & & 1 & & & 28 & 23 & 21 & & & 6.25 & & & 14 & 41 & 3 & 32 & \\
\hline 389.00 & 3.05 & 0 & \begin{tabular}{|l|}
146 \\
\end{tabular} & 0 & 0 & \begin{tabular}{|l|} 
\\
\end{tabular} & 7 & 0 & 0 & 1 & 10 & \begin{tabular}{|l|}
36 \\
\end{tabular} & 0 & 0 & 1.5 & 0 & 1 & 24.5 & 3 & 0 & 7 & 0 \\
\hline 389.69 & .14 & & \begin{tabular}{|l|}
232 \\
\end{tabular} & 6 & 1 & & \begin{tabular}{|l|}
10 \\
\end{tabular} & & & 2 & 5 & \begin{tabular}{|l|}
9 \\
\end{tabular} & & & 2.25 & & & 4 & 4 & & 9 & \\
\hline 391.65 & 41 & 0 & 89 & 2 & 0 & $\begin{array}{ll} \\
\end{array}$ & 7 & 0 & 0 & 13 & 15.5 & 12 & 0 & 0 & 2.25 & 1 & 0 & 56 & 6 & 6 & \begin{tabular}{|l|}
24 \\
\end{tabular} & 1 \\
\hline 394.06 & 43.74 & & 54 & & & & 6 & & & 3 & 5 & \begin{tabular}{|l|}
14 \\
\end{tabular} & & & 5.5 & & & 7.5 & 4.5 & & 1 & \\
\hline 395.95 & 44 & & \begin{tabular}{|l|}
141 \\
\end{tabular} & 1 & & \begin{tabular}{|l|}
1 \\
\end{tabular} & 6 & & & & 40 & 29 & & & 8 & & & 12 & 3 & 4 & & \\
\hline 401.93 & 44.82 & & 190 & & & 1 & 29 & & 3 & 4 & 3.5 & 13 & & & & & & 19 & 7 & & & 1 \\
\hline 405.43 & 45.1 & & \begin{tabular}{|l|}
187 \\
\end{tabular} & & & \begin{tabular}{|l|}
1 \\
\end{tabular} & \begin{tabular}{|l|}
11 \\
\end{tabular} & 4 & & & 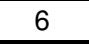 & \begin{tabular}{|l|}
12 \\
\end{tabular} & & & 5.5 & & & 15 & 1 & & & \\
\hline 406.71 & 45.2 & & 98 & & & & \begin{tabular}{|l|}
13 \\
\end{tabular} & 1 & 3 & 1 & 8 & \begin{tabular}{|l|}
9 \\
\end{tabular} & & & 6 & & & 16.5 & & 4 & & 0.5 \\
\hline 407.21 & 45.24 & & 178 & & & & \begin{tabular}{|l|}
13 \\
\end{tabular} & 3 & 1 & 2 & 11 & 9 & & & 11.25 & & & 1 & & & & 1 \\
\hline 408.61 & 45.35 & & 191 & & & & 15 & & & & 16.25 & 14 & & & 8 & & & & 2 & & & \\
\hline 411.79 & 45.6 & 0 & 302 & 2 & 0 & 0 & 39 & 4 & 3 & 8 & 17 & 45 & 0 & 0 & 21.25 & 0 & 0 & 4 & 2 & 2 & 0 & 0 \\
\hline 418.15 & 46.1 & & \begin{tabular}{|l|}
69 \\
\end{tabular} & & & & 8 & & 3 & & 22 & $10 \mid$ & & & 4.5 & & & 9.5 & 1 & 4 & 2 & \\
\hline 420.95 & 46.32 & & 256 & & & 3 & 2 & & 3 & 10.5 & 32 & 30 & & & 11 & & & 7 & 3 & 2 & & \\
\hline 424.51 & 46.6 & 0 & \begin{tabular}{|l|}
124 \\
\end{tabular} & 0 & 0 & \begin{tabular}{|l|} 
\\
\end{tabular} & 6 & 2 & 1 & 51 & 34 & \begin{tabular}{|l|}
3 \\
\end{tabular} & 0 & 0 & 38 & 0 & 0 & 122.5 & 5 & \begin{tabular}{|l|}
16 \\
\end{tabular} & 2 & 2 \\
\hline 426.29 & 46.74 & & \begin{tabular}{|l|}
31 \\
\end{tabular} & & & & 2 & & 2 & 19 & 35 & \begin{tabular}{|l|}
1 \\
\end{tabular} & & & 20.25 & & 1 & 97 & & 2 & 6 & 2 \\
\hline 427.69 & 46.85 & & 4 & & & 2 & 9 & & 9 & 57 & 91 & & & 2 & 72 & & & 107 & 7 & 2 & 8 & \\
\hline 430.87 & 47 & 0 & 36 & 1 & 0 & \begin{tabular}{|l|} 
\\
\end{tabular} & 1 & 0 & 1 & 77 & 139 & 1 & 3 & 0 & 50 & 0 & 1 & 127 & 39 & 8 & 7 & 1 \\
\hline 431.07 & 47.12 & & \begin{tabular}{|l|}
111 \\
\end{tabular} & & & & 15 & 1 & & 8 & 11 & 15 & & & 9.25 & & & 12 & 2 & 2 & 4 & \\
\hline 437.91 & 48.1 & & 1 & & & & & & & 1 & & 1 & & & 2.5 & & & 39.5 & 176 & 3 & & 1 \\
\hline 439.65 & 3.35 & 0 & 13 & 1 & 0 & \begin{tabular}{|l|}
0 \\
\end{tabular} & 1 & 0 & 0 & 6 & 1 & \begin{tabular}{|l|}
0 \\
\end{tabular} & 0 & 0 & n & 0 & 0 & 41.5 & 261 & \begin{tabular}{|l|}
2 \\
\end{tabular} & 8 & 4 \\
\hline 441.40 & 48.6 & & 4 & 1 & & & & & & & 2 & & & & 3 & & & 48 & 241 & & 4 & \\
\hline
\end{tabular}




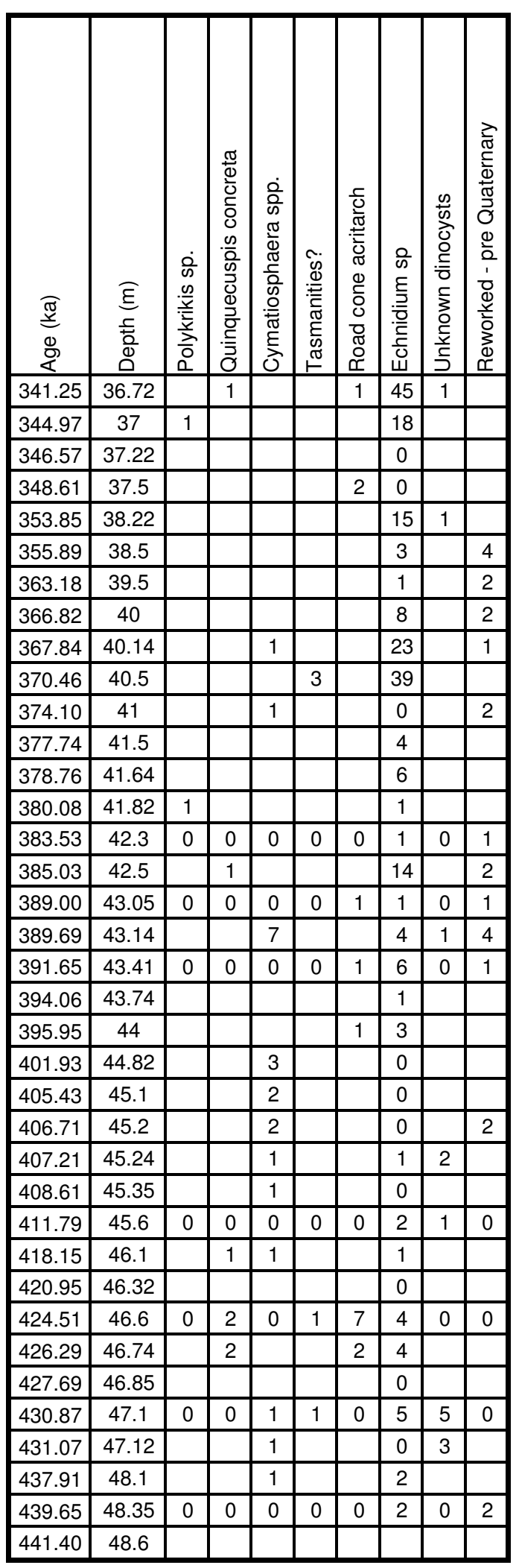




\begin{tabular}{|c|c|c|c|c|c|c|c|c|c|c|c|c|c|}
\hline $\begin{array}{l}\mathbb{\widetilde { T }} \\
\stackrel{\mathbb{2}}{\mathbb{Q}} \\
\mathbb{\mathbb { Q }}\end{array}$ & $\begin{array}{l}\frac{F}{0} \\
\frac{0}{0}\end{array}$ & 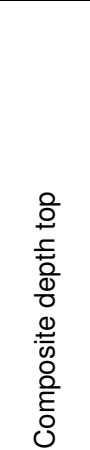 & 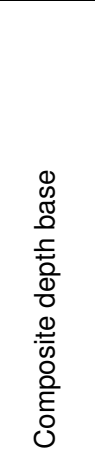 & 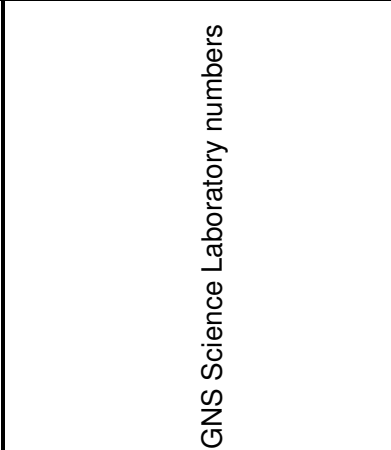 & 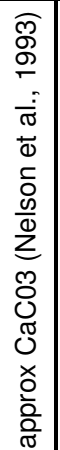 & 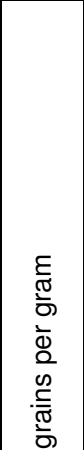 & 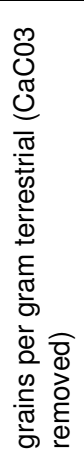 & 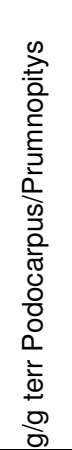 & 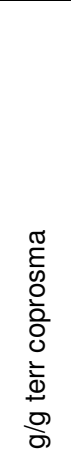 & 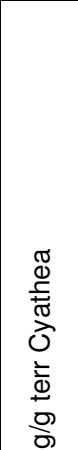 & 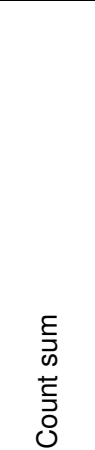 & 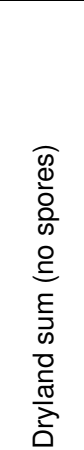 & 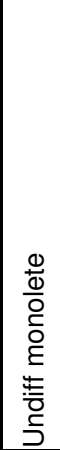 \\
\hline 342.5 & 36.86 & 36.72 & 37 & L25176L25177 & 20 & 154 & 193 & 26 & 13 & 339 & 218.5 & 124.5 & 19 \\
\hline 354.9 & 38.36 & 38.22 & 38.5 & L25182L25183 & 20 & 128 & 160 & 29 & 10 & 615 & 570 & 357 & 27 \\
\hline 359.5 & 39 & & & L25185 & 17 & 131 & 158 & 26 & 7 & 777 & 374 & 242 & \begin{tabular}{|l}
14 \\
\end{tabular} \\
\hline 363.2 & 39.5 & & & L25186 & 18 & 201 & 246 & 31 & 4 & 1805 & 341 & 185 & 29 \\
\hline 367.3 & 40.07 & 40 & 40.14 & L25188L25189 & 25 & 198 & 264 & 44 & 23 & 1126 & 652 & 374 & 36 \\
\hline 370.5 & 40.5 & & & L25191 & 25 & 153 & 203 & 28 & 33 & 1144 & 286 & 165 & 17 \\
\hline 374.1 & 41 & & & L25192 & 25 & 106 & 142 & 11 & 9 & 890 & 249 & 135 & 22 \\
\hline 377.7 & 41.5 & & & L25194 & 35 & 124 & 191 & 20 & 33 & 476 & 393 & 250 & 23 \\
\hline 378.8 & 41.64 & & & L25195 & 38 & 173 & 280 & 33 & 38 & 194 & 407 & 306 & 19 \\
\hline 380.7 & 41.91 & 41.82 & 42 & L25131L25197 & 38 & 434 & 700 & 105 & 80 & 314 & 347.5 & 229.5 & 22 \\
\hline 384.0 & 42.37 & 42.24 & 42.5 & L25134L25135L25198 & 50 & 504 & 1008 & 84 & 83 & 640 & 254 & 181 & 9 \\
\hline 389.1 & 43.05 & 43 & 43.1 & L25200L25137 & 60 & 292 & 729 & 125 & 85 & 298 & 252 & 184 & 4 \\
\hline 389.7 & 43.14 & & & L25201 & 65 & 499 & 1427 & 48 & 88 & 18 & 402 & 358 & 1 \\
\hline 391.0 & 43.16 & & & L25138 & \begin{tabular}{|l|}
65 \\
\end{tabular} & 101 & 290 & 18 & 18 & 37 & 130 & 114 & 3 \\
\hline 392.3 & 43.5 & & & L25203 & 60 & 2537 & 6343 & 491 & 585 & 27 & 423.5 & 368.5 & 7 \\
\hline 394.9 & 43.87 & 43.74 & 44 & L25140L25141L25204 & 70 & 136 & 452 & 66 & 24 & 288 & 497.5 & 341.5 & 25 \\
\hline 402.0 & 44.82 & & & L25206 & 75 & 253 & 1010 & 393 & 76 & 426 & 750 & 306 & 12 \\
\hline 405.6 & 45.1 & & & L25207 & 75 & 286 & 1146 & 940 & 28 & 182 & 551 & 323 & 2 \\
\hline 406.9 & 45.22 & 45.2 & 45.24 & L25146L25147L25208 & 75 & \begin{tabular}{|l|}
464 \\
\end{tabular} & 1856 & 1339 & 52 & 175 & 552.5 & 285.5 & 0 \\
\hline 408.6 & 45.35 & & & L25209 & \begin{tabular}{|l|}
75 \\
\end{tabular} & 279 & 1118 & 824 & 21 & 157 & 612 & 312 & 0 \\
\hline 411.8 & 45.6 & & & L25149L25210 & 75 & 210 & 838 & 550 & 71 & 254 & 755 & 346 & 5 \\
\hline 418.2 & 46.1 & & & L25150 & 65 & 3370 & 9629 & 7869 & 207 & 127 & 325 & 185 & 1 \\
\hline 421.0 & 46.32 & & & L25212 & 60 & 671 & 1677 & 539 & 670 & 158 & 851 & 308 & 42 \\
\hline 424.5 & 46.6 & & & L25152L25213 & 55 & 1104 & 2453 & 729 & 1069 & 693 & 1559 & 300 & 219 \\
\hline 426.9 & 46.795 & 46.74 & 46.85 & L25153L25215 & 45 & 423 & 768 & 43 & 247 & 48 & 879 & 265 & 239 \\
\hline 431.0 & 47.11 & 47.1 & 47.12 & L25155L25216L25156 & 25 & 359 & 479 & 25 & 94 & 48 & 564 & 286 & 60 \\
\hline 436.9 & 47.96 & 47.82 & 48.1 & L25158L25218L25159L25219 & 15 & 215 & 253 & 17 & 9 & 28 & 237 & 168 & 10 \\
\hline 440.5 & 48.475 & 48.35 & 48.6 & L25161L25221L25162L25222 & 14 & 266 & 310 & 22 & 30 & 84 & 442 & 298 & 33 \\
\hline 446.4 & 49.32 & 49.32 & 49.32 & L25164L25224 & 10 & 144 & 161 & 23 & 1 & 326 & 212.5 & 120.5 & 22 \\
\hline
\end{tabular}




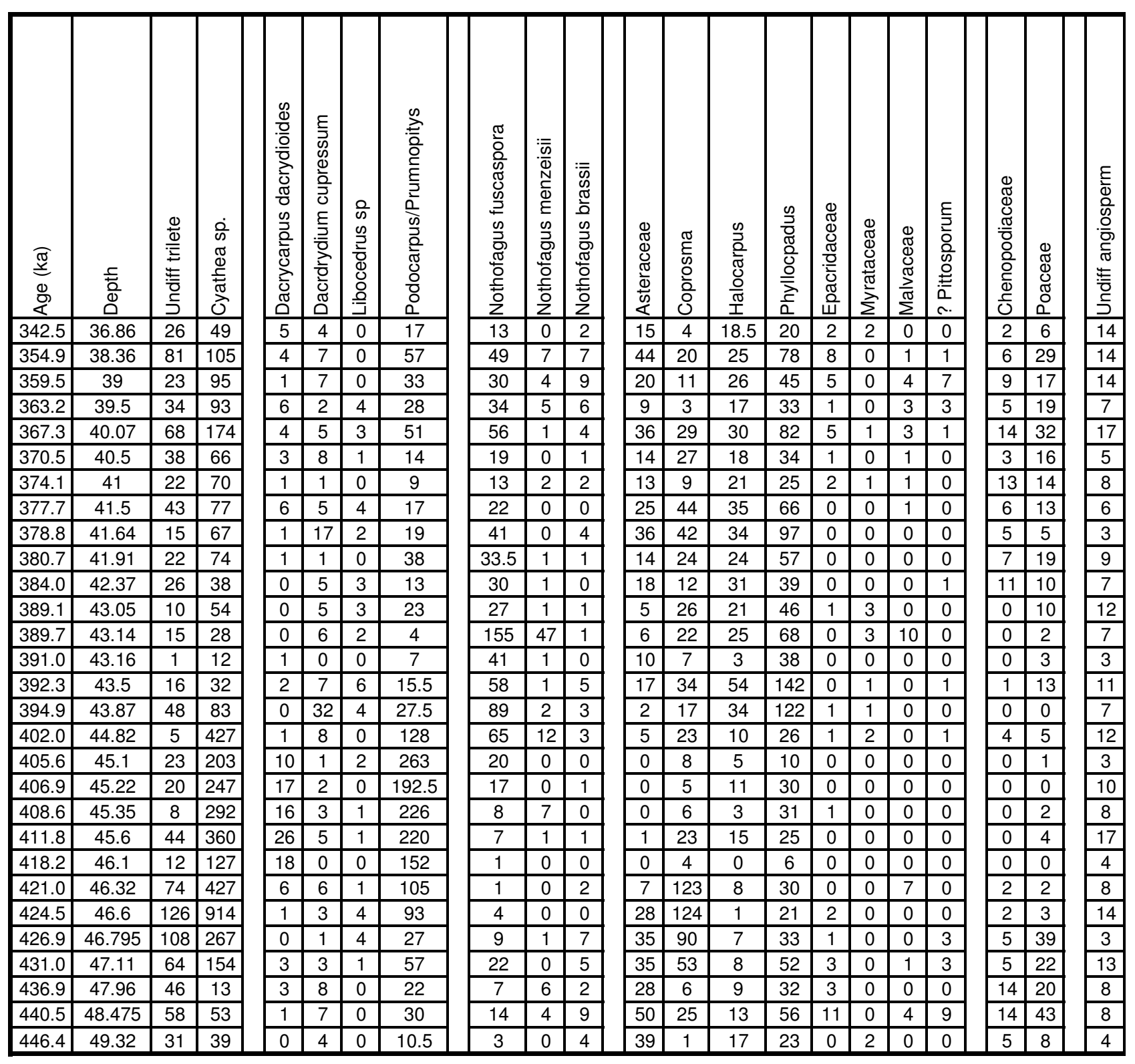




\begin{tabular}{|c|c|c|c|c|}
\hline 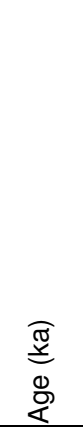 & $\begin{array}{l}\text { 홍 } \\
\text { 임 }\end{array}$ & $\stackrel{\infty}{\vec{E}}$ & 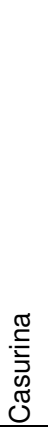 & $\begin{array}{l}\frac{\pi}{0} \\
\mathbb{J} \\
\frac{\mathbb{L}}{4}\end{array}$ \\
\hline 342.5 & 36.86 & 1.5 & 3 & 0 \\
\hline 354.9 & 38.36 & 2.5 & 3 & 0 \\
\hline 359.5 & 39 & 3.5 & 5 & 0 \\
\hline 363.2 & 39.5 & 5 & 5 & 0 \\
\hline 367.3 & 40.07 & 4 & 3 & 1 \\
\hline 370.5 & 40.5 & 10 & 0 & 0 \\
\hline 374.1 & 41 & 3 & 0 & 0 \\
\hline 377.7 & 41.5 & 3 & 1 & 0 \\
\hline 378.8 & 41.64 & 0 & 1 & 0 \\
\hline 380.7 & 41.91 & 1 & 4 & 0 \\
\hline 384.0 & 42.37 & 1 & 1 & 0 \\
\hline 389.1 & 43.05 & 24 & 11 & 0 \\
\hline 389.7 & 43.14 & 0 & 0 & 0 \\
\hline 391.0 & 43.16 & 0 & 1 & 0 \\
\hline 392.3 & 43.5 & 0.5 & 0 & 0 \\
\hline 394.9 & 43.87 & 5.5 & 0 & 0 \\
\hline 402.0 & 44.82 & 1 & 0 & 0 \\
\hline 405.6 & 45.1 & 1 & 0 & 0 \\
\hline 406.9 & 45.22 & 0 & 1 & 0 \\
\hline 408.6 & 45.35 & 0 & 0 & 0 \\
\hline 411.8 & 45.6 & 0 & 1 & 0 \\
\hline 418.2 & 46.1 & 0 & 1 & 0 \\
\hline 421.0 & 46.32 & 0 & 0 & 0 \\
\hline 424.5 & 46.6 & 2 & 1 & 0 \\
\hline 426.9 & 46.795 & 0 & 4 & 0 \\
\hline 431.0 & 47.11 & 3 & 7 & 0 \\
\hline 436.9 & 47.96 & 0 & 0 & 0 \\
\hline 440.5 & 48.475 & 1 & 6 & 0 \\
\hline 446.4 & 49.32 & 0 & 1 & 0 \\
\hline
\end{tabular}

